

\section{Life after logging:}

Reconciling wildlife conservation and production forestry in Indonesian Borneo 



\title{
Life after logging: Reconciling wildlife conservation and production forestry in Indonesian Borneo
}

\author{
Erik Meijaard \\ Douglas Sheil \\ Robert Nasi \\ David Augeri \\ Barry Rosenbaum \\ Djoko Iskandar \\ Titiek Setyawati \\ Martjan Lammertink \\ Ike Rachmatika \\ Anna Wong \\ Tonny Soehartono \\ Scott Stanley \\ Timothy O'Brien
}

With further contributions from Robert Inger, Muchamad Indrawan, Kuswata Kartawinata, Bas van Balen, Gabriella Fredriksson,

Rona Dennis, Stephan Wulffraat, Will Duckworth and Tigga Kingston 
(C) 2005 by CIFOR and UNESCO

All rights reserved. Published in 2005

Printed in Indonesia Printer, Jakarta

Design and layout by Catur Wahyu and Gideon Suharyanto

Cover photos (from left to right):

Large mature trees found in primary forest provide various key habitat functions important for wildlife. (Photo by Herwasono Soedjito)

An orphaned Bornean Gibbon (Hylobates muelleri), one of the victims of poor-logging and illegal hunting. (Photo by Kimabajo)

Roads lead to various impacts such as the fragmentation of forest cover and the siltation of streamother impacts are associated with improved accessibility for people. (Photo by Douglas Sheil)

This book has been published with financial support from UNESCO, ITTO, and SwedBio. The authors are responsible for the choice and presentation of the facts contained in this book and for the opinions expressed therein, which are not necessarily those of CIFOR, UNESCO, ITTO, and SwedBio and do not commit these organisations.

The review and synthesis reflect inputs from many organisations, including MoF, LIPI, WCS, TNC, WWF and CIRAD. This review has also benefited from research, and related activities, supported by grants from ITTO, the European Commission, the World Bank, and the MacArthur Foundation. The opinions expressed in this book are not endorsed by any of these organisations.

ISBN 979-3361-56-5

The Center for International Forestry Research (CIFOR) was established in 1993 as part of the Consultative Group on International Agricultural Research (CGIAR) in response to global concerns about the social, environmental and economic consequences of forest loss and degradation. CIFOR research produces knowledge and methods to improve the well-being of forest-dependent people and to help countries manage their forests wisely for sustainable benefits. This research is conducted in more than two dozen countries, in collaboration with numerous partners. Since it was founded, CIFOR has also played a central role in influencing global and national forestry policies.

\section{National Library of Indonesia Cataloging-in-Publication Data}

Life after logging: Reconciling wildlife conservation and production forestry in Indonesian Borneo/ Meijaard, E., Sheil, D., Nasi, R., Augeri, D., Rosenbaum, B., Iskandar, D., Setyawati, T., Lammertink, M., Rachmatika, I., Wong, A., Soehartono, T., Stanley, S. and O'Brien, T.-Bogor, Indonesia: CIFOR, 2005.

p. $\mathrm{cm}$.

ISBN 979-3361-56-5

1. Forest management 2. Nature conservation 3. Social sciences 4. Wildlife 5. Research 6. East Kalimantan 7. Indonesia

Published by

Center for International Forestry Research

Mailing address: P.O. Box 6596 JKPWB, Jakarta 10065, Indonesia

Office address: Jl. CIFOR, Situ Gede, Sindang Barang, Bogor Barat 16680, Indonesia

Tel.: +62 (251) 622622; Fax: +62 (251) 622100

Email: cifor@cgiar.org

Website: http://www.cifor.cgiar.org 


\section{Contents}

Preamble and intended audience $\quad$ xi

Contributors' biodata xii

$\begin{array}{lll}\text { Acknowledgements } & \mathrm{xV}\end{array}$

Foreword $\quad$ xvi

Executive summary xix

Abbreviations $\quad$ xxii

Introduction $\quad 1$

Justification

Goals 2

Focus and wider relevance $\quad 2$

Wildlife is important 4

$\begin{array}{ll}\text { Focal area } & 7\end{array}$

Location $\quad 7$

People and change 9

Decentralisation $\quad 11$

$\begin{array}{ll}\text { Forest management } & 11\end{array}$

$\begin{array}{lr}\text { Wildlife surveys } & 12\end{array}$

PART I. LITERATURE REVIEW

A literature review of logging and wildlife $\quad 17$

$\begin{array}{ll}\text { Methods } & 17\end{array}$

$\begin{array}{ll}\text { Specialist input } & 20\end{array}$

Methodological limitations $\quad 20$

$\begin{array}{ll}\text { Literature availability } & 23\end{array}$

$\begin{array}{ll}\text { Literature scope } & 26\end{array}$

Bird studies $\quad 26$

$\begin{array}{ll}\text { Mammal studies } & 27\end{array}$

$\begin{array}{ll}\text { Amphibian and reptile studies } & 28\end{array}$

$\begin{array}{ll}\text { Fish studies } & 28\end{array}$ 
Background concepts $\quad 29$

Changing fauna $\quad 29$

Vegetation change $\quad 30$

Limited productivity $\quad 34$

Silvicultural systems $\quad 36$

Management intensity $\quad 37$

Liberation and understorey clearing $\quad 38$

Logged and fragmented landscapes $\quad 39$

$\begin{array}{ll}\text { Landscape features } & 41\end{array}$

$\begin{array}{ll}\text { The threat of hunting } & 42\end{array}$

Subsistence hunting $\quad 43$

Concessions and hunting $\quad 45$

Roads and hunting $\quad 45$

Collected products $\quad 46$

$\begin{array}{ll}\text { Traffic } & 47\end{array}$

Invasive species $\quad 48$

Fire 49

$\begin{array}{ll}\text { Certification } & 51\end{array}$

Birds

General $\quad 53$

Sensitive species $\quad 56$

Hornbills $\quad 57$

Woodpeckers $\quad 59$

Pheasants $\quad 64$

Other taxa $\quad 66$

$\begin{array}{ll}\text { Trogons } & 67\end{array}$

$\begin{array}{ll}\text { Bulbuls } & 67\end{array}$

Babblers $\quad 68$

$\begin{array}{ll}\text { Flycatchers } & 68\end{array}$

Cuckoos, malkohas, coucals and ground-cuckoo $\quad 69$

Raptors $\quad 69$

Mammals $\quad 71$

$\begin{array}{ll}\text { General } & 71\end{array}$

Primates $\quad 72$

$\begin{array}{lr}\text { Squirrels } & 78\end{array}$

Rats and mice $\quad 81$

Insectivores $\quad 81$

$\begin{array}{ll}\text { Treeshrews } & 82\end{array}$

Bats $\quad 83$

Cats $\quad 86$

$\begin{array}{ll}\text { Civets } & 87\end{array}$

Malayan sun bear $\quad 89$

$\begin{array}{ll}\text { Forest ungulates } & 92\end{array}$ 
$\begin{array}{ll}\text { Amphibians and reptiles } & 97\end{array}$

Frogs and toads $\quad 97$

$\begin{array}{lc}\text { Reptiles } & 103\end{array}$

$\begin{array}{ll}\text { Fish } & 107\end{array}$

PART II. ANALYSIS

$\begin{array}{ll}\text { Species sensitivity analysis } & 115\end{array}$

$\begin{array}{ll}\text { Approach and methods } & 115\end{array}$

$\begin{array}{ll}\text { Results } & 117\end{array}$

$\begin{array}{ll}\text { Discussion } & 127\end{array}$

$\begin{array}{ll}\text { Methodological considerations } & 127\end{array}$

$\begin{array}{lr}\text { Direct effects of timber extraction } & 128\end{array}$

Phylogeny, distribution, taxonomy 129

$\begin{array}{ll}\text { Feeding strategies } & 131\end{array}$

The role of timber species $\quad 132$

$\begin{array}{lr}\text { Change in structural characteristics } & 133\end{array}$

Associated effects of timber extraction $\quad 134$

Fragmentation $\quad 134$

$\begin{array}{ll}\text { Hunting } & 137\end{array}$

$\begin{array}{ll}\text { Conclusions } & 139\end{array}$

PART III. MANAGEMENT

Implications for forestry and concession management $\quad 145$

$\begin{array}{ll}\text { Recommendations to managers } & 146\end{array}$

$\begin{array}{ll}\text { Planning before logging } & 147\end{array}$

Minimising damage during logging and related operations 151

Minimising indirect impacts and threats 159

Logging and conservation for local people $\quad 164$

$\begin{array}{ll}\text { Implementation and vigilance } & 165\end{array}$

$\begin{array}{ll}\text { Species-specific suggestions } & 168\end{array}$

$\begin{array}{ll}\text { Recommendations for government planning } & 179\end{array}$

$\begin{array}{ll}\text { The need for a wildlife masterplan } & 179\end{array}$

$\begin{array}{lr}\text { Land tenure agreement } & 180\end{array}$

$\begin{array}{lr}\text { Large-scale planning } & 181\end{array}$

$\begin{array}{lr}\text { Hunting and fishing } & 182\end{array}$

$\begin{array}{ll}\text { Forest law enforcement and governance } & 183\end{array}$

$\begin{array}{ll}\text { Effective implementation } & 186\end{array}$

$\begin{array}{lr}\text { Certification requirements } & 189\end{array}$

PART IV. RESEARCH

$\begin{array}{ll}\text { Recommendations for research and researchers } & 193\end{array}$

$\begin{array}{ll}\text { Recommendations to researchers } & 195\end{array}$

$\begin{array}{ll}\text { Timber harvesting } & 197\end{array}$

$\begin{array}{ll}\text { Concession operations } & 198\end{array}$ 
$\begin{array}{lr}\text { Landscape features } & 198\end{array}$

$\begin{array}{lr}\text { Fruit } & 198\end{array}$

$\begin{array}{lr}\text { Species dependencies } & 199\end{array}$

$\begin{array}{ll}\text { Habitat structure } & 199\end{array}$

$\begin{array}{ll}\text { Connectivity, space and mobility } 200 & 200\end{array}$

$\begin{array}{ll}\text { Hunting } & 201\end{array}$

$\begin{array}{ll}\text { Other threats } & 202\end{array}$

$\begin{array}{ll}\text { Research on birds } & 203\end{array}$

$\begin{array}{ll}\text { Research on mammals } & 204\end{array}$

$\begin{array}{ll}\text { Research on amphibians and reptiles } & 205\end{array}$

Research on fish 206

Index 299

$\begin{array}{ll}\text { Literature cited } & 308\end{array}$

Apendices

Appendix 1. Species data checklist 209

Appendix 2. IUCN Status $\quad 212$

Appendix 3. Importance of vertebrate species in MRF 215

$\begin{array}{lll}\text { Appendix 4. Species summary-Birds } & 217\end{array}$

Appendix 5. Species summary-Mammals 242

$\begin{array}{lll}\text { Appendix 6. Species summary-Amphibians } & 275\end{array}$

$\begin{array}{lll}\text { Appendix 7. Species summary-Reptiles } & 277\end{array}$

Appendix 8. Fish reported from MRF 281

Appendix 9. Act No. 5 of $1990 \quad 283$

Appendix 10. Law Number 41 Year 1999 on forestry 284

Appendix 11. TPTI 288

Appendix 12. Legislation relevant to the harvest of non-protected
wildlife species in Indonesia - 2004

\section{Figures}

Figure 1. Map of Borneo, showing the Indonesian provinces, the Malaysian states, Brunei, and the location of the Malinau District 3

Figure 2. Location diagram of the MRF study site 8

Figure 3. Repeated logging and fires of forests on poor soils in East

Kalimantan resulted in extensive areas of unproductive

Imperata cylindrica grasslands

Figure 4. Roads and the use of heavy machinery cause fragmentation and lead to severe soil disturbance and erosion

Figure 5. A deep wallow in MRF

Figure 6. Blue-crowned Hanging Parrots (Loriculus galgulus) captured in Lalut Birai for trade purposes

Figure 7. Female Great Slaty Woodpecker (Mulleripicus pulverulentus); densities of this woodpecker are strongly reduced in logged forests

Figure 8. Crested Fireback (Lophura ignita) female and male in unlogged forest in the MRF 
Figure 9. Sundasciurus lowii, seen here feeding on Artocarpus fruits, is a common squirrel of undisturbed and disturbed lowland forests

Figure 10. Malay Civet (Viverra tangalunga), one of the Bornean civet species that are negatively affected by the effects of timber harvest

Figure 11. Limnonectes leporinus, a Bornean endemic generally found near large or medium-sized streams

Figure 12. Numbers of amphibians found in an unlogged area in Danum Valley, a area under reduced impact logging (RIL), and an area under conventional logging (CL)

Figure 13. Box-and-whiskers plot of logging tolerance in relation to species age 118

Figure 14. Discriminant analysis of 3 variables (number of small Sundaic islands on which species occurs (after Meijaard 2003b), number of species per genus, and number of subspecies per species) and their predictive value for the sensitivity of mammal species to logging

Figure 15. Box-and-whiskers plot of categories for tolerance to logging in relation to distribution on small islands

Figure 16. Box-and-whiskers plot of categories for tolerance to logging in relation to number of young per nest or litter

Figure 17. Column charts of sensitivity to logging in relation to distribution range

Figure 18. Column charts of sensitivity to logging in relation to feeding strata

Figure 19. Column charts of sensitivity to logging in relation to feeding categories

Figure 20. CATPCA of 21 mammal species, with 5 variables: Sensitivity to logging, feeding strategies, feeding strata, distributional range, and number of offspring

Figure 21. Hollow trees are an important ecological feature of healthy forests. Here a Giant Squirrel (Ratufa affinis) is entering a tree cavity

Figure 22. Logging roads are often unnecessarily wide, increasing the effects of forest fragmentation by inhibiting animal dispersal and increasing sedimentation levels and erosion

Figure 23. Nepenthes gracilis, a pitcher plant found in lowland forest and along forest edges, where it provides an important micro-habitat feature for insects and small vertebrates

Figure 24. Forest remnants in East Kalimantan after repeated fire

Figure 25. Red Leaf Monkeys (Presbytis rubicunda) require canopy connectivity for their arboreal lifestyles

Figure 26. Local researchers assessing post-fire damage in East Kalimantan 194

Figure 27. Sun Bear skins and hornbill feathers used in traditional ceremonies 201

Figure 28. The poorly known Bearded Pig (Sus barbatus) is an important ecosystem engineer and a vital protein source for inland communities

Figure 29. Dead standing trees are important for many species. Here a Rhinoceros hornbill (Buceros rhinoceros) is foraging for insects 
Figure 30. Female Banded Woodpecker (Picus miniaceus); this woodpecker occurs in higher densities in disturbed forests and rural areas than in primary forests

\section{Tables}

Table 1. Protected mammals and birds of the Malinau area 12

Table 2. Hornbills, and their response to logging 58

Table 3. Woodpeckers, and their response to logging 62

Table 4. Pheasants, and their response to logging 66

Table 5. Most commonly trapped small mammals in several studies in Peninsular Malaysia $\quad 71$

Table 6. Primates, and their response to logging 76

Table 7. Non-flying squirrels, and their response to logging 80

Table 8. Civets, and their response to logging 88

Table 9. Changes in cervid and tragulid densities after selective logging 92

Table 10. Comparison of fish abundance and occurrence between unlogged and logged stations in the Seturan River, Malinau 108

Table 11. Fish fauna in ponds caused by poor roading in Malinau 110

Table 12. Comparison of means of 8 predictor variables in relation to the sensitivity of selected mammal species to logging 118

Table 13. Number and mean size of islands in the Indo-Malayan Region on which mammal species from different families occur $\quad 136$

Table 14. A list of Bornean species that would most benefit from more wildlife friendly concession management

Table 15. Species that are in the top 30 of species used by local communities and that are listed on the IUCN Red List of Threatened Species

Table 16. Species listed by IUCN (2002) as Endangered or Vulnerable, but not in high demand by local communities. Also shown is the protection status under Indonesian law. 


\section{Preamble and intended audience}

This book presents a technical review of ecological and life history information on a range of Bornean wildlife species, aimed at identifying what makes these species sensitive to timber harvesting practices and associated impacts. It addresses three audiences: 1) those involved in assessing and regulating timber harvesting activities in Southeast Asia, 2) those involved in trying to achieve conservation goals in the region, and 3) those undertaking research to improve multipurpose forest management. We show that forest management can be improved in many simple ways to allow timber extraction and wildlife conservation to be more compatible than under current practices. These recommendations can also be valuable to the many governmental and non-governmental organisations promoting sustainable forest management and eco-labelling. Finally, we identify a number of shortcomings and gaps in knowledge, which we hope can interest the scientific community and promote further research.

This review is, we feel, an important scientific step toward understanding and improving sustainable forestry practices for long-term biodiversity conservation. Even in the short term, however, significant improvements can be made to improve both conservation and the efficiency of forest management, and there is no need to delay action due to a perceived lack of information. In the longer term we hope that the recommendations from this review will be implemented, and that further research will continue to help foster an acceptable balance among the choices needed to maintain healthy wildlife populations and biodiversity in a productive forest estate.

This English language first edition will, we hope, be followed by a revised Indonesian version. Future revisions may also be possible. A comprehensive synthesis based on such diverse materials and viewpoints, can never be definitive: oversights and errors, and new advances, are inevitable-we would be grateful if readers would notify us of any corrections, suggestions or additions. Contact: Erik at emeijaard@samarinda.org or Douglas at d.sheil@cgiar.org

Erik Meijaard and Douglas Sheil

Bogor, Indonesia

October 12, 2004 


\section{Contributors' biodata}

Augeri, David. Born in 1962 in Connecticut, USA; holds an MSc in Ecology and Forest Sciences and is finalising a Ph.D. in Wildlife Ecology. Has been involved in research and conservation of Indonesian and Southeast Asian wildlife and forests since 1990, primarily focusing on tropical wildlife ecology and the effects of disturbance on the ecology of Sun Bears, other mammals and community dynamics in Borneo and Sumatra.

van Balen, Sebastianus (Bas). Born in 1954 in Arnhem, the Netherlands; obtained a Ph.D. with a thesis on the conservation of Javan forest birds. Has been involved with Indonesian birds since 1980, at present focussing on the birds of the Greater Sundas and Papua.

Dennis, Rona A. Born in 1964 in Inverness, Scotland. Obtained an M.Sc. in Environmental Remote Sensing and since 1988 has primarily focussed on the application of remote sensing and GIS in natural resource monitoring and management in mainland and Southeast Asia, and Indonesia in particular.

Duckworth, Will. Born in 1964 in England, holds a Ph.D. in Zoology; has been involved in research on Southeast Asian wildlife since 1986, primarily focussing on Lao PDR and neighbouring countries.

Fredriksson, Gabriella. Born in 1971 in Amsterdam, the Netherlands; now finalising a Ph.D in Conservation Biology. Has been involved in research on Sun Bears and protected area management in Kalimantan since 1994.

Indrawan, Muchamad. Born in 1962 in Surabaya, Indonesia, holds a doctorate in Conservation Biology; has been involved in research on Indonesian wildlife since 1985. Current interests expand to holistic biodiversity, the environment, and the country's regional autonomy. 
Inger, Robert F. Born 1920, St. Louis, Missouri, USA. Has been engaged in research on systematics and community ecology of amphibians and reptiles of Southeast Asia, principally Borneo, since 1950.

Iskandar, Djoko T. Born in 1950 in Bandung, West Java; obtained a doctorate from Université des Sciences et Technique du Languedoc, Montpellier, France in 1984. Currently Professor of Ecology and Biosystematics. Research interests include the evolution, ecology, conservation and biodiversity of small vertebrates of Southeast Asia.

Kartawinata, Kuswata. Born in 1936 in Garut, West Java, Indonesia, holds a Ph.D. in Plant Ecology; has been involved in research on forest ecology, vegetation, plant taxonomy, conservation and human ecology in Indonesia, especially Kalimantan.

Kingston, Tigga. Born 1968 in Vacoas, Mauritius (UK Citizen). Holds a Ph.D. in Ecology, Behaviour and Evolution. Research associate at Boston University and Director of the Malaysian Bat Conservation Research Unit. Research focuses on the diversity of insectivorous bats in Southeast Asia. Worked in Malaysia, Sulawesi, Indonesia, and Myanmar.

Lammertink, Martjan. Born in 1971 in Amsterdam, the Netherlands, writing a Ph.D. thesis on community ecology and disturbance responses of Asian woodpeckers; started fieldwork in Indonesia in 1997 and studied Eurasian and Neotropical woodpeckers prior to that.

Meijaard, Erik. Born in 1967 in Haarlem, the Netherlands, holds a Ph.D. in Biological Anthropology; has been involved in research on Indonesian wildlife since 1992, primarily focussing on the large mammals of western Indonesia.

Nasi, Robert. Born in 1959 in Nice, France, holds a Ph.D. in Biological Sciences (Ecology). Has been involved in research about biodiversity and managed forests since 1982, primarily focusing on vegetation on West Central Africa, Oceania and insular Southeast Asia. Currently Principal Scientist in the programme on Environmental Services and Sustainable Use of Forests of CIFOR.

O'Brien, Timothy. Born in 1955 in Ashtabula, Ohio, USA, holds a Ph.D. in Wildlife Ecology; has been involved in conservation research and management since 1975, specialising on large mammals and birds in tropical forest ecosystems.

Rachmatika, Ike. Born in 1959 in Kuningan, West Java, holds an M.Sc. in Fisheries and Allied Aquacultures. Since 1983 has been involved in research on fish systematics and ecology, primarily focussing on those in the western part of Indonesia. 
Rosenbaum, Barry. Born in 1953 in the United States. Holds a Ph.D. in Biology. Research since 1990 has focused primarily on the effects of human disturbance on primates in Southeast and South Asia.

Setyawati, Titiek. Born in 1962 in East Java, Indonesia. Currently pursuing a Ph.D. in Forestry and Wildlife Management at the University of Melbourne, Australia, focussing primarily on plant-animal interactions in lowland tropical rain forests of Indonesia.

Sheil, Douglas. Born in 1965 in Belfast, Northern Ireland, holds a D.Phil. in Forest Ecology; research interests centre on the monitoring and ecology of forest change (both natural and induced) in East Africa and Indonesia and the implications for conservation and management. Current initiatives focus on identifying conservation priorities defined by forest dwelling peoples.

Soehartono, Tonny R. Born in 1955 in Sukabumi, Indonesia. Holds a Ph.D. in Forest Ecology, and has been involved in tropical wildlife and forest research and management since 1983, primarily in non-timber forest products of western Indonesia.

Stanley, Scott. Graduated from North Carolina State University in 1981 earned an MSc degree in Forestry with a minor in Ecology. Has worked in the USA, Costa Rica, Bolivia, and Guatemala as a forester and silvicultural researcher. Since 1999, he has headed a community-based forestry project for Harvard University in West Kalimantan, and in 2001 began working for The Nature Conservancy in East Kalimantan.

Wong, Anna. Born in 1965 in Kota Kinabalu, Sabah. Holds an MSc. and is finalising a Ph.D. in Zoology. Has been involved in research on Sabah Wildlife since 1989, primarily focusing on amphibians and reptiles of Sabah and in the neighbouring state of Sarawak. Currently lecturing in Zoology at Universiti Malaysia Sabah.

Wulffraat, Stephan. Born in 1966 in the Netherlands. Landscape Ecologist. Has been working as the Conservation Biology coordinator at the WWF Kayan Mentarang project in East Kalimantan since 1998. Responsible for inventories and research on ecology and wildlife throughout the National Park, and in particular at the Lalut Birai field station. 


\section{Acknowledgements}

We appreciate the support of the Government of Indonesia, the Ministry of Forestry $(\mathrm{MoF})$ and Indonesian Institute of Sciences (LIPI). This study was initiated as part of the project on Forest, Science and Sustainability: Bulungan (Malinau) Model Forest, PD12/97 Rev. 1 (F) funded by the International Tropical Timber Organization (ITTO) and implemented by the Center for International Forestry Research (CIFOR), the Forest Research and Development Agency (FORDA) of the Ministry of Forestry of Indonesia and the forestry department of the Centre de Coopération Internationale pour la Recherche Agronomique en Développement (CIRAD-Forêt). The initial fauna reviews were conducted through a collaboration between CIFOR and the Wildlife Conservation Society Indonesia Program (WCS-IP).

The main funding which allowed us to continue and develop this research came from ITTO, and the European Commission (EC) in support of CIFOR's biodiversity research activities, with additional help from funds from the World Bank and from the MacArthur Foundation. The Swedish International Biodiversity Programme (SwedBio) kindly allowed some remaining funds to be used to support the production of this book. UNESCO provided funds, within the framework of their Man and Biosphere Program (MAB), to assist with the printing and dissemination of this book (special thanks to Hans Qunli, Enis Widjanarti and Kuswata Kartawinata). Individuals from a number of organisations have given freely of their time for which we are grateful.

We thank the experts who have given help and advice on specific aspects of this review including: Chandra Boer (Mulawarman University), Carol Colfer (CIFOR), Ed Colijn (Indonesian Nature Conservation Database), Bas E. van Helvoort (Tropenbos), James Jarvie (The Nature Conservancy), Frank Lambert, Vincent Nijman, Art Klasson, Martin Tyson, Lini Wollenberg (CIFOR) and Carey Yeager (USAID).

We are grateful for comments on the text—and editorial polish—from Marieke Sassen, Meilinda Wan, Sally Wellesley and Claire Miller.

Various people at CIFOR have helped and assisted at different points in this exercise: we especially acknowledge the support and efforts of Petrus Gunarso, Hari Priyadi, Nining Liswanti, Greg Clough, Glen Mulcahy, Ismayadi Samsoedin, Indah Susilanasari, Levania Santosa, Catur Wahyu, Gideon Suharyanto, Luluk Suhada, the CIFOR library staff and the Seturan Camp staff.

We are very grateful to Kimabajo, Rona Dennis, Gabriella Fredriksson, Rob Fimbel, Margaret Kinnaird, Martjan Lammertink, Dave Augeri and Sven Wunder for contributing their photographs to our book without charge. 


\section{Foreword}

Logging of tropical rainforests has a bad public image. Industrial logging is often associated with land clearing for agriculture or plantation crops. The rights of local people are often disregarded by loggers, and corruption and violence are frequently associated with timber operations. It is common for even relatively well-informed commentators to equate logging directly with deforestation and biodiversity loss. The general reaction of the conservation community is to oppose logging.

The reality is much more complex. Logging of tropical forests is often highly selective; sometimes just a few trees per hectare are removed. Numerous studies have shown that logged-over forests retain much of their original biodiversity (Whitmore \& Sayer 1992). Far more forests are allocated for logging than for national parks and equivalent protected areas and logged forests could be valuable resources for biodiversity. Pragmatism would suggest that we attempt to incorporate logged over forests and protected areas into multi-functional conservation landscapes; but little real progress has been made in translating such ideas into realities on the ground. The science that would be needed to achieve this manifestly desirable objective is generally lacking.

However, the recognition that logged-over forests have conservation value should not be interpreted to mean that all remaining Bornean forests should be made available for timber harvesting. Strictly protected areas remain essential for interior forest species. Effective management of both the protected and logged forests remains the key to successful conservation and this must be based on knowledge of the ecology of the forest.

One of the problems with modern conservation is that it is beginning to treat ecology as an irrelevance. The so called "Ecosystem principles" recently adopted by the Conference of the Parties of the Convention on Biological Diversity are mostly social and economic processes. Of the 12 principles only one refers to ecology and surprisingly the two references to the word biodiversity both concern achieving a 
balance between conservation and use (IUCN-WWF 2004). Compare this with the "Ecosystem Management" literature as used in the United States where detailed understanding of ecological processes is the main ingredient for forest management (Inter-Agency Ecosystem Taskforce 1995).

This volume is welcome in bringing new information and analysis to this subject. It is based upon work in the research forest of the Center for International Forestry Research in the Malinau area of Indonesian Borneo. It builds upon a considerable body of earlier work both on the people and the natural resources of the area (Puri 2001; Sellato 2001). CIFOR selected Malinau as a research area because it was an excellent example of an extensive forest area, rich in biodiversity and with significant populations of indigenous people still living close to the forest. At the same time it was rapidly being opened up for industrial logging, mining and estate crop development. It was seen as a location where it ought to be possible to steer development in the direction of a balanced landscape. Protected forests, managed forests and more intensively developed agricultural areas could be combined in a mosaic to achieve both conservation and development objectives.

One of the problems of much of the rhetoric about biodiversity conservation is that it leaves unanswered the fundamental questions about precisely which biodiversity is to be conserved and why. Much conservation appears to be driven simply by the desire to conserve as much biodiversity as possible, irrespective of the costs this might imply for people who depend upon the forests for their livelihoods. Arguments for the importance of biodiversity for ecological functions often exaggerate the potential risks of species loss. This book helps to establish a context for conservation and forest management programmes. It shows how knowledge of the ecology of the forests and their individual species is essential if sensible programmes for conservation are to be put in place. It helps to answer the questions about what would happen if unrestrained development were allowed to run its course.

What really emerges from this volume is that it is possible to assemble enough information on the ecology of an extensive tropical forest landscape to enable predictions to be made about the impacts of different sorts of development scenarios. It shows that different combinations of logging and protection and different patterns of infrastructure development will have different impacts on biodiversity and that these in turn will have impacts on the livelihoods of the people who depend upon this biodiversity.

The book draws on a vast range of literature and expertise. Studies of this kind are essential if we are to begin to address in a pragmatic way the complex realities of conserving tropical nature without placing excessive limits on the development options for the populations of the countries concerned. Ecosystem management is now a reality in many temperate and boreal countries and it is always based upon a deep understanding of the ecology of the forests. The developed world's forests are increasingly being managed in ways that do reconcile conservation needs with those of economics and local livelihoods. Progress in achieving this in the tropical 
xviii | Foreword

forests of the developing world is disappointingly slow. This book makes a major contribution to showing how ecological studies are essential if the benefits of ecosystem approaches to management are to be extended to the tropics.

\section{Professor Jeffrey A. Sayer}

Senior Associate

WWF, Avenue du Mont Blanc

1196, Gland

Switzerland 


\section{Executive summary}

Deforestation, forest degradation and hunting are having an increasing impact on wildlife in Borneo and many species are threatened. The Indonesian government has pledged to do its best to control these problems, a pledge that has been formalized in a range of laws and international agreements. But despite the need for immediate and definitive actions, achieving conservation goals remains fraught with challenges. Part of the problem is that conservation interest has focused on protected and unlogged forest, but we need to recognise that logged forest is a vital component of any comprehensive approach to landscape-scale conservation.

Our review focuses on the ecological and life history aspects of Bornean vertebrates and how these relate to forest management, with a specific emphasis on lowland and hill dipterocarp forest. But ecological studies seldom lead to improved forest management practices. Our review provides three responses to this:

1. Recommendations in the research literature are compiled and translated into management implications. These can be presented to those who need to know about them.

2. Knowing that a species declines with forestry interventions is seldom enough to clarify how forestry practices might be adapted (short of a ban) in order to mitigate the negative impacts. We set out to link species sensitivity with ecological and life history correlates to develop a better understanding of why a given taxon is vulnerable, allowing a more species-specific approach to the protection of habitat characteristics and components.

3. Research needs to answer management relevant questions. We identify priority topics for research.

Our primary intention is thus to identify and clarify what makes fauna vulnerable to various kinds of forestry-related interventions. Based on these results, insights and related hypotheses, we compile and develop recommendations for improved management practices and identify priorities for future research. We are pragmatic: 
we acknowledge the critical role of the socio-political context for implementing our proposals. Yet, while various key issues are raised, the pace of change in Indonesia is currently so rapid and the issues so complex that our discussion of this context cannot resolve all the current and future opportunities. We focus, therefore, on technical ecological information, the validity of which is independent of volatile local politics.

We found a considerable body of ecological information relevant to the management of tropical forests and their wildlife. Improving current management practices requires collaborations between ecologists and forest managers to develop pragmatic guidance for improved practices. The present review and synthesis is one component in achieving this collaboration, focusing upon the fauna of the Malinau area in East Kalimantan (Indonesia).

In Part I of this book we summarize knowledge concerning various forest interventions and how they affect selected wildlife species. We identify a range of effects caused by timber harvesting, and note the associated influences of hunting and forest fragmentation. Additional problems are caused by exotic species, law enforcement, fires and a range of other factors. Yet despite decades of wildlife research on Borneo there is little information on the magnitude and mechanisms of threats to wildlife. Most studies considered in this book report on autecological studies of various species, but do not analyse species characteristics in relation to different threat levels. Still, we are able to draw various conclusions about the effects of timber harvesting and associated factors on wildlife, and provide general management recommendations.

Selective logging has fewer direct negative consequences for many vertebrate species than is sometimes assumed. It certainly affects certain groups of species, like terrestrial, insectivorous birds and mammals, which suffer from the reduced ground cover. This may primarily be caused by the slashing of ground cover and lianas, which is currently required by law. Some species, though, such as deer and banteng, appear well adapted to, and can increase in, the more open habitats that follow logging.

Timber harvesting generally brings a number of associated problems in addition to the direct disturbance of forest habitat. Two important aspects, from a wildlife conservation perspective, are increased hunting and forest fragmentation.

Hunting can pose a considerable threat to some forest fauna and this threat often increases with forestry roads, increased access to forests and the provisioning needs of camps. Improved hunting technologies and increasing availability of guns add to the pressure.

Roads, skid trails and degraded areas fragment forest habitats. Small isolated populations, such as those created by fragmented or heavily harvested landscapes, are at much greater risk of various deleterious effects that can ultimately lead to local extinction. Some species have minimum fragment size requirements for population persistence. Recent research has highlighted the importance of maintaining 'forest-like' habitats, or a network of 'forest stepping-stone' habitats in the intervening landscape. The effects seem likely to be worst in forests with excessive road density, wide clearings, and many large deforested openings. Forest edges can generate significant effects on individual, population, and community dynamics in remaining forest areas. Several studies report that the effects of logging can extend considerable distances into surrounding undisturbed forests. 
In Part II of this book we analyse species in relation to their tolerance to the effects of logging and forest change. Using multivariate analyses we identify various factors associated with bird and mammal species that are vulnerable to logging interventions. These factors are dietary specialization, restricted feeding strata, endemicity, apparent evolutionary age (those that evolved during the Miocene or Early Pliocene) and absence from small islands. Factors which we found not to be significant in our data set are group size, number of young per litter, body weight and home range size. Terrestrial insectivores and frugivores appear particularly sensitive to timber harvest practices, whereas herbivores and omnivores were more tolerant or even benefited from logging.

Based on these findings we provide recommendations on forest management for concession managers, local and national governments, in Part III. We support the application of good conservation planning, good road building and reduced impact logging methods. Specific recommendations include the retention of ecologically important habitat structures (large trees, hollow trees, fruiting species) and locations (salt licks, watercourses). In terms of silvicultural practices we recommend that understorey slashing (currently a legal requirement) be discontinued.

We recommend regulating hunting in timber concessions; law enforcement authorities and concession managers must be able to control this. Hunting of vulnerable species would ideally be eliminated.

It is important to retain a contiguous forest. Where forest areas are broken up by wide-roads, logging and agriculture, forest corridors should be maintained as much as possible to maximize connectivity within the forest matrix. At the concession level, retaining linear forest elements (e.g., riverine forests) as corridors between forest blocks can increase faunal dispersal and thus the chances of species survival in forest patches. Reducing the width of roads and tracks, maintaining canopy connectivity over roads, and limiting felling-gap sizes, should also reduce the effects of fragmentation on arboreal species.

In addition to these more general recommendations, we suggest many specific actions that might help the conservation of several specific species. Examples include the need to set aside sufficiently large areas for protected large carnivores (Malayan Sun Bear, Clouded Leopard), retain large dipterocarp trees for Helmeted Hornbill nesting and for Great Slaty Woodpecker feeding, and regulate collection of freshwater turtles.

We highlight, amongst other things, how governments can better support wildlife conservation in forestry concessions. The government has the important task of evaluating the list of species presently protected in Indonesia, as many rare and endangered species are missing from the list (e.g., Straw-headed Bulbul). We call for an operational action plan to ensure that clear conservation goals are effectively implemented at the concession level (current requirements, though well-intended, have little impact on management choices). We find several areas where effective biodiversity-friendly forestry management is limited by our lack of knowledge. In Part IV we focus on this and provide research recommendations. While research will continue to contribute to our understanding of how timber harvesting practices and their associated impacts might be refined to benefit wildlife conservation, a lack of knowledge cannot be used to justify delay in implementing our main recommendations. We may not yet be in a position to describe and advocate perfect management, but we can definitely propose substantial improvements of current practices. 


\section{Abbreviations}

\begin{tabular}{|c|c|}
\hline $\begin{array}{l}\text { ANOVA } \\
\text { asl }\end{array}$ & $\begin{array}{l}\text { Analysis of Variance (statistical method) } \\
\text { above sea level }\end{array}$ \\
\hline CATPCA & Categorical Principal Components Analysis (statistical method) \\
\hline CIFOR & Center for International Forestry Research \\
\hline CIRAD & $\begin{array}{l}\text { Centre de Coopération Internationale pour la Recherche Agronomique } \\
\text { en Développement }\end{array}$ \\
\hline CITES & Convention on International Trade in Endangered Species \\
\hline dbh & diameter above breast-height \\
\hline EC & European Commission \\
\hline EIA & Environmental Impact Assessment \\
\hline FORDA & Forestry Research and Development Agency \\
\hline FSC & Forest Stewardship Council \\
\hline GIS & Geographical Information System \\
\hline HTI & Hutan Tanaman Industri (Industrial Forest Plantation) \\
\hline ITTO & The International Tropical Timber Organization \\
\hline IUCN & The World Conservation Union \\
\hline KSDA & $\begin{array}{l}\text { Konservasi Sumber Daya Alam (Regional Government Agency for the } \\
\text { Conservation of Natural Resources) }\end{array}$ \\
\hline LIPI & Lembaga Ilmu Pengetahuan Indonesia (Indonesian Institute of Sciences) \\
\hline $\mathrm{MoF}$ & Ministry of Forestry \\
\hline MRF & Malinau Research Forest \\
\hline MUS & Malayan Uniform System \\
\hline Mya & Million years ago \\
\hline NGO & Non-Governmental Organisation \\
\hline NP & National Park \\
\hline NPLD & Non-Pioneer-Light-Demanding species \\
\hline RIL & Reduced Impact Logging \\
\hline SD & Standard Deviation \\
\hline ТHPB & Tebang Habis Permudahan Buatan (clear felling with artificial regeneration) \\
\hline TNC & The (US) Nature Conservancy \\
\hline TPTI & $\begin{array}{l}\text { Tebang Pilih Tanam Indonesia (the Indonesian selective cutting and } \\
\text { replanting system) }\end{array}$ \\
\hline UNESCO & United Nations Educational, Scientific and Cultural Organization \\
\hline WCS & Wildlife Conservation Society \\
\hline WWF & World Wide Fund for Nature \\
\hline
\end{tabular}




\section{Introduction}

\section{Justification}

Tropical rainforests are the most species-rich terrestrial ecosystems on earth, but these forests are rapidly disappearing as land is cleared for timber, agriculture and other uses. Strictly protected areas are never likely to be large enough to conserve all species (Fimbel et al. 2001). Thus, the fate of many species depends upon what happens to forests outside of protected areas.

Forest areas maintained for timber production represent an opportunity for biodiversity conservation. Although not a substitute for nature reserves, many species could be conserved within a forest estate that is carefully managed on an ecologically sustainable level (Frumhoff 1995). Exploitation of natural forests generally involves some modification to the ecosystem, resulting in some change in the flora and fauna. However, management choices and operational practices can greatly influence the nature and degree of these changes. Since most tropical forests are considered poorly managed, not just for biodiversity conservation but also for productive exploitation (Poore et al. 1989; Putz et al. 2000, 2001a), there is much room for improvement (Hunter 1990; Johns 1997; Sheil \& van Heist 2000). Various national and international initiatives are seeking constructive ways of responding to this challenge and must be encouraged to recognise the significance and value of available knowledge and attainable improvements in management.

Current efforts to improve tropical forest management are largely preoccupied with silvicultural (timber production related) practices and socio-cultural issues. Yet, many ecological and zoological studies, while not addressing forest impacts directly, contain relevant information about life history and habitat requirements for potentially vulnerable taxa and various forest values. Ecological studies of individual species can identify possible changes in feeding, seed dispersal, pollination, ranging or other behaviour following logging, and how these changes may affect both animal population change and forest ecology. Such information can guide forestry activities and supplement studies examining logging impacts on density and distribution. 
This review is based on the premise that sustaining biological diversity in production forests requires environmentally sound management practices that incorporate available knowledge concerning species vulnerability to interventions, and that this is achievable. Tropical ecologists often choose to emphasise how little is known about tropical forests. Obviously more research would be useful, but 'lack of knowledge' cannot be an excuse for the prevalence of poor practices in tropical forest management. We recognise that many of those involved in tropical forest management have limited access to the ecological literature and subsequent insights required for effective action, or indeed lack the means to translate such information into real actions. Thus, help and collaboration are needed from the many researchers in tropical biology disciplines who have completed work directly or indirectly relevant to improving forestry practices in tropical landscapes (Sheil \& van Heist 2000).

\section{Goals}

Many studies have attempted to identify which taxa are vulnerable to timber harvesting. Researchers normally claim the goal of informing better conservation. However, their findings seem to have little influence at present. We consider and address three problems that appear related to this. Firstly, the recommendations made by past studies have seldom been compiled and presented as recommendations to those who need to know about them in order to manage forests better-to address this we intend to search publications to compile such proposals. Secondly, a study may show that a species declines, but this is seldom enough to clarify how forestry practices might be adapted (short of a ban) in order to mitigate the negative impacts - to address this we set out, as part of our review, to try and link species sensitivity with ecological and life history correlates. This might allow us to develop a better understanding of why a given taxa is (or might be) vulnerable, which would permit both a more nuanced approach to wildlife conservation in forest concessions by working with managers to improve the protection of specific habitat characteristics or components, and a more hypothesis-driven approach to forest management science. Thirdly, research can be examined in order to clarify how it might be made more relevant (is it answering the right questions? What are the right questions?) —-we suggest a number of priority topics based on our review.

\section{Focus and wider relevance}

We are primarily concerned with lower altitude dipterocarp forests $(<600 \mathrm{~m}$ asl $)$ in Borneo, although much of our discussion may be applicable wherever forests share similar structure and fauna. Our review focuses on the forests and forest fauna of the Malinau watershed, Malinau District, East Kalimantan, Indonesia (Fig. 1), where CIFOR has been conducting a range of studies in the Malinau Research Forest (MRF, see later for details). Until recently, the Malinau watershed was little known biologically. The rugged and forested landscape, close to the Kayan Mentarang National Park, is suspected to have a high value in terms of its plants and animals. For example, Meijaard and Nijman (2003) recently found that this area has the 
highest primate diversity in Borneo; data from forest plots suggest higher tree species densities than yet recorded elsewhere in Indonesia (CIFOR unpubl.).

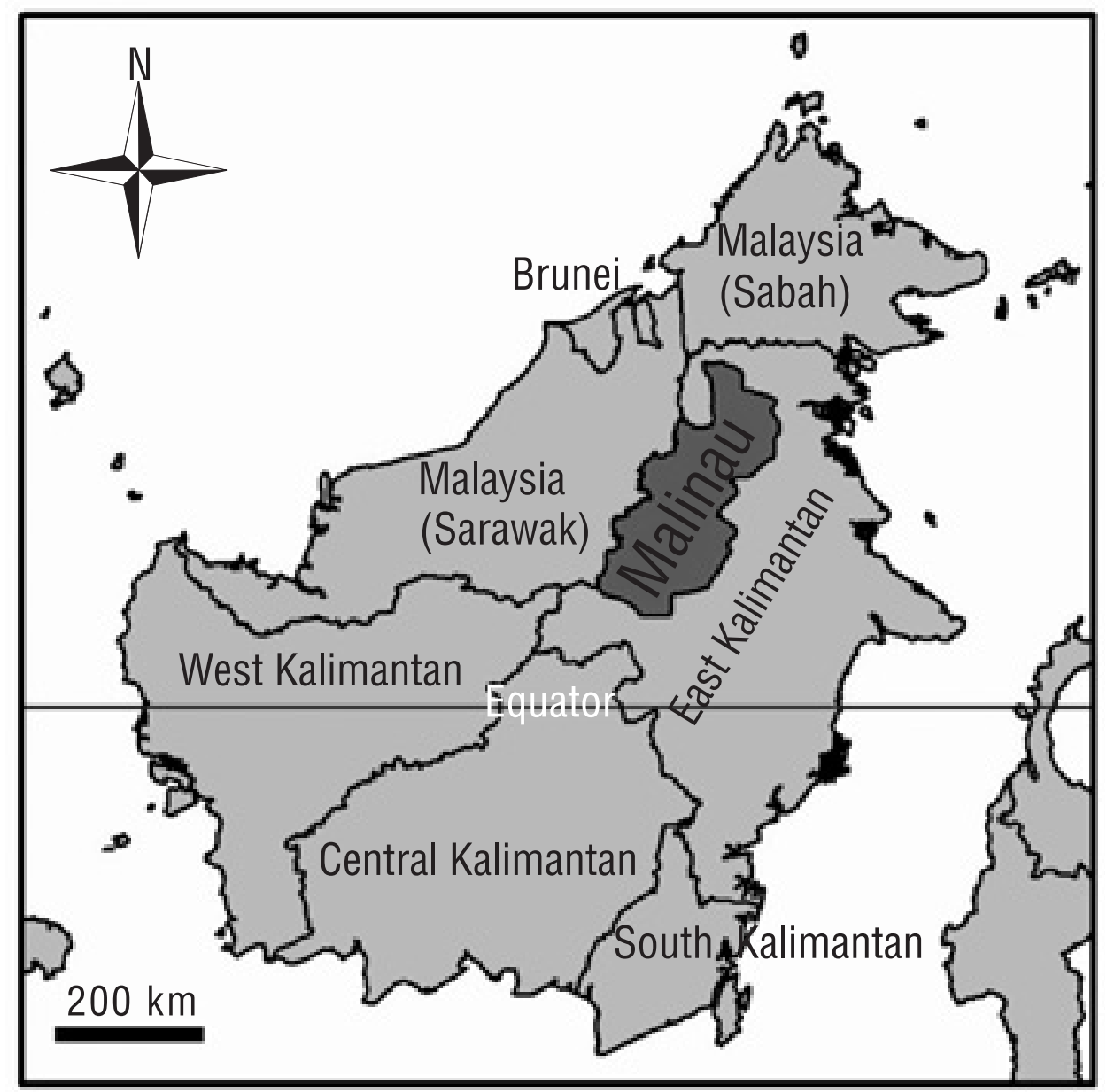

Figure 1. Map of Borneo, showing the Indonesian provinces, the Malaysian states, Brunei, and the location of the Malinau District.

A major emphasis of CIFOR's research in collaboration with LIPI, FORDA, WCS and others (see Abbreviations), has been to document this biological wealth. This research has three major strands: 1) determining the distribution of fauna and flora (Hedges \& Dwiyahreni 2002; Iskandar 2004; O’Brien 1998; O’Brien \& Fimbel 2002; Rachmatika et al. 2005), 2) assessing to whom this biodiversity matters and in what way (e.g., Sheil et al. 2003a), and 3) identifying the steps needed to maintain this in the future (e.g., this document). Together, these three strands of information can inform a wide range of processes, from local considerations for the development of reduced impact logging guidelines to international forestry and conservation policy.

The species we consider are generally found in other parts of Borneo (including the Malaysian states of Sabah and Sarawak and the Sultanate of Brunei), and in similar forests in Sumatra and Peninsular Malaysia. Indeed, in assembling what is 
known about the wildlife in Malinau we draw on many studies from other parts of the region. Peat swamp and heath forests (kerangas) are beyond the scope of our review due to their distinct ecological features. But many aspects, including our conclusions, will have wider relevance to other Southeast Asian dipterocarp forests.

It is often difficult to determine the mechanisms by which forestry interventions affect wildlife. A study may show that a species is rarer in logged forest than in primary areas, yet without an understanding of the mechanisms and processes underlying such differences it is difficult to determine how forest management practices could or should be modified to have fewer impacts.

Ecological studies help determine a range of actual and potential factors that may influence various taxa under particular circumstances. A clearly argued account of the various ecological details that might be addressed in good harvesting practices can serve as a guide to the development of more wildlife-friendly logging practices.

\section{Wildlife is important}

Why does Indonesia want to conserve wildlife? Firstly, Law of the Republic of Indonesia Number 5 Year 1990 legally protects many of the vertebrate species in the Malinau area. This law recognises that all elements of living resources and their ecosystems are interdependent, and deterioration or extinction of one element leads to damaging ecosystems as a whole (Ministry of Forestry 1990). Also, the Act prohibits any activities detrimental to the survival of protected species (Ministry of Forestry 1990) (for details see Appendix 9). The Law of the Republic of Indonesia Number 41 Year 1999 on Forestry (see Appendix 10 for relevant articles) further specifies the need for wildlife conservation. Traditionally, species conservation has been addressed in specially designated areas, but it is increasingly recognised that production forests provide additional opportunities. The improved management of a 'High Conservation Value Forest' has thus become an important new element in national and international forestry policies. High Conservation Value Forests (Colchester 2000; Jarvie et al. 2002; Jennings et al. 2002) also aim to protect wildlife that is highly significant not only to the international community, but also to local communities (Sheil et al. 2003c; P. Levang pers. comm.). For example, the majority of animal protein consumed in most of Borneo's indigenous communities is derived from wild sources, particularly many Bornean vertebrates (e.g., Bennett et al. 1999; Caldecott 1988; Puri 1997; Rijksen \& Meijaard 1999). Animal-based products are also important in trade, e.g., edible swift nests (Collocalia spp.) and bezoar stones (see Puri 2001; Sellato 2001). Further, there is a demand for a number of species, (hornbills, Argus Pheasant, Clouded Leopard) to fulfil ritual and cultural needs, and several species have medicinal values (e.g., Sun Bear and turtle bile to treat eye ailments' and for other purposes) (Sheil et al. 2003b).

During the past two decades field studies of vertebrates have repeatedly demonstrated the significance of mammals and birds as important elements in the complex web of mutualistic relationships that help maintain the taxonomic and structural diversity of tropical forests (Fimbel et al. 2001). Seed dispersal and predation are two of the most studied roles of mammals and birds in tropical rain 
forests (Gautier-Hion 1984; Gautier-Hion et al. 1985). Many mammals and birds exhibit trophic foraging strategies that include the consumption of fruits or their constituent parts. At the same time, a great number of plants rely upon vertebrates as seed dispersers or pollinators. Such services by vertebrates can regulate the recruitment of trees by selectively predating and/or dispersing seeds (Curran \& Webb 2000). By selecting seeds of certain species over others, they can actively influence the competitive hierarchy that establishes the relative recruitment success of co-occurring canopy tree species. Vertebrates have also developed a set of strategies to access scarce food resources and avoid competition with ecologically related species (Brown et al. 1976; Lambert 1989a). The ways in which vertebrates influence forest ecosystems include:

- Herbivory-grazing and browsing animals influence the structure and composition of the vegetation, while heavy and hoofed animals locally compact soils, thereby helping to break up organic matter and influencing erosion;

- Predation on potential animal pest species-predators large and small can check outbreaks of pest species;

- Seed germination - the seeds of certain plant species benefit from passing through the digestive tract of a mammal or bird in order to germinate or to increase ultimate viability. Furthermore, animals bury seeds, or turn them up;

- Habitat engineering - animals excavate holes, create pools and wallows (e.g., Sus barbatus), turn and aerate soil and litter, and help process and break down organic matter. All these activities have various secondary effects on the local ecosystem, for instance, by affecting the turnover and movement of nutrients.

From a forest use perspective there are also numerous reasons to protect wildlife. Many species directly influence the processes of forest regeneration that are required for long-term sustainability of timber production (Kinnaird 1998; Curran \& Leighton 2000; Curran \& Webb 2000). Such roles include pollination and seed dispersal and seed predation. One of the favourite fruit trees in Asia, the durian (Durio spp.) is pollinated by cave-dwelling bats. Commercial crops such as coffee (Coffea canephora) can benefit from a species-rich and abundant bee assemblage, which in turn depends on the preservation of natural forests and forest fragments in the vicinity $(<500 \mathrm{~m})$ of those coffee agroforestry systems (Klein et al. 2003). Payne (1995) reported that at least 450 economic products including timber, fruits, fuelwood, fibre, medicines, tannins and dyes, are derived from plants for which fruit bats are pollinators or dispersal agents. These services are rarely well recognised but their loss has major long-term implications for all forest derived products and services.

The widespread loss of larger forest wildlife throughout the tropics has been called the 'empty forest' syndrome, and some already view such forests as 'ecologically dead' (Redford 1992). The longer-term impacts of animal loss remain hard to specify since we lack basic information, but they are likely to be substantial, involving changes in forest composition and structure (Campbell 1991; De la Cruz \& Dirzo 1987; Sheil 1998) along with the deterioration or loss of important ecological services ('half-empty forest': Redford \& Feinsinger 2001). 
6 | Introduction

In summary, wildlife conservation in logging concessions is not only a legal requirement (for protected species), but can improve the long-term sustainability of timber production. So far, few forestry researchers have addressed wildlife issues. For example, of the more than 1,000 invited and voluntary papers presented at the 2003 World Forestry Congress, only a handful (less than 1\%) discussed issues related to biodiversity, wildlife species, or wildlife ecology. Although many researchers have studied these issues, few seem to be effectively communicating their hard-won research conclusions to those who make decisions on forests. Research objectives and approaches can be revised so as to better meet the crucial need of being able to provide forest managers with information and recommendations on the role of wildlife in forests. 


\section{Focal area}

The rainforests of Borneo are globally renowned for their high species richness and endemism (e.g., MacKinnon et al. 1996; Meijaard \& Nijman 2003). Indeed these forests are some of the most species rich in the world (Richards 1996; Whitmore 1990a), typically with $150-200$ species of trees (>10 cm dbh) per hectare. Borneo has a rich flora, with 10,000 to 15,000 species of flowering plants (MacKinnon et al. 1996). Approximately 37 species of birds, 44 land mammal species and about 34\% of all plants are endemic to the island (MacKinnon et al. 1996).

Borneo still contains important populations of vertebrate species that are now rare or extinct in other parts of their ranges, e.g., the Malayan Sun Bear (Ursus malayanus) ${ }^{1}$ and the Clouded Leopard (Neofelis nebulosa).

\section{Location}

Our focal area lies in Malinau District, in East Kalimantan, about 3 degrees north of the equator in a block $2^{\circ} 45^{\prime}$ to $3^{\circ} 21^{\prime}$ North and $115^{\circ} 48^{\prime}$ to $116^{\circ} 34^{\prime}$ East, adjacent to the Kayan Mentarang National Park. This is the heart of the largest more or less continuous area of rainforests remaining in tropical Asia, representing more than 5 million ha and encompassing parts of Central and East Kalimantan, Sarawak and Sabah (Fig. 2). The climate is equatorial with an annual rainfall measured at ca. 4,000 $\mathrm{mm}$.

When CIFOR was established in 1993, the Indonesian Government committed itself to providing a forest area where CIFOR could conduct long-term research. This location in East Kalimantan was selected in what was then Bulungan District (now Malinau). CIFOR's principal study location since then lies between the Seturan and Rian Rivers (major tributaries to the Malinau) in the upper Malinau catchment, within a 48,000 ha forest concession managed by INHUTANI II, a state-owned timber company.

${ }^{1}$ In light of its relatively recent divergence from other Asian bears, we follow Meijaard's proposal to refer this species to Ursus (Meijaard 2003c, 2004), rather than to its own subgenus. 
Altitudes in the main study area where surveys have been conducted range from 100 to $500 \mathrm{~m}$ asl, with some camera trapping surveys up to $900 \mathrm{~m}$ asl. The topography is deeply eroded with a dense network of steep ridges and drainage gullies. The rugged terrain reveals erosion, even in primary forests, and the general erosion risk is high. In some areas, timber harvesting has led to soil compaction, slowing forest recovery.

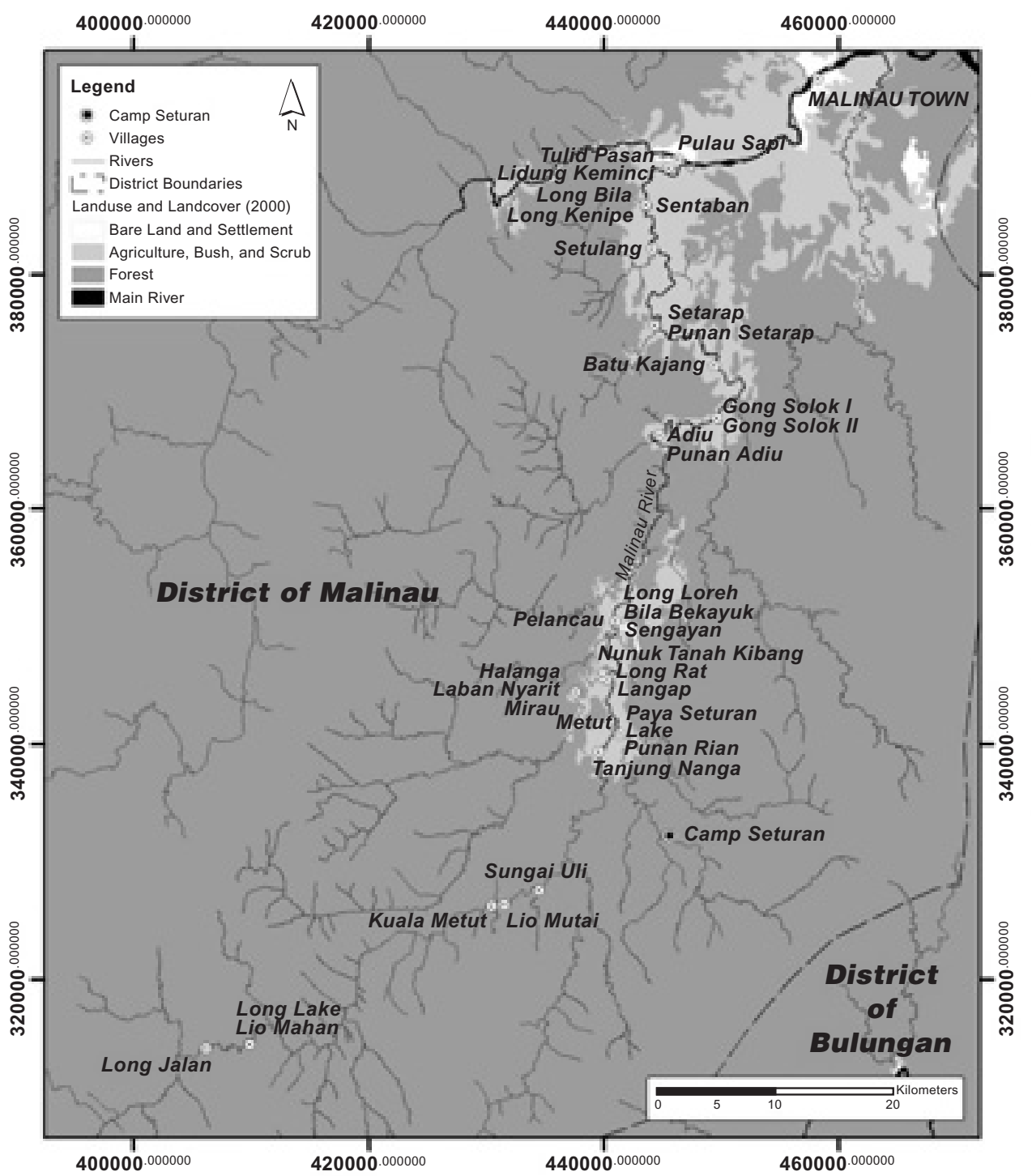

Figure 2. Location diagram of the MRF study site.

The region contains diverse geological formations-volcanic, sedimentary and alluvial-and includes coal seams and ancient limestone reefs, but there is little information on soils or the potential for non-forest land-uses. Research in the region shows that soils, though diverse, are very poor in the nutrients that support plant growth (Basuki \& Sheil 2005). The fertility is low because of high acidity and 
limited cation exchange capacity, organic carbon, phosphorus and base (nutrient) saturation. Pan formation, aluminium toxicity and steep, difficult terrain further limit cultivation opportunities. Soil hardening (hard-pan formation) was evident in almost one third of plots and further reduces land use options. The most fragile soils in terms of sustainability are thin soils (entisols) on steep slopes, and soils developed on white sand (also entisols); natural vegetation cover in these sites can prevent the development of low productivity grasslands (Fig. 3). Basuki and Sheil (2005) indicated that all soils they evaluated across 200 sites in the upper Malinau (including what locally appeared to be the most promising), are unsuitable for sustainable production of crops like pepper, coffee, cocoa, candlenut, rubber and oil palm. However, a few sites have some potential for sustained field rice and coconut cultivation. All the sites deemed suitable for rice are already under cultivation (or fallow) and even these sites are far from ideal, as nutrient status is low and flood risks appear high. General site fragility, especially the high erosion risks, must constrain any plantations outside the limited alluvial plains. There appears, therefore, little room for large-scale plantation agriculture (Basuki \& Sheil 2005).

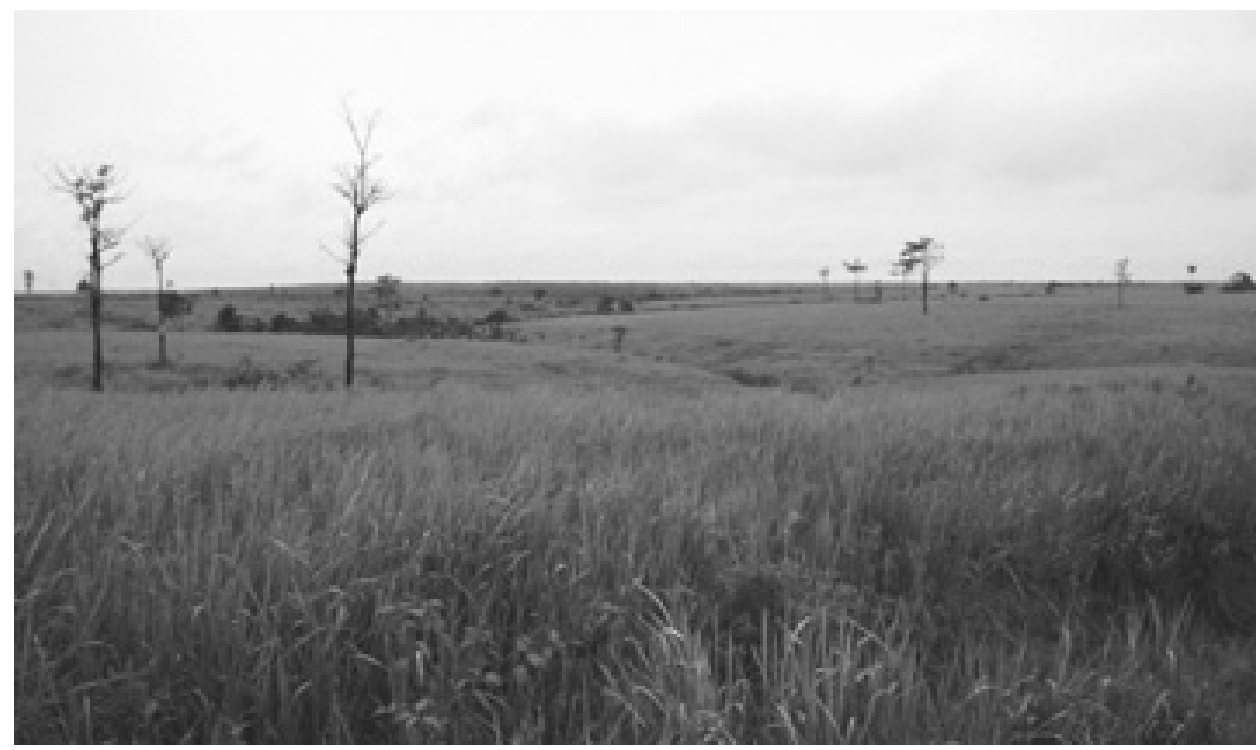

Figure 3. Repeated logging and fires of forests on poor soils in East Kalimantan resulted in extensive areas of unproductive Imperata cylindrica grasslands. (Photo by Rona Dennis)

\section{People and change}

The indigenous population in the Malinau watershed consists of various ethnic groups, including Merap, Punan and Kenyah. There is also a small but influential presence of Javanese and Madurese transmigrants. In some villages, the number of outsiders has changed rapidly due to the reliance by most logging concession activities on a non-local workforce. In some recent cases we also note the implementation of local concessions by senior villagers themselves, but it is unclear how this affects the ratio of local to outside labour. Human population densities across the upper 
watershed remain low $\left(<1 \mathrm{~km}^{2}\right.$, in Sheil et al. 2003c) and most settlements are based near rivers.

Principal livelihood activities are swidden farming and collection of high value forest products (i.e., gaharu (derived from Aquilaria spp.), bird's nests). However, most communities still rely on wild products for many subsistence needs. Animal protein ranks high amongst these. There is also a strong cultural link to many products, including those required for ornamentations (e.g., hornbills, Malayan Sun Bears and Clouded Leopards) (Uluk et al. 2001). Methods of hunting are largely traditional but firearms (although technically illegal) are common. The most popular method for hunting larger animals is the use of dogs to run down pigs and deer. Another favoured approach is to silently ambush animals - sometimes from specially built platforms - in favoured sites such as salt springs or fruit groves. For this the use of poisoned darts from blowpipes remains popular as guns tend to scare off animal groups. Meat trading is an increasingly popular way to earn income and most restaurants serve local deer species (despite these being protected species). For many communities there were traditional prohibitions on the eating of various wildlife species. Although the church has managed to erode these taboos, which are rare amongst younger people, some restraints remain. For example, based on traditional beliefs many older people avoid monkey and snake meat, and women avoid eating bear (Sheil unpubl.).

Roads and motorized boats now mean that the demand for meat in Malinau town is increasingly met in more distant areas. A trade in live animals for halal killing (for Muslim consumption) is also developing in the town. Although data for the Malinau area are lacking, information from adjacent areas such as the Kayan Mentarang National Park (Meijaard 2003a) and large parts of Sarawak (Bennett et al. 1999; Bennett \& Robinson 2000) indicates that hunting is increasingly unsustainable.

Government processes such as those granting concessions or logging permits have long ignored traditional land claims (e.g., Down to Earth 2002). This tension between state tenure and traditional systems is one of the greatest challenges in sustainable forest management, and one that is found in many regions of the world. In the Malinau region, the entire area is divided by traditional claims. Nonetheless, the Indonesian government has allocated most of the area to timber concessions with scant regard for these prior claims. Past government policies have favoured concessionary claims over traditional rights and most of the area is now officially classified as production forest estate. Some of the steeper land is designated as butan lindung or protection forest, though this designation is haphazard. Much of the more accessible land has been logged or will be in the near future. However, many areas that 'have been logged' according to maps, turn out to have been inaccessible, meaning that patches of primary forest vegetation occur in officially 'post-logging areas'.

Some social problems arise from provincial resettlement policies that have moved some previously remote communities into more accessible areas that traditionally belong to other villages. Nevertheless, the government has made special efforts to settle the Punan and other upriver peoples and encourage their agricultural development (Kaskija 1995; Puri 1998; Sellato 2001). Improved health care services and educational opportunities in Malinau and some of the larger neighbouring 
settlements have also attracted families from more remote sites. This gives rise to new local pressures and conflicts, and results in traditional community land claims in areas distant from their present location (van Heist \& Wollenberg 2000).

Economic growth during the late 1970s exerted various influences on local communities, such as easier access to boat engines and chainsaws, along with increasing exposure to national programmes of education and health care. Outside influences further increased when, in 1996, coal mining began to encroach into the area and had a growing impact on the forest resources and immigration. The economic crisis in Indonesia (beginning in 1997) has driven further changes. The depreciation of the Indonesian currency and the increase in the export market value of palm oil and coal led to a rapid expansion of prospecting, often through poorly regulated private investors.

There are several plans for large road building projects. For instance, roads are being designed to connect Malinau with the upper Baram area in Sarawak and another one is under construction between Malinau and Long Alango on the upper Bahau River at the edge of the Kayan Mentarang National Park. These and other roads, the accompanying rights to extract timber from wide strips of forest on either side of the road (as much as a $1 \mathrm{~km}$ strip of forest adjacent to the road is currently allowed in some areas), and the inevitable spur roads, tracks and trails developed off the main road would significantly add to the fragmentation of the landscape. Because of the ruggedness of the terrain, these roads are expensive to build and maintain and the economic viability of these projects remains contested.

\section{Decentralisation}

The decades of the Soeharto era were characterized by centralized control (Lynch \& Harwell 2002). However, since 1999 (Law No. 22/1999 on Regional Autonomy and Law No. 25/2000 on Fiscal Decentralization), the process of regional autonomy has shifted authority for much decision making to district authorities. Local people are finding themselves increasingly empowered in the decisions that affect them, and there is an increasing willingness to bring conflicts or protests to local authorities (for an overview see Sellato 2001).

The recent devolution of power from the central government to the district level is having major effects. Local authorities now allocate logging and land clearing permits. For instance, permits for oil palm estates are given for areas that are still the subject of prior logging agreements. Many of the changes have been challenged, and in Malinau such permits are no longer being granted. At the time of writing, the Central government has been attempting to regain control over various aspects of resource management. The overall situation is one of confusion: regulations, roles and ultimate authority on land issues are in flux (Colfer \& Resosudarmo 2002).

\section{Forest management}

Timber cutting in this area is supposed to follow the TPTI (Indonesian selective cutting and replanting system), a silvicultural system based on minimum cutting 
diameter limits and assisted forest regeneration (see Appendix 11 for details, further discussions follow below). INHUTANI II, a state forestry company, is probably a more conscientious operator than many others, and they often take a much smaller volume than they legally could from any given area.

In addition to certain logging practices, another localized threat to forest and wildlife in the Malinau Research Forest $\left(\mathrm{MRF}^{2}\right)$ area is coal mining. The coal mining is associated with small logging operations and mining staff commonly partake in hunting via existing logging roads. In addition, the rapid development of new settlements close to Long Loreh (see Fig. 2) has led to expansion of gardens.

\section{Wildlife surveys}

To initiate evaluation and monitoring in the Malinau Research Forest (MRF), CIFOR invited the Wildlife Conservation Society-Indonesia Program (WCS-IP) to conduct two preliminary faunal diversity assessments in the region in 1997 and 1999. Among the objectives of these surveys was the development of a baseline dataset for some major vertebrate taxa (birds, primates and other mammals). Standardized surveys resulted in the identification of 37 species of mammals (excluding bats) and 239 species of birds, documenting approximately $56 \%$ and $86 \%$ of mammal and bird species respectively that potentially occur in the MRF (O'Brien 1998; O'Brien \& Fimbel 1999). More recent surveys in 2003, including camera trapping, have validated and added to this mammal list (Augeri in prep). Separate surveys recently documented 42 fish species (Rachmatika et al. 2005, see Appendix 8), 40 amphibian species (Iskandar 2004; Lang \& Hubble 2003, see Appendix 6) and 55 reptile species occurring within the MRF (Appendix 7). Sixty-five of the surveyed species are protected, of which 17 are mammals and 48 are birds (Table 1 and Appendix 9).

Table 1. Protected mammals and birds of the Malinau area (information from Appendices in this report and Ministry of Forestry 1992; PHPA 1996a, b; Noerdjito \& Maryanto 2001).

\begin{tabular}{ll}
\hline Scientific name & English name \\
\hline Tarsius bancanus & Tarsier \\
\hline Nycticebus coucang & Slow Loris \\
\hline Hylobates muelleri & Bornean Gibbon \\
\hline Presbytis rubicunda & Maroon Leaf Monkey \\
\hline Nasalis larvatus & Proboscis Monkey \\
\hline Manis javanica & Pangolin \\
\hline Hystrix brachyura & Common Porcupine \\
\hline Ursus malayanus & Sun Bear \\
\hline Arctictis binturong & Binturong \\
\hline
\end{tabular}

2 The Bulungan Research Forest (BRF) was recently renamed the Malinau Research Forest (MRF); the latter name will be used in the rest of the document. 
Table 1. Continued

\begin{tabular}{|c|c|}
\hline Scientific name & English name \\
\hline Prionodon linsang & Banded Linsang \\
\hline Cynogale bennettii & Otter-Civet \\
\hline Felis bengalensis & Leopard Cat \\
\hline Pardofelis marmorata & Marbled Cat \\
\hline Neofelis nebulosa & Clouded Leopard \\
\hline Bos javanicus & Banteng \\
\hline Cervus unicolor & Sambar Deer \\
\hline Muntiacus muntjak & Red Muntjac \\
\hline Tragulus javanicus & Lesser Mouse Deer \\
\hline Tragulus napu & Greater Mouse Deer \\
\hline Casnierodius albus & Great Egret \\
\hline Egretta intermedia & Plumed Egret \\
\hline Egretta garzetta & Little Egret \\
\hline Aviceda jerdoni & Jerdon's Hawk \\
\hline Pernis ptilorhynchus & Oriental Honey-Buzzard \\
\hline Haliastur indus & Brahminy Kite \\
\hline Ichthyophaga humilis & Lesser Fish-Eagle \\
\hline Spilornis cheela & Crested Serpent-Eagle \\
\hline Accipiter trivirgatus & Crested Goshawk \\
\hline Ictinaetus malayensis & Black Eagle \\
\hline Hieraaetus kienerii & Rufous-bellied Eagle \\
\hline Spizaetus cirrhatus & Changeable Hawk-Eagle \\
\hline Spizaetus alboniger & Blyth's Hawk-Eagle \\
\hline Microhierax fringillarius & Black-thighed Falconet \\
\hline Lobiophasis bulweri & Bulwer's Pheasant \\
\hline Argusianus argus & Great Argus \\
\hline Sterna albifrons & Little Tern \\
\hline Sterna hirundo & Common Tern \\
\hline Harpactes kasumba & Red-Naped Trogon \\
\hline Harpactes diardii & Diard's Trogon \\
\hline Harpactes duvaucelii & Scarlet-rumped Trogon \\
\hline Harpactes oreskios & Orange-breasted Trogon \\
\hline Alcedo atthis & Common Kingfisher \\
\hline Alcedo euryzona & Blue-banded Kingfisher \\
\hline Ceyx erithacus & Oriental Dwarf Kingfisher \\
\hline Pelargopsis capensis & Stork-billed Kingfisher \\
\hline
\end{tabular}


Table 1. Continued

\begin{tabular}{ll}
\hline Scientific name & English name \\
\hline Lacedo pulchella & Banded Kingfisher \\
\hline Halcyon pileata & Black-capped Kingfisher \\
\hline Berenicornis comatus & White-crowned Hornbill \\
\hline Anorrhinus galeritus & Bushy-crested Hornbill \\
\hline Rhyticeros undulatus & Wreathed Hornbill \\
\hline Anthracoceros malayanus & Black Hornbill \\
\hline Buceros rhinoceros & Rhinoceros Hornbill \\
\hline Rhinoplax vigil & Helmeted Hornbill \\
\hline Pitta caerulea & Giant Pitta \\
\hline Pitta granatina & Garnet Pitta \\
\hline Rhipidura javanica & Pied Fantail \\
\hline Anthreptes malacensis & Brown-throated Sunbird \\
\hline Anthreptes rhodolaema & Red-throated Sunbird \\
\hline Anthreptes singalensis & Ruby-cheeked Sunbird \\
\hline Hypogranmia hypogranmmici & Purple-naped Sunbird \\
\hline Nectarinia sperata & Purple-throated Sunbird \\
\hline Aethopyga siparaja & Crimson Sunbird \\
\hline Arachnothera longirostra & Little Spiderhunter \\
\hline Arachnothera robusta & Long-billed Spiderhunter \\
\hline Arachnothera flavigaster & Spectacled Spiderhunter \\
\hline Arachnothera chrysogenys & Yellow-eared Spiderhunter \\
\hline Arachnothera affinis & Grey-breasted Spiderhunter \\
\hline
\end{tabular}




\section{LITERATURE REVIEW}

\section{What do we know about forestry and wildlife?}

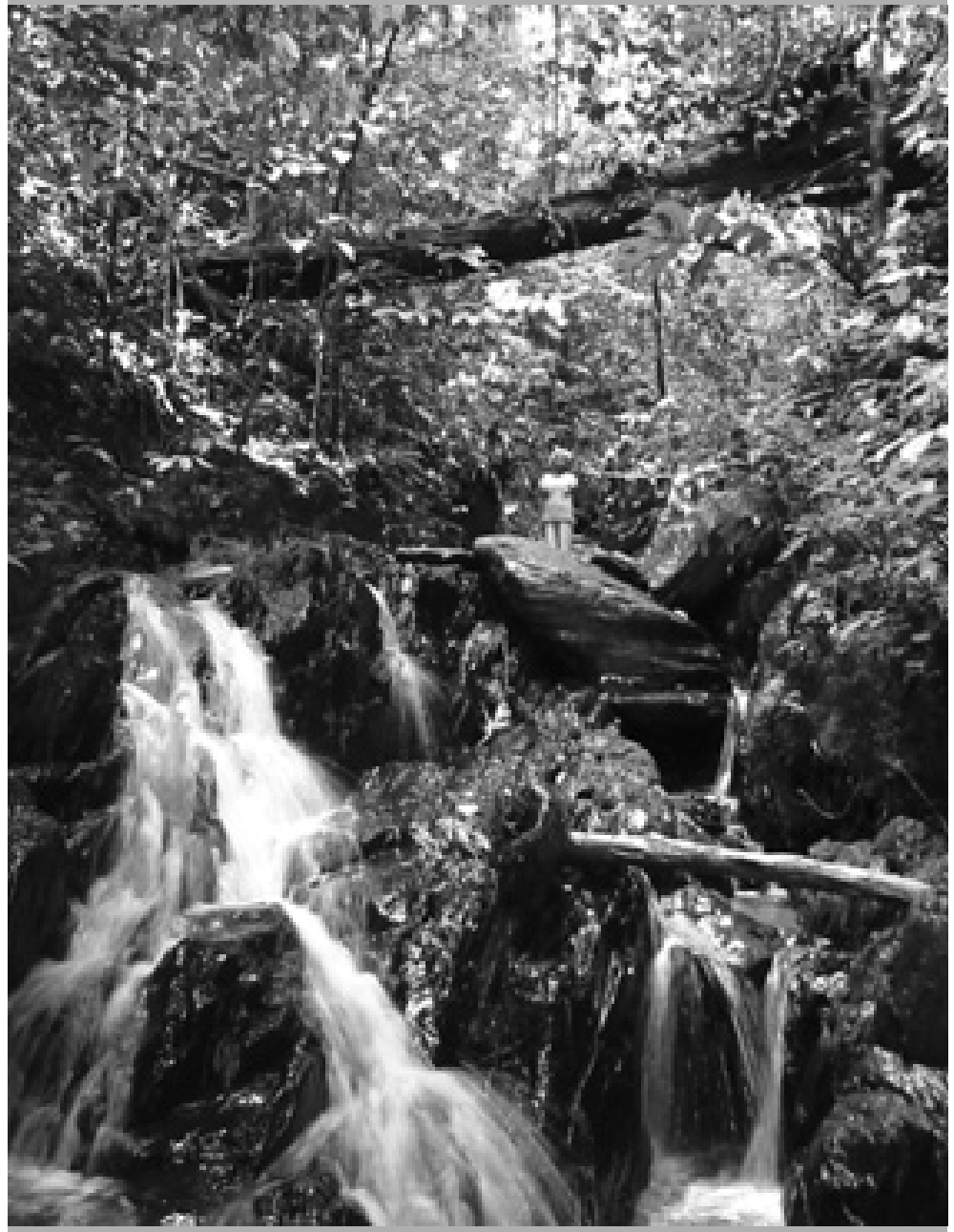

A stream in primary forest the upper Malinau. Various species-not to mention local people-are negatively impacted by the siltation and decrease in water quality that is frequently caused by poor road building and timber extraction. (Photo by Douglas Sheil) 



\section{A literature review of logging and wildlife}

\section{Methods}

From the results of the completed surveys of vertebrates in the upper Malinau, we selected the best-known species groups in order to identify species traits that could help develop more benign timber harvesting practices. Additionally, this process helped to assess the current state of knowledge regarding the biological and ecological requirements of the vertebrate taxa of East Kalimantan's lowland and hill forests. Through a synthesis and critical assessment of literature and other knowledge we set out to document the natural history attributes of each species or species group that make them more or less vulnerable to the impacts of timber harvesting and associated impacts. Once compiled, this database helped us propose some refinement to existing forest management guidelines for dipterocarp forests to make these forests more valuable for wildlife conservation.

Vertebrates represent an important fraction of faunal biomass in tropical forested areas and constitute a major component of ecological processes. Vertebrates are a good group to review due to the availability of research findings, their importance in tropical ecosystem dynamics, their potential usefulness as 'bioindicators', and their general importance in local and international conservation priorities. May (1988) showed that the number of scientific papers for mammals, for example, is 100 times greater than that for insects. Vertebrate species, especially mammals and birds, frequently serve as 'flagship taxa', are fairly easy to observe and their habitat affinities are often known. Amphibians and fish have not been as prevalent in the conservation literature. However, there are good reasons to suspect that these taxa would be very sensitive to logging effects (e.g., microhabitat sites for spawning). These species are also ecologically important for the ecosystem as well as for subsistence cultures. If there is any faunal group in which there is a critical mass of study and literature to help suggest improved forest management goals and practices, the vertebrates are a good starting point.

We assume that to understand the sensitivity of vertebrates to forest disturbance, it is necessary to understand their ecological characteristics and requirements at the 
individual, population and community levels. While many of these factors have not been explored for most vertebrates, the use of ecological predictions supported by local extinction probabilities allows a preliminary assessment of how select taxonomic groups are likely to respond to changes in primary forest conditions. Ochoa (1997) developed an extinction probability model for 140 species of mammals in a timber concession in Venezuela. In Ochoa's analysis, the local extinction probability of different members of the mammal community was related to:

- Species-specific affinity to primary forest environments;

- Dependence on arboreal (mainly canopy) resources;

- Geographic distribution patterns and population densities;

- Estimated ecophysiological requirements;

- Demographic characteristics;

- Vulnerability to the hunting activities of both local people and loggers.

In the present research we compiled the available information on the six variables that Ochoa (1997) identified to make similar predictions on the extinction probability of wildlife species in Malinau. We first reviewed the scientific literature, both peerreviewed and 'grey' literature (e.g., reports and theses), for references to the ecology and natural history of vertebrate species in East Kalimantan. Specialists were invited to contribute relevant information and views regarding the species with which they were familiar. They were also asked to comment upon the results of the initial literature assessment and to make further management suggestions. This information was integrated into the report where appropriate. Furthermore, Sheil and colleagues (2001a, 2003c) recently conducted surveys in the MRF area, which among others identified the perceived values of local landscape units and their associated products. A scoring exercise was used to quantify group assessments of the importance of forests products and landscape units (for details see Sheil et al. 2003c). The details of this research will be published elsewhere, but we include the preliminary results in this study.

We compiled and synthesised information relating to the factors that potentially affected vulnerability for each selected species group (see checklist in Appendix 1). We incorporated as many ecological attributes and categories as could be justified on the basis of information available for the vertebrate fauna. Much of the natural history, such as reproductive ecology, of many species is poorly known. Some attributes that may be useful in explaining vulnerability — such as physiological tolerances—could not be included in the analysis due to lack of information.

Nevertheless, the attributes and categories used represent major modes of ecological differentiation for vertebrates and should be useful in identifying general patterns of vulnerability. We constructed a detailed list of biological and ecological attributes for each species that we believe could increase or decrease vulnerability to the impacts of forestry interventions (Appendix 4-7), i.e., those that lead to a changed likelihood of local extinctions. This list covered the following broad categories:

1. Global range-Species with small geographic ranges might be more vulnerable to disturbance if geographic range correlates with specificity of habitat (e.g., 
Harcourt et al. 2002), because of an increased probability that forestry interventions negatively impact an already narrow ecological niche;

2. Population status and densities on Borneo-Common and widespread species are probably less endangered by logging than rare species with small distribution ranges. The correlation is not exact, however, and population persistence depends on more than numbers of individuals (Gaston et al. 2000). Population density can be considered an indirect measure of population size;

3. Habitat-Habitat includes the degree of structural complexity, including vertical stratification, which is a crude indication of a terrestrial animal's ability or propensity to cross open ground, although ground cover and presence of refugia are also important. Obligatory arboreal species should be at greater risk when the forest is more open or more fragmented (e.g., Laurance \& Laurance 1996). Another important aspect of habitat parameters is knowledge of the altitudinal distribution, and of the types of vegetation in which a species can survive or successfully reproduce;

4. Movement-Home range is an indication of the area necessary for an animal. Migratory species can have very large ranges. The ecological determinants are usually considered in terms of food, but other factors, such as nesting sites, can be relevant. Vagility is also relevant. Examples of seasonally migrating or daily moving species are found amongst the animal groups under study;

5. Feeding ecology_Virtually every aspect of the biology of an animal is linked to what it eats. Species feeding on widely dispersed, rare foods may be threatened more profoundly by interventions that affect these food supplies. The same may also apply to specialists, unless specialists occupy less vulnerable home ranges than generalists (Harris 1984). While the feeding ecology of hornbills and primates are quite well understood other species groups have been much less studied;

6. Breeding ecology_-There appears to be a clear correlation between breeding ecology and extinction risk (e.g., Fagan et al. 2001; Jonsson \& Ebenman 2001), with large, slow-breeding species with a late age of first reproduction being most vulnerable to population collapse. Only a few of the taxa represented in our study, such as hornbills, fruit bats and primates, have been well studied with regard to breeding ecology. Far less is known about other groups, with the exception of certain amphibians with eggs and juveniles having distinct requirements from the adults. These requirements may identify habitat characters of elements vulnerable to interventions;

7. Habitat loss and degradation-The impact of habitat conversion is not the same for all groups under study, and some species will benefit from disturbed habitats while other species will be vulnerable.

To determine the variables that best predicted species sensitivity to logging and associated effects, we selected the species that were best known in terms of their ecological, life history variables, and their response to the effects of logging and fragmentation. We analysed the life history variables in a multivariate analysis to examine which variables would explain most of the variation in sensitivity to logging. Method details are provided in the relevant section below. 
The species selected for review were chosen because (a) they occur in the Malinau area, (b) previous studies documented their vulnerability to logging, or (c) of availability of literature. Species of special concern included, but were not limited to:

1. Birds: cavity-nesting birds, primary forest specialists, territorial species, understorey species;

2. Mammals: cavity specialists, primary forest obligates and/or forage specialists, territorial species, species that make use of dead and down wood, wide-ranging species;

3. Amphibians: focus on breeding sites.

In addition to making general recommendations for improved wildlife management in timber concessions, we also provide specific management recommendations for the vertebrate species of the Malinau region. Our aim is to give guidelines to concession managers as to which species would benefit most from specific management interventions. These species were defined as being those that: (1) had the highest conservation rating according to the IUCN (after IUCN 2002) (see Appendix 2), (2) were protected by Indonesian law (see Table 1) and (3) were in high demand or highly valued by local communities (see Appendix 3). The latter category was established based on work by Sheil et al. (2003c).

\section{Specialist input}

Twenty ecologists were invited to comment on relevant natural history findings for species with which they are familiar and to comment on associated forest management issues. The information gained in these communications was largely anecdotal and most could be found in some form in the published literature. However, the experts were able to synthesize much of the available data into usable information and their comments pointed out particular directions of interest for individual species. Ten of these ecologists were contacted for review and comments on a working draft, and where appropriate their considerations have been added. After the draft report had been finished, we consulted a further 13 experts and asked them to review the report.

\section{Methodological limitations}

The validity of any data analyses and interpretation depends on various factors and assumptions. Problems or failures in any of these will undermine the validity of any quoted results and conclusions. Though not all these factors and assumptions can be explicitly assessed, it is vital to consider the uncertainties that they introduce.

Uncertainties in our review have various causes. Studies are often too short, poorly designed and statistically inadequate. This can result in data that are 'severely limited or restricted', as acknowledged by Johns regarding the interpretation of his 1983 study. Also, not all forests are the same. Invariably, there are both obvious and subtle differences in soils, vegetation, micro-climates, wildlife densities, hunting 
pressure and many other factors, which are rarely assessed adequately at the start of research on the effects of logging. Many researchers are aware of this and acknowledge that their data are limited and restricted, but the nature of these limitations is hard to reflect in a larger review.

Our examination of the literature has found that even within the same ecosystem, slight differences in geography or habitat can influence how a system and its community will respond to perturbations, including with events such as El Niñorelated mast fruiting and/or drought. Here again, other factors such as the extent of adjacent undisturbed forest, logging intensities, etc. can interact to influence the system in different ways.

The extrapolation of results and conclusions from one area to another requires careful assessment of the individual studies. Marsh et al. (1987) pointed out the importance of assessing tree extraction densities in relation to density changes in wildlife. For example, Wilson and Wilson's (1975) data on the effects of logging on primate species was conducted in an area where 8-10 trees/ha had been removed; they found relatively small changes in primate population densities. Johns (1983), on the other hand, found a considerable decrease in primate populations in his study area when about 18 trees/ha were removed at a 3.3\% removal rate, but with significant non-target damage. Burgess (1971) pointed to severe effects of logging on resident fauna in an area logged at an intensity of 25 trees/ha. It makes sense that the degree of logging intensity influences the impact on wildlife, but unfortunately this is not always mentioned in studies that investigate the effects of logging on wildlife. Similarly, studies that examine the impact of phenomena such as hunting, fragmentation or road building can only identify and assess influence within the range examined: results that show one factor is more important than another need to explicitly recognise the relative variation considered.

The impact of forest interventions can depend on the scale of observation both in time and space. Amphibians, for example, may decline in the larger gaps created by tree felling and extraction, but such effects may be very local in both space and time, with little impact in either the surrounding vegetation or two to three years later (Iskandar 2004). Such scale influences are especially problematic with edge effects (Laurance 2000) and impacts on wide-ranging species (Curran \& Webb 2000). It is well recognised that many of the changes associated with changing landscapes look different at different scales (Riitters et al. 1997). This is especially true for issues of species diversity (Stoms 1994; Kunin 1998).

Many studies used here have been of relatively short duration (see section on literature availability). Considering the important effects of multi-annual events such as El Niño-related mast fruiting on many vertebrate species populations in Borneo (e.g., Curran \& Leighton 2000; Fredriksson \& Wich in prep.), short-term studies may reveal only a partial view of a species' ecology. For instance, a researcher may conclude that a species shows long-term persistence following logging from shortterm data trajectories. The data may then not reveal that the species first increases but then falls or visa versa. This is also a problem with studies on the effects of logging on wildlife that follow shortly after logging took place. We have only a very limited idea about how long it takes for a species to react following harvesting, or how a species 
reacts to logging cycles. We therefore suggest considerable caution in using the results of studies assessing species in logged or formerly primary forest after only one logging harvest to say how many or what species are lost by logging.

Later (Tables 2-9, see below) we shall show that a variety of studies on a range of species result in different conclusions about the effects of logging. We argue here that this might, at least partly, be due to methodological differences. Several authors (e.g., Bennett \& Dahaban 1995; Lambert 1990a; Lambert \& Collar 2002) have suggested that studies by Johns $(1983,1986 \mathrm{~b}, 1989 \mathrm{~b}, 1996,1997)$ are considered to have suffered from bias relating to the use of logging roads as transects. Lambert and Collar (2002) also pointed out that observer skill and experience can influence the number and type of species that are detected, with secretive species only being effectively detected by observers who know their calls.

There is an added survey bias when observers detect wildlife on sight alone, because species may be more (or indeed less) easily observed in logged forest; the canopy is less dense and birds that are normally restricted to the upper canopy (and therefore difficult to see) may be forced to feed at lower levels where they become more visible. Indeed, in general, there are several aspects of sighting-survey studies in tropical forests leading to bias, particularly detectability, training and the relative ability and search images of different researchers, the time of day surveys are conducted, the size and location of transects, whether transects were existing or newly created trails and roads or whether they were randomly located in the forest, the relative habituation of various target species toward humans, the effects of noise and human scent on the presence of particular species, environmental conditions that influence visibility (e.g., rain, fog, light, etc.) and the cryptic morphologies of different species, and behavioural heterogeneity of individuals and species.

So far we have not discussed statistical power, i.e. the probability of rejecting a null-hypothesis when it is in fact false (and should thus be rejected) - that is, a measure of reaching the correct conclusion. A common error in data interpretation is that failure to reject is often taken as evidence that the null hypothesis is true (Ludwig et al. 2001). As Ludwig et al. point out, however, significance levels in statistical tests only address the issue of false rejection of the null hypothesis, when it is, in fact, true, i.e., a Type 1 error. If the null hypothesis is not rejected, the quantity of interest is the probability of accepting the null hypothesis, even though it is false, i.e., a Type 2 error. The complement of this quantity is termed the power of the test, or in other words the 'strength of the evidence' (Siegel \& Castellan 1988). The power of the test depends on which alternative hypothesis is true (e.g. Hayes \& Steidl 1997; Steidl et al. 1997) and thus on the nature of the alternative hypotheses. This in turn relates to the use of either one- or two-tailed tests, sample size, variance and significance levels (Siegel \& Castellan 1988). Few studies that we reviewed actually specify whether one- or twotailed tests were used. A posteriori conclusions are more appropriate in studies of the effect of logging, requiring clarity concerning the need for one- or two-tailed tests. The use of one-tailed tests, especially with small sample sizes, is definitely unwarranted.

Many of the assumptions made in interpreting trends and patterns in species data are so fundamental that we do not stop and question them. Nonetheless these assumptions may embody questionable ideas. The fact that a given species does not 
decline in density does not mean that there may not be other negative impacts that influence long-term viability. The increase in the abundance of some species observed after a landscape change is generally assumed to be a good thing-yet if the species is generally susceptible to contagious disease such increases may actually make it more vulnerable to lethal epidemics as proposed for Gorillas in Central Africa (Walsh et al. 2003). There may also be undesirable effects such as increased inbreeding following fragmentation.

So where does that leave the reliability of our conclusions? There is likely to be some change in all of the species in response to logging, simply because any change in an environment will lead to a change in how any species uses that environment. Thus we consider the null hypothesis inherently false. We also know that the less damage there is in a forest the smaller the impact logging will have on wildlife, although some species may disappear from forests even after minor disturbances. This general interpretation may be as important as all density assessments together. Much effort has gone into establishing species densities under various threat levels, but no one really knows (or will likely ever know) what the optimum density for a particular species is. Because species densities are intricately linked to all aspects of their forest environment, simple density and abundance assessments may tell us little about the survival chances of a particular species.

\section{Literature availability}

The literature reviewed in this report was gathered from peer-reviewed literature available in books and international journals, and from 'grey' literature in the form of workshop proceedings and reports for non-governmental conservation organisations. Secondary literature, such as guidebooks and general reference materials, was also reviewed. Studies in zoo situations were generally excluded from this review. Although such studies are a source of information regarding animal biology, they have limited value in ecological terms. Few theses from American and European universities were used in this study as these are difficult to access; theses from Indonesian and Malaysian universities were mostly unavailable.

Much animal field research over the last 30 years has emphasised autecological studies (focussing on biological relations between a single species and its environment), particularly distribution and habitat preferences in areas undisturbed by logging. Nevertheless, the state of knowledge on distribution and abundance of species is far from complete, and even less is known of their complex relationships within the array of their habitats.

A total of 145 vertebrate species were reviewed in detail for this study (23 bird, 28 mammal, 54 reptile and 40 amphibian species). There were strong biases in the amount of literature found for the vertebrate taxa. A preliminary assessment of the literature (Rosenbaum 2001) indicated that mammals were the most strongly represented in the literature, followed by birds. Amphibians and reptiles were far behind. For our research we compiled 280 publications on Bornean vertebrates, i.e., wildlife studies based on fieldwork in Borneo. In addition, we used publications from Sumatra, Peninsular Malaysia and from the Asian mainland if these described 
characteristics of species occurring on Borneo as well. Of the 280 Borneo publications $118(=42 \%)$ were based on fieldwork in Kalimantan (Indonesia), $126(=45 \%)$ from Sabah and Sarawak (Malaysia), $9(=3 \%)$ from Brunei, and the remainder referred to research across the island. We think that this sample is representative of all publications on Bornean wildlife, although there is probably a bias to mammal studies. Forty-seven $(=16 \%)$ publications were books or book sections, $153(=55 \%)$ were published in peer-reviewed journals or newsletters, and 80 were unpublished reports or theses.

The articles and reports reviewed can generally be divided into museum records, survey studies and ecological studies. Museum records are useful primarily in determining distribution. Other information can be found in these reports (e.g., size, breeding season, microhabitat, stomach food content, nest records), but the data is inconsistent. It is therefore of limited use for determining the ecological characteristics of species; however, note that inconsistencies are actually quite valuable, i.e., differences in stomach food contents in different locations or conditions can indicate habitat preference and value. With all their limitations, for many species these are the only data available.

Survey studies predominate in the literature. These studies are useful in determining distribution, altitudinal gradients, population densities, habitat preferences, and, to a limited extent, behaviour ecology. The results of comparative surveys in unlogged and logged areas have been used extensively to recognise species' population responses to habitat alteration. However, some of these studies indicate the presence/absence and relative abundance of a species in a particular habitat and, on their own, do not identify the particular ecological characteristics of the habitat by which relative abundance is determined (e.g., Dahaban et al. 1996; Carter 1985; Danielsen \& Heegaard 1994). Still, when several of such studies in different areas show similar abundance trends before and after a logging event it allows us to deduce the effect of logging on particular species, especially if results can be combined with autecological studies on those species.

Monograph studies of individual species are the most useful in identifying changes in feeding, ranging or other behaviour following logging, and how this may affect their population densities in logged forests. However, there are some problems and biases in this body of literature. First is the general under-representation of ecological studies from Indonesia and Southeast Asia in the published literature (Sodhi \& Liow 2000). Although Indonesia is considered a mega-diversity country (Mittermeier \& Mittermeier 1998) the major international ecological journals have published few papers from this region. From 1998 to 2000, Indonesian fauna was the subject of less than 1\% of research papers in the journals Acta Oecologica, Ecology, Functional Ecology, Journal of Ecology, Oecologica and Tropical Ecology. This lack of published information is not limited to Indonesia. Comparatively, for the region as a whole, less than $4 \%$ of the papers published in the above journals were on Southeast Asia. An important exception was the international conservation journal, Oryx, which primarily publishes descriptive research — for example, on the status and distribution of threatened taxa—and Tropical Biodiversity, a regional journal primarily reporting papers from Indonesia. Seven percent of Oryx's research papers and 60\% of Tropical 
Biodiversity's research papers were on Indonesian fauna (Sodhi \& Liow 2000). Furthermore, a number of other regional journals exist that address Southeast Asian species ecology and conservation issues, although these journals are not always easy to access for researchers outside the region: e.g., Kukila, Treubia, Malayan Nature Journal, The Malaysian Forester, Malaysian Applied Biology, Hornbill, Bulletin of Siam Natural History Bulletin and the Raffles Bulletin of Zoology. These examples highlight the need for more studies and the present importance of grey literature in locating ecological information on Indonesian fauna.

A second caveat of the current literature is the limited duration of most reported studies. Most studies were short term (3-6 months) and the average 'long-term study' was approximately 1 year. Due to the variability of annual patterns in forest ecosystems, conclusions from such studies can only be considered as tentative. Few people seem, however, to recognise how inconsistent these short-term studies can be; they might give apparently good results for certain periods, but they may in fact be far from the 'averaged' truth over the long term and across wider geographic extents.

Third, the majority of ecological studies on Borneo were carried out at a few long-established research stations. In East Kalimantan, this includes the International MoF-Tropenbos Kalimantan Program (e.g., van der Hoeven et al. 2000) and the Tropical Rain Forest Research Project (Japan International Cooperation Agency). Elsewhere in Indonesian Borneo, long-term ecological sites are in Central (Barito Ulu, Sebangau and Tanjung Puting) and West (Gunung Palung) Kalimantan. Within primary forest, variation in the relative density of specific habitats and their associated plant and animal species can be considerable over quite short distances and is even greater over large geographic distances. This results in considerable variation between sites in the assemblages of animal species. As the individual species and ecological characteristics of the habitat vary, the functional role and niche of a species within the habitat will also vary, at least to some degree. Therefore species' behaviour is likely to vary between sites. When considered in light of the length bias in studies previously mentioned, information gained on a species from only a few sites further limits the degree of certainty and generality associated with any conclusions.

The grey literature fills in some of the information gaps of published literature. The primary limitation of this information source is the difficulty of obtaining the reports, and secondly the wide variation in quality, partly because of their lack of serious scientific peer review. Most are archived in regional offices and have limited copies available. Some of these offices have limited searchable database systems, resulting in difficulty in making general requests. Usually the specific report needed must already be known. After it is found a copy must be made and then sent. Access to this information is therefore dependent upon both the infrastructure and the time available in individual offices. However, we must acknowledge that most of these offices were very helpful in finding specific reports when requested.

To further analyse the subjects of our publications list, specifically in terms of their usefulness to improved wildlife management, we subdivided them into five categories: 1. Descriptive (taxonomy, species checklists, surveys, morphology); 2. Autecological (movement, feeding behaviour, breeding behaviour, etc. of single species); 3. Synecological (focus on ecological interactions within species groups or 
between species and their environment); 4. Threats (studies of threats to species); and 5. Cause-effect studies (investigating population changes in relation to particular threats). In publications where more than one of the above categories were represented we selected the one that best represented the dominant theme of the publication. A total of $146(=52 \%)$ publications fell into category $1 ; 50(=18 \%)$ in category $2 ; 24$ $(=9 \%)$ in category $3 ; 25(=9 \%)$ in category 4 ; and $35(=12 \%)$ in category 5 . There is thus a strong bias towards studies that focus on describing species' characteristics without looking at threats; i.e., almost $80 \%$ of all publications (categories $1-3$ ). The majority of studies in category 4 involved research on wildlife hunting and trade, with some studies addressing issues such as fires and drought, wildlife disease, or deforestation; none of these, however, quantitatively assessed how these factors affected wildlife population densities. Only the publications in category 5 provided some insight into species' population trends in relation to threats and are therefore of direct use to conservation biology. The latter studies answer an important question in conservation research: which species require conservation attention? Unfortunately, the 35 publications in category 5 are focused on a relatively small number of species groups, with 11 assessing the effects of logging and hunting on primates, and the remainder on Malayan Sun Bears (3), civets (2), ungulates (4), general mammals (4), general birds (4), woodpeckers (2), amphibians (4) and fish (1). Thus the available literature is far from providing a complete overview of Bornean biota and their conservation needs.

\section{Literature scope}

The results of the literature survey emphasise the need for further ecological research on Indonesian fauna. A majority of the species reported from MRF have no literature available beyond distributional ranges, coarse habitat associations and qualitative diet. This is most evident among fishes, amphibians and many birds. Even among mammals, the best-studied vertebrate group, there remain many species that have received no systematic ecological field study. Furthermore, the impacts of logging and logging-related effects are only known for some 20 species.

\section{Bird studies}

Of the 24 bird species selected for review, there was a great range in terms of what has been studied and what is known. The general conclusion is that there are very few species whose ecology is known well through at least one long-term field study within Borneo. The best-known birds are hornbills_-large, diurnal birds that are easily visible. Pheasants are moderately known because they receive much attention and financial support from pheasant enthusiasts. Among the least-known birds are those believed to be most vulnerable to logging - trogons, woodpeckers (although several studies on this group have recently been conducted, see Lammertink 1999, 2004; Styring \& Hussin 2004a), babblers and barbets (Lambert 1992). Flycatchers and wren babblers, groups believed to be very sensitive to logging effects (Lambert 1992), had such a limited amount of species-specific literature available that we decided 
not to include them in the literature review. We decided therefore to concentrate on hornbills, pheasants, woodpecker and trogons for our more detailed analysis of the life history and ecological variables that predict sensitivity to logging.

The limited availability of useful data on birds and the related small number of ecological studies is due to the rarity of many of these Southeast Asian species. The majority of tropical forest birds occur at low densities, often reflecting large home ranges, which in turn often reflects patchiness of suitable microhabitats and/or limited predictability of key resources. Studying them in the field is therefore difficult and time consuming.

\section{Mammal studies}

Although mammals are the best-studied group of vertebrates in Asia a similar pattern in literature availability is found. A total of 25 species of mammals from the 80 species potentially found in the Malinau area were included in the literature review on the basis of availability of ecological literature. Because bats were not surveyed in Malinau we did not conduct species reviews. Instead we provided a general assessment of this group.

Of the mammal species selected, $41 \%$ can be considered to have their biology and ecology well known (i.e., at least one long-term, >2 years, field study), 38\% can be considered moderately known (i.e., at least one short-term study, <2 years), and $21 \%$ can be considered little known. Those well known include five diurnal primates, two deer, one bear (Ursus malayanus), one civet (Viverra tangalunga), one cat (Prionailurus bengalensis), one pig (Sus barbatus) and one giant squirrel (Ratufa affinis). Of these, one deer (Cervus unicolor) and the cat are known primarily from South Asia. The mouse-deer species (Tragulus spp.) are known primarily from one detailed ecological study, but the bear species (Ursus malayanus) has recently seen a considerable increase in research attention (Augeri 2002; Fredriksson 2001; Wong 2002; Wong et al. 2004). Primates are generally well studied, but again, the ecology of one colobine (Presbytis hosei) is known primarily from just one Ph.D. thesis. The least known of the selected mammals include three squirrels, two tree shrews and one civet, all of which may be significant in seed dispersal and forest regeneration.

The reasons for there being so few studies on mammals in Southeast Asia are similar to those suggested for birds. Many species are nocturnal, cryptic and occur at very low density, while several of the larger species may be semi-nomadic. Also, rain forest studies are logistically difficult, often costly, and most species are difficult to observe compared to species in more open vegetation types, especially where species are targeted by hunters and become very shy of humans. Those mammal species that have been best studied are diurnal and easily visible. The problem is not just biological. The Indonesian academic community and the government are conducting limited field research on wildlife and, primarily because of the language barrier, publication of their findings in international peer-reviewed journals remains limited. Much research is done by international researchers. Research permits for international researchers, however, can be difficult to obtain in Indonesia, especially during times of political conflict, or if access is requested to remote, politically unstable areas. 
Furthermore, some international researchers are not coming to Indonesia to conduct research for socio-political reasons.

\section{Amphibian and reptile studies}

The ecological data found for amphibians and reptiles are the result of surveys and thus primarily indicate habitat preferences. Little is known of any food preferences for these taxa. However, the adults of both groups tend to be generalist carnivores, and therefore specific diet preferences may not exist or may not be of general importance. Nevertheless, many amphibians and reptiles have very specific breeding requirements and juvenile and larval forms of amphibians sometimes exhibit very specific morphological adaptations for the prey upon which they feed. Therefore, microhabitat specialization plays an important role in early survival.

\section{Fish studies}

Freshwater fish of Borneo have been studied in some detail, although the literature is mostly taxonomic or focuses on species ecology and distribution. Only a handful of studies address the effects of timber harvest on fish. 


\section{Background concepts}

The global literature on tropical forests and forestry contains some important ideas and concepts. We consider these ideas in the following sections, to provide a more general context for interpreting the species-specific evaluations.

\section{Changing fauna}

Comparative faunal surveys dominate the literature on biodiversity conservation and logging. These surveys, in unlogged and logged forests, track changes in individual species' abundance. The changes are inferred by commonly comparing sites or, less commonly, monitoring over time (for example, Johns 1997). Certain patterns are emerging from the research as to how species and species groups (also called guilds or assemblages) respond to logging.

The literature can be used to identify appropriate biological indicators of forest integrity' following logging (Cleary 2004; Davis 2000; van der Hoeven et al. 2000). These indicators could be important tools in monitoring the effectiveness of forest management. We shall refrain from a detailed discussion of 'indicators' in this report; it is enough to note that managers need to be able to use the information to adapt or modify their practices, and this capacity is uncertain at present. We are more concerned with developing timber production guidelines to reduce negative effects on sensitive species. Although comparative faunal surveys may indicate changes in abundance after logging, such studies are often based on presence/absence information and do not elucidate the mechanisms and processes involved. Other studies do not illustrate how logging practices could be modified to ameliorate such changes.

It is difficult to determine exactly how logging affects vertebrates. The impacts depend on the species, site conditions and other variables, but declining population is the most noticeable change. Declines are often due to: 
- Overcrowding into limited remaining habitat, leading to increased mortality through competition. How long it takes to reach a new 'stable' low is not clear, however, and some studies may fail to detect significant effects if undertaken soon after logging in areas with temporary rises in population density;

- Reduced food supply;

- Loss of key microhabitats, and changes in microclimate and microhabitat;

- Juvenile and adult mortalities from increased predation, hunting, competition, or forage loss. These deaths can alter the demography, lowering mating and reproductive success and fitness. This in turn lowers recruitment into the population, further altering demography and densities. Fewer offspring can also reduce the competition to survive, lessening selection pressure in a less diverse gene pool and ultimately reducing adaptability in the long term;

- Increased juvenile mortality through higher predation levels;

- More open, disturbed habitats favouring introduced and native predators;

- Non-resident or invasive species spreading and sharpening the competition for reduced resources;

- Competitive changes or reductions in critical resources, such as food, shelter, courtship sites or nesting sites;

- Increased morbidity due to new diseases and declining population health;

- Increased hunting pressure;

- Tree felling, skidding, and other timber extraction activities directly killing or fatally injuring individual animals.

In reality, many changes in diversity and abundance occur simultaneously. The changes can then affect other species or aspects of the whole biological community. Ecological studies usually allow us to separate the possibilities, identify the mechanisms responsible for logging's adverse effects, and determine how these vary by site, taxon, and form of intervention. After the most sensitive species have been identified, new guidelines may allow forest managers to develop appropriate action that can be incorporated into management plans and general operations.

\section{Vegetation change}

This book focuses on the consequences of production forestry for the vertebrate fauna of mixed dipterocarp forests in Indonesia. Such consequences are dependent on the resulting forest vegetation. We have not attempted a comprehensive review of vegetation changes with relation to timber extraction, silviculture and related activities, but we can suggest some useful references. Many compilations and syntheses are available. For general discussions concerning how timber management affects forest ecology and conservation values we recommend Bertault \& Sist (1995), Bruenig (1996), Fimbel et al. (2001), Kartawinata \& Vayda (1984), Kartawinata et al. (1989), Putz et al. (2001a), Szaro et al. (1999), Whitmore (1990a, b) and Whitmore \& Sayer (1992). As a general introduction to how Southeast Asian dipterocarp forests respond to logging and other disturbances Whitmore (1984) remains unbeaten, though more recent work on dipterocarps is summarized in 
Appanah \& Turnbull (1998). For examples of more specific studies looking at how forestry practices impact and modify forests in the region see Abdulhadi et al. (1981, 1987), Adjers et al. (1996), Bertault \& Kadir (1998), Bertault \& Sist (1997), Bratawinata (1994), Cannon et al. (1994), Clearwater et al. (1999), Djamaludin (1991), Elias (1998), Gintings (1969), Howlett \& Davidson (1996), Kammesheidt et al. (2003), Kartawinata (1981), Kuusipalo et al. (1996), Nicholson (1979), Nussbaum (1995), Prawiraatmadja (1970), Riswan \& Kartawinata (1991), Sastrawinata \& Effendy (1991), Setyarso (1991), Sist \& Nguyen-Thé (2002), Sist et al. (1998a, 1999), Sudarmaji (1999), Sumitro (1991), Supriyatno \& Becker (1999), Sutisna (1996, 1998), Tinal \& Palinewen (1978), Tuomela et al. (1996), Van Gardingen et al. (1998) and Wyatt-Smith (1995). For more about reduced impact logging and related approaches and their implementation see Applegate et al. (2004), Elias et al. (2001), Enters et al. (2002) and Sist et al. (1998b). What follows here is only a brief introduction.

Canopy gaps have dominated ecological ideas on rainforest dynamics for much of the last decade and more (for example, Brokaw 1987; Brandani et al. 1988; Campbell 1991; Denslow 1987; Whitmore 1997; Whitmore \& Brown 1996). In most circumstances, natural gaps have little influence over the composition and richness of natural forests (for example, Brown \& Jennings 1998; Hubbell et al. 1999). However, these gaps, which are generally small and quickly closed by advanced regeneration, are important for species that thrive on disturbance.

In harvested forests, gaps are generally larger and more numerous, with soils compacted and churned up by heavy machinery. Thus, advanced regeneration is often destroyed. In such cases, pioneer vegetation germinating from seed can dominate initial regrowth (Denslow et al. 1990; Pelissier et al. 1998; Silva et al. 1996; Swaine \& Hall 1983).

An extensive review by Hawthorne et al. (1998) provides a few broad generalizations about forest vegetation types. Non-pioneer-light demanders are species that recruit in shade, but need increased light to reach the canopy, like most dipterocarps. This group generally benefits from some canopy opening, while shadebearers generally decline when gaps open up. Ironwood, Eusideroxylon zwageri, for example, recruits and grows without additional light in a closed forest.

Loading bays and logging roads favour pioneers such as Macaranga spp., Trema orientalis and Ceiba pentandra, but skid trails and logging gaps support a greater concentration of non-pioneer light demanders. Areas close to intact forest usually recover more quickly from any clearance. Maintaining scattered 'reserves' within a managed forest, such as the Virgin Jungle Reserves in Malaysia, is therefore justified as a practical precaution.

Excessive canopy opening can lead to regeneration problems, especially in exposed conditions where soils dry out rapidly and nutrients are lost through runoff. Herbaceous or shrubby vegetation associated with severe opening can interfere with regeneration and impedes recovery (Epp 1987; Hawthorne 1993, 1994). This is especially problematic when the herbs are non-natives and/or the canopy opening is severe and substantially changes soil conditions. Low regrowth can attract ground herbivores. On the one hand, these animals may damage regrowth and maintain open 
areas, but increased densities could contribute positively to natural forest dynamics while providing prey for carnivores and human hunters.

Tree reproduction is a comparatively neglected topic. Trees do not generally have the ability to flower and set seed until they have reached some minimum size. Although reproduction commences at sizes well below felling limits (Jennings et al. 2001), the largest stems normally display the greatest fecundity (Appanah \& Mohdrasol 1990; Thomas 1996). 'Minimum felling size' is inadequate to protect seed production if it is the sole silvicultural control (for example, Fredericksen \& Putz 2003; Sist et al. 2003b).

Even when potential parent trees are present, further protection may be needed. Knowledge of timber tree reproduction is surprisingly limited, but research underlines the role many animal species play in pollination and seed dispersal. A complex body of ecological knowledge exists on this aspect, but it is often species specific and thus not readily generalised (Gautier-Hion et al. 1985). Recent research has also indicated that seed dispersal distances are often much lower than previously thought, even for species spread by animals (for example, Hubbell et al. 1999, but see Webb \& Peart 2001). This realization suggests the need for denser, or at least more even, distribution of retained mother trees. Guiding principles on retention rates should almost certainly be available soon, coupled with advances in seed and fruit classification (for example, Gautier-Hion et al. 1985; Howe \& Westley 1988).

Ultimately, dispersal and pollination syndromes, as well as potential fecundity, must help determine retention rates for mother trees, and associated site management (Baur \& Hadley 1990; Schupp 1990). As an example, dioecious trees should probably be retained at twice the density of equivalent hermaphrodite species (Kigomo et al. 1994; Lawton 1955), but there are few data to define adequate pollination densities for any tropical tree species (for example, Ghazoul et al. 1998; Stacy et al. 1996), and much remains speculative.

Protecting mother trees and unharvested 'reserves' within the forest landscape offers some insurance, but maintaining key animal populations is also necessary to ensure long-term viability, and this may require additional attention (for example, Bakuneeta et al. 1995; Hawthorne \& Parren 2000; Howe \& Westley 1988; Parren 1991). Gordon et al. (1990) showed that some Central-American forest pollinators are themselves dependent on non-forest areas outside gazetted reserves. This implies that such areas and functions need to be included in long-term management.

Remnant trees are more than just seed sources. Most trees survive and grow better near sources of mycorrhizae, a beneficial fungal species associated with the roots of many plants species. Mycorrhizae sources are often other trees (Alexander et al. 1992; Hogberg \& Wester 1998; Moyersoen et al. 1998). Large old trees also have complex structural characteristics that are 'friendly' to wildlife, such as hollow stems, large canopies and decaying parts. The proportion of forest-dwelling species dependent on dead wood is unknown, but in Australia maybe a fifth of taxa are associated only with larger tree size-classes that produce significant amounts of dead wood (Grove 2001).

Many forest taxa use or are dependent on large, old and hollow trees. The taxa include hornbills (Datta 1998; Whitney et al. 1998; Whitney \& Smith 1998), 
woodpeckers (McNally \& Schneider 1996), bears, civets, and porcupines. Important pollinators such as bees (Kerr et al. 1994; McNally \& Schneider 1996) and seed dispersers (Whitney \& Smith 1998; Whitney et al. 1998) also depend on hollow trees, while many animals use fallen hollow trunks for nesting or resting-species such as Lariscus insignis (Yasuma \& Andau 2000) and Tragulus javanicus (Matsubayashi et al. 2003). The loss of large stems can thus have long-term consequences (Gordon et al. 1990), and is a potential cause for otherwise inexplicable declines or failures in forest regeneration around the world (Sheil \& van Heist 2000). Another possible factor is the loss of mycorrhizal fungi slowing down regeneration after clear-fells.

Some fruit trees provide a strong catalytic function by attracting fruit dispersing vertebrates and enriching the local seed-rain (Guevara 1986; Hietz-Seifert et al. 1996). Protecting or planting these species nearby unlogged areas can accelerate recovery in degraded sites.

Some trees, most notably figs (Ficus spp.), are especially important for wildlife because their stands provide fruit throughout the year (Heydon \& Bulloh 1997; Jordano 1983; Kinnaird et al. 1999; Lambert 1989b, c, d, 1990b, 1991; O’Brien et al. 1998a). They meet important nutritional needs, such as calcium in otherwise mineral-poor diets (see O’Brien 1998). Scattered individual fig trees per se do not provide food all year and a large enough area with sufficient trees is needed for a yearround supply. Several studies have reported a decline in fig densities following logging (Heydon \& Bulloh 1997; Johns 1983; Lambert 1990a; Leighton \& Leighton 1983), indicating that logging lowers the forest's carrying capacity for species that primarily feed on these fruits.

Lianas play a significant ecological role, including suppressing tree regeneration and increasing tree mortality. The role has a negative silvicultural connotation, but lianas also influence how trees compete with each other and thus they affect forest composition (Schnitzer \& Bongers 2002). Lianas are also a valuable food source for some animals as well as for some indigenous communities, and they enable canopy-tocanopy access for arboreal species (Emmons \& Gentry 1983; Putz \& Mooney 1991).

Putz (1984) found that approximately $90 \%$ of adult lianas survive when dragged into a gap when a tree is felled. This resilience, combined with an ability to establish in disturbed areas, makes lianas among the most successful colonizers of forest gaps. In logging areas they can therefore have a considerable impact on residual tree stands. Lianas slow down tree growth rates, increase the number of trees killed and damaged during logging, and cause trunks to bend. Such distortions may reduce the tree's value as timber and consequently, many foresters and forest ecologists recommend lianas be actively managed via periodic and pre-harvest cutting. However, because of their ecological value for many animal species and indigenous communities, Schnitzer and Bongers (2002) recommended that liana cutting should be selective on a tree-to-tree basis.

Manipulating the forest composition has implications for herbivores. While the vegetation's chemistry is complex (for example, see Gartlan et al. 1980; Waterman 1983; Waterman et al. 1988), one rough generalization is that slow growing, dense-timbered species such as Eusideroxylon zwageri generally have better defences against browsers and provide fewer resources for vertebrates than faster growing, lighter species (for example, Gartlan et al. 1980; Janzen 1979; Loehle 1988; Sheil \& van Heist 2000). 
Fruiting shows a roughly similar pattern, although such generalization glosses over the many exceptions. Small pioneer species generally disperse their seeds via the wind or birds (Loiselle et al. 1996). Longer-lived, fast-growing species such as Sapotaceae and Moraceae produce larger, fleshy fruits. Many shade-tolerant species have gravitydispersed seeds. It means in some situations, edible fruit and vegetation for generalists is less abundant in old-growth forest. Conversely, some young or disturbed areas can support higher densities of vertebrates than old growth, depending on conditions and variables such as forest age, vegetative biodiversity, habitat type, the extent and intensity of disturbance, and herbaceous growth in clearings.

Several understorey and gap species produce fruit several times a year when in good light (e.g., various Rubiaceae and Moraceae) whereas most climax species in mature forest (like dipterocarps) produce fruit once a year or less (Whitmore 1998). Not all disturbance necessarily brings such benefits as some pioneer species (e.g., Trema spp.) do not provide edible fruits. Also, it must be emphasised that primary forests can be highly productive for a wide variety of vertebrates, while 'specialist' species associated with old growth forests are more vulnerable to disturbances and eradication. These latter species may have a higher conservation status and, therefore, need to be considered in management prescriptions.

Small, isolated populations in fragmented or heavily harvested landscapes run much greater risks of reduced reproduction, genetic deterioration and extinction due to stochastic events (Nason \& Hamrick 1997). Even without isolation, newly created forest edges can significantly affect individual, population, and community dynamics (Augeri 1995; Whitmore 1997; Wiens 1997). Canopy openings and skid trails mean that even forests of several thousand hectares can be dominated by edge effects after logging (Augeri 1995; Chen et al. 1992; Harrison \& Bruna 1999; Wiens 1989, 1992).

Several studies report that effects from logging can extend considerable distances into surrounding undisturbed forests over the long-term (Lovejoy et al. 1986; Augeri 1995; Laurance \& Bierregaard 1997; Bierregaard et al. 2001). The effects create specific micro-climates that in turn affect plant and animal species via declines in seed production, flowering and fruiting (Laurance 2001; Rankin-De Merona \& Hutchings 2001). Edge effects such as micro-climate changes, increased wind turbulence and sunlight can affect flora and fauna hundreds of metres away from the edge inside a forest (Chen et al. 1992; Laurance 1999; Lovejoy et al. 1986; Wiens 1992). Laurance (2001) reports that in the Amazon large trees ( $>60 \mathrm{~cm} \mathrm{dbh})$ are particularly vulnerable to edge effects and can be impacted $>500 \mathrm{~m}$ from the fragment's edge (Laurance pers. comm.). Consequently, biological processes as well as individuals and species within that interior patch can be affected (Forman \& Moore 1992; Gosz 1991; Lovejoy et al. 1986; Wiens 1992). Hunting in fragmented forest patches also has greater impacts on wildlife.

\section{Limited productivity}

Much of Borneo has poor soils, and most of the upper Malinau is exceptionally low in plant nutrients (Basuki \& Sheil 2005). It has long been recognised, though often 
neglected, that forests growing on poor soils offer relatively little food for generalist herbivores (for example, Cebrián 1994; Coley 1987; Coley et al. 1985; Edwards 1989; Loehle 1988). This appears especially clear for dipterocarp forests-these dominant trees fruit irregularly and have highly defended leaves (Janzen 1974), possibly because they spend years as seedlings in the understorey and need protection from browsers.

Fewer food sources appear to result in low herbivore population densities, which in turn may determine absence/presence patterns for large carnivores. Meijaard (2004) reveals that in Kayan Mentarang National Park, ungulate biomass is $107 \mathrm{~kg} /$ $\mathrm{km}^{2}$ (after Yeager 1999), whereas this is up to $631 \mathrm{~kg} / \mathrm{km}^{2}$ in Bukit Barisan National Park in south Sumatra (O'Brien et al. 2003), and $492 \mathrm{~kg} / \mathrm{km}^{2}$ in Ujung Kulon National Park on Java (Hoogerwerf 1970).

Similarly, primate biomass is about $300 \mathrm{~kg} / \mathrm{km}^{2}$ in Borneo, whereas in Sumatra and Peninsular Malaysia it is $>800 \mathrm{~kg} / \mathrm{km}^{2}$ and in parts of Africa $>2,000 \mathrm{~kg} / \mathrm{km}^{2}$. Borneo's figures only surpass some parts of South America and Madagascar (for an overview see Chapman and Lambert 2000). The only large felid on Borneo is the Clouded Leopard (Neofelis nebulosa), whereas, in Sumatra, Clouded Leopard and Tiger (Panthera tigris) occur, and on Java, Leopard (Panthera pardus) and Tiger, which Meijaard (2004) thought to be the result of insufficiently high prey densities on Borneo. Similarly, Payne (1990) pointed out that forests on Peninsular Malaysia support between 5 and 10 times more monkeys than forests in Sabah.

In such a nutrient limited environment further losses are potentially important. Studies confirm that timber harvesting often leads to topsoil losses (where most biologically available nutrients are found), erosion, and accelerated leaching of nutrients (Douglas et al. 1993). An additional loss of nutrients occurs when biomass is removed - as in trees extracted during logging. The mineral nutrients removed are a tiny fraction of the timber mass, but this adds up. When new nutrients enter the system, e.g., from rocks, or fresh sediments, such minor losses would not be a concern-but such inputs are often lacking (i.e. in much of the upper Malinau). Indeed, the removal of biomass has an effect on many nutrients pools (see Nykvist et al. 1994, for some summary estimates with clear felling in Sabah).

The example of calcium illustrates the wider complexity of changing nutrient stocks and flows in disturbed forests. Calcium is commonly viewed as a key mineral in the development of many vertebrate species (see O'Brien 1998) and is likely a key factor accounting for the low abundance of many vertebrates in Malinau. In Borneo, forest clearance has been claimed to deplete calcium (Nykvist 1998, reviews data from various sites and implies that stems $>20 \mathrm{~cm}$ dbh in one site in Sabah contained about $20 \%$ of available calcium). Increases in ground temperature (as when forests are opened) may also accelerate losses of calcium (Innes 1993). Fungi associated with decomposing woody litter may accumulate calcium and phosphorus making it less available temporarily to other organisms (also magnesium, manganese, copper, iron, nitrogen; Coleman \& Crossley 2003; Kurek 2002). Changes in nutrient availability, including calcium depletion and nitrogen retention, will have subtle, long-term effects on forest growth and composition. 


\section{Silvicultural systems}

The dipterocarp forests of Southeast Asia are believed to be amongst the most promising for sustainable management. Appanah (1998) explains that, "If ever management of tropical forests is possible, the best chances are with the dipterocarp forests". The reasons are the high growth rates, rich commercial stocking, and a regeneration ecology well suited to canopy opening (Appanah 1998). Efforts to fulfil this promise have had mixed success from a sustainable timber production perspective (Appanah \& Turnbull 1998).

The following overview of silvicultural systems is drawn primarily from Appanah (1998) and Sist et al. (2003a, b). The dipterocarp forests of Western Malesia are the most productive tropical forest types in Asia, with considerable timber value. In Indonesia, for example, of the 41 million ha in forest concessions, $43 \%$ is still pristine forest, and $27 \%$ of the logged forest is still considered in moderate to good condition. Dipterocarps accounts for most of the commercial timber. Extracted volumes vary from 50-100 $\mathrm{m}^{3} / \mathrm{ha}$. The Borneo forests are generally the most productive, with extracted volumes often exceeding $100 \mathrm{~m}^{3} /$ ha (Sist et al. 1998b).

Dipterocarpaceae are the dominant family representing $25 \%$ of stems (120 stems $>$ dbh $10 \mathrm{~cm} / \mathrm{ha}$ ), with large size stems contributing $75-80 \%$ of the canopy and emergent trees, and half $\left(15 \mathrm{~m}^{2} / \mathrm{ha}\right)$ the total basal area.

The Malayan Uniform System (MUS), introduced in 1948 (see Wyatt-Smith 1963), was among the earliest silvicultural systems. It involved felling all trees above $45 \mathrm{~cm} \mathrm{dbh}$, and poison girdling all defective relics and non-commercial species down to $5 \mathrm{~cm} \mathrm{dbh}$. It required successive 'liberation release' treatments, such as clearing understorey plants and cutting lianas 20,35 and 55 years after logging. This treatment aimed to convert uneven-aged, mixed forest into more timber-rich, even-aged stands.

By the mid-1970s, much of Peninsular Malaysia's lowland forest had been harvested and in many instances converted to plantations. Harvesting subsequently shifted to the hill forests. In these steeper areas, the MUS was judged unsuitable due to patchy regeneration. Although the system was adapted (the Modified Malayan Uniform System) to include enrichment planting when natural regeneration was poor, the outcome was often unsatisfactory and the approach was abandoned.

In the late 1970s, the Selective Management System was developed. This involved felling all commercial species with a $\mathrm{dbh}>45 \mathrm{~cm}$ for non-dipterocarps, and $>50 \mathrm{~cm}$ for dipterocarps-provided sufficient healthy stems remained to support another harvest 30 years later (Appanah 1998). Based on the Malaysian silvicultural experiences, other Southeast Asian countries developed and applied polycyclic (multi-aged) approaches similar to the Selective Management System (see Appanah 1998). These systems are all based on minimum diameter limit rules.

The Indonesian cutting and replanting system known as Tebang Pilih Tanam Indonesia (TPTI, for detail see Appendix 11), is relevant across all Indonesian dipterocarp forests. In the TPTI all commercial trees above $60 \mathrm{~cm}$ dbh can be felled during a 35-year cutting cycle. TPTI relies on leaving behind a minimum density of potential crop trees $(25 / \mathrm{ha})$, which are sound stems of commercial species $(20 \mathrm{~cm}$ $\mathrm{dbh}$ and above). If these are not present, enrichment planting is required three years after logging. Liberation treatment takes place two, four and six years after logging, 
and targets all woody climbers and non-commercial saplings in the understorey. This treatment is supposed to improve regeneration and growth of timber species.

Companies incur significant costs in implementing the TPTI. The quality of treatments often fails to meet the intention of the original TPTI guidelines. For example while pre-harvesting inventories are carried out to obtain the annual allowance cutting, the resulting maps are not then used to plan skid trail networks. Other activities such as post-logging liberation treatments and enrichment planting are widely questioned.

Where forests are timber-rich (for example in East Kalimantan where there are 16-23 merchantable stems/ha), selective logging operations often damage more than $50 \%$ of the stand. This affects both forest structure and productivity, and reduced the available timber volume for at least 30-40 years. The sustainability of such systems is widely questioned (for example in Sabah: Kleine \& Heuveldop 1993; and Indonesia: Sist et al. 1998a, 2003a, b). Over the last 15 years, timber demands have been changing and harvesting is no longer exclusive to Shorea spp. Almost all dipterocarps, except Vatica spp., are now considered commercial. The trend seems to be continuing, with more and more species becoming valuable.

\section{Management intensity}

The specific ecology of Southeast Asian dipterocarp forests, and the silvicultural systems used to manage them have aspects that need to be recognised before it is possible to talk about how management might be improved. Selective logging's relative intensity of disturbance is one such aspect. Fredericksen and Putz (2003) suggested in a recent paper that disturbance and damage need not be viewed as a problem. They contend, by referring to scientific publications, that regenerating many valuable timber-producing species requires larger disturbance than is typically created using low-impact logging techniques. They argue it is often desirable and necessary to create larger gaps to promote seedling establishment and to enhance the growth of light-demanding commercial species. They propose intensifying forest management to allow more extensive unlogged reserves to be retained. As pointed out previously, maintaining a network of connected forest areas is vitally important if viable wildlife populations are to survive. We stress, however, that intensified logging as proposed by Fredericksen and Putz is not the best way to boost production and maintain wildlife in dipterocarp forests (see also Sist \& Brown 2004).

Logging and tree reproduction in Sundaland differ from Bolivia, where Fredericksen and Putz conducted their research. First, there is no seed bank of dipterocarps. Dipterocarp trees sit in the understorey as seedlings and saplings waiting, sometimes for decades (Whitmore \& Brown 1996), for openings in the canopy. They are thus extremely vulnerable to machinery, felling and extraction damage. Seedlings are typically only replenished every few years during a mast, when seeds either germinate immediately or die. So maintaining the forest crucially depends on maintaining the seedling-sapling layer and on maintaining 'seed trees' at adequate densities. Tree fellers, however, often target the big, fecund seed trees because they contain a lot of valuable timber. 
Many trees benefit from canopy opening, and in some parts of the humid tropics this needs to be planned as a 'treatment'. However, this is not an obvious problem in Sundaland's dipterocarp forests, where more trees are extracted per ha than in most South American or African forests, resulting in considerable canopy opening. Marsh and Greer (1992 in Davies et al. 2001) reported that in Borneo, over 10 stems/ha, or 70-130 $\mathrm{m}^{3}$ of timber/ha was harvested. Curran et al. (1999), Pinard and Putz (1996) and Sist et al. (1998a) reported extraction rates of 54 to $104 \mathrm{~m}^{3}$ of timber/ha in different parts of Borneo. (Note that Curran et al. 1999 suggested that only $40-55 \%$ of actual felled volumes were reported). Most large trees in Borneo are timber species (Sist et al. 2003b). In Africa, timber yields are rarely $>13 \mathrm{~m}^{3}$ of timber/ha with 2-3 trees harvested/ha (CIFOR 2004), while yields are even lower in Amazonian forests (Davies et al. 2001). Therefore, logging in Southeast Asian forests has predictably more severe impacts, with as much as $62-80 \%$ damage to the canopy (Johns 1989b).

There is little need for foresters such as Fredericksen and Putz (2003) to demand additional canopy opening. With dipterocarp forests, the trees obviously manage to regenerate naturally without logging (even though they are viewed as light demanding). So the levels of light brought in by logging are an equivocal benefit that must be balanced against the stem damage and understorey destruction. It is possible to have too much opening, as when climbers and weeds blanket the site and stall regeneration. In Bolivia there is some evidence that regeneration benefits from exposing the soil through scarification from machinery (Fredericksen \& Putz 2003), but this is not the case in Southeast Asia. In Sundaland, most machinery is extremely heavy, as typical logs are large, and most soils are vulnerable. The use of machinery can lead to severe soil compaction, which inhibits recovery (Hutchings et al. 2002). Too much canopy opening and heavy machinery also make it harder to avoid erosion, to keep waterways clean, and prevent the understorey drying out. Calling for intensified logging is not a good option in the Sunda region, which includes the most intensively, selectively logged areas in the tropics.

\section{Liberation and understorey clearing}

Within the TPTI regulations, concession-holders are legally required to repeatedly slash all undergrowth and climbers for several years after felling (see Appendix 11 , where such treatment is called 'liberation' and 'thinning'). The intention is presumably to control aggressive 'weeds' and encourage regeneration; in practice, though, this has a deleterious effect on many plant species, including rattan and timber seedlings (see Sheil 2003a; Sheil et al. 2003b), and many terrestrial mammals and birds. Unfortunately conservationists largely have not recognised this activity and it has not been assessed. This means our conclusions remain limited to our own first-hand observations and evaluations (see Sheil et al. 2003a, b; Sist et al. 2003a). In Malinau, where we have observed impacts, they are a serious concern (Sheil et al. 2003b).

Notably, compartments slated for logging in Malinau are often incompletely accessed due to extreme gradients and rugged, difficult terrain, so it is not uncommon 
for more than half a logged compartment to remain unlogged after harvesting is 'complete'. In contrast, the slashing treatment is applied on foot and no areas are omitted, making it a much more general and obvious impact on 'logged areas' (Sheil pers. obs. 1998-2003). Even if applied properly, the technique's silvicultural benefits appear limited while the impacts on biodiversity and communities are considerable. The loss of the forest understorey will, among other things, remove browser species, dry out the leaf litter, destroy understorey microhabitats, and increase visibility (although it is unclear whether this benefits prey or predator). We think that slashing undergrowth and climbers may be as damaging to the forest as logging.

\section{Logged and fragmented landscapes}

Various aspects of timber harvesting and concession development have different impacts on landscapes, habitats, and the life-cycle of endemic species. In forestry concessions, these effects operate in concert, making the specific causes behind changing species abundances hard to identify without detailed study. Nonetheless, there is some understanding of these various processes.

Beyond removing selected timber trees, concerns include damage to residual trees, streams clogged by debris, ground compaction, increased soil erosion and flooding (DFID 1999), and increased access to forests leading to greater threat of further harvesting, clearance for other land-uses and increased hunting pressure (Robinson $\&$ Bennett 2000). Some of these issues are discussed more fully in additional sections below. Poorly planned and implemented logging can result in large, heavily fragmented and unproductive areas, especially in forests with high road density, wide clearings, and many trial-and-error openings (Putz et al. 2000, 2001a, b).

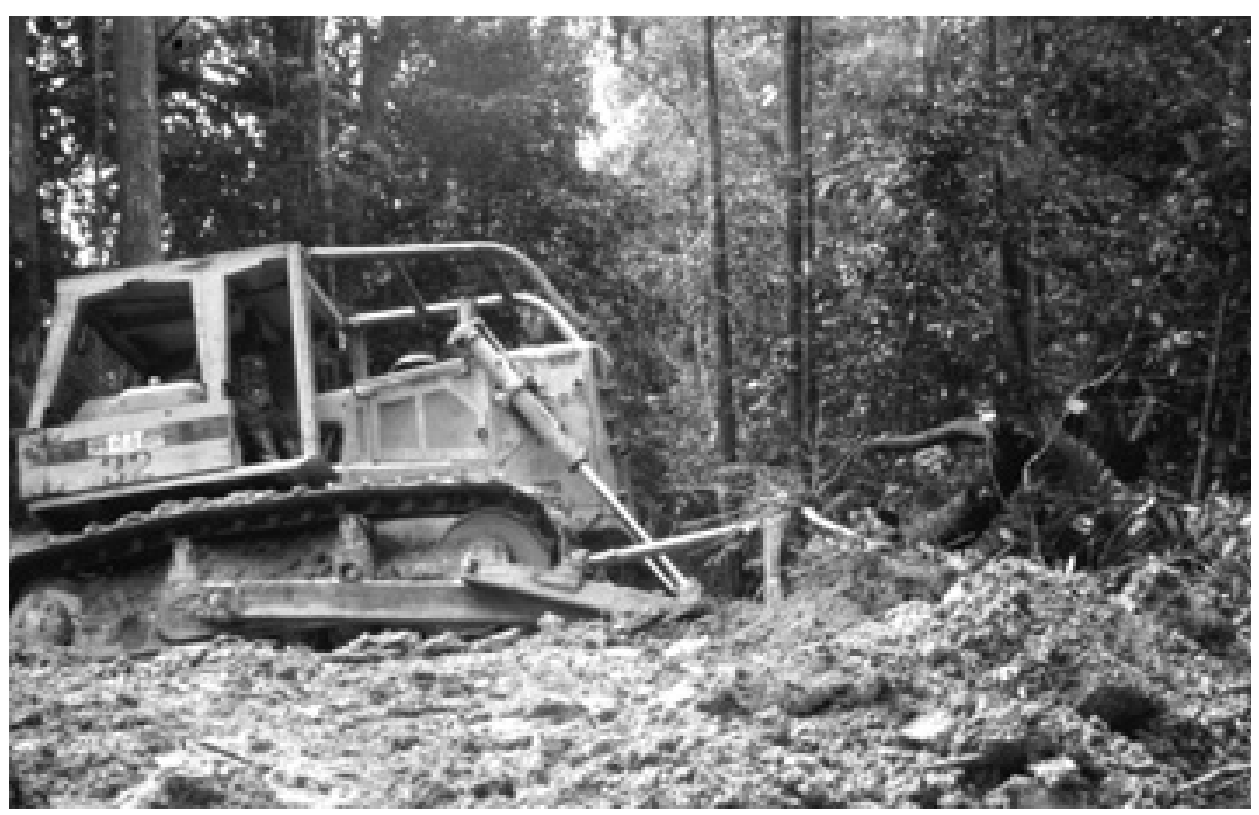

Figure 4. Roads and the use of heavy machinery cause fragmentation and lead to severe soil disturbance and erosion. (Photo by Rob Fimbel) 
Roads and trails contribute considerably to the total canopy loss during logging. For instance, in Queensland, Australia, roads were responsible for $21.8 \%$ of the total canopy loss. (Crome et al. 1992 in Malcolm \& Ray 2000). In several other studies, $40-50 \%$ of post-logging mortality and damage to trees was related to extraction routes (Johns et al. 1996; Webb 1997; White 1994). Research in the Neotropics (on level terrain) shows that planning the log-extraction network as a 'herring-bone pattern' with log-landings sited with reference to a prior harvest assessment, can ameliorate the negative ecological effects of selective logging compared with unplanned trails (Johns et al. 1996).

Research in the Malinau Research Forest concluded that reducing road impacts would increase concession productivity (Dwiprabowo et al. 2002; Sist et al. 2003b). Pinard et al. (2000) reported similar findings from Sabah, where the area covered by roads and trails was reduced from $17 \%$ under conventional harvesting methods, to $6 \%$ under a properly implemented, reduced-impact logging scheme. In conventionally logged plots in CIFOR's study in Malinau, the proportion of trees killed by skidding was twice that killed by felling (Sist et al. 2003b).

In addition to proximate habitat impacts, wildlife is also affected by roads, trails, and forests being patchily converted to other uses. The main issues are decreasing forest connectivity, reduced habitat, increased accessibility and thereby hunting pressure, and slowed forest regeneration (Pinard et al. 1996, 2000). In particular, fragmentation has profound ecological significance. The relevance of these factors to forestry in Borneo is far from clear-what is degradation and what is habitat loss, what is matrix and what is connectivity (Jules \& Shahani 2003)? Though we seldom have the answers, they will certainly depend on the taxa of concern, and be critical to species movements and persistence.

Fragmentation remains a very active research topic within the temperate and Neotropic zones but relatively little information is available from Asia (Laurance \& Bierregaard 1997; O’Brien et al. 1998b; Sitompul et al. in press; Turner 1996; Turner et al. 1996). Nevertheless, some generally accepted relationships exist. Small isolated areas of forest cannot maintain as many species in the long term as when the same area is part of some larger tract (see, for instance, Brook et al. 2003; Harris 1984; Harris \& Silva-Lopez 1992; Laidlaw 2000).

Many species require corridors between forest fragments, but such corridors need to fulfil certain ecological conditions to make them suitable for dispersal. For instance, fragmentation effects will be reduced if the distances between intact forest patches are short. Wildlife species that are especially vulnerable to habitat fragmentation will not cross open areas and will even avoid forest margins (Augeri 1995; Kinnaird et al. 2003; Woodruffe \& Ginsberg 1998, 2000). For example, Newmark (1991) indicated that forest corridors needed to be at least $200 \mathrm{~m}$ wide to allow the free movement of sensitive East African forest birds (see also Beier \& Noss 1998). Thus, research highlights the importance of maintaining 'forest-like' or a matrix of 'forest steppingstone' habitats in the intervening landscape (Gascon et al. 2000; Kinnaird et al. 2003; Laurance \& Bierregaard 1997; Wiens 1989).

Some species have minimum fragment size requirements if the population is to persist. (O’Brien et al. 1998b). In Malaysia, for example, large terrestrial carnivores 
and herbivores were only observed in larger (>6,551 ha) forest fragments. Also, species diversity declined sharply between a forest fragment of 459 ha and one of 164 ha (Laidlaw 2000). Fragmentation appears to affect nocturnal flying animals (including pollinators and seed dispersers) less than diurnal species. For example, moths are less sensitive than butterflies, bats less so than birds (Daily \& Ehrlich 1996). Forest fragments are also especially vulnerable to fire (Buechner \& Dawkins 1961), invasion by weedy species, and other erosive processes (Gascon et al. 2000).

\section{Landscape features}

Some species may depend on specific sites or habitats, and these need to be identified because forestry damage may have a negative impact on the species concerned. In Malinau, such sites include places where animals gather to lick seepages from mineral 'salt springs' ('licks'). Though such sites are studied in some parts of the world (for example, Klaus et al. 1998) they are not well recognised in Malinau, and are frequently destroyed by skid trails even though local people who focus much of their hunting efforts on these sites are acutely aware of their locations. Pools, wallows and river-side habitats offering nesting opportunities for reptiles and amphibians might also warrant protection.

Pools or wallows (Fig. 5) are relatively common in the forest, but little is known about them. Most pools in Kalimantan appear associated with excavations by pigs, although other mammals such as Sambar (Cervus unicolor) may use them as well. Bearded pigs have no sweat glands and so cool themselves in mud and muddy water (Curtis 1983; van Putten 2000). Wallows may be linked to foraging for worms or for soil minerals. Wallows and pools often occur just below ridge tops, or in

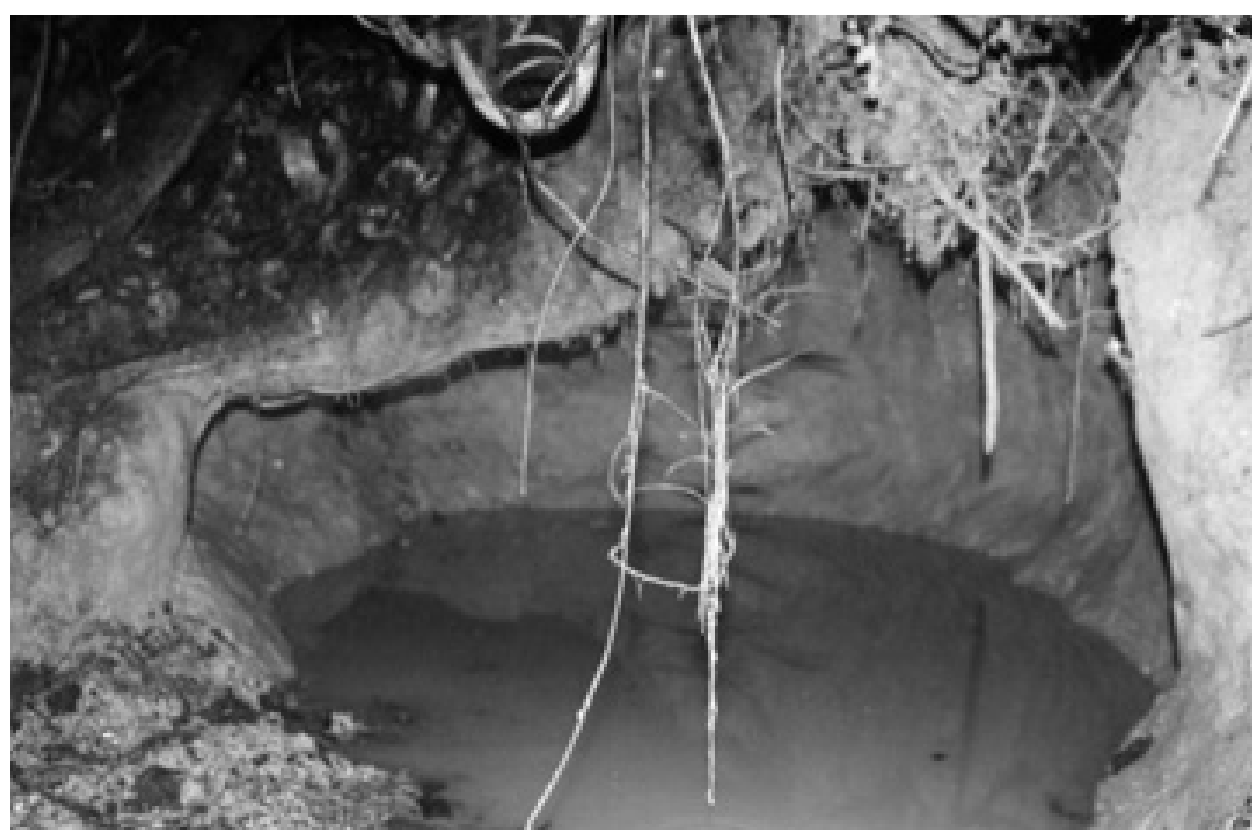

Figure 5. A deep wallow in MRF. (Photo by Titiek Setyawati) 
natural depressions. Soil drainage properties likely govern where water can collect. The average size of pools and wallows in Malinau is $13.9 \mathrm{~m}^{2}(\mathrm{SD}=27.1 ; \mathrm{n}=43$, Setyawati unpubl.). Some pools were very large (up to $165 \mathrm{~m}^{2}$ ) and deep suggesting that Banteng (Bos javanicus) or Rhinoceros (Dicerorhinus sumatrensis) had once been involved in their formation (Wulfraat pers. obs.). Wallows may be important for other vertebrates, such as breeding sites for certain amphibians, but more research is needed. Wallowing and rooting activity may increase soil erosion and change water quality in streams and natural pools (Hone 2002), further affecting aquatic animals.

Badly engineered roads also create ponds, and the effects are very visible along many logging roads in Kalimantan. Some people argue the effects are primarily local. In some cases several hectares of trees die, and a large, stillwater swamp develops as a breeding ground for mosquitos and other pests. Rachmatika et al. (2005) note some change in fish communities associated with such ponds. The wider ecological impacts warrant evaluation.

\section{The threat of hunting}

Hunting poses a greater threat to large forest fauna than timber harvesting in many areas of the humid tropics, (for example, Auzel \& Wilkie 2000; Bennett et al. 2002; Linkie et al. 2003; Mathews \& Matthews 2002; Robinson \& Bennett 2000; Walsh et al. 2003; Wilkie \& Carpenter 1999). It is even sometimes a greater threat to wildlife than habitat loss (Bennett et al. 2002, for areas less affected see Hedges et al. in prep.; Kinnaird et al. 2003; Robertson \& van Schaik 2001).

Many large vertebrates in Borneo and some specifically targeted species such as turtles, crocodiles, and certain birds, have already been hunted to virtual extinction (Bennett et al. 1997, 1999; Bennett \& Robinson 2000; Robinson et al. 1999). Overhunting alters wildlife population densities, distributions, and demography, which can then lead to shifts in seed dispersal, browsing, competition, predation, and other community dynamics.

Despite protected areas being established where the forest remains largely untouched by logging, many reserves are increasingly becoming 'empty forests' (Redford 1992). Local examples were found in the Kayan Mentarang National Park, where a short study indicated that after several years of uncontrolled hunting, primate populations had declined locally despite the forest remaining virtually untouched (Nijman in press). The threat posed by hunting is especially great in Asian tropical forests and in Borneo in particular, because of the extreme scarcity of edible wildlife (Bennett et al. 2002).

Hunting on Borneo appears to have been relatively sustainable, at least until the 1970s, with the exception of the Sumatran Rhinoceros (Dicerorhinus sumatrensis), which was already in decline by the 1930s (NIVN 1939). Since then several factors have changed dramatically, leading to significantly increased hunting pressure and population declines among many vertebrate species. On Borneo, this includes Sambar, Muntjaks, Bearded Pigs, hornbills, some primates, including Bornean Orangutan, and possibly Malayan Sun Bears and Clouded Leopards (Bennett et al. 1999). 
Distribution maps of large Bornean mammals show irregular patterns with large gaps in their distribution despite apparently suitable habitats. Where closely related species occur, some patterns can be explained by inter-specific competition leading to mutual exclusion (for example, some Callosciurus squirrels or Presbytis leaf monkeys). The availability of certain minerals may also explain some presence/absence patterns (Payne 1990), although the geographic correlation between soil and plant chemistry and species distribution remains to be proven. An important factor is likely to be the impact of hunting.

Hunting pressure varies between different parts of Borneo, although no comprehensive studies are available. In Sabah, there appears to be a considerable difference between the rich eastern forests where many large mammals occur in higher densities (including elephants Elephas maximus, Sumatran rhinoceros D. sumatrensis, Bornean Orangutan Pongo pygmaeus, and Banteng Bos javanicus), whereas these species are rare or absent in the state's west. Generally speaking, for cultural and religious reasons, hunting pressure in eastern forests is low compared with the state's west where indigenous hunting cultures predominate.

Similarly, in Kalimantan, Orangutan densities are highest along the coast, or at least were until widespread deforestation occurred. People on the coast are primarily agriculturalists of Muslim religion, and so rarely if ever eat primates, as opposed to the primarily Christian hunter-gatherer and shifting cultivation communities in the island's interior (Rijksen \& Meijaard 1999).

Still, the link between hunting pressure and species distribution remains to be proven and certainly would not explain all unusual distribution patterns. In fact, several factors most likely interact, including:

- Generally low soil fertility in Borneo (compared, for instance, with the volcanic islands of Java and Sumatra), leading to low animal densities;

- Variations in soil chemistry affecting animal densities but also the land's agricultural potential. The latter leads to sedentary, agricultural lifestyles or to nomadic, hunter-gathering, and anything in between.

Superimposed on these interactive human and natural factors are the species' ecological abilities to cope. Knowledge about all these factors remains limited and much research is needed in this important field. Hunting may not necessarily be detrimental to all species. Bennett and Dahaban (1995) found that certain species such as giant and medium-sized squirrels increased significantly in areas subjected to high hunting pressure, probably because the hunters preferred to catch large mammals.

Not all hunting is for food. Many species are taken for medicine, ornaments, and other uses (Puri 2001).

\section{Subsistence hunting}

Subsistence hunting has been a critical source of protein for tropical forest dwellers since the earliest Stone Age (Stanford \& Bunn 2001)—which raises the question why 
it is only now having a massive impact on wildlife populations. In fact, even this is not entirely true, judging by the mass extinctions of mega-faunas across the Americas, Eurasia, and Australia after the last Ice Age. Some extinction events were caused, at least in part, by human hunting, as were the mass extinctions of bird species on Pacific Islands after humans arrived (Duncan et al. 2002).

As a rough rule of thumb, the human population density limit for subsistence hunting in the tropics has been estimated at about one person $/ \mathrm{km}^{2}$ (Robinson $\&$ Bennett 2000). The model has a sound theoretical basis, but makes numerous and often poorly founded assumptions, such as stable demographic traits in unhunted wildlife populations. Many erratic and poorly understood population processes can lead to extirpation, even when the annual harvest rate is well below the calculated maximum sustainable level. Many species in a bounded ecosystem can go extinct in a relatively short time through completely natural processes (for example, Brown et al. 2001). Populations thought to be harvested at sustainable levels might, in fact, be under or over-harvested (Milner-Gulland \& Akçakaya 2001; Slade et al. 1998; Struhsaker 2001).

In any case, in many parts of Borneo, human population densities are higher than $1 / \mathrm{km}^{2}$. The Kayan Mentarang National Park, for instance, occupies an area of about $14,000 \mathrm{~km}^{2}$ and had a total human population of 16,645 in 2001 . The population was estimated to grow to 26,773 by 2025 (Effendi et al. 2002). This suggests that even in remote and mountainous areas, human population densities are too high for sustainable subsistence hunting, especially where forests have been degraded. In the upper Malinau watershed human densities appear to be less than $1 / \mathrm{km}^{2}$ (Sheil 2001a), although these could increase in the near future with increased road building.

Some communities greatly depend on a regular supply of forest-derived protein. Puri (1997) estimated that hunting provided between $20 \%$ and $40 \%$ of the food calories in the Penan people's annual diet in Kayan Mentarang National Park. However, because of the considerable annual variation in wildlife availability, there were times when hunting provided all or none of the Penan's food. Caldecott (1988) suggested that declining wildlife populations might partly explain the chronic undernutrition and growth stunting which Anderson (1979) reported in various rural areas in Sarawak.

If wildlife populations decline significantly these people will have to start paying for food. A clear understanding of this might be a good incentive to work towards sustainable hunting techniques. Traditional hunting is often non-selective, using dogs, traps, or snares; animals are often killed irrespective of their condition-fat or thin, with litter, pregnant or not—and hunting is sometimes wasteful, with only part of the animal taken (Meijaard pers. obs.).

Other factors increasing hunting's impact on Borneo's wildlife include increased forest accessibility; improved transport with cars, motor bikes, motorized canoes, and light planes; guns and ammunition; the erosion of traditional prohibitions on killing and eating certain animals; increased immigration by non-indigenous people to interior areas; and an increasing market for wildlife products either as food, trophies, or medicine. The latter factor does appear to be increasing in Malinau, however. 
Together, these factors often result in hunting becoming commercialised rather than for subsistence alone.

Sheil (2001a) found that many villagers in Malinau perceive a decline in important resources, especially the animals they hunt for food and plants they rely on for daily needs and trade. The villagers generally blame the decline on logging, with indigenous hunters now having to compete with immigrants working in the logging and mining industries (a pattern also observed elsewhere, see following section). Unlogged forest is considered the most important land for communities, with wild pigs and timber trees among the most important species found there. Local communities give low preference to logged-over forest. The reasons include diminished key resources, lower quality habitats for fish and wildlife, reduced physical accessibility and reduced access rights. Pigs, a preferred food species, are said to number fewer in logged areas, although this is hard to assess reliably given the species' large population fluctuations. Logging also unnecessarily depletes certain emergency forest foods, such as sago. Skid trails often damage Eugeissona utilis, the most important sago, which grows on ridge tops (Sheil 2001a). Such impacts may affect demand for other forest foods.

\section{Concessions and hunting}

Hunting pressure increases with improved access through forestry roads and supplies for logging camps (Robinson et al. 1999; Wilkie et al. 2000). Reliable data are not always easy to collect and no figures are available for Malinau, but research elsewhere shows hunting associated with concession activities should be cause for concern. For example, in Sarawak in 1996, the annual catch for a single logging camp of 500 people was 1,150 animals, or 29 tons of meat per year. Workers in such camps throughout the whole of Sarawak were estimated conservatively to have hunted approximately 55,045 animals or 1,400 tons of wild meat per year for their own consumption (Bennett \& Robinson 2000). In a single logging camp of 648 people in the Republic of Congo, the annual harvest was 8,250 animals, equivalent to 123.5 tons of wild meat, which was partly used for personal consumption and partly traded on markets (Auzel \& Wilkie 2000). Such activities cause wildlife densities to thin considerably, particularly those species with inherently small ranges or reduced ranges due to deforestation. Their sustainability remains uncertain.

\section{Roads and hunting}

Bennett et al. (1999) found a relationship between the quality and density of the transport network and hunting in Sarawak and Sabah. Until about 1960, large parts of Sarawak and Sabah were inaccessible to all but occasional hunters trekking for many days on foot. Since then, both logging and other roads have spread and river transport and rural air services have improved. Most forest areas are now less than a day's travel from the nearest settlement, and readily accessible from towns. This has led to a significant increase in hunting pressure. Auzel and Wilkie (2000) and Wilkie et al. (2000) also investigated how roads affect species conservation. Their research in the Republic of Congo shows that roads established and maintained by logging 
concessions intensify bushmeat hunting because they open up relatively unexploited wildlife populations and lower costs to transport bushmeat to markets.

Roads result in over-harvesting and greatly depleted wildlife populations (Bennett et al. 1999; Bennett \& Robinson 2000), due to:

- Facilitating increased immigration;

- Increased forest clearance along road sides, thereby reducing and fragmenting habitats and increasing human population density in the remaining forest;

- Loss of inaccessible and undisturbed 'source' areas to replenish populations;

- Increased access to markets. This allows local people to sell wild meat, and buy in technology such as shotguns, cartridges, snare wires, batteries, vehicles and fuel. These technologies facilitate indiscriminate and excessive hunting while obscuring permitted subsistence hunting and raising the catch to unsustainable levels;

- Increased access by locals and outsiders, often from towns many tens of kilometres away. Some people are hunters, others are traders who buy wild meat or wildlife body parts.

In Part III we will outline how timber concessions can best reduce hunting.

\section{Collected products}

Several researchers have recently investigated the local use of non-timber forest products in the Malinau region (see Puri 2001; Sellato 2001; Sheil 2001a). Local communities use exudates (resins, latexes and gums), rattans, aromatic woods, and various vegetable and animal products. Many wildlife species are used for a variety of purposes, including food, medicine, tools, rituals, decoration, bait, as pets, or as trade items (Puri 2001). Trade in wildlife products includes swift nests, gallstones from leaf monkeys, bears and porcupines, pets like monkeys and bears, teeth, claws and paws, trophies (Banteng, Sambar), meat and fat from Bearded Pig, various deer species, pangolin, python, and primates, to mention a few (Puri 2001; Augeri unpubl.).

Little is known about the sustainability of non-timber forest products, but at least some products are used unsustainably. Sellato (2001) reported that bird's nests caves in the Malinau District have been over-exploited since about 1980, and the yield has fallen to almost nothing. Occasionally new caves are found, leading to a temporary increase in production, but generally nest harvesting appears to be unsustainable.

Some bird species caught for cages, such as Hill Mynahs (Gracula religiosa) and Blue-crowned Hanging Parrots (Loriculus galgulus) (Fig. 6), are still found in fair numbers in the forest. Others, like the Straw-headed Bulbul (Pycnonotus zeylanicus), a popular songbird, appear to have been collected to the point of local extinction (Sheil 2001a).

Trade in freshwater turtles and tortoises for meat and traditional Asian medicine appears to have escalated in the last 10-15 years (Walter 2000). No data exists on how this has affected turtle and tortoise populations in the Malinau region. Elsewhere, however, this largely unregulated trade has led to significant population declines. Several 


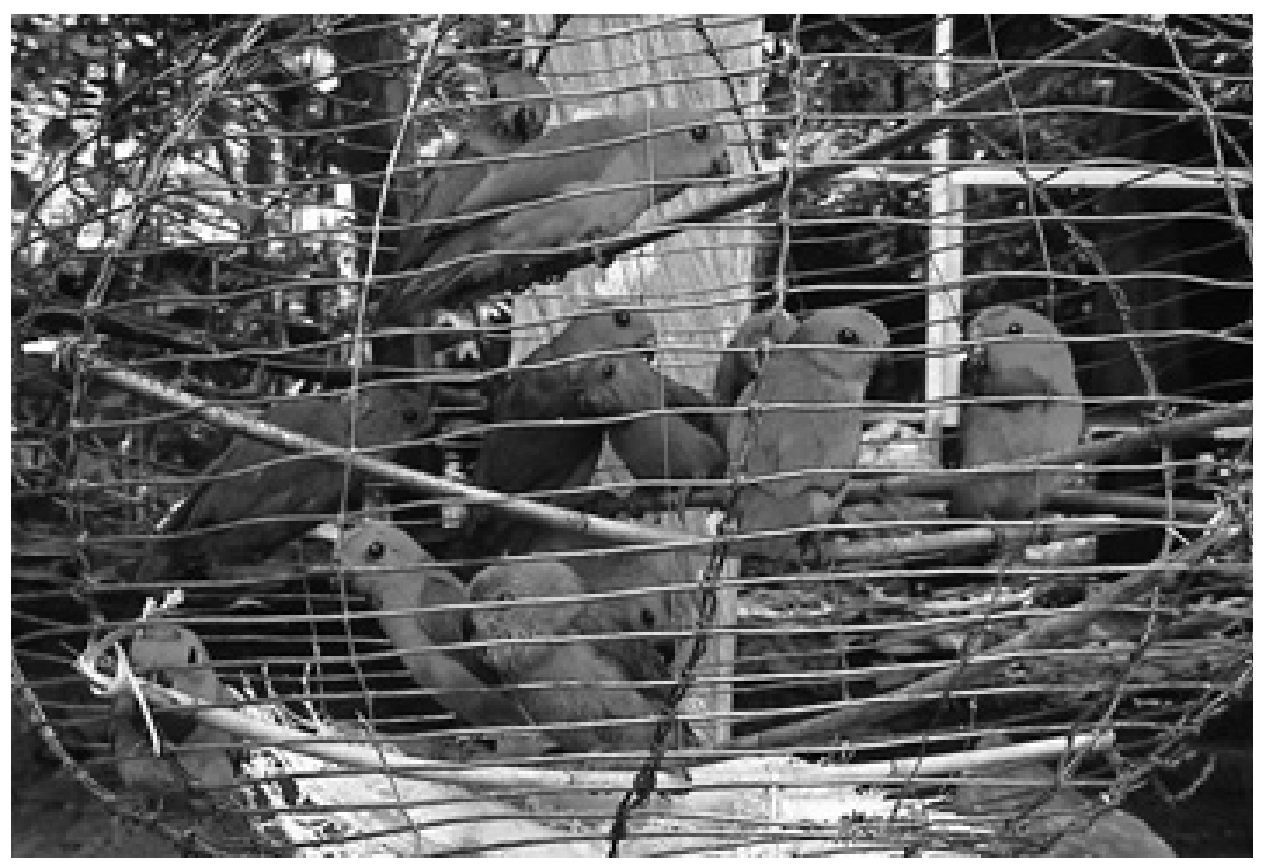

Figure 6. Blue-crowned Hanging Parrots (Loriculus galgulus) captured in Lalut Birai for trade purposes. (Photo by Dave Augeri)

turtle and tortoise species in the Malinau region are listed on the IUCN Red List of Threatened Species (see Hilton-Taylor 2000), but Indonesian law protects none.

\section{Traffic}

We are not aware of any studies in tropical forests, but we suspect traffic has some effect on forest wildlife (see also Forman \& Alexander 1998). The three primary effects are:

- road-kills (for example, Taylor \& Goldingay 2004 on non-forest tropical fauna; and Jackson 2002 on African nightjars; Clevenger et al. 2003 in Canada);

- animals that learn to feed from or are attracted to road kills (Dale 2001);

- noise.

Intermittent traffic generally poses a greater threat than heavy traffic, with the risk increasing with vegetative cover (Clevenger et al. 2003). Some animals appear attracted to the road surface's warmth (Jackson 2002), while other species learn to use roads for movement, especially at night. For some species there may be a seasonal increase in risk that demands extra vigilance. Amphibians are seriously affected in some parts of the world, for example crossing the road in some parts of Europe brings a 30-98\% chance of mortality (Hels \& Buchwald 2001). 


\section{Invasive species}

The immigration of exotic flora and fauna into fragmented forests via logging infrastructures may threaten some wildlife populations, although this subject remains little examined in Southeast Asia. Examples include introduced frogs and fish that might outcompete native species, plants such as Eupatorium (Chromolaena) spp. that become increasingly dominant in the understorey and reduce natural regeneration, and the proliferation of Eichornia crassipes (already present in Malinau) or Salivinia spp. which block waterways and reduce light infiltration into lakes and slow moving rivers.

In Bangladesh, an abrupt decline in regenerative forest species (primarily dipterocarps) was accompanied by an increase in exotic shrubs, grasses and vines typical of open habitats in the degraded forest site. These shrubs (for example, Melastoma spp., Lantana camara, Clerodendrum infortunatum and Jasminium spp.) and grasses and vines (for example, Imperata cylindrica, I. arundinacea, Mikania scandens, Saccharum spontaneum and Eupatorium odoratum) were gradually replacing the primary regenerative forest species (Islam et al. 2001).

Exotic climber species like Mikania micantha, which can blanket open areas, are already a significant problem elsewhere in Indonesia (Whitten et al. 1996). Clidemia hirta is another highly invasive, bird-dispersed shrub in forests throughout the oldworld tropics; it invades forest openings, especially where the soil has been disturbed (Peters 2001; Teo et al. 2003). Many widely planted genera, such as Psidium spp., Passiflora spp. and Leucaena spp. include species known to be invasive in some regions of the world. Such species can be found in natural closed forest, but they are generally favoured by disturbance (Cronk \& Fuller 1994; Sheil 1994).

Roads and logging allow such species to enter and persist in closed forest (Janzen 1983). It is also clear from experience elsewhere that invasiveness often develops over time as a species naturalises and adapts to local conditions. Animals mainly disperse these species, and it seems inevitable they will have some impact on forest fauna, although the nature of such effects is little studied. It appears likely that generalist frugivore species and pollinators will often benefit at the expense of more specialised, less opportunistic species—an effect that can have wider, if as yet unanticipated, ecological ramifications.

The threat is not restricted to plants, but involves a wide range of organisms. The wild Eurasian boar Sus scrofa appears to be recently naturalised in Malinau, and is believed to have displaced S. barbatus in Peninsular Malaysia (MacKinnon 2002). Various parrots such as Rainbow Lorikeet Trichoglossus haematodus, and Lesser Yellow-crested Cockatoo Cacatua sulphurea, are also potential invasives, as are various sparrows, crows and starlings, some of which may carry avian malaria (MacKinnon 2002). The African land snail Achatina fulica, although not appearing to penetrate deep into forests, occurs on edges and is highly adaptable. The 'Golden Snail' Pomacea canaliculatus, from South America, lays pink eggs on the edge of ponds and can destroy 50-80\% of rice crops (Whitten et al. 1996).

Hoplobatrachus rugulosus, a medium-sized frog growing up to $10 \mathrm{~cm}$ was brought to North Borneo to be ranched, but later escaped in the wild. Matsui (1979) first reported it from Sabah in 1978. In East Kalimantan the local people claim they 
first observed the species around 1997, by which time it had covered 400-700 km. The route taken is unclear, but it is likely the species favours disturbed habitats. According to Iskandar (2004), local people note another new frog in Malinau that could threaten local species. It is important this species is clearly identified; it may be H. rugulosus, or Rana catesbeiana, judging from local descriptions. A link to disturbed habitat is unclear.

Finally, the increased proximity of feral animals to their wild relatives increases the transfer of diseases, as has been reported for rinderpest in feral cattle and pigs (Sus scrofa) which wiped out large numbers of Bearded Pigs (Sus barbatus) in the 1870s, 1890s and early 1900s (Feuilletau-de Bruyn 1933; Knapen 1997).

Appropriate strategies can usefully anticipate other threats. The threats include importing soil pathogens such as the Phytophera threatening Australian rain forests (Brown 1976), exotic earthworms (an increasing problem in West Africa, see Sanchez-De Leon et al. 2003), exotic ants (leading to animal blindness in parts of Gabon, Wetterer et al. 1999), and the introduction of the giant African land snail, Achatina fulica, (for example, Civeyrel \& Simberloff 1996). Various ants are already noted as problems in the region (MacKinnon 2002). Measures are needed to ensure minimal transfer of soil and other potentially infected material between sites. A general recommendation is to seek region-wide control regarding the import and movements of live soil, plants and animals, and associated hygiene regulations. The potential seriousness of exotic species is reflected in countries such as Australia and New Zealand, which do everything they can to prevent alien species arriving and impacting native flora and fauna.

\section{Fire}

Wildfires are virtually impossible in most undisturbed, tall, closed-canopy, tropical rain forests under normal conditions: a moist microclimate, moist fuels, low wind speeds and high rainfall create nearly non-flammable conditions (Cochrane et al. 1999; Holdsworth \& Uhl 1997; Kauffmann \& Uhl 1990; Nepstad et al. 1999a, b). However, the general perception that large-scale fires were not a significant threat in these forests has shifted since 1982-83, when a severe drought and accompanying fires destroyed large areas of tropical rain forests in Borneo and West Africa.

Fires in tropical rainforests can be generally classified as either surface fires and deforestation fires (Nepstad et al. 1999a). Deforestation fire is considered the most dramatic in terms of ecological impact. Surface fires that ignite the organic debris lying on the forest floor are often deceptively small and slow moving. As the fire creeps along the ground at a rate of 10-30 metres every hour, a few of the insects, lizards and other ground-dwelling fauna flee while others are less fortunate (Nepstad et al. 1999a). The principle forest damage comes not through the destruction of organic matter, but through tree stems and lianas heating up, (Nepstad et al. 1999a) causing these plants to die months or years later.

Depending on the intensity, fire can kill virtually all seedlings, sprouts, lianas and young trees because they are not protected by thick bark. The most important tree family in Borneo, the Dipterocarpaceae, is adversely affected by fire due to its thin bark, 
flammable resin, and a lack of resprouting capability (Whitmore 1990b). However, dipterocarps can regenerate in lightly burnt areas (Leighton \& Wirawan 1986).

Disturbance correlates strongly with fire susceptibility. In general, most investigators of the 1982-83 fires on Borneo found the degree of damage and fire intensity was related to previous logging intensity and residual debris on the forest floor (Leighton 1984; Lennertz \& Panzer 1983; Mackie 1984; Malingreau et al. 1985; Wirawan 1993; Woods 1989). Logging often leads to woody debris building up on the ground and canopy opening. Consequently, the forest generally "dries out" and light-tolerant species such as grasses and shrubs colonise the forest floor.

Fires increase the probability of burning in subsequent years. As dead trees topple to the ground, they open up the forest to drying by sunlight, while fires favour fire-prone species that add to fuel load. The most destructive fires occur in previously burnt forests (Cochrane \& Schulze 1999). Many forests that burned in Borneo in 1982-83, or during the following El Niño droughts, burned for a second time in 1997-98 (Hoffmann et al. 1999). Repeated burns are a key factor in impoverishing biodiversity in rain forests.

There are still few in-depth studies examining how fire affects tropical forest biodiversity (see Dennis et al. 2001, and Nasi et al. 2002 for a review of the literature), but impacts can be inferred from case studies undertaken after the fires in 1982-83 and 1997-98 in Indonesia. The 1982-83 fires in Kutai National Park, East Kalimantan, resulted in widespread reptilian and amphibian mortality (Leighton 1984; MacKinnon et al. 1996). Fruit-eating birds such as hornbills declined dramatically and only insectivorous birds, such as woodpeckers were common due to an abundance of wood-eating insects. Rabinowitz (1990) reported that small mammals, birds and reptiles were scarce in burnt dipterocarp forests in Thailand, and that carnivores tend to avoid previously burnt areas.

In Sumatra, Kinnaird and O'Brien (1998) described fire damage in the Bukit Barisan Selatan National Park during the fires of 1997. They suggested that the loss of fruit trees reduced the food available to a large number of omnivorous species such as primates and squirrels, Sun Bear (Ursus malayanus) and civets, as well as ungulates such as mouse deer (Tragulus spp.) and muntjac (Muntiacus spp.) (Note: fruit was generally scarce in 1997, even in areas where there was no fire). The reduction in ground squirrels and tree shrews suggested that rodent densities in general declined, adversely affecting the food supply for small carnivores such as the Leopard Cat (Prionailurus bengalensis), although it is unclear whether the fires themselves directly caused populations to fall.

The destruction of tree cavities may also have affected birds and mammals such as tarsiers and bats. Finally, the extensive fires destroyed the leaf litter and its associated arthropod community, reducing the food available for omnivores and carnivores (Kinnaird \& O'Brien 1998). Elsewhere, there was a decline in slowmoving animals, frugivores and much of the litter fauna following surface fires in the Brazilian Amazon (Nepstad et al. 1999a).

Fires are not all bad for wildlife. Some species, such as large herbivores, benefit from the new grass that flourishes after fire. Observations from Cambodia indicate that wild cattle, such as Banteng (Bos javanicus) and Gaur (Bos gaurus), thrive on 
grasses in newly burned forest areas (Wharton 1966). This was also observed in East Kalimantan where local Kenyah and Kayan people regularly burn open areas to attract game, such as deer, muntjac, and Banteng (Hedges \& Meijaard 1999).

Van Nieuwstadt et al. $(2001,2002)$ reported on a detailed study on postfire vegetation dynamics in the unlogged dipterocarp rainforest of Sungai Wain near Balikpapan, East Kalimantan. They showed that forest recovery is possible but that further disturbance (including logging) may lead to forest loss. In brief, one fire alone does not cause conversion to non-forest vegetation. The survival and sprouting capacity of primary forest trees and the seedling establishment of pioneer trees and shrubs suppress the establishment of the worst non-forest species. However, the post-fire vegetation is certainly less resilient than might be assumed by anyone witnessing the vigorous post-fire regrowth and cannot withstand repeated disturbance. Previously sprouted individuals show reduced sprouting potential and survival after being damaged a second time, the seed bank is largely reduced after the initial post-fire burst of germination, and the density of vital seed trees is low. The open areas created in the understorey by the conventional heavy logging machinery used for salvage felling encourage the rapid development of non-forest vegetation, and seriously reduce the potential for recovery.

\section{Certification}

Several certification systems for sustainable forestry concession management are under development in Indonesia. Of these, Lembaga Ekolabel Indonesia (LEI) and the Forest Stewardship Council (FSC) are best known.

Initiated in 1993, LEI has worked out a certification system for Indonesian forest products. The system is based on sustaining economic, ecological, and social values.

FSC is a global organisation founded in 1993 by environmental groups, the timber industry, foresters, indigenous peoples and community groups from 25 countries. FSC principles 6 and 9 are of most concern to this study. Principle 6 addresses environmental impacts of timber extraction, and principle 9 promotes the maintenance of high conservation value forests. Other important principles relate to the local community rights and respect for laws and regulations. FSC principles are outlined on their website (http://www.fscus.org). In a later section we shall briefly discuss how they relate to our recommendations. 



\section{Birds}

\section{General}

A total of 239 bird species were observed in the MRF between September and October 1998 (O’Brien \& Fimbel 2002). This compares favourably with species counts from other areas, some of which covered longer periods and wider elevation ranges, e.g., 187 in Gunung Palung National Park, West Kalimantan (study duration 2-3 years, area $200 \mathrm{ha}$ ) (Laman et al. 1996), or 190 from Barito Ulu (study duration 39 days, area $150 \mathrm{ha}$ ) (Wilkinson et al. 1991). Families with the most species recorded were represented by Timaliidae (18 species), Pycnonotidae (12 species) and Picidae (12 species). Figures illustrating the relationship between survey effort and number of species detected (see O'Brien \& Fimbel 2002) suggest that the sampling intensity applied in the study was insufficient to detect all bird species in the MRF.

The responses of birds, to selective logging and to other forms of forest disturbance, have been more thoroughly studied than the majority of vertebrate taxa. As a group, birds are useful for evaluating the effects of logging on fauna, due to:

1. Their well established taxonomy and capacity to be identified in the field;

2. The availability of biological and ecological information on most bird families and many species;

3. Their apparent sensitivity to specific changes in forest structure, microclimate and composition; and

4. Their ecological role (e.g., pollination, seed dispersal and seed predation, Fimbel et al. 2001).

Sometimes avian species richness declines after logging. Marsden (1998) found 73 bird species in unlogged forests in Seram, Indonesia but only 53 in forest logged 1-5 years previously (logging intensity not given). Thiollay (1992) found in French Guiana that while some species increased in abundance, overall species richness was $47 \%$ lower in forest logged one year previously than in unlogged forest. However, 
other studies have found an increase in bird species richness following logging. Johns (1997) recorded more species in heavily logged dipterocarp forests in Sabah, due principally to the addition of forest edge species. Similarly, Danielsen and Heegard (1994) in Sumatra found an increase in the number of species after logging-but this observation masks the fact that no fewer than 31 species were found only in the primary forests and lightly logged areas (Lambert \& Collar 2002). In a Ugandan forest area, bird species diversity was similar in selectively logged and unlogged forest, although the response was species-specific (Owiunji 2000). Also in Uganda, bird community composition in gaps and adjacent disturbed forest have been found to be very similar, although bird densities in gaps were lower (Ngabo \& Dranzoa 2001). In Belize logging has been found to have little impact on bird diversity (Whitman et al. 1998).

In general, rainforest bird communities appear to lose few species immediately after harvesting. Johns (1996) recorded that all species found in unlogged forest were also present in logged areas in Sabah (but note that Lambert and Collar (2002) pointed out that Johns' studies suffered from bias related to the use of logging roads as transects). A number of studies have shown species diversity to be lower in logged forests and disturbed habitats, and this is often due to the greater dominance of bird fauna by a few species adapted to disturbed habitats. Other studies found certain species to be absent from logged forests. Kofron and Chapman (1995) found that $38 \%$ of forest interior specialists were not present in selectively logged forest in Liberia.

When interpreting such results we need to distinguish richness (total number of species in a given area), diversity (proportional representation of each species), taxonomic similarity and ecological similarity. A community may contain the same number of species, or even the same species, but if the proportional representation of species differs significantly, the functioning and behaviour of the community may be different depending on the ecology of the various species. In addition, changes in species richness are not indicators of taxa vulnerability; nor can changes in species richness be used to identify mechanisms. Moreover, such changes cannot inform scientists and managers about changes in 'conservation value', despite the presently popular assumption that areas with higher species richness of the taxonomic group in question have higher conservation value. For example, Augeri (1995) found that an increase in generalists and edge-related species could lower functional diversity in the system by reducing specialists and increasing the number of generalist species with similar ecological roles. Thus, a form of 'biohomogenization' occurs (Harris \& Silva-Lopez 1992), which could negatively impact endemic or endangered specialists via competition, predation or parasitism, particularly those species associated with interior habitats. Such changes could also impact and alter community-level ecological processes. Thus, an increase in species richness or diversity may not necessarily indicate a positive outcome for that system, particularly if that increase consists of species with similar ecological functions in an area that was historically dominated by specialists. Information from studies that show an increase in species after disturbance must therefore be considered relative to the actual species present as well as their functional role (e.g., generalist, specialist, etc.) and how this will impact 
the system over the long term (see Sheil et al. 1999 and Sheil \& Burslem 2003 for a comparable discussion in relation to the increase in tree diversity that sometimes follows logging).

Mixed feeding flocks are thought to increase feeding efficiency and predator escape in forest bird communities (Julien \& Clobert 2000). Thiollay (1999) compared the composition and frequency of occurrence of mixed flocks of Asian and South American tropical insectivorous birds under various degrees of forest disturbance. Flocking propensity declined from primary lowland forest to open (semi-deciduous), disturbed (logging gaps), and montane or managed forests (broken canopy). Thiollay suggested that predator detectability was the underlying mechanism, with birds being able to detect predators more easily in open forests, thus reducing the need to feed in mixed flocks. Because some species appear to depend on mixed flocks (at least in the Neotropics; see Julien \& Clobert 2000), decreased mixed feeding behaviour following logging may thus have a disproportional effect on certain species.

Across the Asian, African and American continents, certain bird feeding guilds have been found to respond relatively consistently to selective logging. Nectarivores and generalist frugivore/insectivores of the canopy increase with logging (Hussin 1994; Johns 1989a, 1996; Lambert 1992). These wide-ranging generalists appear well adapted to a broad range of successional environments, and many frugivores and nectarivores benefit from the increase in fruit and flowers of plants that colonize disturbed land (Lambert 1992). In general, it appears that the abundance of species in feeding guilds that use two or more groups of food (insectivore/frugivore; insectivore/ nectarivore, etc.) tends to increase after logging, while species from a single source feeding guild often decrease (Setyawati 1999).

Lambert and Collar (2002) suggested that complete forest fragmentation, involving non-forest matrix, has a higher impact on bird populations than the local effects of selective logging. Their data compilation indicates that of the 274 resident forest bird species confined to the lowlands of the Sundaic Subregion (excluding Palawan), 83 (30\% of the avifauna) are adversely affected by fragmentation and $26(9.5 \%)$ negatively affected by logging. This is also reflected in the studies by van Balen (1999c), who found that many species occur only in the largest forest fragments $\left(>100 \mathrm{~km}^{2}\right)$. Interestingly, the taxa that appear most intolerant of degraded forest, e.g., broadbills, barbets, woodpeckers, trogons and one hornbill species, coincide with those that have disappeared from the isolated forests of Singapore (Corlett \& Turner 1997). This may be an indication that species that are intolerant of degradation are also intolerant of isolated forest patches (although the condition of the forest patches in question may also be a significant influence). These findings have important management implications, because maintaining connectivity between forest fragments and protecting large permanent forest areas would become a higher priority, while some selective logging of these forests could occur without having too much of an impact on resident bird populations (except those species that are negatively affected by any logging, e.g., Green Broadbill (Calyptomena viridis), and assuming that hunting and collecting pressure is low (Lambert \& Collar 2002)). 


\section{Sensitive species}

Lambert and Collar (2002) recently listed Sundaic bird species affected by the processes of logging, fragmentation and hunting. Terrestrial and understorey insectivorous species were particularly vulnerable to logging, and to a lesser extent some insectivores, particularly sallying ${ }^{3}$ species, that inhabit the lower and mid-levels of the forest. Birds typical of the canopy appeared more resilient, and, with the exception of the highly specialised Green Broadbill, frugivorous and nectarivorous species seldom declined in logged forests. Groups affected by logging comprise: 1) some extreme lowland specialist species, because logging in these forests is most intense (Black Hornbill Anthracoceros malayanus, Crestless Fireback Lophura erythrophthalma, but see later); 2) nomadic species or species requiring large areas (hornbills, raptors); 3) primary forest species, intolerant of logging disturbance (Great Argus Argusianus argus, some trogons, some woodpeckers, some babblers and some flycatchers); and 4) species that require large tree cavities for nesting.

The most seriously affected taxa are species of the primary forest interior. Terrestrial insectivores and low- to mid-understorey flycatchers are consistently intolerant of logging (Johns 1989a; Lambert 1992; Thiollay 1992) and decline more than other guilds after disturbance. Among avian understorey insectivores, both the number of species present and their proportional representation within the population sample decrease following logging at moderate intensities. Lambert (1992) identified, among others, trogons Harpactes spp., woodpeckers (Picidae), wren babblers (Kenopia striata and Napothera spp.) and flycatchers (Cyornis spp. and Ficedula spp.) as prone to decline in logged forests.

Johns (1996) compared results from two studies (i.e., his own results and those by Lambert (1992)) and identified six species that consistently declined following logging: one terrestrial wren babbler (Kenopia striata), one trogon (Harpactes diardii) and four understorey flycatchers (Culicapa ceylonensis, Rhipidura perlata, Philentoma p. verlatum, and Rhinomyias umbratilis). Declines probably reflect the loss of understorey vegetation, foraging substrata and the associated cryptic insect prey that understorey insectivores specialise on (Robinson 1969). (We note however, physiological conditions (i.e., high temperature and water stress) appear more significant than local food abundance in determining the ranging of some understorey species in Panamanian forests (Karr \& Freemark 1983). Microclimatic conditions are altered by loss in canopy cover and understorey species are often reluctant to cross open spaces or dense second growth that separates remaining patches of undisturbed forest).

Following logging, forest interior insectivores may also be displaced by flycatcher species more characteristic of edge habitat, or by the invasion of bulbuls (Pycnonotidae). These frugivorous species are associated with rapidly growing pioneer species, but also include insects in their diet. The fruits found in young regrowth may support higher abundances of insectivore/frugivores, such as bulbuls, and result in increased competition with specialised insectivores, but evidence is lacking.

${ }^{3}$ Sallying is a foraging technique in which a bird dashes out to obtain a prey in mid-air or from a leaf; flycatchers typically obtain prey in this manner. 


\section{Hornbills}

Hornbills are a group of medium to large sized frugivorous birds, often with quite specialised diets, and which normally need large areas of forest. On Borneo, most hornbill research has taken place in East Kalimantan (Leighton 1982), where a wealth of information on hornbill biology and ecology was gathered. Other important research has been carried out on Penelopides exarhatus and Rhyticeros cassidix, the two hornbills endemic to Sulawesi (Kinnaird 1998; Kinnaird et al. 1996; O’Brien 1997), a hornbill assemblage in Sumatra (Anggraini et al. 2000; Hadiprakarsa et al. in press), and on the Sumba hornbills Rhyticeros everetti (O'Brien et al. 1998b).

Hornbills seem rather unevenly distributed in Kalimantan. Asian Pied hornbills (Anthracoceros albirostris), for instance, have only recently been reported from areas in South and Central Kalimantan (Holmes 1997) from the Mahakam river delta in East Kalimantan (Eve \& Guigue 1989) and from the upper Kapuas swamps in West Kalimantan (Jeanes \& Meijaard 2000), but they are unknown in other lowland sites such as Gunung Palung National Park (Laman et al. 1996). Their scarcity is likely to be caused by hunting (Holmes 1997), as the species is reported to be the most forest degradation-tolerant of all hornbills (MacKinnon \& Phillips 1993). In contrast, seven hornbill species were seen in Kutai National Park (Leighton 1982), and all but the White-Crowned Hornbill (Aceros comatus) were seen in the Upper Mahakam region in 1996 (Sözer in Holmes 1997). Indeed, seven of the eight Bornean hornbills were recorded in the Malinau study area (O'Brien \& Fimbel 1999). The eighth Bornean species, Rhyticeros corrugatus, occurs in the lowlands immediately east of the Malinau study area. This high level of sympatry is possibly due to the cooccurrence of territorial and nomadic species, some divergence in size, and dietary and foraging specialization. The three least-known hornbills-Helmeted (Rhinoplax vigil), Asian Black (Anthracoceros malayanus) and Wrinkled (Aceros corrugatus)—are threatened or near-threatened species according to the IUCN Red List categories (IUCN 2002).

Hornbills have been considered potentially useful indicators of the success of forest regeneration and retention of tree diversity. Among the Asian hornbills, three principal types of fruit are eaten: lipid-rich capsular fruits such as Aglaia spp. and Myristica spp., lipid-rich drupaceous fruits of Lauraceae and Annonaceae, and sugar-rich Ficus spp. Leighton and Leighton (1983) considered figs to be especially important for territorial hornbills in East Kalimantan, although O'Brien et al. (unpubl.) found that, in Sumatra, figs are more important for non-territorial species. Fig trees are often destroyed during logging or silvicultural procedures as the host trees of strangling varieties are frequently canopy timber trees. A 74\% loss rate of fig trees was recorded following logging in Peninsular Malaysia, with an average loss of hornbill food trees of 56\% (Johns 1987); i.e., damage to hornbill fruit trees was random, but figs were destroyed both during harvest and as a silvicultural treatment. Pioneer trees do not generally provide fruit eaten by hornbills, although the sugary fruits from some rapidly growing climbers are eaten by territorial Anthracoceros. The loss of high canopy trees also reduces foraging substrata, such as loose bark and epiphytes, which are probed by some larger hornbills for animal prey that provide important protein and minerals in their diet (Johns 1997). 
Table 2. Hornbills and their response to logging.

\begin{tabular}{lccl}
\hline Species & $\begin{array}{l}\text { Body size } \\
\text { (kg) }\end{array}$ & $\begin{array}{l}\text { Density trend } \\
\text { after logging }\end{array}$ & References \\
\hline Anorrhinus galeritus & 1.17 & - & $\begin{array}{l}\text { (Rijksen 1978) } \\
\text { (Lambert 1992) } \\
\text { (Johns 1997) }\end{array}$ \\
\hline Berenicornis comatus & 1.47 & - & (Lambert \& Collar 2002) \\
\hline Rhyticeros undulatus & 2.52 & $\downarrow$ & (Lambert 1992) \\
\hline Anthracoceros malayanus & 1.05 & - & (Lambert \& Collar 2002) \\
\hline Buceros rhinoceros & 2.72 & $\downarrow$ & (Lambert 1992) \\
& & - & (Rijksen 1978) \\
\hline Rhinoplax vigil & 3.06 & $\downarrow \downarrow$ & (Lambert 1992) \\
& & - & (Wilson \& Wilson 1975) \\
& & $\downarrow$ & (Rijksen 1978) \\
\hline
\end{tabular}

$-=<20 \%$ difference between mean density in logged and primary forests; $\uparrow / \downarrow=$ increase/ decrease of 20 to $60 \%$ between logged and primary forests; $\uparrow \uparrow / \downarrow \downarrow=$ increase/decrease of $>60 \%$ between logged and primary forests. Body weights are for males only.

Despite the reduction in food tree density, hornbill populations are not noticeably reduced in logged forests in Malaysia (Kemp \& Kemp 1975; Johns 1997). C. Francis (pers. comm.) suggested that the main reason for the tolerance of hornbills to logging, at least in the short term, was their longevity, which allowed them to persist even in unsuitable areas for a few years. If a forest has adequate food for adults to survive, but not to breed (which requires a much greater food base as well as nesting sites), then hornbills could persist for many years after a forest became unsuitable for breeding. Although some of these species are territorial, their large ranges also enable them to locate food sources in forests further away. Hunting, primarily for feathers that are used in traditional ceremonies, might be a much more important factor in hornbill decline in some areas than timber harvest (Bennett \& Dahaban 1995). In Malinau, several hornbill species have symbolic (traditional and spiritual) importance to local people, and the animals are collected for their feathers, heads (which are often preserved as ornaments) and eaten for meat: if an active nest is observed in an accessible location it will usually be plundered (Sheil pers. obs.).

Hornbills, especially the nomadic species, are very wide-ranging animals and their abundance fluctuates more in response to seasonal changes in food supply than to local habitat features per se (Kinnaird et al. 1996; Johns 1997). This was the case for Rhinoplax vigil, which is considered the most likely species to suffer from logging, as it is a fig specialist; this species also predominantly nests in large dipterocarps (see below) and is thus likely to be negatively affected by commercial timber harvest. It should be noted that the loss of fruiting trees due to logging can then exacerbate any seasonal effects on forage availability for most hornbills. Furthermore, when density of fruiting trees declines after logging, the number of hornbills visiting each tree increases. This has implications for inter- and intraspecific competition, as Leighton (1982) discussed at length. Although one study found that smaller hornbills are more tolerant of increased competition from resource loss as they are able to move around in the scrubbier, regenerating forest (Wilson \& Johns 1982), this effect might 
be cancelled out by the fact that smaller hornbills are territorial and would not be expected to tolerate intraspecific competition. In species that feed primarily on smaller fruiting trees, the foraging group size declines. For example, the mean group size of Anorrhinus galeritus in Ulu Segama, Sabah, declined from 7.0 in unlogged forest to 3.7 in logged forests (Johns 1997). An additional effect of logging that was discussed by Lambert and Collar (2002) is that by removing food trees through logging, the concentration of such large and edible birds at fewer and fewer trees in more accessible forest areas renders them vulnerable to hunting (Lambert and Collar (2002) give an example from the Philippines of as many as 40 Visayan Wrinkled Hornbills Aceros waldeni, representing at least $25 \%$ of the global population, that were shot in a single day at a single tree in 1997).

While food may not be a limiting factor in logged forests, a reduction of nesting sites might be. Hornbills require large tree holes situated primarily in living trees, with the smaller species seemingly needing trees with $\mathrm{dbh}>50 \mathrm{~cm}$ and larger species $\mathrm{dbh}$ $>60 \mathrm{~cm}$; in Thailand $R$. vigil appears to prefer big $(\mathrm{dbh}>105 \mathrm{~cm})$ dipterocarp species (Hopea spp. and Shorea spp.) for nesting (Thiensongrusamee et al. 2001). Natural holes are generally formed by fungal species that infect the trees through wounds, for instance, where branches have broken off, or where trees have been damaged by tree falls or by human activities (Elouard 1998). Trees with heart rot can exhibit all of the outward signs of healthy and vigorous growth, while heartwood is slowly decaying. Heart rot in commercial timber species can cause much loss of timber; Bakshi et al. (1967), for instance, reported a 9-13\% loss of timber in Shorea robusta, with $73 \%$ of the trees infected. It is therefore important for logging concessionaires to assess which trees are affected by heart rot and leave these trees standing. Such trees produce timber of suboptimal quality (even for pulp), but contribute potential roosting, nesting and food storage sites for many vertebrates. As these trees are larger stems they also contribute a wide range of other important functions (as discussed elsewhere).

\section{Woodpeckers}

Woodpeckers form a specialised guild of bark feeders and hole breeders with adaptations that enable them to excavate nesting cavities in trees, climb vertical tree trunks and maintain a position suitable for foraging and excavating. Since all woodpeckers show these adaptations, competition might be expected to occur among woodpeckers whether or not they are closely related. However, sizes vary from the tiny Rufous Piculet Sasia abnormis (ca. $10 \mathrm{~g}$ ) to the large Great Slaty Woodpecker Mulleripicus pulverulentus (ca. $430 \mathrm{~g}$, up to $563 \mathrm{~g}$ ) (Fig. 7), and feeding modes and locations also vary, especially amongst species of similar size. Multivariate analysis of foraging behaviour indicates that sympatric Bornean woodpeckers primarily differentiate in microhabitat (where they forage) and only secondarily in the foraging techniques or search strategies (how they forage). Important factors in microhabitat differentiation are foraging height, substrate diameter, use of dead or live wood, tree diameter, and the use of non-wood substrates like lianas, rattans and ant or termite nests (Lammertink 2004, b; Styring 2002b; Styring \& Hussin 2004b). In contrast 
with the popular perception of woodpeckers, only two Bornean species are dead wood specialists. These are the White-bellied Woodpecker (Dryocopus javensis) and the Orange-backed Woodpecker (Reinwardtipicus validus); they forage, around 97\% and $58 \%$ of time respectively, on dead wood (Lammertink 2004). Both species have been recorded at Malinau. For nesting, on the other hand, most Bornean woodpeckers prefer standing dead trees or dead parts of trees.

Woodpeckers may play a key ecological role because they excavate tree cavities required by many other vertebrate species. The proportion of tree cavities produced by woodpeckers remains unknown and thus also their relative importance for secondary cavity-use by bats, cavity-nesting passerines, cavity-nesting owls, certain wasp species, snakes, lizards and tree squirrels. Still, because not many other species excavate tree cavities, woodpeckers are likely to be an ecological group with relatively high importance for the conservation of a wide group of tropical vertebrates and invertebrates.

Van Balen (in litt. 9 November 2004) recorded 13 woodpecker species in Malinau; eight of these are described in more detail in Appendix 4. The other five are the White-bellied Woodpecker

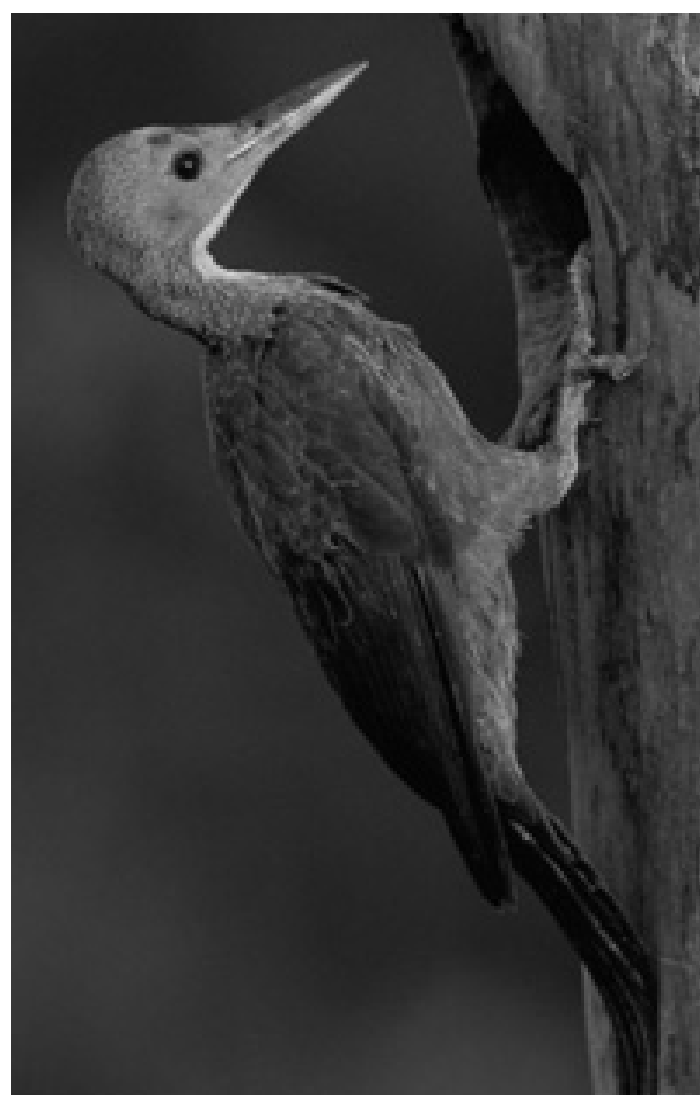

Figure 7. Female Great Slaty Woodpecker (Mulleripicus pulverulentus); densities of this woodpecker are strongly reduced in logged forests. (Photo by Martjan Lammertink)
(Dryocopus javensis), Olivebacked Woodpecker (Dinopium rafflesii), Orange-backed Woodpecker (Reinwardtipicus validus), Grey-and-Buff Woodpecker (Hemicircus concretus), and Great Slaty Woodpecker (Mulleripicus pulverulentus). These species are widespread in Borneo and would be expected to occur in Malinau. In addition, the Speckled Piculet (Picumnus innominatus), which is known from hill forest of northern Borneo, could also occur in the Malinau region, but has not yet been recorded.

Among the woodpeckers found at Malinau, the Maroon Woodpecker Blythipicus rubiginosus engages most extensively in hammering and pecking, even though Rufous Piculet Sasia abnormis and the Crimson-winged Woodpecker Picus puniceus do hammer and peck with considerable 
frequency. These hammering woodpeckers are well separated by foraging height, substrate diameter and choice of substrates, suggesting that they might be differently affected by timber harvest. The remaining, less specialised picids hammer and peck infrequently and feed mainly on ants and termites obtained at the tree surface or by probing into bark fissures and natural hollows. These species differ little in size, but variation in foraging sites, habits, modes, movements and activities limits competition. The Buff-rumped Woodpecker Meiglyptes tristis and Checker-throated Woodpecker Picus mentalis are particularly active foragers that move quickly over substrates and through the forest. M. tristis and Picus puniceus often forage at the underside of horizontal branches, whereas the other Malinau woodpeckers do not (Lammertink 2004). However, some foraging competition is likely to occur, particularly among similarly sized picids whatever their foraging habits, because most woodpeckers are also opportunists (Short 1982). Woodpeckers that excavate in bark and wood can also glean from the surface, thus competing directly with sympatric, gleaning woodpeckers. All woodpeckers likely compete for nesting and roosting sites.

Bornean woodpecker communities are strongly affected by logging (Table 3). Over a gradient of lowland forest sites that covered primary forest to selectively logged concessions, woodpecker biomass was estimated to decline by ca. $60 \%$, and total woodpecker density by ca. $40 \%$. Estimated density declines were even more severe for individual species: Picus mentalis and Mulleripicus pulverulentus declined by more than $80 \%$ (Lammertink 2004). Thus far, however, all primary forest woodpecker species persisted to some degree in logged lowland forests. However, in unlogged hill forests, between 120 and 400 m altitude, woodpecker diversity was significantly lower, indicating that logged lowland forests may have higher conservation potential than primary hill forests, at least for woodpeckers (Lammertink 2004). None of the Bornean woodpecker species are currently globally threatened. Species that are strongly affected by logging either occur in hill forests (e.g., Picus mentalis), where timber harvest has so far been less intensive than in lowlands or where large areas are protected, or have distribution ranges extending beyond the Sunda region (e.g., Mulleripicus pulverulentus). If logging extends throughout the (altitudinal) distribution ranges of these species they may become threatened.

Woodpeckers have also been reported to decrease in density in logged forest in Sabah (Lambert 1992), with estimated reductions in woodpecker density of 23\% and $50 \%$ in logged forests in Sabah (Johns 1996); however, Johns judged these findings inconclusive. Both Lambert (1992) and Johns (1996) examined too few study sites to properly test differences in bird abundances between logged and primary forests.

Styring and Hussin (2004a) claimed that woodpeckers react 'atypically' to logging. Other bird species either drop in abundance in recently logged forest and increase in older logged stands (the amount of increase varying among species), or become more abundant after logging and decrease in abundance in older logged stands. Woodpeckers, on the other hand, were slightly less abundant in recently logged (5-year-old) forest and much less abundant in older logged forests in Peninsular Malaysia. The patterns were best explained by food availability. Meiglyptes tristis, for instance, specialises on ants associated with Macaranga spp. trees, a common species in disturbed habitats, and this woodpecker generally increased in 
Table 3. Woodpeckers and their response to logging.

\begin{tabular}{|c|c|c|c|c|c|}
\hline Species & $\begin{array}{l}\text { Body } \\
\text { mass (g) }\end{array}$ & $\mathbf{N}^{*}$ & $\begin{array}{l}\text { Ecological } \\
\text { stratification }\end{array}$ & $\begin{array}{l}\text { Density } \\
\text { trend after } \\
\text { logging } \\
\end{array}$ & References \\
\hline Sasia abnormis & 9 & $\begin{array}{r}89 \\
? \\
18 \\
9 \\
12 \\
1\end{array}$ & $\begin{array}{l}\text { Understorey, } \\
\text { rattans and } \\
\text { vines }\end{array}$ & $\begin{array}{l}\uparrow \\
- \\
\downarrow \\
\downarrow \\
\downarrow \downarrow\end{array}$ & $\begin{array}{l}\text { (Lammertink 2004) } \\
\text { (Danielsen \& Heegaard 1995) } \\
\text { (Lambert 1992) } \\
\text { (Styring \& Hussin 2004a) } \\
\text { (Johns 1989a) } \\
\text { (Styring \& Ickes 2001a) }\end{array}$ \\
\hline $\begin{array}{l}\text { Dendrocopus } \\
\text { canicapillus }\end{array}$ & 27 & $\begin{array}{l}2 \\
2\end{array}$ & Canopy, twigs & $\overline{\downarrow \downarrow}$ & $\begin{array}{l}\text { (Lammertink 2004) } \\
\text { (Lambert 1992) }\end{array}$ \\
\hline $\begin{array}{l}\text { Celeus } \\
\text { brachyurus }\end{array}$ & 83 & $\begin{array}{r}21 \\
? \\
4 \\
74 \\
6 \\
4\end{array}$ & $\begin{array}{l}\text { Middle and } \\
\text { upper storeys, } \\
\text { live wood }\end{array}$ & $\begin{array}{l}- \\
- \\
- \\
\downarrow \\
\downarrow \\
\downarrow \downarrow\end{array}$ & $\begin{array}{l}\text { (Styring \& Hussin 2004a) } \\
\text { (Danielsen \& Heegaard 1995) } \\
\text { (Johns 1989a) } \\
\text { (Lammertink 2004) } \\
\text { (Styring \& Ickes 2001a) } \\
\text { (Lambert 1992) }\end{array}$ \\
\hline $\begin{array}{l}\text { Dryocopus } \\
\text { javensis }\end{array}$ & 253 & $\begin{array}{r}63 \\
26 \\
? \\
2 \\
7 \\
5\end{array}$ & $\begin{array}{l}\text { Lower and } \\
\text { middle storeys, } \\
\text { dead wood of } \\
\text { large diameters }\end{array}$ & $\begin{array}{l}\uparrow \\
\downarrow \\
\downarrow \\
\downarrow \\
\downarrow \downarrow \\
\downarrow \downarrow\end{array}$ & $\begin{array}{l}\text { (Lammertink 2004) } \\
\text { (Styring \& Hussin 2004a) } \\
\text { (Danielsen \& Heegaard 1995) } \\
\text { (Johns 1989a) } \\
\text { (Styring \& Ickes 2001a) } \\
\text { (Lambert 1992) }\end{array}$ \\
\hline Picus miniaceus & 90 & $\begin{array}{r}25 \\
7 \\
6 \\
? \\
4 \\
2\end{array}$ & $\begin{array}{l}\text { Middle and } \\
\text { upper storeys, } \\
\text { live wood, vines } \\
\text { and lianas }\end{array}$ & $\begin{array}{l}\uparrow \uparrow \\
\uparrow \uparrow \\
\uparrow \\
\uparrow \\
\uparrow \\
\uparrow \\
-\end{array}$ & $\begin{array}{l}\text { (Lammertink 2004) } \\
\text { (Styring \& Hussin 2004a) } \\
\text { (Styring \& Ickes 2001a) } \\
\text { (Danielsen \& Heegaard 1995) } \\
\text { (Johns 1989a) } \\
\text { (Lambert 1992) }\end{array}$ \\
\hline P.puniceus & 81 & $\begin{array}{r}28 \\
? \\
71 \\
28 \\
1 \\
33\end{array}$ & $\begin{array}{l}\text { Middle and } \\
\text { upper storeys, } \\
\text { mostly live } \\
\text { wood }\end{array}$ & $\begin{array}{l}\uparrow \uparrow \\
\uparrow \\
- \\
\downarrow \\
\downarrow \\
\downarrow \downarrow\end{array}$ & $\begin{array}{l}\text { (Styring \& Ickes 2001a) } \\
\text { (Danielsen \& Heegaard 1995) } \\
\text { (Lammertink 2004) } \\
\text { (Styring \& Hussin 2004a) } \\
\text { (Lambert 1992) } \\
\text { (Johns 1989a) }\end{array}$ \\
\hline P. mentalis & 100 & $\begin{array}{r}21 \\
? \\
39 \\
1 \\
116\end{array}$ & $\begin{array}{l}\text { Lower and } \\
\text { middle storeys, } \\
\text { frequently on } \\
\text { lianas }\end{array}$ & $\begin{array}{c}\uparrow \uparrow \\
\uparrow \\
\downarrow \\
\downarrow \\
\downarrow \downarrow\end{array}$ & $\begin{array}{l}\text { (Styring \& Ickes 2001a) } \\
\text { (Danielsen \& Heegaard 1995) } \\
\text { (Styring \& Hussin 2004a) } \\
\text { (Lambert 1992) } \\
\text { (Lammertink 2004) }\end{array}$ \\
\hline $\begin{array}{l}\text { Dinopium } \\
\text { rafflesii }\end{array}$ & 91 & $\begin{array}{r}1 \\
1 \\
? \\
19 \\
2 \\
1\end{array}$ & $\begin{array}{l}\text { Middle and } \\
\text { upper storeys, } \\
\text { excavating live } \\
\text { wood }\end{array}$ & $\begin{array}{l}\uparrow \\
\uparrow \\
\uparrow \\
\\
\downarrow \downarrow \\
\downarrow \downarrow\end{array}$ & $\begin{array}{l}\text { (Danielsen \& Heegaard 1995) } \\
\text { (Styring \& Hussin 2004a) } \\
\text { (Johns 1989a) } \\
\text { (Lammertink 2004) } \\
\text { (Styring \& Ickes 2001a) } \\
\text { (Lambert 1992) }\end{array}$ \\
\hline $\begin{array}{l}\text { Blythipicus } \\
\text { rubiginosus }\end{array}$ & 81 & $\begin{array}{r}35 \\
128 \\
? \\
5 \\
18 \\
24\end{array}$ & $\begin{array}{l}\text { Understorey, } \\
\text { live and dead } \\
\text { wood }\end{array}$ & $\begin{array}{l}\uparrow \uparrow \\
\downarrow \\
\downarrow \\
\downarrow \downarrow \\
\downarrow \downarrow \\
\downarrow \downarrow\end{array}$ & $\begin{array}{l}\text { (Styring \& Hussin 2004a) } \\
\text { (Lammertink 2004) } \\
\text { (Danielsen \& Heegaard 1995) } \\
\text { (Styring \& Ickes 2001a) } \\
\text { (Lambert 1992) } \\
\text { (Johns 1989a) }\end{array}$ \\
\hline
\end{tabular}


Table 3. Continued

\begin{tabular}{|c|c|c|c|c|c|}
\hline Species & $\begin{array}{l}\text { Body } \\
\text { mass }(g)\end{array}$ & $\mathbf{N}^{*}$ & $\begin{array}{l}\text { Ecological } \\
\text { stratification }\end{array}$ & $\begin{array}{l}\text { Density } \\
\text { trend after } \\
\text { logging } \\
\end{array}$ & References \\
\hline $\begin{array}{l}\text { Reinwardtipicus } \\
\text { validus }\end{array}$ & 157 & $\begin{array}{r}17 \\
77 \\
30 \\
? \\
21 \\
4\end{array}$ & $\begin{array}{l}\text { All storeys. } \\
\text { Dead wood } \\
\text { of moderate } \\
\text { diameters }\end{array}$ & $\begin{array}{l}- \\
\downarrow \\
\downarrow \\
\downarrow \\
\downarrow \downarrow \\
\downarrow \downarrow\end{array}$ & $\begin{array}{l}\text { (Johns 1989a) } \\
\text { (Lammertink 2004) } \\
\text { (Styring \& Hussin 2004a) } \\
\text { (Danielsen \& Heegaard 1995) } \\
\text { (Styring \& Ickes 2001a) } \\
\text { (Lambert 1992) }\end{array}$ \\
\hline Meiglyptes tristis & 45 & $\begin{array}{r}20 \\
12 \\
50 \\
? \\
18\end{array}$ & $\begin{array}{l}\text { All storeys, } \\
\text { frequently on } \\
\text { leaves and } \\
\text { twigs }\end{array}$ & $\begin{array}{l}\uparrow \uparrow \\
\uparrow \uparrow \\
\frac{\uparrow}{-} \\
\downarrow \downarrow\end{array}$ & $\begin{array}{l}\text { (Styring \& Hussin 2004a) } \\
\text { (Lambert 1992) } \\
\text { (Lammertink 2004) } \\
\text { (Danielsen \& Heegaard 1995) } \\
\text { (Styring \& Ickes 2001) }\end{array}$ \\
\hline M. tukki & 54 & $\begin{array}{r}4 \\
45 \\
9 \\
? \\
22 \\
24\end{array}$ & $\begin{array}{l}\text { Lower and } \\
\text { middle storeys, } \\
\text { broad range of } \\
\text { substrates }\end{array}$ & $\begin{array}{l}\uparrow \uparrow \\
- \\
- \\
- \\
\downarrow \downarrow\end{array}$ & $\begin{array}{l}\text { (Lambert 1992) } \\
\text { (Lammertink 2004) } \\
\text { (Styring \& Ickes 2001a) } \\
\text { (Danielsen \& Heegaard 1995) } \\
\text { (Johns 1989a) } \\
\text { (Styring \& Hussin 2004a) }\end{array}$ \\
\hline $\begin{array}{l}\text { Hemicircus } \\
\text { concretus }\end{array}$ & 33 & $\begin{array}{r}1 \\
35 \\
1 \\
31 \\
11\end{array}$ & $\begin{array}{l}\text { Middle and } \\
\text { upper storey, } \\
\text { small and large } \\
\text { branches }\end{array}$ & $\begin{array}{l}\uparrow \\
\downarrow \\
\downarrow \\
\downarrow \\
\downarrow \downarrow\end{array}$ & $\begin{array}{l}\text { (Styring \& Ickes 2001a) } \\
\text { (Lammertink 2004) } \\
\text { (Lambert 1992) } \\
\text { (Johns 1989a) } \\
\text { (Styring \& Hussin 2004a) }\end{array}$ \\
\hline $\begin{array}{l}\text { Mulleripicus } \\
\text { pulverulentus }\end{array}$ & 430 & $\begin{array}{r}13 \\
5 \\
61 \\
1\end{array}$ & $\begin{array}{l}\text { Middle and } \\
\text { upper storeys, } \\
\text { large diameter } \\
\text { branches in } \\
\text { large trees }\end{array}$ & $\begin{array}{l}- \\
\downarrow \\
\downarrow \downarrow \\
\downarrow \downarrow\end{array}$ & $\begin{array}{l}\text { (Styring \& Hussin 2004a) } \\
\text { (Lambert 1992) } \\
\text { (Lammertink 2004) } \\
\text { (Styring \& Ickes 2001a) }\end{array}$ \\
\hline
\end{tabular}

$-=<20 \%$ difference between mean density in logged and primary forests; $\uparrow / \downarrow=$ increase/ decrease of 20 to $60 \%$ between logged and primary forests; $\uparrow \uparrow / \downarrow \downarrow=$ increase/decrease of $>60 \%$ between logged and primary forests. ${ }^{*} \mathrm{~N}=$ total number of transect records in a study on which the density trend is based.

abundance following logging (Styring \& Hussin 2004a, b). Other species prefer the canopy and avoid low-stature, recently logged forest; these declined significantly directly following logging. A third group were most common in unlogged and newly logged forest, probably because they specialise on feeding in dense vegetation at low levels, which was generally less common in older regenerating forests.

Reductions in woodpecker density in logged regions may be due primarily to a loss of foraging sites. Within logged regions in West Kalimantan, woodpeckers foraged mainly in unlogged patches. On the other hand, woodpecker population densities may be more closely related to the quantity of timber removed rather than to the remaining areas of unlogged forest, suggesting that the logging intensity in areas surrounding unlogged patches is of overruling importance in determining woodpecker densities (Lammertink 2004).

Table 3 shows that there is considerable variation among studies in the extent and direction of density changes following logging. The species that appear to be negatively 
affected by logging in all or most studies are Dryocopus javensis, Blythipicus rubiginosus, Reinwardtipicus validus, Hemicircus concretus and Mulleripicus pulverulentus. Principal component analyses by Styring and Hussin (2004b) indicate that these species have in common that they feed either high in the canopy on substrates with high diameter, or low to the ground on medium to large substrates. Together with two Picus species (P. mentalis and P. puniceus) Styring and Hussin classified these as 'conventional' woodpeckers, i.e. the larger bodied woodpeckers that foraged either on dead wood patches or on snags. Species that seems more tolerant to the effects of timber harvest, with the possible exception of Hemicircus concretus, coincide with what Styring and Hussin (2004b) name 'novel' woodpeckers, i.e. species feeding on substrates such as bamboo, arboreal ants' nests and leaves of evergreen broadleaved vegetation.

Picus mentalis and Mulleripicus pulverulentus prefer to forage in primary patches within logged landscapes, so their frequency of occurrence may indicate forest quality and recovery after disturbance (i.e., at a scale under home range size). Mulleripicus pulverulentus forages in flocks on live trees, exploiting stingless bee, ant and termite nests in natural cavities in large branches and tree trunks. They primarily feed in large sized trees. It seems likely that these species decline in density in selectively logged forests because large diameter trees are less frequent; Picus mentalis may also decline because the understorey and middle storey of the forest becomes denser (Lammertink unpubl.). The Banded Woodpecker (Picus miniaceus) may be an indicator for moderate disturbance as this species thrives in selectively logged forests.

\section{Pheasants}

Pheasants are large, retiring birds. They are among the first birds to disappear from the forests that surround settlements and logging concessions (e.g., BirdLife International 2001), although this might be more the result of increased hunting than sensitivity to logging itself. Within the Malinau area the presence of three pheasant species has been documented: Great Argus (Argusianus argus), Crested Fireback (Lophura ignita) and Bulwer's pheasant (Lobiophasis bulweri) (Nijman 1997; O'Brien \& Fimbel 2002; Augeri in prep.). A fourth Bornean species, the Crestless Fireback (Lophura erythrophthalma) has not been recorded in the MRF; van Ballen (in O'Brien \& Fimbel 2002) suggested that MRF be outside the elevational range of this extreme lowland specialist. The rare and endangered Bornean Peacock Pheasant Polyplectron schleiermacheri has been recorded from south, north and west of Malinau (BirdLife International 2001), and although its distribution is patchy this species may also occur in the MRF (note that the BirdLife Red Data Book suggests that the species may be practically absent north of $1^{\circ} 20^{\prime} \mathrm{N}$ in East Kalimantan). A recent study showed that Polyplectron schleiermacheri survives in a small (ca. 6,000 ha) forest fragment near the city of Balikpapan, East Kalimantan (Fredriksson \& Nijman 2004), suggesting that it is relatively resitent to fragmentation, at least in the short term.

All Bornean pheasants have a relatively small global range: none occur outside Peninsular Malaysia, Sumatra and Borneo. Most have threatened status. Relatively few ecological studies have been carried out on Bornean wild pheasant species, although the Great Argus has been the subject of several. Rijksen (1978) reported that Argus 


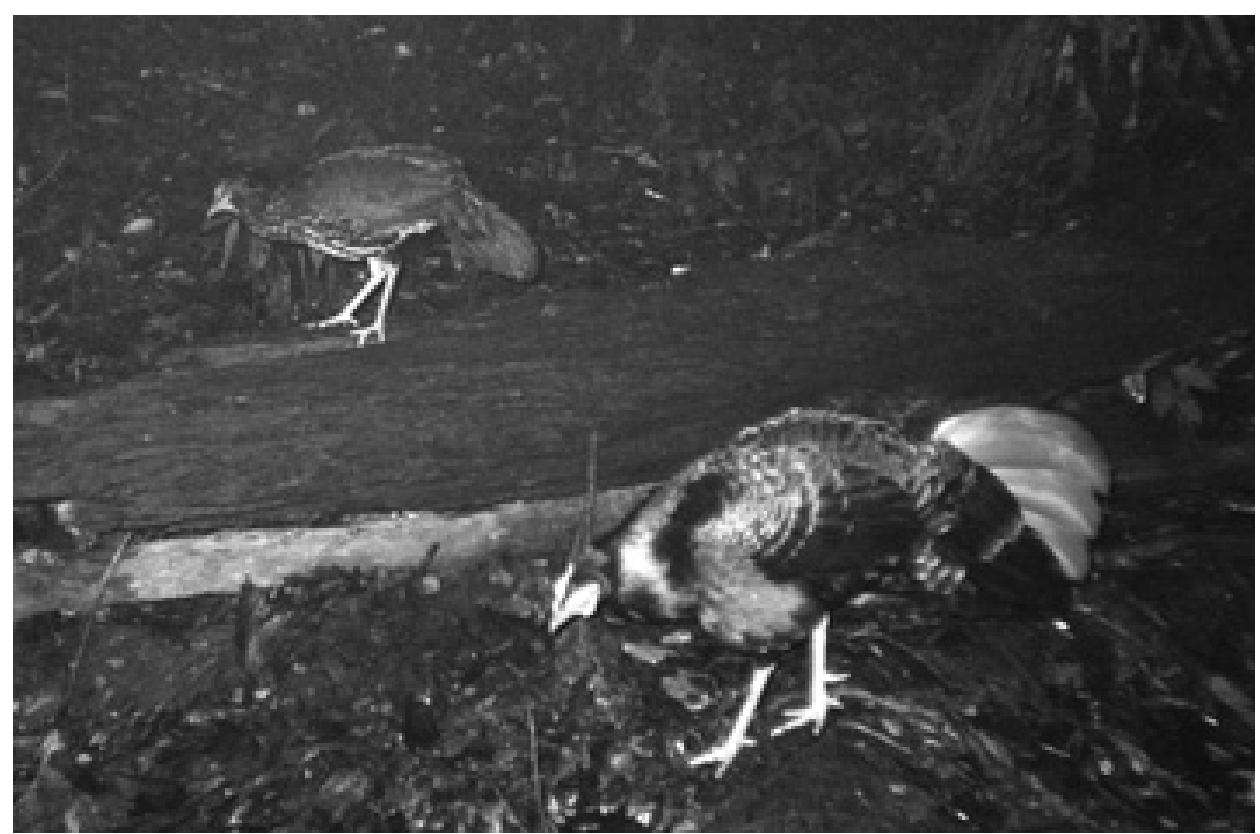

Figure 8. Crested Fireback (Lophura ignita) female and male in unlogged forest in the MRF. (Photo by Dave Augeri)

Pheasant calls did not significantly decline in slightly disturbed forest, although a significant reduction in call frequency was observed in forest under logging. Sözer et al. (1999) reported the Argus Pheasant to be common in both primary and secondary lowland and hill forests, and even found the species in areas under logging. Bennett and Dahaban (1995) found that the Argus Pheasant calls increased significantly $(\mathrm{p}<0.05)$ in old $(30$-year-old) shifting cultivation areas compared to primary forest. Increased calling might be due only to disturbance, but in these areas cultivation took place so long ago that disturbance was unlikely to have affected calling levels. High calling levels probably indicated high density. In a different area, Argus Pheasant calls did decrease with increased hunting pressure (Bennett \& Dahaban 1995). Overall, the Argus Pheasant appears to be relatively tolerant of logging, but not of hunting. This might explain Augeri's findings (unpubl.) which indicate that Argus Pheasant calls, dancing grounds and photo captures were lower in and adjacent to young secondary forests and recently logged and cultivated areas in the MRF, Kayan Mentarang and Leuser ecosystems. These differences may be related to local hunting pressures.

Sözer et al. (1999) found that L. ignita was common in logged forests and even near shifting cultivation. Augeri (unpubl.) found lower photo capture frequencies in disturbed compared to undisturbed forest. O'Brien et al. (1998c) reported that the Bornean Peacock Pheasant (Polyplectron schleiermacheri) is negatively affected by logging, especially because swamp, riverine forest and lowland dipterocarp forestsits favoured habitats (see Fredriksson \& Nijman 2004) —are severely threatened forest types (van Balen \& Holmes 1993; O’Brien et al. 1998c); the species is also targeted by hunters. 
Table 4. Pheasants and their response to logging.

\begin{tabular}{|c|c|c|c|c|}
\hline Species & $\begin{array}{l}\text { Body } \\
\text { size }(\mathbf{k g}) \\
\text { 우 }\end{array}$ & $\begin{array}{l}\text { Ecological } \\
\text { stratification }\end{array}$ & $\begin{array}{l}\text { Density trend } \\
\text { after logging }\end{array}$ & References \\
\hline $\begin{array}{l}\text { Lophura } \\
\text { erythrophthalma }\end{array}$ & 0.85 & $\begin{array}{l}\text { Terrestrial; } \\
\text { frugivorous and } \\
\text { insectivorous }\end{array}$ & $\begin{array}{l}\uparrow \\
-\end{array}$ & $\begin{array}{l}\text { (Davison \& Scriven undated in } \\
\text { BirdLife International 2001) } \\
\text { (Danielsen \& Heegaard 1995) }\end{array}$ \\
\hline Lophura ignita & 1.6 & $\begin{array}{l}\text { Terrestrial; } \\
\text { probably } \\
\text { frugivorous and } \\
\text { insectivorous }\end{array}$ & $\begin{array}{l}\uparrow \\
- \\
-\end{array}$ & $\begin{array}{l}\text { (Danielsen \& Heegaard 1995) } \\
\text { (BirdLife International 2001) } \\
\text { (Sözer et al. 1999) }\end{array}$ \\
\hline $\begin{array}{l}\text { Lobiophasis } \\
\text { bulweri }\end{array}$ & 1 & $\begin{array}{l}\text { Terrestrial; } \\
\text { frugivorous and } \\
\text { insectivorous; } \\
\text { migratory }\end{array}$ & $\downarrow \downarrow$ & (BirdLife International 2001) \\
\hline Argusianus argus & 3 & $\begin{array}{l}\text { Selective feeder } \\
\text { on insects and } \\
\text { fruits }\end{array}$ & $\begin{array}{l}\uparrow \\
- \\
- \\
- \\
-/ \downarrow \\
-\end{array}$ & $\begin{array}{l}\text { (O'Brien et al. 2003) } \\
\text { (Rijksen 1978) } \\
\text { (BirdLife International 2001) } \\
\text { (Sözer et al. 1999) } \\
\text { (Wilson \& Wilson 1975) } \\
\text { (Winarni 2002) } \\
\text { (Danielsen \& Heegaard 1995) } \\
\text { (Bennett \& Dabahan 1995) }\end{array}$ \\
\hline
\end{tabular}

$-=<20 \%$ difference between mean density in logged and primary forests; $\uparrow / \downarrow=$ increase/ decrease of 20 to $60 \%$ between logged and primary forests; $\uparrow \uparrow / \downarrow \downarrow=$ increase/decrease of $>60 \%$ between logged and primary forests.

Datta (2000) published one of the few studies of the effects of logging on pheasant populations. In his site in western Aruchnal Pradesh, India, he recorded the relative abundance of three pheasant species in five different areas, i.e., plantations, semi-disturbed forests, 20-25 year old logged forests, recently logged forests and unlogged forests. The three pheasant species recorded were the Red Jungle Fowl (Gallus gallus), Black-Breasted Kaleej Pheasant (Lophura leucomelana lathami) and the Grey Peacock-Pheasant (Polyplectron bicalcaratum); the latter two genera coexist in Borneo. Overall pheasant abundance was highest in unlogged forest and low in all other areas, while no pheasants were sighted in plantations. Datta (2000) suggested that the main reasons for the lower pheasant abundance in logged forests were: 1) the effects of logging on leaf litter fauna (which was absent from recently logged forest), 2) the destruction of understorey vegetation, and 3) the increase in human disturbance and hunting due to easier access through logging roads. Disturbance during logging and increased accessibility of the area after road construction seemed to negatively affect pheasant abundance, although the possibility that birds were warier and/or more difficult to see in disturbed forest could not be excluded.

\section{Other taxa}

We briefly mention the following taxa. Relevant information is limited but all include species that may be affected by disturbance. 


\section{Trogons}

Trogons (Trogonidae) are sallying substrate-gleaning insectivores of tropical and subtropical forests. In southern Thailand, trogons have been found to be intolerant of degraded forest (Round \& Brockelman 1998). They also appear intolerant of forest fragmentation and isolation, as indicated by the disappearance of the two trogon species from Singapore (Corlett \& Turner 1997), and the survival of only one trogon species in Javan lowland forest fragments, as opposed to the four to five species elsewhere in the Sunda region (van Balen 1999b). The species in the Javan lowlands, $H$. reinwardtii, is a hill species and probably survived because of its ability to use higher altitude forests. Lambert and Collar (2002) concluded that populations of trogons may require careful monitoring, because the evidence suggests they are more vulnerable than most taxa to the changes that are occurring in Sundaic forests. Van Balen (in O'Brien \& Fimbel 2002) identified four species of trogon in the MRF: Harpactes oreskios, $H$. diardii, $H$. duvaucelii and $H$. kasumba. Three of these- $H$. diardii, $H$. duvaucelii, $H$. kasumba - are confined to the lowlands or low hills and may therefore be particularly vulnerable to local extinction (Lambert \& Collar 2002).

\section{Bulbuls}

Bulbuls (Pycnonotidae) are a large family of closely related species with varying habitat preferences. Not much body size differentiation is exhibited, but they are segregated by habitat, altitude, and perhaps some diet and foraging behaviour differentiation (e.g., MacKinnon \& Phillipps 1993). Several species (Pycnonotus cyaniventris, P. squamatus, P. erythropthalmos, P. eutilotus and P. melanoleucos) appear affected by fragmentation (Lambert \& Collar 2002). On the other hand, several bulbul species have been seen to increase in abundance after logging (Hussin 1994; Johns 1989a, 1996; Lambert 1992). Hussin (1996) suggested that the higher numbers of many bulbul species observed feeding on fruits in logged forest may be due to reduced competition owing to the lower numbers of primary forest frugivores such as the Green Broadbill (Calyptomena viridis) and Asian Fairy Bluebird (Irena puella). Some changes may also be related to changes in foraging heights because many of the bulbuls typically associated with edges are also found in the canopy of primary forest (Hussin \& Francis 2001). However, the main factor is most likely related to the increased availability of many small fruits associated with certain pioneer tree species (n.b. many pioneer species do not produce edible fruit, and many more produce small fruits that appear specialised for bird dispersal). These generalist frugivore/ insectivores feed readily on the fruits of some pioneer species and likely play an important role in the rapid spread of these plants species into selectively logged areas (Hussin 1996), although other animals such as bats may also be involved in dispersal (Hussin \& Francis 2001). Pioneer tree species grow rapidly and some produce fruit when still only a few years old, providing a ready source of additional food in logged forests. Finally, the Straw-headed Bulbul (Pycnonotus zeylanicus) is in demand as a cage bird (it already appears locally extinct in the more accessible forests of Malinau) and the increased forest access and high market prices for these birds further add to the pressure on this species. 


\section{Babblers}

Babblers (Timaliidae) form a diverse family of small passerines, with some 27 endemic species in the Sundaic lowlands (Lambert \& Collar 2002). They generally live in the lower and middle levels of the forest. Nine species of Sundaic babblers exhibit strong negative responses to logging and fragmentation, and four species in the family (Striped Wren Babbler Kenopia striata, Rail-babbler Eupetes macrocerus, Bornean Wren Babbler Ptilocichla leucogrammica and White-chested Babbler Trichastoma rostratum) are heavily dependent on lowland forest (Lambert \& Collar 2002). Hussin and Francis (2001), however, argued that many of these species are relatively rare or hard to locate, even in primary forest (Hussin 1994; Karr 1977), making it difficult to obtain conclusive survey results.

Among arboreal foliage-gleaning babblers, some species have been reported to increase in response to logging, such as the Tit-Babblers, Macronous spp., while many other species decrease, although most appear to persist in logged forest. The quantitative results for individual species or species groups vary among study areas. For example, the Scaly-crowned Babbler (Malacopteron cinereum) decreased strongly in abundance in some study sites (Lambert 1992), but much less strongly in others (Johns 1989a; Hussin 1994). Other Malacopteron species remain fairly common in logged forest, but were still at much more reduced levels in some areas (Lambert 1992; Nordin \& Hussin 1996) than others (Johns 1989a).

These declines may be, at least partly, due to loss of a sheltered understorey in large sections of the logged forests (Hussin \& Francis 2001). A few species, such as wren-babblers, avoid crossing sunlit patches or big gaps in the forest (Hussin \& Francis 2001). This agrees with findings from the MRF, where, in an area that had been logged up to six years ago, wren-babblers had yet to return (O'Brien \& Fimbel 2002). Burghouts et al. (1992) and Chung (1993 in Hussin \& Francis 2001) found that changes in microclimate were associated with substantial changes in invertebrate distribution and abundance upon which these babblers depend. On the other hand, Boer (1998) found only a low and insignificant correlation between insect abundance, habitat disturbance and insect diversity, and further work is needed to explore these relationships. Johns (1989a) found that the relative abundance of understorey babblers had increased six years after logging and following the restoration of a closed canopy, although the numbers were still much lower than in primary forests. However, Wong (1985) reported lower densities and diversity of understorey insectivores even 25 years after logging compared with nearby primary forest. Wong (1986) found few differences in arthropod abundance in the two sites, although fruit was less frequently available in the regenerating site.

\section{Flycatchers}

Flycatchers (Muscicapidae) form a group of specialised insectivores occupying a variety of (micro) habitats. The Rhinomyias and Ficedula flycatchers show altitudinal replacements, whereas the members of the genus Cyornis are found in different habitat types within the rainforest (e.g., riverine, mid-canopy, understorey, etc.). Many of the species of this family are negatively affected by logging and/or fragmentation 
(Lambert \& Collar 2002), although one, the Black-naped Monarch (Hypothymis azurea) has been observed to increase significantly following logging (Hussin 1994). The latter may not be too surprising as the species was found to be common in open savanna woodland in East Java (Meijaard pers. obs.), suggesting that it copes well with open forest conditions. The riverine forest specialist Malaysian Blue Flycatcher (Cyornis turcosus) showed decreasing numbers in logged forest, which may be because of the disappearance of sheltering river bank vegetation (O’Brien \& Fimbel 2002).

\section{Cuckoos, malkohas, coucals and ground-cuckoo}

Data from the USA suggest that nest parasites such as the Brown-headed Cowbird (Spizella passerina) become more common in degraded and fragmented forest areas, leading to a higher incidence of nest parasitism for a variety of species (Hobson \& Villard 1998; Twedt et al. 2001). Whether similar patterns are found among Southeast Asian nest parasites remains unclear, but van Balen (in litt. 8 November 2004) mentioned that cuckoos were well represented in the avifauna of a forest in Jambi, Sumatra, that had been logged two years previously. Sample size, however, was too small for meaningful analysis.

\section{Raptors}

The effects of logging on raptors (eagles, hawks, falcons) remain poorly studied in Southeast Asia. Thiollay $(1998,1999)$ provided some data which suggest that interior forest specialists in particular, such as Spizaetus Hawk Eagles, were intolerant of the effects of timber harvest. However, Lambert and Collar (2002) pointed out that these species occur in small forest fragments and are often observed outside forest patches on Java and Sumatra. Furthermore, they claimed that most Sundaic raptors seem to survive in logged forests. Nijman and van Balen (2003) showed that among Javan Hawk Eagles (Spizaetus barteli), juvenile birds were much more likely to disperse between forest fragments than older, more settled birds. 



\section{Mammals}

\section{General}

Harrison $(1968,1969)$ was one of the first scientists to assess the nature of forest dependence amongst Southeast Asian mammals. His data suggested that if rainforest is completely destroyed only introduced rats remain. Since then several short and long-term studies have addressed the effects of selective logging on various mammal species, but cause and effect relationships between species density and activities associated with timber harvest remain hard to interpret.

One of the problems associated with assessing the impact of logging on mammals is that the distribution of many species appears patchy even in undisturbed forest, and densities vary considerably between sites. A list by Zubaid and Khairul (1997) illustrates the variation in the most commonly trapped small mammals found by different authors in logged and unlogged forest plots in Peninsular Malaysia (Table 5). This could mean that comparing species densities between logged and

Table 5. Most commonly trapped small mammals in several studies in Peninsular Malaysia.

\begin{tabular}{|c|c|c|}
\hline $\begin{array}{l}\text { Most common small } \\
\text { mammal species in } \\
\text { unlogged forest }\end{array}$ & $\begin{array}{l}\text { Most common small } \\
\text { mammal species in logged } \\
\text { forest }\end{array}$ & Source \\
\hline $\begin{array}{l}\text { Callosciurus notatus and } \\
\text { Lenothrix canus }\end{array}$ & $\begin{array}{l}\text { Leopoldamys sabanus and } C . \\
\text { notatus }\end{array}$ & (Zubaid \& Khairul 1997) \\
\hline $\begin{array}{l}\text { Tupaia glis and Maxomys } \\
\text { surifer/rajah }\end{array}$ & & $\begin{array}{l}\text { (Jum } 1987 \text { in Zubaid \& } \\
\text { Khairul 1997) }\end{array}$ \\
\hline L. sabanus and T.glis & & (Kemper \& Bell 1985) \\
\hline M. surifer/rajah and L. sabanus & $\begin{array}{l}\text { Rattus tiomanicus and } C . \\
\text { notatus }\end{array}$ & (Harrison 1969) \\
\hline T.glis and M. surifer/rajah & & (Langham 1983) \\
\hline T. glis and L. sabanus & $\begin{array}{l}\text { L. sabanus and Maxomys } \\
\text { surifer }\end{array}$ & (Yasuda et al.2003) \\
\hline L. sabanus and T.glis & & (Kemper \& Bell 1985) \\
\hline
\end{tabular}


unlogged sites would be of little value unless the species composition and density was assessed before logging commenced. If densities between sites already differed before logging, then any species density assessments after logging are more difficult, unless adequate sample designs are used to take full account of all the potentially confounding sources of variation; such designs remain rare. Unfortunately, in many studies regarding the effects of logging, pre-logging baseline studies were not conducted. Most researchers have used only one or two independent plots of treatments (logged vs. primary), making it difficult or impossible to decide whether the observed differences are beyond the usual variation in logged or primary forest and whether perceived differences can be attributed to the differences in treatment (Hurlbert 1984; Oksanen 2001). For investigations into the effects of logging, a study design with multiple, independent study sites is preferable (Augeri 1995; Datta 1998). Basic sampling problems may thus explain the considerable variation between different assessments of the effects of logging on species densities. Still, species density assessments after logging, combined with relevant biological and ecological information of the species, may give some helpful insights.

\section{Primates}

Primates are one of the most noticeable mammal groups in tropical forests, and the ecology of many species is fairly well known. However, most of what is known about Bornean primates is related to their behaviour, demography and movement patterns, while data regarding response to disturbance are comparatively poor. Nonetheless, several studies have provided some information on primate communities living in production forests (see Johns 1997; Johns \& Skorupa 1987; Plumptre \& Johns 2001; Rijksen 1978). In general, primates, especially the more generalist feeders, appear fairly adaptable to selective logging, changing their ranging patterns and diets to accommodate changes in forest structure and composition (Johns 1997).

Johns and Skorupa (1987) reviewed the literature available to them at that time and evaluated the following hypotheses for the world's primates: vulnerability to habitat disturbance increases with body weight and with dietetic diversity, and it decreases with an increasing degree of folivory. Their analysis showed that, generally, a primate species' degree of frugivory shows a significant negative correlation with its ability to persist in recently logged forests, as expressed by comparative population densities in unlogged and adjacent logged forests. However, while the variation explained by percentage frugivory was statistically significant, it was thought to be an insufficient basis for reliably predicting the outcome of individual cases (Johns \& Skorupa 1987). Dietary diversity, on the other hand, does not appear to affect a species' ability to persist following logging activities. The most important factor affecting a species' persistence is an ability to change the relative proportions of different foodtypes in the diet, specifically to exploit available young leaves in the absence of fruit ${ }^{4}$. Highly specialised frugivores are less able to do this. The most

${ }^{4}$ Dietary diversity and the ability to switch diet (dietary specialization) are not the same. An animal may have a low dietary diversity but be able to switch preferred foods (for example, many Presbytis spp.), or have high diversity, but limited switching abilities. 
successful species are those which can survive on a largely folivorous diet, even if they are considered 'frugivorous' in primary forest (Johns 1997). However, a key aspect of this is the increase in juvenile and infant mortality that may result when adults increase folivory. Lactating females become energetically stressed and this may result in abandonment or starvation of infants. Juveniles are less likely to be capable of digesting leaves, increasing the risk of mortality from starvation or from predation, if they choose to forage alone. Again, this suggests that studies in forest logged long ago, which are separated from unlogged forest, would help us to understand what is really happening.

In Southeast Asian forests the main timber trees belong to the family Dipterocarpaceae. These trees are not a recognised food resource for primates. Most Southeast Asian primates are generalists, able to adapt their diets to changing food availabilities in different types of logged forests. Johns (1983) conducted a study of the influences of selective logging on primates over a two-year period in West Malaysia. He found no evidence that any of the common primate species were dependent on mature forest. Johns (1997) suggested that local variation in density due to local environmental or historical factors (e.g., hunting) could be greater than changes brought about by logging. There is also a possible time-lag, with some primate species being able to hang on in essentially non-forest habitat for periods longer than short-term studies can effectively document. Impacts on density may occur over several years. Too often, observational studies are ecologically brief, usually only one or two seasons, and may not document the full effects of perturbations and (supra-) annual cycles. Johns and Skorupa (1987) acknowledged that time-discrete point observations of primate survival in disturbed habitats can be misleading. In terms of point sampling in relation to geographic extent, Johns and Skorupa (1987) concluded that similar problems occur when interpreting observations relative to localized impacts. In such cases, primates that move away from disturbed areas, particularly territorial species, will suffer high mortality rates and this may not be observed within the localized geographic limits or brief periods of some studies.

Still, some species appear constrained in space after logging due to their historical territorial affinity, despite habitat perturbations; others are unable to move to new areas due to either a) isolation in forest patches surrounded by inhospitable terrain, b) excessive canopy gaps requiring ground travel between trees (this is particularly problematic for arboreal species), or c) competitive exclusion and territorial aggression from conspecifics. Thus, these individuals must adapt to the local conditions, which often include attempted shifts in home range and changes from a frugivorous diet to one that is more folivorous (Gilbert \& Setz 2001). For some species, however, such shifts result in health declines (Johns 1983; Gilbert 1994; Gilbert \& Setz 2001). Orangutans Pongo pygmaeus, for instance, survive in degraded forest in Kutai, East Kalimantan (Suzuki pers. comm.) and plantations of Sabah (Ancrenaz pers. comm.), but these may be sink populations, and it is unclear whether such populations are viable in the long term.

In Malaysia, Johns (1983) found that with just a 3.3\% log removal rate, selective logging resulted in 'serious effects' on resident primates, including an abrupt decrease in primate biomass, direct mortality, decreases in recruitment, adverse shifts in diet 
as well as calling behaviour for some species (particularly gibbons), and high levels of infant malnutrition, abandonment and mortality, among other effects. When studies are only able to examine disturbance effects on relatively brief time scales or at only one site, there can be a false perception of minimal effects on some species (Johns \& Skorupa 1987; Lovejoy et al 1986).

In general, primate densities decline following logging, and in some cases they are markedly lower, particularly over the long term (Davies \& Payne 1982; Gilbert 1994; Gilbert \& Setz 2001; Johns 1983; Lovejoy et al. 1986; Rijksen 1978; Terborgh 1983; Wilson \& Johns 1982; Wilson \& Wilson 1975). In addition, felling operations raise infant mortality, but birth rates can quickly return to normal (Johns \& Johns 1995). Apart from temporary increases in the density of Macaca fascicularis (but see Table 6), which tends to invade early successional forest, there are no significant trends in the abundance of common primates up to 18 years following the felling event (Johns \& Johns 1995). In contrast to these results, Rijksen (1978) found that three out of six primate species (two gibbon species and Pig-tailed Macaque Macaca nemestrina) in northern Sumatra were less commonly observed in slightly disturbed forest compared to undisturbed forest. These species were completely absent from forest under logging and in secondary vegetation. One leaf monkey species (Trachypithecus cristatus) was only found in the area which had been most affected by logging.

Marsh et al. (1987) suggested that a second feature that can influence a primate's adaptability is its degree of terrestriality. Some species are primarily arboreal or have strong affinities to canopy strata-canopy gaps may disrupt arboreal pathways for these species. Most Old World species capable of colonizing secondary forest are at least semi-terrestrial in habits, which must facilitate survival in small patches. This behaviour, however, also predisposes them to crop raiding, making them vulnerable to hunting. The two macaque species, both of which are to some extent terrestrial, are often mentioned as pest species, whereas arboreal species such as leaf monkeys and gibbons rarely enter agricultural areas or make forays to the ground. Orangutans (Pongo pygmaeus) occasionally raid crops, especially in areas where intensive deforestation takes place, and are often killed in the process (Meijaard pers. obs.).

Two species studied in detail by Johns (1986a), the Lar Gibbon (Hylobates lar) and the Banded Leaf Monkey (Presbytis femoralis) both showed decreased activity levels following logging, spending less time foraging and travelling, and more time resting. An increase in resting time was necessary to digest the higher proportion of leaf material in the diet. During the first six months after completion of logging, the percentage of feeding time spent ingesting leaves increased from $23 \%$ to $40 \%$ in gibbons, and from $40 \%$ to $58 \%$ in leaf monkeys (Johns 1986a). In unlogged forest gibbons incorporated a high proportion of fruits rich in free sugars into their diet. They were unable to find these fruits immediately after logging and were energetically constrained, reducing day range length by more than 50\%. Leaf monkeys also reduced their day range lengths following logging, but changes in their ranging pattern reflected changes in the distribution of trees rather than energetic constraints. The monkeys were now exploiting common tree species rather than the widely dispersed but highly preferred tree species exploited in mature forest; in terms of optimal foraging strategies (see Stephens \& Krebs 1986) these monkeys may 
be time minimizers rather than energy maximizers. Thus Johns (1983) suggested that opportunistic feeders do better than those with more fixed daily requirements, whether for few or many kinds of food.

Behavioural changes following logging can lead to alterations in social organisation. In the case of the Banded Leaf Monkeys (P. femoralis) studied by Johns (1986a), smaller and more evenly dispersed food sources led to leaf monkey groups splitting into smaller foraging subunits. Leaf monkeys also abandoned territoriality and adopted mutual avoidance as the most efficient means of reducing inter-group competition.

Facultative territoriality is rare (although possibly less so in cercopithecine primates), however, and territorial species typically avoid leaving their prior ranges even during logging. Abandonment occurs only where food resources are critically depleted. Highly territorial animals such as gibbons sometimes remain within their former ranges even following forest clearance or fires which destroy a high proportion of trees (Marsh \& Wilson 1981; Marsh et al. 1986; Nijman 1997). An important aspect on this territoriality is the territorial aggression of adjacent groups: those in logged areas cannot move out even if they need to (Johns 1983). Johns and Skorupa (1987) expect that when such territorial species do move away from the disturbed area, a high mortality rate would occur.

Howell's study of primate densities in the Malinau research area reveals some interesting patterns (Howell 2003). Of her three logged-over study sites, the most recently logged had primate densities higher than those in the unlogged control plots, especially for $P$. hosei and $H$. muelleri. In the older logged plots (logged 4 years prior to the study), however, primate densities were $>60 \%$ lower than in unlogged forest. Howell (2003) suggested that this indicated that $P$. hosei and H. muelleri were initially not able to relocate to another area after logging had affected their forest blocks, but that they did so with time. The strong territoriality of these species may be one of the explanations why it took them several years to move away from logged areas. The normally adaptable $M$. fascicularis was not found at all in the logged forest, and neither was $M$. nemestrina. Howell (2003) speculated that the dense undergrowth in the logged areas presented difficulties to $M$. nemestrina, and possibly explained its absence from logged forests in Malinau. Sample sizes were small and study duration only a few months and caution is therefore needed in interpreting these results.

Table 6 summarizes the reported primate density changes following logging. For the macaque species and tarsiers the data are inconclusive, suggesting that either there is considerable geographic variation in responses to logging and associated effects, and/or that at least some studies are methodologically inadequate. Hylobates muelleri seems to have a generally neutral or negative reaction to logging, while $P$. hosei declined in most studies, although possibly not as a direct result of logging, but through increased hunting pressure. $P$. rubicunda seems to be relatively neutral in its response to logging. This resistance to disturbance finds possible parallels in Davis' (1962) observation that $P$. hosei stands it ground 'until shot at', while P. rubicunda flees immediately. 


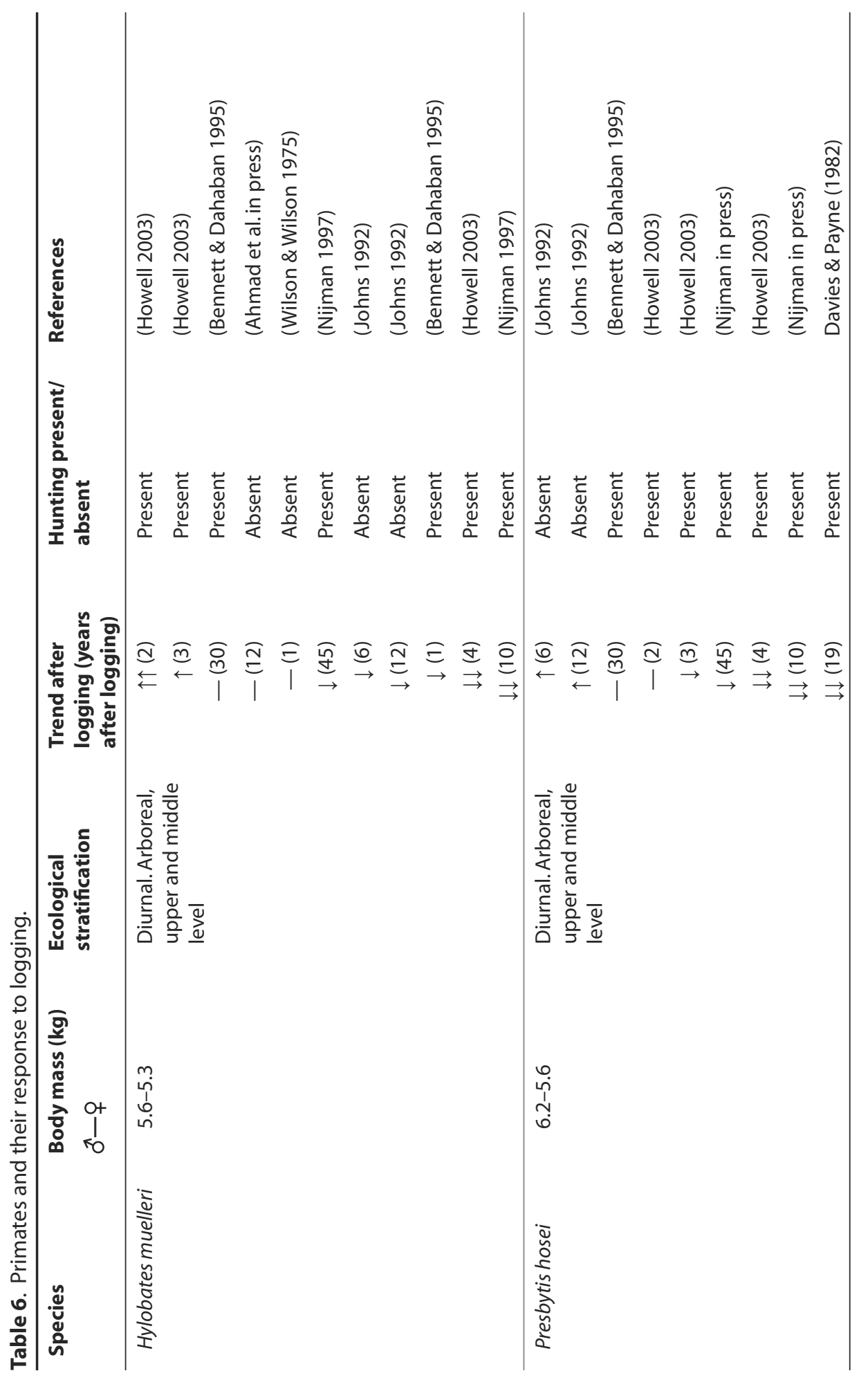




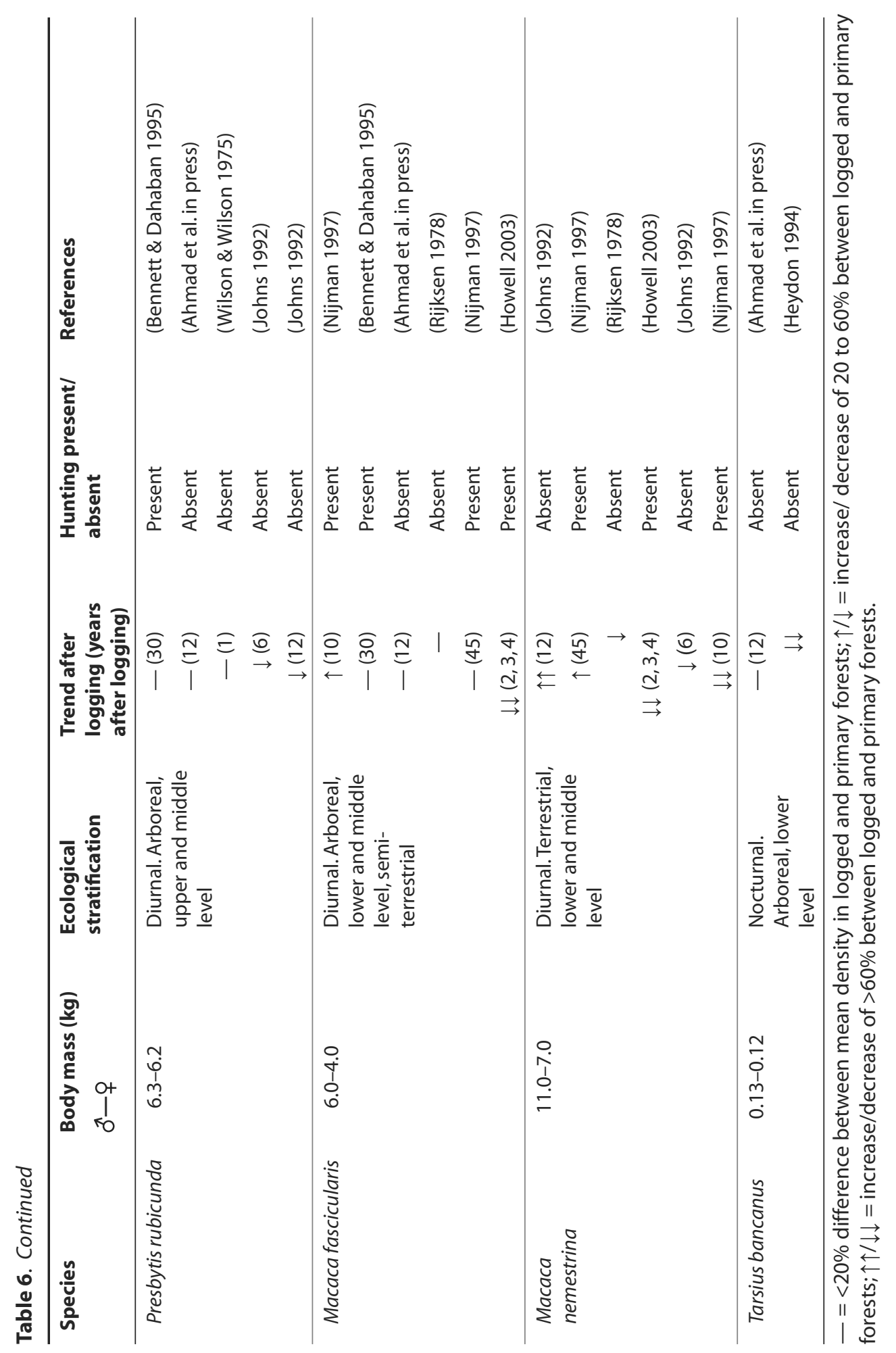




\section{Squirrels}

Many diurnal squirrels often live sympatrically in tropical forest. MacKinnon (1978) and Payne (1979) studied their niche separation under these conditions in Peninsular Malaysia. In Africa the diversity of forest squirrels has been correlated with plant species diversity and the predictability of resources on an annual basis (Emmons 1980). Throughout the year, foraging height and body size segregates species. In Southeast Asian forests, squirrels appear to partition sources by time of activity and foraging location (MacKinnon 1978; Payne 1979). Of the 34 squirrels known from Borneo, 14 are nocturnal and the rest are diurnal. The diurnal squirrels can be divided into terrestrial, arboreal and climbing categories, with different species using various forest strata. In Borneo's dipterocarp forests segregation occurs when fruit is abundant. At times of low fruit availability dietary overlap occurs and competition increases, with all species feeding on a few common fruiting trees and alternative foods (Johns 1983).

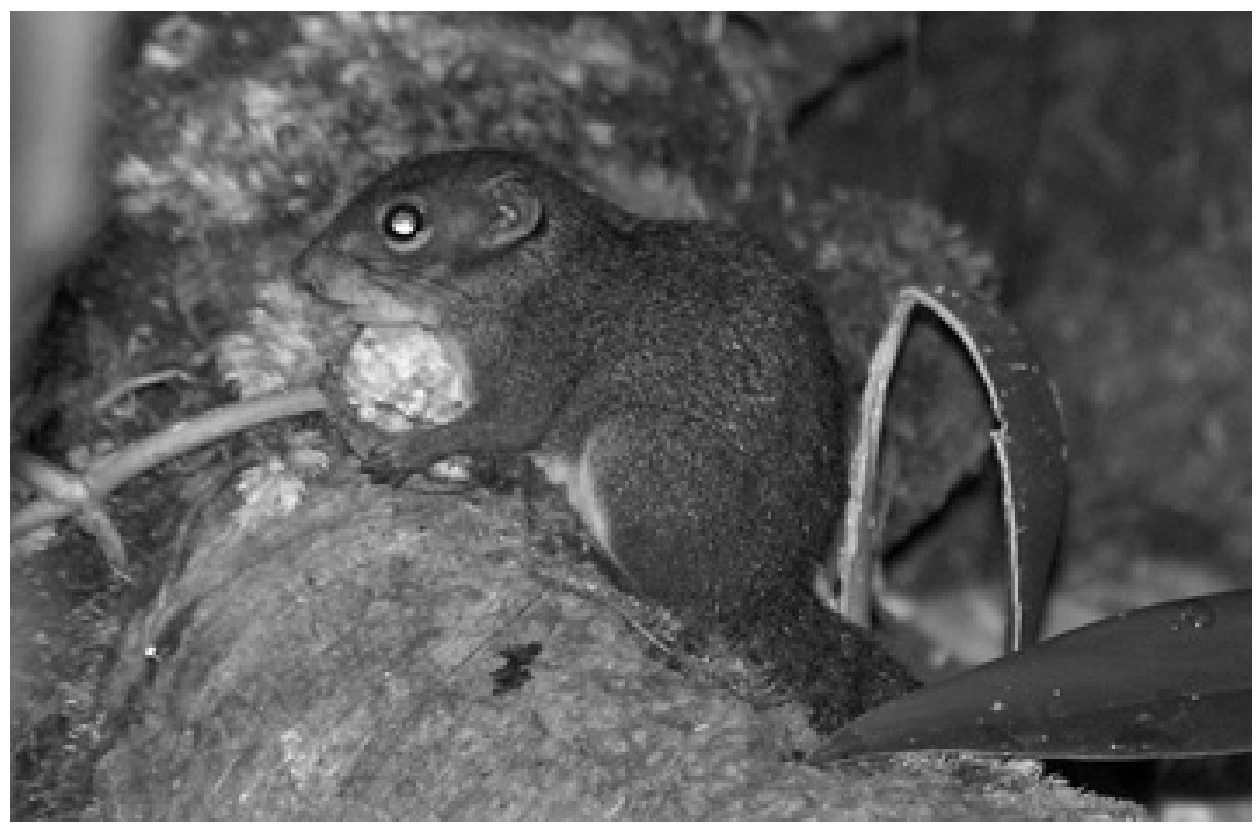

Figure 9. Sundasciurus lowii, seen here feeding on Artocarpus fruits, is a common squirrel of undisturbed and disturbed lowland forests. (Photo by Kimabajo)

Responses of squirrels to logging do not follow clear patterns (see Table 7). There appears to be a reduction in the population density of some species, notably Ratufa bicolor and Lariscus insignis, while populations of $R$. affinis, Callosciurus prevostii, $C$. notatus and S. tenuis (Fig. 9) show increases in some areas (Johns 1997). These latter species, and especially $C$. notatus, were also found to be present in higher densities after logging than before in Sarawak, but $R$. affinis densities decreased by $71 \%$ (Dahaban et al. 1996). Numbers of $R$. affinis also declined after logging for shifting cultivation in another area in Sarawak, while the density of the Callosciurus species did not change significantly (Bennett \& Dahaban 1995). Syakirah et al. (2000) found 
that $R$. affinis was absent in a recently logged and further disturbed lowland forest in Peninsular Malaysia, but present in a nearby plot in which forest had recovered after being logged about 20 years previously.

Bennett and Dahaban (1995) and Dahaban et al. (1996) reported a higher density of small Sundasciurus squirrels (S. tenuis and S. lowii) in shifting cultivation areas that had not been used for 30 years compared to primary forest, which suggest that these species benefit from the disturbance: $S$. hippurus was not found immediately after logging or two years later (Dahaban et al. 1996). This mirrors findings from Peninsular Malaysia, where Laidlaw (2000) only found S. hippurus in Virgin Jungle Reserves (areas set aside to represent ecological types of original conditions) and not in the adjacent logged forests, while S. lowii and S. tenuis occurred in both logged and unlogged forests, although no data on relative densities were provided. Rijksen (1978), on the other hand, found that $S$. tenuis occurred in all forest types from undisturbed forest to secondary forest, but the density declined significantly after logging. S. hippurus was absent from forest under logging and secondary forest, while densities were lower in lightly logged forest compared to primary forest (Rijksen 1978). Another species, L. hosei, was only found in unlogged forest, and 4-year-old logged forest (Dahaban et al. 1996), whereas L. insignis was found in recently logged forest, but not in a secondary forest (Syakirah et al. 2000). Also, the ground squirrel Rhinosciurus laticaudatus was absent from recently logged forest, but present in the secondary forest (Syakirah et al. 2000). Little is known about the Bornean endemic Tufted Ground Squirrel (Rheithrosciurus macrotis), but Fredriksson (pers. obs.) observed the species several times in logged forest areas in East Kalimantan.

Johns (1997) concluded that terrestrial squirrels seem least tolerant to conditions in logged forests. This fits the observed decreases in Lariscus insignis and Rhinosciurus laticaudatus, two insectivorous terrestrial species (MacKinnon et al. 1996, p. 217), and Sundasciurus hippurus, another partly insectivorous species that occurs in low trees and on the ground, as well as the increase in Callosciurus prevostii, which is an upper canopy species. Table 7 suggests, however, that the picture is more complicated, with different responses to logging reported from different areas. In addition, body weight could be a factor with the bigger species being more vulnerable to logging (and hunting).

Responses to logging might also reflect changes in food abundance and competition with other taxa. Dwiyahreni (2003) studied the effects of forest fires on squirrel foraging altitude. She found that ground squirrels moved to slightly higher strata while canopy squirrels moved to lower strata, and suggested that this happened to avoid different predators. Such changes in altitudinal stratification could lead to an increase in inter-specific competition. However, the data remain inadequate to determine when such competition leads to species elimination.

Southeast Asian flying squirrels of the genus Petaurista feed primarily on energyrich soft fruits in mature forests, but an ability to incorporate leaf material into their diet at times of fruit shortage appears to improve their persistence in logged forests compared with strictly frugivorous mammals. In Peninsular Malaysia the proportion of feeding time spent eating leaves by Red Giant Flying Squirrels (Petaurista petaurista) increased from $51 \%$ prior to logging to $78 \%$ in the six months following logging 
Table 7. Non-flying squirrels and their response to logging.

\begin{tabular}{|c|c|c|c|c|}
\hline Species & $\begin{array}{l}\text { Body size } \\
\text { (kg) }\end{array}$ & Ecological stratification & $\begin{array}{l}\text { Density } \\
\text { trend after } \\
\text { logging }\end{array}$ & References \\
\hline \multirow[t]{3}{*}{ Ratufa affinis } & \multirow[t]{3}{*}{$0.90-1.50$} & \multirow[t]{3}{*}{ Canopy, feeds on seeds } & $\uparrow$ & (Johns 1997) \\
\hline & & & $\downarrow$ & (Dahaban et al. 1996) \\
\hline & & & $\downarrow$ & $\begin{array}{l}\text { (Bennett \& Dahaban } \\
\text { 1995) }\end{array}$ \\
\hline Ratufa bicolor & $0.90-1.50$ & $\begin{array}{l}\text { Canopy, feeds on fruits } \\
\text { and nuts }\end{array}$ & $\downarrow$ & (Johns 1997) \\
\hline \multirow{4}{*}{$\begin{array}{l}\text { Sundasciurus } \\
\text { hippurus }\end{array}$} & \multirow[t]{4}{*}{$0.30-0.42$} & \multirow{4}{*}{$\begin{array}{l}\text { Mostly terrestrial, but } \\
\text { uses middle canopy. Diet: } \\
\text { mostly fruits, some seeds } \\
\text { and insects }\end{array}$} & $\uparrow$ & (Wells 2002) \\
\hline & & & $\downarrow$ & (Laidlaw 2000) \\
\hline & & & $\downarrow$ & (Rijksen 1978) \\
\hline & & & $\downarrow$ & (Dahaban et al. 1996) \\
\hline $\begin{array}{l}\text { Callosciurus } \\
\text { prevostii }\end{array}$ & $0.25-0.50$ & $\begin{array}{l}\text { Canopy. Feeds on fruits } \\
\text { and insects }\end{array}$ & $\uparrow$ & (Johns 1997) \\
\hline $\begin{array}{l}\text { Callosciurus } \\
\text { caniceps }\end{array}$ & $0.25-0.50$ & $\begin{array}{l}\text { Middle of canopy. Feeds } \\
\text { on fruits and insects }\end{array}$ & $\uparrow$ & (Laidlaw 2000) \\
\hline $\begin{array}{l}\text { Callosciurus } \\
\text { nigrovittatus }\end{array}$ & $0.15-0.40$ & $\begin{array}{l}\text { Middle of canopy. Feeds } \\
\text { on fruits and insects }\end{array}$ & - & (Laidlaw 2000) \\
\hline \multirow{2}{*}{$\begin{array}{l}\text { Rhinosciurus } \\
\text { laticaudatus }\end{array}$} & \multirow[t]{2}{*}{$0.18-0.26$} & \multirow{2}{*}{$\begin{array}{l}\text { Terrestrial. Feeds mostly } \\
\text { on insects }\end{array}$} & $\downarrow$ & (Laidlaw 2000) \\
\hline & & & $\downarrow$ & (Yasuda et al. 2003) \\
\hline \multirow{4}{*}{$\begin{array}{l}\text { Callosciurus } \\
\text { notatus }\end{array}$} & \multirow[t]{4}{*}{$0.15-0.28$} & \multirow{4}{*}{$\begin{array}{l}\text { Middle of canopy. Feeds } \\
\text { on fruits and insects }\end{array}$} & $\uparrow$ & (Johns 1997) \\
\hline & & & $\uparrow$ & (Dahaban et al. 1996) \\
\hline & & & $\downarrow$ & (Syakirah et al. 2000) \\
\hline & & & $\downarrow$ & (Yasuda et al. 2003) \\
\hline Lariscus hosei & $0.15-0.22$ & $\begin{array}{l}\text { Terrestrial. Feeds on fruits } \\
\text { and roots }\end{array}$ & $\downarrow$ & (Dahaban et al. 1996) \\
\hline \multirow[t]{2}{*}{ Lariscus insignis } & \multirow[t]{2}{*}{$0.12-0.23$} & \multirow{2}{*}{$\begin{array}{l}\text { Terrestrial. Mixed diet of } \\
\text { bark, fruits, leaves and } \\
\text { insects }\end{array}$} & $\downarrow$ & (Johns 1997) \\
\hline & & & $\downarrow$ & (Yasuda et al. 2003) \\
\hline \multirow{3}{*}{$\begin{array}{l}\text { Sundasciurus } \\
\text { lowii }\end{array}$} & \multirow[t]{3}{*}{$0.06-0.12$} & \multirow{3}{*}{$\begin{array}{l}\text { Mainly small trees and } \\
\text { terrestrial. Feeds on fruits, } \\
\text { insects and fungi }\end{array}$} & $\uparrow$ & (Wells 2002) \\
\hline & & & $\uparrow$ & $\begin{array}{l}\text { (Bennett \& Dahaban } \\
\text { 1995) }\end{array}$ \\
\hline & & & $\downarrow$ & (Yasuda et al. 2003) \\
\hline \multirow{3}{*}{$\begin{array}{l}\text { Sundasciurus } \\
\text { tenuis }\end{array}$} & \multirow[t]{3}{*}{$0.06-0.10$} & \multirow{3}{*}{$\begin{array}{l}\text { Mainly small trees and } \\
\text { terrestrial. Feeds on fruits } \\
\text { and seeds }\end{array}$} & $\uparrow$ & (Johns 1997) \\
\hline & & & $\uparrow$ & $\begin{array}{l}\text { (Bennett \& Dahaban } \\
\text { 1995) }\end{array}$ \\
\hline & & & $\downarrow$ & (Rijksen 1978) \\
\hline
\end{tabular}

$\uparrow=$ increase in density after logging; $\downarrow=$ decrease in density or absent from recently logged areas; $-=$ no difference. Information on ecological stratification was obtained from Lekagul and McNeely (1977) and Payne et al. (1985). 
(Barrett 1984), but it is unclear to what extent this could have been caused by normal seasonal effects. Transect surveys suggest that the population densities of $P$. petaurista did not change significantly during the six months following logging (from 34 to 39 individuals $/ \mathrm{km}^{2}$ ). However, despite dietary adaptations that should aid persistence, densities decreased in older logged forests. This may reflect another limiting factor, such as availability of daytime refuges or increased predation or hunting. Such shortterm studies are in any case plagued by various additional uncertainties (as already noted in several sections concerning other taxa).

\section{Rats and mice}

Several studies have examined how densities of rats and mice are affected by logging in Southeast Asia. One study from Peninsular Malaysia found a significantly higher density of Leopoldamys sabanus (an omnivorous species of ground and lower vegetation levels) in old regenerating forest compared to primary forest $(\mathrm{p}<0.001$, Yasuda et al. 2003). Zubaid and Khairul (1997) confirmed this result by capturing 21 specimens in disturbed forest as opposed to only one in undisturbed habitat with approximately similar trapping effort. Rattus tiomanicus, an omnivorous species that uses all vegetation strata, is another species that is rarely found in mature forest but thrives in scrub edge locations, one of the reasons why the species is very common in oil palm plantations (see Buckle et al. 1997). Yasuda et al. (2003) found that two Maxomys species, $M$. rajah and $M$. whiteheadi, both primarily terrestrial, and the latter primarily insectivorous ( $M$. rajah's diet is unknown) were significantly $(\mathrm{p}<0.05)$ more common in primary forest. Zubaid and Khairul (1997) similarly found $M$. rajah only in undisturbed forest, while a third species, M. whiteheadi, appeared to be slightly more common in disturbed forest (difference probably not statistically significant). Niviventer cremoriventer $(\mathrm{n}=9)$ and Lenothrix canus $(\mathrm{n}=14)$, both primarily frugivorous species (Yasuma \& Andau 2000) of lower vegetation and ground levels, were only collected in undisturbed forest.

Bernard (2004) found through multivariate analysis of large datasets on small terrestrial mammal abundance (primarily Maxomys surifer, Tupaia glis, Niviventer cremoriventer, Maxomys whiteheadi and T. tana) that abundance and species richness did not differ much between primary forest and forest logged 11-40 years previously. Small mammal abundance was primarily determined by density of fallen logs and twigs, coverage of rock piles and wet areas, number of tree stumps and vegetation density at low heights $(1-5 \mathrm{~m})$, medium heights $(>5 \mathrm{~m})$ and at canopy level. This mirrors findings by Kemper and Bell (1985). Bernard (2004) suggested that the correlations between mammal presence and the abundance of rock piles, tree stumps and dense ground level vegetation were best explained by improved predator avoidance, as these structures decrease visibility and allow rapid escapes.

\section{Insectivores}

This group, consisting of Moonrat (Echinosorex gymnurus), gymnures and shrews, is poorly known, especially with regard to the effects of logging. All Bornean shrews 
appear to be dependent on closed canopy forest (Payne et al. 1985) and they appear sensitive to fragmentation effects, which may explain their absence from most of Sundaland's small islands (Table 13).

Moonrats are a lowland forest species which feed primarily on worms and arthropods. They require hollow logs and tree-root spaces for resting and nesting. They are known to occasionally occur in plantations (Payne et al. 1985). Augeri (unpubl.) found a twofold higher frequency in photo captures of Moonrats in primary forest compared with logged forest in the MRF and Kayan Mentarang ecosystems, but no statistical assessment of this has yet been made.

\section{Treeshrews}

Treeshrews are endemic to the Indomalayan region. They are a relatively ancient family that originated more than 20 million years ago, probably in or near presentday Borneo (Yasuma 1996). Emmons (2000) pointed out that the name 'treeshrew' is somewhat of a misnomer, as these animals are not shrews and few use trees. In fact, most Tupaia species are primarily terrestrial, and as logging is known to affect understorey vegetation, it is interesting to see how treeshrews are affected. Emmons (2000) studied this in Danum Valley, Sabah by comparing animal captures in logged and unlogged areas at different times of the year. Other data are provided by Stuebing and Gasis (1989), who studied treeshrew populations in logged forest and in monospecific tree plantations of Eucaplyptus deglupta, Gmelina arborea, Albizia falcataria and $A$. falcataria underplanted with cacao Theobroma cacao. The forest of the plantations had been logged seven years previously and their undergrowth was of that age, except that the cacao plantation had been kept clean of undergrowth. The two studies suggested that the only arboreal Tupaia species, the Lesser Treeshrew Tupaia minor was eliminated by logging practices that left other species relatively unaffected. Possibly the high reliance of $T$. minor on lianas and tree canopies, with $87 \%$ of the sightings on these substrates, could explain why this species suffers from the effects of logging (and liana cutting). Still, T. minor was present in all tree plantations except cacao. In addition, Bennett and Dahaban (1995) never recorded this species in unlogged forest, although it was regularly encountered in newly logged forests, which seems to be in contrast with Emmons' findings. T. gracilis, the Slender Treeshrew, was absent from all tree plantations. The Large Treeshrew, T. tana, was absent from tree plantations with the lowest undergrowth densities. The Plain Treeshrew, T. longipes, was absent only from the one plantation with no undergrowth and survived in one habitat where all other species appeared to be extinct. Moreover, T. longipes had an apparently threefold population increase in the habitat where undergrowth was most dense (Emmons 2000; Stuebing \& Gasis 1989). It appears that the arboreal species is most adversely affected by selective logging, probably as a direct result of the destruction of forest canopy.

Emmons (2000) speculated further on the different responses of treeshrew species to logging and undergrowth densities. The large terrestrial treeshrews feed on earthworms and other invertebrates in decomposing wood on and under litter. Where the understorey is dense, the ground surface litter layer is shady and moist, 
and arthropods are abundant near the surface; but in plantations where there is little ground cover, the surface is drier, and arthropods and worms may be less abundant, at least near the surface. Moreover, such tree plantations often lack decomposing wood. This may be why Slender Treeshrews, T. gracilis, were absent from plantations. Also, this species has large home ranges, even in undisturbed forest, and may not be able to find enough resources, especially undergrowth caterpillars (its speciality), in depleted forests (although note that Hill et al. 2003 found that butterfly and therefore presumably caterpillar density in Sabah was determined by rainfall rather than logging intensity). In contrast, $T$. longipes has the broadest habitat tolerance of all tupaiids, and Emmons suggested that this is because it primarily feeds on ants, which sometimes increase in secondary vegetation (see, for instance, Vasconcelos et al. 2000, who found higher ant densities in recently logged forest compared to older logged forest and unlogged forest in central Amazonia). In conclusion, Emmons (2000) proposed that the treeshrew species that are most threatened by forest destruction are those with the narrowest ecological niche and the smallest distribution range; all treeshrews, however, need some kind of forest to survive. Also, importantly, Emmons (2000) mentioned that treeshrews are rarely seen crossing wide roads. These species are therefore likely to be negatively affected by the fragmentary effects of roads and other cleared areas.

\section{Bats}

Bats are a diverse vertebrate group in Old World rainforests and can comprise up to half of all forest mammal species. A single $3 \mathrm{~km}^{2}$ area in Peninsular Malaysia supported 51 species of insectivorous bats and 11 species of Megachiroptera (Kingston et al. 2003). No bat surveys have yet been conducted in Malinau, but on the basis of their distribution in Borneo (Corbet \& Hill 1992; Meijaard unpubl.; Payne et al. 1985; van Strien 2001) it can be predicted that at least 50 species occur in the area.

Bats are vulnerable to environmental disruption. Vulnerability is conferred by life history traits that combine low fecundity, prolonged maternal care and slow development; all adaptations for life in stable, predictable habitats, and where populations are maintained close to the carrying capacity of the environment (Kunz \& Peirson 1994; Purvis et al. 2000). The Global Status Survey and Conservation Action Plan for Microchiropteran Bats designated 22\% of species as threatened and a further 23\% as near threatened (Hutson et al. 2001).

As pointed out earlier in this report, bats are important pollinators of trees and valued crops, and are significant seed dispersers. Fruit bats, such as those of the genera Pteropus and Cynopterus, disperse seeds of a great variety of plants including Psidium guajava, Elaeocarpus sphaericus, Melia azedarach, Musa spp., Carica papaya, Canarium spp., Mangifera indica, Annona muricata, Manilkara achras, Eugenia spp., Lansium domesticum, Piper aduncum, Sechium edule, various Ficus species, and a range of palms including Livistona spp., Bactris spp., Chrysalidocarpus spp., Caryota spp. and Cynometra cauliflora (plant names changed following taxonomy by Backer \& Bakhuizen-van den Brink (1963-1968)) (note that Psidium and Carica are South 
American exotics). In a review of the role of bats in plant propagation in 59 plant families from the Old World, Fujitta and Tuttle (1991) found that at least 289 plant species rely to varying degrees on pteropodids for pollination or seed dispersal. The family Moraceae contains the largest number of species visited for fruit (39 species), primarily of the genus Ficus, followed by Sapotaceae (8), Ancardiaceae (7), Ebenaceae (6), Guttiferae (5) and Meliaceae (5). Bats are particularly good dispersers because they may fly long distances from the parent tree before processing the fruit, and in many cases extract just the juice and fruit pulp and spit out the seeds largely undamaged (van der Pijl 1935). Alternatively, some species selectively ingest viable seeds, increasing the probability that the dispersed seeds will germinate (Utzurrum \& Heideman 1991; Utzurrum 1995).

Species relying on bats for pollination in Southeast Asia are most common in the family Myrtaceae (59), with Leguminosae (12), Bignoneaceae (9), Proteaceae (6) Bombacaceae (5), Sonneratiaceae (5) and Musaceae (4) also well represented. At least 448 products of value to humans were found to be derived from 186 species (Fujita \& Tuttle 1991). These products include fruit, drinks, foods, ornamentals, timber, fibres, tannings, dyes, medicinals, animal fodder and fuel. The durian (Durio spp.) trade in Southeast Asia was valued at US \$120 million in the mid-1980s (Myers 1985), and annual sales of petai (Parkia speciosa) in Peninsular Malaysia were worth $\$ 15$ million ( $\mathrm{Ng} \mathrm{1980)}$; in the late 1990s petai sales in the area surrounding Kuala Lumpur, Malaysia, generated approximately US \$2.8 million annually (Chuen et al. 1998) further indicating the economic importance of these crops. Durians depend on nectar-feeding bats (especially the cave-dwelling Eonycteris spelea and the forest bat Macroglossus minimus). When durians are not in flower, these bats depend on other tree species for nectar (presumably requiring a relatively diverse community to provide food over the year). Loss of forest can lead to local loss of bats and failure of valuable durian crops (Start \& Marshall 1976).

Many fruit bats do not depend wholly on closed forest for their survival, and persist quite well in human-dominated landscapes (e.g., Cynopterus brachyotis, C. horsfieldii). For much of Southeast Asia (including Borneo), tropical rainforests are dominated by wind/gravity-dispersed dipterocarps. Plant resources available to fruit bats are relatively low, and highly dispersed in both time and space. This may have favoured the high mobility, large size and more generalised feeding habits that distinguish the pteropodids from their Neotropical plant-visiting counterparts (the Phyllostomidae) (Fleming 1987, 1993). The paucity of asynchronous fruiting shrubs in the region also means that few species habitually forage in the forest understorey (exceptions being Cynopterus brachyotis and Balionycteris maculata). Rather, many species specialise on the abundant but ephemeral crops of large canopy trees, and as a consequence are morphologically equipped to commute long distances and fly in and above the canopy (Hodgkison 2001). Although some fruit bat species are undoubtedly dependent on intact stands of forest (e.g., Balionycteris maculata, Chironax melanocephalus), other species may be able to capitalize on their commuting abilities (which can exceed $70 \mathrm{~km}$ per night: Start 1974) to persist in a fragmented/logged landscape. Nonetheless, some species like Pteropus vampyrus require undisturbed areas for roosting (Gumal 2004). 
Similarly, insectivorous bats that forage in the open spaces above the forest and in large forest gaps (e.g. Molossidae, Taphozous spp.), as well as those that utilize the forest edge and tree fall gaps (vespertilionids of the subfamilies Miniopterinae and Vespertilionae) may also be somewhat adaptable to a more open landscape. The ecomorphological adaptations for foraging in open and edge habitats actually preclude many species from entering the more dense vegetation of the forest interior; these are typically fast-flying species with efficient flight, and echolocation adapted to detect insects over medium to long distances in open environments with limited background vegetation. Many species are prevalent in urban, suburban and rural environments (e.g. Pipistrellus spp., Myotis spp., Scotophilus spp.), and several roost in buildings and other structures, while others are capable of commuting long distances from their roosts.

Insectivorous bats of the forest interior, however, may be much more affected by the effects of logging and fragmentation (Kingston et al. 2003). Not only are they affected by quantitative loss of habitat as forests are fragmented and degraded, but they also experience qualitative habitat changes as edge effects alter the forest microclimate (Kapos 1989; Saunders et al. 1991), and impact insect availability (Johns 1997).

The susceptibility of forest bats to disturbance is further heightened by specializations of wing morphology and echolocation specialization that equip them to forage in the dense clutter of the forest understorey, but constrain their ecological flexibility. Echolocation signals must be designed so that the bat can distinguish prey items from the surrounding vegetation. The Hipposideridae and Rhinolophidae families and the vespertilionid Kerivoulinae and Murininae have all evolved effective responses to this problem that work well inside the forest where prey densities are relatively high. However, their efficacy in more open habitats, where prey densities are lower, is greatly reduced; the effective operating range of the echolocation signals is very limited in some cases (Kerivoulinae, Murininae, high frequency rhinolophoids) and unsuited to the detection of distant prey items distributed at low density. To compound the situation, bats capable of foraging in cluttered environments need to be highly manoeuvrable. Manoeuvrability is conferred by low wing loading, rounded wingtips and low aspect ratio (Norberg \& Rayner 1987). However, this manoeuvrability comes at a price; flight is slow and energetically costly, precluding the fast, efficient flight necessary to exploit low prey densities in open habitats.

It is this combination of clutter-resistant echolocation and energetically costly but highly manoeuvrable flight that confines many insectivorous bats to the rainforest interior. They are ill-suited for prey detection and/or capture in the more open habitats that tend to arise from disturbance events such as logging and fragmentation, and thus are highly dependent on intact expanses of forest. Moreover, many forest species are further confined to good quality forest by their choice of roost, particularly those species that depend upon large tree hollows (standing or fallen, and in various states of decay), as the availability of such large trees will be contingent upon the type and prevalence of logging activities. For example, Hipposideros ridleyi is a rare, IUCN red-listed species from Malaysia and Borneo, and is expected to occur in the Malinau area. Ten individuals have been radio-tracked in Krau Wildlife Reserve (Peninsular 
Malaysia), and all have selected large $(>70 \mathrm{~cm}$ dbh) fallen trees with deep hollows $(>5 \mathrm{~m})$ and large entrance dimensions $(0.5 \mathrm{~m} \times 1 \mathrm{~m})$ (C. Fletcher unpubl.). Other species from Borneo that utilize tree hollows in forests and are likely to be at risk from logging practices include: Nycteris tragata, Megaderma spasma, Rhinolophus sedulus, Kerivoula papillosa. Some of these species may adapt to artificial structures (culverts, drains), and many species of Rhinolophidae and Hipposideridae are cave-dependent. However, few forest interior species can commute more than a few kilometres, so their ability to persist in logged or fragmented landscapes will be determined by the distance between the roost or cave refuge and intact forest, and the quality of the intervening habitat.

As a consequence of their ecomorphological specializations and roosting requirements, insectivorous bats of the forest interior are likely to experience a severe decline in diversity as forest habitats are logged and fragmented. A few preliminary studies have found that species diversity in insectivorous bats does indeed decline following logging (Danielsen \& Heegaard 1994; Zubaid 1993), and extensive urbanization in Singapore has reduced bat species from the forest interior to only four, all of which are locally endangered (Pottie 1996).

\section{Cats}

Cats have been little studied in relation to logging in Southeast Asian forests. Santiapillai \& Supraham (1985) speculated that secondary forest may be the preferred habitat of the Leopard Cat Prionailurus bengalensis, but there are no scientifically convincing data to substantiate this. Camera trapping photos (Augeri unpubl.) suggest higher densities of this species in primary versus secondary forests, but statistical analysis is needed to investigate whether the differences are significant.

Rabinowitz et al. (1987) suggested that deforestation is the principal threat to Clouded Leopard (Neofelis nebulosa) in Borneo, but did not discuss the ecological effects of logging. Elsewhere in this report we point out that this species is widely hunted for its teeth and decorative pelt, and for the traditional Asian medicinal trade. Augeri (unpubl.) suggests, based on local interviews, that several Clouded Leopards were hunted each year per village in Malinau. People noted that the species was scarce and difficult to hunt. Nonetheless, there is little evidence that Clouded Leopard populations in Borneo have declined because of hunting, although Schwaner (18531854) remarked that the species had become very rare in the upper Kahayan area (in present-day Central Kalimantan), where it used to be numerous in the past.

Data on the Marbled Cat Pardofelis marmorata, suggest that densities were four times higher in logged forest compared to unlogged forest (Johns 1983). However, sampling in this study was inadequate and observations were opportunistic, resulting in limited data. Thus, the results may be insufficient to draw such conclusions. Augeri (in prep.) found a higher incidence of Marbled Cat sign and photo captures in primary forest than in disturbed and logged forests in the MRF and Kayan Mentarang ecosystems; again, these data require further statistical analysis.

Top carnivores might be expected to benefit from increased herbivore and rodent densities that usually follow selective logging (e.g., Davies et al. 2001; Malcom \& Ray 
2000, but see Wu et al. 1996). Abundant food could boost cat populations, although it is unclear how this is counteracted by their sensitivity to fragmentation and disturbance (see discussion), and the fact that they are often targeted by hunters.

\section{Civets}

Civets form a diverse and prominent group of carnivores in the Old World tropics. Borneo has nine species (Payne et al. 1985). Seven species have been reported at MRF: four direct sightings (Common Palm Civet Paradoxurus hermaphroditus, Masked Palm Civet Paguma larvata, Binturong Arctictis binturong and Banded Civet Hemigalus derbyanus) (O’Brien \& Fimbel 2002) and a further three by camera trapping (Otter-Civet Cynogale bennettii, Banded Linsang Prionodon linsang and Malay Civet (Viverra tangalunga) (Fig. 10) (Augeri unpubl.). An eighth species, Arctogalidia trivirgata, is likely to occur but, being arboreal, is hard to detect.

Although most civets are strictly nocturnal, other aspects of foraging behaviour have undergone considerable adaptive radiation. There are both terrestrial and arboreal species. In addition, despite their taxonomic status within the Carnivora, some civets feed almost exclusively on fruit, generally favouring sugar-rich and soft-pulped fruit (Heydon \& Bulloh 1996; Rabinowitz 1991). As such, civets, and especially the more frugivorous species $P$. hermaphroditus and Arctogalidia trivirgata (Small-toothed Palm Civet) may be important seed dispersers (Medway 1978; Payne 1995).

In Sabah, Heydon and Bulloh (1996) recorded a marked decrease in civet density from 31.5 individuals $/ \mathrm{km}^{2}$ in unlogged forest to 6.4 individuals $/ \mathrm{km}^{2}$ in logged forests. Predominantly carnivorous species, mainly feeding on invertebrates,

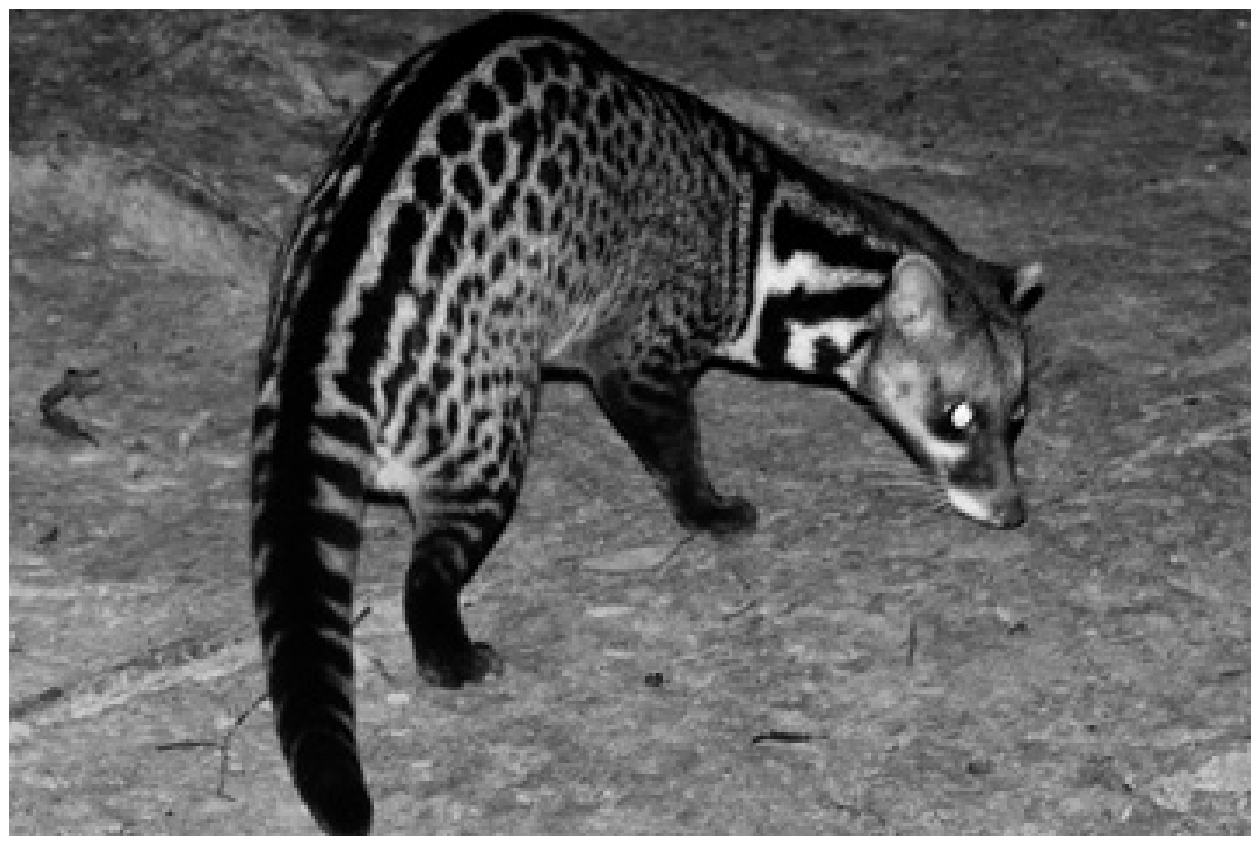

Figure 10. Malay Civet (Viverra tangalunga), one of the Bornean civet species that are negatively affected by the effects of timber harvest. (Photo by Kimabajo) 
were reduced in greater extent than palm civets, which incorporate larger quantities of fruit into their diet. In Peninsular Malaysia, Johns (1983) recorded civets as being extremely scarce in unlogged forest. Immediately following the onset of logging, however, several additional species of civet moved into the area. Densities of 8 individuals $/ \mathrm{km}^{2}$ were recorded 12 years post logging. A similar result was reported by Syakirah et al. (2000), who recorded the Malay Civet Viverra tangalunga only in recently logged forest, but not in forest logged over 20 years previously, while Stuebing and Gasis (1989) found Paradoxurus hermaphroditus in plantation areas but not in logged forest. In contrast with the previous results and some of Heyden and Bulloh's (1996) observations, Colón (1999) found in a two-year study that densities of $V$. tangalunga were $57 \%$ higher in an unlogged site than in a logged one; also, fruit comprised a larger proportion of the diet in unlogged forest compared to logged forest. The small-toothed palm civet Arctogalidia trivirgata was only found in regenerated and unlogged forest, but not in recently logged forest (Syakirah et al. 2000). Augeri (unpubl.) found that $V$. tangalunga was at least $50 \%$ more common in primary forest than in secondary or disturbed areas in the MRF and Kayan Mentarang. Binturong (Arctictis binturong) was also more common in primary forest, as was the Banded Linsang (Prionodon linsang) and the Banded Palm Civet (Hemigalus derbyanus). Table 8 summarizes civet population trends in relation to logging.

Table 8. Civets and their response to logging.

\begin{tabular}{|c|c|c|c|}
\hline Species & Ecological stratification & $\begin{array}{l}\text { Density trend } \\
\text { after logging }\end{array}$ & References \\
\hline \multirow{2}{*}{$\begin{array}{l}\text { Paradoxurus } \\
\text { hermaphroditus }\end{array}$} & \multirow{2}{*}{$\begin{array}{l}\text { Arboreal and terrestrial. } \\
\text { Feeds primarily on fruit }\end{array}$} & $\downarrow$ & (Heydon \& Bulloh 1996) \\
\hline & & $\uparrow$ & (Stuebing \& Gasis 1989) \\
\hline \multirow[t]{2}{*}{ Arctogalidia trivirgata } & \multirow{2}{*}{$\begin{array}{l}\text { Arboreal. Feeds primarily } \\
\text { on fruit }\end{array}$} & - & (Heydon \& Bulloh 1996) \\
\hline & & $\downarrow$ & (Syakirah et al. 2000) \\
\hline Arctictis binturong & $\begin{array}{l}\text { Arboreal. Feeds primarily } \\
\text { on fruit }\end{array}$ & - & (Heydon \& Bulloh 1996) \\
\hline Paguma larvata & $\begin{array}{l}\text { Arboreal and terrestrial. } \\
\text { Probably feeds on insects } \\
\text { and fruit }\end{array}$ & $\begin{array}{l}\text { Insufficient } \\
\text { information } \\
\text { available }\end{array}$ & (Heydon \& Bulloh 1996) \\
\hline Hemigalus derbyanus & Terrestrial. Carnivorous & $\downarrow$ & (Heydon \& Bulloh 1996) \\
\hline Cynogale bennettii & $\begin{array}{l}\text { Terrestrial/aquatic. } \\
\text { Carnivorous }\end{array}$ & $\begin{array}{l}\text { Insufficient } \\
\text { information } \\
\text { available }\end{array}$ & (Heydon \& Bulloh 1996) \\
\hline \multirow[t]{4}{*}{ Viverra tangalunga } & \multirow{4}{*}{$\begin{array}{l}\text { Terrestrial. Feeds on } \\
\text { insects, vertebrates and } \\
\text { fruit }\end{array}$} & $\downarrow$ & (Heydon \& Bulloh 1996) \\
\hline & & $\downarrow$ & (Colón 1999) \\
\hline & & $\downarrow$ & (Augeri unpubl.) \\
\hline & & $\uparrow$ & (Syakirah et al.2000) \\
\hline Prionodon linsang & $\begin{array}{l}\text { Arboreal and terrestrial. } \\
\text { Carnivorous }\end{array}$ & $\downarrow$ & (Heydon \& Bulloh 1996) \\
\hline
\end{tabular}

$\uparrow=$ increase in density after logging; $\downarrow=$ decrease in density or absent from recently logged areas; $-=$ no significant difference. Information on ecological stratification was obtained from Heydon and Bulloh (1996) and Payne et al. (1985). 
Data in Table 8 suggest that arboreal, frugivorous civets are less affected by logging, probably dependent on the degree to which fruit availability changes. Terrestrial species that are carnivorous or feed on insects are more sensitive. An explanation for the decline in the latter group is not straightforward. Colón (1999) did not find a decline in the availability of invertebrates in logged forest. As suggested above the reduced fruit availability was the cause of its decline after logging. This appears to be in contrast to the increased densities of other frugivorous civets (see Table 8). Logging possibly leads to increased competition for fruit, in which $V$. tangalunga loses out to other species.

\section{Malayan sun bear}

Sun Bears (Ursus (Helarctos) malayanus) need further study and evaluation (Servheen 1999). Apart from a scattering of small investigations, only four significant field research studies have focused on wild Sun Bears, while another study looked into Sun Bear trade and other threats (Meijaard 1999a, 2001a). Wong (2002) and Wong et al. (2004) examined basic ecology in the Danum Valley, Sabah; Nomura (2003) looked at oil palm plantation use, also in Sabah; Fredriksson (2001) examined the use of burned forest and feeding ecology at Sungai Wain, East Kalimantan; while Augeri (2003) studied the effects of logging, habitat fragmentation and human disturbances on Sun Bear ecology and habitat use in East Kalimantan (including Malinau) and in northern Sumatra. A fifth study on Sun Bear and Asiatic Black Bear sympatric habitat use is being conducted in Thailand (Steinmetz in prep.). In Indonesia the main threats to Sun Bears are habitat loss and people (Augeri 2001, 2003; MacKinnon et al. 1996; Santiapillai \& Santiapillai 1996; Servheen et al. 1999; Whitten et al. 1987).

Fruit availability and diversity are highly important for Sun Bear nutritional stability. Wong (2002) suggested that the poor physical condition and mortality of some bears observed in his study resulted from a prolonged scarcity of fruit. Fredriksson (2001) suspected similar nutritional deficiencies and proposed that Sun Bears accumulate fat reserves during mast-fruiting events to sustain themselves during the extended intermast intervals, such as during the prolonged period of extreme fruit lows and drought following the masting event in 1997-1998 (see also Fredriksson \&Wich in prep.). During this period, however, key non-masting fruit species (particularly figs) were disrupted and provided little fruit (Harrison 2001), possibly affecting bears (Fredriksson \& Wich in prep.). Insects, their other main food resource outside mast periods, also seemed reduced (Fredriksson pers. obs.). Where alternative food was available, such as near an oil palm plantation in Sabah, and in large contiguous primary forests like the Kayan Mentarang and Gunung Leuser National Parks, bears were in good condition through the 1997-1998 droughts and beyond (Augeri 2002; Nomura 2003; Leuser Management Unit unpubl.; Wulfraat pers. obs.).

When fruit availability is low, species like Sun Bears, with a high percentage of fruit in their diet, depend on other food sources, especially in small forests where key food resources may be less diverse or abundant, obliging bears to rely on forage 
outside the forest boundary (Augeri 2004a; Wulfraat pers. obs.). In contrast, large contiguous primary forests maintain more stable micro-climatic conditions and availability of more diverse and abundant forage resources across the landscape.

Augeri (2002, 2003), Fredriksson (2001) and Wong (2002) all observed that alternative foods, such as above-ground termite colonies, beetles, bee hives and ants are important foraging resources for Sun Bears, but Augeri $(2002,2003)$ found these to be less abundant in young, newly logged areas. Fredriksson (pers. obs.) also found lower densities of stingless bees and above-ground termite colonies in recently logged areas, but she noted that below-ground termite colonies are a major food source for bears. Less than $20 \%$ of termites consumed by Sun Bears in Fredriksson's study in East Kalimantan were from visible termite mounds (Fredriksson, in litt., 31 August 2004). However, the effect of logging on the density of below-ground species also appears to be negative, causing a decline in abundance at higher levels of disturbance (Jones et al. 2003).

Augeri (2003) noted significantly higher bear habitat use in older, more heterogeneous primary forests. Overall he found significant positive relationships between habitat use and higher levels of forage diversity, canopy cover, ground cover, escape cover and the predominance of large mature fruiting trees. In the Malinau and Kayan Mentarang ecosystems the latter trees primarily consisted of Dipterocarpaceae, Euphorbiaceae, Fagaceae, Lauraceae, Moraceae, Myrtaceae and Sapindaceae $>40-45$ $\mathrm{cm}$ dbh.

Some workers suggest bears may be active relatively close to disturbances. For example, no significant differences were found in sign densities between logged and unlogged areas in the PT Daisy logging concession in Berau, East Kalimantan (Eames et al. 2001); however, bear activity relative to forest age and logging intensity was not clear. Furthermore, a high density of large strangling fig trees (an important resource for Sun Bears) was retained in the logged areas.

Forest age and the timing and intensity of disturbance are important factors when considering Sun Bear activity in disturbed forests. Augeri (2004a) found that $>98 \%$ of all observed bear signs were generated either before, or were not created on average until $>8-10$ years after, low to moderate levels of logging. Results indicated that bears used primary forests significantly more than disturbed areas or homogenous/young secondary forests $(\mathrm{P}<0.00001)$. Habitat use by bears was also significantly greater as distance from disturbance increased, and it did not approach consistent levels until 3-4 km from heavily disturbed areas. Some bears occasionally used post-disturbed primary and secondary forests, but mainly in regenerated forests $>15-20$ years old with substantive food productivity, minimal or no habitat disturbance over the previous 10 years, and no or low levels of human activity. Bear activity was not observed or reported in areas with ongoing logging or clearance. Although food is of primary importance, results showed that logging, agriculture and persistent human activity were the most statistically significant factors negatively associated with habitat use (Augeri 2002, 2003, 2004a).

Current data indicate that various logging practices can notably affect Sun Bear habitat use, foraging patterns and persistence, particularly in small or isolated forest patches and reserves. Forest clearing can play an important and sometimes 
dominant role in the ecological dynamics of interior forest and edge communities, particularly in small forest 'island' reserves and those with a substantial edge-area ratio (e.g., Laurance \& Bierregaard 1997; Lovejoy et al. 1986). This can affect Sun Bears by a) preventing access to productive forage areas; b) reducing the diversity and abundance of key resources; c) intensifying or creating drought effects and altering fruit productivity, availability, and distribution at local and regional levels; and $\mathrm{d}$ ) increasing access for hunters (Augeri 2003).

Of those undisturbed primary forests avoided or minimally used by Sun Bears in East Kalimantan and northern Sumatra, $>80 \%$ had persistent human activity, primarily in the form of hunting, non-timber forest product gathering, timber cruising or research (Augeri 2003). In primary forest, Augeri (2003) found that bears appeared more sensitive and avoided minor human activity and habitat disturbances (e.g., gaharu harvesting) to a more significant degree, where the highest abundances were observed in more remote locations with minimal to no human activity (Augeri 2004a). Of the surveyed areas avoided or minimally used by Sun Bears in Malinau and Kayan Mentarang National Park, 90\% and 80\% respectively were subject to persistent human activity.

Stochastic events leading to local food shortages for bears can be exacerbated by logging, forest loss, fire and other disturbances (Augeri 2004a; Mattson et al 1996; Merrill et al. 1999). This is particularly true in smaller forest patches or reserves. In large contiguous tracts of primary forest, even stochastic events like the absence of mast fruiting over a long period would not create as significant an effect as in smaller forest reserves subject to disturbance (see Augeri 2004a; Bierregaard et al. 2001; Wulfraat pers. obs.).

Conflicts with humans, hunting and illegal commerce of bears and bear parts are also prominent factors threatening Sun Bear survival, particularly in mainland Asia (Mills \& Servheen 1994). Augeri (unpubl.) conducted interviews with regional and village heads and traditional leaders (kepala adat) in the Malinau and Kayan Mentarang areas regarding Sun Bears killed by hunters. Results indicated that between 2000 and 2003, an average of 10-20 Sun Bears were taken per village per year for medicine and ornaments. Village leaders also stated that more bears are hunted, taken for the pet trade, or are killed as perceived pests, but these bears are not accounted for. Such off-take levels are very high in comparison with other hunting studies in Borneo (e.g. Fredriksson \& Wich in press; Puri 1997; Wadley et al. 1997), which may indicate that there is an increasing market for bears and bear parts. If this level of hunting represents average take across the region, it amounts to hundreds of bears per year. With increased access to and influence from outside markets and exports, such hunting pressure can result in significant declines in this species (Servheen 1999). Studies in seven local communities in Malinau show that bears (gall bladders, claws and skins) are considered important both culturally and as trade items, and the meat is sometimes eaten (Sheil et al. in prep.). Bears are amongst the most locally feared species and some local people claim that if they see them while out hunting for other species, they prefer to kill them (Sheil pers. obs.). The decline of bear populations from hunting and habitat loss in Malaysian Borneo and mainland Southeast Asia may also provoke a shift in demand to Indonesian Sun Bear 
populations for live bears for pets along with bear gall bladders and other body parts for Asian medicines and cosmetics (Augeri 2004a; Meijaard 2001a). Despite the Sun Bear's legal protection internationally as well as in Indonesia and Malaysia, hunting and commerce are increasingly significant threats to its survival.

\section{Forest ungulates}

There is very little information on the ecology of forest ungulates and their responses to logging. Long-term studies are especially scarce. However, it is important to study the effects of logging on ungulate populations as they are: (1) important sources of protein for local communities, (2) integral to various ecosystem processes, and (3) major determinants of forest vegetation structure and composition (Davies et al. 2001). There are two distinct groups of small forest ungulates found in eastern Borneo: mouse-deer (genus Tragulus), and muntjacs (genus Muntiacus). Additionally, there are three larger species: Sambar (Cervus unicolor), Bearded Pig (Sus barbatus), and Banteng (Bos javanicus).

Muntiacus and Tragulus genera are represented by two sympatric species in each genus: Tragulus javanicus (note that this species was renamed T. kanchil by Meijaard \& Groves 2004) and T. napu (the Lesser and Greater Mouse-Deer, respectively) and Muntiacus atherodes and M. muntjak (the Yellow and Red Muntjac, respectively). Currently, distinctions between these species are primarily limited to morphological differences (Groves \& Grubb 1982; Meijaard \& Groves 2004). Payne et al. (1985) and Augeri (in prep.) reported altitudinal range differences within both the

Table 9. Changes in cervid and tragulid densities after selective logging.

\begin{tabular}{|c|c|c|c|c|}
\hline Species & $\begin{array}{l}\text { Body size } \\
(\mathbf{k g})\end{array}$ & Ecological stratification & $\begin{array}{l}\text { Density } \\
\text { trend after } \\
\text { logging }\end{array}$ & References \\
\hline \multirow[t]{2}{*}{ Cervus unicolor } & \multirow[t]{2}{*}{100} & \multirow[t]{2}{*}{ Terrestrial herbivore } & $\uparrow \uparrow$ & (Heydon 1994) \\
\hline & & & - & (Rijksen 1978) \\
\hline $\begin{array}{l}\text { Muntiacus } \\
\text { atherodes }\end{array}$ & 15 & $\begin{array}{l}\text { Terrestrial, mainly } \\
\text { frugivorous }\end{array}$ & $\downarrow$ & (Heydon 1994) \\
\hline \multirow{2}{*}{$\begin{array}{l}\text { Muntiacus } \\
\text { muntjak }\end{array}$} & \multirow[t]{2}{*}{20} & \multirow{2}{*}{$\begin{array}{l}\text { Terrestrial, mainly } \\
\text { frugivorous }\end{array}$} & $\uparrow \uparrow$ & (Heydon 1994) \\
\hline & & & $\uparrow$ & (Duff et al. 1984) \\
\hline Tragulus napu & 4 & $\begin{array}{l}\text { Terrestrial, mainly } \\
\text { frugivorous }\end{array}$ & $\downarrow \downarrow$ & (Heydon 1994) \\
\hline Tragulus kanchil & 2 & $\begin{array}{l}\text { Terrestrial, mainly } \\
\text { frugivorous }\end{array}$ & $\downarrow \downarrow$ & (Heydon 1994) \\
\hline \multirow[t]{3}{*}{ Sus barbatus } & \multirow[t]{3}{*}{125} & \multirow[t]{3}{*}{ Omnivorous } & - & (Davies et al. 2001) \\
\hline & & & - & (Linkie \& Sadikin 2003) \\
\hline & & & $\downarrow^{*}$ & (Wilson \& Johns 1982) \\
\hline
\end{tabular}

$-=<20 \%$ difference between mean density in logged and primary forests; $\uparrow / \downarrow=$ increase/ decrease of 20 to $60 \%$ between logged and primary forests; $\uparrow \uparrow / \downarrow \downarrow=$ increase/decrease of $>60 \%$ between logged and primary forests. *Effect ascribed to hunting. 
Muntiacus and Tragulus genera. Niche separation, however, has not been adequately investigated for either genus. $M$. atherodes may be a lowland specialist, whereas $M$. muntjak is more common at higher altitudes (Augeri unpubl.; Payne et al. 1985). This was also indicated by hunting trophies found by Hedges and Meijaard (1999) in several villages in the upper Bahau River area (altitude ca. $350 \mathrm{~m}$ asl) in the Kayan Mentarang National Park. They found 105 M. muntjak skulls as opposed to six of $M$. atherodes. Whether altitude was the key determinant of this difference is unclear. The foot morphology of the two mouse-deer species may suggest a preference of T. napu for more swampy habitats (Chasen 1940; Smit-van Dort 1989). This was corroborated by Duckworth (1997a) and Bennett (pers. comm. in Duckworth 1997a) who suggested that T. javanicus occurs primarily in hilly areas.

Ungulates can be categorized by general feeding behaviour and habitat selection. Both species of mouse-deer are especially dependent upon the fallen fruit of strangling figs (Ficus spp.) (Heydon \& Bulloh 1997), although they also feed on other items, such as leaves (e.g., Octomeles sumatrana) or mushrooms (Russula sp.) (Matsubayashi et al. 2003). Of all the Bornean ungulates, mouse-deer appear to utilize the most nutrient-rich food items. The two species of muntjac feed primarily on fruits and browse, being selective for plant parts, and remain within one or a few vegetation types throughout the year. Sambar deer are found throughout the forests of South and Southeast Asia. They occur in forest edges, riverbanks, grassy clearings, secondary scrub and open farmlands (Nowak 1999), but they are also common in both open and dense interior forest. Sambar deer are generalist grazers and browsers that feed on a range of grasses and plant parts.

The intensity of logging that can be tolerated by small forest ungulates depends upon the extent to which they need a mix of fruit, forest and non-forest plants. Johns (1997) found Tragulus to be more common in logged forests than in mature forests in Peninsular Malaysia. Densities tended to decrease again in older logged forests. However, in Sabah, Heydon (1994) and Davies et al. (2001) reported an average decrease of $55-66 \%$ in the density of T. javanicus and a 71-90\% decrease in the density of T. napu in selectively logged forest compared to unlogged forest (Table 9). Augeri's camera trapping data (unpubl.) similarly suggest that both Tragulus species have densities in secondary forests that are ca. 65\% lower than in primary forest.

Heydon (1994) found that mouse-deer densities are positively correlated with fruit abundance and suggested that their near-obligate frugivory limited their ability to compensate for declines in fruit availability. However, the apparent ecological adaptability of mouse-deer was observed by Laidlaw (2000), who regularly encountered Tragulus spp. (not identified to species level) in tree plantations and bushland in Peninsular Malaysia. In addition, Duckworth (pers. obs.) noted that in Indochina, T. javanicus appears to be a species of the forest edge rather than the forest interior. T. javanicus' utilization of disturbed habitats was confirmed by Matsubayashi et al. (2003) in Sabah, who found they feed primarily in tree-fall gaps and areas dominated by bamboo, probably because they prefer fruits and foliage of pioneer plants that occur in areas with bamboo. For frugivorous animals these tree-fall gaps are good foraging sites because some gap species produce fruit several times a year, whereas most climax species in mature forest produce fruit once a year or less (Whitmore 
1998). On the other hand, Matsubayashi et al. (2003) found that T. javanicus rested during the night on open forest floors without undergrowth, probably to enable them to spot predators more effectively (during daylight hours animals rested primarily in shelters such as fallen tree trunks or branches). Open forest floors and an abundance of hollow, fallen trees occur frequently in primary forests.

The Yellow Muntjac is usually more common than the Red Muntjac in unlogged forest (although this may also depend on altitude). Heydon (1994) found an increase in Red Muntjac in logged forests and a concurrent decrease in Yellow Muntjac (Table 9). Duff and colleagues (1984) also reported an increase in the frequency of Red Muntjac sightings in logged forests compared to unlogged forests. The Red Muntjac appears to include a higher proportion of browse within its diet than does the Yellow Muntjac (or either of the two species of mouse-deer) (Barrette 1977), which may explain its higher viability in logged forests.

Grazers are generally neither dependent upon undisturbed forests nor negatively affected by logging (Davies et al. 2001). Sambar makes use of logging roads to feed on roadside grasses; it appears that they use such roads as alternative forage areas and as corridors between favourable forest sites, including logged areas. Their numbers are positively correlated with the area of severely degraded forest and negatively associated with the area of primary forest (Table 9) (Heydon 1994). Rijksen (1978) also noted that Sambar are more common in secondary vegetation than in undisturbed forest, but they appear to avoid areas that are under logging, possibly because of the human presence and hunting. Sign and camera trapping surveys in the Leuser Ecosystem (Sumatra), the MRF, and the Kayan Mentarang National Park (East Kalimantan) concur with Rijksen that Sambar are uncommon in disturbed areas $<5$ years old and indicate that, while Sambar show a high occurrence in primary forest, they appear to occur in slightly higher frequencies in older and more open secondary forest (Augeri 2003). However, statistical analyses show the difference in relative occurrence between undisturbed and secondary forest is insignificant (Augeri 2004). Local people also report that Sambar is less affected by logging than many food species and is the main species killed in degraded areas (Sheil pers. obs.). Sambar therefore appears to be a species that benefits from timber harvest, although hunting of this protected species potentially outweighs these positive effects.

Maintaining Bearded Pig (Sus barbatus) populations is important for the wellbeing of many local communities. Bearded Pigs constitute between 50 and 75\% of the total weight of animals hunted in Borneo (e.g., Caldecott 1988; Puri 1997; Bennett et al. 1999), and as a principle source of animal protein and fat are a critical nutritional and economic product in the livelihood and culture of many peoples living throughout the island. In Malinau, meat from domestic pigs is considerably less popular than that of wild Bearded Pigs for indigenous people, logging employees and newly arrived migrants alike (Ndan 2003). In the Malinau area, local people perceived a decline in most forest ungulates, especially Bearded Pigs (Sheil et al. 2003c), while similar trends were found in the adjacent Kayan Mentarang National Park (Meijaard 2003a).

MacKinnon et al. (1996) suggested that Bearded Pigs are important seed dispersers that, for instance, play a role in the dispersal of Rafflesia plants. Pigs are also 
thought to assist in dispersal of durian (Durio spp.) seeds by feeding on fallen fruit and dispersing the undigested seeds through their faeces, although Setyawati pointed out that these seeds are probably too large to pass undamaged through the pig's gut. Faecal analysis by Setyawati (unpubl.) and stomach contents analysis by Meijaard and Wulffraat (unpubl.) also suggest that most large seeds are cracked before being swallowed, making effective dispersal of large seeds by pigs unlikely.

Curran and Webb (2000) and Curran and Leighton (2000) investigated mastfruiting Dipterocarpaceae, their seed and seedling survival and the vertebrate response to seed survival. Bearded Pigs were the most important seed predators. In the 1986 minor mast-fruiting event, 21 dipterocarp species that produced 60,000 seeds/ha lost all monitored viable seeds to a diversity of resident and nomadic vertebrates, including Bearded Pigs (Curran \& Leighton 2000). However, in both the 1987 and the 1991 mast events, resident vertebrates fed on only a small portion of the seed production. Nomadic vertebrates arrived late in the fruit fall period during both major mast events and thus, were able to feed only on seed dispersed in the final one to three weeks of fruit fall. Seed escape, and thus regeneration, only occurred in major mast events when all dipterocarp species across large areas participated. Based on limited knowledge of Bearded Pig ecology it can be inferred that logging impacts on major fruiting crops can affect their migratory patterns, distributions and possibly densities, thereby influencing dispersal and regeneration of other fruiting species.

Although Banteng (Bos javanicus) were not reported during the Malinau biodiversity surveys (see O’Brien \& Fimbel 1999), Hedges and Meijaard (1999) found evidence of Banteng populations further west around the Bahau River, an area that includes some extensive grasslands. Hoogerwerf (1938 in Brookfield 1997) suggested that grasslands, savannas and secondary forests are the favoured Banteng habitats rather than rainforest. This was also reported by Banks (1931), who claimed that Banteng depend on forest areas that were cleared for agriculture, as they feed in secondary forest and on agricultural fields, and that dense forest areas are of little use to this species. Wharton (1968) made similar claims. Because Banteng are sometimes found in the vicinity of agricultural fields and forest gardens, where they destroy crops, they are occasionally hunted as pests, for instance by Kenyah people in the upper Bahau River area. In East Kalimantan and Sarawak, there is also a demand for Banteng trophies (Hedges \& Meijaard 1999). Banteng appears to benefit from forest gaps and clearing, except when high hunting pressure limits populations.

In general, the changing abundance of ungulate species may be determined mainly by hunting. Such impacts are well studied in Sarawak (e.g., Bennett et al. 1999; Bennett \& Robinson 2000; Robinson et al. 1999). Thus, even if logging benefits grazers by increasing the amount of food plants, the improved accessibility of these areas (logging roads and tracks) can result in higher hunting pressure. 



\section{Amphibians and reptiles}

Amphibians reach their highest diversity in the tropical forests of the world, and represent a significant portion of the vertebrate fauna of tropical forests. They are important components of tropical food webs, where they are probably the principal terrestrial insectivores (Reagan \& Waide 1996). Yet the ecology of this component of Southeast Asian rainforests has been dealt with in only relatively few papers. An even lower number have specifically studied the response of the herpetofauna to logging (e.g., Iskandar 1999a; Iskandar \& Setyanto 1999; see also Iskandar \& Colijn 2000, for species listing).

\section{Frogs and toads}

Amphibians, and especially tropical forest amphibians, appear to be in dramatic global decline due to a range of factors including habitat loss, climate change and disease (e.g., Daszak et al. 2001), although unidentified processes are estimated to threaten $48 \%$ of rapidly declining species, and are driving species most quickly to extinction (Stuart et al. 2004). Declines are non-random in terms of species' ecological preferences, geographic ranges and taxonomic associations. The lack of conservation remedies for these poorly understood declines means that hundreds of amphibian species now face extinction (Stuart et al. 2004).

Frogs and toads (known as anurans) display a large diversity of reproductive modes with complex life cycles that include a larvae (tadpoles) requiring different habitats and resources than the adults (e.g., Inger \& Voris 2001). Streams and ponds provide microhabitats for anurans and most anurans require aquatic habitats for reproduction. Frog species that rely on water held in plants and tree holes will be heavily impacted by the direct loss of these sites. During development and metamorphosis, larval anurans are sensitive to changes in water chemistry and physical characteristics of aquatic habitats. 
At a global level, many species of amphibians carry out their entire life cycles in leaf litter, including deposition of terrestrial eggs that undergo direct development. In Borneo this occurs in only 12 out of a total of 142 known species (Inger, in litt., 8 October 2003). Other species inhabit the lower canopy only, using water holding plants (mainly vines and tree hollows) and substrates for egg deposition and tadpole development. Anurans appear sensitive to various aspects of habitat quality because to complete their life cycles they often require a variety of specialised resources in a specified order.

Forty species of amphibians were identified at MRF, 36 of which were either seen or collected, while four more were reported by local people (Iskandar 2004); the species are listed in Appendix 6. Two assemblages_riparian and non-riparian-can be differentiated. Of the 40 identified species in Malinau, 24 are riparian breeders and 16 are pond breeders, although Inger (pers. obs.) suggested that this distinction is not always clear-cut. Most riparian species breed and feed along streams and are thus fully restricted to this environment. The other species breed in streams or in rock pools at the sides of streams, but spread widely through the forest and apparently spend their adult lives away from flowing water. Among the non-riparian frogs, the majority require pools or ponds to lay their eggs. Four species require tree holes and three require swamps or seepages. Philautus species in Borneo typically lay their eggs directly on the forest floor, omitting an aquatic larval stage. No species of this genus have yet been identified in Malinau, although Philautus hosii was found in nonriparian forest of a reduced impact logging area in the Ulu Segama Forest Reserve ca. $150 \mathrm{~km}$ north of Malinau (Wong in press a, b).

Adult anurans are generally opportunistic in their feeding with little specialization. Most feed on a variety of non-aquatic invertebrates and overlap between diets is extensive. Some species may specialise on ants (e.g., Microhylidae, Das 1996; Bufonidae, Inger 1969 and Wong in press a) and there may be some correlation between the size of the frog and the size of the prey consumed (Inger 1969), which might reduce competition between species of different sizes.

Stream environments furnish frog larvae with a variety of habitats, which can be arranged in a graded series according to current. At the swift end of the scale are stretches of strong rapids where the bottom is formed of large boulders and bedrock. At the slow end, pockets of still water occur where banks have been undercut or root masses project into the stream. Gravel bars often isolate pools from the main stream after a few days without rain.

Riparian species of tadpoles are not uniformly distributed among stream habitats. Stream width and gradient have a significant effect upon communities (Inger $\&$ Voris 1993). An extreme example of the effect of stream gradient was found by Inger and Voris (1993), where a stream with a silt bottom and completely lacking riffles and torrents lacked all the species known to breed in clear, turbulent water, which was roughly half their sample. Thus, runoff and siltation from logging (e.g., Douglas et al. 1992, 1993) will likely impact these clear water species.

Stream tadpole communities have two more-or-less consistent characteristics: certain taxa consistently co-occur together and different assemblages occur in differing microhabitats. There are also indications of stability in species composition 
within sites over periods longer than 1 year (Inger et al. 1986), and Inger and Voris (1993) gave evidence of stability over a 22-year period. These trends in organisation appear to be mediated by three factors:

1) Reproductive behaviour of adults: Egg-laying behaviour determines the range of possible habitats in which tadpoles of a particular species may be found. At the coarsest level, females may oviposit in streams or in the forest at some distance from a stream. Three of the four larval forms of Microhyla identified at MRF are found in small pools on the forest floor (Inger 1985).

2) Responses of morphotypes to physical conditions: Tadpoles are specialised for the physical structure and environmental conditions of the habitats in which they live. There are several clear examples, among them larval Ansonia albomaculata, which have streamlined bodies and expanded suctorial lips (Inger 1985). Larval Meristogenys have abdominal suckers enabling them to cling to rocks and maintain position in strong currents (Inger et al. 1986). Probably none of these suctorial devices function well in the silty substrates that might occur as a result of the higher runoff documented in forests after logging, limiting the occurrence of larval $A$. albomaculata. The slender body of Leptobrachella mjobergi larvae allows them to wriggle into crevices and avoid the force of the current in riffles and torrents (Inger 1983). The spheroidal bodies and deep tail fins of Bufo divergens and Rhacophorus pardalis are confined to areas of weak or no current (Inger 1985). To the extent that morphology restricts distribution, variation among types of microhabitats in average current conditions leads to association of some larval forms.

3) Methods of feeding: Five feeding types can be recognised among tadpoles (Inger 1986): obligate benthic, generalist, macrophagous, midwater suspension feeding, and particulate surface film feeding. Among the species identified at MRF, Ansonia albomaculata uses the first mode, Bufo divergens and Rana chalconota the second, Leptobrachium abbotti the third, Microhyla borneensis the fourth, and Megophrys nasuta the fifth. Each species of tadpole functions best within a limited range of habitats.

There is an indication of more time and space specialists among non-riparian amphibians than among the streamside species (but see Inger 1969). Borneo's watercourses are characterised by occasional violent floods. All species inhabiting this habitat need to be able to endure rapid increases in flow rates_-such adaptations may limit niche opportunities. Diversity in the non-riparian assemblage is much higher than in the riparian one. Species show relatively few resource-sharing habits, reflecting greater specialization in the use of time and space in the more stable nonriparian environments (Das 1996).

Logging may directly and indirectly affect anurans through its impact upon ponds and streams in the immediate vicinity of logging operations, on watersheds throughout the area, and on microhabitat conditions in the forest leaf litter in nonriparian habitats. Research in Sabah showed that destruction of the lower vegetation and destruction of the floor litter leads to extreme levels of erosion during rains with 
enormous increase in sedimentation levels in streams. Selective logging increased sediment loads in nearby streams 18 -fold within five months after logging, while a year after logging monthly sediment yields were still four times those of undisturbed catchments; water chemistry also changed considerably after logging (Douglas et al. 1992, 1993). Changes in nutrient composition, $\mathrm{pH}$ levels and temperature may lead to malformations and death among larval anurans (Feder \& Burggren 1992; Ouellet et al. 1997). Sedimentation has a clear, detrimental effect on reproduction in several species of stream-breeding frogs, effectively preventing survival of tadpoles (Inger, in litt., 3 October 2003).

Wong (in press a) studied environmental factors in tropical forests in Sabah in relation to species composition in frog communities. She found that the factors that can significantly affect frog communities were conductivity and $\mathrm{pH}$ of stream water, temperature and humidity of non-riparian forest, and forest structure. Additionally, the availability of food resources (e.g., density of insects) was positively correlated with frog species richness, but the correlation was weak and not significant (Wong in press $a, b)$.

Virtually all leaf litter anurans depend upon the constant diversity of the leaf litter microhabitat for predator escape, nesting, protection from desiccation and invertebrate prey (Scott 1976; Vitt \& Caldwell 1994, 2001). Canopy opening drastically affects the ground level forest environment (e.g., incident light, temperature, humidity and rates of litter accumulation). The removal or change in quality of the leaf litter directly and indirectly affects anurans (Zou et al. 1995). The greatest diversity of leaf litter arthropods in Amazonia was in the mature forest (Vitt \& Caldwell 1994). The effect of variation in leaf litter arthropods-the primary food of leaf litter anurans - on anuran growth and reproduction on anurans is virtually unstudied in the tropics (see Vitt \& Caldwell 1994).

Evidence for negative effects of logging and related changes in the leaf litter was provided by Iskandar (1999a, b), who studied this in North Sumatra. He found that logged forests contained only about $20 \%$ of the individuals found in an unlogged forest of the same area. Their abundance was strongly correlated with the amount of forest litter. As opposed to these findings, Iskandar (2004) reported that in a part of the MRF where logging was performed in 1995-1996, the relative abundance of amphibians and reptiles was about 2.1 specimens per plot $(n=21)$, but in unlogged forest the relative abundance was only about 0.95 specimen per plot $(n=51)$. At present, we have no explanation as to why the unlogged area had fewer specimens compared to other areas affected by logging, although the species composition in these areas is more or less the same. Possible explanations could be a) unobserved habitat differences; b) relative forest age; and c) the fact that both the reduced impact logging and conventional logging plots in Malinau still had more or less closed canopy forest, and that the difference between these plots and unlogged forest was small. In the North Sumatran study mentioned above, every large tree had been cut in the logged areas. Severe desiccation associated with the El Niño droughts may also have accentuated differences in ground exposure. No such droughts struck in Malinau.

One of the more striking findings of the research by Iskandar (2004) and colleagues was that most of the Limnonectes species collected were either juveniles 
or young adults. Among 57 specimens, only five were close to maximum size (four Limnonectes leporinus (see Fig. 11) and one L. ibanorum). Iskandar inquired about the local use of these two species, but apparently the local people only collect them occasionally, so there is no real collection pressure. The possibility that they were indirectly poisoned by local fishing activities remains unknown. The forest and rivers of the associated areas were little damaged, and the use of poison for fishing is not locally prevalent.

Similar to Iskandar, Wong (in press a), who studied the effects of timber harvest on amphibians between March 2000 and July 2003, also found that selective logging had little impact on frog communities (Fig. 12). Data from her study sites in Sabah in an unlogged forest, a reduced impact logging (RIL) area, and a conventionally logged (CL) area (both RIL and CL were logged in 1993), suggested that selectively logged areas had more frog species $(n=33)$ than her unlogged control plots $(n=26)$, but that a conventionally logged area had fewer species $(n=23)$ (Fig. 12). The high number of frog species in the reduced impact logging area was due to the availability of more microhabitats (e.g., logging creates depressions that are suitable for pond breeders). This attracted frog species that are not normally found in primary forest (e.g., Rhacophorus pardalis, Polypedates colletti, P. macrotis, Leptobrachium montanum, Rana nicobariensis and $R$. signata). In addition, several of the RIL only species are pond breeders: Polypedates colletti, P. macrotis, Rhacophorus dulitensis, Rh. nigropalmatus and $R h$. pardalis. From the species composition it appeared that reduced impact logging attracted disturbance-tolerant species, while also maintaining most species of primary and 30-year-old logged forest. Wong's study tentatively concluded that few species

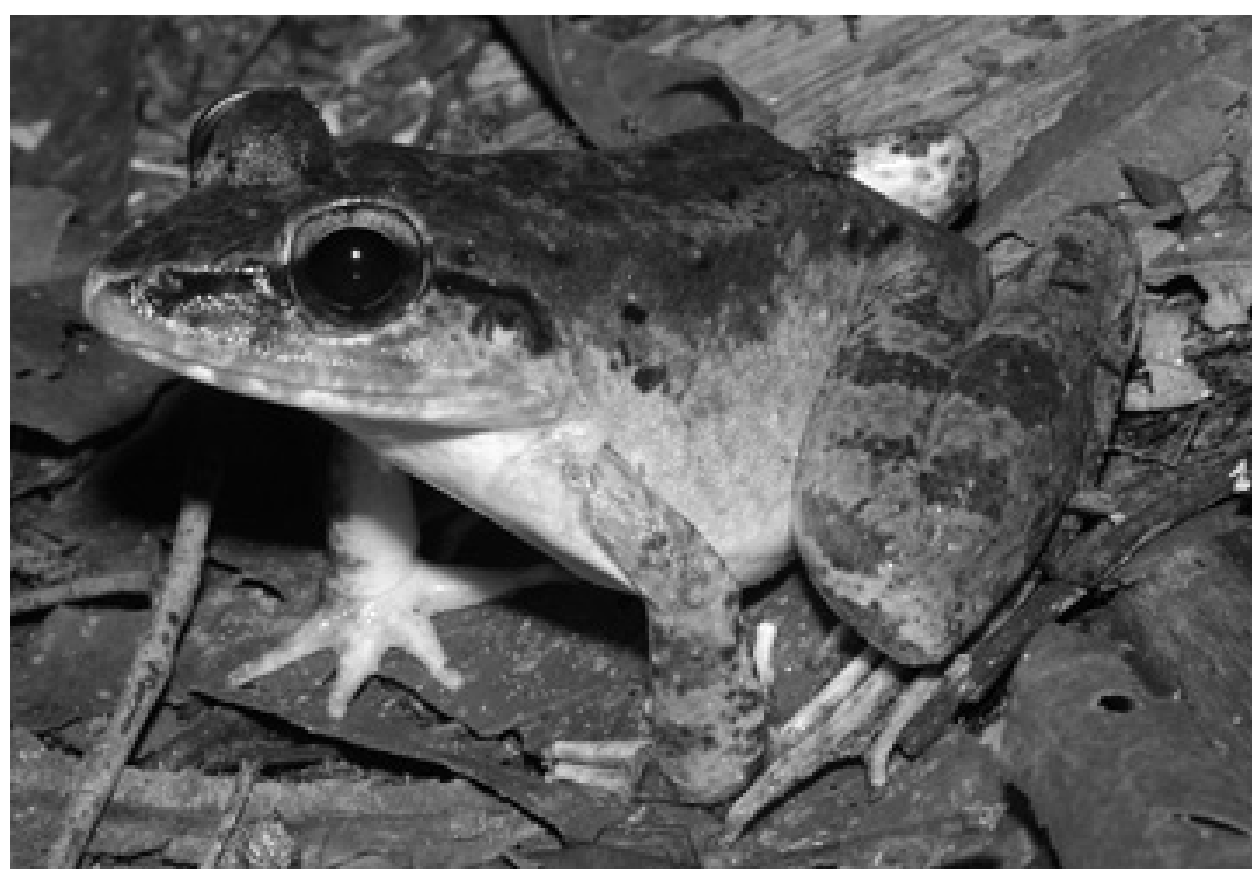

Figure 11. Limnonectes leporinus, a Bornean endemic generally found near large or medium-sized streams. (Photo by Kimabajo) 


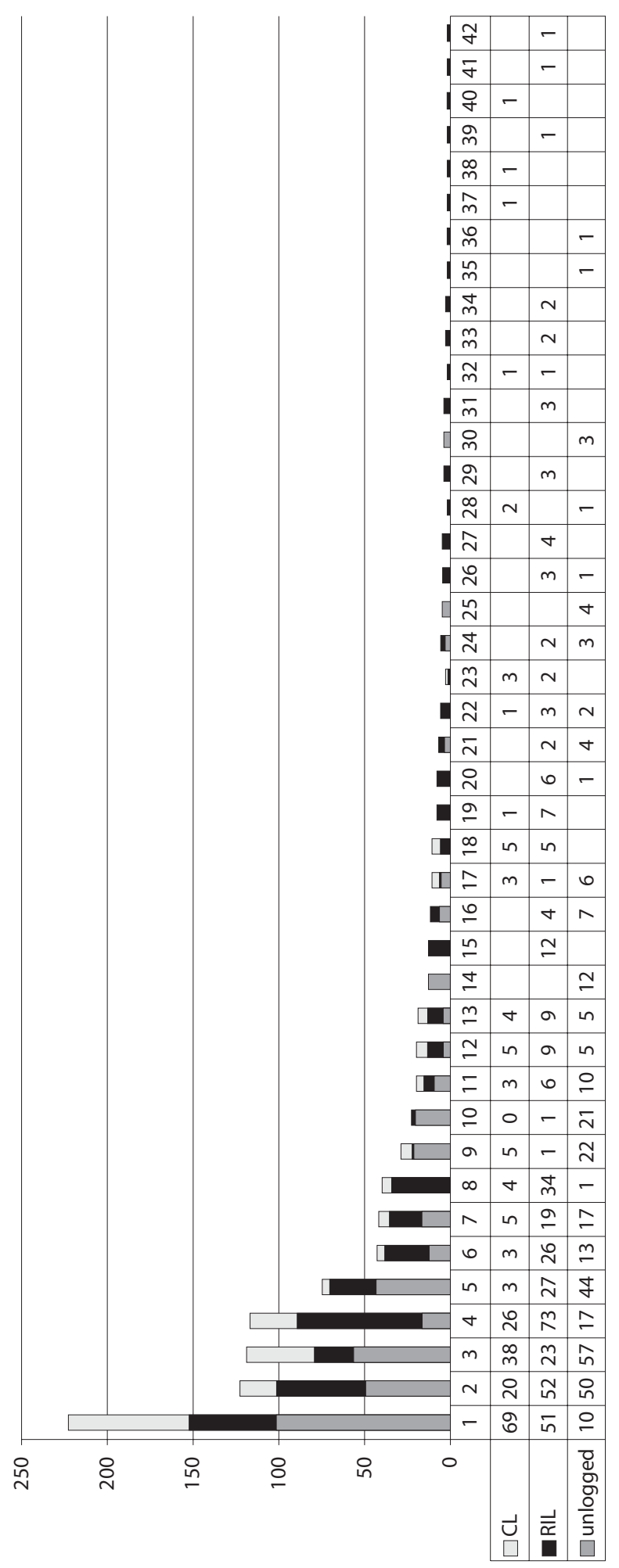

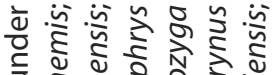

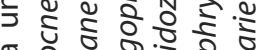
ซ

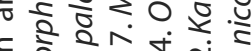
๙

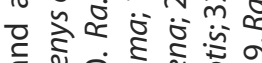

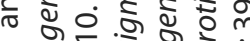

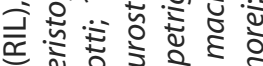

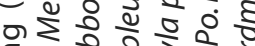

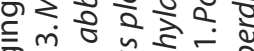
कू⿻ ठ․․ำ

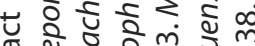

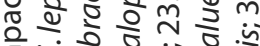
है: 영 웡 \&

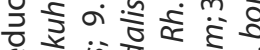

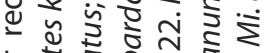
过

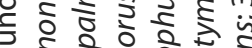

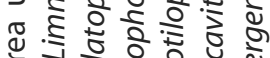

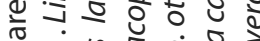
ब.

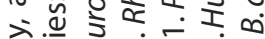

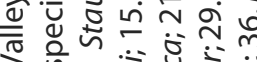

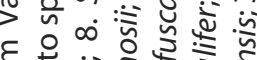

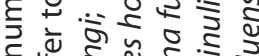
뜬

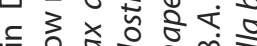

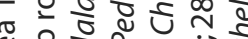

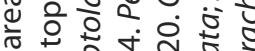

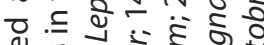

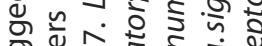

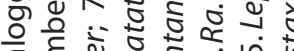

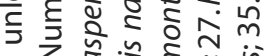

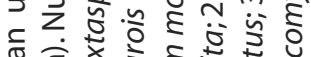

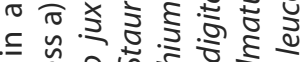

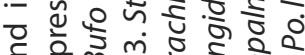

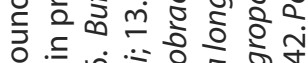

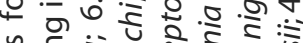

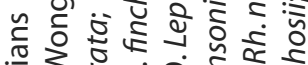

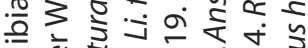

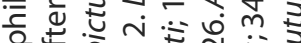
है

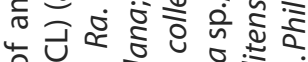

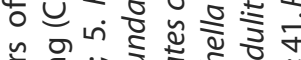
㐫. 可

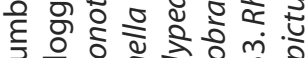

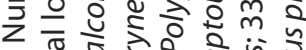
่

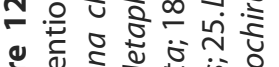

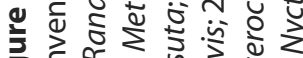

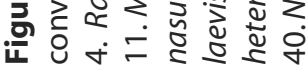


are vulnerable to careful logging, or at least not in the longer term (8-10 years after logging), although the long-term implications of the additional pond breeder species remain unknown. In Bolivia, Fredericksen and Fredericksen (2004) also found that frog densities remained unchanged in forests that had been logged one year previously compared to primary forest. One larger toad species, Bufo typhonia, had increased in density, possibly because its main food, larger sized arthropods such as grasshoppers, caterpillars and spiders, had become more common in forest gaps compared to unlogged areas. Also, toads are not as dependent on moisture as frogs, allowing them to better tolerate the higher temperatures in disturbed areas.

Several frog species are eaten or otherwise used in the Malinau area, including Flying Frogs Rhacophorus spp., Masked Tree Frog Polypedates macrotis, Greater Swamp Frog Limnonectes ingeri, four species of the genus Limnonectes (ibanorum, ingeri, leporinus and kublii), Fejervarya cancrivora and Hoplobatrachus rugulosus (Iskandar 2004; Puri 2001). These species are opportunistically taken by local people, but neither especially prized nor traded. Very little is known, however, about the effects of this harvest on population trends. As there does not appear to be any mass harvesting, it is not of current concern.

Finally, according to local people an exotic frog has recently been invading the region. Iskandar (2004) mentioned that it is important that this species is clearly identified; although the local name is linked to Hoplobatrachus rugulosus, it remains possible (from the local descriptions) that it could be Rana catesbeiana. This could pose a danger to local species.

In conclusion, the wide range of ecological specializations in Bornean frogs makes it hard to generalise about the effect of logging on species richness and abundance, but it appears that at least some species are little affected by logging while others are more affected. Clearly, species such as Fejervarya cancrivora and Rana nicobariensis cope with logging as these are commensals of man and not rainforest species. Whether any forest species are truly unaffected by selective logging remains unclear.

\section{Reptiles}

The study of Southeast Asian, and in particular Bornean reptiles has focused on taxonomy. The turtles can be identified using Lim and Das (1999) or Moll and Sharma (2000); Iskandar (2004) also includes crocodiles. Stuebing and Inger (1999) describe the snakes of Borneo, David and Vogel (1996) describe reptile species of Sumatra, and Das (2002) provides a useful introduction to many of the amphibians and reptiles in the region, while Iskandar and Colijn $(2000,2002)$ provided checklists for the reptiles of Southeast Asia. Inger and Tan (1996) show some lizards, snakes and frogs that are common in Sabah, while their book can also be used to some extent to identify Bornean lizards.

Some reptiles may play important roles in ecosystems. For instance, turtles eat carrion, thereby helping the release of locked-up nutrients; they feed on organisms that cause diseases in humans (e.g., malaria, schistosomiasis); they eat and prevent the spread of exotic water weeds and thus help maintain open water, and control insects 
that breed in stagnant waters (Lim \& Das 1999). Other reptiles, especially snakes, can control pests such as commensal rats, while reptiles also provide food for other animals, not to mention many humans (Lim \& Das 1999).

Iskandar (2004) conducted a survey in the MRF to prepare an initial checklist of the amphibian and reptile fauna in the area bounded by the Seturan and Rian Rivers (see Fig. 2). He annotated the list when possible with information on habitat, life history requirements, and possible vulnerability from harvesting and forest conversion. Furthermore, he identified if any of the species are used by, or valued by the people from the villages of Langap, Loreh and Seturan, and if so why, in what manner and by whom (see Appendix 7).

The Malinau area appears to be rich in reptile species, but these occur in low densities (Iskandar 2004). As mentioned in the section on amphibians, Iskandar (2004) found that the unlogged area had fewer specimens than the logged areas, but little additional information is really available on the effects of logging on reptiles. Species composition between the logged and unlogged areas appears to be more or less the same, although Bennet and Dahaban (1995) found that the Burmese Brown Tortoise (Geochelone emys) occurred in unlogged forests in Sarawak, but it was not seen again after timber harvest. It is unclear whether the apparent decreased densities were the result of environmental and ecological changes following timber harvest or whether these species had been collected by logging workers.

In the MRF area, most local people are afraid of snakes, even the small ones, and other than pythons, which are eaten, most seem reluctant to capture them. Among lizards, local people only eat monitor lizards (Varanus spp.). According to the local people, there are three species of monitors in the area though only two were recorded ( $V$. salvator, $V$. rudicollis). Another small blackish monitor lizards is seldom eaten, but Iskandar and his colleagues were unable to acquire a specimen and were unable to determine whether it is $V$. heteropholis or an undescribed species. All species of turtle are consumed locally. Shells are also occasionally used for decoration (Sheil pers. obs.). Soft-shelled species, sometimes of considerable size, are frequently caught with a baited hook. Bile from these species is prized for its reputed medicinal values (Sheil pers. obs.). In certain parts of Kalimantan (e.g., Mahakam lakes, upper Kapuas lakes), turtles are collected by setting fire to bush land or forest and picking up the exposed animals (Meijaard pers. obs.).

Schwaner (1853-1854) reported that at that time crocodiles occurred in every Bornean river, from the mouth up to the source, and in every lake and swamp. In the 1930s, Crocodylus porosus was still found to be numerous near river mouths, while Tomistoma schlegelii, the False Gharial, was said to be common in the Malinau and Bulungan areas (Nederlandsch-Indische Vereeniging tot Natuurbescherming 1939). Crocodiles are now very rare in the region, but communities recall a time only a few decades ago when they were much more plentiful (Sheil unpubl.). Some suggest that a small team of outside hunters working with local people made a major but rapid 'harvest' of the crocodiles. If true, there may indeed still be remnant populations in less accessible sites such as mountain lakes and tributaries as local people claim but this has not been verified. The local people in Setulang (lower Malinau) claim that at least one large crocodile still occurs in some nearby location (I. Ramses pers. 
comm.). The species is unclear, though the jaws are broad on large specimens recently noted on the lower Malinau (three eyewitness accounts), which suggest that either Crocodylus porosus or C. siamensis occurs. C. porosus certainly occurs amongst the mangroves bordering the Sesayap River nearer to Tarakan. 



\section{Fish}

Borneo has about 350 species of obligate freshwater fish species, of which about 135 appear endemic to the island (Kottelat et al. 1993). Molengraaff and Weber (1920) pointed out long ago that east Bornean rivers are likely to have higher levels of fish endemism than the rivers on the southern and western sides of the island, because the latter rivers would have been connected to rivers from Java, Sumatra and the Malay Peninsula during times of low sea-level, whereas the former faunas remained isolated. This pattern seems to be borne out by recent surveys, including those in Malinau (Rachmatika et al. 2005), though the regional freshwater fish fauna remains poorly characterised and new species are still being discovered.

Kottelat et al. (1993) listed the main threats to tropical freshwater fish species, and highlight forest loss as the most serious for four reasons:

1. Many species are dependent on animals and plant material falling into water from overhanging vegetation, and most are dependent either directly or indirectly on leaves and other material being washed into the water. Clearing of streamside vegetation reduces food for fish;

2. Water temperature rises with decreased shading. This leads to decreased oxygen levels in the water, while warmer water raises the metabolic rate of fish and thereby their oxygen demand. Oxygen shortages can be exacerbated by decaying matter entering the waterways and leading to mass fish mortality;

3. Increased turbidity can directly kill fish, as the silt can accumulate on the gills, resulting in death from suffocation. When the flow in a river slows, silt settles and can smother food resources, eggs and spawning grounds, as well as reduce the depth and the width of the channel. This can seriously affect bottomdwelling fish such as loaches;

4. Forests (particularly seasonally inundated forests) create habitat diversity and heterogeneity which is reflected by species diversity of fish and other aquatic species (e.g., Iwata et al. 2003). 
Martin-Smith (1998c) found in his research sites in Sabah that species such as Garra borneensis, Lobocheilos bo and Osteochilus chinni were the only species that appear to suffer from selective logging, although his overall conclusion was that selective logging has a low impact on fish faunas, primarily because of a) their persistence when logging is ongoing or b) their ability to recolonise rivers several years after logging.

Rachmatika et al. (2005) conducted surveys of the fish faunas of the upper and lower Seturan River in the MRF. Among other questions, they investigated how fish species are affected by logging. They did this by comparing stations that were logged a few years before or during the survey and stations that had never been logged, excluding ponds, stations logged more than five years before the survey and in specific habitats from the comparison. This gave them the following samples:

- For 1999: unlogged (32 stations), logged either before or during the 1999 survey (9 stations), ponds (4 stations);

- For 2000: unlogged (41 stations), logged either before or during the 2000 survey (10 stations), ponds caused by poor roading (3 stations), special habitat (1 station-salt water seep "air asin").

The comparison for 1999 (Table 10) shows a clear difference in the number of potentially vulnerable species both in terms of abundance and presence in the stations. Hillstream loaches and other site-specific bottom-dwelling species (Gastromyzon spp., Garra borneensis, etc.) seem the most affected, but some near-bottom dwelling herbivorous or frugivorous species (Lobocheilos bo and Tor spp.) were absent in logged stations. The difference is less striking for the year 2000 but this may be because six of the studied stations were logged at the time of survey, making it too early to assess impacts. If we compare the areas unlogged in 2000 with the stations logged before the survey, then we find the same pattern as for 1999: smaller numbers and the reduced presence of potentially vulnerable species in the logged areas. Rachmatika et al. consider that their results are consistent with expectations based on knowledge of the life history of the species present (e.g., Martin-Smith 1998a, b).

Table 10. Comparison of fish abundance and occurrence between unlogged and logged stations in the Seturan River, Malinau (Rachmatika et al. 2005).

\begin{tabular}{lrrrrrrrrr}
\hline \multirow{2}{*}{ Species } & \multicolumn{4}{c}{ Unlogged } & \multicolumn{5}{c}{ Logged over } \\
\cline { 2 - 11 } & \multicolumn{2}{c}{ Individuals } & \multicolumn{1}{c}{ Occurrence } & \multicolumn{2}{c}{ Individuals } & \multicolumn{2}{c}{ Occurrence } \\
\cline { 2 - 11 } & $\mathbf{N}$ & $\%$ & Stations & $\%$ & $\mathbf{N}$ & $\%$ & Stations & $\%$ \\
\hline Nematabramis everetti & 127 & 9.6 & 23 & 71.9 & 65 & 35.5 & 9 & 100.0 \\
\hline Osteochilus waandersii & 146 & 11.0 & 22 & 68.8 & 8 & 4.4 & 6 & 66.7 \\
\hline Rasbora elegans & 92 & 6.9 & 17 & 53.1 & 4 & 2.2 & 2 & 22.2 \\
\hline Hampala macrolepidota & 43 & 3.2 & 16 & 50.0 & 1 & 0.5 & 1 & 11.1 \\
\hline Hemibagrus cf. nemurus & 26 & 2.0 & 16 & 50.0 & 11 & 6.0 & 7 & 77.8 \\
\hline Mastacembelus unicolor & 41 & 3.1 & 15 & 46.9 & 0 & 0.0 & 0 & 0.0 \\
\hline Garra borneensis & 247 & 18.6 & 14 & 43.8 & 0 & 0.0 & 0 & 0.0 \\
\hline Gastromyzon sp. (nov?) & 131 & 9.9 & 14 & 43.8 & 0 & 0.0 & 0 & 0.0 \\
\hline G. cf. lepidogaster & 113 & 8.5 & 14 & 43.8 & 4 & 2.2 & 2 & 22.2 \\
\hline
\end{tabular}


Table 10. Continued.

\begin{tabular}{lcccccccc}
\hline & \multicolumn{4}{c}{ Unlogged } & \multicolumn{5}{c}{ Logged over } \\
\cline { 2 - 11 } \multicolumn{1}{c}{ Species } & Individuals & Occurrence & \multicolumn{1}{c}{ Individuals } & Occurrence \\
\cline { 2 - 11 } & $\mathbf{N}$ & $\%$ & Stations & $\%$ & N & $\%$ & Stations & \multicolumn{1}{c}{$\%$} \\
\hline Nemacheilus selangoricus & 31 & 2.3 & 11 & 34.4 & 2 & 1.1 & 1 & 11.1 \\
\hline Anguilla malgumora & 19 & 1.4 & 11 & 34.4 & 5 & 2.7 & 4 & 44.4 \\
\hline Rasbora caudimaculata & 21 & 1.6 & 10 & 31.3 & 23 & 12.6 & 7 & 77.8 \\
\hline Puntius sp. (nov?) & 18 & 1.4 & 10 & 31.3 & 2 & 1.1 & 2 & 22.2 \\
\hline Cyclocheilichthys armatus & 22 & 1.7 & 9 & 28.1 & 2 & 1.1 & 1 & 11.1 \\
\hline C.repasson & 34 & 2.6 & 8 & 25.0 & 1 & 0.5 & 1 & 11.1 \\
\hline Puntius binotatus & 21 & 1.6 & 8 & 25.0 & 12 & 6.6 & 7 & 77.8 \\
\hline Rasbora lateristriata & 17 & 1.3 & 8 & 25.0 & 9 & 4.9 & 4 & 44.4 \\
\hline Homaloptera stephensoni & 13 & 1.0 & 8 & 25.0 & 0 & 0.0 & 0 & 0.0 \\
\hline Barbodes cf.balleroides & 38 & 2.9 & 7 & 21.9 & 0 & 0.0 & 0 & 0.0 \\
\hline Tor tambra & 17 & 1.3 & 7 & 21.9 & 0 & 0.0 & 0 & 0.0 \\
\hline Glyptothorax platypogonoides & 10 & 0.8 & 7 & 21.9 & 1 & 0.5 & 1 & 11.1 \\
\hline Parachela ingerkongi & 13 & 1.0 & 6 & 18.8 & 1 & 0.5 & 1 & 11.1 \\
\hline Lobocheilos cf. bo & 12 & 0.9 & 6 & 18.8 & 0 & 0.0 & 0 & 0.0 \\
\hline Leptobarbus melanotaenia & 9 & 0.7 & 6 & 18.8 & 3 & 1.6 & 1 & 11.1 \\
\hline Ompok cf. bimaculatus & 7 & 0.5 & 6 & 18.8 & 1 & 0.5 & 1 & 11.1 \\
\hline Leiocassis sp. & 7 & 0.5 & 6 & 18.8 & 0 & 0.0 & 0 & 0.0 \\
\hline Nemacheilus saravacensis & 7 & 0.5 & 5 & 15.6 & 0 & 0.0 & 0 & 0.0 \\
\hline Rasbora argyrotaenia & 6 & 0.5 & 5 & 15.6 & 0 & 0.0 & 0 & 0.0 \\
\hline Neogastromyzon & 9 & 0.7 & 4 & 12.5 & 0 & 0.0 & 0 & 0.0 \\
nieuwenhuisi & & & & & & & & \\
\hline Hemibagrus baramensis & 7 & 0.5 & 4 & 12.5 & 0 & 0.0 & 0 & 0.0 \\
\hline Puntius sealei & 4 & 0.3 & 3 & 9.4 & 8 & 4.4 & 4 & 44.4 \\
\hline & & & & & & & & \\
\hline
\end{tabular}

A very depauperate fauna characterized ponds created by dams and roads built to access timber. Merging the results of the two surveys, a total of 16 species have been recorded from this type of environment (Table 11). All the vulnerable demersal species were absent except for one specimen of Anguilla malgumora at the outlet of one of the ponds. Some species appeared common in ponds:

- In the 1999 survey: Cyclocheilichthys armatus (44\% of the individuals were found in ponds), Nemacheilus saravacensis (36\%), Puntius sealei (29\%).

- In the 2000 survey: Cyclocheilichthys armatus (13\% of the individuals were found in ponds), C. repasson (29\%), Nemacheilus saravacensis (25\%), Puntius sealei $(31 \%)$.

Betta unimaculata seemed to prefer outlets and was absent or rare in the ponds proper. This species was also the only one that was collected in the salt water seep station.

Several of the surveyed species present specific autecological or biological features that might be of importance in the context of existing logging or coal mining operations in the region. Since demersal species live on or near the river bottom and feed on benthic organisms, they could be affected by excessive siltation created 
Table 11. Fish fauna in ponds caused by poor roading in Malinau (Rachmatika et al. 2005).

\begin{tabular}{|c|c|c|c|c|c|c|}
\hline \multirow[t]{2}{*}{ Species } & \multicolumn{2}{|c|}{$\begin{array}{l}\text { Individuals in } \\
\text { ponds }\end{array}$} & \multicolumn{2}{|c|}{$\begin{array}{l}\text { Individuals in } \\
\text { total sample }\end{array}$} & \multicolumn{2}{|c|}{$\%$} \\
\hline & 1999 & 2000 & 1999 & 2000 & 1999 & 2000 \\
\hline Cyclocheilichthys armatus* & 19 & 2 & 43 & 16 & 44.2 & 12.5 \\
\hline Betta unimaculata & 14 & 5 & 30 & 12 & 46.7 & 41.7 \\
\hline Nematabramis everettii & 11 & 1 & 203 & 185 & 5.4 & 0.5 \\
\hline Puntius binotatus & 7 & 6 & 49 & 28 & 14.3 & 21.4 \\
\hline Rasbora elegans & 7 & 4 & 103 & 48 & 6.8 & 8.3 \\
\hline Rasbora caudimaculata & 7 & & 51 & 71 & 13.7 & 0.0 \\
\hline Puntius sealei & 5 & 10 & 17 & 32 & 29.4 & 31.3 \\
\hline Puntius sp. & 5 & & 25 & 17 & 20.0 & 0.0 \\
\hline Nemacheilus saravacensis & 4 & 2 & 11 & 8 & 36.4 & 25.0 \\
\hline Nemacheilus selangoricus & 4 & & 37 & 2 & 10.8 & 0.0 \\
\hline Hemibagrus cf. nemurus & 2 & 1 & 39 & 18 & 5.1 & 5.6 \\
\hline Leptobarbus melanotaenia & 2 & & & & & \\
\hline Nemacheilus spiniferus & 2 & & & & & \\
\hline Anguilla malgumora & 1 & & & & & \\
\hline Hampala macrolepidota & 1 & & & & & \\
\hline Cyclocheilichthys repasson* & & 11 & 31 & 38 & 0.0 & 28.9 \\
\hline
\end{tabular}

*There is possible taxonomic confusion between Cyclocheilichthys armatus and C. repasson that might explain the complementary variation of the two species.

by logging infrastructure (culverts, crossing of river by heavy equipment, etc.). Eels (Anguilla spp.), spiny eels (Mastacembelus spp., Macrognathus spp.), Bagrid or Sisorid catfishes, and hillstream loaches (Gastromyzon spp., Neogastromyzon spp., etc.) are all demersal fishes.

Among the demersal species, some have special apparatus to fix themselves on substratum (rocks, boulders, logs, etc.) in fast flowing waters. A flattened ventral surface and a down-turned mouth to graze algae characterize these species. Generally grouped under the generic names of 'hillstream loaches' or 'sucker-belly fishes', they belong to three families (not just loaches):

- Balitoridae (genera Gastromyzon, Homaloptera, Neogastromyzon, Parhomaloptera, Protomyzon). These are the 'true' hillstream loaches. As the name implies, these fishes come from fast flowing streams and rivers. There are dozens of species that range throughout most of Southeast Asia. They have adapted to these fast, turbulent waters by developing suction mechanisms in their bellies and fins, and downturned mouths to graze the algae beds found there.

- Cyprinidae (genus Garra). Species of this genus include G. borneensis, one of the most abundant species in the Malinau survey, sometimes referred to as 'stonelapping minnows' because of an upper lip modified into a suctional disk.

- Sisoridae (Sisorid catfishes). The only one of these species found in our survey, Glyptothorax platypogonoides, has a specialised adhesive apparatus made of smooth folded skin on its anterior flattened ventral fin that enables it to attach onto rocky surfaces. 
Because of their peculiar biology these species are likely to be vulnerable to increased siltation (destruction of the algae beds and inability to attach on rocks).

Other potentially vulnerable species are the benthopelagic fishes that feed on micro-algae, diatoms (Lobocheilos bo, some Osteochilus spp., Tor spp.) and on forest fruits and plants (Leptobarbus melanotaenia, Tor spp.) (Sulastri et al. 1985; Tan 1979). These fishes can be affected by a reduction in food availability following logging.

Pangasius spp. is a migratory species that seems to be in considerable demand and has high market value. Unfortunately its spawning behaviour makes it easy to catch in nets and this species has already been virtually eliminated in the middle and upper Malinau (Rachmatika et al. 2005). Tor spp. also seem vulnerable to overcollection and are highly sought after in Malinau (Rachmatika et al. 2005). 



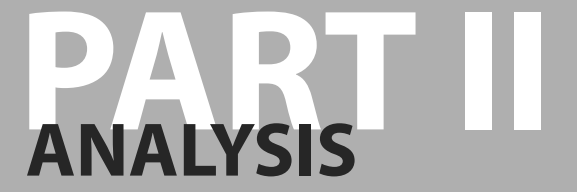

\section{A statistical analysis of species sensitivity}

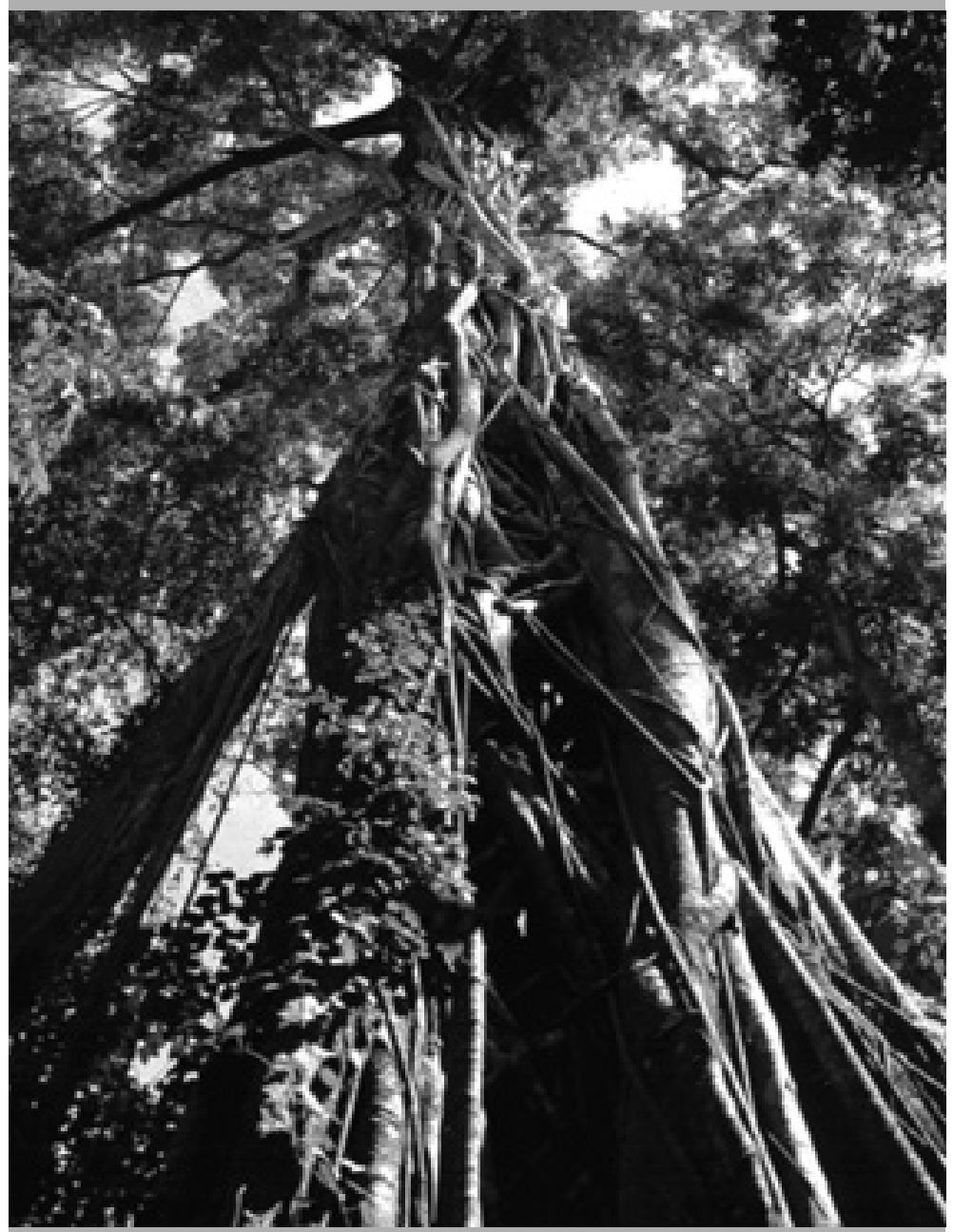

Ficus spp. Figs are one of the better recognised species with considerable benefit to wildlife. (Photo by Margaret F. Kinnaird) 



\section{Species sensitivity analysis}

\section{Approach and methods}

We analysed species characteristics in relation to their sensitivity to logging and fragmentation using multivariate statistics. For this we selected 23 bird species (6 hornbills, 13 woodpeckers, 4 pheasants) and 27 mammal species (7 primates, 9 squirrels, 6 ungulates, 4 viverrids, 1 ursid) for which the response to logging had been studied and reported in peer-reviewed journals or books (see Appendices 4 and 5). Our predictor variables included the following data categories: taxonomy, distribution, habitat, natural history, seasonal cycles, ranging behaviour, growth and development, reproduction behaviour, and ecological interactions. We used discriminant analyses, correspondence analyses and principal component analyses to investigate the correlations between sensitivity to logging and fragmentation and the predictor variables. Standard principal components analysis assumes linear relationships between numeric variables, and because most of the predictor variables were categorical rather than numerical, we used a categorical principal components analysis (CATPCA) (Data Theory Scaling System Group 1999) procedure to simultaneously quantify categorical variables while reducing the dimensionality of the data.

Our independent variables were categorized as follows:

- Number of species per genus (numerical): after Corbet and Hill (1992), unless more recent taxonomic reviews were available;

- Number of subspecies per species (numerical): after Corbet and Hill (1992), unless more recent taxonomic reviews were available;

- Phylogenetic age of genus (numerical)-age in millions of years of divergence from sister genus (after Meijaard 2003c)—only available for mammals;

- Phylogenetic age of species (numerical)-age in millions of years of divergence from sister species (after Meijaard 2003c)—only available for mammals;

- Number of small Sundaic islands on which species occurs (numerical) (after Meijaard 2003b); 
- Home range (numerical): average female home range reported in the literature;

- Body weight (numerical): weight of adult females as reported in various literature sources;

- Number of young per litter (numerical);

- Age of first reproduction (numerical): female age of first reproduction (months);

- Distribution (categorical): (1) endemic to Borneo, (2) endemic to the Sundaic Subregion, (3) occurring in both the Sundaic and Indochinese Subregions;

- Migration: (1) Species migrate between isolated forest patches on a regular basis, (2) Species do not regularly migrate;

- Group size (categorical): (1) 1-2 animals per group, (2) 2-5 animals per group, (3) 5-10 animals per group, (4) generally >10 animals per group;

- Density (categorical): Average density over different unlogged vegetation types (1) $<1$ individual $/ \mathrm{km}^{2},(2)>1$ and $<2$ individuals $/ \mathrm{km}^{2},(3)>2$ and $<5$ individuals $/ \mathrm{km}^{2}$, (4) $>5$ individuals $/ \mathrm{km}^{2}$;

- Feeding categories (categorical): (1) $>70 \%$ frugivorous, (2) fruits and leaves (animal matter $<10 \%$ ), (3) omnivorous (no category $>40 \%$ ), (4) fruit and animal matter (other plant parts $<10 \%$ ), (5) $>70 \%$ insectivorous or carnivorous, (6) $>70 \%$ herbivorous;

- Feeding stratum (categorical): (1) terrestrial, (2) ground-understorey, (3) lowermiddle strata, (4) ground-canopy.

Our dependent variable was reported sensitivity to logging, which was coded as follows:

- Intolerant: Severely impacted by selective logging, i.e. densities decline by $>20 \%$ in the first year after logging, and do not recover until 5 years post-logging;

- Neutral: No effects from selective logging, i.e. no significant changes in densities have been reported following logging;

- Tolerant: Positive effect of logging, i.e. densities increased by $>20 \%$ within the first year after logging.

Our per-species cases are not independent because of phylogenetic relationships. Elsewhere (Meijaard et al. in prep.) we have tested this using phylogenetic regression techniques and found that the present simplified approach gives similar results, thereby suggesting that case interdependence is not a major issue here, and that similar result occur amongst unrelated taxonomic groups. 


\section{Results}

As shown in Tables 2-9 the impact of logging on population densities of our test species is often unclear, with some researches showing increases following logging and other decreases. For each species we tried to generalise the impact of logging, assessing density trends in relation to age of logging and absence and presence of hunting. This is somewhat dependent on judgement and necessarily lacks purely objective criteria.

Because there are no published data on the effects of fragmentation on Sundaic mammals, we used the number of Southeast Asian islands on which each species occurs (after Meijaard 2003b) as a measure of their long-term tolerance of fragmentation. We reckon that the correlation between the occurrence of Sundaic species on islands and their sensitivity to fragmentation remains untested, and that other factors can influence the presence or absence of a species on an island. Still, the fact that certain species are able to survive on small islands indicates that area size does not have a major impact on their survival, although clearly there must be a lower limit. For birds we also intended to use the occurrence on islands to assess their sensitivity to fragmentation, but our initial analysis indicated that lists of bird distribution on islands are incomplete and often incorrect (Lammertink pers. obs.) and birds were therefore not included in that part of the analysis.

For mammals only, we used non-parametric statistics to test whether taxa with different sensitivity levels to logging could be distinguished for 8 different numerical variables (Table 12). Only the number of subspecies per species differed significantly between these 3 groups. Because we are primarily interested in the species intolerant to logging we lumped the neutral and tolerant groups and retested the group differences for the 8 numerical variables in Table 12. A Mann-Whitney test showed that species age and number of subspecies per species differed significantly for the 2 groups $(p<0.05)$. This is also indicated in Fig. 13, which shows that logging tolerant species have generally diverged from their nearest ancestor more recently than logging intolerant species. 
Table 12. Comparison of means of 8 predictor variables in relation to the sensitivity of selected mammal species to logging.

\begin{tabular}{|c|c|c|c|c|}
\hline & Intolerant & Neutral & Tolerant & Kruskal-Wallis \\
\hline Species age (Mya) & $\begin{array}{c}4.4 \\
S D=1.7 ; n=7\end{array}$ & $\begin{array}{c}3.0 \\
S D=0.6 ; n=5\end{array}$ & $\begin{array}{c}2.5 \\
\mathrm{SD}=2.2 ; \mathrm{n}=11\end{array}$ & ns \\
\hline Island number & $\begin{array}{c}7.1 \\
S D=8.0 ; n=15\end{array}$ & $\begin{array}{c}15.1 \\
S D=16.1 ; n=12\end{array}$ & $\begin{array}{c}16.3 \\
S D=15.3 ; n=13\end{array}$ & ns \\
\hline Species per genus & $\begin{array}{c}5.7 \\
\mathrm{SD}=4.4 ; \mathrm{n}=15\end{array}$ & $\begin{array}{c}7.2 \\
\mathrm{SD}=4.5 ; \mathrm{n}=13\end{array}$ & $\begin{array}{c}12.6 \\
S D=13.8 ; n=13\end{array}$ & ns \\
\hline $\begin{array}{l}\text { Subspecies per } \\
\text { species }\end{array}$ & $\begin{array}{c}3.9 \\
\mathrm{SD}=3.4 ; \mathrm{n}=15\end{array}$ & $\begin{array}{c}9.0 \\
S D=11.2 ; n=12\end{array}$ & $\begin{array}{c}11.0 \\
S D=13.0 ; n=13\end{array}$ & $\begin{array}{c}p<0.05 \\
\mathrm{Chi}^{2}=6.29, \mathrm{df}=2\end{array}$ \\
\hline Groupsize & $\begin{array}{c}6.0 \\
S D=11.4 ; n=9\end{array}$ & $\begin{array}{c}3.3 \\
\mathrm{SD}=3.2 ; \mathrm{n}=9\end{array}$ & $\begin{array}{c}16.0 \\
\mathrm{SD}=12.3 ; \mathrm{n}=5\end{array}$ & ns \\
\hline $\begin{array}{l}\text { Number of young } \\
\text { per litter }\end{array}$ & $\begin{array}{c}1.6 \\
\mathrm{SD}=0.7 ; \mathrm{n}=13\end{array}$ & $\begin{array}{c}1.9 \\
\mathrm{SD}=1.5 ; \mathrm{n}=8\end{array}$ & $\begin{array}{c}2.1 \\
\mathrm{SD}=1.0 ; \mathrm{n}=11\end{array}$ & ns \\
\hline Body weight & $\begin{array}{c}6.4 \\
S D=12.7 ; n=15\end{array}$ & $\begin{array}{c}19.8 \\
\mathrm{SD}=43.4 ; \mathrm{n}=13\end{array}$ & $\begin{array}{c}194.2 \\
\mathrm{SD}=554.8 ; \mathrm{n}=13\end{array}$ & ns \\
\hline Home range (ha) & $\begin{array}{c}104 \\
S D=151 ; n=6\end{array}$ & $\begin{array}{c}35 \\
\mathrm{SD}=64 ; \mathrm{n}=9\end{array}$ & $\begin{array}{c}651 \\
S D=1233 ; n=4\end{array}$ & ns \\
\hline
\end{tabular}

NS = non-significant difference

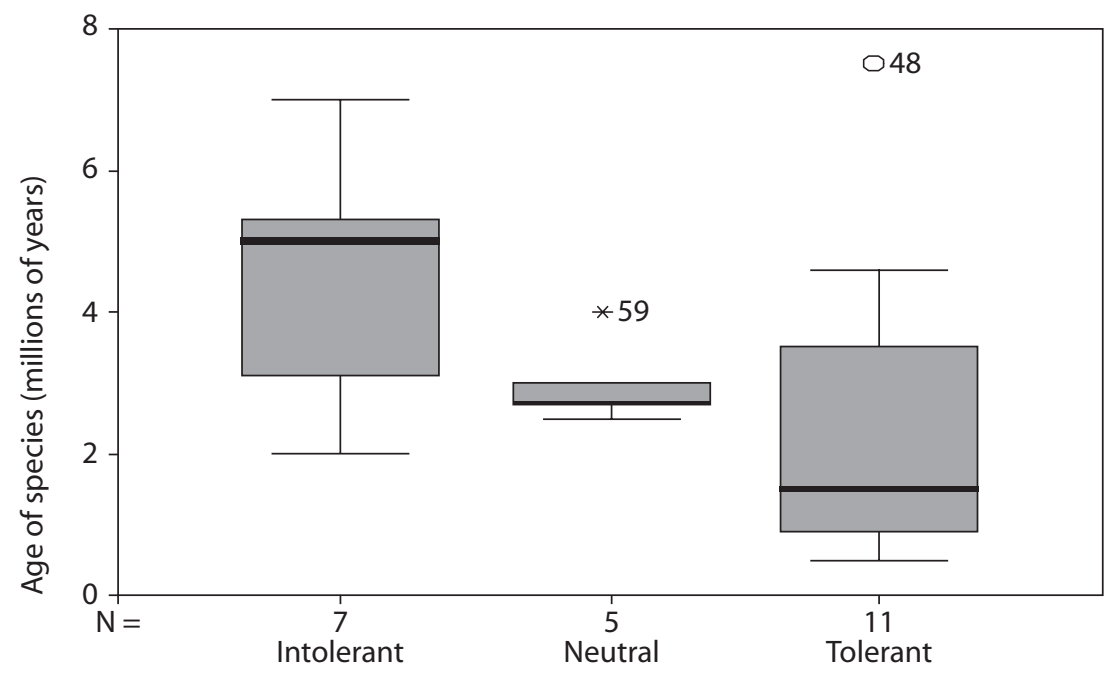

Figure 13. Box-and-whiskers plot of logging tolerance in relation to species age. The box represents the interquartile range which contains $50 \%$ of values. The whiskers are lines that extend from the box to the highest and lowest values, excluding outliers. A line across the box indicates the median.

A discriminant analysis of the numerical variables (number of species per genus; numbers of subspecies per species; number of islands on which species occurs) showed that these three variables can predict sensitivity to logging in mammals with $79 \%$ accuracy. For this analysis we log-transformed the predictor variables to ensure a multivariate normal distribution; we added 1 to all island counts to ensure that species that did not occur on small islands $(n=0)$ would contribute a valid log-transformed data point $\left(\log _{10} 0=\right.$ invalid $)$. 
The resulting graph (Fig. 14) shows that the 3 categories are reasonably well separated. Species that decline following logging are primarily those that occur on few islands (low value of function 1); these species are also characterized by few subspecies per species. However, because many island taxa are assigned to distinct subspecies these two predictor variables are not independent. Species that are relatively tolerant to logging are those that occur on many small islands, which probably reflects their ecological flexibility and their ability to survive in relatively small forest patches with high disturbance and significant edge effects. The outlying point (see arrow in Fig. 12) represents Macaca nemestrina, a species that is found on 10 islands and has 15 subspecies, but which appears to be negatively affected by logging. The relationship between sensitivity to logging and distribution on small islands is also clear when represented in a box plot (Fig. 15).

The above results are interesting but not particularly informative, because it is unclear whether the sensitivity data, as reported in the sources cited in this book, reflect the direct effects of logging or more indirectly the effects of forest fragmentation. Furthermore, taxonomic indices are hardly objective as some taxonomic groups have been studied in much detail, possibly leading to the designation of many subspecies, whereas others remain poorly studied and their geographical variation unknown and unnamed. Still, the observed patterns are potentially useful in predicting the sensitivity of poorly studied species to logging and fragmentation effects. Hypotheses can thus be generated and tested in the field.

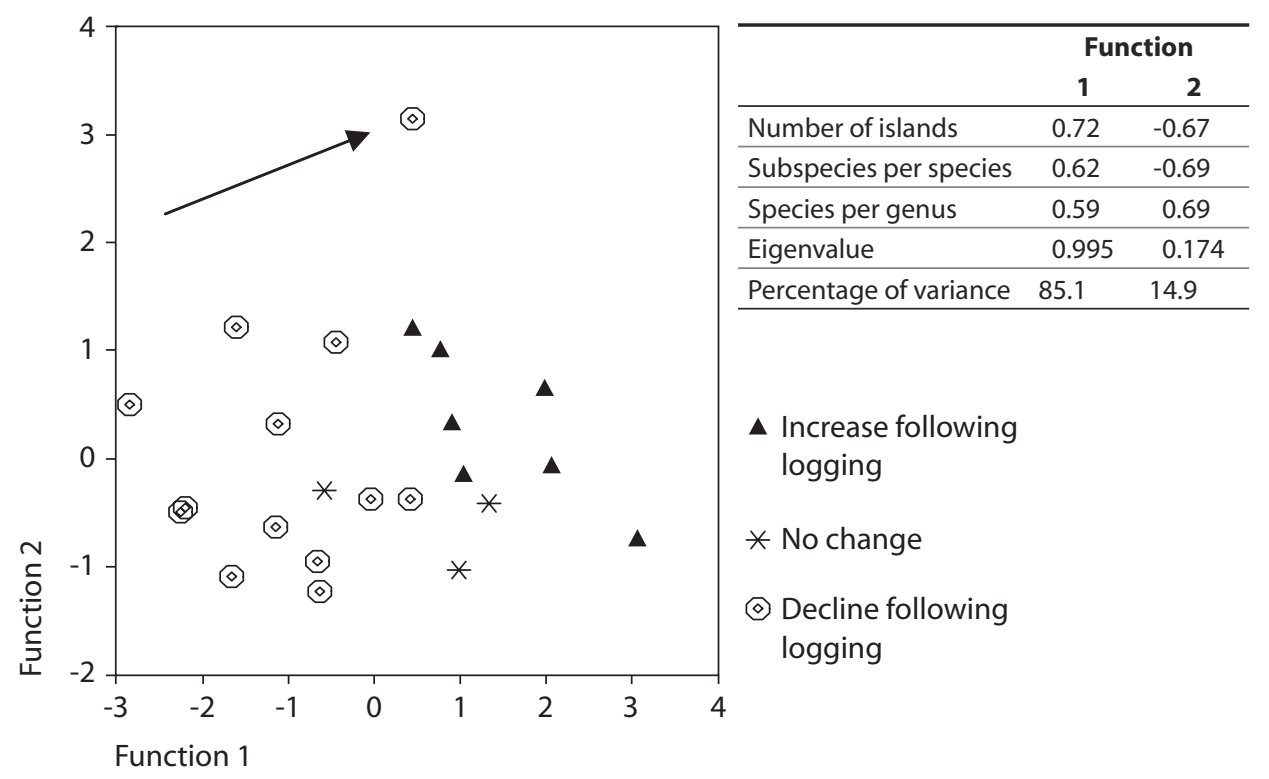

Figure 14. Discriminant analysis of 3 variables (number of small Sundaic islands on which species occurs (after Meijaard 2003b), number of species per genus, and number of subspecies per species) and their predictive value for the sensitivity of mammal species to logging. Arrow indicates the outlying Macaca nemestrina. 


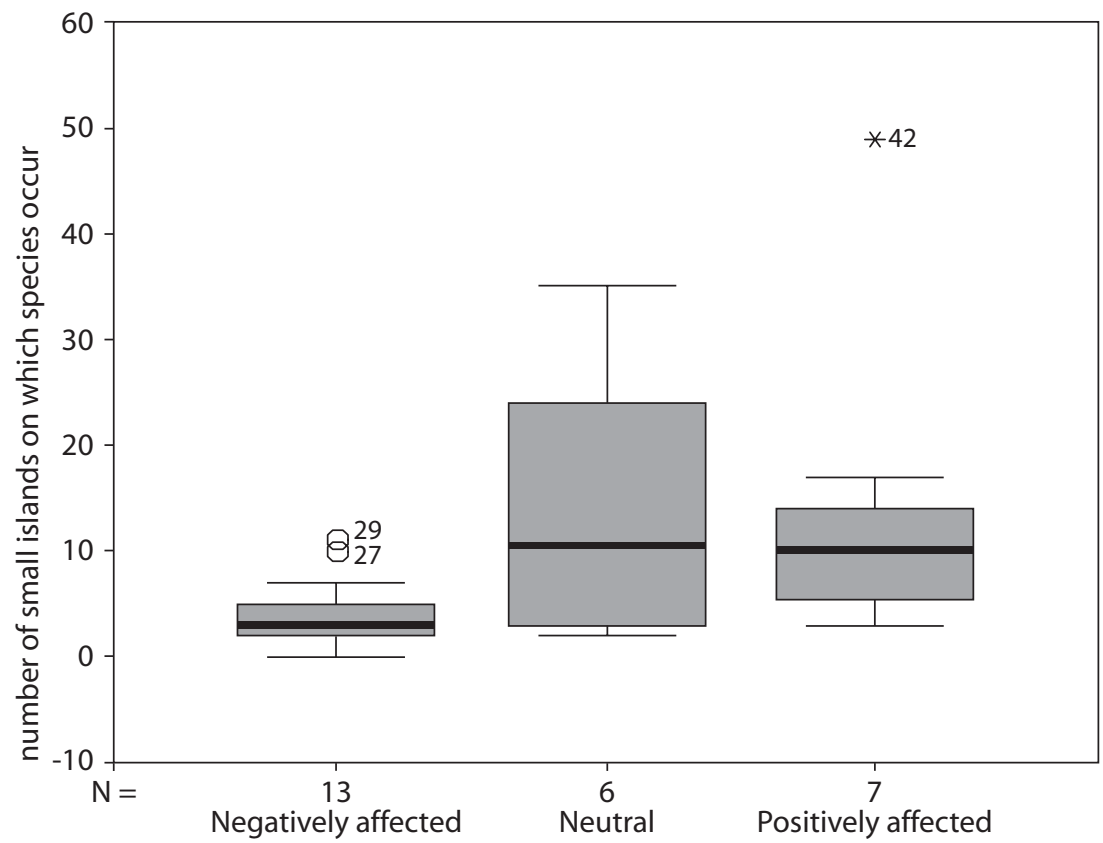

Figure 15. Box-and-whiskers plot of categories for tolerance to logging in relation to distribution on small islands (mammals only). The box represents the interquartile range which contains the $50 \%$ of values. The whiskers are lines that extend from the box to the highest and lowest values, excluding outliers. A line across the box indicates the median.

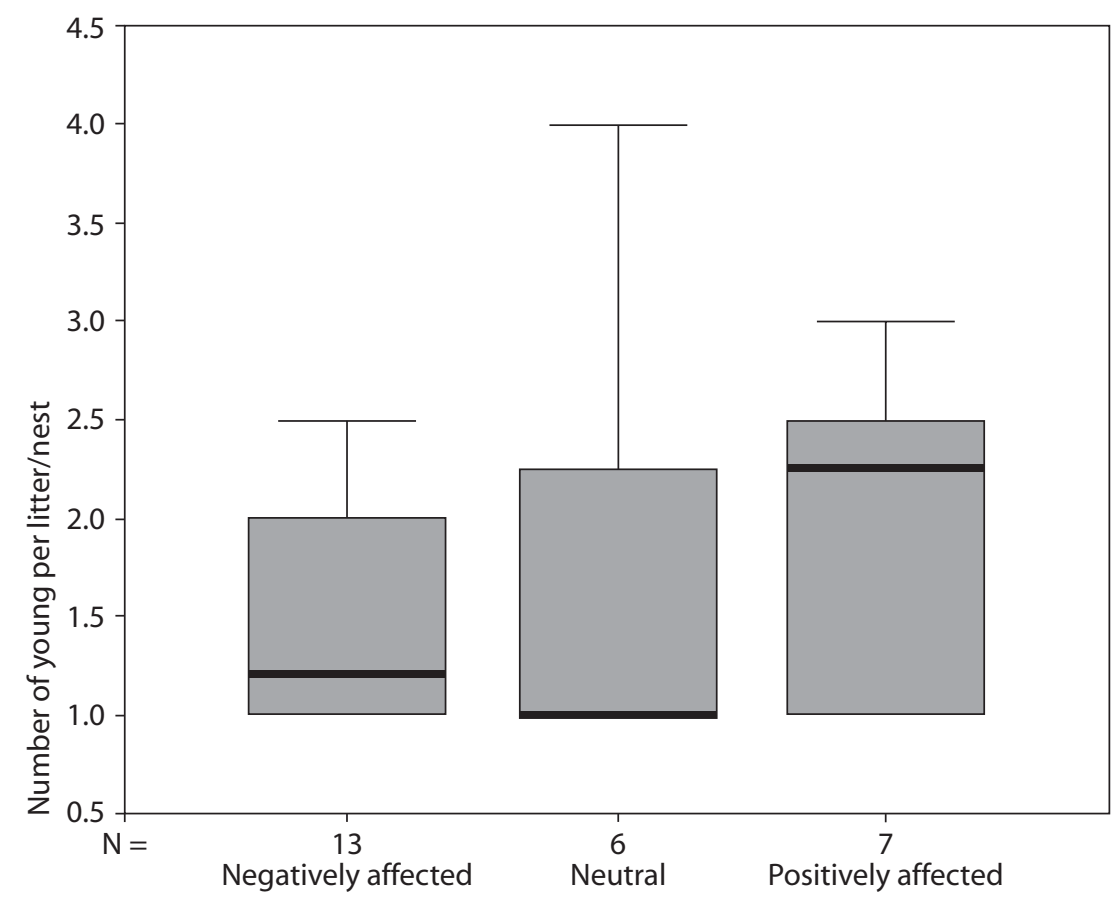

Figure 16. Box-and-whiskers plot of categories for tolerance to logging in relation to number of young per nest or litter (birds and mammals combined). The box represents the interquartile range which contains the $50 \%$ of values. The whiskers are lines that extend from the box to the highest and lowest values, excluding outliers. A line across the box indicates the median. 
Further exploration of the numerical predictor variables in relation to sensitivity to logging and fragmentation showed that sensitivity to logging appeared to decrease with number of young per litter (birds and mammals combined) (Fig. 16). We tested the significance of this relationship by comparing the means by one-way analysis of variance (ANOVA), but these did not differ significantly. Species that were sensitive to logging averaged $1.57(\mathrm{n}=17)$ young per litter, logging-neutral species $1.77(\mathrm{n}=11)$, and species that benefited from logging $1.94(\mathrm{n}=8)$ young per litter. Although the differences are not significant the observed relationships are interesting and further research is needed to investigate the predictive power of fecundity for sensitivity to logging. For most species, we lacked reproductive data on number of litters per year, age at first reproduction, recruitment, and longevity, but these would be other likely predictor variables that correlate with sensitivity to logging.

To describe the relationships between the categorical predictor variables and the dependent variables we used correspondence analyses. There were no significant relationships between the predictor variables and the degree of sensitivity to logging for mammals and birds combined. Still, some trends are worth pointing out. Species that are sensitive to logging are often Bornean or Sundaic endemics, i.e., 5 out of 6 $(=83 \%)$ Bornean endemics and 19 out of $32(=59 \%)$ Sundaland endemics were sensitive to logging (Fig. 17). Of the 14 terrestrial species, 7 (=50\%) were considered to be sensitive to logging (with 5 being neutral and 2 positive in their reaction). Similarly, of the 9 middle-upper canopy species, 7 (=78\%) were considered to be negatively affected to logging (with 1 being neutral and 1 positive in their reaction to logging). On the other hand, of the 9 species that increased in density following logging, 56\% occurred in the lower vegetation strata (Fig. 18). This could suggest that logging primarily affects species that are specialised at living in ground or canopy strata. The correspondence analysis also showed that of the 26 species that were negatively affected by logging, 18 (69\%) were either frugivorous or insectivorous/ carnivorous (Fig. 19).

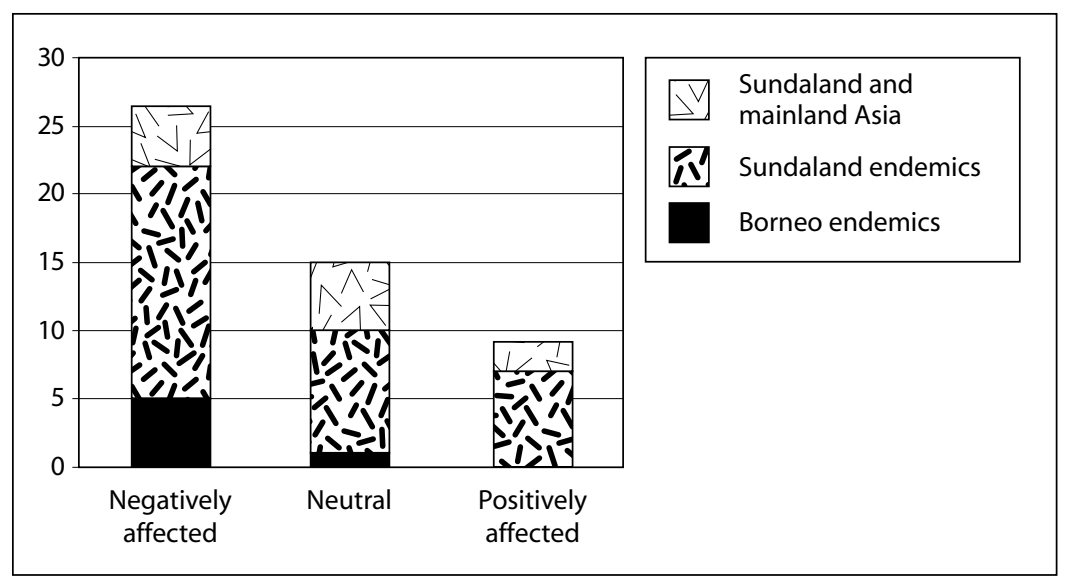

Figure 17. Column charts of sensitivity to logging in relation to distribution range (Borneo endemics vs. Sundaland endemics vs. species in Sundaland and mainland SE Asia). 


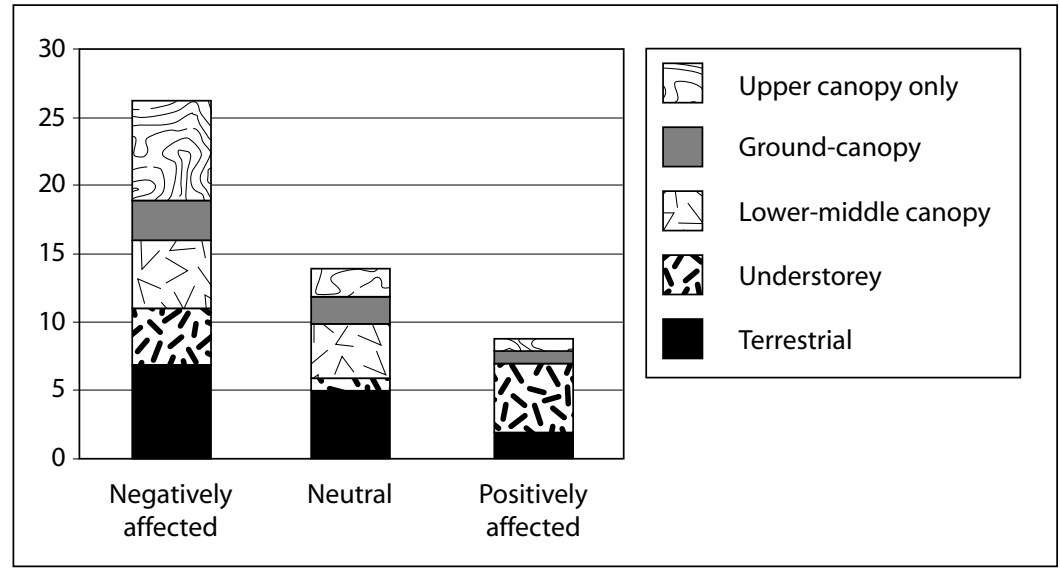

Figure 18. Column charts of sensitivity to logging in relation to feeding strata.

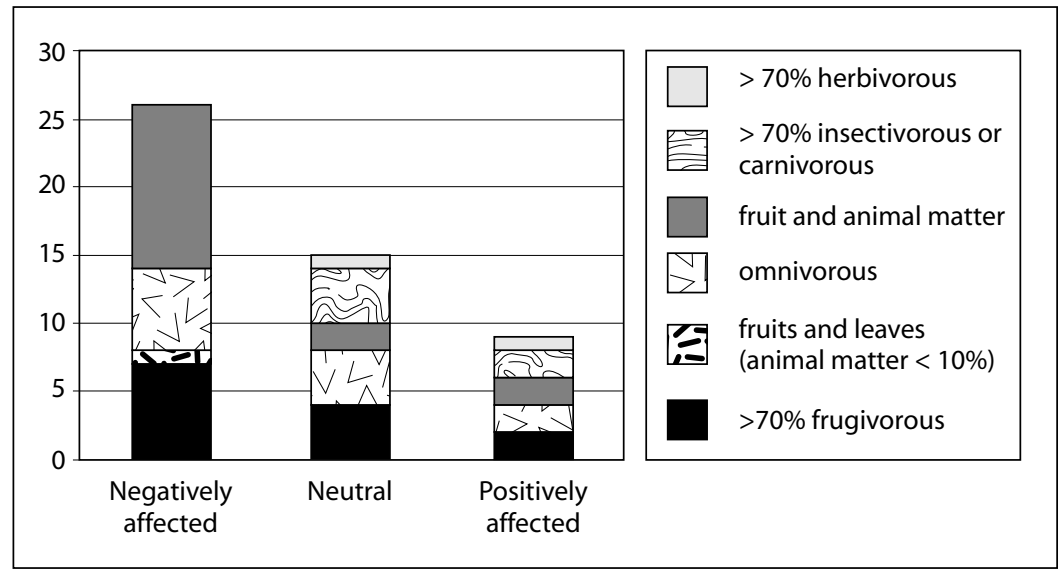

Figure 19. Column charts of sensitivity to logging in relation to feeding categories.

When we conducted the same correspondence analyses for mammals only, an interesting result was that all species with primarily insectivorous and carnivorous feeding strategies were sensitive to logging (Rhinosciurus laticaudatus, Hemigalus derbyanus, Arctogalidia trivirgata, Viverra tangalunga, Tarsius bancanus). Also, 6 out of the 10 terrestrial species were sensitive to logging.

An analysis of the relationship between our predictor variables and the sensitivity (of birds) to fragmentation did not result in any useful findings, because all but 2 (Lophura ignita and Picus puniceus) of our test species had been reported to be sensitive to fragmentation; sample size of fragmentation tolerant species was therefore too low. One predictor variable, feeding category, corresponded significantly with sensitivity to fragmentation, but this was probably a data artefact; Lambert and Collar (2002) considered all woodpeckers to be sensitive to fragmentation, and all woodpeckers 
feed on arthropods, thus leading to a strong correlation between the two variables. We do not, however, consider this to be sufficient evidence of a significant functional relationship between insectivorous feeding strategies and sensitivity to fragmentation in general.

Because the correspondence analyses showed some interesting patterns, albeit statistically not significant, we used categorical principal components analyses (CATPCA) to analyse the relationship between all categorical variables. We used an object principal normalisation method, which should optimise distances between species. Figures $20 \mathrm{a}-\mathrm{e}$ graphically express the bivariate relationships that we found in the correspondence analyses. Mammal species that are sensitive to logging group together, primarily determined by feeding strata and feeding categories (see Fig. 20b). Inspection of these two variables (in Figs. $20 \mathrm{~d}$ and 20e) indicates that mammals that are sensitive to logging are primarily those exclusively feeding on vertebrates and invertebrates (no. 5 in Fig. 20d) and those exclusively feeding on fruits (no. 1 in Fig. 20d). On the other hand, the herbivorous (no. 6 in Fig. 20d) and omnivorous (no. 3 in Fig. 20d) species appear to be more tolerant to logging. Also, the loggingsensitive species are disproportionally represented by terrestrial species (no. 1 in Fig. $20 \mathrm{e}$ ), although not exclusively. Figure 20e further indicates that species of lower strata (understorey; no. 2 in Fig. 20e) are relatively tolerant of logging.

A similar exercise for birds did not provide any additional insights, primarily, as expressed above, because this group was dominated by the woodpeckers that, at least at our level of analysis, had similar feeding strategies and strata.

The results of these statistical analyses showed that even with the relatively limited information available for this research, we were able to identify patterns in the characteristics of species that were either sensitive or tolerant to logging. Firstly, species that are tolerant to logging also appear to be common on small islands. The relationship is not necessarily reciprocal, however, and some species that occur on many islands, such as mouse-deer Tragulus spp., can be sensitive to logging. It is likely that these species are terrestrial (as in mouse-deer) or have a specialised diet being exclusively frugivorous, carnivorous, or insectivorous. The wider the ecological niche of a species, the more tolerant to logging it appears. Such preliminary findings are useful for developing hypotheses regarding other poorly known species; this is especially important if species are endangered but ecologically poorly known, e.g., Catopuma badia, the Bornean Bay Cat and Pardofelis marmorata, the Marbled Cat. 
a
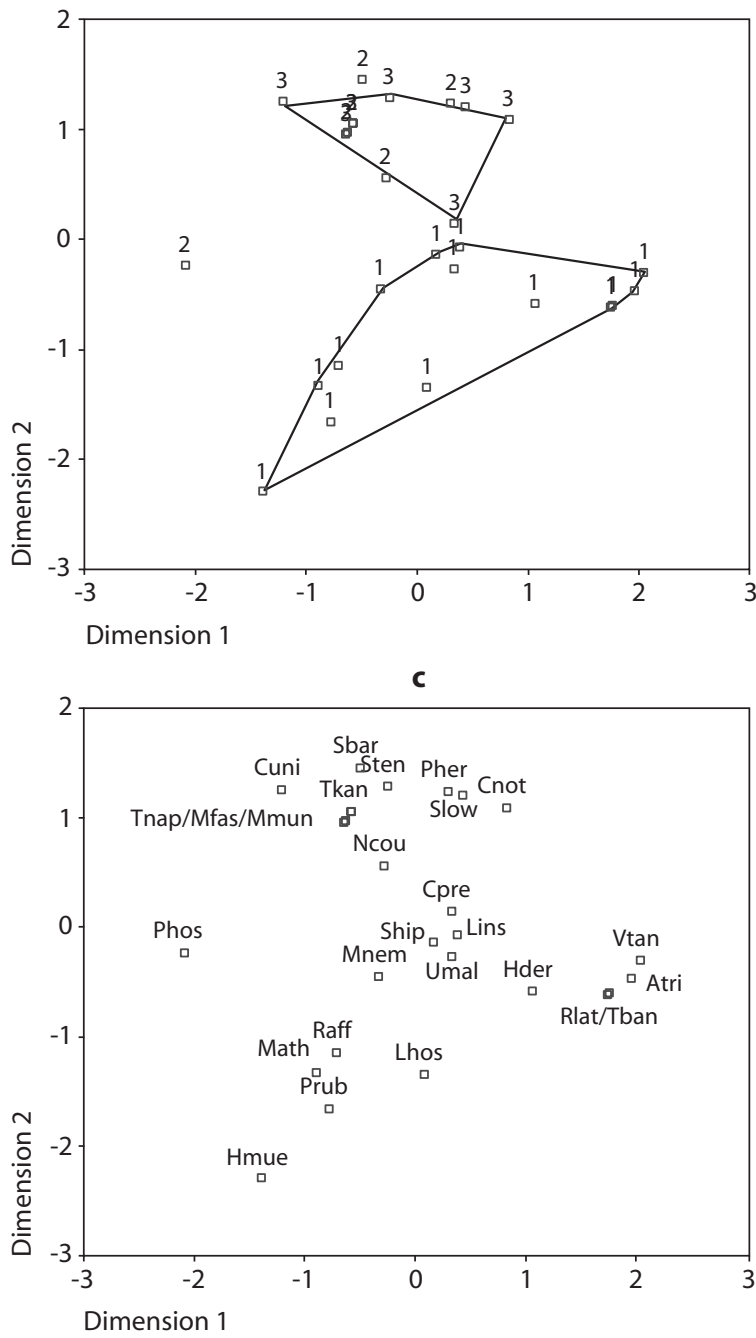

$1=$ sensitive to logging

$2=$ neutral

$3=$ benefiting from logging

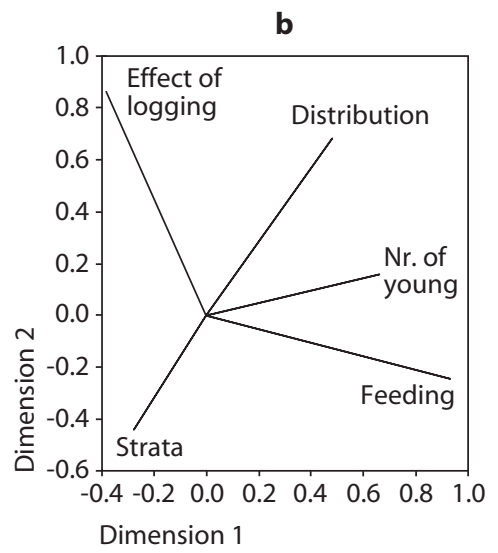

Figure 20a-c. CATPCA of 21 mammal species, with 5 variables: Sensitivity to logging, feeding strategies, feeding strata, distributional range, and number of offspring. Fig. 20a shows the object points labelled by sensitivity to logging; Fig. 20b shows the component loadings of each of the variables; Fig. 20c shows the abbreviated species names: Atri=Arctogalidia trivirgata; $C$ not $=$ Callosciurus notatus; $C p r e=C$. prevostii; Cuni $=$ Cervus unicolor; Hder=Hemigalus derbyanus; Hmue=Hylobates muelleri; Lhos=Lariscus hosei; Lins=L. insignis; Math=Muntiacus atherodes; Mmun=Mu. muntjac; Mfas=Macaca fascicularis; Mnem=Ma. nemestrina; Ncou=Nycticebus coucang; Pher=Paradoxurus hermaphroditus; Phos=Presbytis hosei; Prub=P. rubicunda; Raff=Ratufa affinis; Rlat=Rhinosciurus laticaudatus; Sbar=Sus barbatus; Ship=Sundasciurus hippurus; Slow=Sun. lowii; Sten=Sun. tenuis; Tban=Tarsius bancanus; Tkan=Tragulus kanchil; Tnap=Tr. napu; Umal=Ursus malayanus; and Vtan=Viverra tangalunga. 


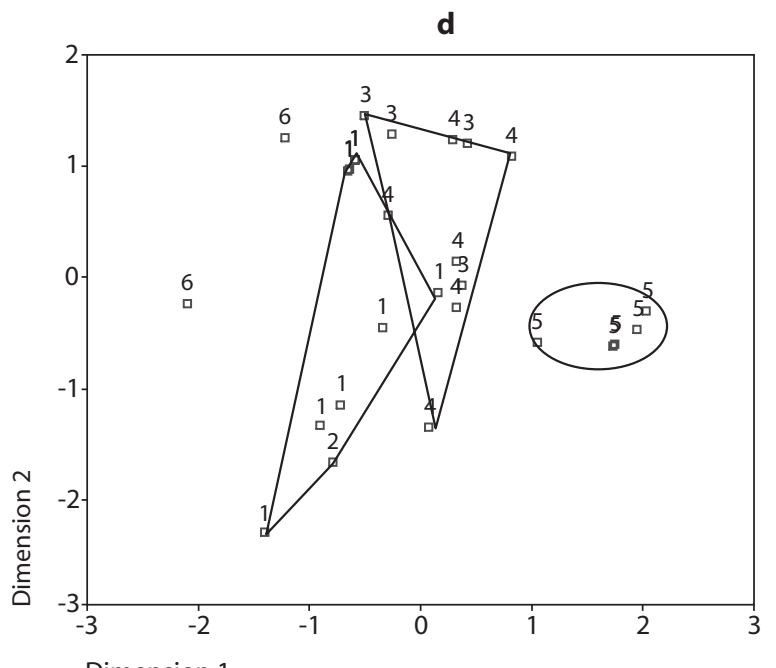

$$
\begin{aligned}
& 1=\text { frugivores } \\
& 2=\text { frugi/herbivores } \\
& 3=\text { omnivores } \\
& 4=\text { frugi/carni/insectivores } \\
& 5=\text { carni/insectivores } \\
& 6=\text { herbivores }
\end{aligned}
$$

Dimension 1

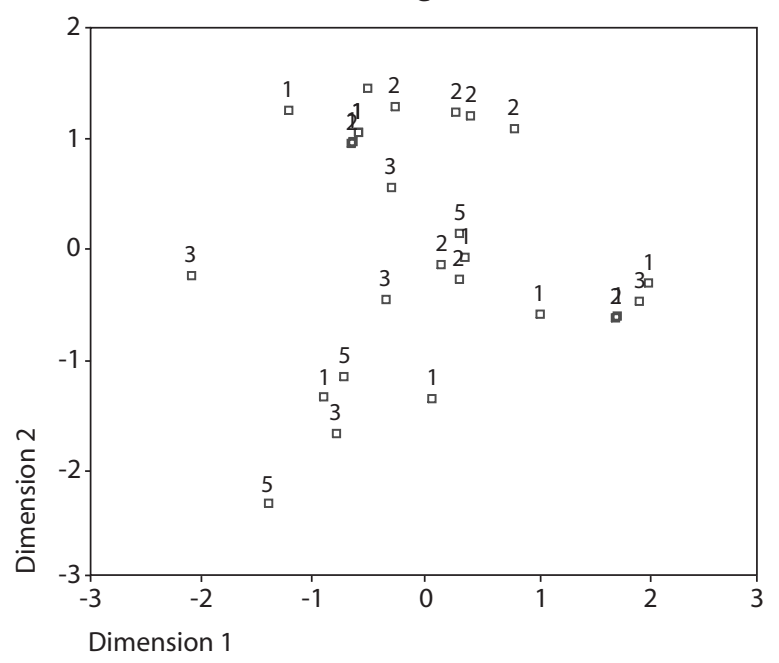

$$
\begin{aligned}
& 1=\text { terrestrial } \\
& 2=\text { ground }- \text { understorey } \\
& 3=\text { lower }- \text { middle strata } \\
& 5=\text { middle }- \text { upper strata }
\end{aligned}
$$

Figure 20d, e. CATPCA of 21 mammal species. Fig. 20d shows the object points labelled by feeding strategy; Fig. 20e shows object points labelled by feeding strata. 



\section{Discussion}

We aim to identify and clarify opportunities to improve forestry practices and the value of timber concessions for conserving wildlife. We do not claim that loggedover forest can be equal to primary forest in its conservation values, or that strictly protected areas are not needed. We assume:

1) That logged forests are, and will likely continue to be, a significant land use in Borneo, and in Sundaland more generally;

2) That these forests have significant conservation values compared with other land uses such as oil palm or acacia plantations;

3) That these values can be improved by modifying forestry practices; and

4) That such improvements can be economically implemented.

This last assumption is perhaps the most problematic: past efforts to improve management have met with little success. Three recent developments give however some cause for hope. First, certification schemes have become increasingly relevant in the last few years and concession managers are more interested in developing and applying standards. Second, several influential conservation NGOs have recognised the potential for working with timber concessionaires to address conservation goals. Third, some local authorities are aware of the need for long-term planning for natural resources, and are beginning to examine how forestry and conservation should be integrated in this process. Our goal is to provide informed advice supporting these developments.

In the following discussion we evaluate some aspects of our findings in the context of the wider literature; other aspects have already been extensively dealt with in our more specialised literature review above.

\section{Methodological considerations}

The main null hypothesis used to gauge studies of logging impact on species density is to assume no change. Our review does not formally test this null hypothesis, or 
gauge the confidence we might place in assessing the magnitude of any departurethese questions would require careful re-analyses of each study. Instead, we estimated a percentage change following logging, without assessing the statistical power of the analysis, or the per-study uncertainty related to this change (see Tables 2-9). Logging's effects on the population densities of our selected species are not always clear or consistent, with some research showing increases following logging and others indicating decreases. For each species we tried to generalise by assessing density trends from a range of studies in relation to age of logging and the absence or presence of hunting, while also assessing study design. Still, our interpretation depends on the quantity and quality of the information available.

We realise the potential problem of making recommendations on the basis of data, that are often suggestive more than conclusive (Mangel et al.1996). However, because of the generally poor nature of existing data sets on changes in species density, we decided to focus on estimating parameters to describe how a given response related to a putative cause, thus focusing on the mechanisms of the change rather than on the change itself. In doing this, we also recognise that Bornean ecosystems typically show large random fluctuations that obscure timber harvesting's ecological effects. Our conclusions are therefore based on assessing various hypotheses in which we weighed differing scenarios by their plausibility.

For instance, Bornean Gibbons (Hylobates muelleri) were judged to decline following logging in six out of 11 studies (see Table 6), with two (very short-term) studies noting an increase. Further data suggested that important factors were heavy reliance on fruit, difficulty in moving through a broken canopy, a reluctance to move over open ground, and vulnerability to hunting. We thus considered a decline after logging as the most logical response and rejected several alternative hypotheses. For instance, we considered unlikely that the species could increase following logging because although there is more fruit in low-pioneer vegetation, it appears to be outside the gibbon's feeding strata.

In our recommendations we emphasise management changes conforming to combined general ecological principles and our interpretation of the logging data sets. For example, we suggest maintaining fruit trees and canopy connectivity, and reducing forest fragmentation and hunting effects. This is not a fixed or general 'gibbon law', but rather a pragmatic approach acknowledging that while we might not know everything, we do know enough to suggest beneficial changes. When new data becomes available on gibbons, and these advance our understanding, these new insights should be incorporated into the management recommendations. We consider our approach justified because of the inherently uncertain nature of forest and wildlife ecology and the pressing need for improved conservation management. Concluding that 'more research is needed' would not be enough.

\section{Direct effects of timber extraction}

As we have shown, vertebrates respond in various ways to timber harvesting, habitat fragmentation and hunting. These influences change simultaneously and interact in various ways, and it is rarely possible to determine their individual contributions to a 
perceived population change. Here we shall try and consider the implications of each factor with reference to our own analyses.

Lambert and Collar (2002) found that selective timber harvesting has little detectable effect on most bird species; usually only a few particular specialists decline dramatically. A compilation of 34 bird studies from Africa, Asia and the Americas concluded that selective logging did not significantly reduce species diversity relative to mature forest (Dunn 2004), although relative abundance and species composition do reveal changes. Crome et al. (1996) found that few, if any, bird and small mammal species were negatively affected by selective logging in the Australian tropics. Observations of small mammal communities generally imply increased abundances and species richness following logging in Bolivia (Fredericksen \& Fredericksen 2002), China (Wu et al. 1996) and Venezuela (Ochoa 2000).

The generality of such findings is broadly supported by our own mammal summary (see section on multivariate analysis), with 15 out of 41 species declining significantly following logging, 13 showing little clear change and 13 increasing. Our summary of bird species responses appears less consistent with the overall pattern, but is biased by the available literature focusing more on sensitive species: more than half (12) of the 23 species we considered declined significantly following logging.

Data on amphibians and reptiles were limited. Amphibians appear little affected by a light logging regime, at least initially. In fact, reduced impact logging increased diversity, with new microhabitats being created for species that normally do not occur in primary forests. Our data are too limited to determine the wider implications of these changes in amphibian communities. Other studies, however (Inger 1980a; Iskandar 1999a; Iskandar \& Setyanto 1999), have found that in Southeast Asia, hotter, drier forests support fewer arboreal and terrestrial frogs, and fewer diurnal arboreal lizards, but more terrestrial lizards, than lowland primary rainforests. The variations in the macro- and microclimates affect amphibian and reptilian species differently according to their general susceptibility to hot, dry conditions, their sites of oviposition, their daily activity cycle, and the opportunities to retreat from inclement weather. Terrestrial lizard eggs are more resistant to dry conditions and are laid in relatively stable micro-environments. Since terrestrial frogs and lizards in Bornean forests are potential competitors for food and habitat resources, a significant decrease in the abundance of frogs might result in an increase in lizards. Alternatively, in some lizard groups, abundance and diversity may decline (Inger pers. obs.), such as secretive skinks that use the forest floor litter, canopy dwelling skinks and perhaps several Draco species. All agamid lizards oviposit on the forest floor by digging a shallow hole in the ground and covering it afterwards. Desiccation of that stratum following logging would probably reduce this group's abundance. Such issues require clarification.

\section{Phylogeny, distribution, taxonomy}

Endemic mammal species from Borneo or Sundaland that evolved during the Miocene or Early Pliocene appear more intolerant of logging than other groups. There is little geographical variation in morphology (few subspecies) among this group, and they 
are generally rare on small islands, with the exception of Ratufa affinis, Arctogalidia trivirgata, and Viverra tangalunga. They tend to have narrow ecological niches, and many have strictly frugivorous, carnivorous or insectivorous feeding habits. Some are restricted to terrestrial feeding strata although others also occur higher up in trees and the understorey.

In contrast, mammals that cope well with logging generally appear to be younger species: mostly from the Late Pliocene or Pleistocene. They are common on small islands and often occur throughout Southeast Asia, where they exhibit significant morphological variation. Most tolerant species are herbivores or omnivores that include significant amounts of foliage or other vegetal matter in their diets. Many live in the lower vegetation strata (including terrestrial), although some are found at all forest levels.

Logging's ecological impacts on birds are not as well documented as for mammals. Our sample was dominated by one group, the woodpeckers, which, in terms of feeding strata and strategies, are relatively similar. Furthermore, Lambert and Collar (2002) considered all but two of our test species to be sensitive to fragmentation and it was thus not possible to make formal comparisons to assess which specific factors contribute to this vulnerability to fragmentation. We did not investigate the relationship between the age of bird species and their sensitivity to logging because the necessary information was not available. Two papers, however, address the phylogeny of Asian pheasants (Kimball et al. 2001; Randi et al. 2001). The two species of Lophura were thought to be either positively affected or neutral to logging effects (see Table 4) and both species diverged from their nearest living relatives during the Late Pliocene or Pleistocene, which supports our general finding for mammals. Logging seems to negatively affect Lobiophasis bulweri. If indeed $L$. bulweri has been correctly assigned to its own monotypic genus (the phylogenetic relationship of L. bulweri to Lophura remains poorly resolved, Randi et al. 2001), its divergence from other pheasants would have likely preceded the divergence of Lophura species, and the species could be of Early-Middle Pliocene age. Although pheasants seem to conform to the expected relationship between species age and logging tolerance, such a conclusion remain provisional.

What are the plausible underlying mechanisms for the patterns identified in this study? To our knowledge we are the first to report the correlation between mammal species age and sensitivity to logging, although others have noted that older evolutionary bird and marsupial lineages seem more prone to extinction (e.g., Gaston \& Blackburn 1997; Johnson et al. 2002). Older lineages may typically be relics with restricted geographical ranges or populations (Fisher \& Owens 2004; Gaston \& Blackburn 1997). Older lineages might also contain more specialists, which could increase their extinction risk following disturbances like logging (Johnson et al. 2002; Fisher et al. 2003; Fisher \& Owens 2004). The second explanation gains some support in our analyses, but we link our findings to the palaeo-environmental conditions under which many species evolved (after Meijaard 2003c).

Between 5.5 and 4.5 Mya at the start of the Pliocene, grasslands and other open vegetation types expanded in Southeast Asia, leading, among other changes, to the rapid speciation of deer (Meijaard 2003c; Meijaard \& Groves 2004; Pitra et al. 2004) 
as well as Southeast Asian bovids (e.g., Hassanin \& Ropiquet 2004). Such species would be well adapted to the more open or mosaic conditions in forests that logging creates. Between 4 and 3 Mya warmer and wetter conditions prevailed once more, and much of the Sundaic Subregion was covered in evergreen rainforest (Morley 2000). We suggest therefore that Southeast Asian forest species that evolved during the Late Miocene (11.1-5.3 Mya) did so in an environment where rainforests were more widespread than in recent times (Morley 2000). From then on, much cooler and drier conditions became the norm through the Pleistocene climatic fluctuations and ice ages. Species that evolved during the Pliocene dry period and the Pleistocene are, we suggest, better adapted to changing conditions, including open, fragmented forests, and therefore often able to cope better with logging-induced changes in vegetation.

The finding that there are more subspecies among logging-tolerant species should be viewed with caution. Taxonomic indices may lack objectivity as subspecific characterisation depends as much on the extent and nature of any investigation as upon any intraspecific variation. Also, in Southeast Asian taxonomy, many species occurring on the small islands of the Sunda Shelf have been given subspecific status, and these two variables (number of subspecies and number of small island occurrences, see analyses above) were indeed significantly correlated (Pearson correlation $=0.84, p<0.001)$. Still, there is an interesting trend in the number of islands on which species occur and their tolerance of logging, which warrants further investigation. Interestingly, this trend appears to be largely independent of the species age pattern discussed above. An explanation could be that species that survive on small islands generally cope well with habitat fragmentation-notably the ecological effects of living in a restricted area with relatively high disturbance and edge effects (e.g. Denslow 2003). Assuming that many taxa that have colonised small islands in the past have not survived into modern times, it seems reasonable to assume that small island populations can provide some measure, at least in a crudely indicative sense, of relative adaptability during climatic disruption, disturbance and, perhaps, anthropogenic influences.

\section{Feeding strategies}

Ecological specialisation is thought to increase the probability of decline and extinction under changing environmental conditions (Harcourt et al. 2002; Owens $\&$ Bennett 2000). Our analyses indicate that, generally, species with wider ecological niches, i.e., those that easily adapt to disturbed conditions or feed on many different food items, are more tolerant than those with more narrowly defined ecological needs. Heydon and Bulloh (1997) showed that specialised carnivores, insectivores and frugivores were affected by logging in Borneo. Lambert and Collar (2002) also found that specialised feeders appear to suffer most from logging. It is likely that a species' ability to switch between dietary components allows it to compensate when logging directly causes certain foods to decline. Species that can switch diets following disturbances should logically be more tolerant, an example being the small woodpecker Sasia abnormis that forages on bamboo in logged forest and lianas in 
unlogged forest (Styring \& Hussin 2004a). As a general rule it appears that the wider a species' ecological niche, the greater its tolerance to logging.

Generalisations from past investigations have implied that species at higher trophic levels (carnivores, insectivores) are more vulnerable to disturbance than species lower down the food chain (herbivores) (Diamond 1984). In Venezuelan forests, Ochoa (2000) found that logging simplified the trophic structure of nonvolant species, with semi-arboreal predator-omnivores becoming the dominant guild, followed by terrestrial frugivore-omnivores; there was also a significant reduction in the relative abundance of mainly canopy-associated species. Such patterns could reflect specialisation rather than trophic level per se.

Our data suggest that logging has a greater effect on species that are restricted to either the canopy or the ground, compared with those that can use various vegetation strata. Why are terrestrial or canopy species with specialised feeding strategies more intolerant of logging? Several non-independent explanations are possible:

1. logging creates fragmentation at ground level (through roads and skid trails);

2. debris and thick bushy understorey may hinder movement for some animals;

3. logging creates gaps in the canopy, making movement more difficult for arboreal species; and,

4. opening up the canopy (and in some cases slashing ground vegetation) has various effects on understorey vegetation, in turn affecting understorey invertebrates and thus perhaps the taxa that feed on them. For instance, termite species richness and abundance declined significantly after primary forests were logged in Sumatra (Jones et al. 2003). The relationship between invertebrates and logging is, however, not clear: in Sabah, there was no obvious decline between primary forest and two selectively logged forest types (Eggleton et al. 1997).

Further work is needed to determine the main reasons why species restricted to ground levels or the canopy suffer especially from logging.

\section{The role of timber species}

Logging in Borneo primarily targets dipterocarps and it would be expected that vertebrates depending on these trees (or indeed on any other heavily targeted commercial timber species such as Agathis) would be disproportionately affected. Few vertebrate species have a clear dependency on dipterocarps (or indeed on Agathis). Large dipterocarp trees (with cavities) may serve as important nest sites of species like hornbills (though it remains uncertain if this role cannot be provided by other large tree species). It is unclear whether any vertebrates depend on dipterocarp leaves. Whilst some colobine monkeys such as Presbytis rubicunda may occasionally eat some leaves, it is recognised that dipterocarp foliage is well defended against generalist herbivores and generally unpalatable to them (Janzen 1974; Waterman et al. 1988). Seed eaters such as Sun Bears, Bearded Pigs, Muntiacus species, porcupines, certain squirrels and some hornbills feed on dipterocarp fruits when they are available, but must eat other foods most of the time. Nonetheless, mast fruiting episodes involving 
dipterocarps may be critical for the long-term persistence of several species, including pigs and bears which put on fat and breed more successfully following such events.

Despite the various roles played by dipterocarp species, the very low vertebrate abundances found in areas like Malinau can likely be attributed to the low abundance of fruits and palatable foliage (Janzen 1974). This suggests that the resource availability of a logged dipterocarp forest could be increased by replanting with trees that increase the availability of food for wildlife. Ideally this might involve species that provide valuable timber as well as fruit, e.g. genera like Durio, Campnosperma, Pometia, Calophyllum, Dialium and families like Sapotaceae (e.g. Madhuca, Palaquium Payena Pouteria spp.), Fagaceae (Castanopsis, Lithocarpus, Quercus) and Moraceae, and even some specific dipterocarps such as Shorea pinanga that are known to provide valued seeds or fruits.

\section{Change in structural characteristics}

Larger-stemmed trees provide wildlife with hollows for nesting and food storage of many species. Practices that remove trees with cavities, as well as dead snags, may be one reason why hole-nesting birds such as hornbills suffer from logging, especially those like Rhinoplax vigil that primarily nest in large dipterocarps (see section on birds in part 1). Certain hollow-using civets and squirrels, especially species like Ratufa affinis (Fig. 21), may also suffer from the disappearance of hollow trees after logging.

There is strikingly little information about the distribution, determinants and character of tree hollows in dipterocarp forests. For example, a recent state-of-the-art review on dipterocarp trees (Appanah \& Turnbull 1998) makes no reference to the factors that lead to hollow stems, other than briefly mentioning heart rot. Cavities

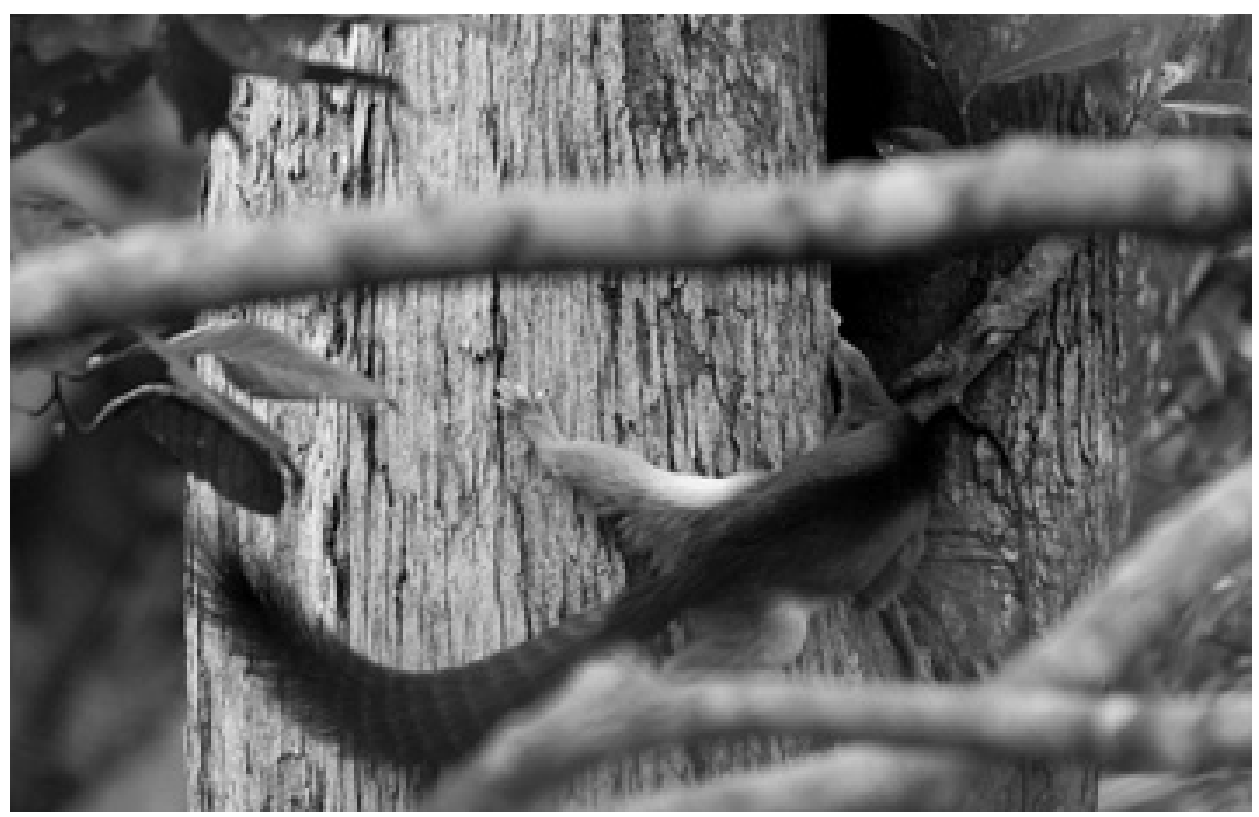

Figure 21. Hollow trees are an important ecological feature of healthy forests. Here a Giant Squirrel (Ratufa bicolor) is entering a tree cavity. (Photo by Kimabajo) 
appear more likely in larger-stemmed heartwood-forming species with relatively light timber. Initially, after limited timber removal, large and damaged trees may provide ample cavity-forming opportunities, but this may change if larger trees are ultimately removed, perhaps over several cutting cycles. Some Southeast Asian forest trees, such as Dyera spp. do not produce heartwood ( $\mathrm{Ng} 1986)$ and seem unlikely to develop large cavities, but the subject is little studied. Regenerating forest stands may not contain significant amounts of heart rot and may not develop the large cavities used by, for instance, hornbills (McClure 1968). In addition, the shape and architecture of cavities and whether they collect water is likely to be influenced by the characteristic angle that branches make with the main trunk, the details of self pruning, and active and passive responses to stem damage (e.g., Loehle 1988) — topics that remain poorly researched.

Various microclimatic changes occur in a forest that has been subjected to timber harvesting. Incident light, humidity, wind, temperature and other microclimatic characteristics are altered, which can subsequently affect the physiologically narrow environmental parameters some species require for nesting, incubation, growth, lactation, etc. Overall these microclimatic factors are seldom identified as determining faunistic changes. Nonetheless, for certain groups such as ground nesting anurans and agamid lizards, such factors may be critical.

Specific vertebrates may depend on particular structures for perching, foraging, breeding or resting (e.g., we know that gibbons are obligate canopy dwellers that require intact canopy structure, that Ratufa prefer upper canopy, that binturong are reluctant to travel on the ground, and that hornbills rely on branches for insect foraging), but only woodpeckers have been well studied in this respect. For example, woodpeckers specialising in foraging on larger dead trees suffer in older logged stands in Peninsular Malaysia where such habitat is scarce (Styring \& Hussin 2004a). Well supported generalisations with regard to most other species remain elusive. Some will benefit from the creation of gaps (e.g., deer) and others will fail to find food there (e.g., interior forest bats like Hipposideros spp. and Rhinolophus spp.). Some species (e.g., some small rodents) benefit from the denser, more complex understorey conditions that follow logging, while others seem to require the orderly and open structure of primary forests (e.g., forest owls like Otus rufescens and frogmouths Batrachostomus spp.). Again, the more adaptable a species' behaviour, the greater the chance that it can cope with logging.

\section{Associated effects of timber extraction}

Having established some tentative general patterns for species' tolerance to timber harvesting, we investigate how the direct ecological impacts compare with associated effects such as forest fragmentation and increased hunting pressure.

\section{Fragmentation}

Studies suggest that fragmentation affects a broader range of bird species,- - omnivores, insectivores, frugivores and nectarivores - than does selective logging, though various generalists and non-forest species, increase in density (Lambert \& Collar 2002). No 
detailed studies have been conducted on fragmentation's effects on Sundaic mammals, although some studies have linked evolutionary relationships between species to their relative sensitivity to fragmentation (e.g., Harcourt \& Schwartz 2001; Ruedi \& Fumagalli 1996). A study by Brook et al. (2003) also linked mammal extinctions on the island of Singapore to the reduction of available habitat (see also Kinnaird et al. 2003 for some discussion in relation to protected areas in Sumatra).

Meijaard (2003b) investigated mammals on islands on the Sunda Shelf, which were all isolated after the last glacial maximum some 14,000 years ago. These data provide a model that might be used to assess the effects of habitat fragmentation, because these islands were surrounded by a much larger forest area before they were isolated by rising sea levels. It needs to be realised, however, that not all islands were covered in tropical evergreen forest (see Heaney 1986; Meijaard 2003b; Bird in prep.). More precisely, these island faunas are the result of combined fragmentation, hunting, and habitat change, since most islands have been inhabited by people for many centuries. Meijaard's (2003b) data show that the four large carnivores Panthera tigris (Tiger), P. pardus (Leopard), Neofelis nebulosa (Clouded Leopard) and Ursus malayanus (Malayan Sun Bear, insofar as we can call it a carnivore) occur on islands that are either large or very close to the Malay Peninsula, Sumatra, Borneo or Java (see Table 13). These observations suggest that forest areas much smaller than ca. $5,000 \mathrm{~km}^{2}$ are unable to sustain viable populations of large carnivores, unless there are regular immigration opportunities from outside and low levels of hunting.

Similar relationships between the occurrence of carnivores, their body size, fragment area and isolation were reported by Crooks (2002) and Laidlaw (2000) in California and Peninsular Malaysia respectively, with the largest carnivores only persisting in the largest patches relatively close to source areas. As expected, the larger carnivores appear unable to survive on small islands, but less anticipated is that smaller carnivores and insectivores (Herpestidae, Soricidae, Tarsiidae and Mustelidae) are also restricted to larger forest areas (Table 13). This may relate to their being at the top of the food chain, a factor which, in combination with small geographic range, is known to significantly increase the likelihood of extinction (Purvis et al. 2000). Thus, vulnerability may relate to trophic level.

Island faunas however differ from those in forest fragments in several key respects. Forest patches will usually maintain greater dispersal opportunities to other forest areas than most islands. Recent research has shown that matrix habitats can profoundly influence within-fragment dynamics (Jules \& Shahani 2003). Still, trends in the island fauna data are suggestive. The terrestrial, carnivorous/insectivorous mongooses and shrews only occur on a few of the largest islands. At the spectrum's other end, the ungulates (pigs, deer and mouse-deer) occur on many islands, including small ones. The herbivorous Flying Lemur (Cynocephalus variegatus) also survives in many small areas, including Perhentian Island with a land area of only $2 \mathrm{~km}^{2}$.

Conclusions remain tentative, but simple relationships between body size and extinction risk in habitat fragments (e.g., Belovsky 1987) seem inadequate to explain the observed patterns (pigs are large and so are tigers, bears and leopards, but the former survive on isolated small islands whereas the latter persist mainly on large or less isolated islands). Biedermann (2003) suggested that a direct relationship 
Table 13. Number and mean size of islands in the Indo-Malayan Region on which mammal species from different families occur. We excluded all species that were probably introduced. The analysis is based on data by Meijaard (2003b).

\begin{tabular}{|c|c|c|c|c|}
\hline Family & $\begin{array}{l}\text { number of } \\
\text { species in } \\
\text { family that } \\
\text { occur on small } \\
\text { islands }\end{array}$ & $\begin{array}{l}\text { average } \\
\text { number of } \\
\text { islands on } \\
\text { which species } \\
\text { occur }\end{array}$ & $\begin{array}{l}\text { average size } \\
\text { of island }\left(\mathbf{k m}^{2}\right)\end{array}$ & $\begin{array}{l}\text { minimum size } \\
\text { of island }\left(\mathbf{k m}^{2}\right)\end{array}$ \\
\hline $\begin{array}{l}\text { Mustelidae (martens, } \\
\text { badgers and otters) }\end{array}$ & 5 & 5.0 & 4,564 & 1 \\
\hline Herpestidae (mongooses) & 2 & 2.0 & 4,519 & 1 \\
\hline Tarsiidae (tarsier) & 1 & 4.0 & 4,109 & 54 \\
\hline Ursidae (bears) & 1 & 4.0 & 3,735 & 929 \\
\hline Soricidae (shrews) & 2 & 2.7 & 3,594 & 228 \\
\hline Felidae (cats) & 4 & 4.8 & 2,613 & 17 \\
\hline Viverridae (civets) & 8 & 7.3 & 2,536 & 1 \\
\hline Muridae (rats and mice) & 26 & 8.2 & 2,350 & 2 \\
\hline Suidae (pigs) & 2 & 10.5 & 2,163 & 1 \\
\hline Tupaiidae (treeshrews) & 10 & 8.4 & 2,096 & 1 \\
\hline Sciuridae (squirrels) & 17 & 8.8 & 1,933 & 2 \\
\hline Hystricidae (porcupines) & 4 & 2.8 & 1,825 & 10 \\
\hline $\begin{array}{l}\text { Pteromyidae (flying } \\
\text { squirrels) }\end{array}$ & 14 & 2.9 & 1,634 & 24 \\
\hline Manidae (Pangolin) & 1 & 23.0 & 1,565 & 7 \\
\hline Hylobatidae (gibbons) & 1 & 4.0 & 1,487 & 530 \\
\hline Loridae (Slow Loris) & 1 & 18.0 & 1,038 & 20 \\
\hline Cervidae (deer) & 2 & 8.5 & 1,018 & 1 \\
\hline $\begin{array}{l}\text { Cercopithecidae } \\
\text { (monkeys) }\end{array}$ & 7 & 6.1 & 871 & 1 \\
\hline Tragulidae (mouse-deer) & 2 & 39.0 & 781 & 1 \\
\hline $\begin{array}{l}\text { Erinaceidae (Moonrat and } \\
\text { Lesser Gymnure) }\end{array}$ & 2 & 1.5 & 630 & 6 \\
\hline $\begin{array}{l}\text { Cynocephalidae (Flying } \\
\text { Lemur) }\end{array}$ & 1 & 37.0 & 614 & 2 \\
\hline
\end{tabular}

between habitat area, body size and extinction risk might only apply to ecological specialists, not to generalists. Also, trophic levels need to be taken into account, with top predators needing sufficient prey. Swihart et al. (2003) reported a negative correlation between niche breadth and extinction risks in fragmented forest areas for a range of mammalian and amphibian species in North America. This pattern is consistent with small mammal data from the Australian tropics, where edge specialists and those species able to utilise the matrix between forest fragments increased following fragmentation, whereas forest specialists declined (Harrington et al. 2001). Extinction became increasingly likely when the animal's home range was not many times smaller than the fragment (Harrington et al. 2001). Fragment size appears therefore to be a key factor in the population viability of forest interior specialists in fragments (Kinnaird et al. 2003). 
It is not surprising that timber extraction and fragmentation affect species in different ways. Timber extraction modifies the physical environment, such as nest sites, cover, home range needs, or a moist leaf litter and understorey, and thereby affects species that depend on these features. Larger-scale fragmentation, on the other hand, is more likely to influence population characteristics such as demography and dispersal processes because it reduces effective population sizes. Fragmentation also affects species on individual and autecological levels, including survival rates in smaller patches. This in turn influences reproductive rates, recruitment and demographic ratios.

Fragmentation in the Neotropics appears to reduce diversity across a broad taxa spectrum, although some species, like medium-sized herbivores, benefit when large carnivores disappear (Terborgh 1992). Such 'benefits' can lead to an overabundance causing, for example, increased seedling damage and seed predation, and competition with more vulnerable species (e.g., Asquith et al. 1997). Soulé et al. (1988) suggested that smaller omnivorous species become very abundant in fragments, a problem they term 'the mesopredator release'. How this affects prey populations remains poorly known, but Laurance (1997) hypothesised that larger prey species would benefit from large carnivores disappearing (possibly explaining why mouse-deer (Tragulus spp.) are so common on many islands), while pressure on smaller vertebrates is likely to increase.

Edge effects and the ability of different species to move through matrix or degraded forest habitat are poorly known in Southeast Asia. Such information is however vital to understanding persistence in highly fragmented landscapes.

\section{Hunting}

Besides fragmentation, hunting is a significant factor in wildlife decline in many timber concessions and indeed in unlogged forests (Robinson \& Bennett 1999; Fimbel et al. 2001). Our analysis has not shed much light on hunting's impacts on species density changes following timber harvesting. This is due to the lack of information on hunting pressure in logging studies, although for some species groups we were able to infer impacts (see, for instance, Table 6). Nonetheless, several studies allow us to conclude that hunting can reduce or even eliminate species from sizeable forest areas (Bennett \& Gumal 2001; Bennett et al. 1999; Nijman in press; Walter 2000). Hunting affects species sought for food or trade, i.e., pigs, deer, muntjacs, mouse-deer and turtles, although methods such as snaring are indiscriminate and can cause more general impacts. Even moderate hunting at low human densities can lead to changes in wildlife populations. Collection for the live animal trade is also a significant concern for certain bird taxa.

Given that our own analysis adds little to the considerable literature already available on the subject (see above), we shall not restate the well-established arguments here. Instead we will focus on management recommendations that should reduce hunting pressure in timber concessions. Controlling hunting of vulnerable species, especially commercial hunting, is a difficult but important management goal in developing the wildlife conservation value of timber concessions. 



\section{Conclusions}

Our review has shown that selective logging, in a commercial concession context, can have a significant negative impact on Bornean vertebrates. Though some of these effects are the direct consequences of timber cutting and extraction, or of roadbuilding, many others are associated with the changes, such as habitat fragmentation and increased hunting, that commonly occur in concessions. All these influences can be reduced by suitable and effective management.

Sustainable forestry may be the most politically viable means to maintain forest cover in much of Borneo. Conservation of many wide ranging and low density species require large forest landscapes. Recent data show that Kalimantan's forest are disappearing more rapidly (in absolute terms) within protected areas (actual and proposed) than outside (Fuller et al. 2003). Kalimantan's protected area network, which was designed to provide a safety net for these species, is thus failing to achieve its main objective, i.e., to preserve diversity of plant and animal species (Ministry of Forestry 1990, Ch. 1, Art. 1.13). In addition, Kalimantan's protected area network is too small and fragmented to ensure the survival of all elements of biodiversity, especially species with large home ranges or migrations (Jepson et al. 2002). In the light of this, biodiversity conservation outside 'protected areas' is becoming increasingly important, which is indicated by the growing attention from conservation NGOs such as The Nature Conservancy (TNC), World Wide Fund for Nature (WWF) and the Wildlife Conservation Society (WCS) for conservation in used forest areas (although there are critics, see, for example, Gullison (2003) though not referring specifically to Borneo). In our view, if successful long-term survival of Borneo's vertebrate biodiversity is seriously envisaged, recognising the value of forestry concessions for biodiversity conservation is vitally important. Furthermore, as already noted, concessionaires are legally obliged to ensure the survival of protected species in their forests. This should include protection of the habitats that these species need to survive (although this is not explicitly stated in the Indonesian conservation laws). 
In Part II of this book we have discussed and analysed a range of better studied species in relation to their tolerance to the effects of logging and associated pressures. The factors that we find to be associated with vulnerability to logging are dietary specialization, restricted feeding strata, endemicity, apparent evolutionary age (those that evolved during the Miocene or Early Pliocene) and absence from small islands. Terrestrial insectivores and frugivores appear particularly sensitive to timber harvest practices, whereas herbivores and omnivores were more tolerant or even benefited from logging. Despite these insights, we are also struck by the lack of management guidance available from past research. We find many key areas (such as roading) where more effective biodiversity-friendly forestry management remains limited by our lack of knowledge.

In Part III of this book we provide recommendations for more wildlife-friendly management of forestry concessions. In Part IV we focus on the role of research and suggest ways to improve the efficiency of wildlife research and increased applicability to the problems faced in conservation biology. In Table 14 we list the species that will benefit most from improved management of logging concessions. We realise that because of the limited knowledge of Bornean vertebrates and the threats to their survival, this list remains incomplete.

Table 14. A list of Bornean species that would most benefit from more wildlife friendly concession management. LR/nr = Lower Risk/near threatened.

\begin{tabular}{|c|c|c|}
\hline Species (common name) & Main threat & Remarks \\
\hline Sus barbatus (Bearded Pig) & Hunting & Not threatened on Borneo \\
\hline Ursus malayanus (Sun Bear) & $\begin{array}{l}\text { Ecological effects of logging, } \\
\text { hunting, disturbance, and } \\
\text { fragmentation }\end{array}$ & $\begin{array}{l}\text { Data Deficient, proposed } \\
\text { as Vulnerable (IUCN 2003); } \\
\text { legally protected }\end{array}$ \\
\hline $\begin{array}{l}\text { Muntiacus atherodes (Bornean } \\
\text { Muntjac) }\end{array}$ & $\begin{array}{l}\text { Logging and hunting } \\
\text { (especially in lowlands) }\end{array}$ & Not listed by IUCN \\
\hline Presbytis spp. (leaf monkeys) & $\begin{array}{l}\text { Logging-related hunting and } \\
\text { targeted collection of bezoar } \\
\text { stones }\end{array}$ & $\begin{array}{l}\text { P. hosei and P. frontata listed as } \\
\text { Data Deficient (IUCN 2003) }\end{array}$ \\
\hline Tragulus spp. (mouse-deer) & $\begin{array}{l}\text { Ecological effects of logging; } \\
\text { hunting }\end{array}$ & $\begin{array}{l}\text { Not listed by IUCN; legally } \\
\text { protected }\end{array}$ \\
\hline $\begin{array}{l}\text { Hylobates muelleri (Bornean } \\
\text { Gibbon) }\end{array}$ & $\begin{array}{l}\text { Ecological effects of logging; } \\
\text { hunting }\end{array}$ & $\begin{array}{l}\text { Listed as LR/nr; legally } \\
\text { protected }\end{array}$ \\
\hline $\begin{array}{l}\text { Pongo pygmaeus (Bornean } \\
\text { Orangutan) }\end{array}$ & Hunting and pet trade & $\begin{array}{l}\text { Listed as Endangered by IUCN } \\
\text { (2003); legally protected }\end{array}$ \\
\hline Cervus unicolor (Sambar) & $\begin{array}{l}\text { Although benefiting } \\
\text { ecologically from logging, } \\
\text { much affected by hunting }\end{array}$ & Legally protected \\
\hline Neofelis nebulosa & $\begin{array}{l}\text { Little known; probably limited } \\
\text { by prey availability; also } \\
\text { targeted for hunting }\end{array}$ & $\begin{array}{l}\text { Listed as Vulnerable by IUCN } \\
\text { (2003); legally protected }\end{array}$ \\
\hline $\begin{array}{l}\text { Most small carnivores (cats, } \\
\text { mongooses and civets) }\end{array}$ & $\begin{array}{l}\text { Probably affected by } \\
\text { fragmentation }\end{array}$ & $\begin{array}{l}\text { Cynogale bennettii and } \\
\text { Catopuma badia are listed as } \\
\text { Endangered }\end{array}$ \\
\hline
\end{tabular}


Table 14. Continued

\begin{tabular}{|c|c|c|}
\hline Species (common name) & Main threat & Remarks \\
\hline $\begin{array}{l}\text { Ratufa affinis (Pale Giant } \\
\text { Squirrel) }\end{array}$ & $\begin{array}{l}\text { Ecological effects of logging; } \\
\text { hunting }\end{array}$ & Not listed by IUCN \\
\hline $\begin{array}{l}\text { Sundasciurus hippurus (Horse- } \\
\text { tailed Squirrel) }\end{array}$ & Ecological effects of logging & Not listed by IUCN \\
\hline $\begin{array}{l}\text { Rhinosciurus laticaudatus } \\
\text { (Shrew-faced Ground } \\
\text { Squirrel) }\end{array}$ & Ecological effects of logging & Not listed by IUCN \\
\hline $\begin{array}{l}\text { Lariscus hosei (Four-striped } \\
\text { Ground Squirrel) }\end{array}$ & Ecological effects of logging & $\begin{array}{l}\text { Listed as Vulnerable (IUCN } \\
\text { 2003) }\end{array}$ \\
\hline $\begin{array}{l}\text { Lariscus insignis (Three-striped } \\
\text { Ground Squirrel) }\end{array}$ & Ecological effects of logging & Not listed by IUCN \\
\hline Most flying squirrels & $\begin{array}{l}\text { Probably much affected by } \\
\text { fragmentation; ecologically } \\
\text { poorly known }\end{array}$ & Not listed by IUCN \\
\hline All hornbill species & $\begin{array}{l}\text { Ecological effects of logging, } \\
\text { and especially fragmentation; } \\
\text { hunting for food, feathers, and } \\
\text { trophies }\end{array}$ & $\begin{array}{l}\text { Anthracoceros malayanus, } \\
\text { Buceros rhinoceros and } \\
\text { Rhinoplax vigil are listed as } \\
\text { LR/nr }\end{array}$ \\
\hline $\begin{array}{l}\text { Most of the woodpecker } \\
\text { species }\end{array}$ & Ecological effects of logging & $\begin{array}{l}\text { Dinopium rafflesii and } \\
\text { Meiglyptes tukki are listed } \\
\text { as LR/nr but do not seem to } \\
\text { suffer much from logging. } \\
\text { Others are not listed but are } \\
\text { much affected by logging }\end{array}$ \\
\hline Most trogons and broadbills & $\begin{array}{l}\text { Appear to be affected by } \\
\text { logging and especially } \\
\text { fragmentation. }\end{array}$ & $\begin{array}{l}4 \text { trogons and } 2 \text { broadbills are } \\
\text { listed as } L R / n r\end{array}$ \\
\hline All pheasants & Hunting & $\begin{array}{l}\text { Although pheasants are } \\
\text { probably quite tolerant of the } \\
\text { effects of logging, they are } \\
\text { much affected by hunting }\end{array}$ \\
\hline $\begin{array}{l}\text { Several owls, frogmouths, and } \\
\text { raptors }\end{array}$ & $\begin{array}{l}\text { Especially interior forest } \\
\text { specialists are affected by } \\
\text { fragmentation, although most } \\
\text { species probably also hunt } \\
\text { outside forests }\end{array}$ & $\begin{array}{l}\text { Many of these species are } \\
\text { protected and listed by IUCN }\end{array}$ \\
\hline Gracula religiosa (Hill Myna) & Affected by trapping & $\begin{array}{l}\text { Not listed by IUCN, not } \\
\text { protected }\end{array}$ \\
\hline $\begin{array}{l}\text { Irena puella (Asian Fairy } \\
\text { Bluebird) }\end{array}$ & $\begin{array}{l}\text { Ecological effects of logging } \\
\text { and fragmentation }\end{array}$ & Not listed by IUCN \\
\hline Several Malacopteron babbles & Ecological effects of logging & $\begin{array}{l}\text { Logging intolerant species are } \\
\text { not listed by IUCN }\end{array}$ \\
\hline $\begin{array}{l}\text { Alcedo euryzona (Blue-banded } \\
\text { Kingfisher) and Lacedo } \\
\text { pulchella (Banded Kingfisher) }\end{array}$ & $\begin{array}{l}\text { Both affected by logging and } \\
\text { fragmentation }\end{array}$ & $\begin{array}{l}\text { Not listed by IUCN, but both } \\
\text { legally protected }\end{array}$ \\
\hline
\end{tabular}


Table 14. Continued

\begin{tabular}{lll}
\hline Species (common name) & Main threat & Remarks \\
\hline Pigeons & $\begin{array}{l}\text { Especially frugivore specialists } \\
\text { are sensitive to the ecological } \\
\text { effects of logging; many } \\
\text { pigeons are hunted }\end{array}$ & $\begin{array}{l}\text { Treron fulvicollis is LR/nr; } \\
\text { Ducula pickeringii and } \\
\text { Treron capellei are listed as } \\
\text { Vulnerable }\end{array}$ \\
\hline All crocodiles & Hunted and collected & $\begin{array}{l}\text { Not protected in Indonesia } \\
\text { All turtles }\end{array}$ \\
& Hunted and collected & $\begin{array}{l}\text { Most are listed as Critically } \\
\text { Endangered, Endangered, } \\
\text { or Vulnerable; none are } \\
\text { protected in Indonesia }\end{array}$ \\
\hline $\begin{array}{l}\text { Certain fish species, such as } \\
\text { Tor tambra }\end{array}$ & $\begin{array}{l}\text { Ecological effects of logging; } \\
\text { overfishing }\end{array}$ & Not listed by IUCN \\
\hline
\end{tabular}




\section{MANAGEMENT}

\section{Implications for forestry and concession management}

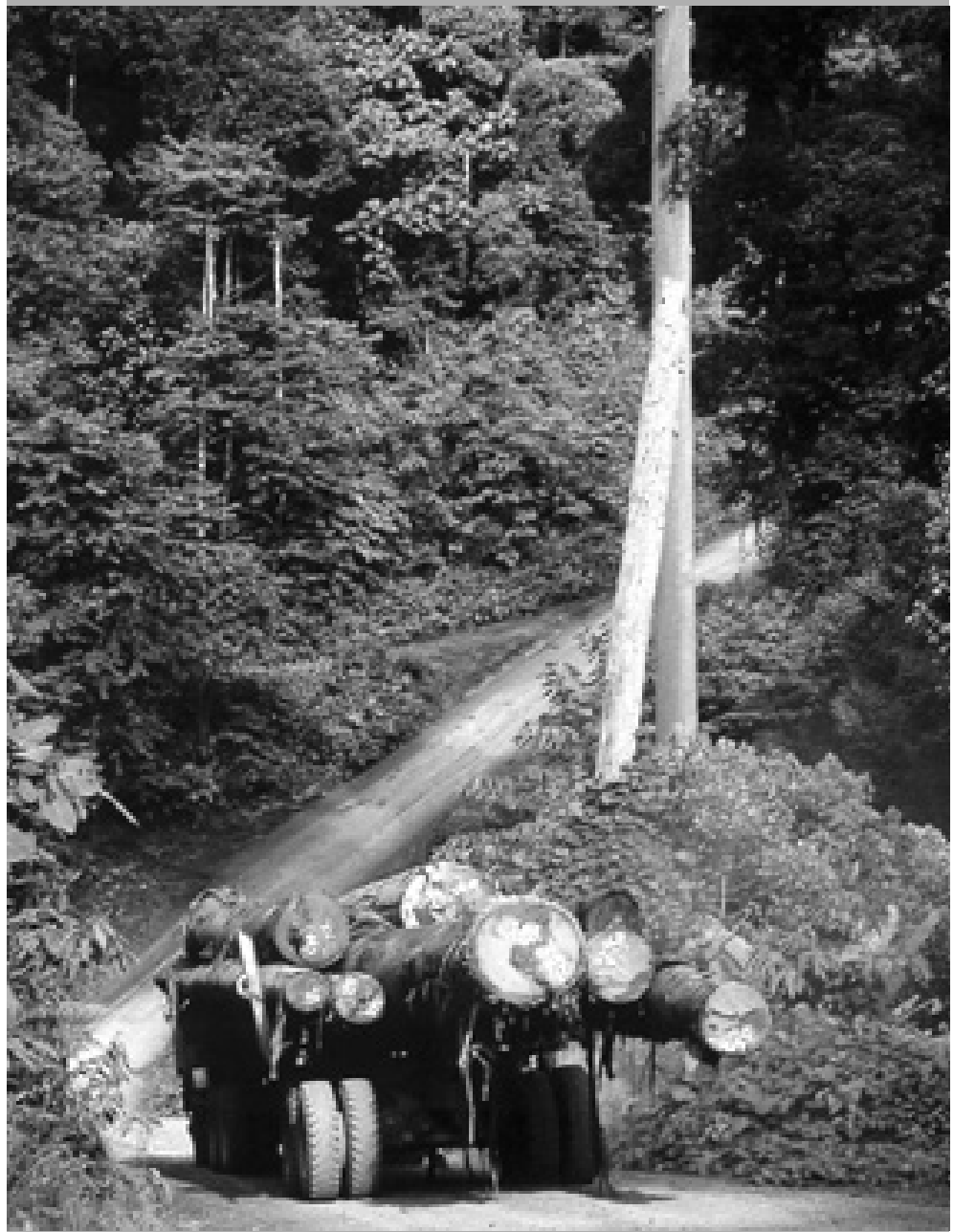

Timber on its way to Malinau Town. Various management activities can improve the value of logged over forest for wildlife conservation. (Photo by Charlie Pye-Smith) 



\section{Implications for forestry and concession management}

The review in Part I and the analyses in Part II of this book indicate that various wildlife species are affected by the ecological repercussions of selective logging and related interventions, but also that forest fragmentation, hunting and other threats can also be significant threats in some circumstances. While harvesting operations can be modified in various ways, the need to maintain forest connectivity, to regulate hunting and to address wider threats poses new challenges and responsibilities. It may not be possible to provide optimal procedures, but it is possible to indicate areas where improvements are likely. Though we have already outlined the arguments for many of these changes in the earlier sections of this book, we provide a brief outline of the key arguments behind the proposals here. This allows the ideas to be challenged in circumstances where they are inappropriate or when ideas and understanding change and, perhaps more importantly, ensures that those looking for ideas for improving specific aspects of management do not feel that they need read the whole book to find the necessary guidance.

There are many challenges in making regulations that reconcile timber harvesting and conservation. For example, we may recognise and agree the need for clear controls and limits but whatever terms and definitions are proposed often reflects a compromise: a cut-off point on a continuum of trade-offs. Why cut only trees over $60 \mathrm{~cm}$ diameter (rather than perhaps 65 or 55)? Or limit cutting only on streams wider than $1 \mathrm{~m}$, or on slopes more than $50 \%$. Rules need to be clear, but probably of greater value in the longer terms will be if those that need to implement them recognise their meaning and intent and can ensure plans and actions reflect that understanding. Many of the specific criteria we propose derive from the judgement of the authors in consultation with those who work with forest management.

Sceptical readers might feel that our proposals are merely a wish-list. This would be missing a key point: yes, it is indeed a wish-list, but a pragmatic one. More review and data gathering will always be needed, regulations can always be improved or adapted, and the details of any change could be argued ad nauseam but we already 
have knowledge of what is bad for wildlife and what can and should be done about it. Why wait?

Furthermore, what might appear unwieldy and impractical can turn out to be easier and more useful than anticipated. For example, the proposition that concessions should prepare and improve nesting holes to benefit hornbills arguably sounds far-fetched, but a recent report from Thailand shows that it can be done, and it does benefit hornbills (Poonswad et al. 2004).

We assume that regulatory responsibilities and jurisdictions can be clarified, for example between MoF and the local authorities (Dinas Kehutanan) at the district level. Guidelines and regulations must be consistently implemented. For that they must be clear and implementable-though apparently simple, this is often harder than it appears. For example, the application of clear slope limits in line with current regulations would make most remaining forests in Kalimantan economically unharvestable: this may be a good short-term conservation outcome but it won't be acceptable to those who want to use forest lands for timber production. We also note a need to harmonise current regulations and guidelines: for example the protected area definitions around streams differ in the TPTI (regulations), the FAO Code of Practice for Forest Harvesting in Asia-Pacific (to which Indonesia has signed) and the currently preferred RIL guidelines endorsed by the MoF (Elias et al. 2001). Developing this harmonisation is the role of government, and markets (i.e. through certification standards), but it is vital that forest managers — and biologists - play an active role in helping this process arrive at not just a bureaucratic end-point, but a workable, and conservation benefiting outcome.

Not everything can be prescribed by rules and regulations: management will always involve dealing with conflicting priorities, local insights or innovations. A clear vision is needed. Our primary goals are: 1) to maintain large well-connected forest landscapes (including unlogged areas) containing as complete as possible a range of local forest types, and maintaining the key landscape elements and wildlife resources within it; 2) to identify the major threats to forest wildlife in this landscape and take steps to address them.

How can our findings be translated into practical recommendations for people that deal with forestry and wildlife issues on a daily basis? We do this by addressing three main groups of stakeholders:

1. managers of timber concessions

2. governments and regulatory bodies

3. researchers and conservation biologists

\section{Recommendations to managers}

Forest managers have certain rights to remove timber but they also have responsibilities for their concessions. This must include responsibilities to address and confront threats to the forest and its wildlife. This is not a minor responsibility, and it poses questions that managers may not feel well equipped to answer. Guidance, on identifying the main priorities and on what to do about them, is scarce. 
We start by proposing measures that can be taken during harvest planning and implementation. Habitat heterogeneity and structural diversity are amongst the most important factors determining species-rich communities in natural forest settings, and the maintenance of these factors is important. Interventions may also be directed towards conserving specific resources or features (e.g., food trees, lianas, salt licks, caves, clean rivers) with importance for certain taxa. Such measures are relevant in the identification of larger areas that might be excluded from any harvesting, and in the designation of harvesting zones. We do not describe classical RIL concepts and procedures covered in other sources such as planned skid trails and directional felling (see Elias et al. 2001 for a clear and practical guide). Our recommendations should be viewed as biodiversity friendly additions to, and as added support for, RIL practices. We rate each of the management recommendations as either 'mandatory', 'strongly recommended' or 'recommended'. A fourth category 'mandatory/requires regulatory change' is for very important recommendations that require amendments of existing laws or establishment of new ones. In general, we endorse most recommendations of the TPTI (with some specific exceptions), and the refinements of Elias et al. (2001) as the best current consensus of practical RIL and good practice.

\section{Planning before logging}

- Any logging should be preceded by carefully designed surveys and planning that include silvicultural and logging rules, engineering data, demarcation of production and protection areas, hydrography and road network (mandatory);

\section{Planning for a purpose}

Our aim is to improve the 'persistence' of logging-and fragmentation-sensitive animals in logged-over forests. Many references that address landscape monitoring emphasise the calculation of numerous indices using remote sensing and Geographical Information System (GIS). These appear in criteria and indicators tool-boxes (C\&I, e.g., Stork et al. 1997). GIS may be more useful to some managers than to others. We favour an emphasis on spatial planning in which different road and fragmentation alternatives are clearly anticipated, so that the consequences can be recognised and weighed appropriately. Planning should allow for remedial actions in degraded areas and a comprehensive consideration of neighbouring lands and the threats that arise from them. For example, firebreaks may be considered more important in some locations than the edge effect that firebreaks might create. In some cases, forest edges might be identified as a preferred niche for a specific valued species. All such factors would have to be considered and weighed. Plans could then be assessed as having explicitly balanced spatial integrity against other considerations, including the more generalised preferences of distant stakeholders. Once a plan is agreed upon, it becomes a statement of what can be verified. No abstract indices are necessary.

At a minimum, such a planning process should ensure that known rare, unusual, or sensitive habitats and species receive due attention. An assessment would identify who contributed information to the plan and whether key expertise, including local knowledge, was omitted. Additional management goals to balance with other 
demands might be to maintain forest connectivity, minimize road width and length, avoid undesirable edge creation, and maintain representative portions of all natural habitats. An assessment would also seek evidence that both management and wildlife concerns have influenced choices (e.g., Given the choice of options $A, B$ and $C, C$ was selected because...). Such specific and locally relevant statements lend themselves to direct assessment, as is already practised at the operational scale in several millions of hectares of Congo Basin forests (Nasi \& Forni 2003).

In terms of zoning, Elias et al. (2001) note the need to set up various kinds of exclusion zones: cultural areas, watercourses, water bodies and shore-lines, landslip areas, conservation and protection zones, community forest and local community zones, biological diversity conservation zones, wildlife conservation zones, scientific research zones and buffer zones. These should be planned and mapped.

\section{Environmental impact assessment and inventory}

In Indonesia, all logging related activities should be preceded by an environmental impact assessment, as stipulated in the Indonesian Forestry Act (1999), Part Two, Article 13:

(1) Forest Inventory shall be implemented to know and obtain data and information on resources, forest natural richness and its environment in a comprehensive way.

(2) Forest inventory as referred to in paragraph (1) shall be implemented through a survey on status and physical conditions of forests, flora and fauna, human resources, and social condition of communities living within and around the forest.

(3) Forest inventory as referred to in paragraph (2) shall consist of: forest inventory at national level, forest inventory at regional level, forest inventory at watershed level, and forest inventory at management unit level.

Results of forest inventory as referred to in paragraph (1), paragraph (2) and paragraph (3) shall be used among others as a basis for gazetting a forest area, preparation of forest resources' balance, preparation of forestry plans and forestry information systems.

If carried out to a reasonable technical standard and used as a genuine input to defining management options and alternate choices, we believe these activities can go a long way to promoting conservation. We recommend that these inventories shall specifically address the status of locally important species. Special attention should be given to the distribution of and threats to species that are:

- Protected by national law (see, for instance, Noerdjito \& Maryanto 2001) (mandatory);

- Given a high conservation status by the World Conservation Union (see IUCN 2002, 2003) (mandatory);

- Much affected by logging and associated effects, for instance, species that only occur near exclusively in primary forest or undisturbed streams (see Table 14) (strongly recommended);

- Much used by, or significant to, local communities (see Table 15) (mandatory/ requires regulatory change). 
We strongly advocate for a clear link between the collection of these data and the management activities that are based on them; preferably such data shall be presented in a GIS format. Currently, much data are collected as a bureaucratic task where reports and records merely have to exist but do not necessarily need to be incorporated into planning and are commonly ignored.

- Areas with different planned uses should be clearly marked on maps (mandatory) and physical boundaries should be established in the field (mandatory). Elias et al. (2001) recommended marking the perimeter of buffer zones by painting an 'inverted $\mathrm{T}$ ' as high as possible on tree sides facing the logging area (strongly recommended). Also, signs should be established that clearly indicate the status of forest blocks and the activities that are and are not allowed (strongly recommended).

\section{Planning for conservation}

- Each protected area needs to be clearly delineated on logging maps of each concession and clearly marked on the ground (mandatory). This is essential to prevent the protected area moving around a concession and thereby being logged, while still being protected on paper (This has happened in a protected area in East Kalimantan and Virgin Jungle Reserves in Peninsular Malaysia) (Wildlife Conservation Society (WCS) \& Sarawak Forest Department 1996; Rijksen \& Meijaard 1999);

- The habitat of all protected species has to be managed in a way that prohibits activities detrimental to their survival. Clearly, this requires a balanced approach, with a planning procedure that assesses which species are priorities in any particular concession, and how their long-term survival can and should be safeguarded. Such procedures need to be periodically reviewed and amended according to new information and the predicted risks for particular species (strongly recommended);

- Some logging concessions may be assigned a compulsory biodiversity goal related to the specific values of their particular location, e.g., a certain concession could have a relatively high number of a certain rare species, and their management would then be required to protect habitat and address threats relevant to that species (recommended);

- If the conservation of certain species is planned, species-specific management, expert guidance, local knowledge and ecological research must be considered along with how this may interact with the protection of other species prior to logging (strongly recommended);

- Establish and maintain a paper or GIS database for recording the occurrence of priority species (see section on Species-specific management below) and their key ecological requirements (particular grazing areas, salt springs, etc.) (recommended);

- At least $10 \%$ of the commercial forest area should be protected as connected unlogged patches that could serve first as refuges, then as sources of species for recolonising the surrounding areas (Fimbel et al. 1998) (strongly recommended). It is important to note that, although lowland forest on level ground often provides 
high value commercially timber, this is also a very important wildlife habitat and a proportion of it should be excluded from logging (strongly recommended);

- Rocky outcrops (generally limestone) and caves are vulnerable primarily as a source of roading material, for mining. In Malinau several such areas have been damaged by roads. The identification of such areas for protection provides a good basis for developing protected areas in the wider forest landscape and should be carried out prior to logging (strongly recommended);

- Dispersing annual felling coupes throughout the forest can help facilitate regeneration and migration of wildlife disturbed by logging (DFID 1999), though it does make road planning, supervision and oversight harder (recommended).

\section{Maintaining landscape connectivity and watershed protection}

Maintaining corridors of interior forest can have positive effects on the vertebrate fauna (Marcot et al. 2001). Many species that respond negatively to fragmentation-and thus could benefit from the use of corridors-are largely confined to primary forest (Lovejoy et al. 1986; Laurance 1991; Stouffer \& Bierregaard 1995; Bierregaard \& Stouffer 1997). Wherever possible, gaps in corridors should be avoided. Many forestdependent birds (Bierregaard et al. 1992) and mammals (Laurance 1990; Goosem 1997) have been shown to avoid even narrow (50-100 m wide) clearings, especially if the clearing is maintained as open habitat (Stouffer \& Bierregaard 1995; Malcolm $\&$ Ray 2000). We recommend retaining a forest area network based on two elements: reserved areas and linking corridors. Reserved areas are designated and protected for what they are or what they do (e.g., watershed protection, hunting areas, graveyards, critical habitat for particular species). These could include catchment areas, steep land, riverine buffers strips, areas around breeding sites of endangered species, etc. Corridor forests are sections of forest required to keep these reserved areas connected to each other. Even though some of these areas will be small (e.g., a graveyard or protected salt lick), the wider network of forest corridors, including river-side and steep slope forests, should, as far as possible, be planned to connect these areas.

We note considerable inconsistency between different guidelines on river and stream buffer-zones, and how they are to be applied. In this case both TPTI and Elias et al. (2001) lack clarity (e.g., the TPTI requires "100 m buffer on each side of big rivers and $50 \mathrm{~m}$ on each side of each tributary", but does not explain how to distinguish a 'big river', etc.; similarly for Elias et al. 2001 "class 1 stream = $30 \mathrm{~m}$ each side, class 2 stream $=20 \mathrm{~m}$ each side, class $3=10 \mathrm{~m}$ each side).

- Current regulations require the establishment of logging exclusion zones to protect streams, rivers and other water features maintaining protection corridors along larger watercourses (mandatory).

How regulations should be applied to rivers and streams is less clear.

- We advocate following Sist et al. (1998a): based on maximum width (for two or more months of the year), (strongly recommended) exceptions made for necessary road crossings; 


\begin{tabular}{rc}
\hline River width $(\mathbf{m})$ & Protect $(\mathbf{m})$ on each side \\
\hline$>40$ & 100 \\
\hline $21-40$ & 40 \\
\hline $11-20$ & 25 \\
\hline $1-10$ & 10 \\
\hline$<1$ & none \\
\hline
\end{tabular}

- Stream protection includes marking exclusion zones clearly along streams-both on operational maps and on the ground-before road building and logging begin (strongly recommended) and making regular checks that felling and extraction of logs are not taking place in exclusion zones (strongly recommended). Protection zones with sufficient forest buffer on either side provide a valuable network of relatively undisturbed forest maintaining connectivity across the landscape;

- HTI and THPB (see Abbreviations)-areas dominated by low diversity industrial forests, plantations or tree farms (either exotic or indigenous timber), have less value for wildlife in comparison with mixed native forests. But in some cases they can serve as connecting corridors between natural forest areas for some species (Laidlaw 2000). We recommend that plantations are favoured in locations where they help connect otherwise disjointed tracts of forest (recommended);

- All these corridors and reserved areas should be mapped and maintained (strongly recommended);

- Overhead canopy contact should be locally maintained (strongly recommended). WWF Malaysia recommends a crossing point every $100 \mathrm{~m}$ of road (Muziol et al. 2000). Manual road clearing, instead of pushing them over with heavy machinery, and generally restricting the use of bulldozers makes this easier. Overhead canopy contact may also help reduce rain contact with the road thereby reducing runoff, compaction, and formation of ruts.

\section{Minimising damage during logging and related operations}

\section{Roads and infrastructure}

- Logging camps should be strategically located in the forest, as far away as practical from logging exclusions zones, especially those intended to benefit wildlife (strongly recommended);

- Roads should be located at least $100 \mathrm{~m}$ from streams whenever possible (Elisa et al. 2001) (strongly recommended);

- Roads and trails should be planned carefully and constructed in a way that minimizes canopy damage (DFID 1999) (mandatory). In Sabah, such planning significantly increased the efficiency and reduced costs of yarding, from US\$ 4.51/ $\mathrm{m}^{3}$ in conventional unplanned logging to US $\$ 1.98 / \mathrm{m}^{3}$ in reduced impact logging (Tay 1999);

- Road gradients should generally be less than $10 \%\left(<6^{\circ}\right)$. When other disturbance is being avoided slopes of up to $20 \%\left(<12^{\circ}\right)$ can be tolerated, but never exceed, for 
distances not greater than $500 \mathrm{~m}$ (see Elias et al. 2001 for more detailed guidance by road type) (strongly recommended);

- There are conflicting opinions as to whether roads should be as straight as possible thereby reducing building costs and area affected, or whether they should be constructed around tall trees that will not be logged, as this will minimize canopy damage. Straight roads force indiscriminate toppling of large trees and may cause extensive damage to the original canopy (Malcolm \& Ray 2000). However, there is a significant ecological and financial benefit from straight roads since it minimizes the total area disturbed and reduces log hauling times and the relative trade-offs of ecological and economic benefits need to be balanced in the planning process (strongly recommended);

- On level ground a planned 'herring-bone' layout of the roads and skid trails, and regular placement of log landing reduces damage to remaining vegetation and increases harvest efficiency (Johns et al. 1996) (recommended);

- Halt the current 'matahari felling' practice of pushing all the edge trees over to allow the road surface to dry in direct sunlight (strongly recommended). This practice often results in overall width well in excess of $50 \mathrm{~m}$. This has a large impact on sedimentation levels and erosion (Fig. 22) and is not necessary if roads are properly built. DFID (1999) recommended a maximum overall width of 4 m (also Elias et al. 2001), while Dykstra and Heinrich (1996) and Mason and Thiollay (2001a) suggested that the maximum clearing width should be $7.5 \mathrm{~m}$ for major haul roads and $5 \mathrm{~m}$ for minor roads;

- Construction of roads and major skid trails should be done in dry weather and only shortly before felling starts (DFID 1999; Elias et al. 2001) (strongly recommended);

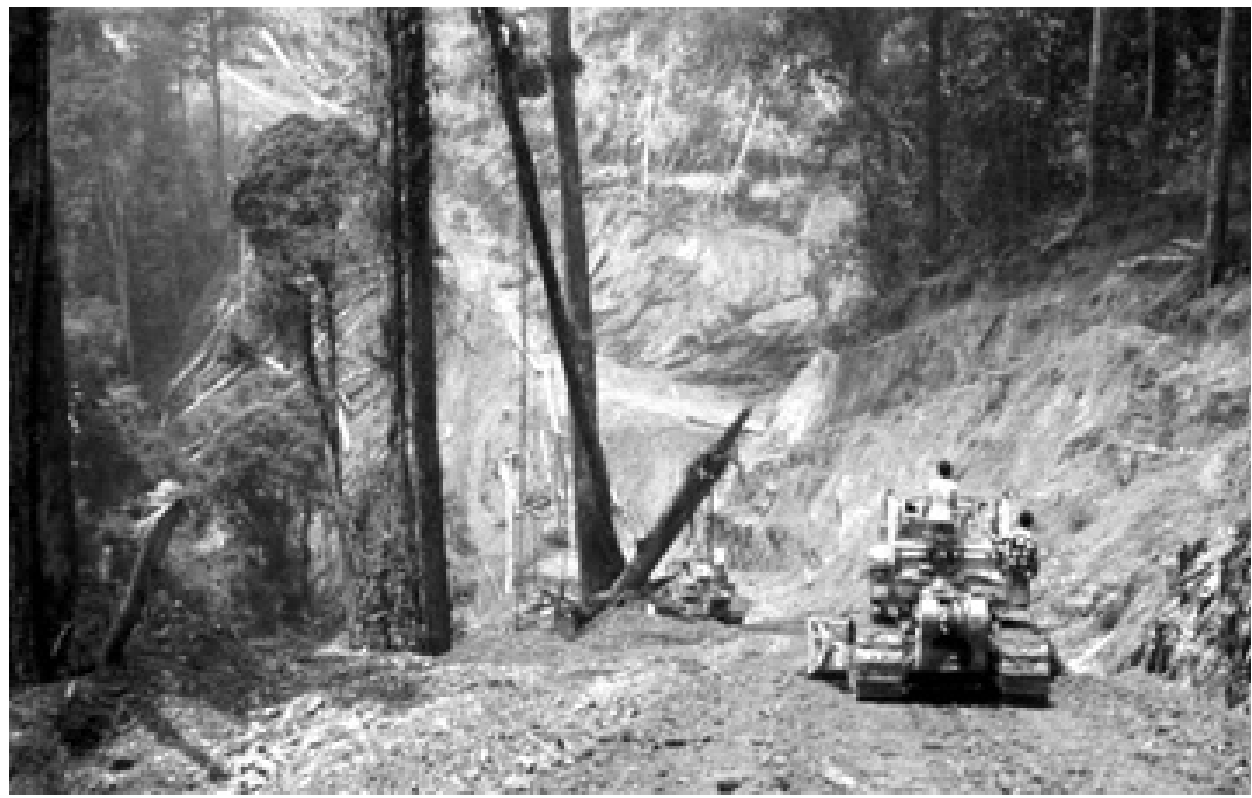

Figure 22. Logging roads are often poorly engineered unnecessarily wide, increasing forest fragmentation and a range of negative impacts. (Photo by Rob Fimbel) 
- Skid trails should be planned ahead of felling (DFID 1999; Elias et al. 2001) (mandatory);

- Skid trails are designed as short as possible, following contours (Elias et al. 2001), and their construction should avoid felling tall trees that would otherwise be left (strongly recommended). They should avoid steep areas, ravines, swamps, and unstable ground and minimize the number of stream crossings (strongly recommended). Trails should never exceed $45 \%$ (strongly recommended). If they cross a stream, a small bridge should be constructed (strongly recommended) (Elias et al. 2001);

- Roots, branches and vegetation should be retained on the skid trail as much as possible (DFID 1999). The use of these harvesting residues (brash) in areas with much machinery traffic may reduce soil compaction and aid forest regeneration (Brearley et al. 2003) (strongly recommended);

- Log-landings should be sited in flat areas $10 \%$ slope $\left(<6^{\circ}\right)$ or hill tops, away from stream and watercourses, and (of course) outside protection zones (mandatory).

Many amphibians, fish, some reptiles, birds, and possibly otters and the Otter Civet (Cynogale bennettii) depend on clear water for breeding and feeding. Proper drainage systems that feed into vegetated areas and well-constructed and wellmaintained bridges and culverts are important in keeping streams clear. Much of the following is based on DFID (1999). Water quality is also a major concern for all humans and wildlife living downstream.

- Bridge construction should be sufficient to allow floodwater to pass without damaging the structure (strongly recommended). Abutments should be well anchored to prevent them from being washed away, and the stream banks above and below the bridge need to be stabilized by wings of durable logs (e.g., Dialium indum (keranji), Cotylelobium spp. (giam, resak gagil), Dipterocarpus spp. (keruing), Dryobalanops spp. (kapur), some of the heavier species of Hopea spp. (merawan) and Vatica spp. (resak)), stonework or concrete. A membrane such as 'geotextile' or polythene is placed between the main supporting logs and the soil covering them (such plastic should be carefully disposed of and not be allowed to wash into river systems). A guard log is placed on each side of the bridge to stop soil from the approach roads falling into the watercourse. The gaps between the main stringer logs are filled with smaller logs, saplings of non-commercial species, sawmill offcuts, or similar material, before the membrane is put into place (see Elias et al. 2001);

- Ponds caused by roads or trail crossings, or other site engineering, impacting local drainage (though largely unstudied) should be avoided (recommended);

- The shaping of the roads and landings is done so that water runs off into the vegetation and not directly into watercourses. This is best achieved by diverting drain out-flows into surrounding vegetation at least $50 \mathrm{~m}$ before a watercourse (Elias et al. 2001) (strongly recommended);

- Use silt traps and flumes where they are needed (strongly recommended); 
- Drainage culverts should be installed (recommended) to facilitate water flow and facilitate road crossings by mammal, reptile and amphibian species (e.g., Clevenger et al. 2001);

- Culverts and drainage pipes need to be cleaned regularly (strongly recommended);

- All roads and skid-trails should be engineered to drain effectively; berms (raised ridges) must not be created on the sides as they prevent water draining off the track (strongly recommended).

\section{Protecting reserved areas}

- Areas excluded (reserved areas and linking corridors) from logging are managed as follows (after Elias et al. 2001):

a) No trees to be felled within exclusion areas and their buffer zones (mandatory);

b) Machine access is prohibited, except where planned roads cross the area. All such roads and watercourse crossings must be well engineered and streams carefully protected (strongly recommended);

c) No earthworks or spoil from earthworks is to fall within the exclusion areas (strongly recommended);

d) No logging debris is to be pushed into the exclusion areas, particularly into water courses (strongly recommended);

e) Trees should be felled away from buffer zones and watercourses (strongly recommended);

- Increase harvest cycles to at least 40 years (strongly recommended). Harvesting rotations in Indonesia are generally planned as 35 years, but this is currently under review. Various studies show that lengthening of the cutting cycle would not only improve biodiversity conservation but improve the sustainability of timber production (Muziol et al. 2000; van Gardingen et al. 2003; Sist et al. 2003a, b).

\section{Minimising damage in production areas}

Reducing incidental damage will generally lessen the impact of logging on vertebrates. Forest damage along tractor skid trails and log-loading sites should be reduced. Damaged areas are usually colonized first by vines and later by pioneer tree species. In general, these pioneers are not good food resource for frugivores. Most arboreal mammals are affected by large gaps in the canopy (see Putz et al. 2001b for a review) and maintaining a relatively intact and interconnected canopy/mid-canopy would benefit these species. Sist et al. (2003b) recommended ensuring a minimum spacing distance between the stumps of harvested trees: this rule aims to reduce both felling intensity and gap size. Experiments in East Kalimantan have demonstrated that logging damage can only be significantly reduced if RIL techniques are used below a felling intensity of 10 trees/ha. A spacing of at least $35 \mathrm{~m}$ between felled trees would theoretically achieve this density. Further work is however required to determine if such rules can be reliably applied in the field. 
- We recommend pre-felling identification of critical habitats and habitat features that should be protected in the forest (ideally with staff having been trained as to what the local priorities are and how to recognise them) and ensuring that they are protected whenever possible (strongly recommended). To prevent this becoming an excessive burden on the concession it might be agreed that only a certain number of such sites and stems can be protected per-coupe (e.g. up to 5 stems and 2 sites per ha);

- We recommend limiting harvesting to commercial trees within a dbh range of 60$100 \mathrm{~cm}$, which allows lighter machinery and should not be a significant production constraint (Sist et al. 2003a) (strongly recommended). Not harvesting trees with $\mathrm{dbh}>100 \mathrm{~cm}$ stems will limit gap sizes. Such trees are often difficult to fell and extract without splitting or damaging non-target trees, are usually reproductive and can serve as seed trees, and are more likely to be rotten or hollow;

- Ensure that commercial trees are felled in the direction of least damage to the residual stand (DFID 1999) (strongly recommended). Specifying the best configuration of directional felling involves more than ease of skidding and winching or reductions in residual damage, and choices remain debateable. Dispersed gaps have the advantage that felled trees will not be tangled (Johns et al. 1996), and that the resulting openings will be relatively small, but felling so that crowns fall on top of each other (or into existing gaps) can reduce the total amount of canopy damage (Malcolm \& Ray 2000) though such large multi-tree gaps are in general undesirable. Decisions on felling direction need to be taken on a caseby-case basis, depending on local conservation and management objectives;

- In areas of very shallow soils or patches of white sandy soils, it would be advisable to refrain from cutting the trees regardless of the economic benefits of the logs as the land is generally unable to recover vegetation of any value (Chunkao 1978) (strongly recommended). In Kalimantan such areas are more common in regions with Kerangas forests;

- The use of skylines can be considered in especially sensitive areas for instance, if a rare, easily disturbed key species occurs (recommended). These techniques are generally more expensive than ground skidding on all but the most difficult terrain (Aulerich et al. 1974 in Pinard et al. 2000) and the costs of such techniques and their potential benefits for wildlife need to be carefully assessed, (by opening up areas that might otherwise remain unlogged the conservation value remains equivocal);

- Plan different working areas for dry weather and wet weather to minimize erosion and soil compaction (strongly recommended). Extraction should not take place during wet periods in areas that are particularly sensitive to disturbance (Pringle $\&$ Benstead 2001). Ground skidding should be avoided during very wet periods and on steep slopes (Mason \& Putz 2001) (strongly recommended);

- Keep soil and forest floor disturbance to a minimum as many invertebrates, reptiles and amphibians use the soil as a refuge (Fimbel et al. 2001) (strongly recommended);

- Skid trails should not be graded, i.e., when timber is dragged out, bulldozers should move with their blades up, so no slash piles are created and disruption of the forest floor is less severe (Malcolm \& Ray 2000) (strongly recommended); 
- Blading (i.e., use of the bulldozer blade) should be restricted to slopes $<45 \%$ $\left(<24^{\circ}\right)$ where this is needed to increase stability and control (Stuart \& Carr 1991 in Pinard et al. 2000) (strongly recommended);

- Bulldozers with narrow blades should be used (DFID 1999) (strongly recommended);

- Slope limits would ideally reflect local conditions. Experts suggest a maximum slope of $50 \%$ (i.e. $<27^{\circ}$ ) for felling (strongly recommended) and a skid trail gradient maximum of $35 \%$ (or $<20^{\circ}$ ) (up to $40 \%$ (or $<22^{\circ}$ ) under especially favourable soil conditions only) (strongly recommended);

- Earthmoving is done by bulldozers over short distances only; dump trucks and loaders are used for longer distances (Elias et al. 2001), although such transport should be minimized as well to prevent excessive damage to vegetation and further soil compaction (strongly recommended);

- Winches should be used as much as possible to drag timber towards larger skid trails from where they are further transported by skidders (strongly recommended);

- Skidders should reverse out of skid trails, and teams should explore extraction routes on foot rather than from the cab (strongly recommended);

- Other low-impact extraction methods should be explored; these include extraction by draught animals, lighter machinery, and machinery with broad rubber tires (recommended). These can considerably reduce soil compaction, erosion, and damage to non-harvested vegetation.

\section{Maintaining habitat complexity and diversity}

- Hollow trees should be retained as much as possible as these provide cavities of importance to vertebrates that use them for breeding, nesting and food storage (mandatory);

- Arboreal water is very important to a number of species. Key aspects are pitcher plants (Fig. 23) and hollows in certain tree species. While it is clearly difficult to plan logging around such micro-habitat features, the maintenance of large stems and the marking of pitcher plants to avoid damage is proposed (recommended). If there are identified pitcher plant habitats then the larger habitat should be given special consideration (recommended);

- Maintain stand structures that allow the continued generation of dead wood in a full range of sizes. Especially, leave large ( $>100 \mathrm{~cm}$ diameter), old and dead standing trees to provide dead wood and suitable sites for hole and crevice nesting birds and mammals (e.g., Styring \& Hussin 2004a) (strongly recommended);

- Rotting tree stumps are used by species such as squirrels, Sun Bear (Ursus malayanus), trogons, forest kingfishers and forest bee-eaters (Lambert \& Collar 2002), and as much as possible these stumps should be retained (strongly recommended);

- Preparation of the site for regeneration by burning should be avoided (strongly recommended) as it reduces habitat heterogeneity and destroys many resources and microhabitats used by invertebrates (Ghazoul \& Hill 2001);

- Rocky outcrops provide nesting and roosting spaces for a variety of species, 


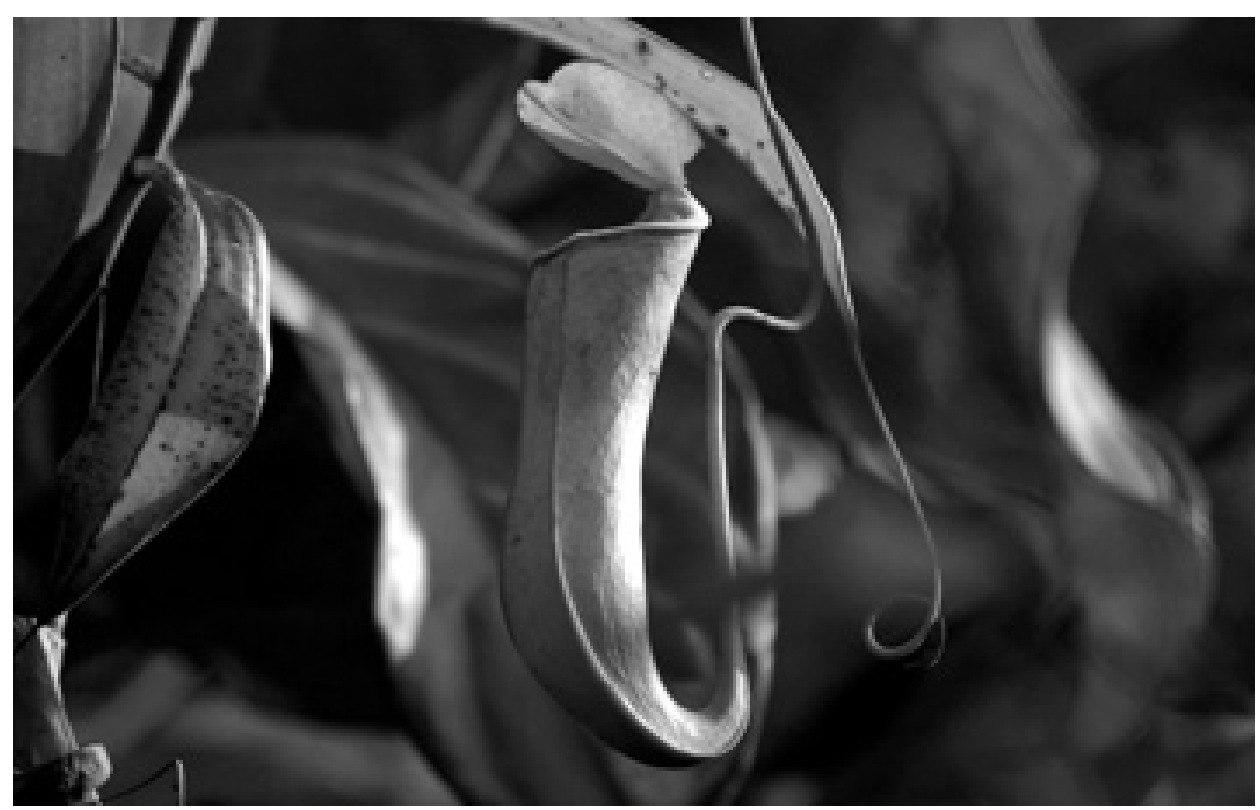

Figure 23. Nepenthes gracilis, a pitcher plant found in lowland forest, where it provides important habitat for insects and small vertebrates. (Photo by Kimabajo)

including reptiles, birds (raptors, swifts) and small mammals, and provide refuge against predators (Bernard 2004). In areas where limestone occurs, mining of outcrops should be avoided as much as possible and any mining carefully regulated if it cannot be prevented (strongly recommended);

- If a cave provides habitat for protected and/or rare and endangered species, then prohibiting entry into caves and elimination of road building and skidding in the vicinity should be considered. If the caves are a bird nest source then, in collaboration with local stakeholders, these caves should be protected as nologging zones (strongly recommended);

- Wallows and pools over $1 \mathrm{~m}$ wide, and sites of permanent or near-permanent water, should be protected from skid trails (recommended);

- 'Salt springs', 'salt earths' and sites with clays eaten by animals, should be located and incorporated in area planning (local people can usually help locate these). They should not be disturbed (strongly recommended);

- Liana cutting should be considered on a tree-to-tree basis. The advantages (reduced damage) should be weighed against the disadvantages (reduced vegetation diversity and fruit) (recommended);

- Logs should be de-barked, as far as possible, in situ before skidding to keep vital nutrients in the system (Nykvist et al. 1994) (recommended). Practical procedures need development.

\section{Keeping keystone resources}

- Retain as many large fruiting trees as possible, particularly those that fruit throughout the year and may be critically important for canopy frugivores during lean periods (Leighton \& Leighton 1983; Lambert 1991) (strongly 
recommended). Especially important fruit resources include figs, palms, Anacardiaceae (Dracontomelon spp., Koordersiondendron spp.), Euphorbiaceae (mainly Baccaurea spp.), Guttiferae (Garcinia spp.), Sapindaceae (Dimocarpus spp., Nephelium spp.), Tiliaceae (Microros spp.), various Fagaceae, Myrtaceae and many woody climbers, particularly Annonaceae, and less or non-seasonally fruiting species, e.g., understorey Rubiaceae, gingers, and (often) swamp area vegetation. Conserving the mid-canopy by minimising incidental tree damage is a good strategy for conserving a whole host of palms, Annonaceae, Myristicaceae and Lauraceae (strongly recommended);

- Figs (Ficus spp.) are especially important for wildlife as they provide fruit throughout the year, and fulfil vital nutritional needs (see O’Brien et al. 1998a). Efforts should be made to conserve as many figs as possible, regardless of age (mandatory/requires regulatory change);

- Fruit tree groves, old fruit gardens and abandoned villages are recognised by local people as good hunting sites and provide resources for frugivores. Such sites should be protected from logging and road building (strongly recommended);

- There is a wealth of indigenous knowledge regarding tree species that are important for maintaining wildlife populations. Such local knowledge should be evaluated and as much as possible incorporated in concession management (strongly recommended).

\section{Post-logging operations}

- After finishing an annual felling coupe some roads need to be closed (even if temporarily) so that animals can migrate undisturbed and hunting pressure is reduced (strongly recommended). This can be achieved by dismantling river crossings (culverts and bridges) or by gating. When roads are no longer in use they should be closed (blocked or partially destroyed) (Mason \& Thiollay 2001a) (strongly recommended).

TPTI prescribes slashing of ground vegetation to speed up regeneration. We argue that this is worse than the logging as the extreme terrain in Malinau means logging is patchy; ground-tending crews, however, work on foot and slash everything, which removes a lot of vegetation from the forest-and is perceived by local people as excessively damaging to many valued non-timber resources (Sheil et al. 2003a, b). This has almost certainly a negative impact on many terrestrial animal species (see, for instance, Bernard 2004). In practice this activity is already ignored in many concessions.

- Slashing practices should be carefully reviewed and abandoned when not specifically required (mandatory/requires regulatory change).

Rehabilitation of harvested areas can be part of the measures aimed at a) reducing soil erosion and sedimentation and b) maintaining/increasing vegetation diversity for wildlife conservation purposes. DFID (1999) noted that this has never been done in effectively Indonesia, and enforcing rehabilitation is still argued by 
many to be an essential reform in lowland and hill forest concessions. If forest are well managed large-scale reforestation should be unnecessary, but protecting certain sites from erosion is important.

The main rehabilitation work required is (after DFID 1999):

- Placing cross-drainage on compacted areas on landings and feeder roads to ensure proper drainage (mandatory/requires regulatory change);

- Top soil deposits on quarries and landings should be distributed over the entire area (strongly recommended);

- There should be a systematic post-logging rehabilitation of log landings and stream crossings - primarily to reduce soil erosion. In cases where roads or landing will not be used in future harvest cycles effort needs to be made to re-forest them (mandatory/requires regulatory change);

- Rehabilitation with replanting if needed should be done continuously as harvesting based on each landing is completed, rather than waiting until the whole compartment has been worked over (strongly recommended).

Rehabilitation of deforested or severely degraded land can serve a useful conservation role (e.g., Dunn 2004; Goosem \& Tucker 1995). This is especially likely when such rehabilitation makes use of a variety of native tree species that are both of value to the timber industry and to wildlife, and increases connections between original forest areas, or serves to buffer forest edges.

- Areas without any remaining tree cover should be replanted with vigorous pioneer species (recommended). In Malinau this might include species like Trema able to persist and grow in bright open conditions. These trees should encourage the establishment and growth of shade-dependent forest species;

- When replanting is required include native tree species that are important

a) for wildlife, such as non-dipterocarps like Parkia speciosa, P. javanica, Baccaurea spp., Nephelium spp., Ficus spp., Mangifera spp. and Pithecellobium spp.; or

b) for timber and wildlife e.g., Tetramarista glabra, Meliosma sumatrana, some of Artocarpus, Aglaia and Dysoxylum species (good timber), Santiria oblongifolia, Durio zibethinus and D. oxleyanus (general utility timber) and Dracontomelon dao (Keßler \& Sidiyasa 1994).

\section{Minimising indirect impacts and threats}

\section{Hunting and extraction}

In Borneo, as in most tropical forests, forest productivity limits sustainable exploitation. Hunting associated with logging places additional pressures on wildlife and other components of biodiversity. There needs to be clear regulations concerning wildlife hunting and trading in the concession area. Zone boundaries and meanings must be clearly identified on the ground and recognised by all local actors. Similarly all regulations and local agreements concerning use and protection of species or sites 
must be known by all resource users who should be guided by, or seek to enforce, them. Our suggestions (modified from Bennett \& Robinson 2000 and Fimbel et al. 2001) of how to curtail hunting in forest concessions include:

- A prohibition on hunting of protected species (see Table 1) (mandatory);

- The banning of commercial hunting throughout the concession (if local communities already have hunting rights negotiation to establish limits will be needed) (mandatory/requires regulatory change). Regulation is likely to be difficult but we look to Sarawak (e.g., WCS 1998) to show what is possible with adequate political will;

- Prohibit and enforce bans on trade in all wildlife and animal parts, particularly of protected, rare, endemic, endangered, threatened, vulnerable, or slowly reproducing species within, from and to concessions (mandatory/requires regulatory change);

- Ensure that the legal and practical mechanisms are in place for local communities to be involved in decision-making and management regarding wildlife resources and hunting in their area (mandatory/requires regulatory change). This must be done so that the necessary checks and balances are in place to prevent over-exploitation. Co-management or collaborative management partnerships between local communities and technical/scientific advisors (government or nongovernment) may ensure this;

- If subsistence hunting is to continue, clear procedures and checks are required to ensure the process is not abused (mandatory/requires regulatory change);

- The establishment of conservation zones within the concession where hunting is forbidden (mandatory/requires regulatory change);

- Closing non-essential roads as soon as the operations are complete (as already recommended above) (mandatory/requires regulatory change);

- The use of electric shocks, bombs and poison in fishing is destructive to many components of the aquatic ecosystem and thus kill many more animals than are actually collected. These non-specific means should be stopped (mandatory/ requires regulatory change). Fishing may be permitted outside of strictly protected areas, but only by specific and relatively selective techniques (thrown net, baited hook);

- The establishment of exclusive hunting rights for the original inhabitants of certain areas, which could limit the impact of hunting by outsiders. Such controls can be based on adat claims and councils but with written documents where rights and responsibilities are clearly defined (strongly recommended);

- Preventing logging company vehicles from carrying wildlife, thereby ensuring that they cannot be used for wild meat trade (mandatory). Security checks at concession entry/exit points can enforce this measure as well as increasing security and preventing log theft;

- A prohibition on snare hunting and trap hunting as unselective and wasteful (also see Fa et al. 2004) (strongly recommended);

- Link pay of concession staff to quality of work and productivity in an effort to reduce time available to employees for hunting (strongly recommended); 
- Use contractual clauses specifying that violation of regulations may result in penalties and dismissal (strongly recommended);

- Concession staff should be instructed regarding the use of wildlife resources in the concession. Staff should not feel free to collect whatever they wish from a concession and should be strictly regulated in terms of all wildlife collection (strongly recommended);

- The production of simple but precise educational and public information materials that can be disseminated through official channels, schools, traders, etc. should be considered (we note that a lack of clarity on many past rules and laws has allowed them to be ignored, misunderstood and even abused) (strongly recommended).

Bennett (2002) and Lee (2000) argue that a reduction in hunting pressure on tropical wildlife is more likely if people have alternative sources of protein. They suggest that concessions could be required to subsidise and import meat and/or to encourage small scale localised farming (chickens, pigs or fish). Timber concessions could assist in the development of farming programmes, although the cultural acceptance of domestic sources of protein as opposed to wildlife remains an obstacle in many locations. We note also the threat to wild species posed by domestic livestock: particularly diseases and cross-breeding. Care most be taken not to release stock: especially domesticated pigs and Bali cattle (domesticated Banteng), which may interbreed with wild populations.

- Require that logging companies provide adequate protein supplies to all staff and workers, thereby removing the need for them to hunt (strongly recommended);

- Our preference is that concessions should import and subsidise meat and fish from non-forest sources (strongly recommended). Access to and subsidy of technological improvements in storing meat (freezing and refrigeration) can help decrease waste (but also potentially increases the risk of storage for commercial purposes).

\section{Fire}

Recent major fire events, such as those in 1997-1998 which devastated large areas of forest in East Kalimantan (Siegert et al. 2001) show the considerable damage fires can cause to forests and wildlife, especially when coupled to the poor logging practices (Fig. 24). Smoke has also a severe impact on people and the environment. This is especially true in the drier parts of Borneo where fires do have the ability to destroy large areas of selectively logged forest (Leighton \& Wirawan 1986; Woods 1989). It is important that a fire management strategy is in place and that the resources are available to implement this immediately. At a monitoring level, satellite-based fire early warning systems detecting active fires (hot spots) and dryness indices provide valuable information for forest managers (Hoffmann et al. 1999). A number of these systems are operational in Indonesia (Dennis 1999). In theory, such systems provide fire managers with the necessary information to carry out hazard reduction and removal, establishment of fire breaks to protect valuable resources, and up-to-date fire situation information during an active fire emergency. 


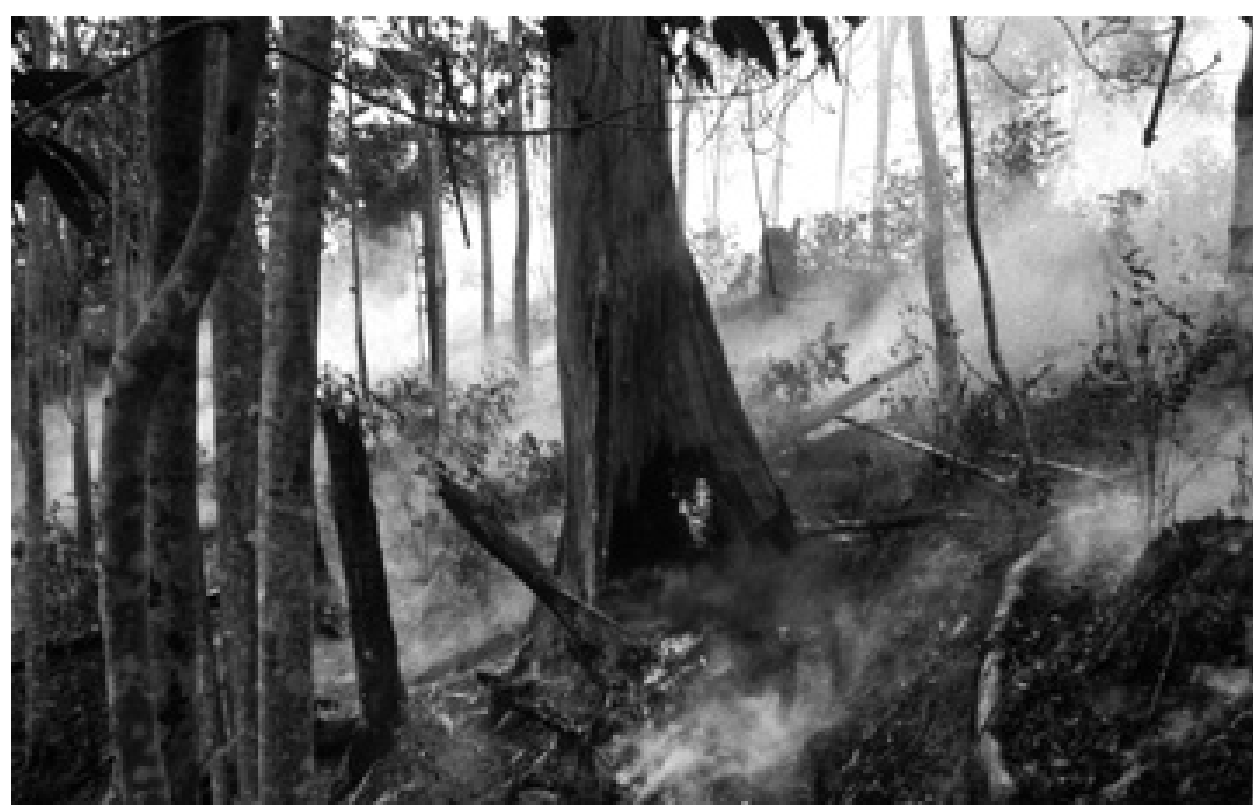

Figure 24. Forest remnants in East Kalimantan after repeated fire. (Photo by Gabriella Fredriksson)

- There is a need for trained fire fighters to be on call at the forest management unit, concession and district level, and at least one trained manager who monitors fires and coordinates fire fighting and prevention activities during periods of threat in each concession (strongly recommended);

- Establishing working relationships with local communities that traditionally use fire for agricultural activities or for attracting wildlife in the vicinity of logging concessions (e.g., Dennis et al. in prep.) would further help reduce the risk of unwanted fires in the vicinity of forest areas (strongly recommended);

- Van Nieuwstadt et al. $(2001,2002)$ showed that current practices of salvage harvesting need to be revised. In Indonesia, concession holders cannot normally re-cut harvested forest areas without waiting the statutory period (a 35-yr cutting cycle is the norm). However, fire removes this restriction, and allows further cutting with little cost. Such incentives encourage arson and must be avoided (mandatory/requires regulatory change).

\section{Exotic and invasive species}

- Logging concessionaires should monitor exotic species in their area, and actively remove them before they become a problem for wildlife and forest regeneration. Species and genera known to cause problems elsewhere should be actively guarded against (strongly recommended);

- Reforestation programmes should avoid exotic species as far as is practical-if they must be used species must be selected with care and the results should be monitored (strongly recommended);

- Some agency, or co-operative, should publish and update lists of invasive exotic species, how to recognise them, and how to combat them (strongly 
recommended). Rejmanek (1999) provided a scheme for screening high-risk woody exotics;

- Measures are needed to ensure minimal transfer of soil and other potentially infected material between sites. A general recommendation is to seek region-wide control regarding the import and movements of live soil, plants and animals_-and associated hygiene regulations. Many useful templates for such regulations exist, with Australia providing very detailed prescriptions (strongly recommended);

- Obviously, implementation of these recommendations requires increased awareness of the issues at the community, local government and concession levels. Producing well targeted extension materials may make a significant contribution (strongly recommended).

\section{Domestic animals}

Domestic animals such as cattle, dogs and cats can be major threats to native wildlife, either directly (e.g., Clarke \& Pacin 2002; May \& Norton 1996) or indirectly as sources of disease. Knapen (1997) reported on a rinderpest epidemic that killed a large proportion of the cattle population of Southeast Borneo between 1871 and 1872 before spreading to the Bearded Pig population, which it affected in areas as far afield as the Upper Kahayan and Kapuas Rivers in Central Kalimantan. In 1878, rinderpest struck once more, again hitting the cattle population first and later killing pigs in large numbers. Another epidemic was reported by Nieuwenhuis (1907, Vol. 1, p. 196), who mentioned that during his journey through central Borneo in 1894 pigs were rare, because both the wild and domestic population had been killed off by an epidemic in central Borneo in 1888 and 1889. The spread of rabies and distemper from domestic dogs to wildlife as well as various avian diseases spread by domestic fowl is an additional threat to native species (e.g. Butler et al. 2004).

- Prohibit free-ranging pets and livestock in the concessions (recommended). Domestic cattle, goats, pigs and chickens should confined, preferably penned, in specific areas and not be allowed to run free in order to minimize risk of disease transmission to and from native species (recommended);

- Feral dogs should be controlled (recommended). Also, although we do not know what impact domestic cats have on native wildlife, it can potentially be serious. In North America, estimates in the late 1990s suggested at least 40 million song birds per year are killed by domestic cats. Domestic cats should be controlled in logging concessions (recommended).

\section{Traffic}

- We recommend regulation of road use which would also limit illegal hunting and timber extraction (strongly recommended). These regulations should include closure to non-essential traffic at night, checkpoints to monitor wildlife and timber trade, prohibition of foot traffic on roads, prohibition of transport of hunting weapons, traps, snares, etc. on concession roads;

- Traffic needs to be regulated. Speed limits not only reduce road kills of wildlife but also accidents (recommended); 
- All vehicles brought in from outside the concession area need to be washed-down to remove weed seed and cuttings of exotic species (recommended).

\section{Pollution}

- All refuse from camp and workshop areas should be removed, and all solid waste should be placed in a refuse pit and buried (Elias et al. 2001). Rubbish should never be pushed into the watercourses. All refuse, including rubbish, solid waste, oils and chemicals, if no longer suitable for re-use should be disposed in an environmentally friendly manner at off-site locations (strongly recommended).

\section{Logging and conservation for local people}

Much of the research conducted in Malinau to date, has sought common ground with local people as a basis for developing conservation activities outside of strictly protected areas (e.g. Sheil 2003a, b). Some of these ideas have already been noted elsewhere (e.g. protecting salt-licks, clean water and valued wildlife resources). Additional points worth noting include:

- Consultation with communities accessing the concession is required to both guide and inform management (mandatory);

- Even if a concession gains legal rights over a large tract of forest there is still much to be gained by identifying and clearly protecting sites with local heritage values or other local significance (grave-sites, old villages, sacred locations, salt springs, etc.) (strongly recommended);

- Also areas that have high abundance of important products (even if legal rights are unclear) such as gaharu, rattan and trees with boat sealing latex, should be identified and protected (strongly recommended). Local guidance should be sought to locate such sites;

- Koompassia spp. are protected by both harvesting regulations and by local people's practices. They are the focus of large comb building bees (Apis spp.) that are considered desirable for honey and pollination services. These trees should never be cut (in line with current regulations: mandatory);

- Ulin (Eusideroxylon zwageri) is also granted special status and cannot be harvested under government regulations as it is protected for local use. This species appears to be the most valued individual species of all from a local perspective (Sheil et al. unpubl.). Ulin should not be logged (mandatory) except for local people uses. Abuses of current regulations are widespread at present;

- Various species of rattan are collected and used locally for a variety of crafts and construction activities. In some areas these have been cultivated. Some types have become depleted close to settlements - though in general rattans seem to benefit from forest disturbance. The main threat appears to be the compulsory understorey cleaning that follows timber harvesting, and, as we have recommended above, this should be stopped or minimized as much as possible (mandatory/requires regulatory change); 
- Old village sites and fruit orchards should be protected against logging and other damage (strongly recommended). Old village sites maintain heritage value to the peoples who have lived there, but a more tangible factor is the abundance of fruit species scattered around such sites, making durian (Durio spp.), coconuts (Cocos nucifera), Artocarpus spp., mangos (Mangifera spp.), etc. relatively plentiful in some river side areas and appear to be a significant attraction to various frugivores;

- Eugeissona ulitis palms, which grow primarily on ridge-tops and are therefore vulnerable to skid-trails. These palms are (at least in Malinau) an important famine food for local people and should be protected by good skid-trail planning (strongly recommended);

- Limestone outcrops and caves constitute a very special feature in some tropical forests as already stated above. These areas are home of swiftlets (mostly Collocalia spp.) whose nests have considerable cultural and commercial significance and can be the basis of protected areas (as in the 1 kilometre exclusion zones in Malinau) (strongly recommended);

- Cultural needs of local communities need to be assessed and incorporated in a wildlife management plan, such as the cultural need for hornbill feathers or certain subsistence medicinal uses (Sheil et al. 2003c) (strongly recommended). There is a need to protect culturally important species too-local people would not wish to eliminate hornbills by over-collecting them. For this, adequate controls and agreements are needed, which will protect the cultural needs outlined above, as long as the demand is from within the communities, does not threaten species viability and does not service outside markets.

\section{Implementation and vigilance}

\section{Monitoring}

Sheil et al. (2004) suggested an initial emphasis on conventions, laws and locally negotiated rules. The purpose of monitoring programmes should then be to check that these regulations are accepted and are implemented. A basis for local verifiers could include:

1) What are the current major threats in the vicinity? What are the most likely future threats? Are these reflected in pre-emptive monitoring?

2) What proportion of the responsible parties knows the agreed-upon rules and responsibilities?

3) How many times have rules been enforced, over time? What has happened as a result?

4) What are the estimated amounts of illegal hunting produce found by spotchecks in local areas (number of animals or $\mathrm{kg}$ found per day)?

5) What is the percentage of forest workers who have affordable alternative sources of protein?

6) What are the numbers of tools, trophies, or other items associated with illegal hunting activities found in inappropriate locations per population? 
We suspect that qualitative assessments (i.e., spot-checks) will often suffice to identify whether or not there is a serious problem with commercialised hunting. The verifiers and milestones would relate to specific knowledge of the rules and agreements, evidence of capacity and efforts to enforce them, and a search for evidence regarding implementation.

There may be good reasons to monitor selected wildlife populations directly, as sometimes proposed (e.g., Stork et al. 1997), but this needs to be the result of careful deliberation. Indirect monitoring may be more efficient.

- We recommend monitoring of management interventions as well as changes in indices of wildlife abundance when this can guide management-perhaps with outside assistance to ensure expert guidance and evaluation. The specific criteria for this could be stated in a local management plan and a code-of-practice (i.e. what will be done and how). We believe that this 2-prong approach would provide a solid foundation to improve logging practices and make them more compatible with wildlife conservation (Sheil et al. 2004) (strongly recommended);

- Each unlogged area (not equivalent to 'protected areas' or 'protected zones' as logging is determined by various other factors) should be monitored and recorded on logging maps of each concession (strongly recommended).

\section{Legal aspects, implementation and control}

- All concession staff and actors working within the concession should recognise and understand all regulations concerning their activities (mandatory). This should become the basis of review and of spot-checks (strongly recommended);

- Adverse environmental impacts of poor logging practices are aggravated where there is high-intensity felling of preferred commercial species, and where workers are paid on piecework rates with minimum supervision (DFID 1999). Logging activities should therefore be constantly supervised at different levels (strongly recommended). This should include production supervisors, block inspectors, and felling and skidding foremen (Elias et al. 2001);

- Close non-essential roads as soon as the operations are complete. This prevents hunters using those roads and it also reduces the opportunities for illegal re-entry logging (Bennett \& Robinson 2000) and other undesirable activity, e.g., agriculture or risk, e.g. fire. This can be done by destroying bridges, gouging the surface of roads, and otherwise blocking off access to roads (strongly recommended);

- To minimize corruption and maximize efficiency, wildlife law enforcers should not be paid directly by the logging concessions. Instead, the companies should be required to post a bond, paid to the appropriate government ministry, for an amount indexed to the area of forest to be exploited that year (Wilkie et al. 2001) (mandatory/requires regulatory change);

- Means of enforcement should be built into guidelines (strongly recommended). Since the Ministry of Forestry and local governments control logging and the concession controls security, it should be a combination of self-policing with check-ups by KSDA and other designated government representatives. Ideally these staff would include trained and authorized biologists. Other stakeholders 
(community representatives, NGOs, etc.) should be given opportunities for involvement and verification (strongly recommended);

- We recommend forestry certification audits by accredited organisations, if applicable, as a means to gauge success (strongly recommended);

- We recommend that timber certification guidelines of the Forest Stewardship Council, ITTO, and other relevant bodies incorporate principles that directly address conservation of biodiversity and especially wildlife (strongly recommended). These principles should be explicit rather than vague, and should cover the specific threats faced by wildlife in logging concessions (Bennett \& Gumal 2001);

- An officially authorized independent biologist should be allowed access to all sites before, during and after operations and should be able to closely collaborate with the concession management (the rules for this authorization and collaboration should be determined within a larger framework such as a certification programmes) (strongly recommended);

- Establish and enforce laws and/or regulations to make logging companies operating in the country responsible for preventing hunting by their staff, for providing them with fresh domestic protein sources, and for preventing their vehicles being used to transport hunters and wild meat (strongly recommended). Such measures must be accompanied by an education programme aimed at loggers and local communities, explaining why timber companies can no longer carry wildlife for villagers. The laws/regulations should be tied to measures to ensure compliance by companies; ideally, the penalty for non-compliance would be revocation of the timber license. Logging companies should be required to pay for wildlife enforcement (whether done by logging, government or other agency staff) in their concession (Bennett \& Robinson 2000);

- In areas where no logging is allowed and threats from illegal logging are high, legally endorsed and supervised tree spiking could provide an effective, low-cost technique to stop illegal timber harvest (Foreman \& Haywood 1989; Meijaard 2001 b; Fredriksson et al. unpubl.). A trial project in the Sungai Wain forest area near Balikpapan, East Kalimantan, has been successful in curbing illegal logging. Key ingredients to this success were local political support, coordinated law enforcement, multi-stakeholder participation, and considerable media attention (Fredriksson et al. unpubl.). We recommend an assessment of where and when tree-spiking could be used (strongly recommended);

- Manned booths with security guards should be established at the main entry points, i.e., the primary roads, where logging vehicles are entering. If vehicles are seen who have entered without a permit from the local authority: (1) request them to leave immediately, (2) reprimand staff, who manned the booth, and (3) notify the management authority (Muziol et al. 2000) (recommendations dependent on legal status: mandatory or strongly recommended).

\section{Awareness and training}

Currently poor harvesting and road building practices are partly the result of lack of knowledge supervision and incentives. It is necessary to build awareness and 
understanding of RIL and its link to sustainable forest management among all personnel involved in harvesting and roading in the forest, especially key individuals such as chainsaw operators, tree inventory and marking teams, harvesting and roading supervisors, log extraction and roading crews, machine operators, and log scalers. Regular and well structured training in the following topics would be beneficial (after DFID 1999) (strongly recommended):

- Chainsaw operation;

- Directional felling;

- Cross cutting;

- Vine cutting;

- Planning of roads, landings, and skid trails;

- Supervision;

- Construction of roads, water crossings, landings, and skid trails;

- Rehabilitation of roads, water crossings, landings, and bulldozed skid trails.

In addition to this, training should address:

- Protected status of species and other legal aspects regarding hunting and trade (including awareness and knowledge of law enforcement authorities and mechanisms);

- What to do when protected species are in the direct vicinity of a felling site.

\section{Species-specific suggestions}

\section{Demand, importance for local people and protection status}

In the previous section we provided management recommendations that would generally be beneficial to the functioning of a timber concession's ecosystem. Some wildlife species would benefit from these measures. In general, our recommendations should favour the more sensitive forest species, while implementation of our recommendations should improve forest regeneration and maintain higher levels of most forest products and services.

What we have not incorporated in our recommendations so far is specific advice on how to protect 'important' local wildlife species. Such importance depends on the stakeholders' perspectives and is thus difficult to define in a generic manner. One approach is to consider national and international protection and conservation status, the degree of local use and cultural significance, and its range (for instance, a Bornean endemic is of more importance than a widespread species). Thus, we used the IUCN status of Malinau's species (see Appendix 2), their protection status under Indonesian law (see Table 1), and their importance to local communities (see Appendix 3).

Table 15 shows the species that are threatened with worldwide extinction and are in relatively high demand by local communities. The table also shows that the IUCN-listed species are not always protected by Indonesian law. For instance, the now rare Straw-headed Bulbul (Pycnonotus zeylanicus) and Crestless Fireback 
Table 15. Species that are in the top 30 of species used by local communities (after Sheil et al. 2003c), and that are listed on the IUCN Red List of Threatened Species (after IUCN 2002). Also shown is the protection status under Indonesian law.

\begin{tabular}{llll}
\hline \multicolumn{2}{c}{ Species name } & \multicolumn{1}{c}{ IUCN status } & $\begin{array}{l}\text { protection } \\
\text { status }\end{array}$ \\
\hline Neofelis nebulosa & Clouded Leopard & Vulnerable & yes \\
\hline Lophura erythrophthalma & Crestless Fireback & Vulnerable & no \\
\hline Pycnonotus zeylanicus & Straw-headed Bulbul & Vulnerable & no \\
\hline Anthracoceros malayanus & Black Hornbill & Lower Risk/near threatened & yes \\
\hline Macaca fascicularis & Long-tailed Macaque & Lower Risk/near threatened & no \\
\hline Manis javanica & Pangolin & Lower Risk/near threatened & yes \\
\hline Argusianus argus & Great Argus & Lower Risk/near threatened & yes \\
\hline Presbytis hosei & Hose's Leaf Monkey & Data Deficient & no \\
\hline Buceros rhinoceros & Rhinoceros Hornbill & Lower Risk/near threatened & yes \\
\hline Ursus malayanus & Sun Bear & Vulnerable/Data Deficient & yes \\
\hline
\end{tabular}

(Lophura erythrophthalma) (see BirdLife International 2001), although protected in other countries, can still be legally collected or hunted in the wild (although officially harvesting quota need to be set, see Appendix 12), which points towards a considerable short-coming in the Indonesian legal system.

None of the species in Table 15, with the possible exception of the Black Hornbill (Anthracoceros malayanus), Great Argus (Argusianus argus) and Sun Bear (Ursus malayanus) are thought to be much affected by the direct effects of selective logging, and the disturbance following logging will temporarily displace these species. Reducing hunting or harvesting pressure is therefore important to prevent these species from becoming rare or even extinct locally. In terms of management recommendations, the species in Table 15 that are protected by Indonesian law take priority. Concessionaires and government agencies must take steps to protect Neofelis nebulosa, Anthracoceros malayanus, Manis javanica, Argusianus argus, Buceros rbinoceros, and Ursus malayanus. None of these protected species are primarily hunted or collected for food, and all are of medicinal, trade and cultural rather than nutritional importance (Puri 2001). However as these species are in relatively high demand from local communities, hunting or collecting prohibition will need to be combined with information campaigns. Trade in these species must be stopped and hunting phased out.

Another category is the species listed as Endangered or Vulnerable by the IUCN but that are not among the top 30 species in terms of their local use (Table 16). Again, it is striking that some of the species classified as Endangered or Vulnerable by the IUCN (2002) are not protected by Indonesian law. Although it is beyond the main focus of this report, an overhaul of the act on protected species is needed.

Of the species in Table 16, the pheasant, wren babbler and pigeon are probably among the species most affected by the direct effects of logging. Bulwer's Pheasant (Lobiophasis bulweri) is a Bornean endemic of submontane and hilly areas that is probably nomadic and may depend on major fruiting events in lowland dipterocarp 
Table 16. Species listed by IUCN (2002) as Endangered or Vulnerable, but not in high demand by local communities. Also shown is the protection status under Indonesian law.

\begin{tabular}{llll}
\hline & Species name & IUCN status & Protection status \\
\hline Bos javanicus & Banteng & Endangered & yes \\
\hline Nasalis larvatus & Proboscis Monkey & Endangered & yes \\
\hline Ciconia stormi & Storm's Stork & Endangered & no \\
\hline Manouria emys & Brown Giant Tortoise & Endangered & no \\
\hline Orlitia borneensis & Great River Terrapin & Endangered & no \\
\hline Pelochelys cantorii & Giant Soft-shell Turtle & Endangered & no \\
\hline Alcedo euryzona & Blue-banded Kingfisher & Vulnerable & yes \\
\hline Cynogale bennettii & Otter-Civet & Endangered & yes \\
\hline Lobiophasis bulweri & Bulwer's Pheasant & Vulnerable & yes \\
\hline Nycticebus coucang & Slow Loris & Vulnerable & yes \\
\hline Ptilocichla leucogrammica & Bomean Wren Babbler & Vulnerable & no \\
\hline Rollulus roulroul & Crested Partridge & Vulnerable & no \\
\hline Spilornis kinabaluensis & Kinabalu Serpent-Eagle & Vulnerable & no \\
\hline Treron capellei & Large Green Pigeon & Vulnerable & no \\
\hline Macaca nemestrina & Pig-tailed Macaque & Vulnerable & no \\
\hline Amyda cartilaginea & Common Soft-Shell Turtle & Vulnerable & no \\
\hline Notochelys platynota & Malayan Flat-shelled Turtle & Vulnerable & no \\
\hline
\end{tabular}

forest as a spur to breeding. It is rarely found in opened forest and probably needs extensive contiguous forest areas (BirdLife International 2001). The Bornean Wren Babbler (Ptilocichla leucogrammica) is restricted to low attitude forest in the northern half of Borneo (BirdLife International 2001), and it is much rarer in logged than in unlogged forest (Lambert 1992); it therefore depends on intact lowland forests for its survival, and the Malinau Region contains one of the last remaining tracts of suitable habitat. The Large Green Pigeon (Treron capellei) is a fig specialist restricted to lowland forests (BirdLife International 2001), and removal of its food trees will likely lead to further population declines. These three species might benefit from the detailed management recommendations that we provided above.

Little is known about the effects of logging on turtle, tortoise and terrapin populations, but it is expected that these species are primarily affected by collecting for food and medicine, rather than by selective logging. Turtles/terrapins are much sought after in Kalimantan and, for instance, Dudgeon (2000) reported that 13.5 million kg of live tortoises and terrapins were imported to Hong Kong in 1998, the majority of which originated from Indonesia and Thailand. Of all the freshwater turtles/terrapins that are consumed (primarily in China and Taiwan), softshells (Family Trionychidae) are considered the best, due to low bone-to-body ratio and the larger proportion of cartilage and gelatinous skin. Several authors have stated that at least half of the international trade in terrapins and tortoises is in softshells, mostly Amyda cartilaginea (Walter 2000), and this might be the species that is also targeted most in the MRF 
area, although quantative data are lacking. Walter (2000) reported that each year ca. $35,000 \mathrm{~kg}$ of turtles/terrapins are traded from the Danau Sentarum National Park in West Kalimantan, which earned local hunters between US\$ 50,000 and 75,000 per year; or about $4.5 \%$ of the gross income for the people in the park. Similar data are lacking from MRF, but the trade in turtles/terrapins is potentially of local economic importance. As none of the local turtle, tortoise and terrapin species are protected, we can only recommend aiming at more sustainable collecting strategies in MRF. Indonesia has set export quotas for species such as Pelochelys cantorii (100/year) and Manouria emys (500/year) (see CITES website: http://www.cites.org/index.html), but it is unclear to what extent this is enforced. A recent workshop on Asian turtle/terrapin trade (see van Dijk et al. 2000) recommended that all Asian species of freshwater turtles/terrapins should be considered for listing on at least Appendix II of CITES, meaning that trade in these species would become much more restricted.

Other species in Table 16, such as Banteng and Proboscis Monkey, are rare in MRF, and one could argue that they are best protected in their prime habitat, i.e., the grasslands of the Kayan Mentarang NP for Banteng (see Hedges \& Meijaard 1999), and the mangroves and riverine forest near the coast for Proboscis Monkeys (see Meijaard \& Nijman 2000).

Finally, there may also be a need to limit the off-take of species that are neither protected nor IUCN-listed, but in high demand by local communities (see Appendix 3). This primarily concerns Sus barbatus, while Cervus unicolor and Tragulus spp. are formally protected. However, hunting of these species is common and laws are rarely, if ever implemented. The porcupine Hystrix brachyura is listed as Vulnerable by the IUCN and protected in Indonesia, although the species appears to be locally common and is in high demand for its meat. Research is needed on this species to see whether their status as a protected species is indeed warranted.

S. barbatus, the Bearded Pig, is one of the most important sources of animal protein in this part of Borneo. Puri (1997) reported that Bearded Pigs contributed $79.8 \%$ of all catches and $91 \%$ of all the edible meat yielded in the Kayan Mentarang National Park, which concurs with Chin's (2001) work in Sarawak that found that the percentage of Bearded Pig meat in total hunted biomass varied from 67.4 to 97\%. Over-hunting of Bearded Pigs has led to their local extinction in many parts of Borneo (e.g., Bennett \& Dahaban 1995; Bennett et al. 1999), while according to Davies et al. (2001) the species has become extinct in Peninsular Malaysia. A recent analysis of the total value of all Bearded Pig meat consumed in the Kayan Mentarang National Park estimated that this amounted to a total yearly value of approximately US\$ 3,500,000 (based on a total human population of 16,645 in 2001, a monthly consumption of $10 \mathrm{~kg}$ of meat per person (which appears high), and a price of 12,000 $\mathrm{Rp} / \mathrm{kg}$ ) (Effendi et al. 2002). Bearded Pigs are therefore of considerable nutritional and economic importance. Once pigs disappear, local communities not only lose an important protein source likely resulting in higher living expenses as meat will have to be bought, also it is expected a shift to other, less preferred species may occur. Pig hunting in this part of Borneo is very wasteful, with only small parts of the pig being used and the remainder discarded (Augeri pers. obs.; Meijaard pers. obs.; R. Puri pers. comm.). Many villagers in Malinau already report a decline in the availability of wild 
pigs. If more sustainable hunting (e.g., not targeting pregnant females, underweight animals or juveniles), transportation, and storage methods were developed, hunting pressure could be reduced. In addition, the development of domestic breeding of pigs, deer and cattle would also reduce the hunting pressure on these populations.

For some of the protected species mentioned above (Cervus, Tragulus and Hystrix) one could argue that improved law enforcement would reduce hunting pressure. Considering, however, that such laws are rarely implemented and that these species are considered by many to be an important free resource, it may be better to closely monitor off-take and population trends and to work towards a sustainable harvest strategy. For C. unicolor, which may benefit from the increased availability of grasses after logging, a management strategy that incorporates the establishment of limited or zero hunting zones could benefit the species and allow some harvesting. To implement new management zones for hunted protected species, agreement from government authorities is required as it would clash with the protected status of the species. A revision of the legal protected status to recognise the role of wildlife in the protein needs of local people might need to be considered, as implementation of the law is almost impossible and distracts heavily from achievable goals.

\section{Primates}

Bornean Gibbon (Hylobates muelleri), Hose's Leaf Monkey (Presbytis hosei), Maroon Leaf Monkey (P. rubicunda) (Fig. 25), Proboscis Monkey (Nasalis larvatus), Slow Loris (Nycticebus coucang), Pig-tailed Macaque (Macaca nemestrina) and Long-tailed Macaque (M. fascicularis): the main threat to these species is probably hunting and habitat loss. The Malinau region is one of the most primate species-rich of Borneo (Meijaard \& Nijman 2003), and as there is no protected lowland forest in the region, appropriate management of primates in logging concessions is very important.

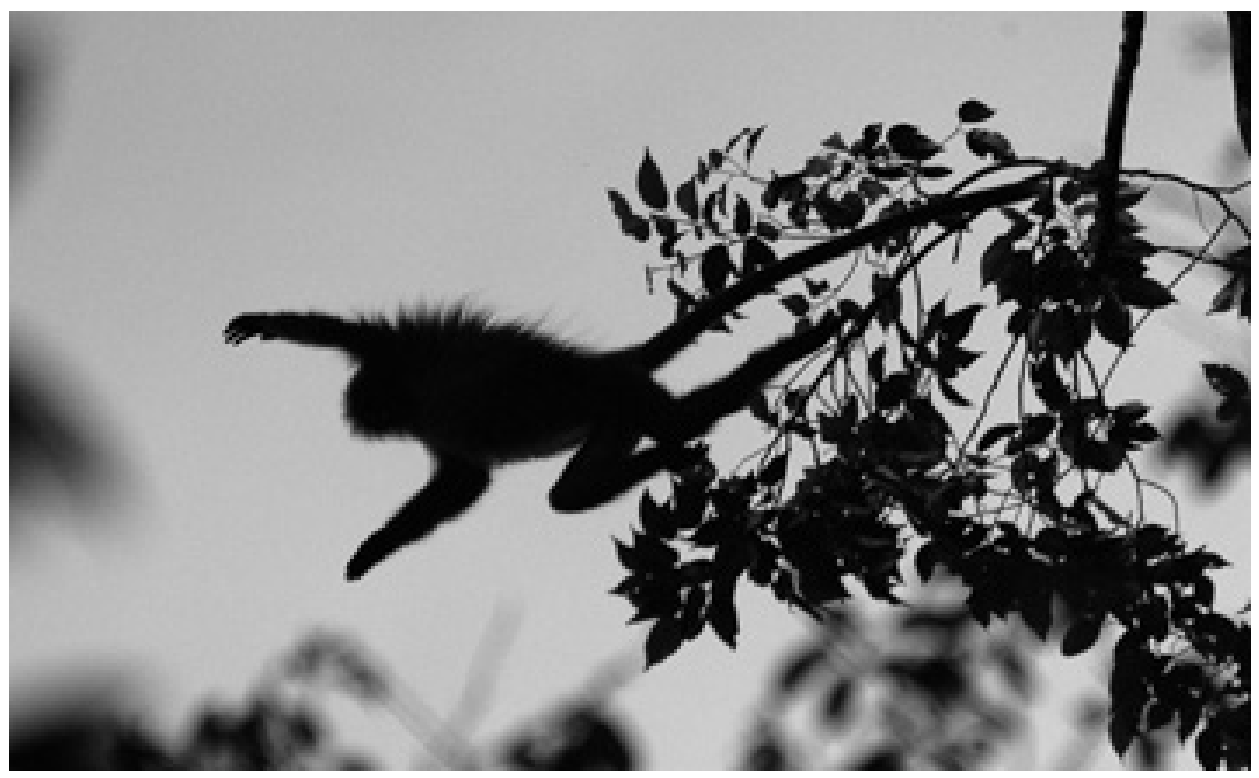

Figure 25. Red Leaf Monkeys (Presbytis rubicunda) require canopy connectivity for their arboreal lifestyles. (Photo by Kimabajo) 
The Bornean Gibbon, Proboscis Monkey, Slow Loris and Maroon Leaf Monkey are protected by Indonesian law and should not be hunted. Information should be provided to logging employees regarding this prohibition, and patrols should enforce the law (mandatory). Hose's Leaf Monkey and the macaque species are hunted for a variety of reasons. It is important to investigate the effect of hunting on these species to work towards sustainable hunting levels (strongly recommended). Hose's leaf monkey should be protected (strongly recommended) because the local subspecies (see Brandon-Jones 1996) is likely to be upgraded to species level (Meijaard \& Groves unpubl.), and that species would be restricted to a very small distribution range.

\section{Other mammals}

1. Clouded Leopard (Neofelis nebulosa). Deforestation appears to be the foremost threat to this species (Rabinowitz et al. 1987). The Clouded Leopard is also widely hunted for its teeth and pelt, and for bones for the traditional Asian medicinal trade (Nowell \& Jackson 1996). Skins are found in ceremonial clothes in many villages in the Malinau region (Sheil pers. obs.).

1a. Clouded Leopards are locally important for cultural use (Puri 2001), and they appear to be becoming increasingly rare in the wild. Unless, global conservation is given priority over local needs the species will likely follow the same path towards extinction as the tiger (Panthera tigris). The Clouded Leopard is protected by Indonesian and International laws and should not be hunted. Information should be provided to logging employees regarding this prohibition, and concession staff should be aware of and enforce the law (mandatory).

1b. A primary objective for management of Clouded Leopards should be to establish where the species occurs in a logging concession. Sightings and signs should be reported to biologist monitors, and it should be established in which forest types the species occurs. With the exception of radio telemetry, camera trapping is the best way to establish species ranging and the number of individuals in a concession. It is also important to record and protect Clouded Leopard prey bases and the habitat of their prey species (strongly recommended).

2. Malayan Sun Bear (Ursus malayanus) appears to be negatively affected by logging and hunting, while fragmentation probably leaves it with habitat patches that are too small for long-term viability (Augeri 2004a, b). Also, there is a considerable demand for bear products, such as gall bladders and claws, especially in East Asia. Now that bear populations in East Asia are rapidly declining (see Servheen et al. 1999), the demand for such products from Kalimantan might increase.

2a. Malayan Sun Bears are protected by Indonesian and International laws and should not be hunted. Information should be provided to logging employees regarding this prohibition, and concession staff should be aware of and should enforce the law (mandatory).

2b. It is important to record and protect Malayan Sun Bear food resources (strongly recommended), such as major fruit trees, trees containing bees' nests, and termite colonies (see Appendix 5 for details). 
3. Pangolin (Manis javanica). This species is locally collected for use as food, medicine and pets (Puri 2001). In the late 1970s and early 1980s it was an important international trade item with up to 30,000 skins being traded to the United States from primarily Indonesia and Malaysia (Anonymous 1981). Pangolins still are traded in Southeast Asia, mostly to China and a recently confiscated shipment of 88 pounds of pangolin scales to Australia (Reuters 2003) suggests that Indonesian trade still continues. The species is presently listed by CITES as an Appendix II species, and the species is protected by Indonesian law. The species should therefore not be hunted. Information should be provided to logging employees regarding this prohibition, and concession staff should be aware of and should enforce the law (mandatory). Furthermore, primary food resources such as ant and termite colonies should be maintained (strongly recommended).

\section{Birds}

4. Hornbills (Helmeted Hornbill (Rhinoplax vigil), Rhinoceros Hornbill (B. rhinoceros), Black Hornbill (Anthracoceros malayanus) and Wrinkled Hornbills (A. corrugatus)) are primarily affected by hunting, loss of breeding space and loss of food sources.

4a. These species are protected by Indonesian law and should not be hunted, unless permission is given to hunt birds for cultural needs. Information should be provided to logging employees regarding this prohibition, signs should show their protective status, and concession staff should be aware of enforce the law (mandatory).

4b. The use of nest boxes should be investigated (recommended). Wreathed (Aceros undulatus) and Southern Pied Hornbills (Anthracoceros albirostris) have bred in conventional nest boxes $\left(50 \mathrm{~cm}^{2}\right.$ by $1 \mathrm{~m}$ high) and large hollowed out logs, but it is not known whether the priority species in Malinau will breed in nest boxes. Several nest box designs should be tested for breeding success. Note that Mckenney \& Lindenmayer (1994) found that in most scenarios nest boxes cost more than logging bans even under a variety of discount rates.

4c. Hornbills do not excavate, but they may enlarge cavities made by woodpeckers and other species. Hornbills need large trees, and trees with a minimum dbh of $50 \mathrm{~cm}$ need to be left standing to allow for hornbill nesting (strongly recommended). Especially Rhinoplax vigil appears to require very large $(\mathrm{dbh}>105 \mathrm{~cm})$ dipterocarp trees for nesting and such trees need to be retained (as already mentioned above) (strongly recommended).

4d. If hornbill nests are found in trees selected for logging, this should indicate that the tree has heart rot and the tree should be left standing since hornbills tend to use cavities for many years (strongly recommended).

4e. In selected areas, trees that bear lipid-rich capsular fruits such as Aglaia and Myristica, lipid-rich drupaceous fruits of Lauraceae and Annonaceae, and sugar-rich fruits of Ficus should be left standing to provide sufficient food sources for these birds (strongly recommended). This can be achieved by minimising non-target tree damage. 
4f. Hornbill species tend to breed during periods of high fruit availability. If possible, logging should be suspended during these periods, especially when close to important fruit trees (strongly recommended). It could also be considered to temporarily set aside important nesting areas until breeding has finished (strongly recommended). Vigilance is required to ensure that hornbills are not hunted during the breeding season (Datta 1998).

5. Pheasants (Bulwer's Pheasant (Lobiophasis bulweri), Crestless Fireback (Lophura erythrophthalma), Crested Fireback (Lophura ignita) and Great Argus (Argusianus argus)) are primarily affected by hunting, loss of food sources and human disturbance.

5a. Bulwer's Pheasant and Great Argus are protected by Indonesian law and should not be hunted. Information should be provided to logging employees regarding this prohibition, and concession staff should be aware of and should enforce the law (mandatory).

5b. Counteracting the combined effects of habitat destruction, loss of food sources (fallen fruit and invertebrates in leaf litter) and human disturbance is best achieved by setting aside sufficiently large forest areas in which populations of these birds are protected. The Crestless Fireback is speculated to be a valley-bottom specialist (McGowan \& Garson 1995 in BirdLife International 2001), especially when Crested Fireback (Lophura ignita) is absent. Crestless Fireback may, however, also occur in hill forest. Bulwer's Pheasant is primarily found in untouched forest in hilly country. If forest areas in logging concessions are protected for the support of these pheasant species they should be sufficiently large and include undisturbed sections of hill forest and alluvial valleys (strongly recommended).

6. Straw-headed Bulbul (Pycnonotus zeylanicus). This species is much sought after as a cage bird (Holden 1997 in BirdLife International 2001). Populations are in severe decline and it 'has been virtually exterminated as a wild bird' in Indonesia (Holmes 1995 in BirdLife International 2001). Remote populations in East Kalimantan, however, are critical for conserving the species as they may serve as sources of re-colonization. This requires legal protection of the species, which should be arranged by the government and improvement of the guarding system and law enforcement (once the species is legally protected) in logging concessions (strongly recommended).

7. Raptors (Kinabalu Serpent-Eagle (Spilornis kinabaluensis) and Crested Goshawk (Accipiter trivirgatus)).

7a. The Kinabalu Serpent-Eagle is mostly affected by destruction of its submontane habitat (Collar \& Andrew 1988 in BirdLife International 2001).The record of Kinabalu Serpent-Eagle from East Kalimantan is the only one from Indonesia, and a primary research objective should be to monitor the population of this species (establish numbers, ranges, habitat use) (recommended).

7b. Crested Goshawk is protected by Indonesian law, the species should therefore not be hunted and its habitat should be protected (mandatory). 
8. Blue-banded Kingfisher (Alcedo euryzona). A bird of mid-sized, permanently flowing, clear, rocky and shingly streams within lowland and low foothill tropical forest (BirdLife International 2001). It is mostly affected by destruction of its stream-side forest habitat, stream siltation, and in some areas increasing riverine traffic.

8a. Surveys are required to determine where this species occurs in the Malinau region. Siltation of streams should be prevented in areas where this species occurs (strongly recommended).

8b. Wells (1999) calls for an evaluation of the effects of logging on this species, research that could well be conducted under controlled conditions in the Malinau logging concessions (recommended).

9. Large Green Pigeon (Treron capellei). This species is a bird of level lowland and low foothill primary forest, and a specialised feeder on figs. This species may be particularly compromised by forest degradation, as it is only half as abundant in logged areas as in primary forest (Lambert 1992). The species is probably much hunted for food (BirdLife International 2001).

9a. Retention of enough large figs of the right species (e.g., Ficus drupacea) (Lambert 1989c; Wells 1999), to provide a dependable year-round supply of fruit, is critical to the survival of the species (Wells 1999) (strongly recommended).

9b. Hunting of this species should be investigated and a sustainable level of hunting should be advocated which maybe zero in logged forest (strongly recommended).

10. Great Slaty Woodpecker (Mulleripicus pulverulentus). As with the Large Green Pigeon, this is a species of level lowland forest; its density is reduced $>80 \%$ in logged forest compared to primary forests (Lammertink 2004). It requires large diameter, live trees for foraging on stingless bee, ant and termite nests that are located in natural cavities in large branches and tree trunks. Retention of large diameter live trees, dipterocarps and others, in level lowland forests will result in less severe density declines in this species after logging (strongly recommended).

\section{Turtles, tortoise and terrapins}

Turtles (Malayan Flat-shelled Turtle/Terrapin (Notochelys platynota), Brown Giant Tortoise (Manouria emys), possibly also Common Soft-shell Turtle/Terrapin (Amyda cartilaginea)). These species are all threatened by over-harvesting while not protected by Indonesian law. Local people eat these animals when they are caught and some valued medicinal uses are associated with gall bladder (Sheil pers. obs.). A primary objective should be to establish densities and numbers for the various species and work towards a sustainable level of harvesting (strongly recommended).

\section{Fish}

Carps (Tor spp. and Pangasius spp.). These fish species are among the most sought after fish species in MRF (see Appendix 3). Pangasius are migratory and are easily caught as they aggregate in a predictable manner. There are a few useful 
recommendations concerning carps that are relevant in this more general context. These fish are the most preferred by villagers (interviewed in three villages) and also have cultural significance. The Tor adults live in deep clear pools in the forest while the juveniles live in shallower tributaries. They are fruit and algae eaters, and are believed to be associated with the presence of Dipterocarpus or Ficus growing along the bank. These fish should be viewed as vulnerable as they require clear water, are dependent on forest vegetation and silt force rivers, are easily caught, have a relatively low reproductive rate and are keenly sought. Indeed, these fish are not found in areas affected by the siltation of rivers caused by forest cutting or road building, and they generally do not occur in more open areas. A primary objective should be to establish densities and numbers for the various species and work towards a sustainable level of harvesting (strongly recommended). Furthermore, careful stream management (see also various roads and infrastructure recommendations above) should ensure clear streams and pools and that populations of these fish species are not negatively affected by logging operations (Rachmatika et al. 2005) (strongly recommended). 



\title{
Recommendations for government planning
}

\begin{abstract}
A recent ITTO mission to Indonesia (Yeom \& Chandrasekharan 2001) stated that Indonesian forestry is at a critical crossroads. There are two choices: continue on a path of forest depletion leading to a precipitous decline in the sector's contribution to socio-economic and environmental well-being or shift towards sustainable contributions over the longer term. There can be no doubt that the long-term costs of the former option are greater than those of the latter. Here we consider how improved government planning and implementation would contribute to the survival of East Kalimantan's forests and wildlife and what steps might prove most useful.
\end{abstract}

\section{The need for a wildlife masterplan}

According to Indonesian conservation and forest use laws, timber concessions have a range of conservation obligations, which need to be incorporated in their planning procedures. However, the terms of these obligations often remain unclear and though some aspects are meticulously adhered to, at least in some cases, other are commonly ignored in practice. For example, Article 5 of Law No. 5 (MoF 1990), which appears to be one of the most relevant statements, says 'conservation of living resources and their ecosystems shall be brought about through the following activities: a) protection of life support systems; b) preservation of plant and animal species diversity and their ecosystems; c) sustainable utilization of living resources and their ecosystems.' Similarly, Government Regulation No. 34 of 2002 concerning Forest Management and Utilization includes regulations regarding wildlife in concession areas. While it is hard to fault the intention of such statements they fall far short in terms of operational guidance on how it might be achieved. A clearer set of guidelines with articulated goals, rules, rights and responsibilities set out in pragmatic and operational terms appears to be a major requirement. A single coherent document-a wildlife masterplan (e.g., Bennett et al. 1996)—would be of considerable value.

Government agencies should also take responsibility for ensuring that threats, especially new ones, are adequately recognised and suitable precautions and actions 
are taken. Examples would include issues such as approaches for forest fire prevention and monitoring, identifying aggressive exotic species and developing national conservation schemes that account for climate changes.

\section{Land tenure agreement}

Long-term forest management benefits from agreement on land and usufruct rights. Without recognition (or settlement) of long-standing indigenous and other local claims, conflicts are likely to recur. There are pre-existing claims in the sense of traditional adat rules which are seldom recognised legally in Indonesia, but there are also pre-existing rights such as those given to concessions or government departments under past regimes (C. Colfer, in litt., 17 October 2003). Law No. 41 of 1999 regarding the Basic Principles of Forestry recognises the right of adat (Article 67), as does the Decree of the Minister of Forestry and Plantations regarding Community Forests (Keputusan Menteri Kehutanan dan Perkebunan Tentang Hutan Kemasyarakatan): 677/Kpts-II/1998. There is, however, a lack of legal guidance on how to interpret and implement these laws. These issues are complicated in Indonesia as conflicting claims can often draw on contradictory legal statements (see, e.g., Lynch \& Harwell 2002).

Accepted mechanisms for determining rights are needed. Notice should be given to allow customary land claims to be determined and addressed in an ethical manner. Furthermore, there is a need for procedures and mechanisms to resolve disputes. Negotiation and legal clarity are needed. Our review focuses on timber harvesting and wildlife conservation: while we recognise the fundamental importance of ownership claims and tenure, we also acknowledge that we cannot give an adequate account of these complex issues and how they might best be resolved. Those interested in these important topics will find richer sources in texts such as Lynch and Harwell (2002), who describe the history of forest land claims in Indonesia; Colfer and Resosudarmo (2002), who discuss the obstacles to resolving these and related issues; and Wollenberg et al. (2001), who discuss how multiple stakeholders might be accommodated in (mainly community) forest management. Once the various stakeholders in a proposed timber concession have come to a land tenure agreement, boundary negotiations in the planned concession should take into account, in relation to each village:

- Terrain, topography, rivers and major drainage patterns;

- Functions of forest;

- Special features (gravesites, old villages, heritage sites, etc.)

- History of the village, the village people, and their land and usufruct claim(s);

- Customary use of forest resources (e.g., rattan, wildlife);

- Current use and concerns in the surrounding landscape;

- Number of families and population;

- Sources of livelihood (especially who uses the forest for what);

- Education and experience;

- Infrastructure, particularly access to the forest by roads and rivers; 
- Location: whether the village is outside, on the border or partly inside, or completely inside the concession.

\section{Large-scale planning}

This should be a government action at higher spatial scales. Designing and implementing a landscape level spatial plan for land use in the Malinau area is necessary to ensure that forest fragmentation is minimized as much as possible and that connectivity between production and protected forest areas is maximized. The National Conservation Plan for Indonesia (FAO 1981) proposed such a network of forest areas that would include the lowland forests of Sebuku and Sembakung north of Malinau, coastal and lowland reserves (Muara Kayan and Gunung Berau), and the upland areas of the Kayan Mentarang National Park and the watersheds of the main rivers that run east-west between the coast and the mountains. There remains an urgent need to create a representative protected forest network in East Kalimantan by first gazetting proposed protected areas and implementing proper protection of protection forests (Hutan Lindung). A further important issue is that no agricultural expansion should take place at the expense of forests in areas where poor soils and exceptionally difficult terrain preclude economically viable development.

As we have pointed out above, fragmentation of habitat is one of the main factors threatening the survival of viable populations of forest bird species, and it appears to be similarly affecting forest mammals. Jepson et al. (2002) recently pointed out that the network of protected areas in East Kalimantan is either yet to be established or consists of degraded elements. This has happened despite the fact that the Indonesian government adopted a policy for landscape level planning of a connected forest area in 1982. Clearly, there is a need to develop a more effective planning and implementation procedure that incorporates all relevant departments and institutions (both at national and district/province level) and other key stakeholders. Under the UU No. 24/1992 Spatial Management Law, provinces and districts are required to prepare spatial plans (known as Rencana Tata Ruang Wilayah Propinsi/Kabupaten $=$ RTRWP/K), but in East Kalimantan these plans do not envisage the establishment of a contiguous forest area large enough for the long-term survival of wildlife (Jepson et al. 2002). Also, these plans ignored many of the watershed protection forests and new protected areas that were proposed in Indonesia's National Conservation Plan in 1981/1982 (FAO 1981). Still, recent forest maps by the Indonesian Ministry of Forestry indicate that a sufficiently large contiguous forest area remains in northern East Kalimantan; and the challenge will be to retain this forest cover, especially large areas of lowland forest, without jeopardizing local economic development. The province of East Kalimantan revised its spatial plan in 1999 into what they called the harmonized spatial plan. This plan aims to integrate the land use plans for forestry and everyone else. The revised plan, however, has not yet been agreed on by all parties due to the perceived conflicts with the many new spatial plans at the district level.

Clearly, the development and maintenance of a protected area network and a permanent forest estate should be reconciled with other development objectives 
(roads, agriculture, forestry, etc.). Wherever possible, however, the permanent forest estate should be kept contiguous with the strictly protected area(s) to allow animals to move freely between the two. This will help ensure protection of all species, and a sustainable food supply for rural hunters who depend on wild protein. Such areas can include production and protection forests that are managed to maintain forest cover and biodiversity as well as their production objectives. While much of what we are suggesting may appear unrealistic we note the relative success of many of these measures in Sarawak (e.g., WCS 1998).

To be more specific, it is vital to establish a system of land use comprising a network of protected areas and contiguous extractive reserves, including totally protected areas where hunting is not allowed, or is very strictly limited. Two main types of protected area are needed:

- Large areas $\left(>100 \mathrm{~km}^{2}\right)$, big enough to protect viable populations of game species, that act as 'sources' to replenish surrounding 'sinks' where people hunt;

- Smaller or connecting areas to protect places where species are especially vulnerable (such as communal nesting areas, salt licks, corridors, areas rich in key plant sources or known breeding areas).

\section{Hunting and fishing}

The Indonesian government has a potentially important role in enhancing the sustainability of hunting. A legal framework for this has been laid out in Government Regulation No. 13 of 1994 on Hunting Wildlife. Further legal guidance is provided by the following regulations:

- Government Regulation No. 8 of 1999 regarding the Use of Plant and Animal Species;

- Ministerial Decree No. 447/Kpts-II/2003 regarding the Administration of the Removal or Capture and Distribution of Plants and Animals;

- Decree of the Director General of Forest Protection and Nature Conservation No. 158/KPTS/DJ-IV/2003 regarding Quota for Harvest of Natural Vegetation and Animal Capture for 2004.

These regulations stipulate that, for all wildlife-whether protected or unprotected - maximum quotas need to be established for harvest from natural areas (see Appendix 12). Generally, however, harvest of unprotected species (and in some cases protected species) is mostly unregulated. Again, a clearer set of guidelines set out in pragmatic and operational terms is needed. The Sarawak Wildlife Masterplan provides useful guidance for this. Based on this (modified after Bennett \& Robinson 2000) we highlight:

- Establishing further areas where hunting is controlled or prohibited;

- Controlling hunting and fishing access to key areas (by excluding outsiders from traditional hunting and fishing areas); 
- Controlling or banning the commercial trade of wildlife, including its transport and sale;

- Establishing and enforcing laws to protect vulnerable species;

- Establishing and enforcing regulations that limit or prohibit the hunting and fishing of seasonally vulnerable species;

- Establishing and enforcing laws on the use of different non-selective hunting and destructive fishing technologies;

- Creating mechanisms and an atmosphere to promote education and awareness programmes on wildlife conservation and the need to reduce hunting and over-fishing, at all levels: decision makers, general public, schools and local communities.

In addition, governments could work towards reducing the need for wild meat by establishing, subsidizing or otherwise promoting programmes to provide alternative sources of protein for rural nutritional needs. Such programmes would include production of domestic animals, reared fish or plant products. This must be done as part of overall land use planning. On its own, this will not prevent over-hunting, but should be part of a holistic approach if other hunting control systems are to work.

Lee (2000) suggested that the government should work towards a more realistic set of fines and penalties for illegal hunting. As stipulated in Law No. 5 of 1990, the penalty for hunting protected species holds a maximum fine of 100,000,000 rupiah (or US\$ 45,454) and/or up to 5 years in prison. Considering that the average per capita annual income in Indonesia is less then one-tenth of this, and that few perpetrators would be able to pay such fines, a review of these laws is needed. Clayton and Milner-Gulland (2000) suggested that fines on dealers in bushmeat are probably a more effective way to curb hunting pressure on commercially hunted species.

\section{Forest law enforcement and governance}

There is an urgent need for central provincial and district governments in Indonesia to implement laws and regulations that protect forests and take sustainable forest management as their guiding principle. Many of the existing Indonesian laws and regulations relevant to our recommendations could be strengthened or at least better implemented. They were articulated in haste, based on rather poor scientific or technical knowledge, did not allow room for public participation and did not incorporate cross-sectoral referencing (mining, agriculture, land use policies). This is recognised in Indonesia and the present dynamic reform has already resulted in several thousand new legal products being issued over the last few years. It is therefore likely that laws (e.g., Law 41 of 1999, see Appendix 10) might be in the process of transformation, which makes it hard for us to make recommendations for specific legal changes. The recent forestry ministerial decree 162/kpts-ii/2003, for instance, which aims to accelerate HTI (plantation) development to meet the demand from the pulp and paper industries, stipulates that clearcutting is allowed in natural forest areas where the sustainable use of a forest plantation system is implemented. This law appears to be in conflict with earlier laws prohibiting clearcutting in natural forest areas. The most important legal changes we recommend are: 
- The legal designation of a maximum diameter above which trees should not be cut;

- A clear stipulation that conserving 'protected species' requires the defence of their habitats, and a matching set of directives on how this should happen (the current legal framework relevant to this does not provide prescriptions to safeguard the habitat of protected species, although there is a requirement to preserve protected species themselves both in and outside natural sanctuary reserves (see Rijksen $\&$ Meijaard 1999, p. 321));

- Cancellation of the obligatory slashing of climbers and ground vegetation as stipulated in silvicultural requirements (TPTI);

- Systematic post-logging rehabilitation of log landings and stream crossings;

- Closure of non-essential roads as soon as the operations are complete. This prevents hunters using those roads and it also reduces opportunities for illegal reentry logging, agriculture and fires;

- Banning of commercial hunting and collecting in concessions (for details see the section on Recommendations to Managers; controlling hunting and extraction);

- Enactment and enforcement of bans on trade in all wildlife and animal parts in concessions;

- Legal and practical mechanisms need to be established for local communities to be involved in decision making and management regarding wildlife resources and hunting in their area;

- The establishment of conservation zones within concessions where hunting is forbidden;

- A ban on the use of electric shocks, bombs and poison in fishing;

- The occurrence of fire removes the restriction on concession holders to refrain from re-cutting harvested forest areas before the end of a statutory period. Legal changes are needed that prohibit this;

- Requirement for logging companies to post a bond, paid to the appropriate government ministry, for an amount indexed to the area of forest to be exploited that year and to be used for wildlife enforcement;

- Reassessment of the protected status of species that are endangered (according to IUCN) or which are under very high hunting/collecting pressure (see list below).

Further complications have arisen from the national government's attempt to decentralize governing institutions. Now that districts can issue their own regulations, it is of the utmost importance to clarify the legal status of national vs. district/provincial laws.

There are signs that the national government is now trying to impose national forestry and conservation laws in the districts. For instance, a road building agreement in the Kayan Mentarang National Park, East Kalimantan, between Sabah Forest Industries and Yayasan Pendidikan Pembangunan Perbatasan Kalimantan Timur was deemed illegal by the national director of conservation, who stated that 'all national parks in Indonesia are under the control of the Director General of Forest Protection and Nature Conservation within the ministry, and not the district governments of Nunukan or Malinau or the provincial government of East Kalimantan' (Francis 
2003). It is indeed clearly stipulated in Law No. 22/1999 that conservation areas are to remain under central government control.

We consider law enforcement to be a key element of improved forest management, although clearly forestry practices are only as good as the governance system through which the system operates. We therefore give our recommendations in the knowledge that some of these may already be in the process of being incorporated into Indonesia's legal system.

Many of our recommendations are in fact already incorporated into Indonesia's legal system, for instance, in Government Regulation No. 13 of 1994, regarding hunting of game species. Among other things, the regulation clearly prohibits the use of illegal hunting techniques, such as chemicals, snares and pit traps. Still, these laws are rarely enforced, while there are also, as mentioned elsewhere in the report, considerable discrepancies between the protection status of species and their actual protection needs. Thus, some very rare species can still be legally hunted or collected because they have not yet been included in the list of protected species in Indonesia (see list below, but note that unprotected species also require quotas for legal harvest-see Appendix 12). There is an immediate need to address this issue by investigating which IUCN listed species are presently not protected in Indonesia. Puslitbang Biologi LIPI (the Indonesian Institute of Sciences) is currently working on a review of the list of Indonesia's protected species that was published in 2001 (Noerdjito \& Maryanto 2001). With regard to species in Malinau, prime candidates for inclusion on the list are:

- Storm's Stork Ciconia stormi (listed as Endangered by the IUCN)

- Brown Giant Tortoise Manouria emys (listed as Endangered by the IUCN)

- Great River Terrapin Orlitia borneensis (listed as Endangered by the IUCN)

- Giant Soft-shell Turtle Pelochelys cantorii (listed as Endangered by the IUCN)

- Crestless Fireback Lophura erythrophthalma (listed as Vulnerable by the IUCN)

- Straw-headed Bulbul Pycnonotus zeylanicus (listed as Vulnerable by the IUCN)

- Bornean Wren Babbler Ptilocichla leucogrammica (listed as Vulnerable by the IUCN)

- Crested Partridge Rollulus rouloul (listed as Vulnerable by the IUCN)

- Kinabalu Serpent-Eagle Spilornis kinabaluensis (listed as Vulnerable by the IUCN)

- Large Green Pigeon Treron capellei (listed as Vulnerable by the IUCN)

- Common Soft-Shell Turtle Amyda cartilaginea (listed as Vulnerable by the IUCN)

- Malayan Flat-shelled Turtle Notochelys platynota (listed as Vulnerable by the IUCN)

- Pig-tailed Macaque Macaca nemestrina (listed as Vulnerable by the IUCN)

- Hose's Leaf Monkey Presbytis hosei (listed as Data Deficient by the IUCN)

The government should investigate whether some species that are presently protected can be legally hunted for subsistence, e.g., Cervus unicolor, Muntiacus muntjak, Tragulus javanicus, T. napu and Hystrix brachyura. This would require a 
change in the legally protected status of these species. Before doing so, the government should bear in mind that forest-dependent species such as mouse-deer (Tragulus spp.) require the protection of large forest areas from settlement and fragmentation before any hunting can be considered potentially sustainable.

Finally, law enforcement can be substantially boosted by using more sophisticated systems to detect illegal activities (such as logging and forest clearing or illegal use of fire). Remote sensing techniques allow detailed monitoring of road building, forest degradation and deforestation, and fires. The further development of remote monitoring systems and the incorporation of such data in law enforcement systems should be encouraged, although such techniques can only become effective after institutional reforms result in effective law enforcement on the ground. As long as the rich and powerful manage to evade prosecution there is little hope for effective combating of illegal logging, hunting and other activities that negatively affect wildlife populations in Indonesia. Much of this is related to corruption, both in the public and private sectors. This emphasises the need for transparent planning in the forestry sector, involvement of all relevant stakeholders from planning to implementation, and an effective monitoring system run by public and private institutions.

\section{Effective implementation}

Improved forestry practices can be encouraged by more than legal enforcement alone: contexts, capacities and opportunities are vital. Is it possible for concession managers to find new management paradigms? Forest policies in Indonesia are primarily driven by economic considerations, and despite a positive contribution from more conservation-guided approaches, forest conversion and degradation continue at an alarming rate (e.g., Holmes 2000; Jepson et al. 2001). Even protected areas are not immune to complete clearance, as, for example, in the Kutai National Park in East Kalimantan, where very little forest now remains (Soehartono \& Mardiastuti 2001). The situation is similar in other parts of Indonesia: the province of South Sumatra, where there are six 'protected areas' (with a total area of 2,580 $\mathrm{km}^{2}$ ), no longer posses any forest cover whatsoever (Holmes 2000). In the Malinau area, several major road development projects are planned and partly executed. This will further fragment the still extensive lowland forest area, increase pressure on wildlife populations and on other non-timber forest products, and increase the risk of fire. Within this context, we remain uncertain how our recommendations for improved concession management can be successfully implemented.

The spectrum of policies that would aid the implementation of our recommendations ranges from top-down, government-driven enforcement of laws, to bottom-up, community-based strategies. In between, there are more marketdriven opportunities such as those based on forest certification. The recent history of forest policies in Indonesia indicates the problems associated with implementing government policies on forestry and conservation, especially now that governing power is being decentralized (e.g., Colfer \& Resosudarmo 2002), and there is little clarity about the relationship between national, regional, and district level laws on land-use planning. The national legal system does indeed need to be incorporated 
into concession management planning (for instance, regarding a prohibition on the hunting of protected species, or the creation of new protected areas), but considering the general lack of enforcement of these laws, an approach that demonstrates the benefits of sustainable managed forests to local stakeholders is more likely to have success. We believe that forest certification and participatory forest management are the most promising strategies to ensure that forests in the Malinau area are more sustainably managed.

We do not suggest immediately handing all responsibility to local communities. Certification and participatory management strategies need to be carefully introduced and effectively combined with government policies in a way that makes them palatable to local stakeholders.

In addition, there has to be strict and independent monitoring of the progress of such strategies. How such monitoring can be an effective feedback tool to guide improved management is difficult to answer. If foreign investment is involved, pressure groups could use their influence to ensure that such investment is only guided towards properly managed forestry projects. This has been successful in some timber certification projects in various parts of the world, and, for instance, in the oil palm industry, where major donors have agreed to a code of conduct that adheres to national laws and is open to independent inspection (see http://www.rabobank.com/ repository/position/palmoilcode_rabobank.pdf). It remains to be seen how this will work out in Malinau and the rest of Indonesia, but there are some positive signs, with timber certification for timber from natural forests finally becoming a reality. 



\section{Certification requirements}

This report does not intend to analyse criteria and indicators in detail, but we do want to briefly compare our findings with the mostly widely recognised criteria for sustainable forestry management recommendations. Generally, there is much overlap between our recommendations, or at least the intentions behind them, and those based on the Forest Stewardship Council (FSC) principles. For instance, FSC principle 6.2 stresses the need to control 'inappropriate hunting, fishing, trapping and collecting', while principle 1.1 stipulates that 'forest management shall respect all national and local laws and administrative requirements'. Principle 9 states that 'management activities in high conservation value forests shall maintain or enhance the attributes which define such forests.' Furthermore, principle 10 discusses the need to maintain connectivity of natural forests, although it does this in relation to the planning of plantations, which are only allowed to play a minimal role in concession planning (see principle 6.10). But maintenance of ecological integrity and connectivity in production forests appears inadequately addressed in the FSC criteria.

Our review indicates that forest fragmentation is one of the most important factors in the decline of wildlife populations It is therefore of vital importance to ensure that forest within a concession remains connected as much as possible while, at a landscape level, any forest blocks should be connected to large protected forest areas. The best solution depends on the context and the options available: requiring a pragmatic set of choices and balances to be struck. This cannot easily be reduced to a series of basic criteria. Rather careful planning is required to consider the best means to maintain connectivity (Sheil et al. 2004).

The FSC criterion on hunting, fishing, trapping and collecting (see above) also fails to provide exact guidelines on how concessionaires should deal with these issues in their areas; the term 'inappropriate' in principle 6.2 leaves much to the interpretation by the concession manager. We consider it more suitable if FSC principles would stress the need to assess species priority listings in a concession 
(similar to those provided in this report) and based on these compile specific action plans for each of the high priority species. This should include assessments of habitat and ranges, key resources for particular species (certain trees, saltlicks, caves, etc.), logging strategies that encourage the species to persist, and recommendations on sustainable hunting levels or bans on hunting. We also find that the FSC criteria do not provide enough detail on how to deal with every-day situations in which protected species are directly threatened by logging, e.g., a hornbill nesting in a tree which is scheduled for felling.

Furthermore, there appear to be no criteria on how to regulate wild meat harvest in a concession (unless this is stipulated by national law). Again, clear guidance is necessary in part because many hunted species are important for the long-term health of a production forest. Finally, as we explained above, dead wood is a very important component of healthy forests, and the best way to ensure a constant supply of dead wood at least in the medium term, is to retain large, fecund trees and focus timber harvest on medium-sized trees.

In conclusion, it appears that certification criteria, and related procedures and guidelines, can be made more useful regarding the incorporation of sustainable wildlife management in forestry to ensure the long-term survival of viable wildlife populations in logging concessions. Although the need for protection of high conservation value forest and their species is promoted, not enough detail is provided on how to deal with day-to-day situations in which FSC recommendations are common but problematic (e.g., hunting a protected species, such as Sambar (Cervus unicolor), felling a tree occupied by rare or protected species). Therefore, we recommend revision of the certification process to include clear demonstrations-in planning, operations, threat-preparedness, and all aspects of management-that reflect explicit and clearly articulated wildlife conservation priorities, concerns and goals for each concession (see also Sheil et al. 2004). 


\section{PEART IV}

\section{Recommendations for research and researchers}

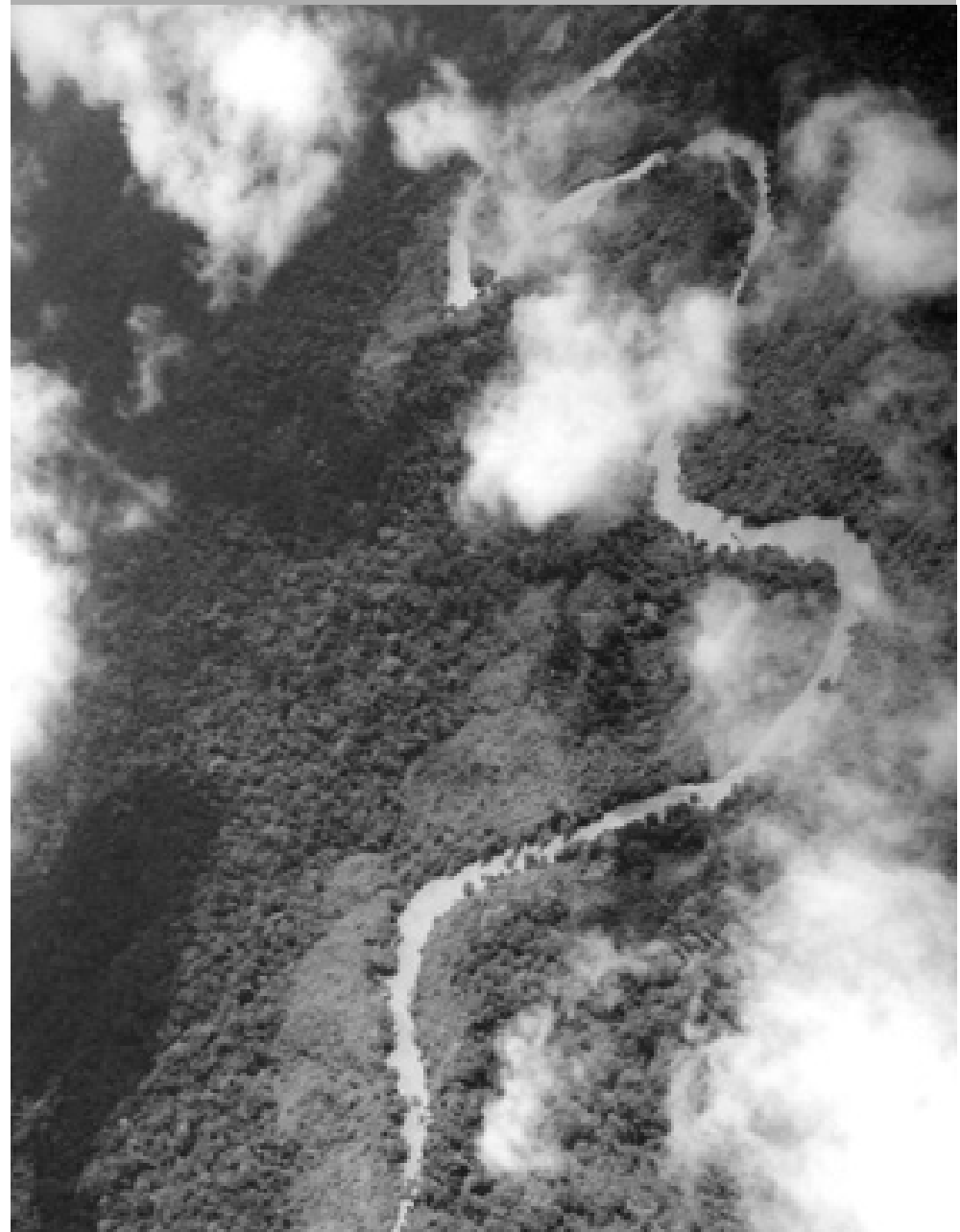

Aerial view of tributary of the Malinau River including areas of young re-growth. We must use timber concessions as part of a process to plan and maintain large well-connected forest landscapes. (Photo by Sven Wunder) 



\section{Recommendations for research and researchers}

Our review shows that Bornean wildlife is — with a few exceptions-poorly known, and that threats are poorly investigated. Threats have been best studied in Sarawak, where researchers have looked at the effects of hunting (including that related to timber concessions) on birds and mammals (Bennett et al. 1997; Bennett et al. 1999; Bennett \& Gumal 2001), and in the Danum Valley Field Center, Sabah (e.g., Heydon \& Bulloh 1997; Colón 1999). In Kalimantan, only primates (especially Orangutans, Pongo pygmaeus) have received much investigation of threats, though we know of some useful recent studies which focus on the Malayan Sun Bear (Ursus malayanus) and the bearded pig (Sus barbatus) (Curran et al. 1999; Meijaard 2003a; Hancock et al. in press).

Clearly, there is a need to step up research efforts and collect the required data. We need more emphasis on pragmatic studies that can directly clarify conservation needs and/or opportunities, and call for more applied wildlife studies, with less concentration on species-specific density monitoring, and more focus on the direct effects of particular threats and on means to address these effects.

The lack of threat assessments for Borneo's fauna is striking. From a local perspective, there is generally little difficulty in identifying threats to biodiversity-predominantly habitat loss (particularly the loss of natural forest cover), encroachment, unregulated exploitation and various forms of environmental degradation. Undeniably, information on distribution, feeding requirements, nesting requirements and even morphology, genetics and taxonomy can be important, but they have seldom contributed directly to improved conservation management. The main reason might be that management implications of this research are seldom clearly articulated.

Why have so few field researchers made or published observations on species trends and threats? In some cases their research may have had quite different objectives. Obtaining detailed ecological insights into species and their interactions with their (disturbed) environments may require more time than is generally available for an 
individual researcher. Nonetheless, with relatively limited effort Bornean research projects might have established extensive data sets on how species react to particular threats. Such data could be derived from simple observations (e.g., a particular species crossed a $3 \mathrm{~m}$ wide logging road at $3.30 \mathrm{p} . \mathrm{m}$.), routinely recorded as part of regular research work. In fact, many of the important questions that we suggest below might already have been answered if data had been consistently compiled. Such conclusions are easier to make retrospectively. Our point here is not to apportion blame-we are as guilty as any-but rather to emphasise that better approaches for research to be relevant are needed and to suggest what these might entail. We would hope that future efforts may allow a more consistent emphasis on gathering and reporting key information. Such goals should become an integral part of each wildlife research project, and preferably be incorporated into a Borneo-wide database.

Based on the need for relevant research, and the various priority issues noted in our review, we can now begin to outline research recommendations for wildlife species in logging areas. Besides additional research on animal species and their interactions with vegetation and other species, there is also a need for further socioeconomic research. Such research should address issues such as sustainable harvest levels for unprotected wildlife species, and explore the viability of developing facilities in timber concessions that could be used by visitors interested in sustainably managed logging areas, the associated wildlife species and local cultural values.

One important caveat in the following suggestions is that they are not exhaustive. They are limited by our knowledge, assumptions and imagination. Shifts in the way we are willing to think about conservation might make other kinds of research more useful: for example, in Puerto Rico, forest operations are restricted by season to reduce disturbance to the breeding of the endangered Puerto Rican Parrot (Amazona vittata)

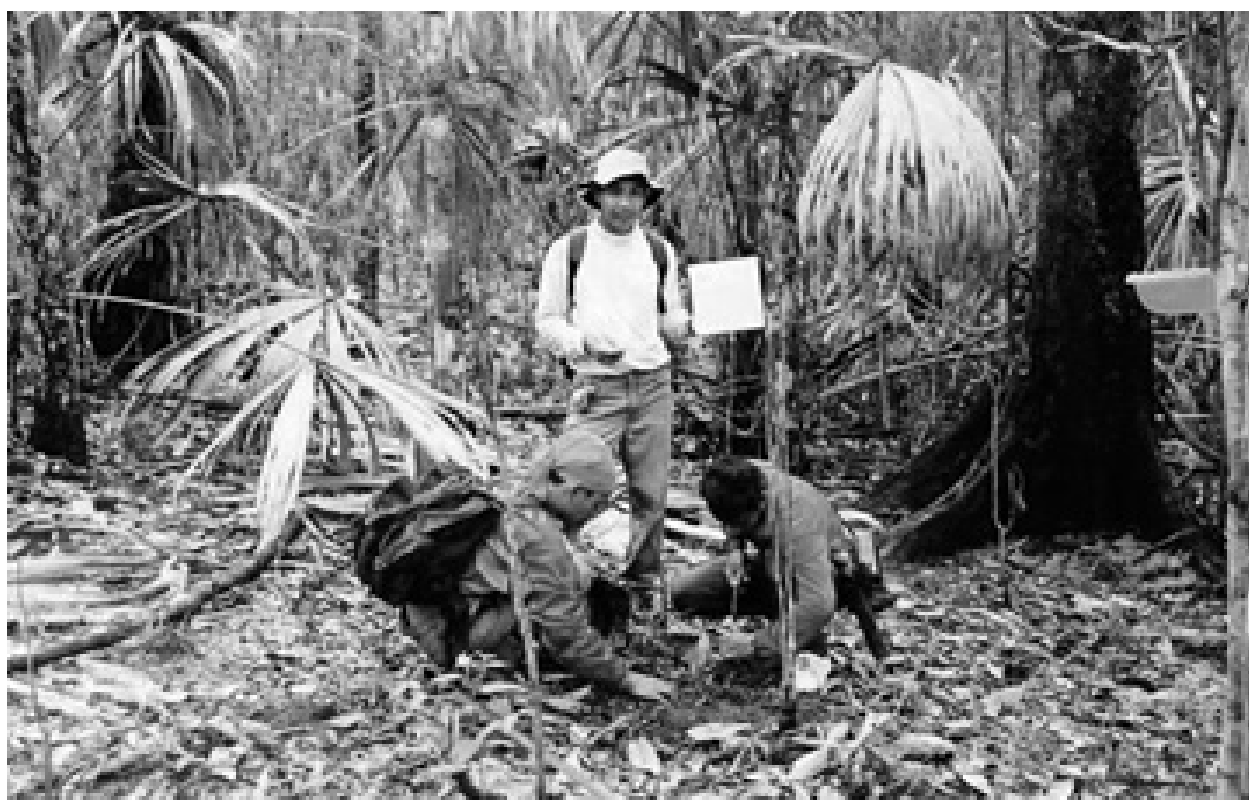

Figure 26. Local researchers assessing post-fire damage in East Kalimantan. (Photo by Gabriella Fredriksson) 
(Caribbean National Forest 1997; Scatena 2001; Snyder et al. 1987). Pursuing such developments in Borneo would appear a distant dream, but perhaps the situation may change in the future. For now, our recommendations focus on a pragmatic assessment of priority concerns: what do we need to know to improve the conservation value of timber concessions for wildlife?

\section{Recommendations to researchers}

Conceptual recommendations to researchers to design relevant programmes include the following:

- Consider how forestry regulations and operations might most easily be modified to be beneficial to wildlife (for example, understorey clearing is not challenged in recent literature);

- Recognise the legal and management context. Attention should be given to refining and implementing existing regulations and procedures;

- Ensure proposed management interventions are viable (and understood): such recommendations should be reviewed in conjunction with concessions, communities, government and other actors;

- Ensure all rule-based controls have clear and precise operational definitions that exclude conflicting interpretations. For example, how do we show that an area is too steep to harvest? If the limit is set at X degrees, how do we show that a slope is more than X degrees? Experience in Indonesia shows it is not enough to define the angle without stating how it is measured in relation to local terrain and concession maps (Sheil pers. obs.). Similar concerns arise in other contexts: e.g., what is the definition of a stream requiring protection?;

- Be pragmatic. Studies that can provide rapid and practical improvements in forest management should be given a higher priority than long-term academic studies that may cost a great deal and contribute little to conservation;

- Emphasise efforts to solve conservation problems over watching these problems develop (Sheil 2001b);

- Make clear recommendations whenever possible. Research papers that claim to 'benefit conservation' should spell out these benefits in specific and pragmatic terms. Research that intends to give practical recommendations for improved management should provide them. Ideally such recommendations should be discussed with those they are intended to address to ensure they are clear and realistic;

- Examine species ecologies in relation to habitat use, and forest changes, and relate these to management choices. The observation that a species 'declines following logging' is a poor basis for developing improved forestry practices;

- Undertake species inventories with a clear strategy to use the information. Basic species inventories are justified in poorly explored regions such as Malinau if the resources and expertise are available. Recent studies in Malinau have noted a number of apparently undescribed vertebrate taxa (Iskandar pers. obs.; Rachmatika et al. 2005), and we should anticipate that more remain to be recorded. The distribution of such apparently restricted species may imply considerable global 
conservation significance. Better information on species distributions and status in Borneo and the Sundaic Region should allow better conservation planning. However, willingness by someone to respond to such data would ideally be assured whenever such surveys are pursued as a priority. Further questions are who should pay, and is it reasonable to ask concessions to undertake such tasks;

- Determine how to effectively reconcile the priorities and concerns of local stakeholders and resource users with those of international conservation, and develop guiding priorities in conservation plans that can be integrated into local management and decision making;

- Identify and assess barriers and impediments to the effective implementation of improved management practices and associated regulations and restraints;

- Explain and promote study results to local audiences (e.g., resource users and decision makers) whenever possible;

- Give explicit attention to the differing effects of timber removal, road building, fragmentation, hunting and other impacts, how they co-vary, and how they interact;

- Conduct (or coordinate) studies over sufficiently long periods and over geographically extensive and diverse sites, preferably adequate to incorporate normal annual and supra-annual variation in species densities;

- Coordinate among different researchers and institutions. Long-term large-scale designs and cross site comparisons will benefit from such collaboration. The results can provide much more comprehensive and detailed information regarding species sensitivity, and efficient, ecologically appropriate management techniques;

- Design all field studies with a more explicit attention to scales, contexts, multiple ecological process, and confounding effects (and to the types of basic parameters required to conduct more powerful meta-analyses);

- Identify which species are vulnerable to which types of interventions (or combinations of interventions) and evaluate a more explicit recognition of tradeoffs amongst conservation aims and other management goals;

- Develop guidelines to prioritise which species are most in need of which kind of active management interventions, and how these can be tailored to specific concessions;

- Evaluate, refine and revise the hypotheses already developed in this study (identify generalities and exceptions) and examine how far practical recommendations can be derived from these (for identifying sensitive species, which types of interventions are most damaging, and what actions can ameliorate these);

- Continue to review and synthesise available information in order to develop and examine additional hypotheses not yet adequately addressed (e.g., the idea that diurnal habits, and/or strong territoriality contribute to greater sensitivity to fragmentation and habitat opening).

Though institutional issues have not been the focus of our review we also suggest that conservation researchers should consider some additional roles and responsibilities (see also Bennett \& Robinson 2000): 
- Act as intermediaries between government and international agencies, local communities and logging companies to increase conservation benefits for local communities;

- Promote monitoring systems which can be assisted or conducted by local stakeholders so that they assume 'ownership' and responsibility for management recommendations;

- Promote and conduct education and awareness programmes aimed at all local stakeholders;

- Provide training to improve the management capacity available to address biological resource use and local development needs.

Topic-oriented suggestions include:

\section{Timber harvesting}

Timber harvesting can be conducted in different ways with different restrictions and controls. Effort is needed to evaluate how these differences might translate into benefits for wildlife conservation. One argument for allowing more intensive logging in some locations is that it may relieve pressure in others. The basis for making such arguments (specific or general) is not currently available but should be considered a reasonable long-term objective.

Forestry operations that should be 'researched' from a wildlife perspective include the following:

- The implications of logging on already logged over forests (second, third cut, etc.). Most studies have focused on logged versus unlogged. In the future the choices will increasingly relate to when and how to $\log$ areas that have already been exploited;

- Road and bridge building and maintenance standards;

- Machinery types and operations;

- Site drainage;

- Information developed in pre-harvest surveys and how this might allow local adaptation;

- Spatial layout of harvest coupes;

- Climber cutting;

- Identification and retention of seed trees;

- Protection of advanced regeneration;

- Protection of slopes, watercourses and other features;

- Optimisation of skid trail coverage;

- Damage reduction (directional felling, blade-up skidding, log size limits, etc.)

- Harvest rotations;

- Felling intensities (stem size and other controls and limits);

- Replanting (species and methods);

- The need for fertilisation in tropical forests after harvesting (see Nykvist 1998 for the arguments); 
- Tree spiking as a forest concession protection tool. Further research is needed to identify specific situations where this technique can be applied and under what circumstances (e.g., on the boundary with protected areas).

\section{Concession operations}

- Seek a better understanding of how concession staff and their activities affect the local environment. Evaluations might look at the level of staff knowledge and understanding of national, local and concession level controls and rules and how these can be improved. Evaluation of attitudes to conservation and how these might be nurtured would also be valuable;

- Review all aspects of concession development (road building and maintenance, water use, logging bay locations, flooding caused by roads, etc.), operations (traffic, fuel storage, demand for local meat and other products, patrolling) and closure (closing roads, bridge maintenance) to identify their actual environmental impacts, their influence on threats, and what might be done about them;

- The use of harvesting residues (brash) in areas with heavy machinery can reduce soil compaction and aid forest regeneration. Research is needed on how thick these brash mats should be to maximize benefits to forest regeneration (see Hutchings et al. 2002);

- Determine the impact of ponds caused by roads, etc. on both aquatic and terrestrial fauna;

- Clarify the types of in-the-field supervision and incentive schemes that are most effective for conservation and acceptable to commercial companies;

- Assess trade-offs as to whether (and in what contexts) logging operations should be localised or dispersed. Dispersed operations may have a lower overall impact, but may cost more, and make controls harder to implement. Such issues need explicit appraisal.

\section{Landscape features}

- Investigate what specific features in the landscape are critical for a specific wildlife species or guild (e.g., salt springs, caves, sandy riversides). How can such sites be effectively mapped and their values safeguarded?

- Assess the nature and importance of pools and wallows that occur through the forest. How are these formed, what role do they serve in local ecology, how they are affected by logging and by changes in animal abundances?

- Clarify what species rely on which habitats for what needs. Where do frugivores go when fruit abundance is low? Where do bat species roost?

- Evaluate if key landscape features (e.g. salt licks) can be replaced artificially.

\section{Fruit}

- Assess the ecology of Ficus spp. in logged forest and how fruit availability changes following intervention. Research has established the ecological factors limiting 
fig recruitment in the canopy and the possible ways increased fig densities might be 'ecologically engineered' (Laman 1995a, b, 1996a, b; Leighton \& Leighton 1983). Further research is needed on the effects of logging on keystone fig resources;

- Evaluate the importance and ecology of other fruiting species, and what affects their persistence and fruiting. For example, lianas in the family Annonaceae have been identified as possibly keystone resources for some vertebrates, and they can quickly become common in gaps created by logging. Further research is needed to determine the extent to which these plants (and probably various others that still need to be identified) contribute to forest recovery by attracting frugivores to logged areas;

- Assess fruit-bearing pioneer species that provide food for frugivores. Attracting frugivores to pioneer forest could speed up forest regeneration by increasing the amount of primary forest fruits that are deposited in regenerating areas;

- Assess how fruiting species and fruit availability are affected by different aspects of forest management, and how this affects frugivores. (We note some apparent contradictions in the literature regarding fruit availability following forest operations);

- Assess the options for replanting logged forest with timber trees that are valuable both as a source of timber and as a resource for wildlife. Working with local people is one way to identify other multifunctional species; there is a need to study tree species that fulfil both these silvicultural and ecological criteria.

\section{Species dependencies}

- Research the use of timber species, either dietary or structural, by wildlife, and how these species are affected by the selective removal of these trees. Our review recognises very few vertebrate species that are clearly dependent on dipterocarp or other timber species (e.g., Agathis borneensis, Eusideroxylon zwageri).

\section{Habitat structure}

- Research the effect of changes in forest structure on vulnerable species. Certain species likely require emergent trees for nesting (e.g., large hornbills, bees, possibly certain raptors, and bats (see Harrison 1962b));

- Research the fauna that depends on larger diameter, senescent trees;

- Assess the availability of tree hollows in different species of commercial and noncommercial timber trees. A simple monitoring programme could be developed that checks logged trees for such hollows;

- Investigate the role of tree hollows (in dead and living, standing and fallen trees) for nesting and breeding, roosting, sources of arboreal water within the forest (amphibian breeding) and food storage, and how the availability of such habitat is related to forestry management;

- Review the costs and benefits of the silvicultural technique (for fighting heart rot fungi) of removing dying and dead trees and burning them (Elouard 1998); 
- Trockenbrodt et al. (2002) reported that during logging operations in Deramakot, Sabah, up to $50 \%$ of the trees marked for harvesting were considered to be hollow, but they considered detection rates to be insufficient. There is a need to develop a reliable detection test for tree hollows;

- Piles of logs directly provide habitats for a variety of species (see Lindenmayer \& Hobbs 2004). Whether windrows of leftover timber could be advantageous in managed tropical forest areas needs to be investigated;

- Consider the role of understorey vegetation. Much of the emphasis on how logging changes vegetation, and thus food and habitat for vertebrates, focuses on trees. Many understorey species, including herbs (e.g., Zingiberaceae, Marantaceae, Musaceae, Poaceae) serve as key resources for many species (e.g., for pigs Sus barbatus) and produce significant amounts of fruit and nectar. The significance of these species deserves attention (which species are important, where they occur, how they respond to different aspects of forest management; how they can be maintained);

- Assess the impact of understorey slashing on terrestrial and fossorial species and analyse the silvicultural cost effectiveness of this technique.

\section{Connectivity, space and mobility}

- Assess the effect of the road and trail network on wildlife movement, including aspects such as road width, road substrate, ditches, road use, roadside vegetation, terrain placement and overhead canopy contact. This research may be best conducted using manned observation posts overlooking roads or a network of camera traps; alternatively, marked capture-recapture techniques applied on either side of particular barriers (e.g., McDonald \& St Clair 2004) may give insight into which species are restricted by certain barriers;

- Examine the ability of species to move through (or over) various logged forest areas in relation to the role of small forest reserves, including source-sink phenomena, re-colonisation roles and maintenance value in managed landscapes;

- Investigate the spatial distribution and size of wildlife source and sink areas; what inhibits and encourages the movement of particular species into post-harvest forest;

- Examine forest connectivity, forest corridors and the opportunities provided by forest rehabilitation techniques;

- Evaluate the influence of edge affects with relation to scales and the nature of the matrix;

- Identify and characterise which habitats play key or limiting roles to wildlife for specific seasons or life-cycle stages;

- Assess which environmental gradients are most valuable to be maintained in continuous forest cover and how this might be achieved in practice;

- Assess the optimal placement of logging free zones from both an ecological and an operational perspective. 


\section{Hunting}

- Assess the geographical variation in hunting intensity and species-specific hunting pressure. Understanding the spatial patterns of hunting on regional and local scales would provide important input to improved conservation management;

- Identify the hunting techniques that are least damaging to wildlife, and the optimal sustainable yield for each species;

- Evaluate source-sink dynamics of hunting, and how habitat connectivity is determined, (especially for wide-ranging, migratory and mobile species);

- Examine whether hunting free zones allow sustained or increased off-take in adjoining territories;

- Examine nutritional, cultural and social needs of local communities that engage in hunting and determine how these might be substituted. This could include the feasibility of developing a local livestock industry, or of substituting hornbill feathers, which are used in traditional ceremonies (Fig. 27), with those of turkeys, etc.;

- Assess the effects of different hunting and fishing methods on the animal community;

- Investigate whether there are specific seasons when, due to breeding, migration or food availability, species are more or less vulnerable to the impacts of hunting;

- Address the regulation or reduction of subsistence hunting: what types of controls and incentives are effective? Research is needed into the different ways to enforce hunting laws: e.g., the effectiveness of patrolling, guard posts, gun registration, hunting licenses, and the use of traditional bans or limitations on hunting certain species.

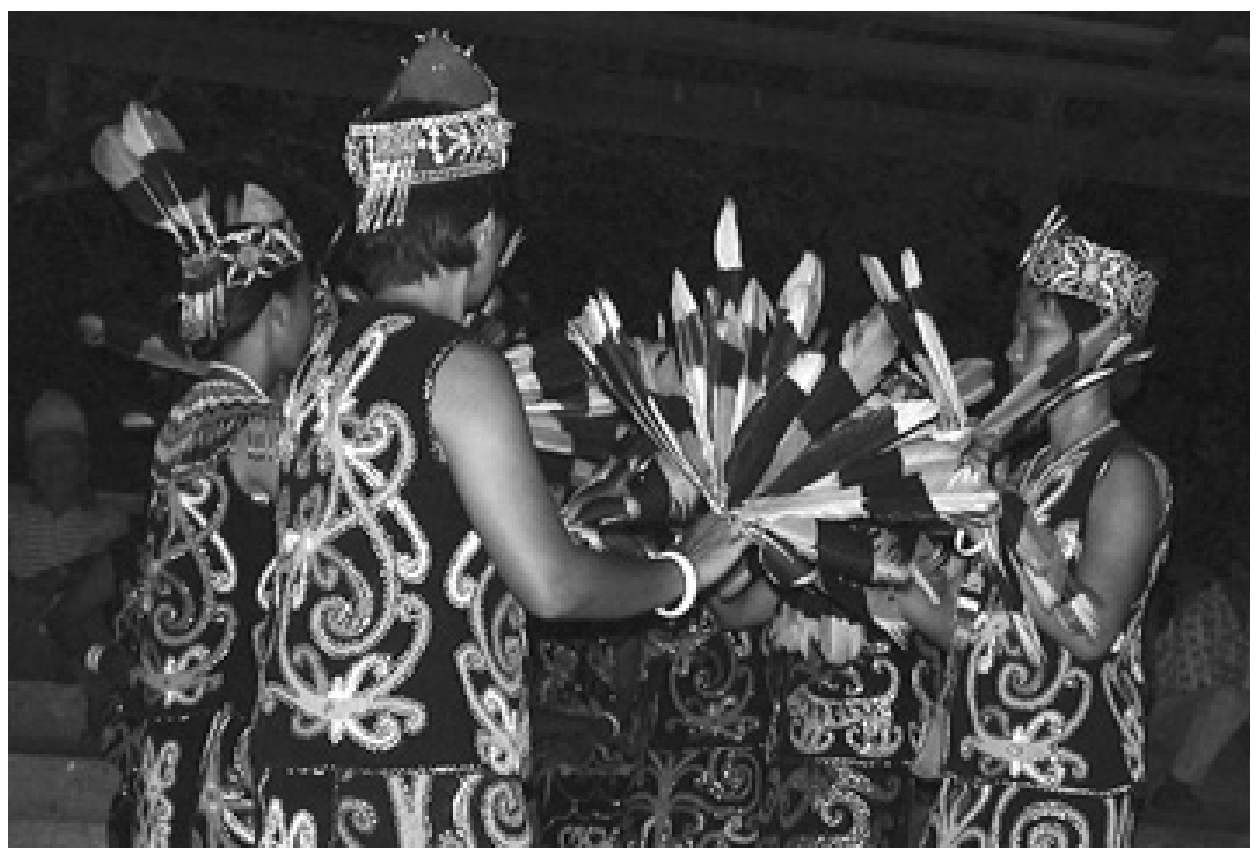

Figure 27. Sun Bear skins and hornbill feathers used in traditional ceremonies. (Photo by Dave Augeri) 


\section{Other threats}

- Develop operational methods to recognise and monitor any perceived threats and devise suitable rapid responses to them (readiness);

- Develop practical means to prevent the introduction of invasive species;

- If already introduced, develop practical means to assist in the identification, control and possible elimination of invasive species;

- Develop practical means to assist in the identification and control of high-risk areas for fire;

- Identify non-invasive, native fire-resistant species and investigate whether these can be planted as fire breaks around vulnerable forests, especially where such forests border high-frequency fire areas (e.g., areas of shifting cultivation);

- Investigate or model the effects of climate change on wildlife populations. How will species be affected by changes in temperature, seasonality or precipitation patterns? What are the implications?

Issues that appear to have lower priority, but warrant consideration, include the following:

- Examine the impact of dogs. Dogs are generally considered a threat to native wildlife in many parts of the world (e.g., Butler et al. 2004). There are no studies, however, on the effects of hunting dogs on Bornean wildlife. These dogs assist in the hunt and share in the meat. They will also affect wildlife populations if they go astray or become feral, either through direct predation or by transmitting diseases such as rabies and canine distemper;

- Examine the impact of feral animals. It has been suggested that the spread of feral cats and dogs and their impact on native forest fauna might be positively correlated to the density of roads (May \& Norton 1996). This needs to be investigated on Borneo;

- Research on how forestry practices can influence reservoirs or vectors of disease or pests. For example, forestry interventions commonly lead to changes in mosquito communities, thereby changing the incidence of diseases such as malaria and dengue (Chang et al. 1997; Overgaard et al. 2003). The nature of these changes depends on local soil conditions and the ecology of the vector. In some cases mechanised logging leads to large bodies of still water in the landscape, greatly increasing local mosquito densities. Such changes have potential significance for both human and animal populations;

- Survey road kills in forestry concessions (where they happen, what species are affected, their sex, condition and the season) and examine how they might be reduced;

- Consider the forest-agriculture boundary, its impact on wildlife, and how people view and respond to wildlife. Many mammals and some birds enter gardens adjacent to forests to feed on crops, especially Bearded Pig (Sus barbatus), Sambar (Cervus unicolor), muntjacs (Muntiacus spp.), macaques (Macaca spp.), Banteng (Bos javanicus), Sun Bear (Ursus malayanus) and munias (Lonchura spp.) (Meijaard pers. obs.). Such animals are killed. Research is needed on the extent to which 
this contributes to wildlife declines, and which benign controls can alleviate the impact of crop raiding on wildlife;

- Clarify the best management options for areas of forest that have already burnt.

\section{Research on birds}

Logging opens the forest, changing habitat in a positive way for some species and in a negative way for others. Opening forests increases access for all kinds of hunting, trapping and predation. There are, however, few data.

- Investigate the impact of hunting, bird catching, increased predation, and trade in live birds on wild-living populations. Detailed surveys are required for potentially affected species, including identification of core habitats and nesting sites, while ecological studies should clarify population density, breeding success, feeding patterns, dispersal and survival (Collar et al. 1994);

- Study the avifauna of typical logged forest areas that are isolated from sources of re-colonisation to determine their true capacity to retain species (Lambert \& Collar 2002). Most studies have neglected the effects of nearby intact forest. Offshore islands for which the pre-logging avifauna is well known, but which has since been logged, might be suitable test cases for such research. Such research could be compared with studies of the avifauna of isolated, but relatively wellprotected forest fragments on the mainland (e.g., the Sungai Wain Protection Forest near Balikpapan);

- Assess the key factors that govern the species composition dynamics of tropical avifauna. This is complex and difficult to interpret without detailed knowledge of the ecology of individual species and cannot be provided from studies that sample a population at one point in time. Mist netting should be carried out over long periods to provide data on turnover rates, breeding activity, recruitment, site fidelity and longevity in logged and unlogged forests. (n.b. while mist-netting is most effective for understorey communities, it is possible to work at greater heights - the nets and poles have to be on pulleys with running lines going to the height at which the birds are to be caught, Roy Dennis pers. comm.);

- Clarify the landscape level movement patterns of large seed predators and seed dispersers. Research is needed on ranging patterns of these species. Satellite tracking the larger species ( $>1 \mathrm{~kg}$ bodyweight, Roy Dennis pers. comm.) is possible and would provide vital clues about factors determining ranging patterns;

- Clarify which species are most vulnerable to habitat loss in what locations. Lowland and lowland slope species are especially vulnerable to deforestation. Assessment of the altitudinal ranges and other determinants of bird distributions are needed to inform management;

- Determine habitat needs. Studies of foraging behaviour should be included in survey data to determine whether these species are sensitive to the destruction of specific components of their habitat;

- Assess the impact of habitat changes on pheasants. Although most species may be found in selectively logged forest, the limits of their tolerances to habitat alteration are not known. Also, little can be said of the competitive interactions 
between species of pheasants. We recommend camera trapping studies for these species to relate densities to local landscape characteristics and hunting pressures;

- Van Balen (in O’Brien \& Fimbel 2002) observed three types of mixed-species flocks in Malinau, with little or no species overlap between them: 1) canopydwelling flocks with core species that include Green Iora (Aegithina tiphia), Blue-winged Leafbird (Chloropsis cochinchinensis), Black-winged Hemipus (Hemipus hirundinaceus), Lesser Cuckoo-shrike (Coracina fimbriata) and minivets (Pericrocotus spp.) (Chloropseid/Campephagid flock); 2) lower story-dwelling flocks with Malacopteron and Stachyris babblers as core species (Timalid flocks); and 3) Woodpecker flocks. Mixed flock data should be collected to clarify the response of these different kinds of flocks to forest fragmentation and degradation;

- Evaluate predation and nest predation with respect to different pre- and postlogging forest habitats;

- Examine nest parasitism with respect to different pre- and post-logging forest habitats;

- Examine the feeding behaviour of predatory bird species (raptors and owls) with respect to different pre- and post-logging forest habitats, and evaluate the impact on prey species;

- Clarify options and benefits from species-specific interventions, and develop guidelines. When specific needs are identified for a bird species, conservation interventions should be developed that address the needs of that species (e.g., artificial nest sites could be developed for vulnerable species).

\section{Research on mammals}

- Much research on the effects of logging on mammal species has focussed on assessing species density before and after timber harvesting. For long-lived species, however, such assessments may not reveal the true effects of logging, especially if the species manages to survive on depleted resources but fails to reproduce, because this would not be expressed in a density decline over the short term. Demographic, habitat preference and synecological studies are therefore needed, especially for large, slow-breeding mammals, such as the Sun Bear (Ursus malayanus), Clouded Leopard (Neofelis nebulosa), Bay Cat (Catopuma badia), Marbled Cat (Pardofelis marmorata) and gibbons (Hylobates spp.);

- Conduct long-term research regarding the effects of isolation and fragmentation on species with wide ranging patterns, large territories and multiple habitat preferences (e.g, Sun Bear, Clouded Leopard, Bay Cat, Marbled Cat, Sambar Deer (Cervus unicolor), Orangutan (Pongo pygmaeus), etc.) and on those with full or semi-migratory behaviour (e.g., Bearded Pig (Sus barbatus));

- Design and undertake studies which differentiate habitat changes and hunting effects on ungulates;

- Examine long-term trends. Long-term research is needed on the population dynamics of pigs and deer, and how this is affected by habitat fragmentation and alteration (opening up of the forest may favour some species) and by hunting;

- Investigate how non-volant arboreal mammals are affected by discontinuities 


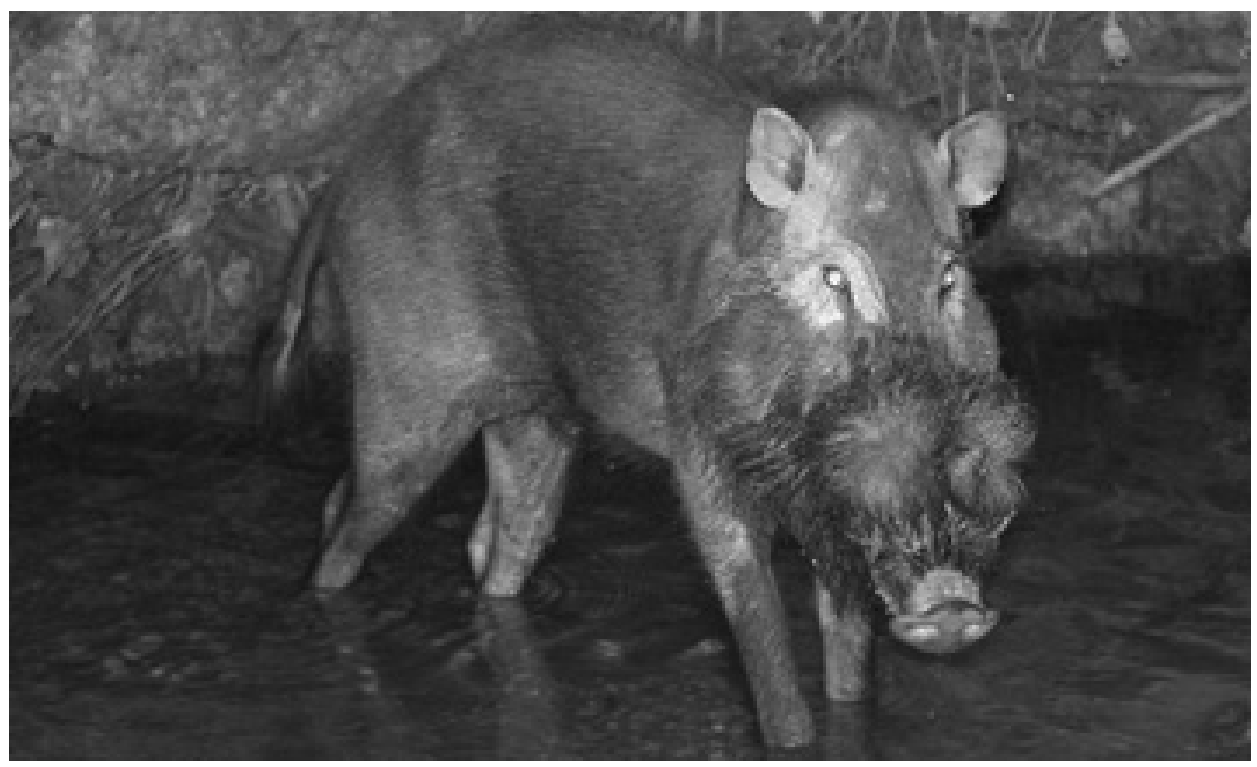

Figure 28. The poorly known Bearded Pig (Sus barbatus) is an important ecosystem engineer and a vital protein source for inland communities. (Photo by Kimabajo)

in the canopy caused by logging, and how this relates to food distribution and abundance, as well as vulnerability to predation (Putz et al. 2001);

- Clarify the key factors in pig population dynamics and their forest movements. There is an urgent need to develop successful and long-term approaches to sustainable management and protection of Bornean ecosystems, as well as to design effective policy guidelines for the harvest and trade of bushmeat;

- Clarify the threats to leaf monkeys, especially Hose's, White-fronted and Maroon (Presbytis spp.), which are commonly hunted for bezoar stones and meat. The latter species is protected, but the former two are not. An assessment should be made of how these species are affected by the combined effects of loss of habitat and hunting, and management guidelines should be developed for sustainable harvest or protection;

- Undertake further research on isolated 'island' faunas to provide a better understanding of the long-term effects of forest fragmentation;

- Examine the effects of forest degradation and fragmentation on interior forest bat species like Hipposideridae, Rhinolophidae and vespertilionid Kerivoulinae and Murininae;

- Clarify the relationships between Bearded Pigs and other seed and seedling predators, mast fruiting, and forest regeneration, the changes in these relationships as a result of deforestation, fragmentation of the forest landscape, and hunting of Bearded Pigs (Fig. 28).

\section{Research on amphibians and reptiles}

Frogs are easy to sample (although identification is sometimes difficult) and may be sensitive to habitat disturbance, but we have few data on the abundance and diversity 
of frogs in Bornean forests. Further study of amphibian and lizard populations in logged and unlogged forests is recommended;

- Assess the effect of variation in leaf litter arthropods on the growth and reproduction of leaf litter anurans;

- Clarify the long-term implications of increased densities of pond-breeding amphibian species in selectively logged forests. Many of these species are not normally found in primary forest and may compete with primary forest species.

- Clarify the sensitivity of insectivorous species to habitat change. Timber harvesting would likely impact the relative abundance and number of species of insects in various direct and indirect ways, leading to changes in species composition and the number of insectivorous predators like amphibians (and birds). Research is needed to examine these relationships in more detail over time;

- Assess the threat caused by the trade in threatened turtle/terrapin species, such as Orlitia borneensis and Manouria emys. Investigate habitat use, nesting sites and demographics, and provide recommendations on either a harvest moratorium or the sustainable harvest of these species. As these species are unprotected in Indonesia, a community-based programme is most likely to lead to successful management of the species. Similar research is needed for other important trade species, such as Crocodylus porosus and pythons (Python spp.);

- Assess local harvesting impacts and how they in turn are affected by changing conditions. Local people talk about certain sandy river sites as being especially good for turtle/terrapin hunting and egg collection. The ecological significance of these sites, the threats to them, and whether they can be protected in concessions requires attention;

- Clarify how changes in understorey microclimate associated with timber removal, affects the survival and hatching of land-nesting anurans and agamid lizards;

- Identify, and assess the nature of the threat caused by exotic species;

- Assess remaining crocodile populations. What species are present, are populations viable, what can be done to protect them?

\section{Research on fish}

- Assess how to establish, protect and manage sustainable fisheries on river systems and catchments;

- Assess the direct impact of logging operations on forest fish populations. Topics include the impact of stream closure and pond formation due to roads and felling operations; the impact of turbidity and silting on habitat quality and nesting sites; and the impact of changes in water temperature regime due to decreased canopy cover;

- Assess the importance of riverside vegetation (habitats and species). Forest canopies over streams and riversides provide shade and food sources for fishes. However, the contribution of vegetable matter such as the flowers and fruits of riparian vegetation (Dipterocarpus spp., Ficus spp., etc.) on the diet of fishes 
(cyprinids) should be further studied to investigate the direct importance of these tree species for fish;

- Identify critical sites in the river that allow species to persist. The mouths of tributaries/streams provide refugee sites for fishes when main rivers are in flood and have become turbid. Some large fishes such as Tor spp. and Barbodes spp. take shelter in such clear water sites, and the identification of these vital habitat types is important to protect populations of these species. Research is needed on the relationships between turbidity and other biochemical aspects of river water and the local occurrence of species;

- Investigate the rearing of indigenous fishes such as Tor spp., Barbodes spp. and Leptobarbus spp. What are the technical and economic determinants of success? This could provide people with a regular source of protein and potential income, and would take pressure off wild stocks;

- Clarify the ecology (and taxonomic identity) of vulnerable migratory fish species such as Pangasius spp. These species require large parts of river systems, including parts of the MRF and Kayan Mentarang National Park (see Hartyono 1992) at different times of their life cycles. Currently these species are over-fished as they aggregate to breed because local people know when and where to net them. Little is known about migratory movements, and tracking fish and assessing local people's knowledge would be a way to identify key habitat sites. 



\section{Appendix 1 \\ Species data checklist}

Taxonomy

Common name(s)

Scientific name

Number of species within genus

Number of subspecies within species

\section{Distribution}

Global range

Borneo

General occurrence of taxa

\section{Habitat}

Elevational range

Topographic setting

Vegetation of habitat

Known habitat preferences or limitations (substrates, elevations, ground cover, etc.)

- Substrates

- Altitudinal distributions

- Ground cover

- Forest types

- Structural characteristics

- Migratory habits

- Access to running water

- Water quality needs

\section{Natural history}

Diet

- General

- Qualitative composition 
- Quantitative composition

- Seasonal variation

- Maturational changes

\section{Feeding behaviour (dependencies and distributions,} influences of habitat change)

- Foraging substrates

- Foraging techniques

- Diet breadth

\section{Seasonal cycle}

Reproduction

- Seasonality

- Estrous pattern

- Age at first reproduction: Males: Females:

- Gestation period

- Litter size

- Lactation Period

Dependence on specific landscape features, resources, or substrates

- Clay for nests

- Caves for shelters

- Forest/grassland mosaics for browsing

- Lakes

- Edge specialists

\section{Ranging behaviour}

- General pattern

- Density

- Influences of habitat change

- Home range size

- Territoriality

- Daily vs. monthly vs. seasonal movement patterns

- Migration behaviour (dependencies and disruptions)

- Mobility and ability to cross non-forest and other 'barriers'

- Dispersal behaviour and ability to recolonise empty or damaged habitat

\section{Growth and development}

- Age at weaning

- Nesting behaviour

- Parental care

- Developmental rate curve

- Mortality factors

- Survivorship curve

- Longevity:

wild:

captivity: 


\section{Aspects of reproduction}

- Breeding system

- Temporal aspects of reproduction

- Age of sexual maturity

- Interbirth interval

- Parasites

- Clutch/litter/number of offspring per attempt

- Reproductive success

- Intra-specific differences

- Breeding grounds (defining characteristics, seasons, dependencies)

- Nest sites/spawning sites/cavities, etc. (as much specific criteria as possible)

\section{Behaviour}

- Vocalizations

- Sensory acuity

- Sociability

- Agonistic behaviour

- Response to humans

\section{Ecological role}

- Interspecific relationships

- Predators

- Diseases

\section{Others}

- Commercial status and uses of taxa (types of threat and impact upon populations)

- Potential causes of decline/death/reduced resilience

- Specific notes on RIL guidelines that should be clearly stated

- Remaining unknowns that have considerable significance for determining better forestry practices with respect to this taxon

- Conservation status (National, IUCN) 


\section{Appendix 2 IUCN status}

Vertebrates of the Malinau area and, in descending order of conservation importance, their international conservation status; only species that are mentioned by the IUCN (2002) are listed. For IUCN criteria see below; further details are provided by IUCN (2002).

\begin{tabular}{lll}
\hline Birds & Species & $\begin{array}{l}\text { International conservation } \\
\text { status }\end{array}$ \\
Ciconia stormi & Storm's Stork & Endangered \\
\hline Lobiophasis bulweri & Bulwer's Pheasant & Vulnerable \\
\hline Lophura erythrophthalma & Crestless Fireback & Vulnerable \\
\hline Rollulus roulroul & Crested Wood-Partridge & Vulnerable \\
\hline Spilornis kinabaluensis & Kinabalu Serpent-Eagle & Vulnerable \\
\hline Treron capellei & Large Green Pigeon & Vulnerable \\
\hline Alcedo euryzona & Blue-banded Kingfisher & Vulnerable \\
\hline Pycnonotus zeylanicus & Straw-headed Bulbul & Vulnerable \\
\hline Ptilocichla leucogrammica & Bomean Wren Babbler & Vulnerable \\
\hline Rhinoplax vigil & Helmeted Hornbill & Lower Risk/near threatened \\
\hline Argusianus argus & Great Argus & Lower Risk/near threatened \\
\hline Ichthyophaga humilis & Lesser Fish-Eagle & Lower Risk/near threatened \\
\hline Actenoides concretus & Rufous-collared Kingfisher & Lower Risk/near threatened \\
\hline Anthracoceros malayanus & Black Hornbill & Lower Risk/near threatened \\
\hline Buceros rhinoceros & Rhinoceros Hornbill & Lower Risk/near threatened \\
\hline Calyptomena hosii & Hose's Broadbill & Lower Risk/near threatened \\
\hline Pycnonotus melanoleucos & Black Bulbul & Lower Risk/near threatened \\
\hline Pycnonotus squamatus & Scaly-breasted Bulbul & Lower Risk/near threatened \\
\hline Cuculus vagans & Moustached Hawk-Cuckoo & Lower Risk/near threatened \\
\hline Enicurus ruficapillus & Chestnut-naped Forktail & Lower Risk/near threatened \\
\hline Calyptomena viridis & Green Broadbill & Lower Risk/near threatened \\
\hline & &
\end{tabular}




\begin{tabular}{|c|c|c|}
\hline \multicolumn{2}{|c|}{ Species } & $\begin{array}{l}\text { International conservation } \\
\text { status }\end{array}$ \\
\hline \multicolumn{3}{|l|}{ Birds } \\
\hline Eurylaimus ochromalus & Black-and-Yellow Broadbill & Lower Risk/near threatened \\
\hline Harpactes diardii & Diard's Trogon & Lower Risk/near threatened \\
\hline Harpactes duvaucelii & Scarlet-rumped Trogon & Lower Risk/near threatened \\
\hline Harpactes kasumba & Red-Naped Trogon & Lower Risk/near threatened \\
\hline Kenopia striata & Striped Wren Babbler & Lower Risk/near threatened \\
\hline Macronous ptilosus & Fluffy-backed Tit-Babbler & Lower Risk/near threatened \\
\hline Malacopteron affine & Sooty-capped Babbler & Lower Risk/near threatened \\
\hline Malacopteron magnum & Rufous-crowned Babbler & Lower Risk/near threatened \\
\hline Stachyris maculata & Chestnut-rumped Babbler & Lower Risk/near threatened \\
\hline Stachyris nigricollis & Black-throated Babbler & Lower Risk/near threatened \\
\hline Trichastoma rostratum & White-chested Babbler & Lower Risk/near threatened \\
\hline Alcippe brunneicauda & Brown Fulvetta & Lower Risk/near threatened \\
\hline Megalaima henricii & Yellow-crowned Barbet & Lower Risk/near threatened \\
\hline Megalaima mystacophanos & Red-throated Barbet & Lower Risk/near threatened \\
\hline Megalaima rafflesii & Red-crowned Barbet & Lower Risk/near threatened \\
\hline Meiglyptes tukki & Buff-necked Woodpecker & Lower Risk/near threatened \\
\hline Oriolus xanthonotus & Dark-throated Oriole & Lower Risk/near threatened \\
\hline Philentoma velatum & Maroon-breasted Philentoma & Lower Risk/near threatened \\
\hline Cyornis turcosus & Malaysian Blue Flycatcher & Lower Risk/near threatened \\
\hline Anthreptes rhodolaema & Red-throated Sunbird & Lower Risk/near threatened \\
\hline Pitta caerulea & Giant Pitta & Lower Risk/near threatened \\
\hline Pitta granatina & Garnet Pitta & Lower Risk/near threatened \\
\hline \multicolumn{3}{|l|}{ Mammals } \\
\hline Bos javanicus & Banteng & Endangered \\
\hline Nasalis larvatus & Proboscis Monkey & Endangered \\
\hline Macaca nemestrina & Pig-tailed Macaque & Vulnerable \\
\hline Nycticebus coucang & Slow Loris & Vulnerable \\
\hline Neofelis nebulosa & Clouded Leopard & Vulnerable \\
\hline Ursus malayanus & Malayan Sun Bear & Data Deficient (Vulnerable) \\
\hline Presbytis hosei & Hose's Leaf Monkey & Data Deficient \\
\hline Presbytis rubicunda & Maroon Leaf Monkey & Data Deficient \\
\hline Tarsius bancanus & Tarsier & Data Deficient \\
\hline Pardofelis marmorata & Marbled Cat & Data Deficient \\
\hline Lutra spp. & Otter & Data Deficient \\
\hline Hylobates muelleri & Bornean Gibbon & Lower Risk/near threatened \\
\hline Macaca fascicularis & Long-tailed Macaque & Lower Risk/near threatened \\
\hline Manis javanica & Pangolin & Lower Risk/near threatened \\
\hline \multicolumn{3}{|l|}{ Reptiles } \\
\hline Manouria emys & Brown Giant Tortoise & Endangered \\
\hline Orlitia borneensis & Great River Terrapin & Endangered \\
\hline Pelochelys cantorii & Giant Soft-shell Turtle & Endangered \\
\hline Amyda cartilaginea & Common Soft-Shell Turtle & Vulnerable \\
\hline Notochelys platynota & Malayan Flat-shelled Turtle & Vulnerable \\
\hline
\end{tabular}




\section{Critically Endangered (CR)}

A taxon is Critically Endangered when the best available evidence indicates that it meets any of the criteria A to E for Critically Endangered, and it is therefore considered to be facing an extremely high risk of extinction in the wild.

\section{Endangered (EN)}

A taxon is Endangered when the best available evidence indicates that it meets any of the criteria A to E for Endangered, and it is therefore considered to be facing a very high risk of extinction in the wild.

\section{Vulnerable (VU)}

A taxon is Vulnerable when the best available evidence indicates that it meets any of the criteria A to E for Vulnerable, and it is therefore considered to be facing a high risk of extinction in the wild.

\section{Near Threatened (NT)}

A taxon is Near Threatened when it has been evaluated against the criteria but does not qualify for Critically Endangered, Endangered or Vulnerable now, but is close to qualifying for or is likely to qualify for a threatened category in the near future.

\section{Least Concern (LC)}

A taxon is Least Concern when it has been evaluated against the criteria and does not qualify for Critically Endangered, Endangered, Vulnerable or Near Threatened. Widespread and abundant taxa are included in this category.

\section{Data Deficient (DD)}

A taxon is Data Deficient when there is inadequate information to make a direct, or indirect, assessment of its risk of extinction based on its distribution and/or population status. A taxon in this category may be well studied, and its biology well known, but appropriate data on abundance and/or distribution are lacking. Data Deficient is therefore not a category of threat. Listing of taxa in this category indicates that more information is required and acknowledges the possibility that future research will show that threatened classification is appropriate. It is important to make positive use of whatever data are available. In many cases great care should be exercised in choosing between DD and a threatened status. If the range of a taxon is suspected to be relatively circumscribed, and a considerable period of time has elapsed since the last record of the taxon, threatened status may well be justified. 


\section{Appendix 3}

\section{Assessment by local communities of the importance of vertebrate species in MRF}

Vertebrates of the Malinau area and, in descending order, their importance as assessed by local communities in the MRF area; details are provided by Sheil et al. (2003c).

\begin{tabular}{llrl}
\hline Scientific Name & English Name & Score & Use \\
\hline Cervus unicolor & Sambar (deer) & 30.1 & $\begin{array}{l}\text { food, decoration, market trade, } \\
\text { tool }\end{array}$ \\
\hline Sus barbatus & Bearded Pig & 25.2 & food, market trade, medicine \\
\hline Ursus malayanus & Sun Bear & 14.8 & food, medicine, decoration \\
\hline Hystrix brachyura & Common Porcupine & 13.7 & food, medicine \\
\hline Tragulus napu & Greater Mouse-deer & 12.6 & market trade, medicine, food, \\
& & & decoration \\
\hline Buceros vigil & Helmeted Hornbill & 11.7 & decoration, market trade, \\
& & & medicine \\
\hline Buceros rhinoceros & Rhinoceros Hornbill & 10.1 & decoration, market trade \\
\hline Gracula religosa & Hill Myna & 9.8 & market trade, decoration \\
\hline Muntiacus muntjak & Red Muntjac & 9.8 & food, market trade, decoration \\
\hline Presbytis hosei & Hose's Leaf Monkey & 9.1 & food, tool, medicine, market trade \\
\hline Fish/Tor tambra* & Carp & 8.9 & market trade \\
\hline Pycnonotus zeylanicus & Straw-headed Bulbul & 8.8 & market trade \\
\hline Python reticulatus & Reticulated Python & 8.7 & medicine, decoration \\
\hline Copsychus malabaricus & White-rumped Shama & 8.2 & market trade \\
\hline Cyclemis dentata & Asian Leaf Turtle & 6.5 & decoration, food, medicine \\
\hline Collocalia fuciphaga & Brown-rumped Swiftlet & 6.4 & market trade, medicine \\
\hline Argusianus argus & Great Argus & 6.3 & decoration, food \\
\hline Mustela nudipes & Malayan Weasel & 6.1 & medicine \\
\hline Manis javanica & Malayan Pangolin & 4.9 & decoration, medicine \\
\hline & & &
\end{tabular}


216 | Appendix 3. Assessment by local communities

\begin{tabular}{|c|c|c|c|}
\hline Scientific Name & English Name & Score & Use \\
\hline Arctictis binturong & Binturong & 4.4 & medicine, food \\
\hline Aceros corrugatus & Wrinkled Hornbill & 4.1 & decoration, market trade \\
\hline Macaca fascicularis & Long-tailed Macaque & 4.1 & food \\
\hline Lophura ignita & Crested Fireback & 3.6 & food, market trade \\
\hline $\begin{array}{l}\text { Paradoxurus } \\
\text { hermaphroditus }\end{array}$ & Common Palm Civet & 3.3 & food, decoration \\
\hline Apis dorsata & Giant Honey Bee & 3.0 & medicine \\
\hline Anorrhinus galeritus & Bushy-crested Hornbill & 3.0 & decoration, market trade \\
\hline Hylobates muelleri & Bornean Gibbon & 2.9 & market trade \\
\hline $\begin{array}{l}\text { Anthracoceros } \\
\text { malayanus }\end{array}$ & Black Hornbill & 2.9 & decoration, market trade \\
\hline Neofelis nebulosa & Clouded Leopard & 2.5 & decoration \\
\hline Loriculus galgulus & $\begin{array}{l}\text { Blue-crowned Hanging } \\
\text { Parrot }\end{array}$ & 2.0 & market trade \\
\hline Formicidae & ants & 1.9 & medicine \\
\hline Trichys fasciculata & Long-tailed Porcupine & 1.5 & medicine \\
\hline Gallus spp. ${ }^{* *}$ & domesticated chicken & 0.9 & food \\
\hline Nyticebus coucang & Slow Loris & 0.8 & medicine \\
\hline Ophiophagus hannah & King Cobra & 0.8 & bahan berburu \\
\hline Treron curvirostra & $\begin{array}{l}\text { Thick-billed Green } \\
\text { Pigeon }\end{array}$ & 0.7 & decoration \\
\hline Dogania subplana & $\begin{array}{l}\text { Malayan Soft-shelled } \\
\text { Turtle }\end{array}$ & 0.6 & food \\
\hline Pardofelis marmorata & Marbled Cat & 0.6 & decoration \\
\hline Pteropus vampyrus & Flying Fox & 0.5 & decoration, medicine \\
\hline Haliastur indus & Brahmany Kite & 0.2 & market trade \\
\hline Rattus tiomanicus & Malaysian Field Rat & 0.2 & medicine \\
\hline Varanus rudicolis & Rough-necked Monitor & 0.1 & food \\
\hline
\end{tabular}

* Some confusion arose in these exercises between specific species versus fish in general.

** Chickens were not really intended to be included as 'forest animals', but were mentioned by two of the more down-stream communities (Gong Solok and Seturan) that have less access to forest meat-despite the guidance associated with these exercises. 


\section{Appendix 4 \\ Species summary-birds}

\section{Bushy-Crested Hornbill Anorrhinus galeritus}

Taxonomy There are two species in this genus, and no subspecies in Anorrhinus galeritus.

Global range Borneo, Sumatra, Thai/Malay Peninsula and Tenasserim.

Population status and densities on Borneo Widespread throughout the existing forest, including selectively logged areas, though it appears to be absent from some coastal areas such as Tanjung Puting. Densities: $1.2-5.6 \mathrm{~km}^{2} /$ group depending on habitat quality (Kemp \& Kemp 1975; Leighton 1982; Johns 1987).

Occurrence on small SE Asian islands Bunguran ( $\mathrm{n}=1)$.

Habitat Most common, with the largest groups in medium- to low elevation forest with good fig populations, including peat swamp forest (Kemp 1995). Dense (semi-)evergreen lowland forest, mature and well-generated; from sea level to 1,600 m (Mt. Lunjut, Kayan Mentarang National Park), and up to 1,600 m in Sumatra (van Marle \& Voous 1988). Can generally subsist among smaller trees than other hornbills (van Marle \& Voous 1988).

Feeding ecology Moves systematically through foliage, taking fruit in passing and then moving on, never into emergent canopy but often down to ground level; food delivered at nest is mainly fruit but also arthropods, lizards and frogs (Kemp 1995). A wide variety of fruit is taken (Kemp 1995); not completely dependent on figs and amongst non-figs, nutmegs are regular food (Wells 1999). Capsular, large-seeded, dehiscent, and drupaceous lipid-rich fruits are most important in diet (especially Meliaceae and Myristicaceae) (Leighton \& Leighton 1983; Hadiprakarsa \& Kinnaird 2001); prises off bark, digs among epiphytes, and splits husks and capsules, the last especially important during low fruit availability (Kemp 1995).

Social organisation Territorial, in groups of an average of seven birds in primary forest (larger during fruit abundance, smaller during fruit scarcity); has fixed roost sites, usually in isolated trees near streams (Kemp \& Kemp 1975; Leighton 1982). Large groups gang up to drive off other species at fruiting trees (Leighton 1986). 
Breeding ecology Monogamous, cooperative breeder in groups of seven to ten birds; nesting cycle 75 days (30 days incubation; 60 days nestling period); laying dates January and March; chicks bred and fledged during fruit peaks (Leighton \& Leighton 1983), but no obvious breeding season (Madge 1969). Usually two, sometimes three young raised per nesting attempt (Leighton 1986). Nest hole at 10-25 m up in the trunk of live or dead trees (Kemp 1995). May breed again immediately after a successful brood if food is available (Leighton 1986).

Influence of habitat change Not as heavily pressured by logging as other hornbill species because of capacity to feed in mid- and lower stratum vegetation (Wells 1999); group size not altered in forest 5-6 years after logging (Johns 1989a).

Conservation status Protected by Indonesian law and included on CITES Appendix II. Not listed by IUCN.

\section{White-Crowned Hornbill Berenicornis comatus}

Taxonomy One species in the genus and no subspecies.

Global range South Thailand and south Tenasserim, Malaya, Sumatra and Borneo.

Population status and densities on Borneo No recent records from Borneo (Holmes \& Burton 1987), but subsequently in five out of eight best-surveyed areas the hornbill was found, albeit in low numbers (van Balen 1999a). Densities: one group/10 $\mathrm{km}^{2}$ in Sabah (Johns 1988); 6.3 groups $10 \mathrm{~km}^{2}$ in Sarawak (Kemp \& Kemp 1975).

Occurrence on small SE Asian islands Not known from offshore islands $(\mathrm{n}=0)$.

Habitat Primary evergreen lowland forest, up to $600 \mathrm{~m}$, but uncommon above $200 \mathrm{~m}$; Prefers riverine gallery, tidal swamp, mixed deciduous, and even tall secondary or selectively logged forest (Kemp 1995); 70\% of observations seen below low canopy (Leighton 1986; Johns 1987). Favours extensive areas of thick tangled growth.

Feeding ecology Forages at all levels in foliage, from largest emergents in primary forest to ground level in selectively logged forest (Kemp \& Kemp 1975; Johns 1987; Kemp 1995); feeds on abundant arthropods and small vertebrates, including small snakes, lizards, and small birds found in ground litter of oil palm plantations, or on wood-boring insects and larvae excavated from logging debris (Johns 1987); also eats many fruits. In Kalimantan, lipid-rich capsules and drupes are most important fruits in the diet; sugar-rich figs are taken much less (Kemp 1995).

Breeding ecology Nests in tree holes 10-30 m above ground; the same cavities are used in successive years. Found breeding in natural holes in trees in logged and unlogged forest (Johns 1987). Nesting cycle ca. 130 days. Female leaves nest after fledging of chick (after 3 months). Usually only one chick in the nest, but two possibly raised at times (Frith \& Douglas 1978; Smythies 1981).

Social organisation Flocks or family groups (Johns 1987); usually in pairs or groups of 3-4, or (rarely) 7-8; most groups consist of a pair with 1-3 helpers and some juveniles (Kemp 1995); groups are larger during fruit-rich times, helpers splitting off for all or part of the time when little fruit is available (Leighton 1982).

Interspecific relationships When sympatric with other hornbill species, larger hornbills spend a longer period of time at each source and pick only the ripest fruit, 
whereas the smaller hornbills remain at a source for only a short period of time and are less selective in terms of fruit eaten. The inter-specific between the medium-sized White-crowned Hornbill and other hornbill species is unknown.

Influence of habitat change Survives in small conserved forest patches, from which it ranges into surrounding secondary forest (Kemp 1995); note, however, that little is known about minimum fragment size for survival and the effect of surrounding vegetation on survival. The species' ability to persist at higher elevations, where forest destruction has been less severe, means that its decline has been less rapid (BirdLife International 2001).

Conservation status Protected by Indonesian law and included on CITES Appendix II. Not listed by IUCN.

\section{Wreathed Hornbill Rhyticeros undulatus}

Taxonomy Five species are recognised within the genus. Sanft (1960) recognised three subspecies, including the Bornean $R$. u. aequabilis, with smaller size and reduced development of the ridges across base of mandibles. The validity of the Bornean subspecies seems, however, to be doubtful (Kemp 1995).

Global range East India to southwest India, Andaman Island, Southeast Asia, Sumatra, Borneo, Java and Bali.

Population status and densities on Borneo Widespread, but generally uncommon (Kemp 1995); Densities c. $1.3 \mathrm{~km}^{2} /$ bird in West Malaysia (Johns 1987); $0.2 \mathrm{~km}^{2} /$ bird in unlogged, and $0.15 \mathrm{~km}^{2} /$ bird in 12-year logged forest in Sabah (Johns 1988).

Occurrence on small SE Asian islands Batu Islands, Laut, Lingga Islands, Musala and Panaitan $(\mathrm{n}=5)$.

Habitat Favours extensive primary evergreen forest, especially in foothills and on mountains, up to $1,800 \mathrm{~m}$ in Borneo (Smythies 1981).

Feeding ecology Omnivorous and generalised feeder, feeds from upper canopy to the ground. Lipid-rich drupes (Lauraceae, Burseraceae) form the major food in Kalimantan (Leighton 1986) and Sumatra (Hadiprakarsa \& Kinnaird 2001), but are more seasonal available than capsules (Leighton 1986). Sugar-rich figs form only $10 \%$ of diet by number, and animal food even less (Leighton 1986). Alternates visits to fruit trees with bouts of hunting animals (Kemp 1995); when breeding in Thailand, diet consists of 57\% figs, 29\% non-figs, and 5\% animals by weight. Fruits include 26 spp. in 12 families and 19 genera (Poonswad et al. 1983, 1988); congregates in fruiting trees.

Ranging behaviour Mean home range of males was $10 \mathrm{~km}^{2}$ when breeding, and $28 \mathrm{~km}^{2}$ at non-breeding times (Poonswad \& Tsuji 1994); departs when fruit stocks drop but returns when even only one species again becomes productive, suggesting good sampling abilities (Leighton \& Leighton 1983).

Breeding ecology Nesting cycle of 111-137 days; female and chick emerge together; bred in Kalimantan January-May during fruit abundance but not bred again within the next two years (Leighton \& Leighton 1983). Usually two eggs are laid, or (rarely) one or three, but records suggest that at most one chick fledges (Kemp 
1995). Nests in natural holes in forest trees, often in large emergent trees, at 18-26 $\mathrm{m}$ above the ground (Bartels \& Bartels 1937).

Social organisation Fission/fusion; non-territorial species, in pairs or groups of 4-14 (but much larger groups when roosting, see below). Less dominant at trees than territorial residents, even the smaller species (Leighton 1986).

Movements and daily migration Nomadic; may range over at least $100 \mathrm{~km}^{2}$ daily. Radio-tracked birds left roost to feed in valleys within an area of 6-8 $\mathrm{km}^{2}$ (Tsuji et al. 1987). Immature birds occur in separate flocks. Sleeps in communal roosts of up to 400 or even 1000 birds.

Influence of habitat change Uses and breeds extensively in selectively logged forests (Kemp 1995); nests often felled during logging (Kemp \& Kemp 1975).

Conservation status Protected by Indonesian law and included on CITES Appendix II. Not listed by IUCN.

\section{Asian Black Hornbill Anthracoceros malayanus}

Taxonomy Five species have been described in this genus, and two subspecies: $A$. $m$. albirostris and $A$. m. convexus.

Global range Southern peninsular Thailand, Malaya, Borneo and Sumatra.

Population status and densities on Borneo One of the three commonest lowland hornbills (Holmes \& Burton 1987). Densities: 1 km²/pair in East Kalimantan (Leighton 1986); 0.5-5 pairs $/ \mathrm{km}^{2}$ in Sabah (Johns 1988); 3.40 individuals $/ \mathrm{km}^{2}$ (Galetti \& McConkey 1998), and 0.6 km²/pair in Sarawak (Kemp \& Kemp 1975).

Occurrence on small SE Asian islands Bangka, Belitung and Lingga ( $n=3)$.

Habitat Primary evergreen lowland forest, at up to $600 \mathrm{~m}$, but rarely above 200 $\mathrm{m}$; may be a lowland specialist. Found more in the centre of forests, but may occupy riverine galleries, tidal swamps, mixed deciduous and even tall secondary forests (Kemp 1995). Prefers a central stand of large trees with adjacent tangles. Occupies the canopy and middle storey. Rarely seen outside forest areas (Bartels \& Bartels 1937).

Feeding ecology Opportunistic frugivore. Diet of diverse, often large fruits, especially large-seeded dehiscent Meliaceae and Myristicaceae (Leighton \& Leighton 1983); feeds regularly on figs, including the very large fruits of Ficus auranticacea, and 17 other fig species (Lambert 1989b). Sugar-rich fruits form $40 \%$ of the diet; lipid-rich fruits are important when other fruits are limited. Animals are only taken occasionally, with low hunting returns per unit time (Leighton 1986). Forages mostly in dense tangles, where it hops and creeps about, down to ground level (Kemp 1995). Only some feeding in canopy as when taking figs and other fruits (Kemp 1995).

Breeding ecology Little is known (Kemp 1995). Monogamous in separate pairs without helpers (Kemp 1995). Cycle at least 80 days, laying dates January (2), August (3), December (2). In Kalimantan, chicks were bred and fledged during a peak of fruit availability (Leighton \& Leighton 1983). Clutches: 2-3, but often only one chick is raised. In Kalimantan, only one attempt over a 2-year period (Leighton \& Leighton 1983). Sealed cavity nest. One nest was found $4.5 \mathrm{~m}$ up in a live mediumsized forest tree (Bartels \& Bartels 1937). 
Social organisation Resident in year-round territories, in pairs, sometimes joining neighbours in groups of 5-6, rarely up to 33 together (Johns 1987; Medway \& Wells 1976).

Interspecific relationships Principal seed disperser for several large seeded Aglaia species (Meliaceae) with capsular fruits (Becker \& Wong 1985). Subordinate to all other hornbill spp. at fruiting trees; tends to arrive late at some shared trees (Leighton 1986). Regularly displaced by some squirrels (Becker \& Wong 1985).

Habitat loss and degradation Tolerant of some habitat disturbance, but restricted to lowland forest and therefore threatened by forest destruction.

Conservation status Protected by Indonesian law and included on CITES Appendix II. Listed as Lower risk/near threatened in the Red Data Book of threatened birds of Asia (BirdLife International 2001) and by IUCN (2002).

\section{Rhinoceros Hornbill Buceros rhinoceros}

Taxonomy Three species have been described in this genus, and 3-4 subspecies are recognised. The Bornean race B. r. borneoensis (Fig. 29) is distinguished by its smaller size, and shorter, broader casque rolled back more sharply at the back.

Global range Southern peninsular Thailand, Malaya, Sumatra, Borneo and Java.

Population status and densities on Borneo One of the three commonest lowland hornbills in Kalimantan (Holmes \& Burton 1987). Densities: 0.3-1.6 km²/ pair, up to $0.1 \mathrm{~km}^{2} /$ pair in Sabah (Johns 1988); up to $1.2 \mathrm{~km}^{2} /$ pair in Sarawak (Kemp \& Kemp 1975); 2-3 km²/pair in East Kalimantan (Leighton 1986). Population probably below 2,500 on Borneo (Worth et al. 1994), or below 1,220 m according to Robson (2000).

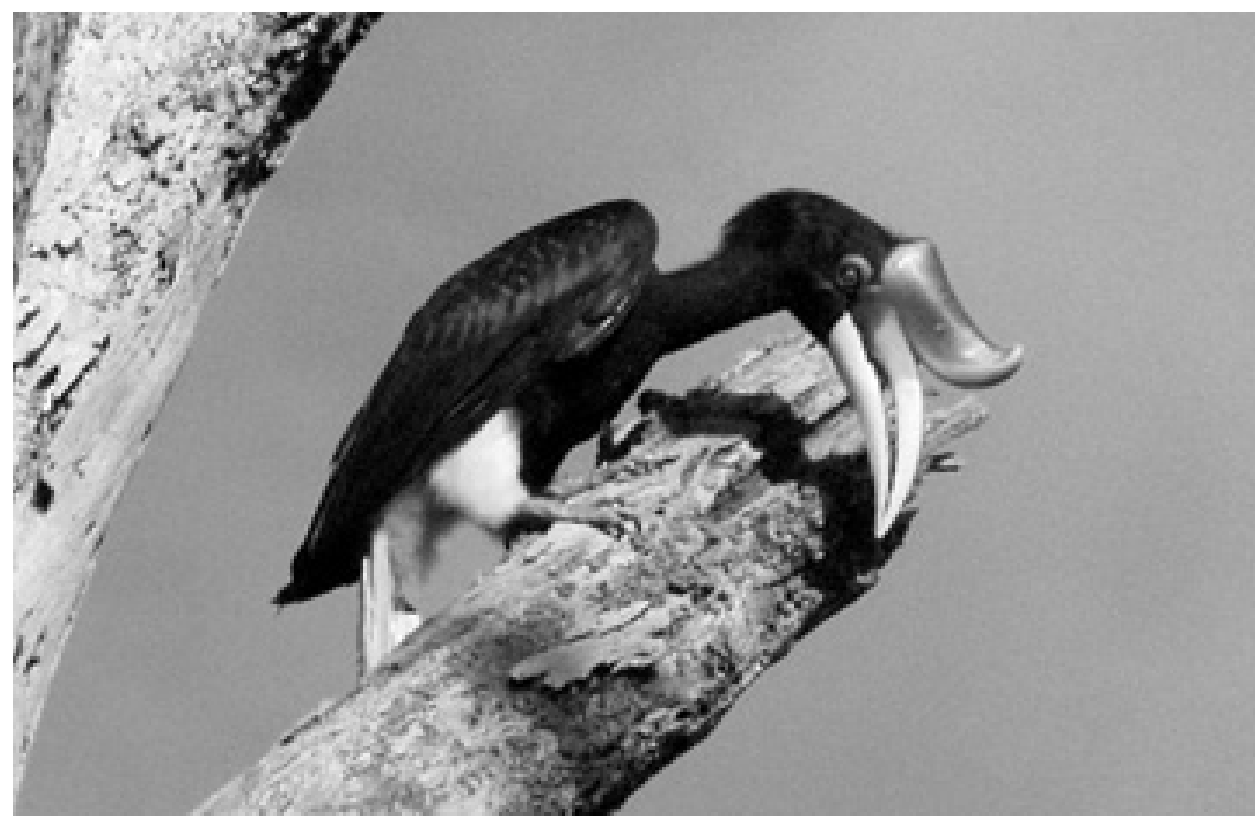

Figure 29. Dead standing trees are important for many species. Here a Rhinoceros hornbill (Buceros rhinoceros) is foraging for insects. (Photo by Kimabajo) 
Occurrence on small SE Asian islands Laut $(\mathrm{n}=1)$.

Habitat Dense lowland evergreen forest, especially swamp forest, hill dipterocarp forest, up to $1,200 \mathrm{~m}$; occupies and breeds in selectively logged forests (Johns 1987).

Feeding ecology Tends to travel long distances in search of food. Probably learns locations of fruit trees within territories through visual inspection. Primary energetic cost for feeding is searching for fruit resources. Animal resources are more evenly but thinly distributed than fruit-less energy to locate, but more energy to process. Overall, hornbills must spend longer periods foraging for animals to reap equivalent returns (Leighton 1986). Sugar-rich fruits form 40-60\% of diet; actively hunts animals $50 \%$ of the time, including lizards, tree frogs, insects, and birds eggs (Bartels \& Bartels 1937), or 23.1\% on animals and non-fig fruits, and $76.9 \%$ on figs (Hadiprakarsa \& Kinnaird 2001). Fruit diet includes figs, Santiria laevigata, Sterculia parvifolis, Meliaceae, wild nutmeg, and oil palm (McClure 1966). Uses at least 13 species of fig in Malaysia (Lambert 1989a). Able to break into $2 \mathrm{~cm}$ diameter Shorea xanthophylla, but not the larger fruits of five other species of dipterocarps (Gould \& Andau 1989). Also, forages under bark of dead tree trunks (Bartels \& Bartels 1937).

Breeding ecology Monogamous pairs. Nests in natural holes in large forest trees at medium or high level off the ground (Bartels \& Bartels 1937). Two out of seven nests (Johns 1982) or one out of four (Bartels \& Bartels 1937) are in dead trees. Selects an elongate entrance slit just small enough to admit the female. Nesting coincides with fruiting season in the forest (Johns 1982). Nesting cycle 105-126 days; laying dates in Borneo: January, May-June, September; clutch 1-2, but normally one chick is fledged. Probably does not breed annually, though reuses nest holes annually at times (Bartels \& Bartels 1937).

Social organisation Mostly as resident, territorial pairs; small flocks of subadults and non-breeding adults range widely over hundreds of $\mathrm{km}^{2}$ (Wells 1974; Leighton 1986). Monogamous, possibly with helpers at times.

Interspecific relationships Defends territory only against own species, so may coexist with other hornbill species. Often arrives later at fig trees, but displaces smaller hornbill species. May be effective seed dispersers.

Habitat loss and degradation Some logging is apparently tolerated (see Johns 1987), but this species may be extinct-prone in smaller forest fragments (Lambert \& Collar 2002).

Conservation status Protected by Indonesian law and included on CITES Appendix II. Tail feathers are much sought after for headdresses, and preserved heads and casques are often kept as ornaments (Kemp 1995). Listed as Lower risk/near threatened in the Red Data Book of threatened birds of Asia (BirdLife International 2001) and by IUCN (2002).

\section{Helmeted Hornbill Rhinoplax vigil}

Taxonomy This is a monotypic genus without subspecies.

Global range Peninsular Thailand, Malaya, Sumatra and Borneo.

Population status and densities on Borneo Densities: $1.8 \mathrm{~km}^{2} /$ pair in logged 
forest, up to $0.9 \mathrm{~km}^{2} /$ pair and $0.5 \mathrm{~km} 2 /$ pair in 6-year logged forest and small isolates in Sabah (Johns 1988); $0.12 \mathrm{~km}^{2} /$ pair in primary foothill forest in Sarawak (Kemp \& Kemp 1975); 7-8 km²/pair in East Kalimantan (Leighton 1986). Anggraini et al. (2000) reported densities of 1.9 birds $/ \mathrm{km}^{2}$ in Bukit Barisan National Park, Sumatra.

Occurrence on small SE Asian islands Not known from offshore islands $(\mathrm{n}=0)$.

Habitat Moist evergreen forest at up to $1,100 \mathrm{~m}$, absent from coastal peatswamp forests (Smythies 1957). Most abundant among foothills in the tops of large trees.

Feeding ecology According to Leighton (1986) diet consists of fruits (Ficus spp., Parkia speciosa, Urostigma spp.), and half of the time is spent foraging for animal foods, including squirrels and birds. Hadiprakarsa and Kinnaird (2001), however, found that this species fed almost exclusively on figs (98.6\% of diet) and only a small proportion of animals (1.4\%).

Breeding ecology Little studied. No obvious seasonality, clutch size $1-2$, but only one chick ever recorded with adults. Nest holes in isolated forest trees (van Marle \& Voous 1988); in Thailand the majority of nest trees are in the family Diptocarpaceae, particularly Hopea spp. and Shorea spp., with dbh ranging from 105-216.6 cm (Thiensongrusamee et al. 2001); female emerges some time before the chick. Bred during fruiting peak and not in the year thereafter (Leighton 1986); home range size 770 ha (Leighton 1982).

Social organisation Resident as territorial monogamous pairs, apart from nomadic groups of subadults (Leighton \& Leighton 1983). Mostly singly or in pairs; small flocks of eight, comprised of juveniles, subadults and non-breeding adults move and forage steadily through the canopy (Leighton 1986).

Habitat loss and degradation Extends into selectively logged but not secondary forests (Kemp 1995); it may be extinct-prone in smaller forest fragments (Lambert \& Collar 2002), and is considered the most likely species to suffer from logging, as it is a fig specialist.

Conservation status Protected by Indonesian law and included on CITES Appendix II. Subject to loss of prime habitat through shifting cultivation and deforestation, and being killed for carving and medicinal use of ivory. Tail feathers are valued for war helmets. Listed as Lower risk/near threatened in the Red Data Book of threatened birds of Asia (BirdLife International 2001) and by IUCN (2002).

\section{Crestless Fireback Lophura erythrophthalma}

Taxonomy Ten species in the genus. Two subspecies have been described; on Borneo the species is represented by the distinct endemic race pyronota.

Global range Peninsular Malaysia, Sumatra and Borneo.

Population status and densities on Borneo Only few recent records from Kalimantan: a bird held captive at Sukamandang (Holmes \& Burton 1987), upper Barito at 200 m (Wilkinson et al. 1991); Tanjung Puting (Holmes 1997); Gunung Palung (Laman et al. 1996); most recently a female with chicks along the Tubu river in November 1997.

Occurrence on small SE Asian islands Not known from offshore islands $(\mathrm{n}=0)$. 
Habitat Lowland primary forest, but found in Malaysia up to $300 \mathrm{~m}$, where it may tolerate logged forest (Lambert in Holmes 1989; del Hoyo et al. 1997). It has been speculated to be a valley-bottom specialist (McGowan \& Garson 1995).

Feeding ecology Little known, takes fallen fruit; animal and plant material found in roughly equal proportions within stomach (del Hoyo et al. 1997). One pair seen pecking at fallen Knema fruits (del Hoyo et al. 1997); group searching for invertebrates; loners and groups (at different times of the year) work restricted patches for short periods before moving on within an overall larger activity-space (Davison 1981b). Roughly equal quantities of plant and animal material have been found in the crops of birds, with termites frequently taken, ticks and grubs less often; small hard berries were in two males (Beebe 1918-1922).

Movements No available information.

Breeding ecology The Crestless Fireback is often encountered in parties (in one case as many as 22, possibly representing several families united after breeding) with an equal distribution of sexes (Beebe 1918-1922) or usually with one adult male (Robinson \& Chasen 1936), and on the latter evidence it seems likely to be polygynous (BirdLife International 2001). Nests are depressions in litter between buttresses of forest trees, or on top of soil termitariums; four to six eggs are laid March-June; all incubation and chick-tending is by the lone female; captive birds started to lay in the third year (Wells 1999); one nest of twigs was located between the buttress roots of a dying tree (del Hoyo et al. 1997).

Interspecific interactions Where sympatric with Lophura ignita it avoids the latter's preferred valley-bottom habitat (Davison 1981b). There appears to be competitive exclusion between the two species such that their home ranges may or do not overlap (at least in Peninsular Malaysia), with L. ignita chiefly occupying riverine forest and L. erythrophthalma using both riverine and hilly forest, but only if L. ignita is absent (Davison 1981b; BirdLife International 2001).

Habitat loss and degradation Yatim (1993) stated that the species is 'often encountered near forest edge, in cultivation, and along streams in lowland dipterocarp forest' (note that BirdLife 2002, qualified this and suggested that occurrence in cultivation was unlikely). There is evidence of some tolerance of degraded habitat, but this is mostly in Peninsular Malaysia. There, densities were highest $\left(6 / \mathrm{km}^{2}\right)$ in logged forest on hilly ground with a dense palm undergrowth, lower $\left(3 / \mathrm{km}^{2}\right)$ in level lowland forest with mixed dry and swampy terrain, and lowest $\left(0.6 / \mathrm{km}^{2}\right)$ in level lowland forest in mixed alluvial terrace, dry and swampy land (Davison \& Scriven undated in BirdLife International 2001). In Borneo there is less evidence of use of disturbed forest, and indeed Beebe (1918-1922) thought the species on Borneo was less tolerant of human presence (in the form of settlements) than it was in the Peninsula (BirdLife International 2001). This may, however, also be the result of different hunting pressures.

Conservation status Globally vulnerable (Collar et al. 1994); endangered (McGowan \& Garson 1995). Plains-forest specialist at risk from habitat loss (Wells 1999). Threatened by habitat degradation and loss to agriculture. Listed as Vulnerable by IUCN (2002). 


\section{Crested Fireback Lophura ignita}

Taxonomy Ten species in the genus. Four races are recognised, of which two occur in Borneo: the nominate race in Kalimantan (and Bangka Island) and the larger nobilis, endemic to Sabah and Sarawak. Pfeffer (1960) identified the birds collected by him in Kayan Mentarang National Park as nobilis, and presumably the Malinau population belong to this subspecies as well.

Global range Peninsular Malaysia, Sumatra (rufa), Southeast Sumatra (macartneyi), Bangka, Kalimantan (ignita), and northern Borneo (nobilis).

Population status and densities on Borneo Recorded throughout the lowland forest of Borneo. Formerly a common bird of the forest floor but now with patchy distribution and rarely abundant due to habitat destruction and hunting (MacKinnon \& Phillipps 1993).

Occurrence on small SE Asian islands Not known from offshore islands $(n=0)$.

Habitat In Sumatra and Kalimantan, considered a lowland forest specialist (del Hoyo et al. 1997); in Malaysia, the floor of tall, closed-canopy lowland forest, from sea level to $1,200 \mathrm{~m}$ in lower montane forest, but with a bias to damp, flooded valley-bottom habitat, especially close to rivers in areas that are occasionally, but not permanently swampy (Wells 1999); recorded in logged and secondary forest, but not known from swamp forest (del Hoyo et al. 1997).

Feeding ecology No firm information, other than gut contents of leaves and seeds, and some insects; species seen feeding on fallen figs.

Movements No available information. Encounters are made unpredictably throughout suitable habitat (del Hoyo et al. 1997); reported to be fairly mobile, using different parts every few days.

Breeding ecology Little information on breeding season, with four recently hatched chicks caught in Borneo in July (del Hoyo et al. 1997). Nest composed of dead leaves, grass and bamboo built under thick, low bushes (Robinson \& Chasen 1936); clutch of 4-8 eggs.

Habitat loss and degradation BirdLife International (2001) reported that the species survives in logged, disturbed and secondary forest, but it is unclear whether its density declines following logging.

Conservation status Threatened by habitat destruction for agriculture, and probably extirpated from areas where lowland forest has been lost. Has been recorded from logged and secondary forest, but the limits of its tolerance to habitat alteration are not known. Listed as Lower Risk/near threatened by IUCN (2002).

Census practicalities Vocalization very similar to the Crestless and apparently useless for census purposes.

\section{Bulwer's Pheasant Lobiophasis bulweri}

Taxonomy Bulwer's Pheasant is a monotypic species endemic to Borneo; sometimes put in the genus Lophura.

Global range Endemic to Borneo. 
Population status and densities on Borneo Local and patchy distribution, with in Kalimantan no sightings within $200 \mathrm{~km}$ of the east and south coast; in some locations relatively common, but difficult to see (BirdLife International 2001).

Occurrence on small SE Asian islands Not known from offshore islands $(\mathrm{n}=0)$.

Habitat Primary submontane old forest, up to $1,500 \mathrm{~m}$, especially on sloping terrain. Beebe (1918-1922) judged that it commonly inhabits the first forested ridge around a river's headwaters, and sometimes also the second, but not more; he invariably found it along (usually larger) rivers and creeks in the dry season, while at the start of the wet season it came less often to riverbanks, presumably finding moisture in forest pools (BirdLife International 2001). It core habitat is probably between 500 and $1,000 \mathrm{~m}$.

Feeding ecology Food consists equally of insects and fruit (Smythies 1981). Seems to be associated with wild pig, with which it comes in as visitor on the Kelabit uplands (Smythies 1981).

Movement It appears from fragments of evidence that this species is nomadic, at times moving in groups in search of areas with fruiting trees (BirdLife International 2001).

Breeding ecology Probably five eggs are laid, but nest and incubation are unknown (Smythies 1981). Little is known about their mating system, but presumed polygynous with some possibility of monogamy (Johnsgard 1999).

Habitat loss and degradation Avoids cultivated and cleared areas and keeps almost exclusively to primary forest; it is likely to be sensitive to logging.

Conservation status This pheasant is classified as Vulnerable by IUCN (2002) because it is inferred to be declining rapidly owing to extensive and ongoing habitat loss, compounded by hunting. It is also assumed to have a small population which is likely to be experiencing increasingly severe fragmentation, particularly as it may be dependent on nomadic visits to lowland areas (BirdLife International 2001); protected by Indonesian law.

\section{Great Argus Argusianus argus}

Taxonomy This is a monotypic genus, although the Javan form could be a distinct species. Two subspecies are renognized. On Borneo it is represented by the endemic race $A$. a. grayi, distinguished from the nominate race by its smaller size, whiter spots on upper parts, more orange on the upper breast and pinkish buff back of the male.

Global range Peninsular Malaysia, Sumatra and Borneo.

Population status and densities on Borneo Becoming scarcer in middle and lower river reaches as shotguns and snares multiply (Smythies 1981). Decreasing in numbers (Smythies 1981); common in dry lowland and hill forest throughout, but in the long term it should be regarded as secure only in reserves and well-managed production forest (Holmes 1989). Especially common at Talisayan, East Kalimantan, in 1985 (Holmes \& Burton 1987). In Malaysia, sample densities of 1.5-2.25 displaycourt-holding males per $\mathrm{km}^{2}$ in hilly terrain, versus $0.15-0.54$ in plains-level forest over the same year, and courts spaced a mean 375 and $435 \mathrm{~m}$ apart (Davison 1981a), but shorter distances of 40-140 m ( $=4)$ have been found (Hernowo 1989). Nijman 
(1998) found 0.25 (riverine forest) to almost 2.0 (primary forest) calling males per $\mathrm{km}^{2}$ in Kayan-Mentarang National Park, East Kalimantan. Kawanishi (2002) found densities between 0.15 and 0.79 individuals $/ \mathrm{km}^{2}$ in Taman Negara National Park, Peninsular Malaysia. Sözer et al. (1997) reported population densities of 2-8 individuals $/ \mathrm{km}^{2}$ in Kalimantan.

Occurrence on small SE Asian islands Not known from offshore islands $(\mathrm{n}=0)$.

Habitat Dryland evergreen to near-evergreen forests, including selectively logged sites (Wells 1999). From sea level, normally up to $1,000 \mathrm{~m}$, but occasionally up to 1,500 m (Mjöberg 1929, p. 52). Rare to absent in lowland peatswamp and whitesand heath forest (Davison \& Scriven 1987; Wells 1999). Nijman (1998) found that Great Argus density was positively correlated with tree diameter, tree height, height of first bough and canopy cover, distance from large rivers and more uphill habitat, but these correlations do not necessarily indicate causal relationships.

Feeding ecology Unlike other, more social pheasants, the Great Argus never rakes litter to uncover invertebrates, but searches for rarer but larger items whilst walking slowly through the forest (Wells 1999). In particular, giant ants Camponotus gigas, and other larger sized arthropods are selected, as well as leaf material and fruit (Wells 1999). Fruits of climbers and understratum palms are favoured, as distinct from mass falls of fruits only rich in sugars; this richer but rarer food source would make them more vulnerable to periodic shortages than dietary generalists (Davison 1981a).

Breeding ecology Two (seldom three) eggs in a hollow on the forest floor, lined with twigs, root fibres, grass, leaves and down (Davison \& Scriven 1987; Wells 1999). No apparent breeding season (Davison \& Scriven, 1987), and egg dates may depend on mast fruiting (Wells 1999). Polygynous, probably promiscuous mating system. Short-call advertisements are given from courts (arenas) kept meticulously clean in the forest, typically along ridges. Females may select males on loudness and persistence of calls given from these courts (Wells 1999). Both sexes lead solitary lives; home range size between 7 and 32 ha (Winarni 2002).

Habitat loss and degradation This species has probably not declined very rapidly because it ranges up to elevations where forest loss is less severe and occurs in selectively logged sites (Wells 1999). Still, Winarni (2002) reported that undisturbed forest with large trees was identified as the most important habitat for Great Argus males within their home ranges.

Conservation status Considered Vulnerable (McGowan \& Garson 1995), because of the rapid rate of deforestation. Protected by Indonesian law and included on CITES Appendix II. Listed as Lower Risk/near threatened by IUCN (2002). Not threatened at present, which is quite surprising for such a large and easily trapped bird (Wells 1999). Some forest disturbance is tolerated, but the rapid rate forest clearance, fragmentation and hunting pressure may become serious threats in the future (Nijman 1998).

\section{Crimson-winged Woodpecker Picus puniceus}

Taxonomy The genus Picus is distributed over Eurasia and contains 14 species, of which 3 occur on Borneo. The Bornean populations of P. puniceus belong to the 
subspecies observandus which occupies the range of the species (see below) except Java and Nias island (Winkler et al. 1995).

Global range Peninsular Thailand and Tenaserrim, southward through Malaya, Sumatra, Borneo, Bangka Island, Nias Island, and Java (Short 1982); a Sundaland endemic.

Population status and densities on Borneo Occurs in rather low densities in Borneo (it ranks among the four scarcest woodpeckers, out of 14, in primary lowland forest), however it is widespread throughout the island. Average density in lowland forest $\left(0.78\right.$ individuals $\left./ \mathrm{km}^{2}\right)$ is higher than in hill forest $\left(0.45\right.$ individuals $\left./ \mathrm{km}^{2}\right)$ (Lammertink 2004).

Occurrence on small SE Asian islands Bangka and Nias $(\mathrm{n}=2)$.

Habitat Average density in primary lowland forest $\left(0.81\right.$ individuals $\left./ \mathrm{km}^{2}\right)$ similar to that found in logged lowland forests $\left(0.76\right.$ individuals $\left./ \mathrm{km}^{2}\right)$. Perhaps most common at the interface of tall secondary and primary forests (Short 1982). Ranges into foothills, but rarely exceeds $560 \mathrm{~m}$ on the mainland; on Borneo, where congener P. chlorophus is absent, ranges to $1,500 \mathrm{~m}$ (Harrisson in Short 1982); Ranging into secondary forest where sufficient large trees are left (Short 1982); within a logged landscape, they occur more often in primary patches than in logged patches (Lammertink 1999).

Movements and daily migration Occasional excursions are made across $0.5 \mathrm{~km}$ or more open country to visit suitable lone trees (Short 1978). Occurred in a 150 ha forest patch separated by a $1 \mathrm{~km}$ wide gap from continuous forest in Gunung Palung National Park (Lammertink 1999).

Feeding ecology Main foraging modes are hammering (26\% of foraging time) and pecking (16\%) and therefore the Crimson-winged Woodpecker is more of a hammering woodpecker than its Bornean congeners P. mentalis and P. miniaceus. Crimson-winged Woodpecker furthermore differs from the congeners in foraging slightly higher (on average $2 \mathrm{~m}$ higher) in the vegetation and by foraging frequently (15\% of foraging time) at the underside of branches. Unlike the congeners, it hardly ever forages on lianas and epiphytes. It forages $12 \%$ of time on dead branches but never in entirely dead trees; this is similar to its congeners. Foraging height is $15.6 \pm 7.3 \mathrm{~m}$ in trees of $20.8 \pm 7.5 \mathrm{~m}$ height, i.e., at $75 \%$ of total tree height. Foraging trees have a dbh of $21.8 \pm 10.5 \mathrm{~cm}$. Diameter of the foraging substrate is $9.3 \pm 7.9 \mathrm{~cm}$ (Lammertink unpubl.).

Forages principally in canopy on trunks and larger branches, especially those of emergent trees and of trees bordering clearings. Eats almost exclusively ants (Short 1982). Foraging associations: 38\% alone; 25\% with other Crimson-winged Woodpeckers (then usually in pairs); 38\% mixed flocks (Lammertink unpubl.). Forages singly, or loosely in pairs (Lagendijk 2000; Short 1982; Winkler et al. 1995). Mean number of encountered individuals is 1.22 (Lammertink 2004).

Breeding ecology Appears to breed during the dry season (Short 1982). Nesting and roosting sites tend to be in rather small dead limbs, $20 \mathrm{~m}$ or more in large trees (Short 1978, 1982); a suggestion that the nesting site may be developed from the roosting cavity of the male (Short 1982). 
Interspecific interactions Recorded in mixed flocks with a wide variety of other birds: Checker-throated Woodpecker (Picus mentalis), Buff-rumped Woodpecker (Meiglyptes tristis), Buff-necked Woodpecker (M. tukki), Maroon Woodpecker (Blythipicus rubiginosus), Olive-backed Woodpecker (Dinopium rafflesii), Greyand-Buff Woodpecker (Hemicircus concretus), Chestnut-breasted Malkoha (Phaenicophaeus curvirostris), Raffles Malkoha (P. chlorophaeus), Greater Racket-tailed Drongo (Dicrurus paradiseus), Hook-billed Bulbul (Setornis criniger), Spotted Fantail (Rhipidura perlata), Gold-whiskered Barbet (Megalaima chrysopogon), Chestnutwinged Babbler (Stachyris erythroptera), Chestnut-rumped Babbler (S. maculata), Black-throated Babbler (S. nigricollis), and Striped Tit-babbler (Macronous gularis) (Lammertink unpubl.); also see (Winkler et al. 1995; Lagendijk 2000; Styring \& Ickes 2001a).

Conservation status Not globally threatened. Has disappeared from cleared Bornean lowland forests, but similar abundance in logged and primary forest, and occurrence in hill forest, indicate that a large and relatively secure population remains in Borneo. Not listed by IUCN (2002).

\section{Checker-throated Woodpecker Picus mentalis}

Taxonomy Contains two subspecies: mentalis which is endemic to Java, and now occurs in W. Java only, where it is rare, and humii which occupies the remainder of the range including Borneo (Winkler et al. 1995).

Global range Peninsular Thailand and Tenaserrim, southward through Malaya, Sumatra, Bangka, Borneo, and Java (Short 1982); a Sundaland endemic (but extending its range slightly north of the Isthmus of Kra, the faunistic boundary between the Sundaic and Indochinese Subregions).

Population status and densities on Borneo This is one of the two Bornean woodpeckers that are highly sensitive to logging disturbance (the other sensitive woodpecker being Great Slaty Woodpecker Mulleripicus pulverulentus). Checkerthroated Woodpecker declined a mean $85 \%$ in density over eight lowland sites covering a gradient from primary forest to selectively logged forest in W. Borneo (Lammertink 2004). Densities of this woodpecker are also strongly reduced in burnt forest (van Balen pers. obs.). Ranges up to 1,600 m elevation in Borneo (Winkler et al. 1995), but densities in primary hill forest are lower $\left(2.16\right.$ individuals $\left./ \mathrm{km}^{2}\right)$ than in primary lowland forest (4.18 individuals $/ \mathrm{km}^{2}$ ) (Lammertink 2004).

Occurrence on small SE Asian islands Bangka $(n=1)$.

Habitat Within a logged landscape, the species is more frequent in primary patches than in logged patches (Lammertink 1999). Prefers primary forests with a relatively open understorey, probably because such open forests allow for the rapid foraging movement by this woodpecker over and between substrates (Lammertink 1999). Logged-over forest have a more closed understorey that is avoided by this woodpecker. However, in a 40-year old logged forest in Peninsular Malaysia, which had been treated silviculturally (the understorey was thinned and lianas and vines had been removed) and had a more open understorey than primary forest, Checker-throated Woodpeckers were more abundant than in primary forest (Styring \& Ickes 2001b). 
Movements and daily migration. Occurred in 150 ha and 1,500 ha forest patches separated by a $1 \mathrm{~km}$ wide gap from continuous forest in Gunung Palung National Park (Lammertink 1999).

Feeding ecology Main foraging modes are climb \& search (42\% of foraging time), probe (21\%) and glean (16\%). Does more climbing $\&$ searching, and probing, than the Bornean congeners. It spends $13 \%$ of time on lianas, and $12 \%$ on dead wood. Foraging height is $13.6 \pm 8.2 \mathrm{~m}$ in trees of $21.0 \pm 9.7 \mathrm{~m}$ height, i.e., at $65 \%$ of total tree height. Foraging trees have a dbh of $26.8 \pm 16.5 \mathrm{~cm}$. Diameter of the foraging substrate is $12.6 \pm 12.0 \mathrm{~cm}$ (Lammertink unpubl.).

Forages in the lower and middle storeys $(3-15 \mathrm{~m})$. Eats ants, termites, larvae, beetles, grasshoppers, cockroaches and other insects, with occasional berries (Winkler et al. 1995). Foraging associations: $12 \%$ alone; $35 \%$ with other Checkerthroated Woodpeckers; 53\% mixed flocks (Lammertink unpubl.). Mean number of encountered individuals is 1.38 (Lammertink 2004).

Breeding ecology Breeding recorded in February to June in Borneo. Nest excavated in dead stubs. Clutch 2 or 3 eggs (Winkler et al. 1995).

Interspecific interactions Recorded in mixed flocks with Crimson-winged Woodpecker (Picus puniceus), Banded Woodpecker (P. miniaceus), Buff-necked Woodpecker (Meiglyptes tukki), Maroon Woodpecker (Blythipicus rubiginosus), Olive-backed Woodpecker (Dinopium rafflesii), Grey-and-Buff Woodpecker (Hemicircus concretus), Rufous Woodpecker (Celeus brachyurus), Orange-backed Woodpecker (Reinwardtipicus validus), Rufous Piculet (Sasia abnormis), Raffles Malkoha (Phaenicophaeus chlorophaeus), Greater Racket-tailed Drongo (Dicrurus paradiseus), Yellow-bellied Bulbul (Alophoixus phaeocephalus), Scaly-crowned Babbler (Malacopteron cinereum), Scarlet-rumped Trogon (Harpactes duvaucelii), and Striped Tit-babbler (Macronous gularis) (Lammertink unpubl.).

Conservation status Not globally threatened. Lowland populations throughout the Sundaic Subregion have been strongly reduced with clearing, logging and burning of lowland forests, however this woodpecker still occurs in moderate densities in extensive hill forest areas. Not listed by IUCN (2002).

\section{Banded Woodpecker Picus miniaceus}

Taxonomy Bornean populations belong to the subspecies malaccensis (Fig. 30) which is also found in Peninsular Malaysia and Sumatra. Other subspecies are perlutus in Peninsular Birma and Thailand; niasensis from Nias Island; and miniaceus from Java (Winkler et al. 1995).

Global range Southeastern Asia from peninsular Thailand and Tenasserim, south through Malaysia to Sumatra, Nias Island, Borneo, and Java; thus a Sundaland endemic.

Population status and densities on Borneo Among Bornean woodpeckers, Banded Woodpeckers is one of the most tolerant species to forest disturbance. Average density in logged forest $\left(0.60\right.$ individuals $\left./ \mathrm{km}^{2}\right)$ higher than in primary lowland forest $\left(0.05\right.$ individuals $\left./ \mathrm{km}^{2}\right)$; highest density probably reached in rural areas with woodlots and coconut groves (Lammertink 2004). 
Occurrence on small SE Asian islands Bangka, Belitung and Nias ( $\mathrm{n}=3)$.

Habitat Common in lowland and montane forest to $1,400 \mathrm{~m}$ (MacKinnon \& Phillipps 1993), however in Gunung Palung National Park in West Kalimantan only recorded below 200 m elevation (Laman et al. 1996; Lammertink 2004). Rarely reaches $1,000 \mathrm{~m}$ on mainland and Sumatra, but occurs as high as 1,500 $\mathrm{m}$ on Java and 1,700 $\mathrm{m}$ on Borneo (Short 1982). Occurs in high densities in rural areas with coconut groves (Lammertink unpubl.).

Movements and daily migration No available information.

Feeding ecology Main foraging modes are climbing and searching (27\% of foraging time), pecking (19\%), gleaning (17\%), and probing (14\%). Primarily feeds on ants, but occasionally it eats other insects and fruit. Banded Woodpecker is intermediate between its congeners $P$. puniceus and $P$. mentalis in terms of climbing and searching activities, in contradiction of Short (1978) who reported Banded Woodpecker to be the least active forager of the three species. Banded Woodpecker spends $20 \%$ of foraging time on lianas, which is more than its congeners. $10 \%$ of foraging is on dead wood. Foraging height is $13.2 \pm 5.5 \mathrm{~m}$ in trees of $19.2 \pm 9.4 \mathrm{~m}$ height, i.e., at $69 \%$ of total tree height. Foraging trees have a dbh of $20.1 \pm 10.0 \mathrm{~cm}$. Diameter of the foraging substrate is $8.1 \pm 9.5 \mathrm{~cm}$ (Lammertink unpubl.).

Forages at all levels in vines, fallen logs, stubs, trunks, epiphytes and branches of forest trees (Short 1982); only occasionally does it reach the canopy as it slowly makes

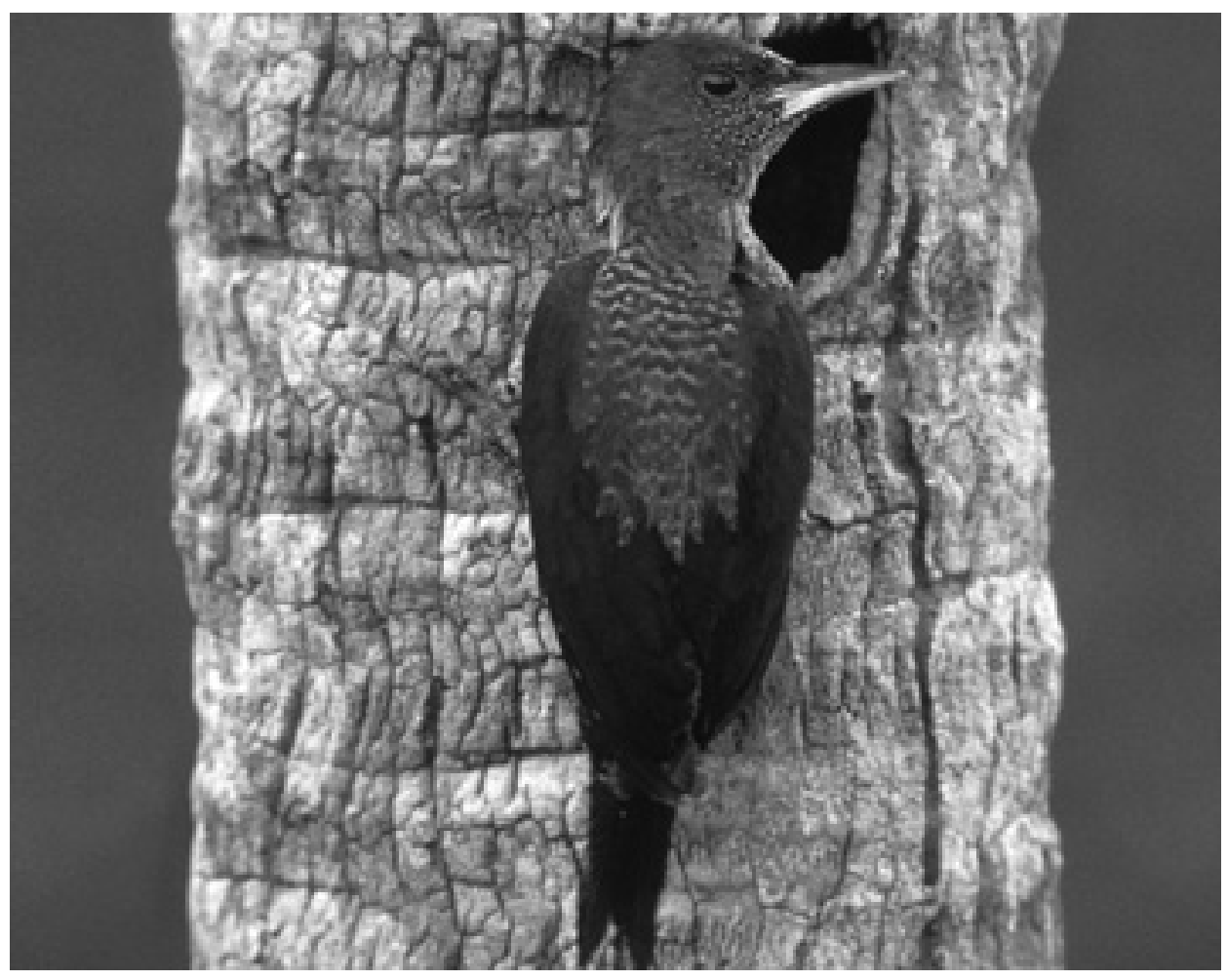

Figure 30. Female Banded Woodpecker (Picus miniaceus); this woodpecker occurs in higher densities in disturbed forests and rural areas than in primary forests. (Photo by Martjan Lammertink) 
its way along vines, fallen trees, and vine-covered saplings (Short 1978). Foraging associations: $30 \%$ alone; in 50\% of occasions it forages with one or two other Banded Woodpekers; in 20\% of observations in mixed flocks (Lammertink unpubl.). Forages alone or often in pairs (Short 1978). Mean encountered number of individuals 1.33 (Lammertink 2004).

Breeding ecology Monogamous; nest excavated in well-decayed stubs of live or dead trees at any height (Short 1978); both sexes work to excavate nests, but male more often than female (Short 1982); male roosts in nest cavity (Short 1982); nothing known of the feeding or care of young; breeding season begins in February or March and lasts as long as June in Malaya, and young birds from Borneo are found in August (Short 1982); two or three eggs form a clutch (Short 1982); many nesting attempts fail (Short 1982); nests are constructed in dead stubs from 4.5-20 m up (Short 1982). In rural areas in west Borneo it often nests in dead coconut trees with a broken top. Breeding observed in west Borneo in January, June, July and October (Lammertink unpubl.).

Interspecific interactions Recorded in mixed flocks with Checker-throated Woodpecker (Picus mentalis), Rufous Piculet (Sasia abnormis), Buff-necked Woodpecker (Meiglyptes tukki), and Yellow-bellied Bulbul (Alophoixus phaeocephalus) (Lammertink unpubl.).

Conservation status Abundance increased in Bornean lowland areas with opening of primary forests, thus of little conservation concern (Lammertink 2004). Not listed by IUCN (2002).

\section{Maroon Woodpecker Blythipicus rubiginosus}

Taxonomy Closely related to larger Bay Woodpecker (B. pyrrhotis), which occupies highlands in parts of the Malay Peninsula and throughout Southeast Asia. No subspecific separations are warranted (Winkler et al. 1995).

Global range Occurs from southern Burma and peninsular Thailand through Malaya and south to Sumatra and Borneo (Short 1982); thus a Sundaland endemic.

Population status and densities on Borneo About 2 pairs $/ \mathrm{km}^{2}$ ( 4 individuals/ $\mathrm{km}^{2}$ ) in Peninsular Malaysia, based on a small sample effort (Short 1978). In W. Borneo, 2.14 individuals $/ \mathrm{km}^{2}$ in lowlands but only 0.69 individuals $/ \mathrm{km}^{2}$ in hill forest over 200 m elevation (Lammertink 2004).

Occurrence on small SE Asian islands Not known from offshore islands ( $\mathrm{n}=0)$.

Habitat On average less abundant in logged lowland forest (1.85 individuals/ $\mathrm{km}^{2}$ ) than in primary lowland forests $\left(2.62\right.$ individuals $/ \mathrm{km}^{2}$ ). However, variation in density in both habitat types is high and no significant correlation was found between density and logging disturbance (Lammertink 2004). Prefers primary patches within a logged landscape (Lammertink 1999). Dense lowland forest, usually primary but also to a lesser extent in dense secondary forest (Short 1978); ranging to 1,000 m. On Borneo, found in low densities in highlands up to 2,200 m (Winkler et al. 1995), which is higher than in the parts of its range where it overlaps with its highland relative $B$. pyrrhotis. 
Movements and daily migration No available information.

Feeding ecology With the exception of Rufous Piculet (Sasia abnormis), forages lower in the vegetation than any other Bornean woodpecker. Foraging height is $5.0 \pm 5.1$ $\mathrm{m}$ in trees of $12.6 \pm 7.7 \mathrm{~m}$ height, i.e., at $39 \%$ of total tree height. Main foraging modes are hammering (62\% of foraging time) and climbing and searching (13\%). Forages $21 \%$ of time on dead wood and $9 \%$ on sick branches or trunks. Thus less emphasis on dead wood foraging than suggested by Short (1978). However, foraging on dead wood is more prominent in the Maroon Woodpecker than in the other medium-sized or small woodpeckers in Borneo. (The larger woodpeckers Reinwardtipicus validus and Dryocopus javensis are dead wood specialists with respectively $58 \%$ and $97 \%$ of foraging time on dead wood; these woodpeckers forage higher up in the vegetation than Maroon Woodpecker). Occasionally forages on lianas and epiphytes. Foraging associations: $33 \%$ solitary; $61 \%$ in pairs or conspecific groups of 3 individuals; $6 \%$ mixed flocks. Foraging trees have a mean dbh of $17.3 \pm 12.8 \mathrm{~cm}$. Diameter of the foraging substrate is $11.4 \pm 10.5 \mathrm{~cm}$ (Lammertink unpubl.).

Beetle and other unidentified wood-boring larvae comprise most of diet (Short 1978). Forages alone or in pairs that feed loosely together, maintaining vocal contact but using different trees for foraging (Short 1978). Mean number of encountered individuals $=1$ (Lammertink 2004).

Breeding ecology Appears to breed during the dry season (Short 1982); Nesting and roosting sites tend to be in rather small dead limbs, $20 \mathrm{~m}$ or more in large trees (Short 1982); a suggestion that nesting site may be developed from the roosting cavity of the male (Short 1982).

Interspecific interactions Rarely in mixed flocks with Checker-throated Woodpecker (Picus mentalis) and/or Raffles Malkoha (Phaenicophaeus chlorophaeus).

Conservation status Persistence in moderate density in logged forests, and occurrence in some forest fragments, indicate that this woodpecker may persist in the long term in logged-over landscapes. Moreover, it occurs in hills forest and thus is not under immediate threat in Borneo, although preferred lowland habitat is disappearing at alarming rates. Not listed by IUCN (2002).

\section{Rufous Woodpecker Celeus brachyurus}

Taxonomy Sole Asian representative of an otherwise Neotropical genus (Short 1982, but this remains to be examined with molecular techniques); several subspecies. The subspecies badiosus is endemic to Borneo; it is the only subspecies on the island.

Global range Southern Asia from Indian Himalayas, southern China to Ceylon, Burma, Thailand, Vietnam, Hainan, Malaya, Java, Sumatra and Borneo.

Population status and densities on Borneo In lowland forests below $200 \mathrm{~m}$ elevation more common (1.80 individuals $/ \mathrm{km}^{2}$ ) than in hill forests (1.13 individuals/ $\mathrm{km}^{2}$ ) (Lammertink 2004). Population density in Peninsular Malaysia perhaps higher with about 2.3 pairs $/ \mathrm{km}^{2}$ (Short 1982), but this is based on a small sample area and unspecified density estimation techniques.

Occurrence on small SE Asian islands Bangka, Belitung and Nias ( $\mathrm{n}=3)$. 
Habitat More abundant in primary lowland forest $\left(2.77\right.$ individuals $/ \mathrm{km}^{2}$ ) than in logged lowland forest (1.22 individuals $/ \mathrm{km}^{2}$ ), but no significant correlation of density with logging disturbance because of an outlying high density value in one logged forest (Lammertink 2004). Also in secondary forests, palm groves, gardens, cultivated trees, and mangroves (Short 1982; Lammertink unpubl.); in Borneo it has been found up to $1,900 \mathrm{~m}$ (Smythies 1981). Occurred in three out of four forest fragments 90 to 1,500 ha in size adjacent to Gunung Palung National Park (Lammertink unpubl.).

Feeding ecology Mean foraging modes are gleaning (33\%) and hammering $(24 \%)$. Forages $14 \%$ of time in epiphytic plants, this a high score equalled only by Buff-necked Woodpecker (see below). Rufous Woodpecker is an active forager, its mean distance moved by flying per foraging minute is higher than in any other Bornean woodpecker; its climbing movements are surpassed only by Crimsonwinged and Checker-throated Woodpecker. Foraging height is $12.7 \pm 9.1 \mathrm{~m}$ in trees of $24.7 \pm 11.5 \mathrm{~m}$ height (thus forages at $51 \%$ of tree height). Diameter of substrate is $10.5 \pm 7.8 \mathrm{~cm}$ on average, in trees of $21.6 \pm 18.3 \mathrm{~cm} \mathrm{dbh}$. Only $2 \%$ of foraging effort is on dead wood (Lammertink unpubl.).

Various ants, especially of the genera Crematogaster and Phidole, make up much of the diet, but termites and other insects are probably taken (Short 1978). Figs and probably other fruits are taken (Ali 1953). Nectars of various flowers are utilized. Forages in diverse sites, from dung hills, ant hills, and termite mounds on the ground to the foliage of tall trees; large termite and ant nests are pecked and torn apart by feeding Rufous Woodpeckers (Short 1978). Foraging associations: rarely alone (4\%); mostly $(70 \%)$ in pairs or small flocks up to 4 individuals; $26 \%$ in mixed flocks. Mean number of encountered individuals is 1.86 (Lammertink 2004).

Breeding ecology Breeding season is from February to April in Malaya and Sumatra. Nest usually constructed in the carton nests of ants (especially genus Crematogaster), at heights in trees of 3-15 m, although holes are occasionally excavated in tree trunks. Clutch normally comprises two eggs. Incubation period is 12-14 days, and both adults incubate the eggs. Nestlings are fed by regurgitation, presumably mostly ants, ant larvae, pupae, and eggs. Nothing is known of the behaviour of fledged young (Short 1978).

Interspecific interactions A tight relationship with carton-ants (Crematogaster). In much of its range, the woodpecker nests in holes excavated in carton nests occupied by ants. Ants and woodpeckers both inhabit nests at same time. This habit of nesting in ant or termite nests effectively removes the Rufous Woodpecker from nesting and roosting site competition with other woodpeckers (Short 1982).

Loosely joins mixed foraging flocks with Checker-throated Woodpecker (Picus mentalis), Crimson-winged Woodpecker (P. puniceus), and Grey-capped Woodpecker (Dendrocopus canicapillus).

Conservation status Not of conservation concern in Borneo because of persistence in logged areas, secondary forest and rural areas: moreover found in hill forest. Not listed by IUCN (2002). 


\section{Buff-Necked Woodpecker Meiglyptes tukki}

Taxonomy The genus Meiglyptes is confined to Southeast Asia and contains 3 species. $M$ tukki contains 5 subspecies, two of which occur in Borneo: tukki in north Borneo (also in Sumatra and Bangka) and percnerpes which is endemic to south Borneo (Winkler et al. 1995).

Global range Southeast Asia from Tenasserim and peninsular Thailand through Malaya to Borneo, and Sumatra): thus a Sundaland endemic.

Population status and densities on Borneo Common in Bornean lowland forest $\left(2.62\right.$ individuals $\left./ \mathrm{km}^{2}\right)$ and hill forest $\left(2.27\right.$ individuals $\left./ \mathrm{km}^{2}\right)$. Reported to be twice as abundant in Peninsular Malaysia: 2.3-2.7 pairs $/ \mathrm{km}^{2}$, but sample area and density estimation technique not specified (Short 1978).

Occurrence on small SE Asian islands Bangka, Banyak, Batu Islands, Belitung, Bunguran and Nias $(n=6)$.

Habitat Nearly equally abundant in logged forest $\left(2.58\right.$ individuals $\left./ \mathrm{km}^{2}\right)$ as in primary lowland forest (2.69 individuals $/ \mathrm{km}^{2}$ ) (Lammertink 2004). Lowland and hill forests, frequenting primary forest and dense secondary growth (Short 1982); prefers areas with dense understorey, avoiding clearings and edges favoured by congeners (Short 1982); rarely found above $625 \mathrm{~m}$, but sporadically reaches $1,200 \mathrm{~m}$ in the mountains of Malaya (Short 1982) and 1,000 $\mathrm{m}$ in Borneo (Winkler et al. 1995).

Feeding ecology Main foraging activities hammer (27\% of foraging time), climb $\&$ search (25\%) and glean (25\%). Distinguished from its sympatric congener $M$. tristis in Borneo by spending $14 \%$ of foraging time probing in epiphytes (as opposed to $0 \%$ in tristis), and by less foraging on lianas (11\%, against $25 \%$ in tristis). All other foraging behaviour parameters are very similar between the two congeners. Buff-necked Woodpecker foraged $7 \%$ of time on arboreal ant and termite nest structures, this is more than any other Bornean woodpecker: Crimson-winged Woodpecker foraged 3\% of time on such structures; all other woodpeckers $0 \%$ (Lammertink unpubl.). However, for woodpeckers in Peninsular Malaysia, Styring (2002a) reported more frequent foraging on ant- and termite nests, including $42 \%$ for Buff-necked Woodpecker, 25\% for Banded Woodpecker, $18 \%$ for Maroon Woodpecker, and 16\% for Buff-rumped Woodpecker, but $0 \%$ for Crimson-winged Woodpecker. Buff-necked Woodpecker foraging height is $12.2 \pm 8.9 \mathrm{~m}$ in trees of $23.4 \pm 18.9 \mathrm{~m}$ height (thus forages at $52 \%$ of tree height). Diameter of substrate is $12.6 \pm 21.9 \mathrm{~cm}$ on average, in trees of $29.9 \pm 25.6$ $\mathrm{cm} \mathrm{dbh}$. Note the large standard deviations for diameter of substrate and dbh; this shows that this woodpecker forages over a wide variety of substrate and tree diameters. $7 \%$ of foraging effort is on dead wood (Lammertink unpubl.).

Most of the diet consists of ants and termites (Smythies 1986); forages on rotting logs, stubs, twigs and saplings (Short 1982); forages at diverse heights, but preference for dense understorey suggests that low feeding is important (Short 1982). Rapid movements between substrates according to (Short 1982), however, in West Kalimantan ranks $7^{\text {th }}$ among woodpeckers in climbing movements and $4^{\text {th }}$ in flying movements; thus a rather average woodpecker in terms of mobility (Lammertink unpubl.). Mostly forages in pairs or mixed flocks (Winkler et al. 1995); in Borneo, foraging associations are $18 \%$ alone, $38 \%$ with other Buff-necked Woodpeckers, and $46 \%$ in mixed flocks. Mean number of encountered individuals is 1.59 (Lammertink 2004). 
Breeding ecology Both adults attend the young, feeding them apparently by regurgitation and carrying away faecal sacs (Ogilivie 1954 in Short 1982); nesting occurs from March to June; immature birds from June to September; two young birds in one nest studied (Ogilivie 1954 in Short 1982); excavated in stubs of live trees or more often in well-rotted stubs 1-5 $\mathrm{m}$ above the ground (Short 1982). Two nests found in West Kalimantan in June and July, both in well rotted stubs, 6.5 and $1.2 \mathrm{~m}$ from the forest floor (Lammertink unpubl.).

Interspecific interactions Joins mixed flocks with Buff-rumped Woodpecker, Checker-throated Woodpecker, Crimson-winged Woodpecker, Olive-backed Woodpecker (Dinopium rafflesii), Orange-backed Woodpecker (Reinwardtipicus validus), Greater racket-tailed Drongo (Dicrurus paradiseus), Spotted Fantail (Rhipidura perlata), Scarlet-rumped Trogon (Harpactes duvaucelii) and Raffles Malkoha (Phaenicophaeus chlorophaeus). When participating in interspecies foraging flocks, ranges into higher canopy to seek food (Short 1978).

Conservation status Listed as Lower Risk/near threatened by IUCN (2002); Lammertink (2004a) recommends changing status to not threatened because of lack of density decline after logging, and occurrence in rural areas, forest fragments and hill forests.

\section{Buff-Rumped Woodpecker Meiglyptes tristis}

Taxonomy Subspecies grammithorax found in most of range including Borneo; subspecies tristis is endemic to Java and is possibly extinct since there are no recent records (Winkler et al. 1995).

Global range Southeastern Burma in Tenasserim, southern Thailand, Malay Peninsula, Sumatra, Borneo, Java; thus a Sundaland endemic.

Population status and densities on Borneo More common in lowland forest (1.32 individuals $\left./ \mathrm{km}^{2}\right)$ than in hill forest $\left(0.72\right.$ individuals $\left./ \mathrm{km}^{2}\right)$ between 200 and $400 \mathrm{~m}$ elevation. Similar density in lowland forest in Peninsular Malaysia: 0.77 pairs/ $\mathrm{km}^{2}$ (Short 1978).

Occurrence on small SE Asian islands Bangka and Nias $(\mathrm{n}=2)$.

Habitat Nearly equally abundant in logged lowland forest (1.31 individuals $/ \mathrm{km}^{2}$ ) as in primary lowland forest (1.34 individuals $/ \mathrm{km}^{2}$ ) (Lammertink 2004). Ranges to approximately $625 \mathrm{~m}$ on mainland, up to $1,100 \mathrm{~m}$ on Borneo (Winkler et al. 1995).

Feeding ecology Main foraging modes are climb \& search (35\%), glean (30\%), and hammer (20\%). Buff-rumped Woodpecker foraged 5\% of time on leaves, this is more than any other Bornean woodpecker: Grey-and-Buff Woodpecker (Hemicircus concretus) foraged 3\% of time on such structures; all other woodpeckers $0 \%$ (Lammertink unpubl.). More on dead wood than its congener M. tukki (17\% in tristis, versus $7 \%$ in tukki). For other differences with $M$. tukki, see above. Diameter of substrate $11.0 \pm 22.5 \mathrm{~cm}$, dbh $27.1 \pm 27.9 \mathrm{~cm}$. Note large standard deviations for diameters that indicate large variation. Forages at a height of $11.5 \pm 9.0 \mathrm{~m}$ in trees $17.5 \pm 15.2 \mathrm{~m}$ high, i.e., at $68 \%$ of tree height (Lammertink unpubl.). Insectivorous; often high in the canopy (Short 1982). Seems to specialise on ants associated with Macaranga spp. trees, which dominate in regenerating forest (Styring \& Hussin 
2004b). Foraging associations: 3\% alone, $73 \%$ with other Buff-rumped Woodpeckers (flocks of up to 5 individuals), 25\% in mixed flocks (Lammertink unpubl.). Mostly in pairs or mixed flocks (Winkler et al. 1995). Mean number of encountered individuals is 1.64 (Lammertink 2004).

Breeding ecology Construction of nest in Malaya in April; a nest in Malaya with two eggs in late March (Short 1982); juvenile specimens from southern Borneo taken in July, from Northern Borneo during August, and from Java in March (Short 1982); nests in stubs of dead or live trees (Short 1978). Excavation was $8 \mathrm{~m}$ up a 17 $\mathrm{cm}$ wide tree broken off at $12 \mathrm{~m}$ above the ground (Short 1982); nest in a $2 \mathrm{~m}$ tall stump (Short 1982).

Interspecific interactions Fast moving pace and tendency to feed higher in trees separates it from M. tukki (Short 1978), however no difference in mobility or foraging height apparent in west Borneo (Lammertink unpubl.). Regularly associates in mixed species flocks with Buff-necked Woodpecker, Checker-throated Woodpecker, Crimson-winged Woodpecker, Asian Paradise-Flycatcher (Terpsiphone paradisi), Greater Racket-tailed Drongo (Dicrurus paradiseus), Black-naped Monarch (Hypothymis azurea), Rufous-winged Philentoma (Philentoma pyrhopterum), and Chestnut-rumped Babbler (Stachyris maculata) (Lammertink unpubl.).

Conservation Status Not listed by IUCN (2002).

\section{Rufous Piculet Sasia abnormis}

Taxonomy The piculet genus Sasia comprises 3 species, two of which occur in Southeast Asia and one in Africa. Bornean populations belong to the subspecies abnormis, which covers the entire range of the species except Nias where magnirostris is found (Winkler et al. 1995).

Global range Tenasserim (?), peninsular Thailand south through Malaya, Sumatra, Borneo, western Java, Nias; a Sundaland endemic.

Population status and densities on Borneo Common in primary and logged lowland forest at a mean density of 3.30 individuals $/ \mathrm{km}^{2}$. Much less abundant in hill forest at 0.12 individuals $/ \mathrm{km}^{2}$ (Lammertink 2004).

Occurrence on small SE Asian islands Belitung, Bunguran, Laut and Nias $(\mathrm{n}=4)$.

Habitat More abundant in logged lowland forest (3.79 individuals $/ \mathrm{km}^{2}$ ) than in primary lowland forests (2.50 individuals $/ \mathrm{km}^{2}$ ) (Lammertink 2004). Occurs in dense undergrowth in primary forests and dense secondary growth, especially about bamboo thickets, vines, and riverine undergrowth. Ranges into hills to $800 \mathrm{~m}$ in Borneo (Winkler et al. 1995).

Feeding ecology Main foraging modes are hammer (59\%) and climb \& search (17\%). It forages $28 \%$ of time on dead wood, $7 \%$ on fallen braches suspended in the vegetation, $15 \%$ on lianas, and $3 \%$ on thorny rattan vines. Different niche than all other Bornean woodpeckers: smallest substrates $(1.0 \pm 0.6 \mathrm{~cm})$, smallest dbh $(5.6 \pm 6.1$ $\mathrm{cm})$, lowest height $(3.3 \pm 2.0 \mathrm{~m})$ and lowest trees $(6.2 \pm 4.6 \mathrm{~m})$ of the woodpecker community. Diet includes ants, ant eggs, and larvae of various insects. Regularly extracts larvae as large as $2.5 \times 0.4 \mathrm{~cm}$ from dead wood or rattan; for handling 
such prey it may flutter to the forest floor, and swallowing can take several minutes (Lammertink unpubl.). Forages in dense undergrowth of saplings, vines, shrubs, and bamboo, flying some distance between suitable foraging areas; often found near water, probably reflecting its preference for undergrowth (Short 1982). Most often alone (75\% of observations); $7 \%$ in pairs, and $18 \%$ in mixed flocks (Lammertink unpubl.). Mean number of encountered individuals is 1.01 (Lammertink 2004).

Breeding ecology Almost unknown; April to July nesting period; family parties remain intact through post-breeding period; nests are excavated in small stubs.

Interspecific interactions Joins mixed flocks with Scaly-crowned Babbler (Malacopteron cinereum), Spotted Fantail (Rhipidura perlata), Checker-throated Woodpecker, Banded Woodpecker, and Greater Racket-tailed Drongo (Dicrurus paradiseus) (Lammertink unpubl.).

Conservation status Abundant in logged-over forests, but preference for low elevation forest implies a large population reduction if all Sunda lowland forest disappears. Not listed by IUCN (2002).

\section{Diard's Trogon Harpactes diardii}

Taxonomy Two subspecies, $H$. $d$. diardii and $H$. d. sumatranus.

Global range Malay Peninsula and southern Thailand, Sumatra, and Borneo, formerly on Singapore (Robson 2000).

Population status and densities on Borneo Uncommon to occasional species (Johnsgard 2000); up to two pairs found in one 15 ha plot (Wells 1998); solitary species with no reported interactions (Johnsgard 2000).

Occurrence on small SE Asian islands Bangka and Lingga Islands ( $\mathrm{n}=2+$ ).

Habitat Limited to evergreen and semi-evergreen lowland primary forests (Johnsgard 2000); accepts well-generated secondary growth (Johnsgard 2000); middle and lower strata, but highly arboreal; often sits motionless and silent for prolonged periods of time (Johnsgard 2000); up to $950 \mathrm{~m}$ (Johnsgard 2000).

Movements and migration No available information.

Feeding ecology Still hunts from perches and makes short sallies out to catch prey from leaves or other vegetation; feeds on caterpillars, stick insects, locustids, and fruit (large figs) (Smythies 1986).

Breeding ecology Male has been seen attending nest (Wells 1998); laying occurs from February to at least mid-May (Johnsgard 2000); eggs found in May and June (Johnsgard 2000); fledglings found in March (Johnsgard 2000); brood of two fledglings have been seen (Johnsgard 2000); nests located 1.2-2.5 m above ground, in old rotted tree stumps (Wells 1998; Johnsgard 2000); opening $11 \mathrm{~cm}$ in diameter (Johnsgard 2000).

Habitat loss and degradation The species appears to be able to persist in hill-slope and logged forest, and second growth, provided the canopy is not heavily disturbed (Pearson 1975).

Interspecific competition No available information

Conservation status Listed as Lower Risk/near threatened by IUCN (2002). Protected in Indonesia. 


\section{Red-Naped Trogon Harpactes kasumba}

Taxonomy Two subspecies: H. k. impavidus and H. k. kasumba.

Global range Malay Peninsula, Sumatra and Borneo.

Population status and densities on Borneo Uncommon to occasional species (Johnsgard 2000).

Occurrence on small SE Asian islands Not known from offshore islands ( $\mathrm{n}=0)$.

Habitat Lowland primary forests; occasionally in logged forest (Johnsgard 2000); also occurs in peat swamp forest that has reached a closed-canopy stage (Wells 1998 in Johnsgard 2000); up to 625 m (Johnsgard 2000).

Movements and migration No available information.

Social structure Little information available (Johnsgard 2000); appears to be a relatively solitary species.

Feeding ecology Still hunts from perches and makes short sallies out to catch prey from leaves or other vegetation.

Breeding ecology Monogamous; only male incubating (Wells 1998); no information on breeding chronology available (Johnsgard 2000); moult patterns suggest breeding during the dry season (Johnsgard 2000); one active clutch monitored from July 30-August 30; two eggs; one nest found $1.2 \mathrm{~m}$ high in a partially rotted stump $1.6 \mathrm{~m}$ tall and $18 \mathrm{~cm}$ in diameter (Wells 1998).

Habitat loss and degradation Able to colonize mature second-growth forests (Johnsgard 2000). Although intolerant of heavy disturbance to canopy cover, the species' ability to use regenerated forest and its wide occurrence on slopes suggests that it is not immediately threatened (Wells 1999).

Conservation status Listed as Lower Risk/near threatened by IUCN (2002). Protected in Indonesia.

\section{Orange-Breasted Trogon Harpactes oreskios}

Taxonomy 5 subspecies are generally recognised: $H$. o. dulitensis, H. o. nias, $H$. o. oreskios, H. o. stellae, and $H$. o. uniformis.

Global range Southern China, Thailand, Laos, Vietnam, Cambodia, Myanmar, the Malay Peninsula, Nias, Sumatra, Borneo and Java.

Population status and densities on Borneo No available information.

Occurrence on small SE Asian islands Nias $(n=1)$.

Habitat Mostly found in evergreen and semi-evergreen lowland forests, in addition to mature and disturbed swamp forests and lower montane forests (Wells 1998); middle stratum and lower canopy (Johnsgard 2000); said to favour perching on shorter trees, especially those well-overgrown with epiphytic or parasitic vegetation (Johnsgard 2000); on Borneo, mostly found along the central mountain range between 300 and $900 \mathrm{~m}$, although in the Kelabit uplands it is fairly common above $900 \mathrm{~m}$ (Smythies 1986); ranges 625-1,250 $\mathrm{m}$ in the southern Malay Peninsula.

Movements and migration No available information.

Feeding ecology Little information on behaviour is known; no detailed information on foods (Johnsgard 2000); beetles, crickets, locustids, grasshoppers, lizards, ants, fruits, and mixtures of vegetable matter (Smythies 1986). 
Breeding ecology Little information on behaviour is known; monogamous; in Tenasserim, the breeding season extends from at least mid-February to the end of April (Johnsgard 2000); two or three eggs, but four reported to occur rarely (reported in Johnsgard 2000); roosts in understorey vegetation (Johnsgard 2000); in Tenasserim, usually in hollow stumps less than a metre above ground, but some in dead bamboos (reported in Johnsgard 2000); two nests on the Malay Peninsula were 1.5 and $2.0 \mathrm{~m}$ above ground in rotted stumps or trees (Wells 1998).

Habitat loss and degradation No available information.

Interspecific competition Reported to be a part of mixed-species foraging flocks (Wells 1998).

Conservation status Protected in Indonesia. Not listed by IUCN (2002).

\section{Scarlet-Rumped Trogon Harpactes duvaucelii}

Taxonomy No subspecies have been described for this taxon.

Global range Malay Peninsula north to southwestern Thailand, Sumatra, Borneo, Riau Archipelago, Banyak Islands (off west Sumatra), Bangka, Belitung and Natuna.

Population status and densities on Borneo No available information.

Occurrence on small SE Asian islands Bangka, Batu Islands, Belitung, Natuna Islands and Riau Islands $(\mathrm{n}=5+)$

Habitat Primarily lowland forest (Wells 1998; Johnsgard 2000); secondary forests to some extent, but does not extend into mangrove, cultivated areas, or open country (Wells 1998; Johnsgard 2000); occupies the middle, and less often, lower stratum of forests (Wells 1998); recorded as high as 1,100 m (reported in Johnsgard 2000); prefers to perch on the lower branches of trees in deep jungle, especially in shady ravines, sometimes along creeping vines (Robinson 1927 in Johnsgard 2000).

Movements and migration No available information.

Feeding ecology Birds sortie from the middle and lower stratum of forests to catch prey from plant surfaces or sometimes from the air (Wells 1998); moths, beetles, stick insects, caterpillars, and locustid orthopterans, including larval forms (Wells 1998; Johnsgard 2000).

Social structure Birds usually solitary, but at times pairs occur (Johnsgard 2000).

Breeding ecology Monogamous; both parents observed tending their young and providing the majority of the chick's food as late as 17 weeks (Fogden 1972 in Johnsgard 2000); eggs found during May in Perak, Malaysia (reported in Johnsgard 2000); hatched chicks found in mid-March and May (Wells 1998); one questionable record of two eggs (Johnsgard 2000); hollow of old stump in evergreen forest, but Wells (1998) questions the record.

Habitat loss and degradation BirdLife International (2001) referring to Wells (1999) stated that although intolerant of heavy disturbance to canopy cover, the species' ability to use regenerated forest and its wide occurrence on slopes suggests that it is not immediately threatened. 
Interspecific competition Seen following foraging flocks of babblers.

Conservation status Listed as Lower Risk/near threatened by IUCN (2002). Protected in Indonesia.

\section{Cinnamon-Rumped Trogon Harpactes orrhophaeus}

Taxonomy Two subspecies have been described: H. o. orrhophaeus and H. o. vidua.

Global range Peninsular Malaysia, Sumatra, northern and central Borneo (Johnsgard 2000).

Population status and densities on Borneo Uncommon to rare (Johnsgard 2000); four pairs in one 15 ha plot (Wells 1998).

Occurrence on small SE Asian islands Not known from offshore islands ( $\mathrm{n}=0)$.

Habitat Tall lowland forests of Malaysia (Johnsgard 2000); mid-level montane forests to $1500 \mathrm{~m}$ on Sumatra and Borneo (Johnsgard 2000); rare or absent from more seasonal forests such as deciduous or semi-evergreen (Johnsgard 2000); usually found within 2-3 $\mathrm{m}$ of the ground (Wells 1998).

Movements and migration Shows no evidence of movement (Johnsgard 2000). Two of 14 birds banded in one area were present 109 and 115 months later, and another bird retrapped at same site, 156 months after banding (Wells 1998).

Feeding ecology No specifics known; insects and fruits (Johnsgard 2000); stillhunts from branches in rather dense understorey vegetation.

Social structure Solitary species.

Breeding ecology Little information known; monogamous; both sexes known to incubate and tend nestlings (Wells 1998); eggs found early May and mid-June (Wells 1998); nestlings seen in mid-April (Wells 1998); two eggs per clutch (Wells 1998); three nests have been found, all of which were cavities $1-1.5 \mathrm{~m}$ above ground in rotted forest stumps (Wells 1998); one cavity $10 \mathrm{~cm}$ deep (Wells 1998).

Habitat loss and degradation In southern Thailand and Peninsular Malaysia its dependence on plains-level, closed-canopy forest places it at more serious risk than its congeners (Wells 1999 in BirdLife International 2001), but in Borneo it occurs on relatively less threatened forests on slopes (Johnsgard 2000).

Interspecific competition Limited to (sub)montane areas in Borneo, as opposed to southern Thailand and Peninsular Malaysia where it occurs in lowlands (Wells 1999). This may indicate that habitat limitation on Borneo results from competition.

Conservation status Listed as Lower Risk/near threatened by IUCN (2002). Protected in Indonesia. 


\section{Appendix 5 \\ Species summary-mammals}

\section{Sunda Slow Loris Nycticebus coucang}

Taxonomy There are 3 species in the genus, and 3 subspecies within the species (Groves 1998, 2001).

Global range Malay Peninsula from the Isthmus of Kra southward, Sumatra, Java, Borneo, the smaller islands of Tioman, Penang, Singapore, Batam, Galang (Riau Isl.), Bangka, Bunguran, Tawitawi, Siminul, Sanga Sanga and Bongao (Sulu Isl.) (Corbet \& Hill 1992; Groves 1998).

Population and status on Borneo Common.

Occurrence on small SE Asian islands Banggi, Bangka, Batam, Bunguran, Galang, Karimata, King, Letong, Panaitan, Pangkor, Penang, Siantan, Singapore, Tebing Tinggi and Tioman ( $\mathrm{n}=15)$ (Meijaard 2003b).

Genus/species age ca. 6 Mya (see Lu et al. 2001)/2.7 Mya.

Habitat Tropical evergreen rainforest up to $1,300 \mathrm{~m}$; mostly in small to medium-sized trees (Payne et al. 1985); prefer forest edges, which have more insect prey (Johns 1986a), although Slow Loris would also have been more visible along the logging roads and forest edges where Johns worked, and the results might be biased.

Activity Nocturnal and usually arboreal (Payne et al. 1985); uses tangles for sleeping sites.

Movements and migration Not known.

Feeding ecology Small animals, mostly insects, and pulpy fruits (Payne et al. 1985); also large molluscs, birds, small mammals and lizards (Lekagul \& McNeely 1977); fruit 50\%, animal prey 30\%, gums 10\% (Bearder 1987).

Breeding ecology Mainly solitary (Payne et al. 1985), but in mating season sometimes found in groups of up to 6 (Lekagul \& McNeely 1977); gestation period between 90 and 193 days (Lekagul \& McNeely 1977); estrus cycle between 37-54 days (Lekagul \& McNeely 1977); litter size usually 1, or occasionally 2 (Lekagul \& McNeely 1977). 
Habitat loss and degradation Species also occurs in secondary forests, mostly in small to medium-sized trees, and often enters gardens and plantations (Payne et al. 1985; Yasuma \& Andau 2000), suggesting that it copes well with logging disturbance.

Interspecific relationships Inadequately investigated.

Conservation Status Protected by Indonesian law and included on CITES Appendix II. Not listed by IUCN (2002) (only Javan subspecies, considered as a full species by IUCN, is listed as Data Deficient).

\section{Western Tarsier Tarsius bancanus}

Taxonomy The single genus was considered to contain 3 or 4 species (e.g. Hill 1955), but recent acoustic studies have indicated that there may be as many as 13 species (Shekelle in press).

Global range Borneo, Sumatra (only southern tip), Sulawesi, Philippines, and several smaller islands.

Population and status on Borneo MacKinnon (1986) conservatively estimated that 9,912,500 individual T. bancanus occupied 198,250 sq km of suitable remaining habitat in Indonesia, at an average density of $50 / \mathrm{sq} \mathrm{km}$.

Occurrence on small SE Asian islands No available information.

Genus/species age 20.0 Mya/7.5 Mya.

Habitat This species can live in both primary and secondary forests, and it also lives in forests along the coasts or on the edge of plantations (Niemitz 1984).

Activity Nocturnal. The Western Tarsier sleeps alone during the day in a tangle of vines or creepers at a height of 3.5-5 m (Crompton \& Andau 1986); apparently it prefers to sleep on perches that are angled 5 degrees from the vertical (Niemitz 1984).

Movements and migration Niemitz (1984) reported that an adult pair of T. bancanus inhabited a home range of 1-2 ha. Fogden (1974), also working in Borneo, found home ranges to be $2-3$ ha, larger for males than for females. Ranges of individuals of the same sex seemed mostly exclusive, but there was extensive overlap between the ranges of males and females. Despite reports that tarsiers are usually found in pairs, Fogden saw two together only eight times during his study. He recorded immature males mainly in primary forest, which he did not consider to be good habitat, and suggested that these young animals were forced to disperse into marginal areas on attaining independence. Females, however, established ranges near those of their parents. The Western Tarsier is found from ground level up to 8 $\mathrm{m}$ up in the understorey (Fogden 1974). Individuals move through the understorey and forage solitarily, and males tend to move further during the night than females (Crompton \& Andau 1987).

Feeding ecology Tarsiers prey mainly on insects and readily accept small lizards and crustaceans, such as shrimps, in captivity. They are known to occasionally take small birds or snakes. A tarsier watches its moving prey, adjusts its position and focus, then suddenly leaps forward and seizes the prey with both hands. The prey is chewed with side-to-side movements of the jaw while the tarsier sits upright on its hindquarters. These primates drink water by lapping. 
Breeding ecology Fogden (1974) reported that T. bancanus has a sharply defined breeding season, with mating in October-December and births in JanuaryMarch. Van Horn and Eaton (1979), however, questioned Fogden's data and pointed out that earlier investigation had found pregnant females in every month of the year on Bangka Island. Gestation in T. bancanus is ca. 178 days, an unusually long period for such a small mammal, and the estrous cycle is between 18 and 27 days, with a 1to 3-day oestrus (Izard et al. 1985; Wright et al. 1986). The young is born in a fairly well-developed state-well furred, its eyes open, and capable of climbing and making short hops on a level surface. It is unable to leap until 1 month old. The weight at birth is approximately 20-31 grams. Fogden (1974) stated that adult weight was attained at an age of $15-18$ months.

Habitat loss and degradation Tarsiers seem to prefer secondary forest, scrub, and clearings with thick vegetation, but they have also been found in primary forest and mangroves. They are mainly arboreal, but occasionally spend time on the ground feeding (Fogden 1974). They spend the day sleeping in dense vegetation on a vertical branch, or rarely in a hollow tree. It is therefore expected that Western Tarsier does not suffer much from selective logging.

Conservation Status. Protected by Indonesian law and included on CITES Appendix II. Listed as Data Deficient by IUCN (2003).

\section{Long-tailed Macaque Macaca fascicularis}

Taxonomy There are 14-19 species in 4 species groups within the macaques. $M$. fascicularis belongs with 3 other species to the fascicularis group. There are 10 subspecies within the species (Groves 2001).

Global range S. Indochina and Thai/Malay Peninsula, Sumatra, Java, Borneo, Koh Pennan, Koh Samui, Great Redang Isl., Tioman, Tinggi, Anamba, Tambelan, Bunguran, Subi Besar, Serasan, Simalur, Lasia, Nias, Bali, Mata Siri, Bawean (and many more in the Philippines, Nicobar and Megui Isl., lesser Sunda Isl.) (Chasen 1940; Corbet \& Hill 1992).

\section{Population and status on Borneo Common}

Occurrence on small SE Asian islands Aroa Isl, Babi Isl., Balembangan, Banggi, Bangka, Bawal, Bengkalis, Bruit, Con Son, Datuk, Dua, Durian, Jambongan, Jemur, Karimum Jawa, Ketam, Kissaraing, Kram, Kundur, Lamukotan, Lan, Langkawi, Lasia, Laut, Linapacan, Malawali, Maratua , Mataha, Matak, Mendanau, Merah, Mohea, Molleangen, N. Pagai, Nias, Nusa Barung, Padang, Palawan, Panau, Payong, Pemanggil, Penang, Phuket, Pipidon, Sangalan, Sebatik, Sebesi, Setoko, Siantan, Simeulue, Singapore, Sir John Malcolm, Sirhassen, Siumat, Sribuat, St Barbe, Tambelan Besar, Tambelan, Tampel, Tao, Tavoy, Teibeianbesar, Telibon, Tinggi, Wai and Weh $(\mathrm{n}=66+)$ (Meijaard 2003b).

Genus/species age 7.5 Mya/3.0 Mya.

Habitat Found in all habitats except montane (up to 2,000 m) (Wrangham et al. 1983; Rowe 1996). Traditionally associated with riverine and disturbed or edge forest habitats. According to Rodman (1991) the species prefers dense habitat with continuous canopy to support arboreal locomotion, but it is often seen on beaches 
and open ground, and probably more common in disturbed areas. Returns to river's edge for sleeping trees.

Activity Diurnal; most activity between 0 and $22 \mathrm{~m}$ from the ground (Ungar 1995 ) with less than $10 \%$ of initial contacts on ground (MacKinnon \& MacKinnon 1980), although in some areas (e.g., coastal forests on Java, Meijaard pers. obs.) often on ground.

Movements and migration Home range size: 25-200ha (Wolfheim 1983); daily range: 150-1,500 m (Payne et al. 1985); all juvenile males emigrate by age 7 years, and most by age $4-5$ years (van Noordwijk et al. 1993).

Feeding ecology Primarily frugivorous, but very flexible; for example, Berenstain (1986) reports that Long-tailed Macaques fed primarily on fruit until a major fire destroyed this resource base; then they switched to insects, stems, leaves, and dipterocarp seeds. Yeager (1996) reported fruit $66.7 \%$ of diet, foliage $17.2 \%$, flowers $8.9 \%$, insects $4.1 \%$ and $3.2 \%$ unknown. Others also report similar preponderance of fruit: Aldrich-Blake (1980): fruit 62\%, leaves 25\%, invertebrates 3\%, other 11\%; Sterck (1995): 98\% fruit, 0.3\% leaves, $2 \%$ other. Appears to be selective in fruit species they feed upon; fed on some plants more than would be expected by chance (Yeager 1996). Consumes relatively small, ripe fruits, and focuses only $20 \%$ of their time on figs (Ungar 1995).

Social behaviour Multimale groups with several males, females, and offspring (Yeager 1996); Fission-fusion ${ }^{5}$ of subgroups. Average group size: 10-48, up to 100 (Aldrich-Blake 1980; Wolfheim 1983); 2.5 females to one male in average troop (Roonwal \& Mohnot 1977).

Breeding ecology Polygynous; female mean age at first reproduction approximately 3.9 years (Hadidan \& Bernstein 1979) and 51.6 months (Harvey et al. 1987); male age at first reproduction approximately 50.4 months (Harvey et al. 1987); interbirth interval: 13 months (Hadidan \& Bernstein 1979; Ross 1992).

Habitat loss and degradation Species appears to do well in disturbed forests (Wilson \& Wilson 1975), which was also confirmed by Nijman (1997) who found the highest densities in riverine and young secondary forests, and the lowest in primary and old secondary forests.

Interspecific relationships May compete for food with Proboscis Monkeys (Nasalis larvatus); almost two-thirds of the plant resources used by Longtailed Macaques are also used by Proboscis Monkeys (Yeager 1996); however, physiological differences between the two species may reflect diet choice and lessen competition.

May be important seed dispersers, although probably less effective than other frugivores in the range; over $70 \%$ of seeds $>2.3 \mathrm{~mm}$ in width and $<30 \mathrm{~mm}$ in length were spat by Long-tailed Macaques; seeds that were $<2.3 \mathrm{~mm}$ in width were always swallowed; some seeds are transported in cheek pouches; will carry off fruits from tree of origin in order to avoid intraspecific competition (Lucas \& Corlett 1998); seeds of dry fruits always destroyed (Lucas \& Corlett 1998).

\footnotetext{
${ }^{5}$ Fission-fusion is a constantly changing form of social organisation whereby large groups undergo fission into smaller units and small units fuse into larger units in response to the activity of the group and the season of the year.
} 
Conservation Status Not protected by Indonesian law. Included on CITES Appendix II. Listed as Lower Risk/near threatened by IUCN (2002).

\section{Pig-Tailed Macaque Macaca nemestrina}

Taxonomy There are 14-19 species in 4 species groups within the macaques. $M$. nemestrina belongs with 6 other species to the silenus-sylvanus group. There are no subspecies with nemestrina.

Global range Parts of Indochina, Sumatra, Borneo, Bangka, smaller islands of Chance, Sullivan, Phuket, Penang, Tioman, Siberut, Sipura, N. Pagai and S. Pagai (Chasen 1940; Corbet \& Hill 1992).

Population status and densities on Borneo Common; between 250,000 and 375,000 individuals (Nijman \& Meijaard unpubl.); density: $52.8 \mathrm{ind} / \mathrm{km}^{2}$ or 0.94 troops $/ \mathrm{km}^{2}$ (Oi 1990).

Occurrence on small SE Asian islands Alange, Bangka, Bedung, Iyan, Kangean, Klum, Lingung Nias, Payong and Si Chang $(\mathrm{n}=10+)$ (Meijaard 2003b).

Genus/species age 7.5 Mya/5.0 Mya

Habitat Prefers lowland dipterocarp and secondary forests; higher abundance in old secondary compared to primary forest, but not observed in young secondary or riverine forests (Nijman 1997); occasionally seen in plantations (Yasuma \& Andau 2000); found up to 1,700 m (Caldecott 1986); also found in coastal, swamp, dry land and montane forest (Caldecott 1986).

Activity Terrestrial and arboreal; less terrestrial than $M$. fascicularis (Whitten et al. 1987), although this probably depends on forest type; $50 \%$ of time on ground, and rest of time evenly distributed arboreally up to $30 \mathrm{~m}$ (Nijman 1997); but Caldecott (1986) found use of the ground $8.4 \%$, lower canopy $33.8 \%$, middle canopy $47.4 \%$, upper canopy 10.4\% (Caldecott 1986).

Movements and migration Home range 62-828 ha (Caldecott 1986); day range 2,000 $\mathrm{m}$ (Wrangham et al. 1983); males disperse at 5 years of age and remain solitary or peripheral to a group.

Feeding ecology Primarily frugivorous; fruit 88\%; leaves 22\% (Rodman 1978); $73.8 \%$ fruit and seeds, $12.2 \%$ animal prey (including insects, nestling birds, termite eggs and larvae, and river crabs), 5.4\% leaves, 3\% buds, $1.1 \%$ flowers (Caldecott 1986).

Social behaviour Multimale-multifemale matrilineal groups with matrilineal dominance hierarchy; fission/fusion (see footnote under Long-tailed Macaque); average group size of 36 (range 6-81) (Oi 1990), 15-40 (Caldecott 1986), but apparently also seen in larger $(>100)$ groups that are split into loosely-lined subgroups for foraging (Duckworth pers. obs.); ratio of 1 male to 5-8 females (Caldecott 1986).

Breeding ecology Polygynous; female age of first reproduction approximately 3.6 years (Hadidan \& Bernstein 1979) or 35 months (Caldecott 1986); interbirth interval approximately 1.1 years (Hadidan \& Bernstein 1979).

Habitat loss and degradation Nijman (1997) reported small differences in density between primary and old secondary (logged 40 years ago) forests in East 
Kalimantan; the differences were statistically not significant. The species is likely to be affected by deforestation.

Interspecific relationships No available information.

Conservation Status Not protected by Indonesian law. Included on CITES Appendix II. Listed as Vulnerable by IUCN (2002).

\section{Bornean Gibbon Hylobates muelleri}

Taxonomy Two species of Hylobates occur in Borneo, albibarbis in the area west of the Barito River and south of the Kapuas River, and muelleri in the rest of Borneo. On Borneo, three subspecies of $H$. muelleri occur, the nominate form in southeastern Borneo; H. m. funereus in Sabah, East Kalimantan, north of the Mahakam River, and perhaps part of northern Sarawak; and H. m. abbotti in western Borneo, north of the Kapuas River and east as far as the Saribas District in Sarawak (Groves 2001).

Global range Borneo, except southwest.

Population status and densities on Borneo Relatively common; between 250,000 and 375,000 individuals (Nijman \& Meijaard unpubl.). Densities vary between 2 and 2.6 groups $/ \mathrm{km}^{2}$ in Kayan Mentarang NP (Nijman 1997). In badly degraded and fragmented forests of Bukit Suharto Education Forest in East Kalimantan there were about 20 individuals in a $2.5 \mathrm{~km}^{2}$ area, suggesting highly compressed densities of 8 individuals $/ \mathrm{km}^{2}$ (Oka et al. 2000). Small degraded forest blocks, set within an agricultural matrix, and varying in size between 16 and 25 ha, contained between 3 and 6 individuals each (Oka et al. 2000).

Occurrence on small SE Asian islands Not known from offshore islands ( $\mathrm{n}=0$ ) (Meijaard 2003b).

Genus/species age 6.0 Mya/3.5 Mya.

Habitat, Prefers lowland forest, both primary and old secondary, but not young secondary (Nijman 1997); may visit riverine habitats but not resident (Nijman 1997); founds up to $1,500 \mathrm{~m}$ (Leighton 1987) or $1,700 \mathrm{~m}$ in Sabah (Yasuma \& Andau 2000).

Activity Diurnal; uses mid to high canopy (20-50 m) (Nijman 1997), but very occasionally seen on the ground to reach other forest areas (Yasuma \& Andau 2000).

Movements and migration During a 15 month study, Leighton (1987) found an average home range size of 36 ha (range 33-43 ha, $n=4$ ); sexually mature males and females emigrate from the natal group at 8-10 years of age to establish a new group (MacKinnon 1977).

Feeding ecology Frugivorous; 78\% of diet is fruit (Ungar 1995), 58\% fruit; 42\% leaves (Rodman 1978), 69\% fruit and flowers; 29\% leaves; 2\% invertebrates (Chivers 1992); prefers to eat small sweet fruits, especially figs, with nearly half of all feeding events concentrated on Ficus (Ungar 1995); most fruits are ripe, soft-seeded fruits with acidic, fleshy pericarps (Ungar 1995).

Social behaviour Monogamous; group sizes average 3.5 (ranging from 2-5 individuals) (Mitani 1992); groups composed of 1 male and 1 female with offspring; territorial. 
Breeding ecology monogamous; females first menstruate at 8 years of age, and bear their first young at 9 years (Carpenter 1940 in Oka et al. 2000); gestation period is 7 months; interbirth interval of every 2 or more years (Oka et al. 2000). From the limited amount of data available, there appears to be no birth seasonality or birth peak in the grey gibbon population. Usually a single young is born.

Habitat loss and degradation In East Kalimantan, gibbons were observed to be present in equal densities in old secondary (logged 45 years ago) and primary forest, but not in young secondary forest (logged 10-20 years ago); it was unclear to what extent these patterns could be explained by hunting (Nijman 1997). Elsewhere in East Kalimantan, Oka et al. (2000) found that gibbons survived in very high densities in small, degraded forest patches, decades after the area had been largely converted to agriculture and after several bouts of large forest fires. This suggests that gibbons can cope with some habitat disturbance and fragmentation.

Interspecific relationships May compete with other frugivores such as binturongs (also see Nettelbeck 1998).

Conservation Status Protected by Indonesian law. Included on CITES Appendix I. Listed as Lower Risk/near threatened by IUCN (2002).

\section{Hose's Leaf Monkey Presbytis hosei}

Taxonomy There about 11 species in the genus. Groves (2001) suggested that $P$. hosei ought to be divided into three species by raising the $P$. h. cancricus and $P$. $h$. sabana subspecies to specific rank. Preliminary craniometric analysis by Meijaard and Groves (unpubl.) confirmed significant differences between these subspecies.

\section{Global range North-east Borneo}

Population status and densities on Borneo Common; between 250,000 and 375,000 individuals (Nijman \& Meijaard unpubl.); higher densities and larger group sizes in primary forest than secondary (Nijman 1997); primary forest 2.3 groups $/ \mathrm{km}^{2}$; riverine forest 1.13 groups $/ \mathrm{km}^{2}$, old secondary 0.96 groups $/ \mathrm{km}^{2}$, young secondary 0.78 groups $/ \mathrm{km}^{2}$ (Nijman 1997); 4.25 groups $/ \mathrm{km}^{2}$ for lowlands and 3.6 groups $/ \mathrm{km}^{2}$ in uplands (Davies \& Payne 1982), 1.3 groups $/ \mathrm{km}^{2}$ in logged forest (Davies \& Payne 1982).

Occurrence on small SE Asian islands Not known from offshore islands $(\mathrm{n}=0)$ (Meijaard 2003b).

\section{Genus/species age 5.0 Mya/2.7 Mya.}

Habitat Lowland and hill dipterocarp forest, higher densities and larger group sizes in primary forest than secondary; occasionally enters plantations (Payne et al. 1985); found up to $1,000 \mathrm{~m}$ (MacKinnon 1986) and occasionally to 4,000 m (Medway 1969).

Activity Diurnal; majority of activity between 10-30 m from the ground (Mitchell 1994).

Movements and migration Home range size averages 34.5 ha in unlogged forest and 44.8 ha in logged forest (Mitchell 1994), but, according to Suzuki (1991), 120 ha in Kutai National Park; day range in primary forest averages 691 m (Mitchell 1994); day range in logged forest averages 794 m (Mitchell 1994). 
Feeding ecology Primarily folivorous; in primary forest selects $77.8 \%$ leaves, $16.7 \%$ seeds, $19.4 \%$ fruit, and 2.8\% flowers according to Mitchell (1994); Rodman (1978) found the following food selection in primary forest: 68\% leaves, $29 \%$ fruit, and 3\% other (Rodman 1978); in logged forest selects $59.7 \%$ leaves/ $21.3 \%$ seed/ $40.1 \%$ fruit/ $0.2 \%$ flowers (Mitchell 1994); recorded eating large number of seeds in Kutai, east Borneo (Leighton \& Leighton 1983).

Social behaviour Unimale groups; primary forest: 2.3 groups $/ \mathrm{km}^{2}$; riverine forest 1.13 groups $/ \mathrm{km}^{2}$, old secondary 0.96 groups $/ \mathrm{km}^{2}$, young secondary 0.78 groups $/ \mathrm{km}^{2}$ (Nijman 1997); 4.25 groups $/ \mathrm{km}^{2}$ for lowlands and 3.6 groups $/ \mathrm{km}^{2}$ in uplands (Davies \& Payne 1982); 1.3 groups $/ \mathrm{km}^{2}$ in logged forest (Davies \& Payne 1982); Average group size: 9.0 in undisturbed forest (Mitchell 1994), 7.0 in logged forest (Mitchell 1994), 6-8 individuals (Payne et al. 1985; Bennett \& Davies 1994), group size: 8.2 in primary forest, 7.5 in secondary forest, differences were not significant (Nijman 1997).

Breeding ecology Polygynous.

Habitat loss and degradation In Kayan-Mentarang National Park, East Kalimantan, Nijman (1997) found that $P$. hosei obtained their highest densities in primary forest, while he found significantly lower densities in riverine, old secondary and young secondary forests. It is unclear, however, whether density if primarily caused by forest disturbance, or more so by hunting (see Nijman in press). Davies and Payne (1982) found densities of 1.3 groups $/ \mathrm{km}^{2}$ in 19-year old logged forest, compared to 3.6-4.3 groups $/ \mathrm{km}^{2}$ in adjacent unlogged forest. Mitchell (1994) reported that $P$. hosei was absent from heavily logged forest.

Interspecific relationships Sympatric with Presbytis rubicunda. Both species have similar ecological requirements, but Hose's Leaf Monkey may be found more often in the upper canopy and emergents of a forest while Maroon Leaf Monkeys are more often found lower down (reported in Mitchell 1994).

Conservation Status Not protected by Indonesian law. Included on CITES Appendix II. Listed as Data Deficient by IUCN (2002).

\section{Maroon Leaf Monkey Presbytis rubicunda}

Taxonomy There about about 11 species in the genus, and 5 subspecies within the species (Groves 2001).

Global range Borneo and Karimata Island.

Population status and densities on Borneo Very common; estimated at $>1,000,000$ individuals by Nijman and Meijaard (unpubl.); density: 18.9 individuals $/ \mathrm{km}^{2}$ (Davies 1984); average density of 3 studies is 20.7 (van Schaik et al. 1992); average group density of 3 studies is 2.4 groups $/ \mathrm{km}^{2}$ (van Schaik et al. 1992); average group size: 7.0 (range 3-10) (Davies 1984); 6.1 (range 3-8) (Supriatna et al. 1986); average group size of 3 studies is 8.0 (van Schaik et al. 1992).

Occurrence on small SE Asian islands Karimata ( $\mathrm{n}=1$ ) (Meijaard 2003b).

Genus/species age 5.0 Mya/2.0 Mya.

Habitat Lowland dipterocarp, primary and secondary forest (MacKinnon 1986). Can live in certain plantations and may come out of forest into gardens to eat young leaves (Payne et al. 1985); Below 1,500 m (MacKinnon 1986). 
Activity Diurnal. Primarily arboreal, but sometimes descends to ground (Yasuma \& Andau 2000).

Movements and migration Home range size: 70-84.8 ha (Davies 1984); 0.71 $\mathrm{km}^{2}$ (Supriatna et al. 1986); average 64.5 ha of three studies (van Schaik et al. 1992); day range: $890 \mathrm{~m}$ (Davies 1984); average day range of 2 studies is $819 \mathrm{~m}$ (van Schaik et al. 1992).

Feeding ecology Granivorous, frugivorous/folivorous; 37.6\% leaves, 30.1\% seeds, $49.3 \%$ fruit, $11.1 \%$ flowers, and $1.1 \%$ others (Davies 1984), $61 \%$ of diet fruit and seeds (van Schaik et al. 1992). Ate seeds from 48 species of trees and lianas and whole fruits from 24 plant species. Leguminosae contributed more than any other plant family (Davies et al. 1988); Primates in general do not tend to exploit dipterocarp trees for food, but at Sepilok P. rubicunda was seen to eat the seeds and/or leaves from 6 dipterocarp species, including Shorea xanthophylla which contributed $7.8 \%$ of diet in August 1981 (Davies et al. 1988). Food from lianes accounted for a high percentage of the diet (32\%) (Davies 1991). Majority of fruit items (72\%) have thick pericarps; just over half (59\%) had no enclosed flesh. The cotyledons and germ cells were eaten. The remaining half had fibrous flesh, either dry or juicy. These were also largely exploited for their seeds (Davies 1991). Analyses imply that Red Leaf Monkeys select for leaves that are high in protein and low in digestibility-retarding fibre (Davies et al. 1988); seeds had very low levels of condensed tannins and low acid detergent fibre levels, with correspondingly high digestibility (Davies 1991); figs only contribute $1 \%$ of diet (Davies 1991); minor diet items $(<1 \%)$ include soil from termite mounds, bamboo pith, and insects (generally termites) (Bennett \& Davies 1994; Davies 1991).

Social structure One male harems/ extra male groups (Davies 1984); 88.9\% one male groups; $11.1 \%$ monogamous (Supriatna et al. 1986); Average group size: 7.0 (range 3-10) (Davies 1984); 6.1 (range 3-8) (Supriatna et al. 1986); Average of 3 studies is 8.0 (van Schaik et al. 1992).

Breeding ecology Unimale social system and a polygynous mating system (Davies 1987; Suprianta et al. 1986). Groups are composed of one adult male, one or more adult females, subadults, juveniles, and infants (Suprianta et al. 1986).

Habitat loss and degradation $P$. rubicunda appears to have a preference for primary forest (V. Nijman unpubl.).

Interspecific relationships No available information.

Conservation Status Not protected by Indonesian law. Included on CITES Appendix II. Not listed by IUCN (2002).

\section{Plantain Squirrel Callosciurus notatus}

Taxonomy 14 species in the genus (Corbet \& Hill 1992); Maryanto et al. (2002) reviewed the 49 Indonesian subspecies of $C$. notatus. Based on analysis of skull measurements and the study of skins they concluded that there is little variation in skull and dental characteristics among populations from Java and Kalimantan, and that many subspecies can be lumped together.

Global range Malay Peninsula and many nearby islands. Riau Archipelago, Sumatra, Bangka Island, Java, Borneo, Bali and Lombok. 
Population status and densities on Borneo Widespread in the lowlands and hills. Up to 1,700 m (Yasuma \& Andau 2000). Density in Ule Mudah Forest Reserve, Kedah, Peninsular Malaysia was 5.35 individuals $/ \mathrm{km}^{2}$ (Saiful \& Nordin 2004); density in Kayan Mentarang National Park, East Kalimantan was estimated at 8.1 individuals $/ \mathrm{km}^{2}$ (Yeager 1999).

Occurrence on small SE Asian islands Arends, Banggi, Bangka, Bangkaru, Basilan, Bawal, Bengkalis, Bintan, Bulan, Con Dao, Datuk, Dua, High, Jarak, Johore, Kaban, Krakatau, Kram, Lang Tengah, Lang, Mak, Malawali, Mapor, Mataha, Mendol, Merah, Mesan, Miang Besar, Midai, Mohea, N. Pagai, Nias, Nusa Barung, Padang, Panaitan, Panau, Panebangan, Pangkor, Payong, Pengiki, Pipidon, Redang, Samui, Sangalan, Setoko, Siantan, Siminul, Singapore, Sir John Malcolm, Siumat, Sribuat, Sullivan, Tana Bala, Tana Masa, Tebing Tinggi, Telibon, Temaju, Tinggi, Weh and West Perhentian $(n=60+)$ (Meijaard 2003b).

Genus/species age 7.5 Mya/4.0 Mya.

Habitat Most abundant around forest periphery or in patches of secondary growth where there is a greater proportion of low vegetation (MacKinnon 1978); generally not above $15 \mathrm{~m}$ arboreal height (63\%) (Whitten 1981). Rare in tall dipterocarp forests (Yasuma \& Andau 2000).

Activity Diurnal, most active in early morning and late afternoon (Yasuma $\&$ Andau 2000).

Movements and migration In Peninsular Malaysia, home ranges of $C$. notatus varied between $0.7 \pm 0.19$ ha for 4 adult males to $1.85 \pm 0.47$ ha for 6 adult females (Saiful et al. 2001).

Feeding ecology Opportunistic omnivore; large proportion of insects collected from mossy trunks (20\%), some bark (5\%), many leaves (15\%), flowers $(30 \%)$, variety of soft fruits (40\%) (MacKinnon 1978); primarily forages between 5 and 20 meters (mean = 13.5) (MacKinnon 1978).

Breeding ecology Hollow trees or construct nests of leaves and twigs in branches of trees or large bushes; nests situated at 25-30 m (MacKinnon 1978); three pregnant females, each with three embryos, collected in July (Davis 1962).

Habitat loss and degradation This species seems to be more common in disturbed habitats. The Penan people in Kayan Mentarang National Park refer to this species as puan bokken, which translated into English means 'regrowth forest squirrel' (Puri 1997). It appears to benefit from forest disturbance and thrives in gardens and plantations.

Interspecific relationships This medium-sized squirrel uses large trees, where the bigger species $C$. caniceps feeds in smaller trees; the latter species is more common in bushy areas (see Tamura 1995; Saiful et al. 2001).

Conservation Status Not listed by IUCN (2002). Not protected (lower concern) in Indonesia (PHPA 1996b).

\section{Prevost's Squirrel Callosciurus prevostii}

Taxonomy Corbet and Hill (1992) listed 17 subspecies of Callosciurus prevostii, but the validity of these needs to be investigated. 
Global range Malay Peninsula, Riau Archipelago, Sumatra, Borneo and Sulawesi (probably through human introduction).

Population status and densities on Borneo Density in Ule Mudah Forest Reserve, Kedah, Peninsular Malaysia was 3.29 individuals $/ \mathrm{km}^{2}$ (Saiful \& Nordin 2004). Primarily in lowlands, with the highest sighting on Mt. Kinabalu at $550 \mathrm{~m}$ (Yasuma \& Andau 2000).

Occurrence on small SE Asian islands Balembangan, Banggi, Bangka, Bangkaru, Dua, Kompei, Labuan, Lamukotan, Lang, Matak, Mohea, Nusa Barung, Padang, Palawan, Pemanggil, Sedanau, Serutu, Siantan, Sirhassen, Subi Kecil and Tampel $(\mathrm{n}=21)$ (Meijaard 2003b).

Genus/species age Unknown/Unknown.

Habitat High-canopy dweller. Spends most of its time in the main canopy between 25 and $30 \mathrm{~m}$ (MacKinnon 1978). Occurs in lowland dipterocarp forests, both in primary and secondary stands. Occasionally enters gardens and plantations (Yasuma \& Andau 2000).

Activity Diurnal.

Movements and migration No available information.

Feeding ecology Omnivorous; ate young leaves of leguminous trees such as Instia spp. and Koompassia spp. (MacKinnon 1978), Anacardiaceae, Annonaceae, Burseraceae, Euphorbiaceae, Lauraceae, Meliaceae, Myristicaceae, Oxalidaceae, Roseaceae, Sapindaceae, Leguminosae, and Simaroubaceae (Becker \& Wong 1985). Also, seen feeding on figs in Peninsular Malaysia, and known to eat eggs, buds, flowers, other vegetable matter, and insects, including ants, termites, and beetle larvae, although this is not the main staple of their diet (Heaney 1978).

Breeding ecology Pregnant female with two or three embryos collected in June and August (Davis 1962). Pregnancy rates in Peninsular Malaysia has been broadly related to the amount of rainfall (Wang 1964 in Hoffmann 2003).

Habitat loss and degradation May benefit from light forest disturbance, but would be vulnerable to deforestation. May benefit forest regeneration as they drop seeds of some tree species after eating the flesh from the fruit. They disperse these seeds by carrying them away from the parent tree, and the seeds may thus have a lower risk of being eaten compared to ones that are found beneath the parent tree (Becker et al. 1985).

Interspecific relationships Ecological separation of Prevost's squirrel from Giant Squirrel (Ratufa affinis, see below) is along food parameters (Giant Squirrel can eat more hard fruits and does not eat figs).

Conservation Status Not listed by IUCN (2002). Not protected in Indonesia (PHPA 1996b).

\section{Three-Striped Ground Squirrel Lariscus insignis}

Taxonomy Ten subspecies have been described for the species, but only a few seem valid (Corbet \& Hill 1992). On Borneo, L. insignis diversus occurs.

Global range Malay Peninsula and several small nearby islands. Riau Archipelago, Sumatra, Java, Borneo (Nowak 1999); widespread and common. 
Population status and densities on Borneo 0.6-1.9 individuals/ha (Harrison 1969); widespread and common.

Occurrence on small SE Asian islands Bintan, N. Pagai, Penang, Siantan, Singapore, Tana Bala and Tioman ( $\mathrm{n}=7$ ) (Meijaard 2003b).

Genus/species age 7.5 Mya/Unknown.

Habitat Tall and secondary forests (Payne et al. 1985); uses burrows to escape when alarmed (Lekagul \& McNeely 1977); most inhabit mountain elevations at 910-1,510 m according to Nowak (1999), but this may be erroneous as others consider it a lowland species (e.g., Yasuma \& Andau 2000).

Activity Strictly terrestrial (in Whitten 1981); only seen on ground or on fallen wood lying on ground (MacKinnon 1978).

Movements and migration In Peninsular Malaysia, home ranges of L. insignis varied between 0.13 ha for 1 adult female to 4.18 ha for 1 adult male (Saiful et al. 2001).

Feeding ecology Feeds on fruit, plant and insect material (MacKinnon 1978; Payne et al. 1985; Whitten 1981).

Breeding ecology Constructs nest in fallen logs (Nowak 1999); pregnant female with two embryos collected in July (Davis 1962).

Habitat loss and degradation Appears to be sensitive to forest disturbance, especially to changes in its terrestrial habitat. Mechanism of this is poorly understood.

Interspecific relationships No available information.

Conservation Status Not listed by IUCN (2002). Protected in Indonesia (PHPA 1996b).

\section{Four-striped Ground Squirrel Lariscus hosei}

Taxonomy 3 species in the genus; no subspecies within L. hosei (Corbet \& Hill 1992).

Global range Endemic to Borneo.

Population status and densities on Borneo No available information.

Occurrence on small SE Asian islands Not known from offshore islands $(\mathrm{n}=0)$ (Meijaard 2003b).

Genus/species age 7.5 Mya/Unknown.

Habitat Patchily distributed in primary and secondary forests (Payne et al. 1985).

Activity Terrestrial and diurnal (Payne et al. 1985); they are seldom found in trees and construct their nests in fallen logs. It is said that $L$. hosei frequents the banks of jungle streams (Nowak 1999).

Movements and migration No available information.

Feeding ecology Diet includes fruit and insects (Payne et al. 1985).

Breeding ecology A pregnant female $L$. hosei, with two embryos, was collected on 25 July in northern Borneo (Davis 1962).

Habitat loss and degradation The species seems to be sensitive to logging disturbance; it was found in unlogged forest, but not in forest that was recently logged or in 2- and 4-year old logged forest (Dahaban et al. 1996). 
Interspecific relationships No available information.

Conservation Status Listed as Vulnerable by IUCN (2002).

\section{Red Giant Flying Squirrel Petaurista petaurista}

Taxonomy Ten subspecies have been described within the species (Corbet \& Hill 1992), 3 of which occur on Borneo, i.e., P. p. rajah in Sabah and Sarawak, but not around the Sandakan Bay where $P . p$. nigrescens occurs; $P$. $p$. lumboltzi occurs in the rest of Borneo (Payne et al. 1985).

Global range Northern Afghanistan and Kashmir, through the Himalayan foothills to Yunan, south through Burma and Thailand to the Malay Peninsula, Riau Archipelago, Sumatra, Java, Borneo, and Natuna Islands.

Population status and densities on Borneo Generally found in pairs (Medway 1978).

Occurrence on small SE Asian islands Bunguran, Nusa Kembangan and Rupat $(\mathrm{n}=3)$ (Meijaard 2003b).

Genus/species age Unknown/Unknown.

Habitat Occurs both in primary and secondary forest, and is also found in open areas with only a few trees, gardens and plantations (Payne et al. 1985).

Activity Nocturnal and arboreal; using gliding flight to travel between trees; uses upper canopy at heights 15-30 m (Nowak 1999); rests in tree cavities during the day.

Movements and migration Most Petaurista occur above $900 \mathrm{~m}$, but in spring they have been observed at lower altitudes; possibly a migration of short duration at a time when the trees of lower altitudes would provide choice leaflets and flower buds not yet available at higher altitudes. This species can make continuous glides of about 100 m (Payne et al. 1985).

Feeding ecology Folivore.

Breeding ecology Nest occupied permanently by mated pairs (Nowak 1999); usually give birth to one young, occasionally two (Mitchell 1979); a lactating female taken in June (Davis 1962); litter size = 1; breeds infrequently and the single young requires a long time for full development (3-4 months or more).

Habitat loss and degradation High densities may occur in areas of severe cutting (Meijaard pers. obs.), but high density estimates in such areas may also be the result of increased visibility, especially when animals glide between trees shortly before dusk. In southern India, the species appeared to increase in density with increasing forest disturbance (Umapathy \& Kumar 2000), although this may also have been the effect of the reduced densities of other arboreal species in those fragments. Muul and Lim (1978) and Syakirah et al. (2000) found that these flying squirrels can thrive in modified habitat, provided the tall trees in which they nest are not cut down.

Interspecific relationships Replaced at higher elevations and in primary forest by Petaurista elegans.

Conservation Status Not listed by IUCN (2002). Not listed by CITES (ARCBD 2002). Not protected in Indonesia (PHPA 1996b). 


\section{Pale Giant Squirrel Ratufa affinis}

Taxonomy 11 subspecies have been described for this species (Corbet \& Hill 1992).

Global range Malay Peninsula, Riau Archipelago, Sumatra, islands west off Sumatra, Borneo.

Population status and densities on Borneo 11 individuals $/ \mathrm{km}^{2}$ (MacKinnon et al. 1996); density in Ule Mudah Forest Reserve, Kedah, Peninsular Malaysia 1.3 individuals $/ \mathrm{km}^{2}$ (Saiful \& Nordin 2004).

Occurrence on small SE Asian islands Banggi, Bangka, Batam, Belitung, Bintan, Bulan, Bunguran, Karimata, Karimon, Kundur, Labuan, Laut (Natuna Isl.), Laut (SE Borneo), Lingga, Musala, Panebangan, Pinie, Sebuku, Singapore, Singkep, Sirhassen, Sugi, Talang, Tana Bala, Tana Masa and Tuangku ( $\mathrm{n}=26)$ (Meijaard 2003b).

Genus/species age 30.0 Mya/Unknown.

Habitat Travels extensively in main upper canopy, also frequently in lower canopy; Rarely seen on ground (MacKinnon 1978); moves to ground only to chase another squirrel or follow female during breeding season (Nowak 1999), or to cross large gaps in the tree canopy (Payne et al. 1985); mean height use of 23 meter (MacKinnon 1978).

Activity Diurnal; uses holes in trees for shelter (Nowak 1999).

Movements and migration No available information.

Feeding ecology Primarily frugivorous; specialises in relatively large seeds with hard testas (Leighton \& Leighton 1983); fruits, nuts, bark of some trees, insects and bird's eggs (Nowak 1999); soft and hard fruits, some proportion of leaves (MacKinnon 1978); not seen eating figs, but did eat fibrous fruit of Grewia latifolia, which was not eaten by other squirrels, but highly favoured by primates (MacKinnon 1978); observed feeding on dipterocarp fruits (Dipterocarpus confertus and Shorea beccarianna) (Gould \& Andau 1989).

Breeding ecology Large globular nest about the size of an eagle's nest constructed in tree branches (Nowak 1999); young are born and raised in these nests (Nowak 1999); 1-2 young weighing about $77 \mathrm{~g}$ (Nowak 1999).

Habitat loss and degradation This species was only seen in forest areas with a high and closed canopy during small mammal surveys in various areas in Peninsular Malaysia (Syakirah et al. 2000). Also, Banks (1949) reported that the species is found in old jungle only, never in secondary jungle, orchards or plantations, and most studies suggest that the species is negatively affected by logging.

Interspecific relationships No available information.

Conservation Status Not listed by IUCN (2002). Listed on Appendix II of CITES (ARCBD 2002). Not protected in Indonesia (PHPA 1996b).

\section{Horse-tailed Squirrel Sundasciurus hippurus}

Taxonomy 9 species in the genus, and 3-5 subspecies within the species (Corbet $\&$ Hill 1992).

Global range Malay Peninsula, Riau Archipelago, Sumatra and Borneo.

Population status and densities on Borneo Density in Ule Mudah Forest Reserve, Kedah, Peninsular Malaysia was 3.93 individuals $/ \mathrm{km}^{2}$ (Saiful \& Nordin 2004). 
Occurrence on small SE Asian islands Not known from offshore islands $(\mathrm{n}=0)$ (Meijaard 2003b).

Genus/species age 11.0 Mya/Unknown.

Habitat Primary lowland forest, where it spends equal time on forest floor, lower/middle canopy, and upper canopy (MacKinnon 1978).

Activity Diurnal; seen mostly about 3-12 m up in the forest (Davis 1962); demonstrates more even use of all levels of the canopy and ground than other sympatric squirrels (MacKinnon 1978).

Movements and migration No available information.

Feeding ecology Predominantly large hard fruits collected in the upper canopy, but carried in mouth for long distances, often along the ground (MacKinnon 1978); possibly makes food caches (MacKinnon 1978).

Breeding ecology No available information.

Habitat loss and degradation Absent in newly logged and 2-year old logged forest, but present in 4-year old logged forest (Dahaban et al. 1996). Yeager (1999) reported that in the upper Kapuas and upper Mahakan area this species was abundant (41 individuals $/ \mathrm{km}^{2}$; after Istiadi et al. 1994), but that it had never been observed around the field centre in Kayan Mentarang National Park. Rijksen (1978) noted a $50 \%$ decline in slightly disturbed forest compared to undisturbed forest. Also, Banks (1949) reported that the species is found in old jungle only, never in secondary jungle, orchards or plantations.

Interspecific relationships No available information.

Conservation Status Not listed by IUCN (2002). Not listed by CITES (ARCBD 2002). Not protected in Indonesia (PHPA 1996b).

\section{Low's Squirrel Sundasciurus lowii}

Taxonomy 9 species in the genus, and 4 subspecies within the species (Corbet $\&$ Hill 1992).

Global range Found in Malaya, Sumatra, and Borneo (Corbet \& Hill 1992).

Population status and densities on Borneo Recorded on Borneo throughout the lowlands and hills, up to $1,400 \mathrm{~m}$, but usually below $900 \mathrm{~m}$. Also on some islands (Payne et al. 1985). Density in Ule Mudah Forest Reserve, Kedah, Peninsular Malaysia, where it was the most common squirrel was 13 individuals $/ \mathrm{km}^{2}$ (Saiful \& Nordin 2004).

Occurrence on small SE Asian islands Balembangan, Banggi, Bunguran, Kundur, Labuan, Lagong, Laut, Lingung, N. Pagai, Pinie, S. Pagai, Siberut, Sipura, Sirhassen and Tana Bala $(\mathrm{n}=15)$ (Meijaard 2003b).

Genus/species age 11.0 Mya/Unknown.

Habitat Found in tall forest on or near the ground, rarely being seen high in the trees (Medway 1969; Lekagul \& McNeely 1977); prefers primary mixed forest (Whitten 1981). Most active on tree trunks of the lower forest levels (MacKinnon 1978).

Activity Diurnal, most active in the early morning and late afternoon (Payne et al. 1985); forages in terrestrial and lower strata to $5 \mathrm{~m}$; Davis (1962) reports that this 
species was never seen above $3 \mathrm{~m}$; MacKinnon (1978) working in Malaya notes all sightings below $15 \mathrm{~m}$, with $65 \%$ below $7.5 \mathrm{~m}$, and $5 \%$ on the ground; rarely travels between trees through canopy, reaching trees instead from saplings, undergrowth, the ground, or by leaping between trunks = $7 \mathrm{~m}$ above ground (Whitten $\&$ Whitten 1987).

Feeding ecology Insects and fruit (Davis 1962; Harrison 1962a); bark (49\%), moss, lichen, and insects (39\%) (Whitten 1981); selectivity demonstrated in bark feeding. The most common families used are significantly different from the number expected if feeding had been equally distributed among the families present on Siberut Island (Whitten \& Whitten 1987); feeding and the amounts of lichens and vines on trees negatively correlated. The presence of many vines on trees may lessen exposure of bark and may discourage feeding (Whitten \& Whitten 1987).

Breeding ecology Pregnant or lactating females have been taken in Borneo in June and August; known litter size is 2-3.

Habitat loss and degradation Appears to benefit from selective logging (Dahaban et al. 1996; Wells 2002).

Conservation Status Not listed by IUCN (2002). Not listed by CITES (ARCBD 2002). Not protected in Indonesia (PHPA 1996b).

\section{Slender Squirrel Sundasciurus tenuis}

Taxonomy 9 species in the genus and 7 subspecies within the species (Corbet \& Hill 1992).

Global range PeninsularThailand and Malaya, Sumatra, and Borneo (Sundaland endemic (Corbet \& Hill 1992).

Population status and densities on Borneo Widespread on Borneo; no information on densities.

Occurrence on small SE Asian islands Bangkaru, Batam, Jimaja, Labuan, Lingga, MoburMusala, Redang, Siantan, Singapore, Tana Bala, Tana Masa and Tioman $(\mathrm{n}=13)$ (Meijaard 2003b).

Genus/species age 11.0 Mya/Unknown.

Habitat occurs in tall and secondary forests in lowlands and lower mountains up to 1,650 m; primarily active in small trees (Payne et al. 1985). Most active on tree trunks of the lower forest levels (MacKinnon 1978; Meijaard pers. obs.)

Activity diurnal (Meijaard pers. obs.; Yasuma \& Andau 2000)

Movements and migration No available information

Feeding ecology Diet included much bark and sap, also insects, fruits and seeds (Payne et al. 1985; MacKinnon et al. 1996).

Breeding ecology No available information.

Habitat loss and degradation Possibly benefits from some disturbance (see Bennett \& Dahaban 1995).

Interspecific relationships The Slender Squirrel appears to be replaced ecologically by Jentink's squirrel, S. jentinki, in the mountain ranges of northern and central Borneo (Payne et al. 1985).

Conservation Status Not listed by IUCN (2002). 


\section{Shrew-Faced Ground Squirrel Rhinosciurus laticaudatus}

Taxonomy Monotypic genus with 3 subspecies (Corbet \& Hill 1992).

Global range Peninsular Malaysia, Sumatra, Borneo, and several smaller islands (Corbet \& Hill 1992).

Population status and densities on Borneo No available information.

Occurrence on small SE Asian islands Batam, Batan, Bintan, Bunguran, Karimon, Kundur, Lingga, Siantan, Singapore, Sirhassen, Tioman and Tuangku $(\mathrm{n}=12)$ (Meijaard 2003b).

Genus/species age 9.0 Mya/7.0 Mya.

Habitat terrestrial.

Activity diurnal (Yasuma \& Andau 2000).

Movements and migration No available information.

Feeding ecology primarily feeds on insects on fallen wood (MacKinnon 1978); these primarily include large ants, termites, and beetles, but they also eat fruit (Yasuma \& Andau 2000).

Breeding ecology No available information.

Habitat loss and degradation Seems to be negatively affected by logging, and would suffer considerably from deforestation.

Interspecific relationships No available information.

Conservation Status Not listed by IUCN (2002).

\section{Binturong Arctictis binturong}

Taxonomy Single species, with 2 or 3 recognised subspecies; on Borneo $A$. binturong.

Global range From Sikkim to Indochina and the Malay Peninsula, Riau Archipelago, Sumatra, Bangka, Java, Borneo and Palawan.

Population status and densities on Borneo Sighting frequency in primary forest: 1.7 individuals/km trail; nowhere abundant (Nowak 1999); occurs alone or in a small group of adults with immature offspring.

Occurrence on small SE Asian islands Bangka, Batam, Bintan, Kundur, Nias, Palawan, Payong, Tebing Tinggi and Tioman $(\mathrm{n}=9)$ (Meijaard 2003b).

Genus/species age 10.8 Mya/Unknown.

Habitat Dense forests. In Thailand, two animals spend $100 \%$ of their time in semi-evergreen/mixed deciduous forest (Austin \& Tewes 1999).

Activity Arboreal, but also occasionally terrestrial; cathemeral (=active day and night) or nocturnal.

Movements and migration In Thailand, females used a range of approximately $6 \mathrm{~km}^{2}$, with a core area (85\% of locations) of only $1.5 \mathrm{~km}^{2}$. Males used an area of ca. $9.5 \mathrm{~km}^{2}$ (Austin \& Tewes 1999).

Feeding ecology Frugivorous (Heydon \& Bulloh 1996), but also feeding on birds, carrion, leaves, and shoots (Nowak 1999). A scat in Thailand contained only seeds of fig (Ficus sp.) trees (Austin \& Tewes 1999), which is similar to the stomach contents of a binturong mentioned in Rozhnov (1974 in Austin \& Tewes 1999). See also Nettelbeck (1997) for discussion about massive use of fig trees. 
Breeding ecology Breeding seems to occur throughout the year (Lekagul \& McNeely 1977); in captivity, females are non-seasonally polyestrous and may give birth to two litters annually (Nowak 1999); in captivity, the oestrous cycle averages 81.8 days; mean gestation $=91.1$ days; number of young $/$ litter $=1.98$; weaning at 6-8 weeks; sexually mature at 30.4 months for females and 27.7 months for males; sexually active at least 15 years (Nowak 1999).

Habitat loss and degradation Sighting frequency higher in logged forest than in primary forest (2.4 individuals/km trail), but differences were not significant (Heydon \& Bulloh 1996).

Interspecific relationships May experience competition for fruit from gibbons (Nettelbeck 1998).

Conservation Status Not listed by IUCN (2002). Listed on Appendix III of CITES (ARCBD 2002). Protected in Indonesia (PHPA 1996b).

\section{Banded Civet Hemigalus derbyanus}

Taxonomy Two species, although Hose's Civet Diplogale hosei is often included in Hemigalus (Corbet \& Hill 1992; cf. Payne et al. 1985), and Owston's Banded Civet Chrotogale owstoni is usually separated out; genus is therefore often regarded as monospecific. 3 subspecies are recognised, but those in Malaya, Sumatra, and Borneo do not seem to be separable (Corbet \& Hill 1992).

Global range Tenasserim, Malay Peninsula, southern Thailand, Sumatra, Mentawai Islands and Borneo.

Population status and densities on Borneo Recorded in many localities in the lowlands and hills (Payne et al. 1985).

Occurrence on small SE Asian islands S. Pagai and Sipura $(n=2)$ (Meijaard 2003b); these island forms are possibly a distinct species (Screiber et al. 1989).

Genus/species age 11.5 Mya/Unknown.

Habitat Occurs in tall and secondary forests (Payne et al. 1985).

Activity Nocturnal (Davis 1962; Heydon \& Bulloh 1996); largely terrestrial (Medway 1978); at least partly arboreal and climbs well (Lekagul \& McNeely 1977).

Movements and migration Travels and feeds mostly on the ground, but sleeps in holes either in the ground or in trees (Payne et al. 1985).

Feeding ecology Carnivorous (>95\% animal matter) (Heydon \& Bulloh 1996): orthopterans and worms (80\%), and the remaining 20\% consisting mostly of other invertebrates (Nowak 1999); rats (Maxomys rajah), seeds, Brachyura, Chilopoda, Annelida, Coleoptera, Araneae, and composite flowers (Colón 1999).

Breeding ecology Pregnant female with one embryo taken in Borneo in February (Nowak 1999); in captivity eyes open at 8-12 days; first solid food at about 70 days (Ewer 1973).

Habitat loss and degradation Sighting frequencies in 6-year-old logged forest were only $15 \%$ of those in primary forest (Heydon \& Bulloh 1996).

Interspecific relationships No available information.

Conservation status Appendix II of CITES; not well known but probably adversely affected by commercial logging and direct killing by people who consider 
them predators on domestic chickens (Nowak 1999). Not listed by IUCN (2002). Not protected in Indonesia (PHPA 1996b).

\section{Masked Palm Civet Paguma larvata}

Taxonomy Only species in its genus with 13 described subspecies, one of which (P. $l$. leucocephala) occurs on Borneo (Corbet \& Hill 1992).

Global range Northern Pakistan and Kashmir to Indochina and Malay Peninsula, much of southern and eastern China, Andaman Islands, Taiwan, Hainan, Sumatra and Borneo.

Population status and densities on Borneo Payne et al. (1985) reported that the species mostly occurs in the north of Borneo, with the southernmost records from G. Liang Kubung in West Kalimantan and the upper Mahakan River in East Kalimantan. A specimen from Barito River (van Strien 2001) suggests, however, that south Borneo is part of the range. Also records from south of the Mahakan River (G. Frederiksson in litt to Meijaard), and Mahakam Lakes (Gönner 1997); probably also throughout West Kalimantan (Blundell 1996; Jeanes \& Meijaard 2000; Simons 1987).

Occurrence on small SE Asian islands Not known from offshore islands $(\mathrm{n}=0)$ (Meijaard 2003b).

Genus/species age Unknown/Unknown

Habitat Occurs in lowland dipterocarp and lower montane forests, in both primary and secondary stands (Azlan 2003; Yasuma \& Andau 2000); sometimes enters plantations to feed (Yasuma \& Andau 2000).

Activity partly arboreal; not infrequently forages and commutes on the ground; nocturnal; peak of activity between 19.30 and 22.30 (Rabinowitz 1991); nests in upper canopy (Rabinowitz 1991); no evidence of use of other animal's nests (Rabinowitz 1991); do not regularly return to day bed sites (Rabinowitz 1991); day beds found close to streams (Rabinowitz 1991); when found resting on ground, in areas with 80-90\% ground cover (Rabinowitz 1991).

Movements and migration Home range mean $=0.93 \mathrm{~km}^{2}$ (Rabinowitz 1991); a female ranged over $3.7 \mathrm{~km}^{2}$ (Rabinowitz 1991); variable depending upon food availability (Joshi et al. 1995; Rabinowitz 1991); considerable overlap with congenerics (Joshi et al. 1995). In general, monthly home ranges, home range centre shifts, and activity radii showed a linear increase with weight and size of individuals (Rabinowitz 1991); although overall home ranges showed considerable overlap, monthly home ranges were more restricted and did not overlap (Rabinowitz 1991); evidence suggests that civets may be concentrating their movements around particular feeding areas during times of fruit abundance (Rabinowitz 1991); mean daily movement $620 \mathrm{~m}$ (Rabinowitz 1991); mean monthly activity radius $484 \mathrm{~m}$ (Rabinowitz 1991); mean home range centre shift 320 m (Rabinowitz 1991).

Feeding ecology Animal matter makes up 60-90\% of diet (Heydon \& Bulloh 1996), mostly rodents with evidence of insects, insectivores, snakes, lizards, birds, and grass. Also feeds on fruit. Transects for fruiting tree species indicated that the four tree species found most often in civet faeces (60\%) accounted for only $22 \%$ of the trees encountered on transects (Rabinowitz 1991). 
Breeding ecology Raises young in tree holes in Nepal (Nowak 1999); births in Borneo in October (Nowak 1999); breeding season corresponds with the longer of two rainy seasons in Thailand (Lekagul \& McNeely 1977), but this may not be relevant for Borneo; litters contain 1-4 young (Nowak 1999); reaches almost adult size by 3 months (Lekagul \& McNeely 1977).

Habitat loss and degradation Insufficient data; present in both logged and unlogged forest, but sighting frequency too low to evaluate effects (Heydon \& Bulloh 1996).

Interspecific relationships Reported to disperse seeds of a variety of species (reported in Payne et al. 1985).

Conservation Status Conservation Status Not listed by IUCN (2002). Listed on Appendix III of CITES (ARCBD 2002). Not protected in Indonesia (PHPA 1996b).

\section{Common Palm Civet Paradoxurus hermaphroditus}

Taxonomy Four species in genus; with $P$. hermaphroditus being the most widespread of them, the other having distribution ranges in the Mentawai Islands, south-west India, and Sri Lanka. Corbet and Hill (1992) recognise 23 subspecies two of which, $P$. $h$. baritensis and P. h. sabanus occur on Borneo. The species needs a taxonomic review.

Global range All of mainland Southeast Asia, Malay Peninsula, Hainan, Sumatra, Java, Borneo and Palawan.

Population status and densities on Borneo Generally widespread and capable of living in close proximity to human habitation.

Occurrence on small SE Asian islands Alange, Babi Island, Balabac, Banggi, Bangka, Bawean, Bedung, Belitung, Clara, Datuk, Iyan, Karimata, Kateman, Ketam, Kissaraing, Klum, Kram, Kundur, Lagong, Lang, Lingga, Lingung, Mohea, Nias, Padang, Palawan, Payong, Phuket, Pipidon, Redang, Simeulue, Singkep, Sirhassen, St Barbe, Tambelan, Tavoy, Teibeianbesar, Terutau, Tinggi and Wai $(n=40+)$ (Meijaard 2003b).

Genus/species age 4.9 Mya/Unknown.

Habitat On Borneo it occurs in secondary forests, plantations, and gardens, rarely in primary forests (Payne et al. 1985), although elsewhere, e.g., Laos, it does use primary forests.

Activity Nocturnal; arboreal and terrestrial (Duckworth 1997b); utilizes cavities and secluded nooks (Nowak 1999); in Nepal, activity began at ca. 18.00 and ended at ca. 04.00 (Joshi et al. 1995); in Nepal, more active on dark nights than bright, moonlit nights (Joshi et al. 1995); during the day found resting in trees covered with heavy vines $(63 \%)$; also in tree cavities $(21 \%)$, but less so than in trees with vines or holes $(16 \%)$. The extremely dense vines may restrict access to civets by arboreal predators and raptors (Joshi et al. 1995); day beds usually in trees (86\%) and usually near water (Rabinowitz 1991); resting sites uniformly distributed through study area, so not clear whether availability of resting sites had a major influence on foraging patterns. Animals foraged until just before dawn and chose nearby resting site (Joshi et al. 1995); peak of activity between 19.30 and 01.30 (Rabinowitz 1991). 
Movements and migration In Thailand, variable depending upon food availability (Joshi et al. 1995; Rabinowitz 1991); in Nepal, home range size varied with food availability (Joshi et al. 1995); considerable overlap with congenerics (Joshi et al. 1995); In general, monthly home ranges, home range centre shifts, and activity radii showed a linear increase with weight and size of individuals (Rabinowitz 1991); in Nepal, mean total home range was 14.1 ha (Joshi et al. 1995); home range size in mixed, deciduous and dry, evergreen forest in Thailand was 21 times greater than in Nepal (Rabinowitz 1991); although overall home ranges showed considerable overlap, monthly home ranges were more restricted and did not overlap (Rabinowitz 1991); evidence suggests that these civets may be concentrating their movements around particular feeding areas during times of fruit abundance. (Rabinowitz 1991; average monthly range $0.72 \mathrm{~km}^{2}$ (Rabinowitz 1991); during fruit abundance, high activity within a restricted area (Rabinowitz 1991).

Feeding ecology Primarily frugivorous; opportunistic, consuming a variety of plant and animal material (Joshi et al. 1995); in Nepal, $84.5 \%$ of scats contained seeds of fruit (Joshi et al. 1995); in Nepal, shift in diet from fruits to vertebrate and invertebrate taxa when fruits not readily available (Joshi et al. 1995); in Nepal, also fed on nectar from Bombax ceiba and sap from stems of Vallaris solanacea (Joshi et al. 1995); in Sabah, fruit accounted for 45\% of food bulk (Heydon \& Bulloh 1996); transects for fruiting tree species indicated that the four tree species found most often in civet faeces (60\%) accounted for only $22 \%$ of trees encountered on transects (Rabinowitz 1991); generally sugar-rich and soft pulped (Rabinowitz 1991); in Sabah, fruit (Connarus sp.), fruit, seeds, leaves, Annelida, Chilopoda, Araneae, Brachyura, and animal muscle tissue and fat (Colón 1999); in Thailand, palm civets (not identified to species level, either Paguma or Paradoxurus) were shown to feed primarily on fruits of Ficus sp. (24\%), Passiflora foetida (20\%), and Polyalthia sp. (18\%), with $17 \%$ of the faeces containing insect remains (Grassman 1998).

Breeding ecology Gestation period: 60 days (Hayssen et al. 1993); sexual maturity reached 11-12 months (reported in Nowak 1999).

Habitat loss and degradation 30\% reduction in 6-year-old logged forest (Heydon \& Bulloh 1996), but Stuebing and Gassis (1989) found the species exclusively in plantation areas and not in logged forest.

Interspecific relationships Reported to disperse seeds of a variety of plant species (Payne et al. 1985); in Nepal, preyed on by large carnivores (Joshi et al. 1995); predation highest during terrestrial foraging, so individuals retreat to cover in the canopy as soon as possible after feeding (Joshi et al. 1995).

Conservation Status Not listed by IUCN (2002). Listed on Appendix III of CITES. Not protected in Indonesia (ARCBD 2002).

\section{Small-Toothed Palm Civet Arctogalidia trivirgata}

Taxonomy The genus is monospecific, and 7 subspecies have been described based on minor features of pelage and size (Corbet \& Hill 1992). 
Global range The species occurs from Assam, Yunnan and Indochina to Malaya, Sumatra, Borneo and a range of small islands. The population in west Java may need to be assigned to a different species (Schreiber et al. 1989).

Population status and densities on Borneo Heydon and Bulloh (1996) reported a sighting frequency of $2.1 \pm 2.1$ animals $/ 100 \mathrm{~km}$ of transect in primary forest, but numbers were too low to estimate a density from this.

Occurrence on small SE Asian islands Banggi, Bangka, Batam, Belitung, Bintan, Bulan, Bunguran, Galang, Kundur, Langkawi, Lingga, Pinie, Singapore, Singkep, Sugi, Tebing Tinggi, Terutau and Tioman. $(n=18)$ (Meijaard 2003b) (but note that this rarely observed species may be underreported).

Genus/species age 4.9 Mya/Unknown.

Habitat Evergreen forest, with no records from deciduous forests (Duckworth 1997b; Rabinowitz 1991). There are records from 1,500 m on Borneo (Payne et al. 1985).

Activity Animals are entirely arboreal; in Laos no animals were ever observed on the ground, and only one was seen in the canopy (Duckworth 1997b). Species appears to be nocturnal (Duckworth 1997b; Lekagul \& McNeely 1977; Payne et al. 1985; Walston \& Duckworth 2003). In Laos, 6 groups of 2 were seen, compared with 28 singles (Duckworth 1997b).

Movements and migration They are active climbers and leap from branch to branch with considerable agility.

Feeding ecology Diet includes fruits and small animals (Payne et al. 1985). Lekagul and McNeely (1977) described the species as omnivorous, feeding on live prey such as squirrels and birds, but also taken various kinds of fruit, insects, beetles, and frogs.

Breeding ecology Young are reared in hollow trees; litter size seems to be 2 or 3 , and there are probably 2 litters per year (Yasuma \& Andau 2000).

Habitat loss and degradation In Thailand, the species was mostly found in primary forests far from human villages (Lekagul \& McNeely 1977), but Duckworth (1997b) reported that this was not the case in Laos where the species was also found in some severely degraded forests. Data by Heydon \& Bulloh (1996) and Syakirah et al. (2000) suggest that in Borneo the species declined slightly following logging. According to Yasuma \& Andau (2000), the species often enters plantations to feed on fruit.

Interspecific relationships No available information.

Conservation Status Probably little threatened by hunting and trapping because of its strictly arboreal and nocturnal behaviour (Walston \& Duckworth 2003).

\section{Malay Civet Viverra tangalunga}

Taxonomy Two subgenera and four species, with little variation in $V$. tangalunga itself.

Global range Borneo, the Philippines, Sumatra, Riau Archipelago (Nowak 1999).

Population status and densities on Borneo 24.4 individuals $/ 100 \mathrm{~km}$ in primary forest (Heydon \& Bulloh 1996). 
Occurrence on small SE Asian islands Banggi, Bangka, Belitung, Bintan, Bunguran, Karimata, Kundur, Langkawi, Laut (Natuna Isl.), Laut (SE Borneo), Lingga, Palawan, Panebangan, Penang, Rupat and Singapore $(\mathrm{n}=16)$ (Meijaard 2003b).

Genus/species age 13.3 Mya/5.6 Mya.

Habitat Tall primary forest but able to persist in disturbed forest; prefers dense vines, i.e., structural complexity to provide suitable day bed sites.

Activity Terrestrial; nocturnal, generally solitary; day beds located exclusively on the ground in well drained sites (Colón 1999); may live in holes in the ground dug by other animals (Nowak 1999); day beds located either below fallen trees, inside dense vine tangle or within dense ground vegetation near forest edge. Day beds located exclusively on ground in well-drained sites (Colón 1999).

Movements and migration Most of home range used for both foraging and resting (Colón 1999); day ranges (resting areas) and night ranges (foraging areas) not significantly different (Colón 1999); overall daily activity level of 52.0\%. Mean nocturnal activity was 80.9\%; mean diurnal activity level 21.2\% (Colón 1999); nightly activity not continuous, but interrupted by intervals of lower activity, such as rest (Colón 1999); home range: 110.3 ha (Colón 1999); home range mean of males not statistically different than females (Colón 1999); territoriality: extensive home range overlap among individuals in unlogged and logged forests (Colón 1999); males show less home range overlap than females, and overlap within genders is less than overlap between genders (Colón 1999); does not regularly patrol home range boundaries, and thus is probably not territorial. However, individuals are more hyperdispersed than would be expected by chance, indicating that they actively avoid one another when selecting day bed sites (Colón 1999). Daily vs. monthly vs. seasonal movement patterns: seasonal shifts in home range size and location during high and low rainfall reflecting seasonal changes in availability of resources in seasonal forest (Rabinowitz 1991); in aseasonal forest, home range size or location not correlated with rainfall (Colón 1999); no significant difference in home range between genders, although mean values are larger for males in logged and unlogged forests (Colón 1999); no significant difference in daily distance travelled between gender or logged and unlogged forest (range $=1.0 \mathrm{~km}$ in $13 \mathrm{hrs.;} 9.7 \mathrm{~km}$ in 6 hrs.) (Colón 1999); males traverse a significantly larger area and a larger proportion of their home range in a single night than females (Colón 1999); high use of roads (logged forest) and trails (unlogged forest) (Colón 1999).

Feeding ecology Considered primarily carnivorous and insectivorous (Payne et al. 1985); reported to feed on leaves, fruit, and even food scraps (MacDonald \& Wise 1979); invertebrates most commonly observed diet item, followed by fruit (Colón 1999); most frequently encountered invertebrates were beetles (Coleoptera), crabs (Brachyura), scorpions (Palamneus sulpides), and millipedes (Sphaeropieus spp.) (Colón 1999); Fruit $12 \%$ by bulk (Davis 1962); fruit second most commonly encountered diet item after insects. At least 20 species of fruit from 18 genera. Ficus spp., Connarus spp. and Annona spp. were most commonly identified seeds (Colón 1999); fruit comprised a larger proportion of diet in unlogged forest compared to logged forest (Colón 1999); vertebrates consumed included rodents, insectivores, small birds, snakes, and lizards (Colón 1999); bats reported in diet in Sarawak (MacDonald \& 
Wise 1979); diet shows considerable difference from encounter rate frequency of small terrestrial organisms, indicating a degree of prey preference (Colón 1999).

Breeding ecology Breeds all year (Nowak 1999); juveniles more commonly March-May (Colón 1999); September-April more common for sub-adults (Colón 1999); young open eyes after 10 days and begin weaning after one month (Nowak 1999); one to four young, usually two to three (Nowak 1999); young are born in a hole in the ground or in dense vegetation (Nowak 1999).

Habitat loss and degradation 60\% reduction in 6-year logged forest (Heydon $\&$ Bulloh 1996); 95\% MCP mean in unlogged forest $=88.5$ ha (range $=56-111$ ha) vs. 132.0 ha (range 70-284 ha) in logged forest. However, there is no statistical significance with ANOVA (Colón 1999); no statistically different patterns of activity between activity in logged and unlogged forest (Colón 1999); of the invertebrates known to be eaten by civets, only Scorpianidae and Isoptera are significantly more abundant in primary forest, and Coleoptera and Hymenoptera are more common in logged forest (Burghouts et al. 1992). Azlan (2003) found the species to be the most common small carnivore in a 30 year old secondary forest in Peninsular Malaysia.

Interspecific relationships Utilised significantly more invertebrates than other civet species, possibly allowing resource partitioning (Colón 1999); civets may be major agents of seed dispersal for some genera of Asian trees (Corlett 1988); 68\% of scats analysed contained parasites or eggs from 26 separate groups (Colón 1999); a total of five species of ticks identified, the most common being Haemaphysalis asiaticus (Colón 1999).

Conservation Status Not listed by IUCN (2002). Not listed by CITES (ARCBD 2002). Not protected in Indonesia (PHPA 1996b).

\section{Lesser Mouse-Deer Tragulus kanchil}

Taxonomy Recently split from T. javanicus by Meijaard and Groves (2004). Many subspecies have been described, although few of these might be valid. Meijaard and Groves (2004) suggested that 2 subspecies occur on Borneo, i.e., T. k. klossi in east and central Sabah and northern East Kalimantan, and T. k. hosei in Sarawak, West and Central Kalimantan, and the rest of East Kalimantan. T. k. klossi may be a distinct species.

Global range Southern Yunnan, Thailand, Indochina, Malay Peninsula and many small nearby islands, Sumatra and Borneo (Meijaard \& Groves 2004).

Population status and densities on Borneo 21-39 individuals $/ \mathrm{km}^{2}$ (Heydon \& Bulloh 1997); density positively correlated with fruit mass $1-5 \mathrm{~g}$, seed mass $0.01-0.5$ g, and total fruit resources (Heydon \& Bulloh 1997); density negatively correlated with pioneer trees and grass and herbs (Heydon \& Bulloh 1997).

Occurrence on small SE Asian islands Bangka, Bangkaru, Batam, Bengkalis, Bintan, Bunguran, Bunoa, Karimata, Karimon Kecil, Karimon, King, Kissaraing, Labuan, Langkawi, Laut (Natuna Isl.), Laut (SE Borneo), Lingga, Matak, Mendanau, Padang, Panaitan, Panebangan, Penang, Penjalei, Penuba, Phuket, Pinie, Pipidon, Ransang, Rawi, Redang, Rupat, Siantan, Singapore, Singkep, Sullivan, Tambelan Besar, Tana Bala, Tana Masa, Tebing Tinggi and Tuangku ( $\mathrm{n}=41)$ (Meijaard 2003b). 
Genus/species age 18.0 Mya/Unknown.

Habitat Tall forest in lowlands (Medway 1978 in Davison 1980); amidst undergrowth on edges of heavy lowland forest (Nowak 1999). Duckworth (1997a) and Bennett (pers. comm. in Duckworth 1997a) suggested that T. javanicus occurs primarily in hilly areas, but Caldecott (1988) stated that T. javanicus was reported to be absent from areas above $250 \mathrm{~m}$ in Sarawak, whereas T. napu occurred much higher.

Activity Diurnal to cathemeral; singly or in pairs, or in units of a female with one or two young (Ahmad 1994 in Davison 1980; Matsubayashi et al. 2003).

Movements and migration Not territorial; home ranges and core areas overlap considerably and boundary patrolling is lacking (Ahmad 1994); male highly philopatric but female establish new home ranges when giving birth (Ahmad 1994); home range and core area does not differ according to sex, but is determined by body size (Ahmad 1994). Matsubayashi et al. (2003) estimated home-range size for females at 4.4 ha and for males 5.9 ha using the minimum convex polygon method, but the difference between males and females was not significant. Mean daily distance travelled for males was $519.1 \pm 88.8 \mathrm{~m}$, that for females $573.8 \pm 219.7 \mathrm{~m}$.

Feeding ecology Frugivorous; shoots, young leaves, and fallen fruits (Medway 1978 in Davison 1980); fruit mass 1-5 g (Heydon \& Bulloh 1997); seed mass 0.01$0.5 \mathrm{~g}$ (Heydon \& Bulloh 1997).

Breeding ecology Polygynous; post-partum estrus, females almost continuously pregnant (Cadigan 1972 in Davison 1980); gestation = 140-177 days (Boonsong \& McNeely 1977 in Davison 1980); 2-3 young per year (in Davison 1980); fawns kept hidden (Ahmad 1994).

Habitat loss and degradation Scarcer in logged forest, with densities ranging between 10 and 15 animals $/ \mathrm{km}^{2}$; overall density and biomass significantly lower in selectively logged forest than in unlogged forest. Average 60\% decline (Heydon 1994); sensitivity probably a consequence of diet constraints which limit their ability to compensate for the reduced abundance of selected fruits in disturbed forest by utilizing browsing.

Interspecific relationships Competition with T. napu not pronounced, but their daily activity was biased towards reducing competition with other species of animals; in unlogged forest, T. napu significantly more common than T. javanicus. However, following logging, the numerical dominance of T. napu declined, and in 2- and 5-year-old forest T. javanicus was the commonest species. By 12 years post logging, T. napu had reasserted its dominance (Heydon 1994).

Conservation status Not listed by IUCN (2002). Not listed by CITES (ARCBD 2002). Protected in Indonesia (PHPA 1996b).

\section{Greater Mouse-Deer Tragulus napu}

Taxonomy Meijaard and Groves (2004) recognised 7 subspecies of T. napu, but many more have been described and further research into their validity is needed. Only 1 subspecies occurs on Borneo, which is the same one as on Sumatra, the Malay/Thai Peninsula, and southern Burma (Meijaard \& Groves 2004). 
Global range Southern Thailand and Burma, Malay Peninsula and many small nearby islands, Sumatra and Borneo (Nowak 1999).

Population status and densities on Borneo Density positively correlated with large, strangler fig trees and negatively correlated with grass and herbs and vine tangle (Heydon \& Bulloh 1997); primary forest: 37-72 individuals $/ \mathrm{km}^{2}$ (Heydon \& Bulloh 1997); on Tioman Island, densities ranged from 27.8-312.5 individuals $/ \mathrm{km}^{2}$ (Miura \& Idris 1999); home range in primary forest: 7 ha (Ahmad 1994). Mostly solitary, and mean group size: 1.37 (Miura \& Hidris 1999) (but note that these data are from an island and it is unclear to what extent these are relevant for the mainland).

Occurrence on small SE Asian islands Bakong, Balabac, Balembangan, Banggi, Bangka, Batam, Belitung, Bintan, Bulan, Bunguran, Durian, Galang, Iyan, Jimaja, Karimon Kecil, Karimon, Kundur, Langkawi, Laut (SE Borneo), Lingga, Matak, Moro Kecil, Musala, Nias, Penuba, Sebangka, Sebatik, Sebuku, Setoko, Siantan, Singkep, Sirhassen, Subi, Sugi Bawa, Sugi, Tana Bala, Tana Masa and Tioman $(\mathrm{n}=38)$ (Meijaard 2003b).

Genus/species age 18.0 Mya/Unknown.

Habitat Primary forest. The foot morphology of $T$. napu may suggest a preference of for more swampy habitats compared to T. javanicus (Chasen 1940; Smit-van Dort 1989).

Activity Cathemeral (=active day and night).

Movements and migration Not territorial, but males and females intolerant towards the same sex (Ahmad 1994); home range and core area size does not differ according to sex, but is determined by body size of the individuals (Ahmad 1994).

Feeding ecology Frugivorous. Hose (1893, in Caldecott 1988) asserted that $T$. napu are prone to kill chickens, but no further evidence for this was found.

Breeding ecology Possibly polygynous; there is no distinctive mating season and females give birth throughout the year in Peninsular Malaysia (Miura \& Idris 1999); one or rarely two young are born (Yasuma \& Andau 2000).

Habitat loss and degradation Scarcer in logged forest, with densities ranging between 6 and 16 animals $/ \mathrm{km}^{2}$ (Heydon \& Bulloh 1997); daily home range use more extensive in secondary forest; overall density and biomass significantly lower in selectively logged forest than in unlogged forest. Average 86\% decline (Heydon 1994); sensitivity probably a consequence of diet constraints which limit their ability to compensate for the reduced abundance of selected fruits in disturbed forest by utilizing browsing (Heydon \& Bulloh 1997); in 12-year-old logged forest, fewer trees belonging to genera eaten by T. napu (Heydon \& Bulloh 1997). On Tioman Island, densities increased away from human settlements probably in direct relationship to hunting pressure; also $83 \%$ of observations on this island were in primary forests and only $17 \%$ in secondary forests or rubber estates (Miura \& Idris 1999).

Interspecific relationships Appears numerically more abundant than sympatric T. javanicus in primary forest, but in secondary forest the numerical dominance is reversed and T. napu is numerically less abundant than T. javanicus. By 12 years post logging, T. napu had reasserted its dominance (Heydon 1994).

Conservation status Not listed by IUCN (2002). Not listed by CITES (ARCBD 2002). Protected in Indonesia (PHPA 1996b). 


\section{Yellow Muntjac Muntiacus atherodes}

Taxonomy Number of species in the genus is between 8 and 10, while no subspecies have been described.

Global range Bornean endemic (Groves \& Grubb 1982).

Population status and densities on Borneo Group size 1.60 individuals/group (Groves \& Grubb 1982).

Occurrence on small SE Asian islands Not known from offshore islands $(\mathrm{n}=0)$ (Meijaard 2003b).

Genus/species age 6.0 Mya/5.0 Mya.

Habitat Predominates over M. muntjak in forests of low hill ranges and coastal regions (Payne et al. 1985).

Activity Both diurnal and nocturnal activity have been reported in the wild (Nowak 1999); predominantly active during daylight hours; least active just before dawn (coldest part of day) (Heydon 1994); female pairs 59.9\% of time, and solitary muntjacs accounted for $29.1 \%$ of time (Heydon 1994); primarily adult male: female pairs (Heydon 1994).

Movements and migration Home range size similar for adult male and adult female, with considerable overlap between both sexes (Heydon 1994); estimated daily distance travelled by adult male: $6.47 \mathrm{~km}$ and female: $5.92 \mathrm{~km}$ (Heydon 1994); daily home range equivalent to $57.6 \%$ (male) and $64.7 \%$ (female) of overall home range (Heydon 1994).

Feeding ecology Generalist frugivore/browser; rely on fallen fruit (Ahmad 1994; Heydon 1994); frequently seen feeding on fruits dropped by arboreal frugivores (Heydon 1994); appears to act primarily as a seed predator (Heydon 1994); wideranging, utilizing 'primate fruits', 'bird fruits', bat fruits', and wind-dispersed fruits (Heydon 1994); fruits from 17 plant families exploited (Heydon 1994); dipterocarp seeds (Heydon 1994).

Breeding ecology Stable pair bonding and possible monogamy (Heydon 1994). Geist (1998) suggests that compared to M. muntjak, M. atherodes has opted for a more primitive system of territorial defense in productive areas and a more solitary, aggressive existence, with secondarily reduced antlers that are more useful for jabbing than for sparring.

Habitat loss and degradation Selected logging appears to have a slightly negative effect on the density of this muntjac (Heydon 1994).

Interspecific relationships Although $M$. atherodes exists sympatrically with M. muntjak in lowland forest, it is the more common species (83.1\%). However, difference in abundance between the two species is less marked in selectively logged forest (53.1\%) (Heydon 1994).

Conservation status Not listed by IUCN (2002). Not listed by CITES (ARCBD 2002). Despite its endemic status this species is not protected in Indonesia, like the much more widespread M. muntjac (PHPA 1996b).

\section{Red Muntjac, Indian Muntjac Muntiacus muntjak}

Taxonomy Number of species in the genus is between 8 and 10 . 
Global range Northeastern Pakistan, India and Nepal to southern China, Lao, Thai, Myanmar, Cambodia and Vietnam, Malay Peninsula and some nearby islands, Riau Archipelago, Sri Lanka, Hainan, Sumatra and Nias Islands to the west, Bangka, Belitung, Java, Bali and Borneo (Nowak 1999).

Population status and densities on Borneo Mean group size 1.35 individuals (Heydon 1994).

Occurrence on small SE Asian islands Bangka, Bintan, Lingga, Belitung, Galang, Nias, Panaitan, Singapore, Bali, Bawal, Chang, Kangean, Karimum Jawa, Mata Siri, Mesan and Pangkor $(\mathrm{n}=16)$ (Meijaard 2003b).

Genus/species age 6.0 Mya/1.0 Mya.

Habitat Primary forest, but outside Borneo also in more open forest types and grassland.

Activity Most commonly observed as solitary individuals (50.6\% of observations); adult female pairs accounted for only 43.0\% of observations (Heydon 1994).

Movements and migration Preliminary estimates of female in Java suggests ranges may be as small as 6 ha (reported in Heydon 1994).

Feeding ecology Frugivore/browser. Ability to utilize more browse in diet than $M$. atherodes may give it a competitive advantage in disturbed environments.

Breeding ecology Gestation days = 220 days (reported in Geist 1998).

Habitat loss and degradation No available information.

Interspecific relationships Less common than $M$. atherodes in lowland forest (Heydon 1994); predominates over $M$. atherodes in forests of extensive hill and mountain ranges (Payne et al. 1985).

Conservation status Not listed by IUCN (2002). Not listed by CITES (ARCBD 2002). Protected in Indonesia (PHPA 1996b).

\section{Sambar Cervus unicolor}

Taxonomy Approximately 11 species in the genus (Pitra et al. 2004), and 3 subspecies in the species (Corbet \& Hill 1992).

Global range India and Nepal to southern China (Yunnan, Sichuan, Guangdong), Lao, Thai, Myanmar, Cambodia and Vietnam, Malay Peninsula and some nearby islands, Sri Lanka, Hainan, Sumatra and Borneo (Corbet \& Hill 1992).

Population status and densities on Borneo Widespread on Borneo, although reportedly in decline throughout the island (Meijaard pers. obs.). No reliable density estimates are available for Borneo. In tropical southern India, $3.64 \pm 0.63$ individuals/ $\mathrm{km}^{2}$ (Jathanna et al. 2003); in Thailand between 1.0 and 5.4 individuals $/ \mathrm{km}^{2}$, with lower densities in the dry compared to the wet season (Srikosamatara 1993); in southern Sumatra between ca. 0.5 and 2 individuals $/ \mathrm{km}^{2}$ (O'Brien et al. 2003). Considering Borneo's generally low carrying capacity (see Meijaard 2003), Sambar densities in Borneo are probably lower than these estimates, i.e., $<1 / \mathrm{km}^{2}$. Up to 3,350 m on Mt. Kinabalu.

Occurrence on small SE Asian islands Balembangan, Banggi, Bangka, Bedung, Bruit, Iyan, Jolo, Klum, Labuan, Lingung, Malawali, Moro Kecil, Padang, Palawan, Phangan, Tao, Tawitawi and West Perhentian $(\mathrm{n}=18)$ (Meijaard 2003b). 
Genus/species age 6.0 Mya/3.0 Mya.

Habitat Occurs in lowland dipterocarp and lower montane forests, also in swamp forests; enters gardens and plantations to feed (Payne et al. 1985); also in alang-alang (Imperata cylindrica) fields and never far from water (van Bemmel 1949-1950).

Activity Active mainly at night, also early morning and late afternoon (Yasuma \& Andau 2000).

Movements and migration Banks (1931) suggested that Sambar may wander over considerable distances, and that only the males become territorial at certain times of the year. No data are available on Sambar home ranges in the tropics.

Feeding ecology Diet includes grasses, herbs, shrubs, young leaves and woody plants and fallen fruits (Payne et al. 1985).

Breeding ecology Sody (1941) mentioned births in May, June (Kotabumi, Sumatra), October, November (Palembang, Sibolga, both in Sumatra), and mostly between May and September on Borneo; other sources in van Bemmel (1949-1950) suggest that most births occur between March and July, i.e., in the transition period from the dry to the wet season (see Whitten et al. 1987). Rutting occurs in August (van Bemmel 1949-1950; Banks 1931). Generally one young is born.

Habitat loss and degradation Selectively logged, or previously cultivated areas of forest appear to favour increased in population densities of this species (Stuebing 1994).

Interspecific relationships No available information

Conservation status Not listed by IUCN (2002). Protected in Indonesia (Noerdjito \& Maryanto 2001).

\section{Bearded Pig Sus barbatus}

Taxonomy About 10 species have been described for the genus, and 2 subspecies are known (note that the Palawan subspecies is no longer considered to be closely related to $S$. barbatus, Lucchini et al. in press).

Global range Peninsular Malaysia, Sumatra, Borneo and in Palawan and neighbouring islands in the Philippines; limited in Malaysia to small part of historic range; still widespread but declining in Borneo (Caldecott et al. 1993).

Population status and densities on Borneo Widespread and common in most forest areas of Borneo, although increasingly reduced in areas where over-hunted (Bennett et al. 1996, 1999).

Occurrence on small SE Asian islands Balabac, Balembangan, Banggi, Bangka, Batam, Bintan, Bruit, Burung, Durian, Galang, Jambongan, Juanta, Kundur, Malawali, Mapor, Molleangen, Panebangan, Pelapis, Sugi and Tebing Tinggi $(\mathrm{n}=20)$ (Meijaard 2003b).

\section{Genus/species age 7.0 Mya/3.0 Mya.}

Habitat Found throughout all forest habitat and vegetation types in West Kalimantan; Sumatran bearded pigs occur in both the lowlands and the mountains; extensive use of riverbank communities (MacKinnon et al. 1996); in Sumatra it seems to be more of a primary forest animal, with Sus scrofa using secondary and disturbed forest (Meijaard 2000), but the latter species is very rare in the wild on 
Borneo on may consist of some feral populations; peat swamp, freshwater swamp and montane forests provide continual asynchronous fruiting resources for maintenance during non-mast years (Curran pers. comm.).

\section{Activity Diurnal.}

Movements and migration Large-scale movements usually occur when forests have large synchronous fruit production (Curran pers. comm.); especially correlated with illipe nuts Shorea spp. (Caldecott 1988); subject to large scale irregular mass migrations (MacKinnon et al. 1996); large-scale seasonal migrations (thousands of pigs covering great expanses of forest) following fruiting seasons of favourite food trees (MacKinnon et al. 1996); two more or less defined annual migrations (Pfeffer \& Caldecott in Meijaard 2000); daily migrations possible between feeding and resting areas (Meijaard et al. 2000).

Feeding ecology Oil rich seeds of members of the tree families Fagaceae and Dipterocarpaceae are thought to be especially important (Caldecott in Meijaard 2000; Curran pers. comm.); oaks, esp. Castinopsis spp., Lithocarpus spp. and Quercus spp. are favourite foods (Curran pers. comm.); roots, fungi, invertebrates in soil and rotting wood, small vertebrates, turtle eggs, and carrion (Meijaard 2000); will not eat Neesia spp. in the Bombacceae and Ternstroemia magnifica (Curran pers. comm.).

Breeding ecology Age at first pregnancy 10-20 months (Caldecott et al. 1993); gestation $=90$ to 120 days (Caldecott et al. 1993); breed only in ENSO/masting periods in the forest (Curran pers. comm.); rut coincides with synchronised flowering in the forest, with the timing being centred on the transition between late flowering and early fruit formation (Meijaard 2000); variable, depending upon body mass: 3-12 (Caldecott et al. 1993); litter size 6-8 (Curran pers. comm.); certain nutritional status may have to be attained by females before they become receptive. Pregnant females had a median fatness index of 1.5 (Caldecott et al. 1993); nests primarily in freshwater swamp and peat swamp forests although nests found in the understorey of several habitats including logged over forests and belian cuts/secondary forest (Curran pers. comm.). Prefers rattan groves and thickets (Dicranopteris fern, etc.) for nest building, either that or ridges with Sago palms and a nearby stand of oaks (R. Puri pers. comm.).

Habitat loss and degradation No data.

Interspecific relationships Have a direct influence on recruitment of dipterocarp canopy tree species and several hundred other species across several plant families (see Curran et al. 1999; Curran \& Leighton 2000; Curran \& Webb 2000); bearded pigs may play a role in the dispersal of Rafflesia spp. plants by picking up seeds on their hooves (MacKinnon et al. 1996); thought to assist in dispersal of durian (Durio spp.) seeds by feeding on fallen fruit and dispersing undigested seeds through the forest in their faeces (Meijaard 2000); almost solely seed predators (Curran pers. comm.; Curran et al. 1999); Bearded pig is adapted to the less productive dipterocarp forests and 'non-edge' habitats, whereas S. scrofa is adapted to more productive 'edge' habitats. In disturbed forest in Malaya and Sumatra this means that wild boar replaces bearded pig (Caldecott in Meijaard 2000).

Conservation status Not listed by IUCN (2002). Not listed by CITES (ARCBD 2002). Not protected in Indonesia (PHPA 1996b). 


\section{Sun Bear Ursus (Helarctos) malayanus}

Taxonomy Opinions vary as to whether this species should remain in its own genus, Helarctos, or to include it in with other bears in the genus Ursus. In the latter case the genus would contain 4 species. It is currently listed officially by the IUCN Species Survival Commission, the Bear Specialist Group, and by CITES as Helarctos malayanus. Recent work on cranial variation among Sun Bear specimens suggests that the Bornean race of the Sun Bear may be a distinct subspecies, Ursus malayanus euryspilus (Meijaard in press), in which case all other populations would be in U. $m$. malayanus.

Global range Formerly distributed from the hills of northeast India, south of the Brahmaputra river (Choudhury 1997), Yunnan (Yi-Ching 1983), through Burma, Thailand, Laos, Vietnam, Cambodia, and Peninsular Malaysia, to the islands of Sumatra and Borneo (Santiapillai \& Santiapillai 1996; Servheen 1999). Populations likely remain in small to medium-sized pockets within its former range, with possibly larger populations in Cambodia and Burma and the largest extant populations on Borneo and Sumatra.

Population status and densities on Borneo Possibly one bear $/ 4 \mathrm{~km}^{2}$ in Sabah (Davies \& Payne 1982) and 1.13-1.57 bear $/ \mathrm{km}^{2}$ in Taman Negara National Park, Peninsular Malaysia (Kawanishi 2002). Due to methodological shortcomings including the difficulty of recognizing individual bears from camera trap photos, small sample grids, small sample sizes and other weaknesses acknowledged by the original author, we do not accept the estimates of Kawanishi as sound or reliable. Home ranges in Sabah varied between $6.2-20.6 \mathrm{~km}^{2}$ with an average of $14.8 \mathrm{~km}^{2}$ (Wong 2002) and $12-15 \mathrm{~km}^{2}$ in the northern areas of East Kalimantan and northern Sumatra (Augeri 2002). Female home ranges in Sungai Wain, East Kalimantan were ca. 4-5 km² (Fredriksson \& Wich in prep.). Range overlap in Sabah varied from 0.54 $\mathrm{km}^{2}$ to $3.45 \mathrm{~km}^{2}$ (Wong 2002). Sun Bears are usually solitary, but females with cubs, siblings, and occasional groupings of several individuals at large food sources have been observed (Fredriksson pers. obs.; L. Nyagang pers. comm.).

Occurrence on small SE Asian islands Bangka, Bengkalis, Padang, Rupat ( $\mathrm{n}=4$ ) (Meijaard 2003b).

Genus/species age 4.0 Mya/2.7 Mya.

Habitat A higher concentration of Sun Bear activity appears to be in lowland and hill dipterocarp forest (Augeri 2002; Davies \& Payne 1982; Fredriksson \& Wich in prep.). Altitudinal range from 0-2,700 m (Augeri 2004a, b; Payne et al. 1985; R. Steinmetz pers. comm.); rarely enter recently burnt forest or logged areas (Fredriksson \& Wich in prep.; Augeri 2002).

Activity Primarily diurnal in Sungai Wain, East Kalimantan (Fredriksson \& Wich in prep.), in Danum Valley, Sabah (Wong 2002), and in Peninsular Malaysia (Kawanishi 2002). Both diurnal and nocturnal activity patterns in the Kayan Mentarang, Bulungan, and Leuser ecosystems (Augeri 2002, 2003). Nocturnal activity was observed in 'disturbed' areas such as around oil palm plantations (Nomura 2003) and in parts of Sumatra with various forms of human activity (Griffiths \& van Schaik 1993). 
Movements and migration Daily ranging $8 \mathrm{~km}$ (zigzagging) in Sungai Wain (Fredriksson \& Wich in prep.); straight-line distances between daily telemetry coordinates from $141 \mathrm{~m}$ to 5,660 m (Wong 2002); female and cub straight line distance of $11 \mathrm{~km}$ between camera trapping stations in Gunung Leuser National Park (Augeri in prep.). Sun bears probably do not migrate, but may alter their ranges across seasons and years according to food availability, such as during local and seasonal fruiting events or mast-fruiting on Borneo or when shifting to alternative food sources during low fruiting years (Augeri 2004a). Female bears often have overlapping ranges with their mothers while males disperse to new ranges, although ranges of both genders can overlap with other bears (Augeri in prep.).

Feeding ecology Omnivorous; diet includes termites, ants, beetles, larvae, earthworms, bees nests (honey), small animals, fruits, mushrooms, succulent plants, and flowers (Lekagul \& McNeely 1977; Payne et al. 1985; Wong et al. 2002; Augeri 2002, 2003; Fredriksson \& Wich in prep.); also soft growing point of the coconut palm (Meijaard 1999b), oil palm fruits (Nomura 2003) and soft part of Pandanus spp. (Fredriksson unpubl.). Found to feed on at least 113 species of fruit at the Sungai Wain study site, with fruits from the families Moraceae, Burseraceae and Myrtaceae being most common in the diet at lowland sites in East Kalimantan (Fredriksson \& Wich in prep.). Sun Bears in Sungai Wain were found to gorge themselves during masting events on Durio spp. Artocarpus spp. and Dacryodes spp. Ficus spp. was found the most frequently occurring species in the diet during inter-mast periods. Tree fruits primarily fed on by Sun Bears in Kayan Mentarang National Park were from the families Dipterocarpaceae, Euphorbiaceae, Fagaceae, Lauraceae, Moraceae, Myrtaceae, and Sapindaceae with an average dbh of $44.82 \mathrm{~cm}$. Similar feeding patterns were observed in the Malinau Research Forest from trees with an average dbh of $56.84 \mathrm{~cm}$ (Augeri in prep.); tree sizes used by Sun Bears in Kayan Mentarang and Malinau ranged between $7.96-416.36 \mathrm{~cm}$ dbh. Fruits from the Fagaceae family (oaks) probably occur more frequently in the diet at higher elevations (Davies \& Payne 1982; Fredriksson \& Wich in prep.; Augeri 2003), but were also observed at elevations < $400 \mathrm{~m}$ a.s.l. (Augeri 2002, 2003). At the Sungai Wain study site, some 48 species of termites were observed in the Sun Bear's diet, as well as some 60 ant species (Fredriksson \& Wich in prep.). Wong (2002) encountered several vertebrate food sources in 56 Sun Bear scats; these included the remains of Burmese Brown Tortoises (Manouria emys), birds and eggs, reptiles, fish, and several unidentified small vertebrates. Only 5 out of 1,257 scats $(<0.5 \%)$ collected by Fredriksson and Wich (in prep.) in East Kalimantan between 1997-2002 contained fragments of hairs or bone remains. Similarly, preliminary data suggest that less than $1 \%$ of scats examined by Augeri (in prep.) in northern Sumatra and East Kalimantan between 2000-2003 contained vertebrate remains.

Breeding ecology Females with small cubs have been observed throughout the year in East Kalimantan, indicating that breeding may be aseasonal (Fredriksson \& Wich in prep.). In zoos, births can occur at any time of year (Nowak 1991). An average gestation period of 95-107 days was reported from various zoos (Dathe 1970); three pregnancies were reported at the Fort Worth Zoo, lasting 174, 228, and 240 days respectively, possibly due to delayed implantation (McKuster 1974, as cited 
in Nowak 1991), which is common in other bear species. Age of sexual maturity: estrus observed at 3 years of age, but first parturition at 5 years (C. Fredericks pers. comm.; L. Kolter pers. comm.). Interbirth interval: one report of two successful births to a single female in one year (zoo example) and capable of becoming pregnant quickly again if they loose a cub (Dathe 1970). The mother will usually wait until the cub is weaned and large enough before having another; generally one cub, although two cubs have been occasionally observed (Fredriksson pers. obs.; L. Kolter pers. comm.; Nowak 1999). Reported cub weight at birth averaged 325 grams (Nowak 1991). Local people report that Sun Bears give birth in hollow logs or other secure natural cavities at the base of large trees, and a newly born cub was encountered in a log in Sungai Wain after the mother fled due to human disturbance (Fredriksson unpubl.).

Habitat loss and degradation Main threat in Sumatra and Kalimantan is habitat loss (Augeri 2001; Santiapillai \& Santiapillai 1996; Servheen 1999), resulting in restricted movements and altered foraging habits, decreased access to key food and habitats, and fragmented populations (Augeri 2003). Sun Bears are also hunted throughout their range for food, body parts, and for medicine and cosmetic uses, and young bears are taken from their mothers for trade or sale as pets. Trade of Sun Bears is still low in Indonesia although this situation could rapidly change in the future when bears on the mainland become scarce (Meijaard 1999a, 2001a; Servheen 1999).

Interspecific relationships Certain ground birds follow Sun Bears occasionally during termite foraging activities (Fredriksson pers. obs.). Besides humans, there are few local predators on Sun Bears. A reticulated python killed and ate an adult female Sun Bear in Sungai Wain, East Kalimantan (Fredriksson unpubl.), but the frequency of such events is uncertain. During a study on tigers in Taman Negara, Peninsular Malaysia, Kawanishi (2002) encountered one Sun Bear carcass presumed killed by tigers and two tiger scats containing the remains of Sun Bear(s), but again the frequency of these interactions is unknown. At the minimum, tigers and leopards are presumed to be antagonistic when encountering Sun Bears (Augeri 2001). Sun Bears are an important seed disperser (Augeri 2002; Fredriksson unpubl.; McConkey \& Galleti 1999; Wong 2002), especially for large-seeded trees (Durio spp. Artocarpus integer; Dacryodes rugosa) (Fredriksson \& Wich in prep.). Sun Bears are also active in regulating insect populations, such as predating on termite and ant colonies (Augeri 2002, 2003; Fredriksson pers. obs.). For example, in Sungai Wain, approximately 300 live nests/ha of one termite species on average remained active while an average of 300 nests/ha were excavated and destroyed by bears (Fredriksson unpubl.). As an indirect as well as agonistic competitor, Sun Bears also may influence the distribution and/or foraging activities of some rival species, like Pangolin (Manis javanica), by affecting the availability and distribution of live termite nests (Augeri 2003).

Conservation status Protected in Indonesia since 1973. Listed on Appendix I of CITES since 1979. Considered Vulnerable by the IUCN Red List of Threatened Animals (IUCN 2003) and by the most recent IUCN Bear Specialist Group mandate (Garshelis \& McLellan 2004). 


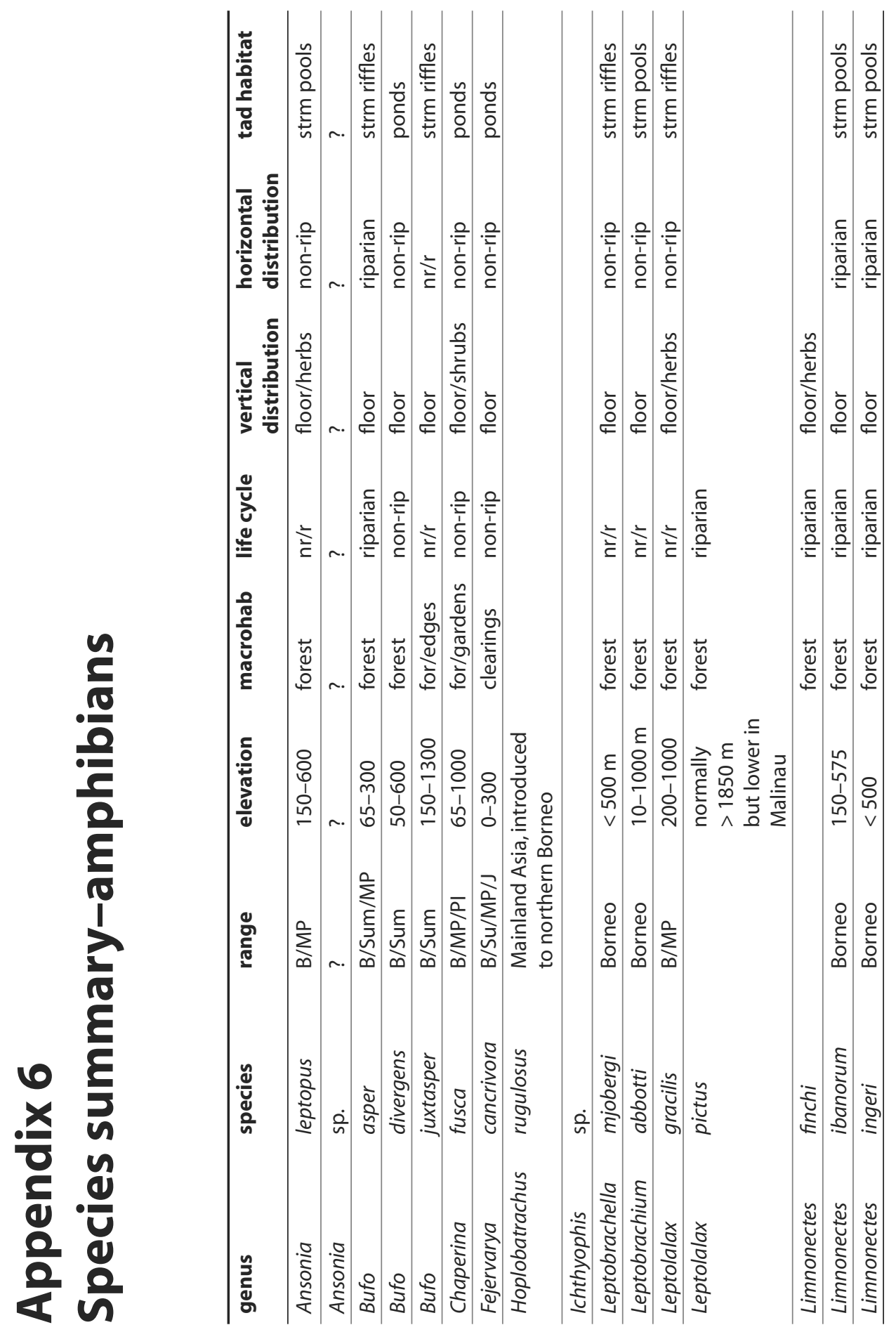




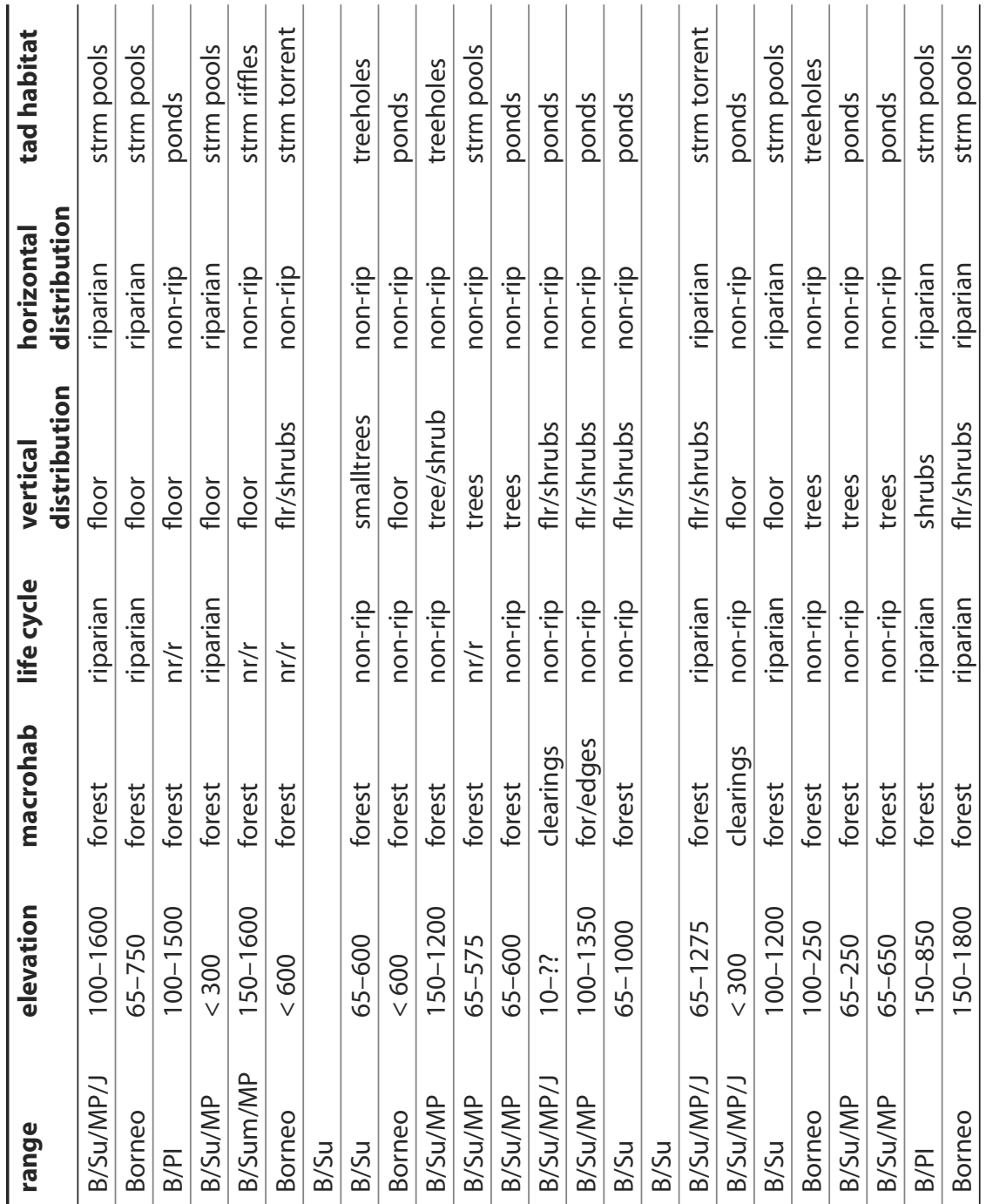

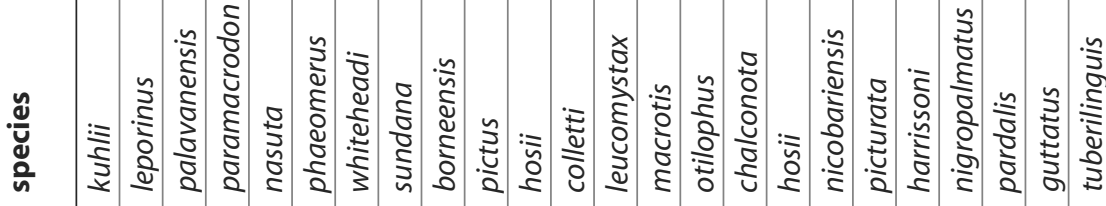

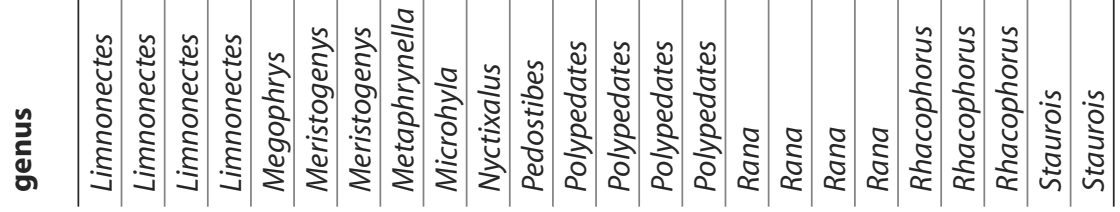




\section{Appendix 7 \\ Species summary-reptiles}

\begin{tabular}{|c|c|c|c|c|}
\hline Species & Macrohabitat & Feeding & $\begin{array}{l}\text { Vertical } \\
\text { distribution }\end{array}$ & Local use \\
\hline Acrochordus javanicus & aquatic & fish & aquatic & not eaten \\
\hline Ahaetulla prasina & $\begin{array}{l}\text { lowland and hill } \\
\text { primary forest }\end{array}$ & $\begin{array}{l}\text { lizards, tree } \\
\text { frogs }\end{array}$ & $\begin{array}{l}\text { arboreal, lower } \\
\text { storey }\end{array}$ & \\
\hline Amyda cartilaginea & aquatic & fish & aquatic & $\begin{array}{l}\text { hunted for food } \\
\text { and live trade }\end{array}$ \\
\hline Boiga cynodon & lowland forest & $\begin{array}{l}\text { birds and bird } \\
\text { eggs }\end{array}$ & arboreal & \\
\hline Boiga dendrophila & near rivers & mammals, birds & arboreal & $\begin{array}{l}\text { collected for } \\
\text { trade }\end{array}$ \\
\hline Boiga jaspidea & $\begin{array}{l}\text { usually } \\
\text { arboreal, lower } \\
\text { story }\end{array}$ & $\begin{array}{l}\text { small lizards, } \\
\text { frogs }\end{array}$ & $\begin{array}{l}\text { arboreal, lower } \\
\text { story }\end{array}$ & \\
\hline Boiga nigriceps & $\begin{array}{l}\text { branches above } \\
\text { rivers }\end{array}$ & $\begin{array}{l}\text { small birds, } \\
\text { lizards, } \\
\text { occasionally } \\
\text { small rodents }\end{array}$ & arboreal & $\begin{array}{l}\text { collected for } \\
\text { trade }\end{array}$ \\
\hline Bronchocela cristatella & $\begin{array}{l}\text { lowland and } \\
\text { hill forest, and } \\
\text { parklands }\end{array}$ & small insects & $\begin{array}{l}\text { arboreal, lower } \\
\text { storey }\end{array}$ & \\
\hline Bungarus flaviceps & $\begin{array}{l}\text { primary and } \\
\text { secondary } \\
\text { rainforest }\end{array}$ & small mammals & terrestrial & $\begin{array}{l}\text { locally eaten } \\
\text { and hunted for } \\
\text { leather }\end{array}$ \\
\hline Calamaria bicolor & leaf litter & $\begin{array}{l}\text { earth worms or } \\
\text { termites }\end{array}$ & semi-fossorial & \\
\hline Calamaria sp. 1 & leaf litter & $\begin{array}{l}\text { earth worms or } \\
\text { termites }\end{array}$ & semi-fossorial & \\
\hline Chrysopelea paradisii & primary forest & $\begin{array}{l}\text { small lizards, } \\
\text { occasionally } \\
\text { frogs }\end{array}$ & arboreal & \\
\hline
\end{tabular}




\begin{tabular}{|c|c|c|c|c|}
\hline Species & Macrohabitat & Feeding & $\begin{array}{l}\text { Vertical } \\
\text { distribution }\end{array}$ & Local use \\
\hline Cosymbotus platyurus & $\begin{array}{l}\text { near human } \\
\text { settlement }\end{array}$ & insects & & \\
\hline Crocodylus porosus & aquatic & $\begin{array}{l}\text { small mammals, } \\
\text { fish, reptiles }\end{array}$ & near rivers & $\begin{array}{l}\text { hunted for skin } \\
\text { and food }\end{array}$ \\
\hline Cyclemys dentata & $\begin{array}{l}\text { shallow rocky } \\
\text { streams in forest }\end{array}$ & plants, fruits & semi-aquatic & eaten \\
\hline Cylindrophis ruffus & riparian & snakes & fossorial & \\
\hline $\begin{array}{l}\text { Cyrtodactylus } \\
\text { malayanus }\end{array}$ & $\begin{array}{l}\text { mostly in } \\
\text { forested areas; } \\
\text { near riverbanks }\end{array}$ & insects & $\begin{array}{l}\text { arboreal, lower } \\
\text { storey }\end{array}$ & \\
\hline $\begin{array}{l}\text { Dendrelaphis } \\
\text { caudolineatus }\end{array}$ & $\begin{array}{l}\text { from primary } \\
\text { forest to } \\
\text { disturbed areas }\end{array}$ & lizards, frogs & $\begin{array}{l}\text { arboreal, but } \\
\text { moves well on } \\
\text { the ground }\end{array}$ & \\
\hline Dendrelaphis formosus & $\begin{array}{l}\text { common in } \\
\text { vegetation on } \\
\text { riverbanks }\end{array}$ & $\begin{array}{l}\text { small lizards, } \\
\text { frogs }\end{array}$ & $\begin{array}{l}\text { arboreal, but } \\
\text { moves well on } \\
\text { the ground }\end{array}$ & \\
\hline Draco cornutus & $\begin{array}{l}\text { close to human } \\
\text { habitation }\end{array}$ & ants, termites & arboreal & \\
\hline Elaphe flavolineata & $\begin{array}{l}\text { from primary } \\
\text { forest to } \\
\text { disturbed areas }\end{array}$ & $\begin{array}{l}\text { small mammals, } \\
\text { birds, frogs, } \\
\text { lizards }\end{array}$ & terrestrial & \\
\hline Enhydris doriae & $\begin{array}{l}\text { abundant in } \\
\text { rice fields or } \\
\text { ponds }\end{array}$ & fish & aquatic & \\
\hline Gekko smithi & $\begin{array}{l}\text { large tree trunks } \\
\text { in primary and } \\
\text { secondary } \\
\text { forest }\end{array}$ & insects & arboreal & \\
\hline Gonocephalus grandis & $\begin{array}{l}\text { gallery forest, } \\
\text { secondary } \\
\text { forest; near } \\
\text { rivers }\end{array}$ & insects & arboreal & \\
\hline $\begin{array}{l}\text { Gonyosoma } \\
\text { oxycephalum }\end{array}$ & usually arboreal & $\begin{array}{l}\text { frogs, lizards, } \\
\text { probably also } \\
\text { small rodents, } \\
\text { birds }\end{array}$ & $\begin{array}{l}\text { arboreal, } \\
\text { terrestrial }\end{array}$ & \\
\hline Heosemys spinosa & $\begin{array}{l}\text { semi aquatic, } \\
\text { also deep into } \\
\text { forest }\end{array}$ & rotten fruits & terrestrial & \\
\hline Lepturophis albofuscus & $\begin{array}{l}\text { usually lowland } \\
\text { forest }\end{array}$ & $\begin{array}{l}\text { small } \\
\text { amphibians } \\
\text { and lizards }\end{array}$ & terrestrial & \\
\hline Lipinia quadrivittata & $\begin{array}{l}\text { usually in large } \\
\text { trees in primary } \\
\text { to secondary } \\
\text { forest, often in } \\
\text { slight open/ } \\
\text { exposed } \\
\text { areas; lowland } \\
\text { species. }\end{array}$ & small insects & arboreal & \\
\hline
\end{tabular}




\begin{tabular}{|c|c|c|c|c|}
\hline Species & Macrohabitat & Feeding & $\begin{array}{l}\text { Vertical } \\
\text { distribution }\end{array}$ & Local use \\
\hline Mabuya rudis & $\begin{array}{l}\text { common in } \\
\text { disturbed areas }\end{array}$ & insects & & locally eaten \\
\hline Manouria emys & $\begin{array}{l}\text { usually in hill } \\
\text { forest }\end{array}$ & $\begin{array}{l}\text { plants, fungi, } \\
\text { fruit }\end{array}$ & terrestrial & \\
\hline Maticora bivirgata & $\begin{array}{l}\text { burrows and } \\
\text { litter }\end{array}$ & small reptiles & semi-fossorial & \\
\hline Maticora intestinalis & $\begin{array}{l}\text { lowland and hill } \\
\text { forest to human } \\
\text { settlements }\end{array}$ & worms, termites & fossorial & $\begin{array}{l}\text { eaten for } \\
\text { medicine }\end{array}$ \\
\hline Naja sumatrana & $\begin{array}{l}\text { forest to open } \\
\text { areas }\end{array}$ & small mammals & terrestrial & \\
\hline Notochelys platynota & hill forests & fruits, leaves & terrestrial & $\begin{array}{l}\text { often hunted } \\
\text { for food }\end{array}$ \\
\hline Oligodon sp. 1 & leaf litter & reptile eggs & terrestrial & \\
\hline Oligodon sp. 2 & $?$ & $?$ & $?$ & \\
\hline Oligodon purpurascens & $\begin{array}{l}\text { lowland, not } \\
\text { necessary } \\
\text { forested areas }\end{array}$ & $\begin{array}{l}\text { mainly feeds on } \\
\text { lizards eggs }\end{array}$ & $\begin{array}{l}\text { terrestrial, } \\
\text { probably } \\
\text { semifossorial }\end{array}$ & \\
\hline Ophiophagus hannah & $\begin{array}{l}\text { primary } \\
\text { rainforest, } \\
\text { sometimes } \\
\text { opes areas }\end{array}$ & snakes & terrestrial & $\begin{array}{l}\text { eaten, venom } \\
\text { for dart poison }\end{array}$ \\
\hline Orlitia borneensis & $\begin{array}{l}\text { lowland, large } \\
\text { rivers, estuaria }\end{array}$ & $\begin{array}{l}\text { leaves, fruits, } \\
\text { large seeds }\end{array}$ & semi-aquatic & $\begin{array}{l}\text { caught for live } \\
\text { trade }\end{array}$ \\
\hline Pelochelys cantorii & $\begin{array}{l}\text { lowland and } \\
\text { coastal, large } \\
\text { river, estuaria }\end{array}$ & fish & aquatic & $\begin{array}{l}\text { highly } \\
\text { exploited for } \\
\text { food }\end{array}$ \\
\hline $\begin{array}{l}\text { Psammodynastes } \\
\text { pulverulentus }\end{array}$ & $\begin{array}{l}\text { leaf litter, lower } \\
\text { story }\end{array}$ & $\begin{array}{l}\text { small lizards, } \\
\text { rarely frogs }\end{array}$ & lower story & \\
\hline $\begin{array}{l}\text { Pseudorhabdion cf. } \\
\text { sarawakensis }\end{array}$ & leaf litter & $\begin{array}{l}\text { small worms, } \\
\text { insect larvae }\end{array}$ & terrestrial & \\
\hline Pseudorhabdion collaris & $\begin{array}{l}\text { lowland } \\
\text { rainforest }\end{array}$ & $\begin{array}{l}\text { feeds on } \\
\text { earthworms }\end{array}$ & semi-fossorial & \\
\hline Ptyas fuscus & $\begin{array}{l}\text { bushes, forest, } \\
\text { but also open } \\
\text { areas }\end{array}$ & $\begin{array}{l}\text { rats, birds, frogs, } \\
\text { small snakes }\end{array}$ & terrestrial & \\
\hline Python curtus & $\begin{array}{l}\text { rare in } \\
\text { the forest, } \\
\text { abundant in } \\
\text { plantations }\end{array}$ & small mammals & semi-fossorial & locally eaten \\
\hline Python reticulatus & $\begin{array}{l}\text { frequents river } \\
\text { banks }\end{array}$ & $\begin{array}{l}\text { amphibians, } \\
\text { reptiles, birds, } \\
\text { small and large } \\
\text { mammals }\end{array}$ & arboreal & $\begin{array}{l}\text { locally eaten } \\
\text { and used for } \\
\text { medicinal } \\
\text { purposes }\end{array}$ \\
\hline $\begin{array}{l}\text { Ramphotyphlops } \\
\text { braminus }\end{array}$ & leaf litter & worms & fossorial & \\
\hline $\begin{array}{l}\text { Sphenomorphus } \\
\text { sabanus }\end{array}$ & $\begin{array}{l}\text { mainly primary } \\
\text { rainforest } \\
\text { at medium } \\
\text { altitudes }\end{array}$ & $?$ & $\begin{array}{l}\text { terestrial on } \\
\text { forest floor }\end{array}$ & \\
\hline
\end{tabular}


280 | Appendix 7. Species summary-reptiles

\begin{tabular}{|c|c|c|c|c|}
\hline Species & Macrohabitat & Feeding & $\begin{array}{l}\text { Vertical } \\
\text { distribution }\end{array}$ & Local use \\
\hline Takydromus sexlineatus & $\begin{array}{l}\text { open areas } \\
\text { such as fields or } \\
\text { grassland }\end{array}$ & small insects & & \\
\hline Trimeresurus albolabris & bushes, forest & $\begin{array}{l}\text { small rodents, } \\
\text { birds, } \\
\text { occasionally } \\
\text { small lizards }\end{array}$ & $\begin{array}{l}\text { usually } \\
\text { arboreal, lower } \\
\text { story }\end{array}$ & \\
\hline Tropidolaemus wagleri & bushes, forest & $\begin{array}{l}\text { birds, arboreal } \\
\text { rodents }\end{array}$ & $\begin{array}{l}\text { arboreal, lower } \\
\text { story }\end{array}$ & $\begin{array}{l}\text { eaten, venom } \\
\text { for dart poison }\end{array}$ \\
\hline Tropidophorus brookei & $\begin{array}{l}\text { ponds and } \\
\text { riverbanks }\end{array}$ & insects & & \\
\hline Varanus rudicollis & $\begin{array}{l}\text { often away } \\
\text { from rivers, } \\
\text { lowland and hill } \\
\text { primary forest }\end{array}$ & $\begin{array}{l}\text { birds, small } \\
\text { mammals, } \\
\text { amphibians, } \\
\text { reptiles }\end{array}$ & usually arboreal & $\begin{array}{l}\text { occasionally } \\
\text { hunted for food }\end{array}$ \\
\hline Varanus salvator & near rivers & $\begin{array}{l}\text { birds, small } \\
\text { mammals, } \\
\text { amphibians, } \\
\text { reptiles }\end{array}$ & & hunted for food \\
\hline
\end{tabular}




\section{Appendix 8 \\ Fish Reported from MRF}

Species list after Rachmatika et al. 2005.

\begin{tabular}{ll}
\hline English name & Scientific name \\
\hline Freshwater Eel & Anguilla malgumora \\
\hline Freshwater Eel & Anguilla nebulosa \\
\hline Barb & Barbodes cf. balleroides \\
\hline Barb & Barbodes sp. \\
\hline Fighting Fish & Betta unimaculata \\
\hline Walking Catfish & Claris anfractus \\
\hline- & Cyclocheilichthys armatus \\
\hline Stone Lapping Fish & Cyclocheilichthys repasson \\
\hline Hill Stream Loach & Garra borneensis \\
\hline Hill Stream Loach & Gastromyzon lepidogaster \\
\hline Sucking Catfish & Gastromyzon sp. \\
\hline Silver and Red Barb & Glyptothorax platypogonoides \\
\hline Hill Stream Loach & Hampala macrolepidota \\
\hline- & Homaloptera stephensoni \\
\hline- & Leptobarbus melanotaenia \\
\hline Bagrid Catfish & Lobocheilos cf. bo \\
\hline Spiny Eel & Leiocassis sp. \\
\hline Spiny Eel & Mastacembelus unicolor \\
\hline Bagrid Catfish & Mastacembelus cf. maculates \\
\hline Bagrid Catfish & Hemibagrus cf. nemurus \\
\hline Hill Stream Loach & Hemibagrus baramensis \\
\hline Hill Stream Loach & Neogastromyzon nieuwenhuisi \\
\hline Hill Stream Loach & Nematrabramis everetti \\
\hline Hill Stream Loach & Nemacheilus saravacensis \\
\hline Sheat Fish & Nemacheilus spiniferus \\
\hline & Nemacheilus selangoricus \\
\hline & Ompok cf. bimaculatus \\
\hline
\end{tabular}




\begin{tabular}{ll}
\hline English name & Scientific name \\
\hline Giant Gourami & Osphronemus septemfasciatus \\
\hline Black-banded Osteochilus & Osteochilus waandersii \\
\hline Spotted Barb & Puntius binotatus \\
\hline Barb & Puntius sealei \\
\hline Barb & Puntius sp. \\
\hline- & Parachela ingerkongi \\
\hline- & Protomyzon griswoldi \\
\hline- & Porhomatoptera microstoma \\
\hline Silver Rasbora & Rasbora argyrotaenia \\
\hline Elegant Rasbora & Rasbora elegans \\
\hline Greater Scissortail & Rasbora caudimaculata \\
\hline- & Rasbora lateristriata \\
\hline Climbing Perch & Trichgaster trichopterus \\
\hline Carp & Tor tambra \\
\hline Carp & Tor tambroides \\
\hline
\end{tabular}




\section{Appendix 9 \\ Relevant articles from \\ the Act No. 5 of 1990 \\ Source: (Ministry of Forestry 1990)}

\section{Chapter 5}

\section{Article 21}

1. (Article 1 deals with protected plants)

2. Any and all persons are prohibited to

a. Catch, injure, kill, keep, posess, care for, transport, and trade in a protected animal in live condition.

b. Keep, posess, care for, transport, and trade in a protected animal in a dead condition.

c. Transfer a protected animal from one place to another, within- or outside Indonesia

d. Trade, keep or posess skin, bodies or other parts of a protected animal, or goods made of parts of the animal, or transfer from one place in Indonesia to another another, within or outside Indonesia.

e. Take, destroy, exterminate, trade, keep, or posess an egg and/or nest of a protected animal

\section{Article 22}

1. Any exception from the prohibition pertaining to Article 22 can only be permitted for purposes of research, science, and/or safeguarding those plants and animals.

2. Safeguarding efforts pertaining to paragraph 1. shall include delivering or exchanging a plant or animal species with foreign institutions, with permit from the Government.

3. An exception to the prohibition to catch, to injure, or to kill a protected animal can only be permitted in case the animal endangers human life

4. The further provisions pertaining to paragraph 1., paragraph 2., and paragraph 3. shall be regulated by a Government Regulation. 


\title{
Appendix 10
}

\section{Relevant Articles from the Law of the Republic of Indonesia No. 41 Year 1999 on Forestry Source: Republic of Indonesia (1999)}

\section{Part Four \\ Forest Rehabilitation and Reclamation}

\begin{abstract}
Article 40
Forest and land rehabilitation shall be intended to recover, maintain and improve the forest and land functions so that its carrying capacity, productivity and role as the supporting life system can be maintained.
\end{abstract}

\section{Article 41}

1. Forest and land rehabilitation shall be implemented through the following activities:

a. reforestation,

b. regreening,

c. tending,

d. enrichment planting, or

e. application of soil conservation through vegetative and mechanical means on critical and non-productive lands.

2. Rehabilitation activities as referred to in paragraph (1) shall be undertaken in all forests and forest areas except in nature reserve and core zone of national park.

\section{Article 42}

1. Forest and land rehabilitation shall be implemented based on specific biophysics conditions.

2. Forest and land rehabilitation shall be implemented, primarily through participatory approach, in the framework of community development and empowerment.

3. Further provisions as referred to in paragraph (1), and paragraph (2) shall be regulated by a Government Regulation. 


\section{Article 43}

1. Each person having, managing and or utilising critical or unproductive forests shall be obliged to rehabilitate the forests for protection and conservation purposes.

2. In implementing the rehabilitation as referred to in paragraph (1), every person can require assistance, service and support of non-governmental organisations, other parties or government.

\section{Article 44}

1. Forest reclamation as referred to in Article 21 point (c) is an effort to improve and recover damaged land and forest vegetation to restore it to its origin to function in an optimal way.

2. Reclamation activities as referred to in paragraph (1) include inventory of locations, designation of location, planning and implementation.

3. Further provisions as referred to in paragraph (1), and paragraph (2) shall be regulated by a Government Regulation.

\section{Article 45}

1. Use of forest area as referred to in Article 38 paragraph (1) which causes forest damage, shall be followed by reclamation and/or rehabilitation with regard to guidelines stipulated by government.

2. Reclamation in ex-mining areas must be undertaken by holders of mining licenses in accordance with the stages of mining activities.

3. Parties who use forest areas for non-forestry purposes and caused changes to soil surface and vegetation cover shall be obliged to pay reclamation and rehabilitation performance bonds.

3. Further provisions as referred to in paragraph (1), paragraph (2) and paragraph (3) shall be regulated by a Government Regulation.

\section{Part Five \\ Forest Protection and Nature Conservation}

\section{Article 46}

Forest protection and nature conservation shall be aimed at keeping the forests, forest area and its environment so that protection, conservation and production functions can be secured in optimal and sustainable ways.

\section{Article 47}

Protection of forest and forest area shall be an effort to:

a. prevent and limit the destruction of forests, forest area and forest products as a result of human and animal conducts, fires, natural hazards, pest and diseases; and

b. maintain and keep the state, community and individual's rights over forest, forest area, forest products, investment and instruments pertaining to forest management. 


\section{Article 48}

1. Government control the forest protection, undertaken either within or outside forest area.

2. Forest protection within state forest shall be undertaken by government.

3. Holders of forest utilization license as referred to in Article 27 and Article 29, and other parties who are granted the authority to manage the forest as referred to in Article 34, shall be obliged to protect the forests in their working area.

4. Forest protection within right forest shall be undertaken by the holder of rights.

5. To secure its sound implementation, community shall be involved in efforts of forest protection.

6. Further provisions as referred to in paragraph (1), paragraph (2), paragraph (3), paragraph (4) and paragraph (5) shall be regulated by a Government Regulation.

\section{Article 49}

Holders of rights or licenses shall be responsible for forest fires occurring in their working area.

\section{Article 50}

1. Any person is prohibited to destroy the infrastructure and facilities of forest protection.

2. Anybody who has received the license of forest area use; the license of utilising environmental services, the right of timber and non-timber forest product utilization, the license of timber and non-timber forest product collection; is not allowed to undertake any activities leading to forest damage.

3. No one is allowed to:

a. cultivate and/or use and/or occupy illegally a forest area;

b. encroach a forest area;

c. cut trees within a radius or distance up to:

- 500 (five hundred) meters from the edge of a lake;

- 200 (two hundred) meters from the edge of water sources and along side rivers in a swamp area;

- 100 (hundred) meters alongside of rivers;

- 50 (fifty) meters along sides of streams

- 2 (two) times the depth of ravine from the edge of ravine;

- 130 (one hundred thirty) times the difference between the highest and the lowest tide, measured from the coastline

d. burn the forests;

e. cut trees or harvest or collect any forest products within the forest area without holding any rights or license issued by authorized officials;

f. receive, buy or sell, receive as an exchange, receive as an entrusted goods, keep or possess any forest products which were allegedly harvested from a forest area through an illegal way.

g. undertake general investigation, activities, exploration or exploitation of 
mine materials within the forest area without Minister's approval;

h. carry, possess or keep forest products without being accompanied by any legal document;

i. graze livestock within the forest area which is not assigned specifically by authorized officials for that purpose;

j. bring heavy equipment or other tools which are commonly used or will presumably be used for loading forest products within forest area, without any legal authorization;

k. bring equipment which are commonly used for felling, cutting, cracking the trees, without any legal authorization;

1. throw any inflammable material into the forest area which may cause forest fires and threat the existence and sustainability of forest functions; and

m. remove, carry, transport plants and wildlife species which are not protected by the law, from forest area without any legal authorization.

n. Further provisions concerning removal, carrying or loading actions of protected plants and animal species, shall be regulated by the prevailing laws and regulations.

\section{Article 51}

1. To ensure the implementation of forest protection, a special police authorization shall be extended to certain forestry officials according to the nature of their responsibilities.

2. The officials bearing the special police authorization as referred to in paragraph

(1) shall be authorized to:

a. execute a patrol activity within forest area of his/her legal territory;

b. verify any papers or documents concerning the transportation of forest products within forest area of his/her legal territory;

c. receive any information on criminal acts pertaining to forests, forest areas and forest products;

d. seek any information and evidences of criminal act pertaining to forests, forest areas and forest products;

e. in a red-handed case, have the obligation to catch the suspects of the criminal act to be brought to authorized officials;

f. prepare any reports and sign the reports of the criminal act pertaining to forests, forest areas and forest products. 


\section{Appendix 11 \\ Selective Cutting and Replanting (TPTI)}

The following account provides an overview of the Silvicultural System of Indonesian Selective Cutting and Replanting (TPTI). Taken word-for-word from: Handbook of Indonesia Forestry. MoF 1997

\section{Introduction}

The Silvicultural of Indonesian Selective Cutting and Replanting (TPTI) is a silvicultural system which comprise of logging practice with diameter limit and forest regeneration. In the beginning, it was referred to as Indonesian Selective Cutting (TPI) in the year 1972. This Silvicultural system is considered the most appropriate in term of economy, ecology and technology to be used in tropical rain forest or other tropical forest in Indonesia. Natural production forests in Indonesia, either in the form of permanent or limited forest, are generally dominated by trees belonging to Dipterocarps family, together with other commercial tree species. Several other tree species, sometimes dominate tropical rain forests which grow on certain sites, for example ramin in peat swamp forest, Agathis in forest with sandy soil, ebony in rocky and somewhat dry areas, eucalypts in dry climate, Rhizophora in mangrove forest, pelawan in heath forest, etc.

The silvicultural system of selective cutting is one of the most difficult silvicultural system to be implemented, especially in the mixed forest of various ages, such as tropical rainforest in Indonesia. However, since the logged over area of selective cutting is opened and disturbed only a little as compared with that of clear cutting system, this system is consider safer for protection and sustainability of tropical rain forest ecosystem. 


\section{Silvicultural System of Indonesian selective cutting and replanting (TPTI)}

Silvicultural system is a series of planned activities to manage the forest which include logging, regeneration and tending of forest stand, to ensure the sustainability of timber production or other forest products. On the other hand, TPTI is a silvicultural system with diameter limit and forest regeneration.

TPTI system based on forest inventory and forest sustainability principle which include production sustainability, soil and water conservation, nature protection, silvical characteristic of the tree species and economic consideration of the company.

The objective of TPTI system is regulating the utilization of natural production forest and improving the value of forest, in terms of quality in the logged over areas, in order that in the next rotation, mixed forest stand can be formed which can function as sustainable raw material supplier for industry.

For achieving the above mentioned objective, silvicultural practice in forest regeneration is directed towards:

- Regulating the composition of tree species in the forest so that it will be more profitable in terms of ecology and economy.

- Regulating the structure and maintaining the optimum density of the forest which is expected to increase the production of round wood as compared to the previous condition.

- Ensuring the forest function for soil and water conservation.

- Ensuring the function of forest protection.

Selective cutting system is in fact more difficult than other silvicultural system, and require forester professionalism. In contrast with the previous TPI, in the present TPTI, each HPH (forest concession) is obliged to establish a department of silviculture separated with department of exploitation or logging. The department of silviculture should be sufficiently supplied with facilities, fund and infrastructure, and should be led and staffed by forestry educated personnel which understand the science and practice of silviculture.

All activities and schedule in TPTI should be understood and implemented. Establishment of TPTI demonstration plots, seed stand and nurseries spread over the logged over area, will support very much the success of TPTI. Therefore, each silviculture staff in $\mathrm{HPH}$ will be easy to refer to the desirable condition according to TPTI technical guidelines.

\section{Series of activities}

To achieve the target expected in TPTI, the following series of activities and schedules are establish:

\begin{tabular}{clc}
\hline No. & Stage of TPTI Activities & Time of Implementation (Year) \\
\hline 1. & Organisation of Working Area & $\mathrm{Et}-3$ \\
\hline 2. & Stand Inventory before Logging & $\mathrm{Et}-2$ \\
\hline 3. & Opening Up of Forest Area & $\mathrm{Et}-1$ \\
\hline
\end{tabular}




\begin{tabular}{cll}
\hline No. & Stage of TPTI Activities & Time of Implementation (Year) \\
\hline 4. & Logging & $\mathrm{Et} \mathrm{0}$ \\
\hline 5. & Liberation & $\mathrm{Et}+1$ \\
\hline 6. & Inventory of Residual Stand & $\mathrm{Et}+1$ \\
\hline 7. & Procurement of Planting Stock & $\mathrm{Et}+2$ \\
\hline 8. & Enrichment /Planting & $\mathrm{Et}+2$ \\
\hline 9. & First Stage Tending & $\mathrm{Et}+3$ \\
\hline 10. & Advanced Tending & \\
\hline & Liberation & $\mathrm{Et}+4$ \\
\hline & Thinning & $\mathrm{Et}+9$ \\
\hline & & $\mathrm{Et}+14$ \\
\hline & & $\mathrm{Et}+19$ \\
\hline 11. & Forest Protection And Research & Continually \\
\hline
\end{tabular}

Note Et: denotes the year when the logging takes places

\section{General provision}

The Implementation of TPTI silviculture system in forest utilization is intended to regulate the cutting and silviculture of natural production forest, which has a minimum number of 25 nucleus trees (seed trees) per hectare. The appointed nucleus or seed trees are preferred as those commercial trees similar with the ones logged, with minimum diameter of $20 \mathrm{~cm}$. If the number is less than 25 trees per hectare, other species can be included.

Annual cutting quota is adjusted with the cutting quota and the standing stock volume of commercial species.

Forest concession holders should prepare:

- Unit of silviculture organisation which is separated from logging organisation.

- Sufficient skilfull forestry technical personnel.

- Sufficient budget for silviculture activities.

In a unit of natural production forest utilization which has a specific stand structure and species composition, an adjustment of TPTI silvicultural system can be made as follow:

In mangrove forest, the silvicultural system guidelines is based on the Decree of Director General of Forestry No : 60/Kpts/DJ/1/1978.

In swamp forest with forest composition comprising specific commercial species, for instance ramin, perupuk, and other commercial species, and the forest concession holders are not able/difficult to conduct planting/enrichment, then the concession holder is allowed only to cut trees maximally $2 / 3$ of the total number of trees according to the species composition.

In swamp forest, in which trees with diameter of $50 \mathrm{~cm}$. upward are not found, for instance in mixed ramin forest, then for specifically ramin forest, reduction of diameter limit to $35 \mathrm{~cm}$. For cutting can be done, with nucleus (seed tree) is minimally 25 trees per hectare. Cutting rotation is established as 25 years. Regulation of trees which are allowed to be cut, follows a provision as in point (b). 
In condition where the nucleus trees with diameter of $20-49 \mathrm{~cm}$ is less than 25 trees per hectare, then the lack of this tree can be compensated by adding with other commercial species with diameter of more than $50 \mathrm{~cm}$ which function also as seed tree. Minimum diameter limit of trees to be cut is $50 \mathrm{~cm}$, with minimum number of nucleus trees is 25 trees per hectare, and the cutting rotation is 35 years.

In condition where some commercial species grow very slowly, and commercial tree species with diameter of $50 \mathrm{~cm}$ upward is difficult to find, such as in mixed ebony forest, then specifically for ebony forest, reduction of diameter limit to $35 \mathrm{~cm}$ for cutting is allowed, with minimum number of nucleus trees 23 trees per hectare (with minimum diameter of $15 \mathrm{~cm}$ ). Cutting rotation is established as 45 years.

Taken from: Handbook of Indonesia Forestry. MoF. 1997 


\section{Appendix 12 \\ Legislation relevant to the harvest of non-protected wildlife species in Indonesia - 2004}

A selection of articles from the following relevant laws and regulations:

- Government Regulation No: 8 year 1999 concerning the utilization of wild plant and animal species.

- Decision Ministry of Foresty No: 447/Kpts-II/2003 concerning exertion in collecting or catching and distribution wild plant and animal.

- Decision Director General Forest Protection and Nature Conservation, No. 158/ KPTS/DJ-IV/2003 concerning quota of collecting wild plants and catching wild animals for the period of year 2004. 


\title{
THE MINISTRY OF FORESTRY OF THE REPUBLIC OF INDONESIA MINISTRY OF FORESTRY DECREE Number 447/Kpts-II/2003
}

CONCERNING

\section{THE ADMINISTRATIVE SYSTEM FOR THE COLLECTION AND DISTRIBUTION OF WILD PLANTS AND ANIMALS}

\author{
Part Two \\ The Collection of Wild Plant and Animal Products from their \\ Natural Habitat \\ Paragraph 1 \\ Determining Quota
}

\section{Section 6}

(1) The quota for the collection of wild plant and animal specimens from their natural habitat shall be limited to the type and total number of specimens of the species that can be obtained or caught from their natural habitat.

(2) The Director General shall determine the quota with recommendations from a specialist every year, starting from 1 January and finishing on 31 December.

\section{Section 7}

(1) Each quota shall consist of: both the Latin and local names of the species, maximum or minimum size, the number of individuals that maybe caught, and the collecting or catching area, at the Provincial level, or the agency's fieldwork area.

(2) A quota should aim for utilization inside and outside of the country (export).

(3) A quota shall be determined for wild plant and animal specimens, included or not included in the list of Appendix CITES, both protected or un-protected species by law.

\section{Section 8}

(1) The recommendation shall be based on scientific data and information obtained from an inventory as a result of the monitoring of a population.

(2) If this type of data and information is not available, relative information may be obtained based on:

a. The condition of the habitat and the species population; 
b. Scientific information and other technical information concerning a population and its habitat or species that has been previously determined;

c. The results of the collection of wild plants and animals from quota data for the previous year;

d. Traditional knowledge

\section{Section 9}

(1) The monitoring and inventory of a wild plant or animal population may be conducted by a specialist, the forestry agency, authorized office under the Province or District/Town, University, or Non Government Organisation, where the main task is to conserve the species.

(2) The monitoring and inventory must be conducted following standard methods that have been decided or developed by a specialist.

(3) The monitoring and inventory results must be given directly to the specialist or the Director General or head of the forestry agency.

(4) If the results of a monitoring programme are conveyed directly to an authorised office/forestry agency, this data shall in turn be passed on to the specialist via the Director General and shall be used in determining any recommendation for a quota for the species in question.

\section{Section 11}

(1) If the population of a particular species is unprotected and it has not been listed on the CITES Appendices, then the specialist can give recommendations to determine the specifics of the restricted species in question, that may be collected or caught. There is no need to determine the limitations of the population of the species.

(2) The specifics may include size, maximum and or minimum weight, year class, sex, location, and time for collecting or catching.

\section{Section 12}

(1) The Director General will analyse the recommendations of the specialist and then determine the quota for the collection of wild plant and animal specimens from the natural habitat.

(2) Based on considerations received from technical management, the Director General may determine a smaller quota than that recommended by the specialist. 
(3) Observations to determine a fixed quota can be conducted throughout the current year, based on the specialist's recommendations.

\section{Paragraph 2 Dividing the Quota and Determining the Location}

\section{Section 13}

(2) The head of the forestry agency may determine the location for the collection of a particular species.

(3) The head of the forestry agency may use the quota as a base to produce a permit for the collection of wild plant and animal specimens.

(4) The head of the forestry agency and Dinas are prohibited from issuing permits for the collection of wild plants and animals without direct reference to the quota, decided by the Director General.

\section{Section 15}

(1) To determine the location, the head of the forestry agency will consider the status of the area, total population, habitat condition, land use plan, and aspects of the local community and their culture.

(2) The location must include information about the name of the place or village, sub-district, district, and or map coordinates and geography.

(3) A map of the location must be produced on a scale of 1:250,000, which must be renewed periodically at least every two years.

\section{Section 16}

(1) To ensure the sustainability of the population, the head of the forestry agency must rotate the collection location within the area.

(2) The rotation time must be determined based on the condition of the population, habitat, biological characteristics, and the determined behaviour of the species. 


\section{CHAPTER III UTILIZATION OF WILD PLANT AND ANIMAL SPECIMENS \\ Part One \\ General}

\section{Section 24}

(1) The utilization of wild plant and animal specimens can be divided into:

a. Non-commercial utilization: for study, research and development purposes, the exhibition of specimens for non-commercial use, exchange, hunting, and cultivation for pleasure;

b. Commercial utilization for rehabilitation, trading, the exhibition of specimens for commercial use, and the cultivation of medicinal plants.

(2) Commercial utilization may only be undertaken by a wild plant and animal distributor (in the country or foreign country)

\section{Section 26}

(1) A permit must be obtained for the collection of wild plants and animals

(2) Commercial distribution may only be permitted for a distributor who is already registered and acknowledgeable, in the country or foreign country.

(3) For collecting and catching commercially, the collector must obtain a permit

\section{Part Two \\ A Permit for Collecting Wild Plants and Animals \\ Paragraph 1 \\ General}

\section{Section 27}

(1) The collection of wild plants and animals must not be undertaken without a permit. The permit must state the location for which the individual or group may undertake the collection. The collection of a plant or animal should not damage the population in its natural habitat.

(2) The assessment must be based on a completed application, which may be approved or refused by the Ministry based on suggestions from the Director General and recommendations from the specialist. The implementation for the collection of specimens should not damage the population in their natural habitat. 


\title{
CHAPTER VI \\ LAW ENFORCEMENT AND SANCTIONS
}

\author{
Part One \\ Law Enforcement
}

Part Two

Confiscation

\section{Section 111}

Wild plant and animal specimens related to a violation will be confiscated by the state as referred to in Government Regulation No. 8 year 1999.

\section{Part Three \\ Sanctions}

\section{Section 112}

(1) All violators will be penalized as per Government Regulation No. 8 year 1999 concerning the utilization of Wild Plants and Animals.

(2) An administration fine and permit revocation will be carried out by the permit authority.

(3) Permit revocation will be effective following three warnings. 


\section{GOVERNMENT REGULATION REPUBLIC INDONESIA \\ NUMBER 8 YEAR 1999}

THE PRESIDENT OF THE REPUBLIK OF INDONESIA,

CONCERNING

THE UTILIZATION OF WILD PLANT AND ANIMAL SPECIMENS

CHAPTER XII

Sanctions

\section{Section 50}

(3) For those who have removed wild plants or animals from their natural habitat without permission an administration fine totalling 40 million Rupiah will be charged and no future permit for the utilization of wild plants and animals will be granted. 


\section{Index}

\section{A}

Accipiter trivirgatus, 13, 175

Aceros comatus, 57

Aceros corrugatus, 57, 216

Aceros undulatus, 174

Aceros waldeni, 59

Achatina fulica, 48, 49

Acrochordus javanicus, 277

Actenoides concretus, 212

Aegithina tiphia, 204

Aethopyga siparaja, 14

Agathis borneensis, 199

Aglaia spp., 57, 159, 174, 221

Ahaetulla prasina, 277

Albizia falcataria, 82

Alcedo atthis, 13

Alcedo euryzona, 13, 141, 170, 176, 212

Alcippe brunneicauda, 213

Alophoixus phaeocephalus, 230, 232

Amazona vittata, 194

Amyda cartilaginea, 170, 176, 185, 213, 277

Anguilla malgumora, 109, 110, 281

Anguilla nebulosa, 281

Annona muricata, 83

Annona spp., 264

Anorrbinus galeritus, 14, 58, 59, 216,
Ansonia albomaculata, 99

Ansonia leptopus, 275

Ansonia longidigita, 103

Ansonia sp., 275

Ansonia spinulifer, 103

Anthracoceros albirostris, 57, 174

Anthracoceros malayanus, 14, 56, 57, 58,

$141,169,174,212,216,220$

Anthreptes malacensis, 14

Anthreptes rhodolaema, 14, 213

Anthreptes singalensis, 14

Apis dorsata, 216

Apis spp., 164

Aquilaria, 10

Arachnothera affinis, 14

Arachnothera chrysogenys, 14

Arachnothera flavigaster, 14

Arachnothera longirostra, 14

Arachnothera robusta, 14

Arctictis binturong, 12, 87, 88, 216, 258

Arctogalidia trivirgata, 87, 88, 122, 124,

262

Argusianus argus, 13, 56, 64, 66, 169,

$175,212,215,226$

Artocarpus integer, 274

Artocarpus spp., 78, 159, 165, 273

Aviceda jerdoni, 13

217 
B

Baccaurea spp., 158, 159

Bactris spp., 83

Balionycteris maculata, 84

Barbodes balleroides, 109, 281

Barbodes spp., 207

Batrachostomus spp., 134

Berenicornis comatus, 14, 58, 218

Betta unimaculata, 109, 110, 281

Blythipicus pyrrhotis, 232

Blythipicus rubiginosus, 60, 62, 229, 230, 232

Boiga cynodon, 277

Boiga dendrophila, 277

Boiga jaspidea, 277

Boiga nigriceps, 277

Bombax ceiba, 262

Bos gaurus, 50

Bos javanicus, 13, 42, 43, 50, 92, 95, 170, 202, 213

Bronchocela cristatella, 277

Buceros rhinoceros, 14, 58, 141, 169, 212, 215, 221,

Buceros vigil, 215

Bufo asper, 275

Bufo divergens, 99, 103, 275

Bufo juxtasper, 102, 275

Bufo typhonia, 103

Bungarus flaviceps, 277

C

Cacatua sulphurea, 48

Calamaria bicolor, 277

Calamaria sp., 277

Calamus spp., 164

Callosciurus caniceps, 80, 251

Callosciurus nigrovittatus, 80

Callosciurus notatus, 71, 78, 80, 124, 250, 251

Callosciurus prevostii, 78, 79, 80, 124, 251

Calophyllum spp., 133

Calyptomena hosii, 212

Calyptomena viridis, 55, 67, 212

Campnosperma spp., 133
Camponotus gigas, 227

Canarium spp., 83

Canis familiaris, 202

Carica papaya, 83

Caryota spp., 83

Casnierodius albus, 13

Castanopsis spp., 133

Castinopsis spp., 271

Catopuma badia, 123, 140, 204

Ceiba pentandra, 31

Celeus brachyurus, 62, 230, 233

Cervus unicolor, 13, 27, 41, 92, 94, 124, 140, 171, 172, 185, 202, 204, 215 . 269

Ceyx erithacus, 13

Chaperina fusca, 103, 275

Chironax melanocephalus, 84

Chloropsis cochinchinensis, 204

Chrotogale owstoni, 259

Chrysalidocarpus spp., 83

Chrysopelea paradisii, 277

Ciconia stormi, 170, 185, 212

Claris anfractus, 281

Clerodendrum infortunatum, 48

Cocos nucifera, 165

Collocalia fuciphaga, 215

Connarus spp., 262, 264

Copsychus malabaricus, 215

Coracina fimbriata, 204

Cosymbotus platyurus, 278

Cotylelobium spp., 153

Crematogaster spp., 234

Crocodylus porosus, 104, 105, 206, 278

Crocodylus siamensis, 105

Cuculus vagans, 212

Culicapa ceylonensis, 56

Cyclemys dentata, 215, 278

Cyclocheilichthys armatus, 109, 110, 281

Cyclocheilichthys repasson, 109, 110, 281

Cylindrophis ruffus, 278

Cynocephalus variegatus, 135, 136

Cynogale bennettii, 13, 87, 88, 140, 153, 170

Cynometra cauliflora, 83

Cynopterus brachyotis, 84 
Cynopterus horsfieldii, 84

Cynopterus spp., 83

Cyornis spp., 56, 68

Cyornis turcosus, 69, 213

Cyrtodactylus malayanus, 278

D

Dacryodes rugosa, 274

Dacryodes spp., 273

Dendrelaphis caudolineatus, 278

Dendrelaphis formosus, 278

Dendrocopus canicapillus, 62, 234

Dialium indum, 153

Dialium spp., 133

Dicerorhinus sumatrensis, 42, 43

Dicranopteris spp., 271

Dicrurus paradiseus, 229, 230, 236, 237, 238

Dimocarpus spp., 158

Dinopium rafflesii, 60, 62, 141, 229, 230, 236

Diplogale hosei, 259

Dipterocarpus confertus, 255

Dipterocarpus spp., 153, 177, 206

Dogania subplana, 216

Draco cornutus, 278

Draco spp., 129

Dracontomelon dao, 159

Dracontomelon spp., 158

Dryobalanops spp., 153

Dryocopus javensis, 60, 62, 233

Ducula pickeringii, 142

Durio oxleyanus, 159

Durio spp., 84, 94, 133, 165, 271, 273, 274

Durio zibethinus, 159

Dyera spp., 134

Dysoxylum spp., 159

\section{$\mathbf{E}$}

Echinosorex gymnurus, 81, 136

Egretta garzetta, 13

Egretta intermedia, 13

Eichornia crassipes, 48

Elaeocarpus sphaericus, 83
Elaphe flavolineata, 278

Elephas maximus, 43

Enhydris doriae, 278

Enicurus ruficapillus, 212

Eonycteris spelea, 84

Eucaplyptus deglupta, 82

Eugeissona spp., 165

Eugeissona utilis, 45

Eugenia spp., 83

Eupatorium odoratum, 48

Eupatorium spp., 48

Eupetes macrocerus, 68

Eurylaimus ochromalus, 213

Eusideroxylon zwageri, 31, 33, 164, 199

$\mathbf{F}$

Fejervarya cancrivora, 103, 275

Felis bengalensis, 13

Ficedula spp., 56, 68

Ficus auranticacea, 220

Ficus drupacea, 176

Ficus spp., 33, 57, 83, 158, 159, 174, 198, 206, 223, 258, 262, 264, 273

$\mathbf{G}$

Gallus gallus, 66

Gallus spp., 216

Garcinia spp., 158

Garra borneensis, 108, 110, 281

Gastromyzon lepidogaster, 108, 281

Gastromyzon spp., 108, 110

Gekko smithi, 278

Geochelone emys, 104

Glyptothorax platypogonoides, 109, 110, 281

Gmelina arborea, 82

Gonocephalus grandis, 278

Gonyosoma oxycephalum, 278

Gracula religiosa, 46, 141, 215

Grewia latifolia, 255

\section{H}

Haemaphysalis asiaticus, 265

Halcyon pileata, 14

Haliastur indus, 13, 216 
Hampala macrolepidota, 108, 110, 281

Harpactes diardii, 13, 56, 67, 213, 238

Harpactes duvaucelii, 13, 67, 213, 230, 236, 240

Harpactes kasumba, 13, 67, 213, 239

Harpactes oreskios, 13, 67, 239

Harpactes orrhophaeus, 241

Harpactes reinwardtii, 67

Harpactes spp., 56

Helarctos malayanus, 193, See Ursus malayanus

Hemibagrus baramensis, 109, 281

Hemibagrus nemurus, 108, 110, 281

Hemicircus concretus, 60, 63, 229, 230, 236

Hemigalus derbyanus, 87, 88, 122, 124, 259

Hemipus hirundinaceus, 204

Heosemys spinosa, 278

Hieraaetus kienerii, 13

Hipposideros ridleyi, 85

Hipposideros spp., 134

Homaloptera spp., 110

Homaloptera stephensoni, 109, 281

Hopea spp., 59, 153, 223

Hoplobatrachus rugulosus, 48, 49, 103, 275

Huia cavitympanum, 103

Hylobates lar, 74

Hylobates muelleri, 12, 75, 76, 124, 128,

140, 172, 213, 216, 247

Hylobates spp., 204

Hylomys suillus, 136

Hypogranmia hypogranmmici, 14

Hypothymis azurea, 69, 237

Hystrix brachyura, 12, 171, 215

I

Ichthyophaga humilis, 13, 212

Ichthyophis sp., 275

Ictinaetus malayensis, 13

Imperata arundinacea, 48

Imperata cylindrica, 9, 48, 270

Instia spp., 252

Irena puella, 67, 141
Jasminium spp., 48

$\mathbf{K}$

Kalophrynus heterochirus, 103

Kalophrynus pleurostigma, 103

Kenopia striata, 56, 68, 213

Kerivoula papillosa, 86

Knema spp., 224

Koompassia spp., 164, 252

Koordersiondendron spp., 158

Lacedo pulchella, 14, 141

Lansium domesticum, 83

Lantana camara, 48

Lariscus hosei, 80, 124, 141, 253

Lariscus insignis, 33, 78, 79, 80, 124, 141, 252, 253

Leiocassis spp., 109, 281

Lenothrix canus, 71, 81

Leopoldamys sabanus, 71, 81

Leptobarbus melanotaenia, 109, 110, 111,281

Leptobarbus spp., 207

Leptobrachella baluensis, 103

Leptobrachella mjobergi, 99, 275

Leptobrachella sp., 103

Leptobrachium abbotti, 99, 102, 275

Leptobrachium montanum, 101, 103

Leptolalax dringi, 102

Leptolalax gracilis, 275

Leptolalax pictus, 275

Lepturophis albofuscus, 278

Leucaena spp., 48

Limnonectes finchi, 102, 275

Limnonectes ibanorum, 101, 103, 275

Limnonectes ingeri, 103, 275

Limnonectes kublii, 102, 103, 276

Limnonectes leporinus, 101, 102, 103, 276

Limnonectes palavanensis, 276

Limnonectes paramacrodon, 276

Limnonectes spp., 100

Lipinia quadrivittata, 278 
Lithocarpus spp., 133, 271

Livistona spp., 83

Lobiophasis bulweri, 13, 64, 66, 130, 169, 170, 175, 212, 225

Lobocheilos bo, 108, 109, 111, 281

Lonchura spp., 202

Lophura bulweri. See Lobiophasis bulweri Lophura erythrophthalma, 56, 64, 66, 168, 169, 175, 185, 212, 223, 224

Lophura ignita, 64, 65, 66, 122, 175 , 216, 224, 225

Lophura leucomelana lathami, 66

Lophura spp., 130

Loriculus galgulus, 46, 216

Lutra spp., 213

\section{M}

Mabuya rudis, 279

Macaca fascicularis, 75, 77, 124, 169, 172, 213, 216, 244, 246

Macaca nemestrina, 74, 75, 77, 119, 124, 170, 172, 185, 213, 246

Macaca spp., 202

Macaranga spp., 31, 61, 236

Macroglossus minimus, 84

Macrognathus spp., 110

Macronous gularis, 229, 230

Macronous ptilosus, 213

Macronous spp., 68

Madhuca spp., 133

Malacopteron affine, 213

Malacopteron cinereum, 68, 230, 238

Malacopteron magnum, 213

Malacopteron spp., 68, 204

Mangifera indica, 83

Mangifera spp., 159, 165

Manilkara achras, 83

Manis javanica, 12, 136, 169, 174, 213, 215, 274

Manouria emys, 170, 171, 176, 185, 206, 213, 273, 279

Mastacembelus maculates, 281

Mastacembelus spp., 110

Mastacembelus unicolor, 108, 281

Maticora bivirgata, 279
Maticora intestinalis, 279

Maxomys rajah, 71, 81, 259

Maxomys surifer, 71, 81

Maxomys whiteheadi, 81

Megaderma spasma, 86

Megalaima chrysopogon, 229

Megalaima henricii, 213

Megalaima mystacophanos, 213

Megalaima rafflesii, 213

Megophrys nasuta, 99, 103, 276

Meiglyptes tristis, 61, 63, 229, 235, 236

Meiglyptes tukki, 141, 213, 229, 230, 232, 235, 236, 237

Melastoma spp., 48

Melia azedarach, 83

Meliosma sumatrana, 159

Meristogenys orphnocnemis, 102

Meristogenys phaeomerus, 276

Meristogenys spp., 99

Meristogenys whiteheadi, 276

Metaphrynella sundana, 102, 276

Microhierax fringillarius, 13

Microhyla berdmorei, 103

Microbyla borneensis, 99, 103, 276

Microhyla petrigena, 103

Microbyla spp., 99

Microros spp., 158

Mikania micantha, 48

Mikania scandens, 48

Mulleripicus pulverulentus, 59, 60, 61, 63, 229

Muntiacus atherodes, 92, 93, 94, 124, 140, 268, 269

Muntiacus muntjak, 13, 92, 93, 94, 124, $185,215,268$

Muntiacus spp., 50

Musa spp., 83

Mustela nudipes, 215

Myotis spp., 85

Myristica spp., 57, 174

$\mathbf{N}$

Naja sumatrana, 279

Napothera spp., 56

Nasalis larvatus, 12, 170, 172, 213, 245 
Nectarinia sperata, 14

Neesia spp., 271

Nemacheilus saravacensis, 109, 110, 281

Nemacheilus selangoricus, 109, 110, 281

Nemacheilus spiniferus, 110, 281

Nematabramis everetti, 108, 110, 281

Neofelis nebulosa, 7, 13, 35, 86, 135, 140, 169, 204, 213, 216

Neogastromyzon nieuwenhuisi, 109, 281

Neogastromyzon spp., 110

Nephelium spp., 158, 159

Niviventer cremoriventer, 81

Notochelys platynota, 170, 176, 185, 213, 279

Nycteris tragata, 86

Nycticebus coucang, 12, 124, 136, 170, $172,213,216,242$

Nyctixalus pictus, 103, 276

$\mathbf{0}$

Occidozyga baluensis, 103

Occidozyga laevis, 103

Octomeles sumatrana, 93

Oligodon purpurascens, 279

Oligodon sp., 279

Ompok bimaculatus, 109, 281

Ophiophagus hannah, 216, 279

Oriolus xanthonotus, 213

Orlitia borneensis, 170, 185, 206, 213, 279

Osphronemus septemfasciatus, 282

Osteochilus chinni, 108

Osteochilus spp., 111

Osteochilus waandersii, 108, 282

Otus rufescens, 134

$\mathbf{P}$

Paguma larvata, 87, 88, 260, 262

Palamneus sulpides, 264

Palaquium spp., 133

Pandanus spp., 273

Pangasius spp., 111, 176, 207

Panthera pardus, 35, 135

Panthera tigris, 35, 135, 173

Parachela ingerkongi, 109, 282
Paradoxurus hermaphroditus, 87, 88, 124, 216, 261, 262

Pardofelis marmorata, 13, 86, 123, 204, 213, 216

Parhomaloptera spp., 110

Parkia javanica, 159

Parkia speciosa, 84, 159, 223

Passiflora foetida, 262

Passiflora spp., 48

Payena spp., 133

Pedostibes hosii, 102, 276

Pelargopsis capensis, 13

Pelochelys cantorii, 170, 171, 185, 213, 279

Penelopides exarhatus, 57

Pericrocotus spp., 204

Pernis ptilorhynchus, 13

Petaurista elegans, 254

Petaurista petaurista, 79, 254

Phaenicophaeus chlorophaeus, 229, 230, 233, 236

Phaenicophaeus curvirostris, 229

Philautus hosii, 98, 103

Philautus spp., 98

Philentoma pyrhopterum, 237

Philentoma velatum, 56, 213

Picumnus innominatus, 60

Picus chlorophus, 228

Picus mentalis, 61, 62, 228, 229, 231, 232, 233, 234

Picus miniaceus, 62, 228, 230, 231

Picus puniceus, 60, 61, 62, 122, 227, 230, 231, 234

Piper aduncum, 83

Pipistrellus spp., 85

Pithecellobium spp., 159

Pitta caerulea, 14, 213

Pitta granatina, 14, 213

Polyalthia spp., 262

Polypedates colletti, 101, 103, 276

Polypedates leucomystax, 103, 276

Polypedates macrotis, 101, 103, 276

Polypedates otilophus, 103, 276

Polyplectron bicalcaratum, 66

Polyplectron schleiermacheri, 64, 65 
Pomacea canaliculatus, 48

Pometia spp., 133

Pongo pygmaeus, 43, 73, 140, 193, 204

Porhomatoptera microstoma, 282

Pouteria spp., 133

Presbytis femoralis, 74, 75

Presbytis frontata, 140

Presbytis hosei, 27, 75, 76, 124, 140, 169, 172, 185, 213, 215, 248, 249

Presbytis rubicunda, 12, 77, 124, 132, 172, 213, 249, 250

Presbytis spp., 43, 205

Prionailurus bengalensis, 27, 50, 86

Prionodon linsang, 13, 87, 88

Protomyzon griswoldi, 282

Protomyzon spp., 110

Psammodynastes pulverulentus, 279

Pseudorhabdion collaris, 279

Pseudorhabdion sarawakensis, 279

Psidium guajava, 83

Psidium spp., 48

Pteropus spp., 83

Pteropus vampyrus, 84, 216

Ptilocichla leucogrammica, 68, 170, 185, 212

Ptyas fuscus, 279

Puntius binotatus, 109, 110, 282

Puntius sealei, 109, 110, 282

Puntius spp., 109

Pycnonotus cyaniventris, 67

Pycnonotus erythropthalmos, 67

Pycnonotus eutilotus, 67

Pycnonotus melanoleucos, 67, 212

Pycnonotus squamatus, 67, 212

Pycnonotus zeylanicus, 46, 67, 168, 169,

$175,185,212,215$

Python curtus, 279

Python reticulatus, 215, 279

Python spp., 206

Q

Quercus spp., 133, 271
$\mathbf{R}$

Rafflesia spp., 94, 271

Ramphotyphlops braminus, 279

Rana catesbeiana, 49, 103

Rana chalconota, 99, 102, 276

Rana hosii, 276

Rana nicobariensis, 101, 103, 276

Rana palavanensis, 102

Rana picturata, 102, 276

Rana signata, 101, 103

Rasbora argyrotaenia, 109, 282

Rasbora caudimaculata, 109, 110, 282

Rasbora elegans, 108, 110, 282

Rasbora lateristriata, 109, 282

Rattus tiomanicus, 71, 81, 216

Ratufa affinis, 27, 78, 80, 124, 130,

133, 141, 252

Ratufa bicolor, 78, 80, 133

Reinwardtipicus validus, 60, 63, 230, 233, 236

Rhacophorus dulitensis, 101, 103

Rhacophorus gauni, 103

Rhacophorus harrissoni, 276

Rhacophorus nigropalmatus, 101, 103, 276

Rhacophorus pardalis, 99, 101, 102, 276

Rhacophorus spp., 103

Rheithrosciurus macrotis, 79

Rhinolophus sedulus, 86

Rhinolophus spp., 134

Rhinomyias spp., 68

Rhinomyias umbratilis, 56

Rhinoplax vigil, 14, 57, 58, 59, 133,

141, 174, 212, 222

Rhinosciurus laticaudatus, 79, 80, 122,

124, 141, 258

Rhipidura javanica, 14

Rhipidura perlata, 56, 229, 236, 238

Rhyticeros cassidix, 57

Rhyticeros corrugatus, 57

Rhyticeros everetti, 57

Rhyticeros undulatus, 14, 58, 219

Rollulus rouloul, 170, 185, 212

Russula sp., 93 


\section{$\mathbf{S}$}

Saccharum spontaneum, 48

Salivinia spp., 48

Santiria laevigata, 222

Santiria oblongifolia, 159

Sasia abnormis, 59, 60, 62, 131, 230, $232,233,237$

Scotophilus spp., 85

Sechium edule, 83

Setornis criniger, 229

Shorea beccarianna, 255

Shorea pinanga, 133

Shorea robusta, 59

Shorea spp., 37, 59, 271

Shorea xanthophylla, 222, 250

Sphaeropieus spp., 264

Sphenomorphus sabanus, 279

Spilornis cheela, 13

Spilornis kinabaluensis, 170, 175, 185, 212

Spizaetus alboniger, 13

Spizaetus barteli, 69

Spizaetus cirrhatus, 13

Spizaetus spp., 69

Spizella passerina, 69

Stachyris erythroptera, 229

Stachyris maculata, 213, 229, 237

Stachyris nigricollis, 213, 229

Stachyris spp., 204

Staurois guttatus, 276

Staurois latopalmatus, 102

Staurois natator, 102

Staurois tuberilinguis, 276

Sterculia parvifolis, 222

Sterna albifrons, 13

Sterna hirundo, 13

Sundasciurus hippurus, 79, 80, 124, 141, 255

Sundasciurus jentinki, 257

Sundasciurus lowii, 79, 80, 124, 256

Sundasciurus tenuis, 78, 79, 80, 124, 257
Sus barbatus, 27, 48, 49, 92, 94, 124,

171, 193, 200, 202, 204, 205, 215. 270

Sus scrofa, 48, 49, 270, 271

$\mathbf{T}$

Takydromus sexlineatus, 280

Taphozous spp, 85

Tarsius bancanus, 12, 77, 122, 124, 213, 243

Ternstroemia magnifica, 271

Terpsiphone paradisi, 237

Tetramarista glabra, 159

Theobroma cacao, 82

Tomistoma schlegelii, 104

Tor spp., 108, 111, 176, 207

Tor tambra, 109, 142, 215, 282

Tor tambroides, 282

Trachypithecus cristatus, 74

Tragulus javanicus, 13, 33, 93, 185, 265, 266

Tragulus kanchil, 92, 124, 265

Tragulus napu, 13, 92, 93, 124, 185, 215, 266, 267

Tragulus spp., 27, 50, 137, 140, 171

Trema, 159

Trema orientalis, 31

Trema spp., 34

Treron capellei, 142, 170, 176, 185, 212

Treron curvirostra, 216

Treron fulvicollis, 142

Trichastoma rostratum, 68, 213

Trichgaster trichopterus, 282

Trichoglossus haematodus, 48

Trichys fasciculata, 216

Trimeresurus albolabris, 280

Tropidolaemus wagleri, 280

Tropidophorus brookei, 280

Tupaia glis, 71, 81

Tupaia gracilis, 82, 83

Tupaia longipes, 82, 83

Tupaia minor, 82

Tupaia tana, 81, 82 


\section{$\mathbf{U}$}

Urostigma spp., 223

Ursus malayanus, 7, 12, 27, 50, 89, 90,

$91,124,135,140,156,169,173$,

201, 202, 204, 213, 215, 272

\section{V}

Vallaris solanacea, 262

Varanus heteropholis, 104

Varanus rudicollis, 104, 216, 280

Varanus salvator, 104, 280

Varanus spp., 104

Vatica spp., 37, 153

Viverra tangalunga, 27, 87, 88, 89, 122, 130, 263 


\section{Literature cited}

Abdulhadi, R., E. Mirmanto, and K. Kartawinata. 1987. A lowland dipterocarp forest in Sekundur, North Sumatra, Indonesia: five years after mechanized logging. Pages 255-273 in A.J.G.H. Kostermans, editor. Proceedings of the third round table conference on dipterocarps, UNESCO/ ROSTSEA. Jakarta, Indonesia.

Abdulhadi, R., K. Kartawinata, and S. Sukardjo. 1981. Effects on mechanized logging in the lowland dipterocarp forest at Lempake, East Kalimantan. Malaysian Forester 44:407-418.

Adjers, G., K. Nuryanto, and J. Kuusipalo. 1996. Rehabilitation of degraded dipterocarp forests: results from South Kalimantan, Indonesia. Pages 316-334 in S. Appanah and K.C. Khoo, editors. Proceedings fifth round table conference on dipterocarps. 7-10 November 1994. Chiang Mai, Thailand. FRIM, Kepong, Malaysia.

Ahmad, A. H. 1994. The Ecology of Mousedeer (Tragulus species) in a Bornean rain forest, Sabah, Malaysia. MSc thesis. University of Aberdeen, Aberdeen, UK.

Ahmad, N. 2001. Frugivores and fruit production in primary and logged tropical rainforests. PhD dissertation. Faculty of Science and Technology. Universitas Kebangsaan Malaysia, Bangi, Malaysia.

Ahmad, N., M. N. Hasan, and A. L. Mohamad. in press. Diversity and density of primates in primary and logged lowland tropical rain forest at Danum Valley, Sabah, Borneo. Biodiversity and Conservation.

Aldrich-Blake, F. P. G. 1980. Long-tailed macaques. Pages 147-165 in D. J. Chivers, editor. Malayan Forest Primates: ten years' study in tropical rain forest. Plenum Press, New York, USA.

Alexander, I., N. Ahmad, and L. S. See. 1992. The role of mycorrhiza in the regeneration of some Malaysian forest trees. Philosophical Transactions of the Royal Society of London. Series B, Biological Sciences 335:379-388.

Ali, S. 1953. The birds of Travancore and Cochin. Oxford University Press, Bombay, India.

Anderson, A. J. U. 1979. Subsistence of the Penan in the Mulu area of Sarawak. Sarawak Gazette 105: 204-216.

Anggraini, K., M. Kinnaird, and T. O'Brien. 2000. The effects of fruit availability and habitat disturbance on an assemblage of Sumatran hornbills. Bird Conservation International 10:189-202.

Anonymous. 1981. Pangolin skins for cowboy boots. Oryx 16:138.

Appanah, S. 1998. Management of natural forests. Pages 133-149 in S. Appanah, and J. M. Turnbull, editors. A review of dipterocarps, taxonomy, ecology and silviculture. CIFOR, Bogor, Indonesia.

Appanah, S. and A. M. Mohd-rasol. 1990. Smaller trees can fruit in logged dipterocarp forests. Journal of Tropical Forest Science 3:80-87.

Appanah, S. and J. M. Turnbull, editors. 1998. A review of dipterocarps. Taxonomy, ecology and silviculture. CIFOR, Bogor, Indonesia. 
Applegate, G., F. E. Putz, L. K. Snook. 2004. Who pays for and who benefits from improved timber harvesting practices in the tropics?: lessons learned and information gaps. CIFOR, Bogor, Indonesia.

Applegate, G., K. Kartawinata, Machfudh, and A. Klassen. 2001. Reduced impact logging guidelines for Indonesia. CIFOR, Bogor, Indonesia.

ARCBD. 2002. Biodiversity information sharing service (BISS). ASEAN Regional Centre for Biodiversity Conservation. http://www.arcbc.org.ph/data_bases.htm.

Asquith, N. M., S. J. Wright, and M. J. Clauss. 1997. Does mammal community composition control recruitment in neotropical forests? Evidence from Panama. Ecology 78:941-946.

Augeri, D. 2004a. Effects of disturbance on Malayan Sun Bear habitat use. Presented paper at the International Conference on Conservation Science, Cambridge, UK.

Augeri, D. 2004b. Disturbance effects on sun bears and their primary competitors in Indonesia. Invited paper. Presented at the Conservation Biology Seminar Series. Department of Zoology, University of Cambridge, UK.

Augeri, D. M. 1994. Assessment of Trans Canada Highway perturbation on Black Bear population, guild and community structures in Banff National Park. Unpublished report and proposal for Parks Canada.

Augeri, D. M. 1995. Natural and anthropogenic disturbance effects on edge character and diversity. MSc Thesis. Department of Forest Sciences \& Program for Ecological Studies, Colorado State University, USA.

Augeri, D. M. 2001. Potential disturbance effects on Malayan Sun Bear (Helarctos malayanus). Ecology, landscape use and conservation in Indonesia and Malaysia. Unpublished report. University of Cambridge, Cambridge, UK.

Augeri, D. M. 2002. Effects on Sun Bear (Helarctos malayanus) habitat selection, ecology and landscape use. Paper presented at the International Bear Association Annual Meeting 2002, Steinkjer, Norway.

Augeri, D. M. 2003. Conservation of the Malayan Sun Bear (Helarctos malayanus) in Indonesia: Mitigating potential bear/human conflicts and disturbance effects on Sun Bear ecology and landscape use. Unpublished report for the Indonesian Institute of Sciences.

Austin, S. C. and M. E. Tewes. 1999. Observation of viverrid, mustelid and herpestid species in Khao Yai NP, Thailand. Small Carnivore Conservation no. 21:13-15.

Auzel, P. and D. S. Wilkie. 2000. Wildlife use in northern Congo: hunting in a commercial logging concession. Pages 413-426 in J. G. Robinson, and E. L. Bennett, editors. Hunting for sustainability in tropical forests. Columbia University Press, New York, USA.

Azlan, J. M. 2003. The diversity and conservation of mustelids, viverrids and herpestids in a disturbed forest in Peninsular Malaysia. Small Carnivore Conservation 29:8-9.

Backer, C. A. and R. C. Bakhuizen-van den Brink Jr. 1963-1968. Flora of Java. Vol. 1-3. WoltersNoordhoff, Groningen, the Netherlands.

Bakshi, B. K., Y. N. Puri, and S. Singh. 1967. Natural decay resistance of Indian timbers. II Decay resistance of sal (Shorea robusta Gaertn.) and teak (Tectona grandis L.f.). Indian Forester 93: 305328.

Bakuneeta, C., K. Johnson, R. Plumptre, and V. Reynolds. 1995. Human uses of tree species whose seeds are dispersed by chimpanzees in the Budongo forest. African Journal of Ecology 33:276-278.

Banks, E. 1931. A popular account of the mammals of Borneo. Journal of the Malayan Branch of the Asiatic Society 9:137.

Banks, E. 1937. The distribution of Bornean birds. Sarawak Museum Journal 4:453-496.

Banks, E. 1949. Bornean mammals. The Kuching Press, Kuching, Sarawak.

Barber, C. V. and J. Schweithelm 2000. Trial by fire. Forest fires and forestry policy in Indonesia's era of crisis and reform. World Resources Institute (WRI), Forest Frontiers Initiative. In collaboration with WWF-Indonesia and Telapak Indonesia Foundation, Washington D.C, USA.

Barrett, E. B. M. 1984. The ecology of some nocturnal arboreal mammals in the rain forest of Peninsular Malaysia. PhD dissertation. University of Cambridge, UK.

Barrette, C. 1977. Some aspects of the behaviour of muntjacs in Wilpattu National Park. Mammalia 41:1-34.

Bartels, M. and H. Bartels. 1937. Uit het leven der Neushoornvogels (I, II, III) (from the Life of Hornbills). Tropische Natuur 26:117-127, 140-147, 166-172. 
Basuki, I. and D. Sheil. 2005. Local perspectives of forest landscapes: A preliminary evaluation of land and soils, and their importance in Malinau, East Kalimantan, Indonesia. CIFOR, Bogor, Indonesia.

Baur, K. S. and M. Hadley. 1990. Reproductive ecology of tropical forest plants. Man and the Biosphere series. UNESCO, Paris, France.

Bearder, S. K. 1987. Lorises, bushbabies, and tarsiers: diverse societies in solitary foragers. Pages 11-24 in B. B. Smuts, D. L. Cheney, S. R.M., R. W. Wrangham, and T. T. Struhsaker, editors. Primate Societies. Univ. of Chicago Press, Chicago, USA.

Becker, P. and M. Wong. 1985. Seed dispersal, seed predation, and juvenile mortality of Aglaia sp. (Meliaceae) in lowland dipterocarp rainforest. Biotropica 17:230-237.

Becker, P., M. Leighton, and J. Payne. 1985. Why tropical squirrels carry seeds out of source crowns. Journal of Tropical Ecology 1:183-186.

Beebe, W. 1918-1922. A monograph of the pheasants. Witherby, London, UK.

Beier, P. and R. F. Noss. 1998. Do habitat corridors provide connectivity? Conservation Biology 12: 1241-1252.

Belovsky, G. E. 1987. Extinction models and mammalian persistence. Pages 35-57 in M. E. Soulé, editor. Viable populations for conservation. Cambridge University Press, Cambridge, UK.

Bennett, E. L. 2002. Is there a link between wild meat and food security. Conservation Biology 16: 590-592.

Bennett, E. L. and A. G. Davies. 1994. The ecology of Asian colobines. Pages 129-171 in A. G. Davies, and J. F. Oates, editors. Colobine monkeys: their ecology, behaviour and evolution. Cambridge University Press, Cambridge, UK.

Bennett, E. L., A. J. Nyaoi, and J. Sompud. 1997. Hornbills Buceros spp. and culture in northern Borneo: Can they continue to coexist? Biological Conservation 82:41-46.

Bennett, E. L., A. J. Nyaoi, and J. Sompud. 1999. Saving Borneo's bacon: The sustainability of hunting in Sarawak and Sabah. Pages 305-324 in J. G. Robinson, and E. L. Bennett, editors. Hunting for sustainability in tropical forests. Columbia University Press, New York, USA.

Bennett, E. L., E. J. Milner-Gulland, M. Bakarr, H. E. Eves, J. G. Robinson, and D. S. Wilkie. 2002. Hunting the world's wildlife to extinction. Oryx 36:328-329.

Bennett, E. L. and J. G. Robinson. 2000. Hunting of wildlife in tropical forests. Implications for biodiversity and forest peoples. The World Bank, Washington, D.C., USA.

Bennett, E. L. and M. T. Gumal. 2001. The inter-relationships of commercial logging, hunting and wildlife in Sarawak, and recommendations for forest management. Pages 359-374 in R. A. Fimbel, A. Grajal, and J. G. Robinson, editors. The cutting edge: conserving wildlife in logged tropical Forest. Columbia University Press, New York, USA.

Bennett, E. L., M. T. Gumal, J. G. Robinson, and A. Rabinowitz. 1996. A masterplan for wildlife in Sarawak. Wildlife Conservation Society and Sarawak Forest Department, Kuching, Malaysia.

Bennett, E. L. and Z. Dahaban. 1995. Wildlife responses to disturbances in Sarawak and their implications for forest management. Pages 66-86 in R. B. Primack, and T. E. Lovejoy, editors. Ecology, conservation and management of South-East Asian rainforests. Yale University Press, New Haven, USA \& London, UK.

Berenstain, L. 1986. Responses of long-tailed macaques to drought and fire in eastern Borneo: a preliminary report. Biotropica 18:257-262.

Bernard, H. 2004. Effects of selective logging on microhabitat-use patterns of non-volant small mammals in a Bornean tropical lowland mixed-dipterocarp forest. Nature and Human Activities $8: 1-11$.

Bertault J. and K. Kadir. 1998. Silvicultural research in a lowland mixed dipterocarp forest of East Kalimantan: the contribution of STREK project. CIRAD Forêt, FORDA and P.T. INHUTANI I. Bogor Indonesia.

Bertault, J-G. and P. Sist. 1995. The effects of logging in natural forests. Bois et Forêts des Tropiques 245:5-20.

Bertault, J-G. and P. Sist. 1997. An experimental comparison of different harvesting intensities with reduced impact and conventional logging in East Kalimantan. Forest Ecology and Management 94:209-218.

Biedermann, R. 2003. Body size and area-incidence relationships: is there a general pattern? Global Ecology \& Biogeography 12:381-387. 
Bierregaard, R. O. J. and P. C. Stouffer. 1997. Understory birds and dynamic habitat mosaics in Amazonian rainforests. Pages 138-155. Tropical forest remnants: ecology, management, and conservation of fragmented communities. University of Chicago Press, Chicago, USA.

Bierregaard, R. O. J., T. E. Lovejoy, V. Kapos, A. A. dos Santos, and R. W. Hutchings. 1992. The biological dynamics of tropical rainforest fragments. Bioscience 42:859-866.

Bierregaard, R. O., C. Gascon, T. E. Lovejoy, and R. Mesquita 2001. Lessons from Amazonia; the ecology and conservation of a fragmented forest. Yale University Press, New Haven, USA.

Bird, M. in prep. A savanna corridor in Sundaland. Quaternary Science Reviews.

BirdLife International 2001. Threatened birds of Asia: the BirdLife International Red Data Book. BirdLife International, Cambridge, UK.

Blundell, A. G. 1996. A preliminary checklist of mammals at Cabang Panti research station, Gunung Palung National Park, West Kalimantan. Tropical Biodiversity 3:251-259.

Boer, C. 1998. Zur Bedeutung von Baumsturzlücken für die Verteilung und Abundanz von Vogelarten des Unterholzes in Primär- und Sekundärregenwäldern Ostkalimantans. PhD dissertation. JuliusMaximilian-Universität, Würzburg, Germany.

Brandani, A., G. S. Hartshorn, and G. H. Orians. 1988. Internal heterogeneity of gaps and species richness in Costa Rican tropical wet forest. Journal of Tropical Ecology 4:99-119.

Brandon-Jones, D. 1996. The zoogeography of sexual dichromatism in the Bornean grizzled sureli, Presbytis comata (Desmarest, 1822). Sarawak Museum Journal V:177-200.

Bratawinata, A. A. 1994. The influence of the Indonesian Selective Cutting and Replanting system on the structure composition species of the Lowland Dipterocarp forest. Paper presented on the fifth round table conference on dipterocarps, 7-10 November 1994.

Brearley, F. Q., M. C. Press, and J. D. Scholes. 2003. Nutrients obtained from leaf litter can improve the growth of dipterocarp seedlings. New Phytologist 160:101-110.

Brokaw, N. 1987. Gap phase regeneration of three pioneer tree species in a tropical forest. Journal of Ecology 75:9-20.

Brook, B. W., N. S. Sodhi, and P. K. L. Ng. 2003. Catastrophic extinctions follow deforestation in Singapore. Nature 424:420-423.

Brookfield, H. 1997. Landscape history. Land degradation in the Indonesian region. Pages 27-60 in P. Boomgaard, F. Colombijn, and D. Henley, editors. Paper Landscapes. Explorations in the environmental history of Indonesia. KITLV Press, Leiden, The Netherlands.

Brown, B. N. 1976. Phytophthora cinnamomi associated with patch death in tropical rain forests in Queensland. APPS-Newsletter 5:1-4.

Brown, J. H., O. J. Reichman, and D. W. Davidson. 1976. Granivory in desert ecosystems. Annual Review of Ecology and Systematics 10:201-227.

Brown, J. H., T. G. Whitham, K. M. Ernest, and C. A. Gehring. 2001. Complex species interactions and the dynamics of ecological systems: long-term experiments. Science 293:643-650.

Brown, N. D. and S. Jennings. 1998. Gap-size niche differentiation by tropical rainforest trees: a testable hypothesis or a broken-down bandwagon? Pages 79-94 in D. M. Newbery, H. H. T. Prins, and N. D. Brown, editors. Dynamics of tropical communities. The 37th symposium of the British Ecological Society, Cambridge University 1996. Blackwell Science, Oxford, UK.

Bruenig, E. 1996. Conservation management of tropical rainforest: an integrated approach to sustainability. CAB International, Wallingford, UK

Buckle, A. P., T. H. Chia, M. G. P. Fenn, and M. Visvalingam. 1997. Ranging behaviour and habitat utilisation of the malayan wood rat (Rattus tiomanicus) in an oil palm plantation in johore, malaysia. Crop Protection 16:467-473.

Buechner, H. K. and H. C. Dawkins. 1961. Vegetation change induced by elephants and fire in Murchison Falls National Park, Uganda. Ecology 42:752-766.

Burgess, P. F. 1971. Effects of logging on hill dipterocarp forest. Malayan Nature Journal 24:231-237.

Burghouts, T., G. Ernsting, G. Korthals, and T. de Vries. 1992. Litterfall, leaf litter, decomposition and litter invertebrates in primary and selectively logged dipterocarp forest in Sabah, Malaysia. Philosophical Transactions of the Royal Society of London. Series B, Biological Sciences 335: 407-416.

Butler, J. R. A., J. T. du Toit, and J. Bingham. 2004. Free-ranging domestic dogs (Canis familiaris) as predators and prey in rural Zimbabwe: threats of competition and disease to large wild carnivores. Biological Conservation 115:369-378. 
Caldecott, J. 1988. Hunting and wildlife management in Sarawak. IUCN, Gland, Switzerland.

Caldecott, J. O. 1986. An ecological and behavioral study of Pig-tailed Macaques. Karger, Basel, Switzerland.

Caldecott, J. O., R. A. Blouch, and A. A. MacDonald. 1993. The bearded pig (Sus barbatus). Pages 136145 in W. L. R. Oliver, editor. Pigs, peccaries, and hippos. Status survey and conservation action plan. IUCN/SSC Pigs and Peccaries Specialist group and IUCN/SSC Hippos Specialist Group, Gland, Switzerland.

Campbell, D. G. 1991. Gap formation in tropical forest canopy by elephants, Oveng, Gabon, Central Africa. Biotropica 23:195-196.

Cannon, C. H., D. R. Peart, M. Leighton, and K. Kartawinata. 1994. The structure of lowland rainforest after selective logging in West Kalimantan, Indonesia. Forest Ecology and Management 67:49-68.

Caribbean National Forest. 1997. Final environmental impacts statement for the revised land and resource management plan, Appendix F. Puerto Rican Parrot Management Situation. USDA Forest Service, Southern Region, USA.

Carter, S. 1985. Comparison of bird numbers in primary and selectively felled tropical rain forests in Brunei. Brunei Museum Journal 6:125-130.

Cebrián, J. D. and C. M. Duarte. 1994. The dependence of herbivory on growth rate in natural plant communities. Functional Ecology 8:518-525.

Chang, M. S., J. Hii, P. Buttner, and F. Mansoor. 1997. Changes in abundance and behaviour of vector mosquitoes induced by land use during the development of an oil palm plantation in sarawak. Transactions of the Royal Society of Tropical Medicine \& Hygiene 91:382-386.

Chapman, C. A. and J. E. Lambert. 2000. Habitat alteration and the conservation of African primates: Case study of Kibale National Park, Uganda. American Journal of Primatology 50:169-185.

Chasen, F. N. 1940. A handlist of Malaysian mammals. A systematic list of the mammals of the Malay Peninsula, Sumatra, Borneo and Java, including the adjacent small islands, Singapore. Bulletin of the Raffles Museum, Singapore, Strait Settlements No. 15.

Chen, J., J. F. Franklin, and T. A. Spies. 1992. Vegetation responses to edge environments in old-growth Douglas-fir forests. Ecological Applications 2:387-396.

Chin, C. 2001. Pig in the pot: Comments on Sus barbatus in the hunting lifestyle of the Penan in Sarawak (Borneo). Asian Wild Pig News 1:10-12.

Chivers, D. J. 1992. Socio-ecology and conservation of gibbons in Southeast Asia with special reference to Borneo. Pages 230-244 in G. Ismail, M. Mohammed, and S. Omar, editors. Forest biology and conservation in Borneo. Center for Borneo Studies Publication No. 2. Yayasan Sabah, Kota Kinabalu, Malaysia.

Choudhury, A. 1997. The status of bears in Assam, India. International Bear News 6:16.

Chuen, W. W., D. Eaton, and D. Y. M. 1998. Estimation of petai consumption in the Klang Valley in Peninsular Malaysia. Pages 212-226 in S. S. Lee, Y. M. Dan, I. Gauld, and J. Bishop, editors. Conservation, management and development of forest resources. Proceedings of the MalaysiaUnited Kingdom Programme Workshop 21-24 October 1996. Forest Research Institute Malaysia.

Chunkao, K. 1978. The effects of logging on soil erosion. Pages 65-72 in R. S. Suparto, I. Soerianegara, Z. Hamzah, H. J. Haeruman, S. Hadi, S. Manan, H. Basjarudin, and W. Sukotjo, editors. Proceeding of the symposium on the long-term effects of logging in Southeast Asia. BIOTROP, Bogor, Indonesia.

CIFOR. 2004. Workshop to develop a regional applied research program in the Congo Basin (ITTC Decision 10(XXXII)): pilot study on the social, environmental and economic sustainability of industrial concessions in the Congo Basin, main report, part D. International Tropical Timber Organization, Tokyo, Japan.

Civeyrel, L. and D. Simberloff. 1996. A tale of two snails: is the cure worse than the disease? Biodiversity and Conservation 5:1231-1252.

Clarke, A. L. and T. Pacin. 2002. Domestic cat "colonies" in natural areas: A growing exotic species threat. Natural Areas Journal 22:154-159.

Clayton, L. and E. J. Milner-Gulland. 2000. The trade in wildlife in North Sulawesi, Indonesia. Pages 473-496 in J. G. Robinson, and E. L. Bennett, editors. Hunting for sustainability in tropical forests. Columbia University Press, New York, USA. 
Clearwater, M.J., T. Nifinluri, and P.R. van Gardingen. 1999. Growth response of wild Shorea seedling to high light intensity. Pages 55-64 in P. Sist, C. Sabogal, and Y. Byron, editors. Management of secondary and logged-over forests in Indonesia: Selected proceedings of an International workshop, 17-19 November 1997, CIFOR, CIRAD and USAID.

Cleary, D. F. R. 2004. Assessing the use of butterflies as indicators of logging in Borneo at three taxonomic levels. Journal of Economic Entomology 97:429-435.

Clevenger, A. P., B. Chruszcz, and K. Gunson. 2001. Drainage culverts as habitat linkages and factors affecting passage by mammals. Journal of Applied Ecology 38:1340-1349

Clevenger, A. P., B. Chruszczc, and K. E. Gunson. 2003. Spatial patterns and factors influencing small vertebrate fauna road-kill aggregations. Biological Conservation 109:15-26.

Cochrane, M. A., A. Alencar, M. D. Schulze, C. M. Souza, D. C. Nepstad, P. Lefebvre, and E. A. Davidson. 1999. Positive feedbacks in the fire dynamic of closed canopy tropical forests. Science 284:1834-1836.

Cochrane, M. and M. Schulze. 1999. Fire as a recurrent event of the eastern Amazon: effects on forest structure, biomass, species composition. Biotropica 31:2-16

Colchester, M. 2000. High conservation value forests, note A. Proposed elements of a new forest policy. 3rd input to the safeguards and definitions focus group of the technical advisory group. Forest Peoples Programme, The World Bank, Washington, USA.

Coleman, D. C. and D. A. J. Crossley. 2003. Fundamental soil ecology. Academic Press, New York, USA and London, UK.

Coley, P. D. 1987. Interspecific variation in plant anti-herbivore properties: the role of habitat quality and rate of disturbance. New Phytologist 109 supplement:251-263.

Coley, P. D., J. P. Bryant, and F. S. Chapin. 1985. Resource availability and plant antiherbivore defense. Science 230:895-899.

Colfer, C. J. P. and I. A. P. Resosudarmo. 2002. Which way forward? People, forests and policymaking in Indonesia. Resources for the Future, Washington D.C., USA.

Collar, N. J., M. J. Crosby, and A. J. Stattersfield. 1994. Birds to watch 2: The world list of threatened birds. BirdLife Conservation Series 4. BirdLife International, Cambridge, UK.

Colón, C. P. 1999. Ecology of the Malay Civet (Viverra tangalunga) in a logged and unlogged forest in Sabah, East Malaysia. PhD dissertation. Fordham University, New York, USA.

Corbet, G. B. and J. E. Hill. 1992. The mammals of the Indomalayan region: A systematic review. Oxford University Press, Oxford, UK.

Corlett, R. T. 1988. Frugivory and seed dispersal by vertebrates in the Oriental (Indomalayan) Region. Biological Review 73:413-448.

Corlett, R. T. and I. M. Turner. 1997. Long-term survival in tropical forest remnants in Singapore and Hong Kong. Pages 333-345 in W. F. Laurance, and R. O. Bierregaard, editors. Tropical forest remnants: ecology, management and conservation of fragmented communities. Chicago University Press, Chicago, USA.

Crome, F. H. J., M. R. Thomas, and L. A. Moore. 1996. A novel bayesian approach to assessing impacts of rain forest logging. Ecological Applications 6:1104-1123.

Crompton, R. H. and P. M. Andau. 1986. Locomotion and habitat utilization in free-ranging Tarsius bancanus: A Preliminary Report. Primates 27:337-355.

Crompton, R. H. and P. M. Andau. 1987. Ranging, activity rhythms, and sociality in free-ranging Tarsius bancanus: A preliminary report. International Journal of Primatology 8:43-71.

Cronk, Q. C. B. and J. L. Fuller 1994. Invasive plants: the threat to natural ecosystems worldwide. A WWF Handbook. Chapman and Hall, London, UK.

Crooks, K. R. 2002. Relative sensitivities of mammalian carnivores to habitat fragmentation. Conservation Biology 16:488-502.

Curran, L. M. and C. O. Webb. 2000. Experimental tests of the spatiotemporal scale of seed predation in mast-fruiting Dipterocarpaceae. Ecological Monographs 70:151-170.

Curran, L. M. and M. Leighton. 2000. Vertebrate responses to spatiotemporal variation in seed production of mast-fruiting Dipterocarpaceae. Ecological Monographs 70:121-150.

Curran, L. M., I. Caniago, G. D. Paoli, D. Astianti, M. Kusenti, C. E. Nirarita, and H. Haeruman. 1999. Impact of El Niño and logging on canopy tree recruitment in Borneo. Science 286:21842188. 
Curtis, S. E. 1983. Environmental management in animal agriculture. Iowa Stae University Press, Ames, Iowa, USA.

Dahaban, Z., M. Nordin, and E. L. Bennett. 1996. Immediate effects on wildlife of selective logging in a hill dipterocarp forest in Sarawak: mammals. Monographiae Biologicae 74:341-346.

Daily, G. C. and P. R. Ehrlich. 1996. Nocturnality and species survival. Proceedings of the National Academy of Sciences USA 93:11709-11712.

Dale, S. 2001. Necrophilic behaviour, corpses as nuclei of resting flock formation, and road-kills of Sand Martins Riparia riparia. Ardea 89:545-547.

Danielsen, F. and M. Heegaard. 1994. The impact of logging and forest conversion of lowland forest birds and other wildlife in Seberida, Riau Province, Sumatra. Pages 59-60 in O. W. Sandbukt, editor. Rainforest and Resource Management. Proceedings of NORINDRA Seminar. Indonesian Institute of Sciences, Jakarta, Indonesia.

Danielsen, F. and M. Heegaard. 1995. The birds of Bukit Tigapuluh, southern Riau, Sumatra. Kukila 7:99-120.

Das, I. 1996. Spatio-temporal resource utilization by a Bornean rainforest herpetofauna: preliminary results. Pages 315-323 in D. S. Edwards, W. E. Booth, and S. C. Choy, editors. Tropical Forest Research - Current Issues. Proceedings of the conference held in Bandar Seri Begawan, April 1993. Monographiae Biologicae 74. Kluwer Academic Publishers, Dordrecht, the Netherlands.

Das, I. 2002. An introduction to the amphibians and reptiles of tropical Asia. Natural History Publication, Kota Kinabalu, Malaysia.

Daszak, P., A. A. Cunningham, and A. D. Hyatt. 2001. Anthropogenic environmental change and the emergence of infectious diseases in wildlife. Acta Tropica 78:103-116.

Data Theory Scaling System Group (DTSS). 1999. CATPCA Version 1.0. Faculty of Social and Behavioral Sciences. Leiden University, The Netherlands, Leiden, the Netherlands.

Dathe, H. 1970. A second generation birth of captive sun bears at East Berlin Zoo. International Zoo Yearbook 10:79.

Datta, A. 1998. Hornbill abundance in unlogged forest, selectively logged forest and a forest plantation in Arunachal Pradesh, India. Oryx 32:285-294.

Datta, A. 2000. Pheasant abundance in selectively logged and unlogged forests of western Arunachal Pradesh, northeast India. Journal of the Bombay Natural History Society 97:177-183.

David, P. and G. Vogel 1996. The snakes of Sumatra: An annotated checklist \& key with natural history notes. Edition Chimaira, Frankfurt am Main, Germany.

Davies, A. G. 1984. An ecological study of the red leaf monkey (Presbytis rubicunda) in dipterocarp forest of northern Borneo. PhD dissertation. University of Cambridge, Cambridge, UK.

Davies, A. G. 1987. Adult male replacement and group formation in Presbytis rubicunda. Folia Primatologica 49:111-114.

Davies, A. G. 1991. Seed-eating by red leaf monkeys (Presbytis rubicunda) in dipterocarp forest of northern Borneo. International Journal of Primatology 12:119-144.

Davies, A. G., E. L. Bennett, and P. G. Waterman. 1988. Food selection by two southeast Asian colobines (Presbytis rubicunda and Presbytis melalophus) in relation to plant chemistry. Biological Journal of the Linnean Society 34:33-56.

Davies, G. and J. Payne. 1982. A faunal survey of Sabah. IUCN/WWF Project No. 1692. World Wildlife Fund Malaysia, Kuala Lumpur, Malaysia.

Davies, G., M. Heydon, N. Leader-Williams, J. MacKinnon, and H. Newing. 2001. The effects of logging on tropical forest ungulates in R. A. Fimbel, A. Grajal, and J. G. Robinson, editors. The cutting edge: Conserving wildlife in logged tropical forest. Columbia University Press, New York, USA.

Davis, A. J. 2000. Does reduced-impact logging help preserve biodiversity in tropical rainforests? A case study from Borneo using dung beetles (Coleoptera: Scarabaeoidea) as indicators. Environmental Entomology 29:467-475.

Davis, D. D. 1962. Mammals of the lowland rainforests of North Borneo. Bulletin of the National Museum of Singapore 31:1-129.

Davison, G. W. H. 1980. Territorial fighting by lesser mouse-deer. Malayan Nature Journal 34:1-6.

Davison, G. W. H. 1981a. Diet and dispersion of the Great Argus Argusianus argus. Ibis 123:485-494.

Davison, G. W. H. 1981b. Habitat requirements and the food supply of the Crested Fireback. World Pheasant Association 6:40-52. 
Davison, G. W. H. and K. Scriven. 1987. Recent pheasant surveys in peninsular Malaysia. Pages 90-101 in C. Savage, and M. W. Ridley, editors. Proceedings of the 2nd International Symposium on the Pheasants in Asia. World Pheasant Association, Exning, Suffolk, UK.

De la Cruz, M. and R. Dirzo. 1987. A survey of the standing levels of herbivory in seedlings from a Mexican rain forest. Biotropica 19:98-106.

del Hoyo, J., A. Elliott, and J. Sargatal. 1997. Handbook of the birds of the world. Volume 4: sandgrouse to cuckoos. Lynx Edicions, Barcelona, Spain.

Delvingt, W. 1997. La chasse villageoise. Rapport du programme ECOFAC. Groupement AGRECO G.E.I.E - BDPA - SCETAGRI - SECA - CIRAD-Forêt. Brussels, Belgium.

Dennis, R. A. 1999. A review of fire projects in Indonesia 1982 - 1998. Page 112. CIFOR, Bogor, Indonesia.

Dennis, R. A., J. Mayer, G. B. Applegate, U. Chokkalingam, C. J. P. Colfer, I. Kurniawan, H. Lachowski, P. Maus, R. P. Permana, Y. Ruchiat, F. Stolle, S. Suyanto, and T. P. Tomich. in prep. Fire, people and pixels: linking social science and remote sensing to understand underlying causes and impacts of fires in Indonesia. Human Ecology.

Dennis, R., E. Meijaard, G. Applegate, R. Nasi, and P. Moore. 2001. Impact of human-caused fires on biodiversity and ecosystem functioning, and their causes in tropical, temperate and boreal forest biomes. CBD Technical Series No. 5. Convention on Biological Diversity, Montreal, Canada.

Denslow, J. S. 1987. Tropical rainforest gaps and tree species diversity. Annual Review of Ecology and Systematics 18:431-451.

Denslow, J. S. 2003. Weeds in paradise: thoughts on the invasibility of tropical islands. Annals of the Missouri Botanical Garden 90:119-127.

Denslow, J. S., A. E. Gomez Dias, and T. A. Spies. 1990. Seed rain to tree fall gaps in a neotropical rainforest. Canadian Journal of Forest Research 20:642-648.

DFID. 1999. Indonesia. Towards sustainable forest management. Final report of the senior management advisory team and the provincial level forest management project. Vol. 2. DFID and Ministry of Forestry, Indonesia, Jakarta, Indonesia.

Diamond, J. M. 1984. 'Normal' extinctions of isolated populations. Pages 191-246 in M. H. Nitecki, editor. Extinctions. Chicago University Press, Chicago, USA

Djamaludin. 1991. The implementation of Indonesian Selective Cutting and Replanting (TPTI) silviculture system for timber improvement in the logged-over areas. In I. Soerianegara, S.S. Tjitrosomo, R.C. Umaly, and I. Umboh, editors. Proceedings of the fourth round table conference on dipterocarps, Bogor, Indonesia. 12-15 December 1989. BIOTROP Special Publication 41:95-110.

Douglas, I., T. Greer, K. Bidin, and M. Spilsbury. 1993. Impacts of rainforest logging on river systems and communities in Malaysia and Kalimantan. Global Ecology and Biogeography Letters 3:245252.

Douglas, I., T. Spencer, T. Greer, K. Bidin, and W. Sinun. 1992. The impact of selective commercial logging on stream hydrology, chemistry and sediment loads in the Ulu Segama Rain Forest, Sabah, Malaysia. Philosophical Transaction of the Royal Society of London. Series B. Biological Sciences 235:397-406.

Down to Earth. 2002. Forest, People and Rights. Page 172. International Campaign for Ecological Justice in Indonesia, London.

Duckworth, J. W. 1997a. Mammals in Similajau National Park, Sarawak, in 1995. The Sarawak Museum Journal 51:171-192.

Duckworth, J. W. 1997b. Small carnivores in Laos: a status review with notes on ecology, behaviour and conservation. Small Carnivore Conservation 16:1-21.

Dudgeon, D. 2000. Riverine biodiversity in Asia: a challenge for conservation biology. Hydrobiologia 418:1-13.

Duff, A. B., R. A. Hall, and C. W. Marsh. 1984. A survey of wildlife in and around commercial tree plantations in Sabah. The Malaysian Forester 47:197-213.

Duncan, R. P., T. M. Blackburn, and T. H. Worthy. 2002. Prehistoric bird extinctions and human hunting. Proceedings of the Royal Society of London - Series B: Biological Sciences 269:517521.

Dunn, R. R. 2004. Managing the tropical landscape: a comparison of the effects of logging and forest conversion to agriculture on ants, birds, and lepidoptera. Forest Ecology and Management 191: 215-225. 
Dwiprabowo, H., S. Grulois, P. Sist, and K. Kartawinata. 2002. Cost-benefit analysis of reduced-impact logging in a lowland Dipterocarp forest in Malinau, East Kalimantan. Pages 39-55. ITTO project PD 12/97 Rev.1 (F): forest, science and sustainability: the Bulungan model forest: Technical report phase 1, 1997-2001. CIFOR and ITTO, Bogor, Indonesia.

Dwiyahreni, A. A. 2003. The effects of forest fire on the squirrel and tree shrew community dynamic in southern Sumatra. In Abstract Booklet 3rd International Colloquium in the ecology of tree squirrels. 7th European squirrel workshop. Ford Castle, Northumberland, UK. 26th-30th May 2003.

Dykstra, D. and R. Heinrich 1996. FAO model code of forest harvesting. FAO, Rome.

Eames, J. C., A. N. Kuznetsov, G. Fredriksson, and B. Jarvis. 2001. A preliminary biological assessment of PT Daisy, Berau District, East Kalimantan, Indonesia. Saigon: Tropical Forest Trust, Saigon, Vietnam.

Edwards, P. J. 1989. Insect herbivory and plant defence theory. Pages 275-297 in P. J. Grubb, and J. B. Whittaker, editors. Towards a more exact ecology. Blackwell Scientific Publications, Oxford, UK.

Effendi, E., B. Shantiko, and V. M. Dewi. 2002. Peranan ekologis Taman Nasional Kayan Mentarang terhadap perekonomian masyarakat dan fiskal kabupaten di sekitar kawasan. Tempayan 21:8-10.

Eggleton, P., R. Homathevi, D. Jeeva, D. T. Jones, R. G. Davies, and M. Maryati. 1997. The species richness and composition of termites (Isoptera) in primary and regenerating lowland dipterocarp forest in Sabah, East Malaysia. Ecotropica 3:119-128.

Elias. 1998. Wood harvesting damages, regeneration and growth in the residual stand of dipterocarp forests. In G.L. Enriquez, U.R. Wasrin, and D. Murdiarso, editors. Tropical Forest Dynamics, BIOTROP Special Publication 60:107-117.

Elias, G. Applegate, K. Kartawinata, Machfudh, and A. Klassen. 2001. Reduced impact logging guidelines for Indonesia. CIFOR, Bogor, Indonesia.

Elouard, C. 1998. Pests and diseases of Dipterocarpaceae. Pages 115-131 in S. Appanah and J.M. Turnbull, editors. A review of dipterocarps: taxonomy, ecology, and silviculture. CIFOR, Bogor, Indonesia.

Emmons, L. H. 1980. Ecology and resource partitioning among nine species of African rain forest squirrels. Ecological Monographs 50:31-54.

Emmons, L. H. 2000. Tupai. A field study of Bornean treeshrews. University of California Press, Berkeley, Los Angeles, London, UK.

Emmons, L. H, and A. H. Gentry. 1983. Tropical forest structure and the distribution of gliding and prehensile tailed vertebrates. American Naturalist 121:513-524.

Enters, T., P. Durst, G. Applegate, P. C. S. Kho, and G. Man. 2002. Applying reduced impact logging to advance sustainable forest management. FAO Regional Office for Asia and the Pacific. Bangkok, Thailand.

Epp, G. A. 1987. The seed bank of Eupatorium odoratum along a successional gradient in a tropical rain forest in Ghana. Journal of Tropical Ecology 3:139-149.

Eve, R. and A. M. Guigue. 1989. Survey of the Mahakam River delta, East Kalimantan with special reference to its waterbirds. Publication No. 45. Asian Wetland Bureau, Kuala Lumpur, Malaysia.

Ewer, R. F. 1973. The carnivores. Cornell University Press, Ithica, USA.

Fa, J. E., S. F. Ryan, and D. J. Bell. 2004. Hunting vulnerability, ecological characteristics and harvest rates of bushmeat species in afrotropical forests. Biological Conservation 121:167-176.

Fagan, W. F., E. Meir, J. Prendergast, A. Folarin, and P. Karieva. 2001. Characterizing population vulnerability for 758 species. Ecology Letters 4:132-138.

FAO. 1981. National conservation plan for Indonesia. Vol. V. Kalimantan. Field report of UNDP/FAO National Parks Development Project INS/78/081. Food and Agricultural Organization of the United Nations, Bogor, Indonesia.

Feder, M. E. and W. W. Burggren. 1992. Environmental physiology of the amphibians. University of Chicago Press, Chicago, USA.

Feuilletau-de Bruyn, W. K. H. 1933. Bijdrage tot de kennis van de afdeeling Hoeloe Soengei (Z. en O.afdeeling Borneo). Koloniale Studiën 171: 53-93 and 183-211.

Fimbel, R. A., A. Grajal, and J. G. Robinson. 2001. Logging and wildlife in the tropics. Pages 667-695 in R. A. Fimbel, A. Grajal, and J. G. Robinson, editors. The cutting edge: conserving wildlife in logged tropical forest. Columbia University Press, New York, USA. 
Fimbel, R. A., E. L. Bennett, R. Z. Donovan, P. C. Frumhoff, A. Grajal, R. E. Gullison, D. J. Mason, F. E. Putz, J. G. Robinson, and D. I. Rumiz. 1998. The potential for sustainable forest management to conserve wildlife within tropical forest landscapes. Issues and Policy Paper no. 4., Bronx, New York. Wildlife Conservation Society, New York, USA.

Fisher, D. O. and I. P. F. Owens. 2004. The comparative method in conservation biology. Trends in Ecology \& Evolution 19:391-398.

Fisher, D. O., S. P. Blomberg, and I. P. F. Owens. 2003. Extrinsic versus intrinsic factors in the decline and extinction of Australian marsupials. Proceedings of the Royal Society of London - Series B: Biological Sciences 270:1801-1808.

Fleming, T. E. 1987. Patterns of tropical vertebrate frugivore diversity. Annual Review of Ecology and Systematics 18:91-109.

Fleming, T. E. 1993. Plant-visiting bats. American Scientist 81:460-468.

Fogden, M. P. L. 1974. A preliminary field study of the western tarsier, Tarsius bancanus Horsfield. Page 151-165 in R. D. Martin, G. A. Doyle, and A. C. Walker, editors. prosimian biology. University of Pittsburgh Press, Pittsburgh, USA.

Foreman, D. and B. Haywood. 1989. Ecodefense: A field guide to monkey wrenching. Second Edition. Ned Ludd Books, Tuscon, AZ, USA.

Forman, R. T. T. and L. E. Alexander. 1998. Roads and their major ecological effects. Annual Review of Ecology \& Systematics 29:207-231.

Forman, R. T. T. and P. N. Moore. 1992. Theoretical fFoundations for understanding boundaries in landscape mosaics in A. J. Hansen, and F. di Castri, editors. Landscape boundaries, Consequences for biotic diversity and ecological flows. Springer-Verlag, New York, USA.

Francis, G. 2003. Indonesian conservationists object to border road. Borneo Bulletin (Brunei), November 11, 2003 issue.

Fredericksen, N. J. and T. S. Fredericksen. 2002. Terrestrial wildlife responses to logging and fire in a Bolivian tropical humid forest. Biodiversity and Conservation 11:27-38.

Fredericksen, N. J. and T. S. Fredericksen. 2004. Impacts of selective logging on amphibians in a Bolivian tropical humid forest. Forest Ecology and Management 191:275-282.

Fredericksen, T. S. and F. E. Putz. 2003. Silvicultural intensification for tropical forest conservation. Biodiversity and Conservation 12:1445-1453.

Fredriksson, G. 2001. Effects of forest fires on Sun Bear conservation in East Kalimantan (Indonesian Borneo). Presented poster at the Thirteenth International Conference on Bear Research and Management, Jackson, Wyoming, USA.

Fredriksson, G. in press. Human-sun bear conflicts in East Kalimantan, Indonesian Borneo. Ursus.

Fredriksson, G. M. and V. Nijman. 2004. Habitat use and conservation status of two elusive ground brids (Carpococcyx radiatus and Polyplectron scheiermacheri) in the Sungai Wain Protection Forest, East Kalimantan, Indonesian Borneo. Oryx 38:297-303.

Fredriksson, G. and S. A. Wich. in prep. Frugivory in sun bears (Helarctos malayanus) linked to El Niñorelated fluctuations in fruit availability in East Kalimantan, Indonesia.

Frith, C. B. and V. E. Douglas. 1978. Notes on ten Asian hornbill species (Aves: Bucerotidae); with particular reference to growth and behaviour. Natural History Bulletin of the Siam Society 27: 35-82.

Frumhoff, P. C. 1995. Conserving wildlife in tropical forests managed for timber - to provide a more viable complement to protected areas. BioScience 45:456-464.

Fujita, M. S. and M. D. Tuttle. 1991. Flying foxes (Chiroptera: Pteropodidae): Threatened animals of key ecological and economic importance. Conservation Biology 5:455-463.

Fuller, D. O., T. C. Jessup, and A. Salim. 2003. Loss of forest cover in Kalimantan, Indonesia, since the 1997-1998 El Niño. Conservation Biology 18:249-254.

Galetti, M. and K. McConkey. 1998. Black hornbill Anthracoceros malayanus following gibbons in central Borneo. Ibis 140:686-687.

Garshelis, D. and B. McLellan. 2004. Bear specialist group quadrennial report. International Bear News 13:10-11.

Gartlan, J. S., D. B. McKey, P. G. Waterman, C. N. Mbi. and T. T. Struhsaker. 1980. A comparative study of the phytochemistry of two African rain forests. Biochemical Systematics and Ecology 8: 401-422. 
Gascon, C., G. B. Williamson, and G. A. B. da Fonseca. 2000. Receding forest edges and vanishing reserves. Science 288:1356-1358.

Gaston, K. J. and T. M. Blackburn. 1997. Evolutionary age and risk of extinction in the global avifauna. Evolutionary Ecology 11:557-565.

Gaston, K. J., T. M. Blackburn, J. J. D. Greenwood, R. D. Gregory, R. M. Quinn, and J. H. Lawton. 2000. Abundance-occupancy relationships. Journal of Applied Ecology 37:39-59.

Gautier-Hion, A. 1984. Seed dispersal by African forest cercopithecines. La Terre et la Vie: Revue d'Ecologie Appliquee 39:159-166.

Gautier-Hion, A., J.-M. Duplantier, R. Quris, F. Feer, C. Sourd, J.-P. Decoux, G. Dubost, L. Emmons, C. Erard, P. Hecketweiler, A. Moungazi, C. Roussilhon, and J.-M. Thiollay. 1985. Fruit characteristics as a basis of fruit choice and seed dispersal in a tropical forest vertebrate community. Oecologia 65:324-337.

Geist, V. 1998. Deer of the world. Their evolution, behaviour, and ecology. Stackpole Books, Mechanicsburg, USA.

Ghazoul, J. and J. Hill. 2001. The impacts of selective logging on tropical forest invertebrates. Pages 261-288 in R. Fimbel, A. Grajal, and J. G. Robinson, editors. The cutting edge: conserving wildlife in logged tropical forest. Columbia University Press, New York, USA.

Ghazoul, J., K. A. Liston, and T. J. B. Boyle. 1998. Disturbance-induced, density dependent seed selection in Shorea siamensis (Dipterocarpaceae), a tropical forest tree. Journal of Ecology 86: 462-473.

Gilbert, K. A. 1994. Endoparasitic infection in Red Howling Monkeys (Aloutta seniculus) in the Central Amazonian Basin: A cost of socialitity? Unpublished PhD Dissertation. Rutgers University, New Brunswick, N.J, USA.

Gilbert, K. A. and E. Z. F. Setz. 2001. Primates in a fragmented landscape: Six species in Central Amazonia. Pages 262-270 in R. O. Bierregaard, G. Gaascon, T. E. Lovejoy, and R. Mesquita, editors. Lessons from the Amazon. Yale University Press, New Haven, CT, USA.

Gintings, A. 1969. The influence of selective felling on the regeneration of Dipterocarpaceae forests in Eastern Sumatra. (In Indonesian) Sarjana Thesis. Fakultas Kehutanan IPB. Bogor, Indonesia.

Gönner, C. 1997. Description of the middle Mahakam area. Unpublished report.

Goosem, M. 1997. Internal fragmentation: Effects of roads, highways, and powerline clearings on movements and mortality of rainforest vertebrates. Pages 241-255 in W. F. Laurance, and R. O. J. Bierregaard, editors. Tropical forest remnants: ecology, management, and conservation of fragmented communities. University of Chicago Press, Chicago, USA.

Goosem, S. and N. I. J. Tucker. 1995. Repairing the rainforest. Theory and practice of rainforest reestablishment in North Queensland's wet tropics. Wet Tropics Management Authority, Cairns, Australia.

Gordon, W. F., S. B. Vinson, L. E. Newstrom, J. F. Barthell, W. A. Haber, and J. K. Frankie. 1990. Plant phenology, pollination ecology, pollinator behaviour and conservation of pollinators in Neotropical dry forest. Pages 37-48 in K. S. Bawa, and M. Hadley, editors. Reproductive ecology of tropical forest plants. MAB series 7. UNESCO, Paris, France.

Gosz, J. R. 1991. Fundamental ecological characteristics of landscape boundaries in M. N. Holland, P. G. Riser, and R. J. Nemine, editors. Ecotones: the role of landscape boundaries in the management and restoration of changing environments. Chapman and Hall, New York, USA.

Gould, K. and M. Andau. 1989. Selection and rejection of five species of Dipterocarp fruits by wild and captive primates, squirrels and hornbills. Malayan Nature Journal 42:245-249.

Grassman, L. I. J. 1998. Movements and fruit selection of two Paradoxurinae species in a dry evergreen forest in southern Thailand. Small Carnivore Conservation no. 19:25-29.

Griffiths, M. and C. P. van Schaik. 1993. The impact of human traffic on the abundance and activity periods of Sumatran rain forest wildlife. Conservation Biology 7:623-626.

Grove, S. J. 2001. Extent and composition of dead wood in Australian lowland tropical rainforest with different management histories. Forest Ecology and Management 154:35-53.

Grove, S. J. 2002a. The influence of forest management history on the integrity of the saproxylic beetle fauna in an Australian lowland tropical rainforest. Biological Conservation 104:149-171.

Grove, S. J. 2002b. Saproxylic insect ecology and the sustainable management of forests. Annual Review of Ecology and Systematics 33:1-23.

Groves, C. P. 1998. Systematics of tarsiers and lorises. Primates 39:13-27. 
Groves, C. P. 2001. Primate Taxonomy. Smithsonian Institution Press, Washington DC, USA.

Groves, C. P. and P. Grubb. 1982. The species of muntjac (genus Muntiacus) in Borneo: Unrecognised sympatry in tropical deer. Zoologische Mededelingen 56:203-215.

Guevara, S. S. 1986. Plant species availability and regeneration in Mexican tropical rain forest. Acta Universitatis Upsaliensis, Comprehensive Summaries of Uppsala Dissertations for the Faculty of Science 48.

Gullison, R. E. 2003. Does forest certification conserve biodiversity? Oryx 37:153-165.

Gumal, M. T. 2004. Diurnal home range and roosting trees of a maternity colony of Pteropus vampyrus natunae (Chiroptera : Pteropodidae) in Sedilu, Sarawak. Journal of Tropical Ecology 20:247258.

Hadidan, J. and I. S. Bernstein. 1979. Female reproductive cycles and birth data from an Old World monkey colony. Primates 20:429-442.

Hadiprakarsa, Y. and M. Kinnaird. 2001. Foraging characteristics of an assemblage of four Sumatran hornbill species. The Third International Hornbill Workshop on the Ecology of Hornbills with Emphasis on Reproduction and Population, 9-18 May 2001, Phuket and Narathiwat, Thailand.

Hadiprakarsa, Y., M. F. Kinnaird, and T. G. O'Brien. in press. Foraging characteristics for an assemblage of four Sumatran hornbill species. Bird Conservation International.

Harcourt, A. H. and M. W. Schwartz. 2001. Primate evolution: A biology of Holocene extinction and survival on the Southeast Asian Sunda Shelf islands. American Journal of Physical Anthropology 114:4-17.

Harcourt, A. H., S. A. Coppeto, and S. A. Parks. 2002. Rarity, specialization and extinction in primates. Journal of Biogeography 29:445-456.

Harrington, G. N., A. N. D. Freeman, and F. H. J. Crome. 2001. The effects of fragmentation of an Australian tropical rain forest on populations and assemblages of small mammals. Journal of Tropical Ecology 17:225-240.

Harris, L. D. 1984. The fragmented forest. University of Chicago Press, Chicago, USA \& London, UK.

Harris, L. D. and G. Silva-Lopez. 1992. Forest fragmentation and the conservation of biological diversity. Pages 197-237 in P. L. Fiedler, and S. K. Jain, editors. Conservation Biology. Chapman and Hall, London, UK.

Harrison, J. L. 1962a. Natural food of some Malayan mammals. Bulletin of the National Museum of Singapore 30:5-18.

Harrison, J. L. 1962b. The distribution and feeding habits among mammals in tropical rainforest. Journal of Animal Ecology 31:53-64.

Harrison, J. L. 1968. The effect of forest clearance on small mammals. Pages 153-158. Conservation in tropical South East Asia. Proceedings of the Conference on Conservation of Nature and Natural Resources in Tropical South East Asia. Bangkok, Thailand. November 29 - December 4, 1965. IUCN Publication New Series No. 10. IUCN, Morges, Switzerland.

Harrison, J. L. 1969. The abundance and population density of mammals in Malayan lowland forests. Malayan Nature Journal 34:174-178.

Harrison, R. D. 2001. Drought and the consequences of El Niño in Borneo: a case study of figs. Population Ecology 43:63-75.

Harrison, S. and E. Bruna. 1999. Habitat fragmentation and large-scale conservation: What do we know for sure? Ecography 22:225-232.

Hartyono 1992. Perikanan dan aspek budayanya pada masyarakat Dayak di sekitar kawasan cagar alam Kayan Mentarang. Paper presented at Borneo Research Council 2nd biannual International Conference, 13-17 July 1992, Kota Kinabalu, Malaysia.

Harvey, P. H., R. D. Martin, and T. H. Clutton-Brock. 1987. Life histories in comparative perspective. Pages 181-196 in B. B. Smuts, D. L. Cheney, S. R.M., R. W. Wrangham, and T. T. Struhsaker, editors. Primate Societies. University of Chicago Press, Chicago, USA.

Hassanin, A. and A. Ropiquet. 2004. Molecular phylogeny of the trive Bovini (Bovidae, Bovinae) and the taxonomic status of the Kouprey, Bos sauveli Urban 1937. Molecular Phylogenetics \& Evolution 33:896-907.

Hawthorne, W. D. 1993. Forest regeneration after logging: findings of a study in the Bia South Game Production Reserve, Ghana. ODA Forestry Series. Natural Resources Institute, Chatham, UK. 
Hawthorne, W. D. 1994. Fire damage and forest regeneration in Ghana. ODA Forestry Series. Natural Resources Institute, Chatham, UK.

Hawthorne, W. D. and M. P. E. Parren. 2000. How important are forest elephants to the survival of woody plant species in upper Guinean forests? Journal of Tropical Ecology 16:133-150.

Hawthorne, W. D., V. K. Agyeman, M. Abu Juam, and E. G. Foli. 1998. Taking stock: An annotated bibliography of logging damage and recovery in tropical forests, and the results of new research in Ghana. Projet Report. Oxford Forestry Institute, Oxford, UK.

Hayes, J. P. and R. J. Steidl. 1997. Statistical power analysis and amphibian population trends. Conservation Biology 11:273-275.

Hayssen, V., A. van Tienhoven, and A. van Tienhoven. 1993. Asdell's patterns of mammalian reproduction: a compendium of species-specific data. Comstock Publishing Associates, Ithaca, USA \& London, UK.

Heaney, L. R. 1978. Island area and body size of insular mammals: Evidence from the tri-colored squirrel (Callosciurus prevosti) of Southeast Asia. Evolution 32:29-44.

Heaney, L. R. 1986. Biogeography of mammals in SE Asia: estimates of rates of colonization, extinction and speciation. Biological Journal of the Linnean Society 28:127-165.

Hedges, S. and A. A. Dwiyahreni. 2002. Reduced impact logging study, Bulungan Research Forest, East Kalimantan, Indonesia. Mammal and hornbill survey. September-October 1998. Preliminary report. CIFOR and WCS, Bogor, Indonesia.

Hedges, S. and E. Meijaard. 1999. Reconnaissance survey for banteng (Bos javanicus) and banteng survey methods training project, Kayan-Mentarang National Park, East Kalimantan, Indonesia. Unpublished report. WWF-Indonesia and CIFOR, Bogor, Indonesia.

Hedges, S., M. J. Tyson, A. F. Sitompul, M. F. Kinnaird, D. Gunaryadi, and A. Baco. in prep. Distribution, status, and conservation needs of Asian elephants (Elephas maximus) in Lampung Province, Sumatra, Indonesia. Biological Conservation.

Hels, T. and E. Buchwald. 2001. The effect of road kills on amphibian populations. Biological Conservation 99:331-340.

Hernowo, J. B. 1989. Studi pendahuluan habitat dan arena tari burung Kuwau (Argusianus argus) di hutan lindung Bukit Soeharto, Kalimantan Timur. Media Konservasi 2:55-63.

Heydon, M. J. 1994. The ecology and management of rain forest ungulates in Sabah, Malaysia: implications of forest disturbance. Final report to ODA/NERC project F3CR26/G1/05. Institute of Tropical Biology, University of Aberdeen, Aberdeen, UK.

Heydon, M. J. and P. Bulloh. 1996. The impact of selective logging on sympatric civet species in Borneo. Oryx 30:31-36.

Heydon, M. J. and P. Bulloh. 1997. Mousedeer densities in a tropical rainforest: the impact of selective logging. Journal of Applied Ecology 34:484-496.

Hietz-Seifert, U., P. Hietz, and S. Guevara. 1996. Epiphyte vegetation and diversity on remnant trees after forest clearance in southern Veracruz, Mexico. Biological Conservation 72:103-111.

Hill, J. K., K. C. Hamer, M. M. Dawood, J. Tangah, and V. K. Chey. 2003. Rainfall but not selective logging affect changes in abundance of tropical forest butterfly in Sabah, Borneo. Journal of Tropical Ecology 19:35-42.

Hill, W. C. O. 1955. Primates: Comparative anatomy and taxonomy. II. Haplorhini: Tarsioidea. Edinburgh University Press, Edinburgh, UK.

Hilton-Taylor, C. 2000. 2000 IUCN Red List of Threatened Species. IUCN, Gland, Switzerland and Cambridge, UK.

Hobson, K. A. and M. A. Villard. 1998. Forest fragmentation affects the behavioral response of american redstarts to the threat of cowbird parasitism. Condor 100:389-394.

Hodgkison, R. 2001. Ecology of the spotted-winged fruit bat (Balionycteris maculata, Thomas) in a lowland Malaysian dipterocarp forest. Unpublished Ph.D. thesis. University of Aberdeen, Aberdeen, UK.

Hoffman, H. 2003. "Callosciurus prevostii" (On-line), Animal Diversity Web. Accessed September 14, 2004 at http://animaldiversity.ummz.umich.edu/site/accounts/information/Callosciurus_ prevostii.html.

Hoffmann, A. A., A. Hinrichs, and F. Siegert. 1999. Fire damage in East Kalimantan in 1997/98 related to land use and vegetation classes: Satellite radar inventory results and proposal for further actions. IFFM-SFMP Report No.1a. MOFEC, GTZ and KfW, Samarinda, East Kalimantan, Indonesia. 
Hogberg, P. and J. Wester. 1998. Root biomass and symbioses in Acacia mangium replacing tropical forest after logging. Forest Ecology and Management 102:333-338.

Holdsworth, A. R. and C. Uhl. 1997. Fire in Amazonian selectively logged rain forest and the potential for fire reduction. Ecological Applications 7:713-725.

Holmes, D. 2000. Deforestation in Indonesia. A review of the situation in 1999. World Bank, Jakarta, Indonesia.

Holmes, D. A. 1989. A status report on Indonesian galliforms. Kukila 4:133-143.

Holmes, D. A. 1997. Kalimantan Bird Report. Kukila 9:141-169.

Holmes, D. A. and K. Burton. 1987. Recent notes on the avifauna of Kalimantan. Kukila 3:2-32.

Hone, J. 2002. Feral pigs in Namadgi National Park, Australia: dynamics, impacts and management. Biological Conservation 105:231-242.

Hoogerwerf, A. 1970. Udjung Kulon. The land of the last Javan rhinoceros. E.J. Brill, Leiden, The Netherlands.

Howe, H. F. and L. C. Westley 1988. Ecological relationships of plants and animals. Oxford University Press, Oxford, UK.

Howell, D. 2003. The effects of human activity on primates and other large mammals in East Kalimantan, Indonesia. MSc Thesis. Central Washington University, USA.

Howlett, B.E. and D.W. Davidson. 1996. Diprterocarp seed and seedling performance in secondary logged forests dominated by Macaranga spp. Pages 256-266 in S. Appanah and K.C. Khoo, editors. Proceedings fifth round table conference on Dipterocarps, Chiang Mai, Thailand. 7-10 November 1994. FRIM, Kepong, Malaysia.

Hubbell, S. P., R. B. Foster, S. T. O’Brien, K. E. Harms, R. Condit, B. Wechsler, S. J. Wright, and S. Loo de Lao. 1999. Light-gap disturbances, recruitment limitation, and tree diversity in a neotropical forest. Science 283:554-557.

Hunter, M. L. J. 1990. Wildlife, forests and forestry: Principles of managing forests for biological diversity. Prentice Hall, Englewood Cliffs, New Jersey, USA.

Hurlbert, S. H. 1984. Pseudoreplication and the design of ecological field experiments. Ecological Monographs 54:187-211.

Hussin, Bin. M. Z. 1994. Ecological effects of selective logging in lowland dipterocarp forest on avifauna, with special reference to frugivorous birds. MSc thesis. Universiti Kebangsaan, Kuala Lumpur, Malaysia.

Hussin, Bin. M. Z. 1996. Can our logged forest fully regenerate naturally? Paper presented at the National Symposium of Natural Resources Science and Technology. Kota Kinabalu, Sabah. November 2223, 1996.

Hussin, Bin. M. Z. and C. M. Francis. 2001. The effects of logging on birds in tropical forests of IndoAustralia. Pages 167-192 in R. A. Fimbel, A. Grahal, and J. G. Robinson, editors. The cutting edge: Conserving wildlife in logged tropical forests. Columbia University Press, USA.

Hutchings, T. R., A. J. Moffat, and C. J. French. 2002. Soil compaction under timber harvesting machinery: a preliminary report on the role of brash mats in its prevention. Soil Use and Management 18:34-38.

Hutson, A. M., S. P. Mickleburg, and P. A. Racey 2001. Microchiropteran bats. Global status and conservation action plan. IUCN/SSC Chiroptera Specialist Group, Gland, Switzerland and Cambridge, UK.

Inger, R. F. 1969. Organization of communities of frogs along small rainforest streams in Sarawak. Journal of Animal Ecology 38:123-148.

Inger, R. F. 1980a. Densities of floor dwelling frogs and lizards in lowland forests of Southeast Asia and Central America. American Naturalist 115:761-770.

Inger, R. F. 1980b. Relative abundances of frogs and lizards in forests of Southeast Asia. Biotropica 12: $14-22$.

Inger, R. F. 1983. Larvae of Southeast Asia species of Leptobrachium and Leptobrachella (Anura: Pelobatidae). Pages 13-32 in A. G. Rhodin, and K. Miyata, editors. Advances in herpetology and evolutionary biology. Museum of Comparative Zoology, Cambridge, MA, USA.

Inger, R. F. 1985. Tadpoles of the forested regions of Borneo. Fieldiana Zoology 26:1-89.

Inger, R. F. 1986. Diets of tadpoles living in a Bornean rain forest. Alytes (Paris) 5:153-164.

Inger, R. F. and F. L. Tan 1996. The natural history of amphibians and reptiles in Sabah. Natural History Publication, Kotakinabalu, Malaysia. 
Inger, R. F. and H. H. K. Voris. 1993. A comparison of amphibian communities through time and from place to place in Bornean forests. Journal of Tropical Ecology 9:409-433.

Inger, R. F., H. K. Voris, and K. J. Frogner. 1986. Organization of a community of tadpoles in rain forest streams in Borneo. Journal of Tropical Ecology 2:193-205.

Inger, R. F. and K. V. Voris. 2001. The biogeographical relations of the frogs and snakes of Sundaland. Journal of Biogeography 28:863-891.

Innes, J. L. 1993. Forest health: Its assessment and status. CABInternational, UK.

Interagency Ecosystem Management Task Force. 1995. The ecosystem approach: Healthy ecosystems and sustainable economies. Volume I-Overview. Office of Environmental Policy, Washington, DC, USA.

Iskandar, D. T. 1998. The amphibians of Java and Bali. Research and Development Centre for BiologyLIPI, Jakarta, Indonesia.

Iskandar, D. T. 1999a. Amphibian declines monitoring in the Leuser Management Unit, Aceh, North Sumatra, Indonesia. Froglog 34:2.

Iskandar, D. T. 1999b. Training on "monitoring methods in amphibians and reptiles fauna" at Soraya and Gunung Air Station, Leuser National Park. Unpublished report. Institute of Technology, Bandung, Indonesia.

Iskandar, D. T. 2004. The amphibians and reptiles of Malinau region, Bulungan research forest, East Kalimantan: Annotated checklist with some notes on ecological preferences of the species and local utilization. CIFOR. Http://www.cifor.org/mla/_ref/publication/amphibian.htm.

Iskandar, D. T. and D. Y. Setyanto. 1999. Environmental impact assessment in four logged forest conditions in South Kalimantan. Presented at Asia Pacific Congress on the Biology of the Environment. Singapore, 21-24 November 1999.

Iskandar, D. T. and E. Colijn. 2000. Checklist of Southeast Asian and New Guinean Herpetofauna I. Amphibians. Treubia 31:1-134.

Iskandar, D. T. and E. Colijn. 2002. Checklist of Southeast Asian \& New Guinean Reptiles I. Snakes. Biodiversity Conservation Project, Jakarta, Indonesia.

Islam, K. R., M. R. Ahmed, M. K. Bhuiyan, and A. Badruddin. 2001. Deforestation effects on vegetative regeneration and soil quality in tropical semi-evergreen degraded and protected forests of Bangladesh. Land Degradation and Development 12:45-56.

Istiadi, Y., D. Priatna, and N. Panekanan. 1994. Inventarisasasidan analisis populasi jenis-jenis mamalia dan burung di pegunungan Müller, Kalimantan Barat--Kalimantan Timur (Ekspedisi KapuasMahakam, 1994). Unpublished report. KOMPAS-GRAMEDIA, Jakarta, Indonesia.

IUCN. 2002. 2002 IUCN Red List of Threatened Species. www.redlist.org. Downloaded on 10 October 2002.

IUCN. 2003. 2003 IUCN Red List of Threatened Species. www.redlist.org. Downloaded on 5 August 2004.

IUCN-WWF. 2004. Changing realities. Ecosytem approaches and sustainable forest management. www.iucn.org/themes/fcp/publications/arborvitae/avnewsletter.

Iwata, T., M. Inoue, S. Nakano, H. Miyasaka, A. Doi, and A. P. Covich. 2003. Shrimp abundance and habitat relationships in tropical rain-forest streams, Sarawak, Borneo. Journal of Tropical Ecology 19:387-395.

Izard, M. K., P. C. Wright, and E. L. Simons. 1985. Gestation length in Tarsius bancanus. American Journal of Primatology 9:327-331.

Jackson, H. D. 2002. A review of Afrotropical nightjar mortality, mainly road kills. Ostrich 73:147-161.

Janzen, D. H. 1974. Tropical blackwater rivers, animals, and mast fruiting by the dipterocarpaceae. Biotropica 6:69-103.

Janzen, D. H. 1979. New horizons in the biology of plant defenses. Pages 331-350 in G. A. Rosenthal, and D. H. Janzen, editors. Herbivores: Their interaction with secondary plant metabolites. Academic Press, London, UK.

Janzen, D. H. 1983. No park is an island: increase in interference from outside as park size decreases. Oikos 41:402-410.

Jarvie, J. M. Hiller, and A. Salim. 2002. HCVF Guidelines for Forest Managers in Indonesia. The Nature Conservancy and The United States Forest Service, USA.

Jathanna, D., K. U. Karanth, and A. J. T. Johnsingh. 2003. Estimation of large herbivore densities in the tropical forests of southern India using distance sampling. Journal of Zoology 261:285-290. 
Jeanes, K. and E. Meijaard. 2000. Danau Sentarum's wildlife. Part 1. Biodiversity value and global importance of Danau Sentarum's wildlife. Borneo Research Bulletin 31:150-229.

Jeanmart, P. 1998. Tentative d'élaboration d'un plan de gestion de la chasse villageoise dans la reserve du Dja. Programme ECOFAC- Composante Cameroun. Groupement AGRECO G.E.I.E - BDPASCETAGRI-SECA -CIRAD-Forêt (Centre de Coopération Internationale pour la Recherche en Développement), Brussels, Belgium.

Jennings, S. B., N. D. Brown, D. H. Boshier, T. C. Whitmore, and J. D. A. Lopes. 2001. Ecology provides a pragmatic solution to the maintenance of genetic diversity in sustainably managed tropical rain forests. Forest Ecology and Management 154:1-10.

Jennings, S., R. Nussbaum, and T. Sysnnott. 2002. A Toolkit for identifying and managing High Conservation Value Forests: Review Draft 1. Prepared by ProForest. Oxford. UK

Jepson, P., F. Momberg, and H. van Noord. 2002. A review of efficacy of the protected area system of East Kalimantan Province. Natural Areas Journal 22:28-42.

Jepson, P., J. K. Jarvie, K. MacKinnon, and K. A. Monk. 2001. The end for Indonesia’s lowland forests? Science 292:859-861.

Johns, A. D. 1982. Observations on nesting behaviour in rhinoceros hornbill, Buceros rhinoceros. Malayan Nature Journal 35:173-177.

Johns, A. D. 1983. Ecological effects of selective logging in a West Malaysian rain forest. PhD dissertation. University of Cambridge, Cambridge, UK.

Johns, A. D. 1986a. Effects of selective logging on the behavioral ecology of west Malaysian Primates. Ecology 67:684-694.

Johns, A. D. 1986b. Effects of selective logging on the ecological organization of a Peninsular Malaysian rainforest avifauna. Forktail 1:65-79.

Johns, A. D. 1987. The use of primary and selectively logged rainforest by Malaysian hornbills (Bucerotidae) and implications for their conservation. Biological Conservation 40:179-190.

Johns, A. D. 1988. Effects of 'selective' timber extraction on rainforest structure and composition and some consequences for frugivores and foliovores. Biotropica 20:31-37.

Johns, A. D. 1989a. Recovery of a peninsular Malaysian avifauna following selective timber logging: the first twelve years. Forktail 4:89-105.

Johns, A. D. 1989b. Timber, the environment and wildlife in Malaysian rain forests. Final report to Institute of South-east Asian Biology. University of Aberdeen, Aberdeen, UK.

Johns, A. D. 1992. Species conservation in managed forests. Pages 15-53 in T. C. Whitmore, and A. J. Sayer, editors. Tropical deforestation and species extinction. Chapman and Hall, London, U.K.

Johns, A. D. 1996. Bird population persistence in Sabahan logging concessions. Biological Conservation 75:3-10.

Johns, A. D. and J. P. Skorupa. 1987. Responses of rainforest primates to habitat disturbance: a review. International Journal of Primatology 8:157-191.

Johns, A. G. 1997. Timber production and biodiversity conservation in tropical rainforests. Cambridge University Press, Cambridge, UK.

Johns, A.G. and Johns, B.G. 1995. Tropical forest primates and logging: long-term coexistence? Oryx 29:205-211.

Johns, J. S., P. Barreto, and C. Uhl. 1996. Logging damage during planned and unplanned logging operations in the eastern Amazon. Forest Ecology and Management 89:59-77.

Johnsgard, P. A. 1999. The pheasants of the world: biology \& natural history. $2^{\text {nd }}$ ed. Smithsonian Institute Press, Washington, D.C., USA.

Johnsgard, P. A. 2000. Trogons and quetzals of the world. Smithsonian Institution Press, Washington, D.C., USA.

Johnson, C. N., S. Delean, and A. Balmford. 2002. Phylogeny and the selectivity of extinction in Australian marsupials. Animal Conservation 5:135-142.

Jones, D. T., F. X. Susilo, D. E. Bignell, S. Hardiwinoto, A. N. Gillison, and P. Eggleton. 2003. Termite assemblage collapse along a land-use intensification gradient in lowland central Sumatra, Indonesia. Journal of Applied Ecology 40:380-391.

Jonsson, A. and B. Ebenman. 2001. Are certain life histories particularly prone to local extinction? Journal of Theoretical Biology 209:455-463.

Jordano, P. 1983. Fig-seed predation and dispersal by birds. Biotropica 15:138-141. 
Joshi, A. R., J. L. D. Smith, and F. J. Cuthbert. 1995. Influence of food distribution and predation pressure on spacing behavior in palm civets. Journal of Mammalogy 76:1205-1212.

Jules, E. S. and P. Shahani. 2003. A broader ecological context to habitat fragmentation: Why matrix habitat is more important than we thought. Journal of Vegetation Science 14:459-464.

Jullien, M. and J. Clobert. 2000. The survival value of flocking in neotropical birds: Reality or fiction? Ecology 81:3416-3430.

Kammesheidt, L., A. A. Dagang, W. Schwarzwäller and H-J. Weidelt. 2003. Growth patterns of dipterocarps in treated and untreated plots Forest Ecology and Management 174:437-445.

Kapos, V. 1989. Effects of isolation on the water status of forest patches in the Brazilian Amazon. Journal of Tropical Ecology 5:173-186.

Karr, J. R. 1977. Ecological correlates of rarity in a tropical forest bird community. Auk 94:240-247.

Karr, J. R. and K. E. Freemark. 1983. Habitat selection and environmental gradients - dynamics in the stable tropics. Ecology 64:1481-1494.

Kartawinata, K. 1981. The environmental consequences of tree removal from the forest in Indonesia. In V.J. Sutlive et al. editors. Where have all the flowers gone: Deforestation in the third World. Studies in Third World Societies 13:191-214.

Kartawinata, K. and A. P. Vayda. 1984. Forest conversion in East Kalimantan, Indonesia: the activities and impact of timber companies, shifting cultivators, migrant pepper-farmers, and others. Pages 98-126 in F. di Castri, F.W.G. Baker, and M. Hadley, editors. Ecology in practice, Part I: Ecosystem Management, Ticooly, Dublin and UNESCO, Paris.

Kartawinata, K., T. C. Jessup, and A. P. Vayda. 1989. Exploitation in Southeast Asia. Pages 591-610 in H. Lieth, and M. J. A. Werger, editors. Tropical Rain Forest Ecosystems: Biogeographical and Ecological Studies, Elsevier, Amsterdam, the Netherlands.

Kaskija, L. 1995. The Punan Malinau: The persistence of an unstable culture. MSc thesis. Department of Anthropology, University of Uppsala, Uppsala, Sweden.

Kauffmann, J. B. and C. Uhl. 1990. Interactions of anthropogenic activities, fire and rain forests in the Amazon Basin. Pages 117-134 in J. G. Goldammer, editor. Fire in the tropical biota: Ecosystem processes and global challenges. Springer-Verlag, Berlin, Germany.

Kawanishi, K. 2002. Population status of tigers (Panthera tigris) in a primary rainforest of Peninsular Malaysia. PhD dissertation. University of Florida, USA.

Keßler, P. J. A., and K. Sidiyasa 1994. Trees of the Balikpapan-Samarinda area, East Kalimantan. A manual to 280 selected species. Tropenbos Series 7. The Tropenbos Foundation, Wageningen, the Netherlands.

Kemp, A. 1995. Bird families of the world. The hornbills: Bucerotiformes. Oxford University Press, Oxford, UK.

Kemp, A. C. and M. I. Kemp. 1975. Report on a study of hornbills in Sarawak, with comments on their conservation. World Wildlife Fund Report 2/74. WWF Malaysia, Kuala Lumpur, Malaysia.

Kemper, C. and D. T. Bell. 1985. Small mammals and habitat structure in lowland rainforest of Peninsular Malaysia. Journal of Tropical Ecology 1:5-22.

Keogh, J. S., D. G. Barker, and R. Shine. 2001. Heavily exploited but poorly known: Systematics and biogeography of commercially harvested pythons (Python curtus group) in Southeast Asia. Biological Journal of the Linnean Society 73:113-129.

Kerr, W. E., V. A. Nascimento, and G. A. Carvalho. 1994. Ha salvacao para os meliponineos? (Is there salvation for meliponine bees?) Pages 60-65. Anais do 1 deg encontro sobro abelhas, de Ribeirao Preto, 2-4 June 1994, USP-Campus de Ribeirao Preto, Brazil.

Kigomo, B. N., S. R. Woodell, and P. S. Savill. 1994. Phenological patterns and some aspects of the reproductive biology of Brachylaea huillensis O. Hoffm. African Journal of Ecology 94:296-307.

Kimball, R. T., E. L. Braun, J. D. Ligon, V. Lucchini, and E. Randi. 2001. A molecular phylogeny of the peacock-pheasants (Galliformes: Polyplectron spp.) indicates loss and reduction of ornamental traits and display behaviours. Biological Journal of the Linnean Society 73:187-198.

Kingston, T. 2004. Malaysian bat conservation. Expedition briefing. http://www.earthwatch.org/ expeditions/kingston/kingston_04.pdf. Downloaded on 10 March 2004.

Kingston, T., C. M. Francis, Z. Akbar, and T. H. Kunz. 2003. Species richness in an insectivorous bat assemblage from Malaysia. Journal of Tropical Ecology 19:67-79.

Kingston, T., G. Jones, A. Zubaid, and T. H. Kunz. 1999. Echolocation signal design in Kerivoulinae an Murininae (Chiroptera: Vespertilionidae) from Malaysia. Journal of Zoology 249:359-374. 
Kinnaird, M. F. 1998. Evidence for effective seed dispersal by the Sulawesi Red-knobbed Hornbill, Aceros cassidix. Biotropica 30:55-55.

Kinnaird, M. F., E. W. Sanderson, T. G. O'Brien, H. T. Wibisono, and G. Woolmer. 2003. Deforestation trends in a tropical landscape and implications for endangered large mammals. Conservation Biology 17:245-257.

Kinnaird, M. F. and T. G. O'Brien. 1998. Ecological effects of wildfire on lowland rainforest in Sumatra. Conservation Biology 12:954-956.

Kinnaird, M. F., T. G. O'Brien, and S. Suryadi. 1996. Population fluctuation in Sulawesi red-knobbed hornbills: tracking figs in space and time. Auk 113:431-440.

Kinnaird, M. F., T. G. O’Brien, and S. Suryadi. 1999. Importance of figs to Sulawesi's imperiled wildlife. Tropical Biodiversity 6:5-18.

Klaus, G., C. Klaus-Hugi, and B. Schmid. 1998. Geophagy by large mammals at natural licks in the rain forest of the Dzanga National Park, Central African Republic. Journal of Tropical Ecology 14:829-839.

Klein, A. M., I. Steffan-Dewenter, and T. Tscharntke. 2003. Pollination of Coffea canephora in relation to local and regional agroforestry management. Journal of Applied Ecology 40:837-845.

Kleine, M. and Heuveldop, J. 1993. A management planning concept for sustained yield of tropical forests in Sabah, Malaysia. Forest Ecology and Management 61: 277-297.

Knapen, H. 1997. Epidemics, droughts, and other uncertainties on Southeast Borneo during the eighteenth and nineteenth centuries. Pages 121-152 in P. Boomgaard, F. Colombijn, and D. Henley, editors. Paper Landscapes. Explorations in the environmental history of Indonesia. KITLV Press, Leiden, the Netherlands.

Kofron, C. P. and A. Chapman. 1995. Deforestation and bird species composition in Liberia, West Africa. Tropical Zoology 8:239-256.

Kottelat, M., A. J. Whitten, S. N. Kartikasari, and S. Wirjoatmodjo. 1993. Freshwater fishes of western Indonesia and Sulawesi. Periplus Editions, Hong Kong.

Kunin, W. E. 1998. Extrapolating species abundance across spatial scale. Science 281:1513-1515

Kunz, T. H. and E. D. Pierson. 1994. Bats of the world: an introduction. Pages 1-46 in R. W. Nowak, editor. Walker's bats of the world. John Hopkins University Press, Baltimore, USA.

Kurek, E. 2002. Microbial mobilization of metal from mineral under aerobic consition. Pages 190225 in P. M. Huang, J. M. Bollag, and N. Sevesi, editors. Interaction between soil particles and microorganism. Impact on the terrestrial ecosystem. Vol. 8. IUSS-UISS-IBU. John Wiley and Sons Ltd., Chichester, UK.

Kuusipalo, J., Y. Jafarsidik, G. Adjers, and K. Tuomela. 1996. Population dynamics of tree seedlings in a mixed dipterocarp rain-forest before and after logging and crown liberation. Forest Ecology and Management 81:85-94.

Lagendijk, J. P. 2000. Differences in foraging behaviour of woodpeckers between pristine and disturbed lowland rainforest in West-Kalimantan, Indonesia. Unpublished report. Department of Biology and Zoological Museum, University of Amsterdam, Amsterdam, The Netherlands.

Laidlaw, R. K. 2000. Effects of habitat disturbance and protected areas on mammals in peninsular Malaysia. Conservation Biology 14:1639-1648.

Laman, T. G. 1995a. The ecology of strangler fig seedling establishment. Selbyana 16:223-229.

Laman, T. G. 1995b. Ficus stupenda germination and seedling establishment in a Bornean rain forest canopy. Ecology 76:2617-2626.

Laman, T. G. 1996a. Ficus seed shadows in a Bornean rain forest. Oecologia 107:347-355.

Laman, T. G. 1996b. Specialization for canopy position by hemiepiphytic Ficus in a Bornean rain forest canopy. Journal of Tropical Ecology 12:789-803.

Laman, T. G., J. C. Gaither, and D. E. Lukas. 1996. Rain forest bird diversity in Gunung Palung National Park, West Kalimantan, Indonesia. Tropical Biodiversity 3:281-296.

Lambert, F. R. 1989a. Daily ranging behaviour of three tropical frugivores. Forktail 4:107-116.

Lambert, F. R. 1989b. Fig eating birds in a Malaysian lowland rainforest. Journal of Tropical Ecology 5:401-412.

Lambert, F. R. 1989c. Fig-eating and seed dispersal by pigeons in a Malaysian lowland forest. Ibis 131: 512-527.

Lambert, F. R. 1989d. Pigeons as seed predators and dispersers of figs in a Malaysian lowland forest. Ibis 131:521-530. 
Lambert, F. R. 1990a. Avifaunal changes following selective logging of a north Bornean rain forest. Unpublished report. University of Aberdeen, Institute of Tropical Biology, Aberdeen, UK.

Lambert, F. R. 1990b. Some notes on fig-eating by arboreal mammals in Malaysia. Primates 31:453-458.

Lambert, F. R. 1991. The conservation of fig-eating birds in Malaysia. Biological Conservation 58: $31-40$.

Lambert, F. R. 1992. The consequences of selective logging for Bornean lowland forest birds. Philosophical Transactions of the Royal Society, London, UK. B 335:443-457.

Lambert, F. R. and J. R. Howes. 1994. Ranging, breeding behaviour and food of the Asian brown tortoise Manouria emys in Borneo. Malayan Nature Journal 48:125-131.

Lambert, F. R. and N. J. Collar. 2002. The future for Sundaic lowland forest birds: long-term effects of commercial logging and fragmentation. Forktail 18:127-146.

Lammertink, M. 1999. Responses of woodpeckers to forest disturbance after selective logging in Kalimantan-preliminary data. MOFEC/Tropenbos/ NWO workshop "The balance between biodiversity conservation and sustainable forest use of tropical rain forest, Balikpapan, Indonesia. Unpublished report. MOFEC/Tropenbos/NWO, Balikpapan, Indonesia.

Lammertink, M. 2004. A multiple-site comparison of woodpecker communities in Bornean lowland and hill forests: effects of logging and conservation implications. Conservation Biology 18.

Lang, D. and D. Hubble. 2003. The impacts of conventional logging on Bufo asper, Rana leporine, Rana kublii \& Rana picturata in dipterocarp forest, East Kalimantan. Student project completion report for CIFOR. Unpublished report. CIFOR, Bogor, Indonesia.

Langham, N. 1983. Distribution and ecology of small mammals in three rain forest localities of peninsular Malaysia with particular reference to Kedah Peak. Biotropica 15:199-206.

Laurance, W. F. 1990. Comparative responses of five arboreal marsupials to tropical forest fragmentation. Journal of Mammalogy 71:641-653.

Laurance, W. F. 1991. Ecological correlates of extinction proneness in Australian tropical rain forest mammals. Conservation Biology 5:79-89.

Laurance, W. F. 1997. Responses of mammals to rainforest fragmentation in tropical queensland-a review and synthesis. Wildlife Research 24:603-612.

Laurance, W. F. 1999. Ecology and management of fragmented tropical landscapes. Biological Conservation 91:101-107.

Laurance, W. F. 2000. Do edge effects occur over large spatial scales? Trends in Ecology and Evolution 15:134-135.

Laurance, W. F. 2001. Fragmentation and plant communities: Synthesis and implications for landscape management. Pages 158-168 in R. O. Bierregaard, C. Gascon, T. E. Lovejoy, and R. Mesquita, editors. Lessons from Amazonia; the ecology and conservation of a fragmented forest. Yale University Press, New Haven, USA.

Laurance, W. F. and R. O. Bierregaard 1997. Tropical forest remnants-ecology management and conservation of fragmented communities. University of Chicago Press, Chicago, USA and London, UK.

Laurance, W. F. and S. G. W. Laurance. 1996. Responses of five arboreal marsupials to recent selective logging in tropical australia. Biotropica 28:310-322.

Laurance, W. F., L. V. Ferreira, J. M. Rankin-de Mérona, and S. G. W. Laurance. 1998. Rain forest fragmentation and the dynamics of Amazonian tree communities. Ecology 79:2032-2040.

Laurance, W. F., R. O. J. Bierregaard, C. Gascon, R. K. Didham, A. P. Smith, A. J. Lynam, V. M. Viana, T. E. Lovejoy, K. E. Sieving, J. W. J. Sites, M. Andersen, M. D. Tocher, E. A. Kramer, C. Restrepo, and C. Moritz. 1997. Tropical forest fragmentation: Synthesis of a diverse and dynamic discipline. Pages 515-525 in W. F. Laurance, and R. O. J. Bierregaard, editors. Tropical forest remnants: ecology, management, and conservation of fragmented communities. University of Chicago Press, Chicago, USA.

Lawton, R. M. 1955. The relationship between crown form and sex in Chlorophora excelsa. Empire Forestry Journal 34:192-193.

Lee, R. L. 2000. Impact of subsistence hunting in North Sulawesi, Indonesia and conservation options. Pages 455-472 in J. G. Robinson, and E. L. Bennett, editors. Hunting for sustainability in tropical forests. Columbia University Press, New York, USA.

Leighton, D. R. 1987. Gibbons: territoriality and monogamy. Pages 35-145 in B. B. Smuts, D. Cheney, R. Seyfarth, R. Wrangham, and T. Struhsaker, editors. Primate societies. University of Chicago Press, Chicago, USA. 
Leighton, M. 1982. Fruit resources and patterns of feeding, spacing, and grouping among sympatric Bornean hornbills (Bucerotidae). PhD dissertation. University of California, Davis, USA.

Leighton, M. 1984. The El Niño Southern Oscillation Event in Southeast Asia: Effects of drought and fire in tropical forest in eastern Borneo. Page 32. WWF-US, Washington D.C, USA.

Leighton, M. 1986. Hornbill social dispersion: variations on a monogamous theme. Pages 108-130 in D. I. Rubenstein, and R. W. Wrangham, editors. Ecological aspects of social evolution. Birds and mammals. Princeton University Press, Princeton, USA.

Leighton, M. 2004. TNC East Kalimantan program review 2004: Draft report on ecological aspects. The Nature Conservancy, Samarinda, Kalimatan, Indonesia.

Leighton, M. and D. R. Leighton. 1983. Vertebrates responses to fruiting seasonality within a Bornean rain forest. Pages 181-196 in S. L. Sutton, T. C. Whitmore, and A. C. Chadwick, editors. Tropical rain forest: Ecology and management. Blackwell Scientific Publications, Oxford, UK.

Leighton, M. and N. Wirawan. 1986. Catastrophic drought and fire in Borneo tropical rain forest associated with the 1982-1983 El Niño southern oscillation event. Pages 75-101 in G. T. Prance, editor. Tropical rain forest and world atmosphere. Westview Press, Boulder, Colorado, USA.

Lekagul, B. and J. A. McNeely. 1977. Mammals of Thailand. Kurusapha Ladproa Press, Bangkok, Thailand.

Lennertz, R. and K. F. Panzer. 1983. Preliminary assessment of the drought and forest fire damage in Kalimantan Timur. Report of the Fact-Finding Mission. Transmigration Area Development Project PN 76.2010.7. DFS German Forestry Service Ltd. for GTZ, Germany.

Lim, B. L. and I. Das 1999. The turtles of Borneo. Natural History Publication, Kotakinabalu, Malaysia.

Lindenmayer, D. B. and R. J. Hobbs. 2004. Fauna conservation in Australian plantation forests-a review. Biological Conservation 119:151-168.

Linkie, M., D. J. Martyr, J. Holden, A. Yanuar, A. T. Hartana, J. Sugardjito, and N. Leader-Williams. 2003. Habitat destruction and poaching threaten the Sumatran tiger in Kerinci Seblat National Park, Sumatra. Oryx 37:41-48.

Linkie, M. and L. Sadikin. 2003. The bearded pig in Kerinci Seblat National Park, Sumatra. Asian Wild Pig News 3:3-9.

Loehle, C. 1988. Tree life history strategies: the role of defences. Canadian Journal of Forest Research 18:209-222.

Loiselle, B. A., E. Ribbens, and O. Vargas. 1996. Spatial and temporal variation of seed rain in a tropical lowland wet forest. Biotropica 28:82-95.

Lovejoy, T. E., B. O. J. Bierregaard, A. B. Rylands, J. R. Malcolm, C. E. Quintela, L. H. Harper, K. S. Brown, A. H. Powell, G. V. N. Powell, H. O. R. Schubart, and M. B. Hays. 1986. Edge and other effects of isolation on Amazon forest fragments. Pages 257-285 in M. E. Soulé, editor. Conservation biology; the science of scarcity and diversity. Sinauer Associates, Inc., Sunderland, MA, USA.

Lu, X.-M., Y.-X. Wang, and Y.-P. Zhang. 2001. Divergence and phylogeny of mitochondrial cytochrome b gene from species in Nycticebus. Zoological Research 22:93-98.

Lucas, P. W. and R. T. Corlett. 1998. Relationship between diet of Macaca fascicularis and forest phenology. Folia Primatologia 57:201-215.

Lucchini, V., E. Meijaard, C. H. Diong, C. P. Groves, and E. Randi. in press. New phylogenetic perspectives among South-East Asian wild pig species based on mtDNA sequences and morphometric data. Journal of Zoology.

Ludwig, D., M. Mangel, and B. Haddad. 2001. Ecology, conservation, and public policy. Annual Review of Ecology and Systematics 32:481-517.

Lynch, O. J. and E. Harwell 2002. Whose natural resources? Whose common good? Towards a paradigm of environmental justice and the national interest in Indonesia. CIEL (Center for International Environmental Law), Washington D.C., USA.

MacDonald, D. W. and M. J. Wise. 1979. Notes on the behavior of the Malay civet Viverra tangalunga Gray. Sarawak Museum Journal 48:295-299.

Mackie, C. 1984. The lessons behind East Kalimantan's forest fires. Borneo Research Bulletin 16:63-74.

MacKinnon, J. 1977. A comparative ecology of Asian apes. Primates 18:747-772.

MacKinnon, J. K. 2002. Invasive alien species in Southeast Asia. ASEAN Review of Biodiversity and Environmental Conservation 2:9-11. 
MacKinnon, J. and K. MacKinnon. 1980. Niche differentiation in a primate community. Pages 167190 in D. J. Chivers, editor. Malayan forest primates: ten years study in tropical rain forests. Plenum Press, New York, USA.

MacKinnon, J. K. and K. Phillipps. 1993. A field guide to the birds of Borneo, Sumatra, Java, and Bali. Oxford University Press, Oxford, UK.

MacKinnon, K. S. 1978. Stratification and feeding differences among Malayan squirrels. Malayan Nature Journal 330:593-608.

MacKinnon, K. S. 1986. Conservation status of Indonesian primates. Primate Eye 29:30-35.

MacKinnon, K., G. Hatta, H. Halim, and A. Mangalik. 1996. The ecology of Kalimantan. Periplus Editions, Singapore.

Madge, S. G. 1969. Notes on the breeding of the Bushy-crested Hornbill Anorrhinus galeritus. Malayan Nature Journal 23:1-6.

Malcolm, J. R. and J. C. Ray. 2000. Influence of timber extraction routes on Central African smallmammal communities, forest structure, and tree diversity. Conservation Biology 14:16231638.

Malingreau, J. P., G. Stephens, and L. Fellows. 1985. Remote sensing of forest fires: Kalimantan and North Borneo in 1982-83. Ambio 14:314-321.

Mangel, M., L. M. Talbot, G. K. Meffe, M. T. Agardy, D. L. Alverson, J. Barlow, D. B. Botkin, G. Budowski, T. Clark, J. Cooke, R. H. Crozier, P. K. Dayton, D. L. Elder, C. W. Fowler, S. Funtowicz, J. Giske, R. J. Hofman, S. J. Holt, S. R. Kellert, L. A. Kimball, D. Ludwig, K. Magnusson, B. S. Malayang, C. Mann, E. A. Norse, and et al. 1996. Principles for the conservation of wild living resources. Ecological Applications 6:338-362.

Marcot, B. G., R. E. Gullison, and J. R. Barborak. 2001. The effects of logging on tropical forest ungulates in R. A. Fimbel, A. Grajal, and J. G. Robinson, editors. The cutting edge. Columbia University Press, New York, USA.

Marks, S. A. 2001. Back to the future: Some unintended consequences of Zambia's Community-Based Wildlife Program (ADMADE). Africa Today 48:121-141.

Marsden, S. J. 1998. Changes in bird abundance following selective logging on Seram, Indonesia. Conservation Biology 12:605-611.

Marsh, C. W., A. D. Johns, and J. M. Ayres. 1987. Effects of habitat disturbance on rain forest primates. Pages 83-107 in C. W. Marsh, and R. A. Mittermeier, editors. Primate conservation in the tropical rain forest. Alan R. Liss, Inc., New York, USA.

Marsh, C. W. and W. L. Wilson. 1981. A survey of primates in peninsular Malaysian forests. Universiti Kebangsaan Malaysia, Kuala Lumpur, Malaysia and University of Cambridge, UK.

Martin-Smith, K. M. 1998a. Relationships between fishes and habitat in rainforest streams in Sabah, Malaysia. Journal of Fish Biology 52:458-482.

Martin-Smith, K. M. 1998b. Temporal variation in fish communities from the upper Segama Roiver, Sabah, Malaysian Borneo. Polskie Archiwum Hydrobiologii 45:185-200.

Martin-Smith, K. M. 1998c. Effects of disturbance caused by selective timber extraction on fish communities in Sabah, Malaysia. Environmental Biology of Fishes 53:155-167.

Maryanto, I., Maharadatunkamsi, and A. Suyanto. 2002. Morphological variation and status of the Plantain Squirrel Callosciurus notatus (Boddaert, 1785) in Indonesia. Treubia 32:39-61.

Mason, D. J. and F. E. Putz. 2001. Reducing the impacts of tropical forestry on wildlife. Pages 473-509 in R. Fimbel, A. Grajal, and J. G. Robinson, editors. The cutting edge: Conserving wildlife in logged tropical forest. Columbia University Press, New York, USA.

Mason, D. J. and J. Thiollay. 2001a. The effects of logging on tropical forest ungulates in R. A. Fimbel, A. Grajal, and J. G. Robinson, editors. The cutting edge: Conserving wildlife in logged tropical forest. Columbia University Press, New York, USA.

Mason, D. J. and J. Thiollay. 2001b. Tropical forestry and the conservation of neotropical birds. Pages 167-191 in R. Fimbel, A. Grajal, and J. G. Robinson, editors. The cutting edge: conserving wildlife in logged tropical forest. Columbia University Press, New York, USA.

Mathews, A. and A. Matthews. 2002. Distribution, population density, and status of sympatric cercopithecids in the Campo-Ma'an area, Southwestern Cameroon. Primates 43:155-168.

Matsubayashi, H., E. Bosi, and S. Kohshima. 2003. Activity and habitat use of lesser mouse-deer (Tragulus javanicus). Journal of Mammalogy 84:234-242. 
Matsui, M. 1979. Amphibians from Sabah. Systematic and natural history notes. Contributions from the Biological Laboratory Kyoto University 25:303-346.

Mattson, D. J., S. Herrero, R. G. Wright, and C. M. Pease. 1996. Designing and managing protected areas for Grizzly Bears: How much is enough? in R. G. Wright, editor. National parks and protected areas: Their role in environmental protection. Blackwell Science, Cambridge, MA, USA.

May, R. M. 1988. How many species are there on earth? Science 241:1441-1449.

May, S. A. and T. W. Norton. 1996. Influence of fragmentation and disturbance on the potential impact of feral predators on native fauna in australian forest ecosystems. Wildlife Research 23:387-400.

McClure, H. E. 1966. Flowering, fruiting, and animals in the canopy of a tropical rain forest. The Malaysian Forester 29:182-203.

McClure, H. E. 1968. Some problems concerning endangered birds in south-eastern Asia. IUCN Publications (New Series) 10:307-311.

McConkey, K. and M. Galetti. 1999. Seed dispersal by the sun bear Helarctos malayanus in Central Borneo. Journal of Tropical Ecology 15:237-241.

McDonald, W. and C. C. St Clair. 2004. Elements that promote highway crossing structure use by small mammals in Banff National Park. Journal of Applied Ecology 41:82-93.

McGowan, P. J. K. and P. J. Garson. 1995. Pheasants status survey and conservation action plan 19951999. IUCN, Gland, Switzerland.

Mckenney, D. W. and D. B. Lindenmayer. 1994. An economic assessment of a nest-box strategy for the conservation of an endangered species. Canadian Journal of Forest Research-Journal Canadien de la Recherche Forestiere 24:2012-2019.

McKinney, M. L. and J. L. Lockwood. 1999. Biotic homogenization: a few winners replacing many losers in the next mass extinction. Trends in Ecology \& Evolution 14:450-453.

McNally, L. C. and S. S. Schneider. 1996. Spatial distribution and nesting biology of colonies of the African honey bee Apis mellifera scutellata (Hymenoptera: Apidae) in Botswana, Africa. Environmental Entomology 25:643-652.

Medway (Lord). 1969. The wild mammals of Malaya and offshore islands including Singapore. Oxford University Press, London, UK.

Medway (Lord). 1978. The wild mammals of Malaya (Peninsular Malaysia) and Singapore. Oxford University Press, Kuala Lumpur, Malaysia.

Medway (Lord) and D. R. Wells 1976. The birds of the Malay Peninsula, Vol 5. Conclusions and survey of every species. Wihterby \& Penerbit University Malaya, London, UK.

Meijaard, E. 1999a. Human-imposed threats to sun bears in Borneo. Ursus 11:185 - 192.

Meijaard, E. 1999b. Ursus malayanus, the neglected Malayan sun bear. Nederlandsche Commissie voor International Natuurbescherming, Leiden, The Netherlands.

Meijaard, E. 2000. Bearded pig (Sus barbatus). Ecology, conservation status, and research methodology. Background document for the electronic conference on bearded pig research, and recommendations for a collaborative research programme. Unpublished report. WWF-Indonesia, CIFOR, and Ecosense Consultants, Bogor, Indonesia.

Meijaard, E. 2001a. Conservation and trade of sun bears in Kalimantan. Pages 26-37 in D. Williamson, editor. Proceedings of the 3rd International Symposium on the Trade in Bear Parts, 26-28 October 1999, Seoul, South Korea.

Meijaard, E. 2001b. Recommendations regarding the use of tree spiking as a legal tool to combat illegal logging in Indonesia. Unpublished report for Directorate General of Nature Conservation. Ministry of Forestry, Indonesia. Australian National University, Canberra, Australia.

Meijaard, E. 2003a. Forest, pigs and people. A plan for the sustainable management of Bearded Pig populations in and around the Kayan Mentarang National Park, East Kalimantan, Indonesia. Unpublished report for WWF-Indonesia. WWF-Indonesia, Jakarta, Indonesia.

Meijaard, E. 2003b. Mammals of South-East Asian islands and their Late Pleistocene environments. Journal of Biogeography 30:1245-1257.

Meijaard, E. 2003c. Solving mammalian riddles. A reconstruction of the Tertiary and Quaternary distribution of mammals and their palaeoenvironments in island South-East Asia. Unpublished $\mathrm{PhD}$ thesis. Department of Anthropology and Archaeology. Australian National University, Canberra, Australia.

Meijaard, E. 2004. A craniometric analysis of the leopard, Panthera pardus, specifically regarding the taxonomic status and biogeographic history of the Javan leopard. Journal of Mammalogy 85: 302-210. 
Meijaard, E. in press. Craniometric differences among Malayan sun bears (Ursus malayanus); evolutionary and taxonomic implications. Raffles Bulletin of Zoology December 2004.

Meijaard, E. and C. P. Groves. 2004. A taxonomic revision of the Tragulus mouse-deer (Artiodactyla). Zoological Journal of the Linnean Society 140: 63-102.

Meijaard, E. and D. Sheil. in prep. Why did the chicken cross the road?-and other unanswered mysteries from Borneo.

Meijaard, E. and V. Nijman. 2000. Distribution and conservation of the proboscis monkey (Nasalis larvatus) in Kalimantan, Indonesia. Biological Conservation 92:15 - 24.

Meijaard, E. and V. Nijman. 2003. Primate hotspots on Borneo: predictive value for general biodiversity and the effects of taxonomy. Conservation Biology 17:725-732.

Meijaard, E. R. Nasi, D. Sheil, and A. Grafen. in prep. Predicting the sensitivity of Bornean mammals to selective logging.

Merrill, T., D. J. Mattson, R. G. Wright, and H. B. Quigley. 1999. Defining landscapes suitable for restoration of Grizzly Bears, Ursus arctos, in Idaho. Biological Conservation 87:231-248.

Mills, J. and C. Servheen. 1994. The Asian trade in bears and bear parts: Impacts and conservation recommendations. International Conference on Bear Research and Management 9:161-167.

Milner-Gulland, E. J. and H. R. Akçakaya. 2001. Sustainability indices for exploited populations. Trends in Ecology \& Evolution 16:686-692.

Ministry of Forestry. 1990. Act of the Republic of Indonesia No. 5 of 1990 concerning conservation of living resources and their ecosystems. Ministry of Forestry of the Republic of Indonesia.

Ministry of Forestry. 1992. Daftar binatang dan tumbuhan yang dilingdungi di Indonesia (list of the protected plants and animals in Indonesia). Unpublished report. Balai Konservasi Sumber Daya Alam I, Kantor Wilayah Propinsi Sumatera Utara, Departmen Kehutanan, Medan, Indonesia.

Mitani, J. C. 1992. Singing behavior of male gibbons: field observations and experiments. Pages 199210 in T. Nishida, W. C. McGrew, P. Marler, M. Pickford, and F. B. M. de Waal, editors. Topics in Primatology: Human Origins. Vol 1. University of Tokyo Press, Tokyo, Japan.

Mitchell, A. H. 1994. Ecology of Hose's Langur, Prebytis hosei, in mixed logged and unlogged dipterocarp forest in north Borneo. Yale University.

Mitchell, R. M. 1979. The sciurid rodents (Rodentia: Sciuridae) of Nepal. Journal of Asian Ecology 1: 21-28.

Mittermeier, R. A. and C. G. Mittermeier 1998. Megadiversity: Earth's biologically wealthiest nations. CEMEX.

Miura, S. and A. H. Idris. 1999. Present status and group size of the mouse-deer on Pulau Tioman, Malaysia. Malayan Nature Journal 53:335-339.

Mjöberg, E. P. 1929. Durch die Insel der Kopfjäger. Brockhaus, Leipzig, Germany.

Molengraaff, G. A. F. and M. Weber. 1920. Het verband tusschen den plistoceenen ijstijd en het ontstaan der Soenda-zee en de invloed daarvan op de verspreiding der koraalriffen en op de fauna. Verslagen der Afdeeling Natuurkunde 28:497-544.

Moll, E. and D. Sharma 2000. The turtles of Peninsular Malaysia. Natural History Publications, Kota Kinabalu, Malaysia.

Morley, R. J. 2000. Origin and evolution of tropical rain forests. John Wiley \& Sons, Ltd, Chichester, UK.

Moyersoen, B., A. H. Fitter, and I. J. Alexander. 1998. Spatial distribution of ectomycorrhizas and arbuscular mycorrhizas in Korup National Park rain forest, Cameroon, in relation to edaphic parameters. New Phytologist 139:311-320.

Murniati, D. P. Garrity, and A. N. Gintings. 2001. The contribution of agroforestry systems to reducing farmers' dependence on the resources of adjacent national parks: a case study from Sumatra, Indonesia. Agroforestry Systems 52:171-184.

Muul, I. and L. B. Liat. 1978. Comparative morphology, food habits, and ecology of some Malaysian arboreal rodents. Pages 361-370 in G. G. Montgomery, editor. The ecology of arboreal folivores. Smithsonian Institution Press, Washington, D.C., USA.

Muziol, C., C. T. Yuan, and G. B. Keong. 2000. Reconciling logging and the conservation of biodiversity: Recommendations for a large timber concession in Terengganu, Peninsular Malaysia. Pages 270-277 in M. S. Bista, R. B. Joshi, S. M. Amatya, A. V. Parajuli, M. K. Adhikari, H. K. Saiju, R. Thakur, K. Suzuki, and K. Ishii, editors. Proceedings of the 8th international workshop of Bio-Refor, Kathmandu, Nepal, November 28 - December 2, 1999. BIO-REFOR, Nepal. 
Myers, N. 1985. The primary source. W.W. Norton and Co, New York, USA.

Nasi, R. and E. Forni. 2003. La gestion durable des forêts. Le Flamboyant 56:39-40.

Nasi, R., R. Dennis, E. Meijaard, G. Applegate, and P. Moore. 2002. Forest fire and biological diversity. Unasylva 53:36-40.

Nason, J. D. and J. L. Hamrick. 1997. Reproductive and genetic consequences of forest fragmentation: two case studies of neotropical canopy trees. Journal of Heredity 88:264-276.

Ndan, I. 2003. Studi perbandingan teknik perburuan tradisional babi hutan (Sus barbatus Muller, 1896) antara suku dayak Kenyah dan suku Punan di kabupaten Malinau. MSc Thesis. Universitas Mulawarman, Samarinda, Indonesia.

Nederlandsch-Indische Vereeniging tot Natuurbescherming. 1939. Natuur in Zuid- en Oost- Borneo. Fauna, flora en natuurbescherming in de Zuider- en Ooster-Afdeeling van Borneo. Pages 334-411 in Nederlandsch-Indische Vereeniging tot Natuurbescherming, editor. 3 Jaren Indisch natuur leven. Opstellen over landschappen, dieren en planten, tevens elfde verslag (1936-1938), Batavia, Indonesia.

Nepstad, D. C., A. G. Moreira, and A. A. Alencar. 1999a. Flames in the rain forest: origins, impacts and alternatives to Amazonian fires. Page 161. Pilot Program to Conserve the Brazilian Rain Forest, Brasilia, Brazil.

Nepstad, D. C., A. Verissimo, A. Alencar, C. Nobre, E. Lima, P. Lefebvre, P. Schlesinger, C. Potter, P. Mountinho, E. Mendoza, M. A. Cochrane, and V. Brooks. 1999b. Large-scale impoverishment of Amazonian forests by logging and fire. Nature 398:505-508.

Nettelbeck, A. R. 1997. Sightings of Binturongs in the Khao Yai National Park, Thailand. Small Carnivore Conservation 16:22-24.

Nettelbeck, A. R. 1998. Encounters between lar gibbons (Hylobates lar) and binturongs (Arctictis binturong). Folia Primatologica 69:392-396.

Newmark, W. D. 1991. Tropical forest fragmentation and the local extinction of understorey birds in the Eastern Usambara Mountains, Tanzania. Conservation Biology 5:67-78.

$\mathrm{Ng}$, F. S. P. 1980. Legumes in forestry. Pages 449-456. Proceedings of the symposium on legumes in the tropics. Faculty Agricultural University Pertanian Malaysia.

Ng, F. S. P. 1986. Tropical sapwood trees. Naturalia Monspeliensia. Colloque International sur l'Arbre: 61-97.

Ngabo, C. K. M. and C. Dranzoa. 2001. Bird communities in gaps of Budongo Forest Reserve, Uganda. Ostrich Supplement 15:38-43.

Nicholson, D. I. 1979. The effects of logging and treatment on the mixed dipterocarp forests of southeast Asia. Report FAO MISC/79/8, FAO, Rome, Italy.

Niemitz, C. 1984. Biology of Tarsiers. Gustav Fischer, Stuttgart, Germany.

Nieuwenhuis, A. W. 1907. Quer durch Borneo. Ergebnisse seiner Reisen in den Jahren 1894, 1896-97 und 1898-1900. E.J. Brill, Leiden, The Netherlands.

Nijman, V. 1997. Preliminary survey on colobine monkeys and other primates, in north-east Kalimantan, Indonesia. Unpublished report. University of Amsterdam, Amsterdam, the Netherlands.

Nijman, V. 1998. Habitat preference of great argus pheasant (Argusianus argus) in Kayan-Mentarang National Park, East Kalimantan, Indonesia. Journal für Ornithologie 139:313-323.

Nijman, V. in press. Effects of habitat disturbance and hunting on densities and biomass of the endemic Hose's leaf monkey Prebytis hosei (Thomas 1989) (Mammalia: Primates: Cercopithecidae) in east Borneo. Contributions to Zoology 74.

Nijman, V. and S. van Balen. 2003. Wandering stars: age-related habitat use and dispersal of Javan Hawk-eagles (Spizaetus bartelsi). Journal of Ornithology 144:451-458.

NIVN (Nederlandsch-Indische Vereeniging tot Natuurbescherming). 1939. Natuur in Zuid- en OostBorneo. Fauna, flora en natuurbescherming in de Zuider- en Ooster-Afdeeling van Borneo. Pages 334-411 in NIVN, editor. 3 Jaren Indisch natuur leven. Opstellen over landschappen, dieren en planten, tevens elfde verslag (1936-1938), Batavia, Indonesia.

Noerdjito, M. and I. Maryanto. 2001. Jenis-jenis hayati yang dilindungi perundang-undangan Indonesia. Balitbang Zoologi (Museum Zoologicum Bogoriense), Puslitbang-LIPI, and The Nature Conservancy, Cibinong, Indonesia.

Nomura, F. 2003. Seasonal trends of habitat usage in two ursine species, a destructive beast Ursus arctos yesoensis and an agricutural pest Helarctos malayanus. $\mathrm{PhD}$ thesis. Graduate School of 
Environmental Earth Science, Division of Bioscience, Laboratory of Environmental Medicine and Informatics. University of Hokkaido, Hokkaido, Japan.

Norberg, U. M. and J. M. V. Rayner. 1987. Ecological morphology and flight in bats: wing adaptations, flight performance, foraging strategy and echolocation. Philosophical Transactions of the Royal Society of London - Series B: Biological Sciences 316:335-427.

Nordin, M. and M. Z. Hussin. 1996. Some effects of logging in mixed lowland dipterocarp forests on birds. CAP-SAM National Conference 5-9 January 1996.

Nowak, R. M. 1991. Walker's Mammals of the World, 5th edition, Vol. II. Johns Hopkins University Press, Baltimore, USA.

Nowak, R. M. 1999. Walker's mammals of the world, 6th edition. Johns Hopkins University Press, Baltimore, USA.

Nowell, K. and P. Jackson, editors. 1996. Wild cats. Status survey and conservation action plan. IUCN/ SSC Cat Specialist Group, Gland, Switzerland.

Nussbaum, R., J. Anderson, and T. Spencer 1995. Factors limiting the growth of indigenous tree seedlings planted on degraded rainforest soils in Sabah, Malaysia. Forest Ecology and Management 74:149-159.

Nykvist, N. 1998. Logging can cause a serious lack of calcium in tropical rainforest ecosytems: an example from Sabah, Malaysia. Pages 87-91 in A. Schulte, and D. Ruhiyat, editors. Soils of tropical forest ecosystems: Characteristics, ecology and management. Springer-Verlag, Berlin, Germany.

Nykvist, N., H. Grip, B. Liang Sim, A. Malmer, and F. Khiong Wong. 1994. Nutrient losses in forest plantations in Sabah, Malaysia. Ambio 23:210-215.

O’Brien, T. G. 1997. Behavourial ecology of the North Sulawesi Taractic Hornbill Penelopides exarhatus during the breeding season. Ibis 119:97-101.

O’Brien, T. G., editor. 1998. Bulungan Biodiversity Survey: Preliminary Results. Unpublished report to CIFOR and Wildlife Conservation Society. Wildlife Conservation Society - Indonesia, Bogor, Indonesia.

O’Brien, T. G., M. F. Kinnaird, E. S. Dierenfeld, N. L. Conklin-Brittain, R. W. Wrangham, and S. C. Silver. 1998a. What's so special about figs? Nature 392:668.

O’Brien, T. G., M. F. Kinnaird, and H. T. Wibisono. 2003. Crouching tigers, hidden prey: Sumatran tiger and prey populations in a tropical forest landscape. Animal Conservation 6:131-139.

O’Brien, T. G., M. F. Kinnaird, P. Jepson, and I. Setiawan. 1998b. Effect of forest size and structure on the distribution of Sumba Wreathed Hornbills, Aceros everetti. Pages 209-218 in P. Poonswad, editor. Proceedings of the Second Asian Hornbill Workshop, Bangkok. BRTP, Bangkok, Thailand.

O’Brien, T. G., N. Laksmi Winarni, F. Mindasari Saanin, M. F. Kinnaird, and P. Jepson. 1998c. Distribution and conservation status of Bornean peacock-pheasant Polyplectron schleiermacheri in central Kalimantan, Indonesia. Bird Conservation International 8:373-385.

O'Brien, T. G. and R. A. Fimbel. 1999. Faunal surveys in unlogged forest of the INHUTANI II Malinau Timber Concession. Unpublished Report to CIFOR and Wildlife Conservation Society. Wildlife Conservation Society - Indonesia, Bogor, Indonesia.

O'Brien, T. G. and R. Fimbel, editors. 2002. Faunal survey in unlogged forest of the INHUTANI II, Malinau Timber Concession. Unpublished report. Wildlife Conservation Society (WCS) and CIFOR, Bogor, Indonesia.

Ochoa, J. 1997. Sensibilidades potenciales de una comunidad de mamiferos en un bosque productor de maderas de la Guayana Venezolana. Interciencia 22:1-15.

Ochoa, J. 2000. Effects of logging on small-mammal diversity in the lowland forests of the Venezuelan Guyana region. Biotropica 32:146-164.

Oi, T. 1990. Population organization of wild pig-tailed macaques (Macaca nemestrina nemestrina) in West Sumatra. Primates 31:15-31.

Oka, T., E. Iskandar, and D. I. Ghozali. 2000. Effects of forest fragmentation on the behavior of gibbons. Pages 229-239 in E. Guhardja, M. Fatawi, M. Sutisna, T. Mori, and S. Ohta, editors. Rainforest ecosystems of East Kalimantan: El Niño, drought, fire and human impacts. SpringerVerlag, Tokyo, Japan.

Oksanen, L. 2001. Logic of experiments in ecology: is pseudoreplication a pseudoissue? Oikos 94:27-38.

Ouellet, M., J. Bonin, J. Rodrigue, J.-L. DesGranges, and S. Lair. 1997. Hindlimb deformities in freeliving anurans from agricultural habitats. Journal of Wildlife Diseases 33:95-104. 
Overgaard, H. J., B. Ekbom, W. Suwonkerd, and M. Takagi. 2003. Effect of landscape structure on anopheline mosquito density and diversity in northern Thailand: Implications for malaria transmission and control. Landscape Ecology 18:605-619.

Owens, I. P. F. and P. M. Bennett. 2000. Ecological basis of extinction risk in birds: habitat loss versus human persecution and introduced predators. Proceedings of the National Academy of Sciences of the United States of America 97:12144-12148.

Owiunji, I. 2000. Changes in avian communities of Budongo Forest Reserve after 70 years of selective logging. Ostrich 71:216-219.

Parren, M. E. 1991. Forest elephant (Loxodonta africana cyclotis Matschie) messenger-boy or bulldozer? The possible impact on the vegetation, with special reference to 41 tree species of Ghana. Department of Forestry, Wageningen Agricultural University, The Netherlands.

Payne, J. 1979. Synecology of Malayan tree squirrels with special reference to the genus Ratufa. PhD dissertation. University of Cambridge, UK.

Payne, J. 1990. Rarity and extinctions of large mammals in Malaysian rainforests. Pages 310-320 in Y. S. Kheong, and L. S. Win, editors. In harmony with nature, Kuala Lumpur, Malaysia.

Payne, J. 1995. Links between vertebrates and the conservation of Southeast Asian rainforests. Pages 54-65 in R. B. Primack, and T. E. Lovejoy, editors. Ecology, conservation and management of Southeast Asian rainforests. Yale University Press, New Haven, USA \& London, UK.

Payne, J., C. M. Francis, and K. Phillipps. 1985. A field guide to the mammals of Borneo. The Sabah Society, Kota Kinabalu.

Pearson, D. L. 1975. A preliminary survey of the birds of the Kutai Reserve, Kalimantan Timur, Indonesia. Treubia 28:157-162.

Pelissier, R., J. P. Pascal, F. Houllier, and H. Laborde. 1998. Impact of selective logging on the dynamics of a low elevation dense moist evergreen forest in the Western Ghats (South India). Forest Ecology and Management 105:107-109.

Peluso, N. L. 1993. Coercing conservation. The politics of state resource control in R. D. Lipschutz, and $\mathrm{K}$. Conca, editors. The state and social power in global environmental politics. Columbia University Press, New York, USA.

Peres, C. A. 2001. Synergistic effects of subsistence hunting and habitat fragmentation on Amazonian forest vertebrates. Conservation Biology 15:1490-1505.

Peters, H. A. 2001. Clidemia hirta invasion at the Pasoh Forest Reserve: An unexpected plant invasion in an undisturbed tropical forest. Biotropica 33:60-68.

Pfeffer, P. 1960. Étude d'une collection d'oiseaux de Bornéo. L'Oiseau et la Revue Française d'Ornithologie 30:191-218 and 31:199-129.

PHPA. 1996a. List of protected faunas: Burung/Aves. Directorate General Forest Protection and Nature Conservation, Ministry of Forestry. http://www2.bonet.co.id/dephut/burung1.htm. Accessed in March 2002.

PHPA. 1996b. List of protected faunas: Mamalia. Directorate General Forest Protection and Nature Conservation, Ministry of Forestry. http://www2.bonet.co.id/dephut/malia.htm. Accessed in March 2002.

Pinard, M. A. and F. E. Putz. 1996. Retaining forest biomass by reducing logging damage. Biotropica 28:278-295.

Pinard, M. A., M. G. Barker, and J. Tay. 2000. Soil disturbance and post-logging forest recovery on bulldozer paths in Sabah, Malaysia. Forest Ecology and Management 130:213-225.

Pinard, M., B. Howlett, and D. D. 1996. Site conditions limit pioneer tree recruitment after logging of dipterocarp forests in Sabah, Malaysia. Biotropica 28:2-12.

Pitra, C., J. Fickel, E. Meijaard, and C. P. Groves. 2004. Evolution and phylogeny of Old World deer. Molecular Phylogenetics \& Evolution 33:880-895.

Plumptre, A. and A. Johns. 2001. The effects of logging on tropical forest ungulates in R. Fimbel, A. Grajal, and J. G. Robinson, editors. The cutting edge: conserving wildlife in logged tropical forest. Columbia University Press, New York, USA.

Poonswad, P. and A. Tsuji. 1994. Ranges of males of the great hornbill Buceros bicornis, brown hornbill, Ptiloaemus, and wreathed hornbill Rhyticeros undulatus in Kha Yai National Park, Thailand. Ibis 136:79-86.

Poonswad, P., A. Tsuji, and C. Ngarmpongsai. 1983. A study of the breeding biology of hornbills (Bucerotidae) in Thailand. Pages 239-265. Proceedings of a Delacour/International Foundation for 
the Conservation of Birds Symposium on Breeding Birds in Captivity. International Foundation for the Conservation of Bird, Los Angeles, USA.

Poonswad, P., A. Tsuji, and C. Ngarmpongsai. 1988. A comparative ecological study of four sympatric hornbills (Family Bucerotidae) in Thailand. Proceedings of the International Ornithological Congress 19:2781-2791.

Poonswad, P., C. Sukkasem, S. Phataramat, S. Hayeemuida, K. Plongmai, P. Chuailua, Preeda Thiensongrusame, and N. Jirawatkavi, 2004. Comparison of cavity modification and community involvement as strategies for hornbill conservation in Thailand. Biological Conservation 122: 385-393.

Poore, D., P. Burgess, J. Palmer, S. Reitbergen, and T. Syncott 1989. No timber without trees: sustainability in the tropical forest. Earthscan Publications, London, UK.

Pottie, S. A. 1996. Studies of the ecology and behaviour of insectivorous bat species in Singapore. Unpublished Masters Thesis. National University of Singapore, Singapore.

Prawiraatmadja, D. R. 1970. The influence of several mechanical logging methods on the natural regeneration of tropical rain forest in East Kalimantan. (In Indonesian). Sarjana Thesis. Fakultas Kehutanan IPB, Bogor, Indonesia.

Pringle, C. M. and J. P. Benstead. 2001. The effects of logging on tropical river ecosystems. Pages 305325 in R. F. Fimbel, A. Grajal, and Robinson.J.G., editors. The cutting edge: Conserving wildlife in logged tropical forest. Columbia University Press, New York, USA.

Puri, R. K. 1997. Hunting knowledge of the Penan Benalui of East Kalimantan, Indonesia. Department of Anthropology. University of Hawaii, USA.

Puri, R. K. 1998. Assessment of the biodiversity of the Bulungan Research Forest: ethnoecology of the Punan Tubu. Unpublished report. Wildlife Conservation Society (WCS)/CIFOR, Bogor, Indonesia.

Puri, R. K. 2001. Bulungan ethnobiology handbook. A field manual for biological and social science research on the knowledge and use of plants and animals among 18 indigenous groups in northern East Kalimantan. CIFOR, Bogor, Indonesia.

Purvis, A., J. L. Gittleman, G. Cowlishaw, and G. M. Mace. 2000. Predicting extinction risk in declining species. Proceedings of the Royal Society of London - Series B: Biological Sciences 267: 1947-1952.

Putz, F. E. 1984. The natural history of lianas on Barro Colorado Island, Panama. Ecology 65:17131724.

Putz F. E., D. P. Dykstra, and R. Heinrich. 2000. Why poor logging practices persist in the tropics. Conservation Biology 14: 951-956.

Putz F. E., G. Blate, K. H. Redford, R. Fimbel, and J. G. Robinson. 2001a. Tropical forest management and conservation of biodiversity: an overview. Conservation Biology 15: 7-20.

Putz, F. E. and H. A. Mooney (eds.) 1991. The biology of vines. Cambridge University Press, Cambridge, UK

Putz, F. E., L. K. Sirot and M. A. Pinard. 2001b. Tropical forest management and wildlife. Silvicultural effects on forest structure, fruit production, and locomotion of arboreal animals. Pages 11-34 in R. A. Fimbel, A. Grajal, and J. G. Robinson, editors. The cutting edge: Conserving wildlife in logged tropical forest. Columbia University Press, New York, USA.

Rabinowitz, A. 1990. Notes on the behavior and movements of leopard cats, Felis bengalensis, in a dry tropical forest mosaic in Thailand. Biotropica 22:379-403.

Rabinowitz, A. R. 1991. Behaviour and movements of sympatric civet species in Huai Kha Khaeng Wildlife Sanctuary, Thailand. Journal of Zoology 223:281-298.

Rabinowitz, A., P. Andau, and P. P. K. Chai. 1987. The clouded leopard in Malaysian Borneo. Oryx 21: 107-111.

Rachmatika, I., R. Nasi, D. Sheil, and M. Wan. 2005. Fish fauna in Bulungan Research Forest (BRF) Malinau, East Kalimantan. CIFOR, Bogor, Indonesia.

Randi, E., V. Lucchini, A. Hennache, R. T. Kimball, E. L. Braun, and J. D. Ligon. 2001. Evolution of the mitochondrial DNA control region and cytochrome $b$ genes and the inference of phylogenetic relationships in the avian genus Lophura (Galliformes). Molecular Phylogenetics and Evolution 19:187-201.

Rankin-De Merona, J. M. and R. W. Hutchings. 2001. Deforestation effects at the edge of an Amazonian forest fragment: Tree mortality, damage, and recruitment. Pages 107-120 in R. O. 
Bierregaard, Gascion, C., Lovejoy, T.E. and R. Mesquita, editor. Lessons from Amazonia; the acology and conservation of a fragmented forest. Yale University Press, New Haven, USA.

Reagan, D. P. and R. B. Waide 1996. The food web of a tropical rain forest. University of Chicago Press, Chicago.

Redford, K. H. 1992. The empty forest. BioScience 42:412-422.

Redford, K. H. and P. Feinsinger. 2001. The half-empty forest: sustainable use and the ecology of interactions in J. D. Reynolds, G. M. Mace, K. H. Redford, and J. G. Robinson, editors. Conservation of exploited species. Cambridge University Press, Cambridge, UK.

Rejmanek, M. 1999. Invasive plant species and invasible ecosystems. Pages 79-102 in O. T. Sandlund, editor. Invasive species and biodiversity management. Kluwer Academic Publishers, Dordrecht, the Netherlands.

Republic of Indonesia. 1999. The law of the Republic of Indonesia number 41 year 1999 on forestry (Unofficial translation by Icel). http://www2. bonet.co.id/dephut/41-99-1.htm.

Reuters. 2003. Tiger parts found in record Australian seizure. http://news.findlaw.com/science/s/ 20031002/australiawildlifedc.html. Accessed on 7 October 2003.

Richards, P. W. 1996. The tropical rain forest. Second edition. Cambridge University Press, Cambridge, UK.

Riitters, K. H., R. V. O’Neill, and K. B. Jones. 1997. Assessing habitat suitability at multiple scales: a landscape-level approach. Biological Conservation 81:191-202.

Rijksen, H. D. 1978. A fieldstudy on Sumatran orang utans (Pongo pygmaeus abelii Lesson 1827). Ecology, behaviour and conservation. Nature Conservation Department. Agricultural University Wageningen, Wageningen, The Netherlands.

Rijksen, H. D. and E. Meijaard. 1999. Our vanishing relative. The status of wild orang-utans at the close of the twentieth century. Kluwer Academic Publishers, Dordrecht, The Netherlands.

Riswan, S. and K. Kartawinata. 1991. Regeneration in a lowland dipterocarp forest in East Kalimantan, Indonesia. Pages 295-301 in: A. Gomez-Pompa, T.C. Whitmore, and M. Hadley, editors. Rain forest regeneration and management. UNESCO, Paris, France.

Robertson, J. M. Y. and C. P. van Schaik. 2001. Causal factors underlying the dramatic decline of the Sumatran orang-utan. Oryx 35:26-38.

Robinson, H. C. and F. N. Chasen. 1936. The birds of the Malay Peninsula. Vol. III. Sporting birds: Birds of the shore and estuaries. Witherby, London, UK.

Robinson, J. G. and E. L. Bennett. 2000. Carrying capacity limits to sustainable hunting in tropical forests. Pages 13-30 in J. G. Robinson, and E. L. Bennett, editors. Hunting for sustainability in tropical forests. Columbia University Press, New York, USA.

Robinson, J. G. and E. L. Bennett. 2002. Will alleviating poverty solve the bushmeat crisis? Oryx 36: 332.

Robinson, J. G., K. H. Redford, and E. L. Bennett. 1999. Wildlife harvest in logged tropical forests. Science 284:595-596.

Robinson, M. H. 1969. The defensive behavior of some orthopteroid insects from Panama. Transactions of the Royal Entomological Socierty of London 121:281-303.

Robson, C. 2000. A field guide to the birds of South-East Asia. New Holland Publishers, London, Cape Town, Sydney, Auckland.

Rodman, P. S. 1978. Diets, densities, and distributions of Bornean primates. Pages 465-478 in G. G. Montgomery, editor. The ecology of arboreal foliovores. Smithsonian Institution Press, Washington, D.C., USA.

Rodman, P. S. 1991. Structural differentiation of microhabitats on sympatric Macaca fascicularis and $M$. nemestrina in East Kalimantan, Indonesia. International Journal of Primatology 12:357-375.

Roonwal, M. L. and S. M. Mohnot. 1977. Primates of South Asia: Ecology, sociology, and behavior. Harvard University Press, Cambridge, UK.

Rosenbaum, B. 2001. Biodiversity review of the vertebrate fauna at Bulungan research forest, East Kalimantan (and recommendations for research). Unpublished report for CIFOR and WCS, Indonesia.

Ross, C. 1992. Life history patterns and ecology of macaque species. Primates 33:207-215.

Round, P. D. and W. Y. Brockelman 1998. Bird communities of disturbed lowland forest habitats in southern Thailand. Natural History Bulletin of the Siam Society 46: 171-196. 
Rousseau, J. 1990. Central Borneo: Ethnic identity and social life in a stratified society. Clarendon Press, Oxford, UK.

Rowe, N. 1996. The pictorial guide to living primates. Pogonias Press, New York, USA.

Ruedi, M. and L. Fumagalli. 1996. Genetic structure of gymnures (genus Hylomys) on continental islands of SE Asia: historical effects of fragmentation. Journal of Zoological Systematics and Evolutionary Research 34:153-162.

Ruslim, Y., A. Hinrichs, B. Sulistioadi, and PT Limbang Ganeca. 2000. Study on implementation of reduced impact logging. Ministry of Forestry and Estate Crops in Cooperation with Deutsche Gesellschaft für Technische Zusammenarbeit, Samarinda, East Kalimantan, Indonesia.

Saiful, A. A., A. H. Idris, Y. N. Rashid, N. Tamura, and F. Hayashi. 2001. Home range size of sympatric squirrel species inhabiting a lowland dipterocarp forest in Malaysia. Biotropica 33: 346-351.

Saiful, A. A. and M. Nordin. 2004. Diversity and density of diurnal squirrels in a primary hill dipterocarp forest, Malaysia. Journal of Tropical Ecology 20:45-49.

Sanchez-De Leon, Y., X. Zou, S. Borges, and H. Ruan. 2003. Recovery of native earthworms in abandoned tropical pastures. Conservation Biology 17:999-1006.

Sanft, K. 1960. Bucerotidae (Aves/Upupae). Das Tierreich 76:1-176.

Santiapillai, A. and C. Santiapillai. 1996. The status, distribution and conservation of the Malayan sun bear (Helarctos malayanus) in Indonesia. Tigerpaper 23:11-16.

Santiapillai, C. and H. Supraham. 1985. On the status of the Leopard Cat (Felis bengalensis) in Sumatra. Tigerpaper 12:8-13.

Sastrawinata, H. A. and R. Effendy. 1991. The influences of several liberation treatment on the natural regeneration of dipterocarps in logged-over forest in Kintap, South Kalimantan. In I. Soerianegara, S. S. Tjitrosomo, R. C. Umaly, and I. Umboh, editors. Proceedings of the fourth round table conference on dipterocarps, Bogor, Indonesia. 12-15 December 1989. BIOTROP Special Publication 41:395-405.

Saunders, D. A., R. J. Hobbs, and C. R. Margules. 1991. Biological consequences of ecosystem fragmentation: A review. Conservation Biology 5:18-32.

Scatena, F. N. 2001. Ecological rhythms and the management of humid tropical forests. Examples from the Caribbean national Forest, Puerto Rico. Forest Ecology and Management 154:453-464.

Schnitzer, S. A. and F. Bongers. 2002. The ecology of lianas and their role in forests. Trends in Ecology and Evolution 17:223-230.

Schreiber, A., R. Wirth, M. Riffel, and H. van Rompaey. 1989. Weasels, civets, mongooses, and their relatives. An Action Plan for the conservation of mustelids and viverrids. IUCN, Gland, Switzerland.

Schupp, E. W. 1990. Annual variation in seedfall, post-dispersal predation and recruitment of a neotropical tree. Ecology 71:504-515.

Schwaner, C. A. L. M. 1853-1854. Borneo. Beschrijving van het stroomgebied van den Barito en reizen lands eenige voorname rivieren van het Zuid-Oostelijke gedeelte van dat eiland. $1^{\text {st }}$ volume. P.N. van Kampen, Amsterdam, the Netherlands.

Scott, N. J. J. 1976. The abundance and diversity of the herpetofaunas of tropical forest litter. Biotropica 8:41-58.

Sellato, B. 1997. Agricultural practices, social organization, settlement patterns, and ethnogenetic processes in East Kalimantan. Pages 27-57 in K. W. Sörensen, and B. Morris, editors. Peoples and plants of Kayan Mentarang. WWF, London, UK.

Sellato, B. 2001. Forest, resources and people in Bulungan. Elements for a history of settlement, trade, and social dynamics in Borneo, 1880-2000. CIFOR, Bogor, Indonesia.

Servheen, C. 1999. Sun bear conservation action plan. Pages 219-224 in C. Servheen, S. Herrero, and B. Peyton, editors. Bears. Status survey and conservation action plan. International Union for Conservation of Nature and Natural Resources, Gland, Switzerland and Cambridge, UK.

Servheen, C., S. Herrero, and B. Peyton, editors. 1999. Bears: status survey and conservation action plan. IUCN, Gland, Switzerland.

Setyarso, A. 1991. Assessment of stand structure and growth after an intensive logging on dipterocarp forest. In I. Soerianegara, S.S. Tjitrosomo, R.C. Umaly, and I. Umboh, editors. Proceedings of the fourth round table conference on dipterocarps, Bogor, Indonesia. 12-15 December 1989. BIOTROP Special Publication 41:191-200. 
Setyawati, T. 1999. Impact of logging on faunal diversity in Wanariset Sangai, Central Kalimantan. Unpublished report. CIFOR, Bogor, Indonesia.

Sheil, D. 1994. Naturalised and invasive plant species in the evergreen forests of the East Usambara Mountains Tanzania. African Journal of Ecology 32:66-71.

Sheil, D. 1998. A half century of permanent plot observation in Budongo Forest, Uganda: histories, highlights and hypotheses. Pages 399-428 in F. Dallmeier, and J. A. Comiskey, editors. Forest biodiversity research, monitoring and modelling: Conceptual background and Old World case studies. Proceedings from the 1995 Smithsonian MAB Washington Symposium. MAB, UNESCO, Paris, France.

Sheil, D. 2001a. Chapter 5. Biodiversity research in Malinau. CIFOR Technical Report. CIFOR, Bogor, Indonesia.

Sheil, D. 2001b. Conservation and biodiversity monitoring in the tropics: Realities, priorities, and distractions. Conservation Biology 15:1179-1182.

Sheil, D. and D. Burslem. 2003. Disturbing hypotheses in tropical forests. Trends in Ecology \& Evolution 18:18-26.

Sheil, D. and M. van Heist. 2000. Ecology for tropical forest management. International Forestry Review 2:261-270.

Sheil, D., J. A. Sayer, and T. O’Brien. 1999. Tree diversity and conservation in logged rainforest. Science 284:1587.

Sheil, D., N. Liswanti, I. Basuki, M. Wan, M. van Heist, I. Samsoedin, K. Kartawinata, Rukmiyati, and M. Agung. 2003a. Prioritas lokal dan keanekaragaman hayati dalam lansekap hutan: apa yang penting menurut masyarakat? Jurnal Hutan Indonesia (Indonesia Forest Journal).

Sheil, D., N. Liswanti, M. van Heist, I. Basuki, Syaefuddin, I. Samsoedin, Rukmiyati, and M. Agung. 2003b. Local priorities and biodiversity in tropical forest landscapes: asking people what matters. Tropical Forest Update 13: http:// www.itto.or.jp/newsletter/Newsletter.html.

Sheil, D., R. K. Puri, I. Basuki, M. van Heist, M. Wan, N. Liswanti, Rukmiyati, M. A. Sardjono, I. Samsoedin, K. Sidiyasa, Chrisandini, E. Permana, E. M. Angi, F. Gatzweiler, B. Johnson and A. Wijaya. 2003c. Exploring biological diversity, environment and local people's perspectives in forest landscapes. CIFOR with ITTO, Bogor, Indonesia.

Sheil, D., R. Nasi, and B. Johnson. 2004. Ecological criteria and indicators for tropical forestlandscapes: Challenges in the search for progress. Ecology and Society 9:article 7. http://www. eologyandsociety.org/vol9/iss $1 /$ art7.

Shekelle, M. in press. Distribution of tarsier acoustic forms, North and Central Sulawesi: With notes on the primary taxonomy of Sulawesi's tarsiers in S. Gursky, P. C. Wright, and E. L. Simons, editors. The Tarsiiformes: Origins, Taxonomy, Behavior and Conservation. Rutgers University Press, USA.

Short, L. L. 1978. Sympatry in woodpeckers of lowland Malaysian forest. Biotropica 10:122-133.

Short, L. L. 1982. Woodpeckers of the world. Monograph Series Delaware Museum of Natural History 4:1-676.

Sibley, C. and B. Monroe. 1990. Distribution and taxonomy of birds of the world. Yale University Press, New Haven, USA.

Siegel, S. and N. J. J. Castellan. 1988. Nonparametric systems for the behavioral sciences. 2nd edition. McGraw-Hill Book Company, New York, USA.

Siegert, F. and A. A. Hoffmann. 2000. The 1998 forest fires in East Kalimantan (Indonesia): A quantitative evaluation using high resolution, multitemporal ERS-2 SAR images and NOAAAVHRR hotspot data. Remote Sensing of Environment 72:64-77.

Siegert, F., G. Ruecker, A. Hinrichs, and A. A. Hoffmann. 2001. Increased damage from fires in logged forests during droughts caused by El Niño. Nature 414:437-440.

Silva, J. N. M., J. O. P. de Carvalho, J. d. C. A. Lopes, R. P. d. K. Oliveira, and L. C. de Oliveira. 1996. Growth and yield studies in the Tapajos region, Central Brazilian Amazon. Commonwealth Forestry Review 75:325-329 and 350-352.

Simons, H. 1987. Gunung Niut Nature Reserve. Proposed Management Plan. Page $42+$ appendices. WWF Indonesia, Jakarta, Indonesia.

Sist, N. and N. Brown. 2004. Silvicultural intensification for tropical forest conservation: a response to Frederickson and Putz. Biodiversity and Conservation 13:2381-2385.

Sist, P. 2001. Why RIL won't work by minimum-diameter cutting alone. ITTO Newsletter 11. 
Sist, P., C. Sabogal, and Y. Byron. 1999. Management of secondary and logged-over forests in Indonesia: Selected proceedings of an international workshop, 17-19 November 1997 CIFOR, Bogor, Indonesia.

Sist, P., D. Sheil, K. Kartawinata, and H. Priyadi. 2003b. Reduced-impact logging in Indonesian Borneo: some results confirming the need for new silvicultural prescriptions. Forest Ecology and Management 179:415-427.

Sist, P., D. P. Dykstra, and R. Fimbel. 1998a. Reduced impact logging guidelines for lowland and hill dipterocarp forest in Indonesia. CIFOR, Bogor, Indonesia.

Sist, P. and N. Nguyen-Thé. 2002. Logging damage and the subsequent dynamics of a dipterocarp forest in East Kalimantan (1990-1996). Forest Ecology and Management 165: 85-103.

Sist, P., R. Fimbel, D. Sheil, R. Nasi, and M.-H. Chevallier. 2003a. Towards sustainable management of mixed dipterocarp forests of South East Asia: Moving beyond minimum diameter cutting limits. Environmental Conservation 30:364-374.

Sist, P., T. Nolan, J. G. Bertault, and D. Dykstra. 1998b. Harvesting intensity versus sustainability in indonesia. Forest Ecology and Management 108:251-260.

Sitompul, A. F., M. F. Kinnaird, and T. G. O’Brien. In press. Size matters: the effects of forest fragmentation and resource availability on a large frugivore, the endemic Sumba Island hornbill. Bird Conservation International.

Slade, N. A., R. Gomulkiewicz, and H. M. Alexander. 1998. Alternatives to Robinson and Redford's method for assessing overharvest from incomplete demographic data. Conservation Biology 12: 148-155.

Slik, J. W. F. 2004. El Niño droughts and their effects on tree species composition and diversity in tropical rain forests. Oecologia 141:114-120.

Smit-van Dort, M. 1989. Skin, skull and skeleton characters of mouse deer (Mammalia, tragulidae), with keys to the species. Bulletin Zoologisch Museum 12:89-95.

Smythies, B. E. 1957. An annotated checklist of the birds of Borneo. Sarawak Museum Journal 7:1296.

Smythies, B. E. 1981. The birds of Borneo (3th ed.). The Sabah Society and the Malayan Nature Society, Kuala Lumpur, Malaysia.

Smythies, B. E. 1986. The birds of Borneo (revised ed.). Nimrod Press Ltd \& Silvio Mattacchione \& Co., Liss, Hampshire \& Pickering, Ontario, Canada.

Snyder, N. F. R., J. W. Wiley, and C. B. Kepler 1987. The parrots of Luquillo: natural history and conservation of the Puerto Rican Parrot. Western Foundation of Vertebrate Zoology, Los Angles, CA, USA.

Sodhi, N. S. and L. H. Liow. 2000. Improving conservation biology research in Southeast Asia. Conservation Biology 14:1211.

Sody, H. J. V. 1941. Tweede bijdrage over de voortplantingstijden der Indische zoogdieren. Nederlandsch-Indische Jager 11:198-201.

Soehartono, T. and A. Mardiastuti. 2001. Kutai National Park: Where to go. Tropical Biodiversity 7: 83-101.

Soulé, M. E., D. T. Bolger, A. C. Alberts, J. Wright, M. Sorice, and S. Hill. 1988. Reconstructed dynamics of rapid extinctions of chaparral-requiring birds in urban habitat islands. Conservation Biology 2:75-92.

Sözer, R., A. M. Rachmat, and Artinsyah. 1997. The status of the Bornean Peacock Pheasant Polyplectron schleiermacheri in Kalimantan, Indonesia. Preliminary results of the Kalimantan Pheasant Project 1995-1998. Pages 116-129 in N. Sugiri, D. M. Prawiradilaga, K. G. Wiryawan, and A. S. Adhikerana, editors. Prosiding Seminar Nasional Pelestarian Burung dan Ekosistemnya. Institut Pertanian Bogor, Bogor, Indonesia.

Sözer, R., I. Setiawan, A. P. Setiadi, A. M. Rachmat, and A. Adut. 1999. Survey of the Bornean Peacock Pheasant Polyplectron schleiermacheri and assessment of status, threats, and distribution of other Galliformes in West, Central, and East Kalimantan, Indonesia. Kalimantan Pheasant Project, Sukabumi, Indonesia.

Srikosamatara, S. 1993. Density and biomass of large herbivores and other mammals in a dry tropical forest, western Thailand. Journal of Tropical Ecology 9:33-43.

Stacy, E. A., J. L. Hamrick, J. D. Nason, S. P. Hubbell, R. B. Foster, and R. Condit. 1996. Pollen dispersal in low-density populations of three neotropical tree species. The American Naturalist 148:275-298. 
Stanford, C. B. and H. T. Bunn 2001. Meat-eating and human evolution. Oxford University Press, Oxford, UK.

Start, A. N. 1974. The feeding biology in relation to food sources of nectarivorous bats (Chiroptera: Macroglossinae) in Malaysia. Unpublished Ph.D. thesis. University of Aberdeen, Aberdeen, UK.

Start, A. N. and A. G. Marshall. 1976. Nectarivorous bats as pollinators of trees in West Malaysia in J. Burley, and B. T. Styles, editors. Tropical trees: variation breeding and conservation. Academic Press, London, UK.

Steidl, R. J., J. P. Hayes, and E. Schauber. 1997. Statistical power analysis in wildlife research. Journal of Wildlife Management 61:270-279.

Stephens, D. W. and J. R. Krebs 1986. Foraging theory. Princeton University Press, Princeton, NJ.

Sterck, E. H. M. 1995. Females, foods and fights. A socioecological comparison of the sympatric Thomas Langur and Long-tailed Macaque. PhD dissertation. Utrecht University, Utrecht, the Netherlands.

Stoms, D. M. 1994. Scale dependence of species richness maps. Professional Geographer 46: 346-358

Stork, N. E., T. J. B. Boyle, V. Dale, H. Eeley, B. Finegan, M. Lawes, N. Manokaran, R. Prabhu, and J. Soberon. 1997. Criteria and indicators for assessing the sustainability of forest management: conservation of biodiversity. CIFOR Working Paper Number 17. URL: http://www.cifor.cgiar.org/ docs/_ref/publications/workingpapers.htm. CIFOR, Bogor, Indonesia.

Stouffer, P. C. and R. O. J. Bierregaard. 1995. Use of Amazonian forest fragments by understory insectivorous birds. Ecology 76:2429-2445.

Struhsaker, T. T. 2001. Unsustainable hunting in tropical forests. Trends in Ecology and Evolution 6: 163-164.

Stuart, S. N., J. S. Chanson, N. A. Cox, B. E. Young, A. S. L. Rodrigues, D. L. Fischman, and R. W. Waller. Published online 14 October 2004. Status and trends of amphibians declines and extinctions worldwide (in Science Express Reports).

Stuebing, R. 1994. Wildlife abundance, diversity and management. Unpublished technical report, ITTO Model Forest Management Area, Sarawak. Project ITTO PD 105/90 Rev. 1(F). ITTO Unit, Sarawak Forest Department, Kuching, Malaysia.

Stuebing, R. B. and J. Gasis. 1989. A survey of small mammals within a tree plantation in Malaysia. Journal of Tropical Ecology 5:203-214.

Stuebing, R. B. and R. F. Inger 1999. The snakes of Borneo. Natural History Publication, Kota Kinabalu, Malaysia.

Styring, A. R. 2002a. Effects of selective logging on a guild of 13 syntopic woodpecker species in a Malaysian forest reserve. Pages 165-171 in P. Pechacek, and W. d'Oleire-Oltmanns, editors. International Woodpecker Symposium 23-25 March 2001 in Berchtesgarden, Germany. Forschungsbericht 48. Nationalparkverwaltung, Berchtesgaden, Germany.

Styring, A. R. 2002b. Local, regional and global patterns of woodpecker (Picidae) diversity: ecological explanations and practical applications. PhD dissertation. Louisiana State University, Baton Rouge, USA.

Styring, A. R. and K. Ickes. 2001a. Woodpecker abundance in a logged (40 years ago) vs. unlogged lowland dipterocarp forest in Peninsular Malaysia. Journal of Tropical Ecology 17:261-268.

Styring, A. R. and K. Ickes. 2001b. Woodpecker participation in mixed species flocks in peninsular Malaysia. Wilson Bulletin 113:342-345.

Styring, A. R. and M. Z. Hussin. 2004a. Effects of logging on woodpeckers in a Malaysian rainforest: the relationship betwen resource availability and woodpecker abundance. Journal of Tropical Ecology 20:495-504.

Styring, A. R. and M. Z. Hussin. 2004b. Foraging ecology of woodpeckers in lowland Malaysian rain forests. Journal of Tropical Ecology 20:487-494.

Sudarmaji, T. 1999. Impact of logging and forest fires on soil erosion in tropical humid forest, East Kalimantan. Paper presented at the International Workshop on the Rehabilitation of Degraded Tropical Forest Ecosystems, CIFOR, Bogor, Indonesia. 2-4 November 1999.

Sulastri, I. Rachmatika, and D. I. Hartoto. 1985. Pola makan dan reproduksi ikan Tor spp. sebagai dasar budidayanya. Berita Biologi 3:84-90.

Sumitro, A. 1991. The cutting of climax trees of dipterocarps stand under intensive management. In I. Soerianegara, S.S. Tjitrosomo, R.C. Umaly and I. Umboh, editors. Proceedings of the fourth round table conference on dipterocarps, Bogor, Indonesia. 12-15 December 1989. BIOTROP Special Publication 41:201-212. 
Supriatna, J., B. O. Manullang, and E. Soekara. 1986. Group composition, home range, and diet of the maroon leaf monkey (Presbytis rubicunda) at Tanjung Puting Reserve, Central Kalimantan. Primates 27:185-190.

Supriyatno, N. and G. Becker. 1999. Secondary logging in natural forests in Central Kalimantan: operational design, production and damage assessment. Pages 65-70 in P. Sist, C. Sabogal, and Y. Byron, editors. Management of secondary and logged-over forests in Indonesia: Selected proceedings of an International workshop, 17-19 November 1997, CIFOR, CIRAD and USAID, CIFOR, Bogor Indonesia.

Sutisna, M. 1996. The importance of selective tending to improve productivity of I logged-over dipterocarp forest in Indonesia. Pages 279-287 in S. Appanah, and K.C. Khoo, editors. Proceedings fifth round table conference on dipterocarps, Chiang Mai, Thailand. 7-10 November 1994, Forest Research Institute Malaysia, Kepong. Malaysia.

Sutisna, M. 1998. Growth of a tropical lowland forest in East Kalimantan. In G.L. Enriquez, U.R. Wasrin, and D. Murdiarso, editors. Tropical Forest Dynamics, BIOTROP Special Publication 60: 81-91.

Suzuki, A. 1991. Forest fire effects on the population of primates in Kutai National Park. East Kalimantan, Indonesia. Pages 51-54 in A. Ehara and T. Kimura, editors. Primatology today. Elsevier Science Publishers, Amsterdam, the Netherlands.

Swaine, M. D. and J. B. Hall. 1983. Early succession on cleared forest land in Ghana. Journal of Ecology 71:601-627.

Swihart, R. K., T. M. Gehring, M. B. Kolozsvary, and T. E. Nupp. 2003. Responses of 'resistant' vertebrates to habitat loss and fragmentation: the importance of niche breadth and range boundaries. Diversity and Distributions 9:1-18.

Syakirah, S., A. Zubaid, C. Prentice, A. Lopez, M. R. Azmin, and A. Mohd-Yusof. 2000. A smallmammal survey at Tasek Bera, Pahang, Malaysia’s first Ramsar site. Malayan Nature Journal 54: $31-41$.

Szaro R. C., J. A. Sayer, D. Sheil, L. K. Snook, and A. Gillison. 1999. Biodiversity conservation in production forests. IUFRO-SPDC and CIFOR Discussion Paper commissioned by GEF. IUFRO, Vienna, Austria.

Tamura, N. 1995. Space use by sympatric tree squirrels in Malaysian tropical forests. Tropics 4:337343.

Tan, E. S. P. 1979. Some aspects of the biology of Malaysian riverine cyprinids. Aquaculture 3:281289.

Tay, J. 1999. Economic assessment of reduced impact logging techniques in Sabah, Malaysia. PhD dissertation. University of Wales, Bangor, UK.

Taylor, B. D. and R. L. Goldingay. 2004. Wildlife road-kills on three major roads in north-eastern New South Wales. Wildlife Research 31:83-91.

Teo, D. H. L., H. T. W. Tan, R. T. Corlett, C. M. Wong, and S. K. Y. Lum. 2003. Continental rain forest fragments in Singapore resist invasion by exotic plants. Journal of Biogeography 30:305-310.

Terborgh, J. 1983. Five New World primates: A study in comparative ecology. Princeton University Press, Princeton, N.J., USA

Terborgh, J. 1992. Maintenance of diversity in tropical forests. Biotropica 24: 283-292.

Thiensongrusamee, P., P. Poonswaad, and S. Hayeemuida. 2001. Characteristics of Helmeted Hornbill nests in Thailand. The Third International hornbill workshop on the ecology of hornbills with emphasis on reproduction and population, 9-18 May 2001, Phuket and Narathiwat, Thailand. Abstracts of paper presentations.

Thiollay, J. M. 1992. Influence of selective logging on bird species diversity in a Guianan rain forest. Conservation Biology 6:47-63.

Thiollay, J. M. 1995. The role of traditional agroforests in the conservation of rain forest bird diversity in Sumatra. Conservation Biology 9:335-353.

Thiollay, J. M. 1998. Distribution patterns and insular biogeography of south asian raptor communities. Journal of Biogeography 25:57-72.

Thiollay, J. M. 1999. Responses of an avian community to rain forest degradation. Biodiversity and Conservation 8:513-534.

Thomas, S. C. 1996. Relative size at onset of maturity in rain forest trees: a comparative analysis of 37 Malaysian species. Oikos 76:145-154. 
Tinal, U. and J. Palinewen. 1978. Mechanical logging damage after selective cutting in the lowland Dipterocarp forest at Beloro, East Kalimantan. In: Proceeding of the symposium on long term effect of logging in Southeast Asia. BIOTROP Special Publication 3:91-96.

Townsend, W. R. 2000. The sustainability of subsistence hunting by the Sirionó Indians of Bolivia. Pages 267-281 in J. G. Robinson, and E. L. Bennett, editors. Hunting for sustainability in tropical forests. Columbia University Press, New York, USA.

Trockenbrodt, M., Z. Imiyabir, and J. Josue. 2002. Hollow logs and logging residues from Deramakot Forest Reserve, Sabah, Malaysia. Forest Ecology and Management 165:141-150.

Tsuji, A., P. Poonswaad, and N. Jirawatkavi. 1987. Application of radio-tracking to study hornbills (Bucerotidae) in Thailand. Pages 316-351. Proceedings 1987 Jean Delacour/FCB Symposium on Breeding Birds in Captivity. International Foundation for the Conservation of Birds, North Hollywood, CA, USA.

Tuomela, K., K. Jussi, L. Vesa, K. Nuryanto, A.P.S. Sagala, and G. Adjers. 1996. Growth of dipterocarp seedling in artificial gaps: an experiment in logged-over rainforest in South Kalimantan, Indonesia. Forest Ecology and Management 81:95-100.

Turner, I. M. 1996. Species loss in fragments of tropical rainforests: a review of evidence. Journal of Applied Ecology 33:200-209.

Turner, I. M., K. S. Chua, J. S. Y. Ong, B. C. Soong, and H. T. W. Tan. 1996. A century of plant species loss from an isolated fragment of lowland tropical rain forest. Conservation Biology 10: 1229-1244.

Twedt, D. J., R. R. Wilson, J. L. Henne-Kerr, and R. B. Hamilton. 2001. Nest survival of forest birds in the Mississippi Alluvial Valley. Journal of Wildlife Management 65:450-460.

Uluk, A., M. Sudana, and L. Wollenberg. 2001. Ketergantungan masyarakat Dayak terhadap hutan di sekitar Taman Nasional Kayan Mentarang. Unpublished report. CIFOR, Bogor, Indonesia.

Umapathy, G. and A. Kumar. 2000. The occurrence of arboreal mammals in the rain forest fragments in the Anamalai Hills, south India. Biological Conservation 92:311-319.

Ungar, P. S. 1995. Fruit preferences of four sympatric primate species at Ketambe, Northern Sumatra, Indonesia. International Journal of Primatology 16:221-245.

Utzurrum, R. C. B. 1995. Feeding ecology of Philippine fruit bats: patterns of resrouce use and seed disperseal. Symposium of the Zoological Society of London 67:63-77.

Utzurrum, R. C. B. and P. D. Heideman. 1991. Differential ingestion of viable vs non viable Ficus seeds by fruit bats. Biotropica 23:311-322.

van Balen, B. 1999a. The birds of Kayan Mentarang National Park, Unpublished report. WWFIndonesia, Jakarta, Indonesia.

van Balen, B. 1999b. Differential extinction patterns in Javan forest birds. Pages 37-57. Birds of fragmented islands: Persistence in the forests of Java and Bali. PhD dissertation. Wageningen University and Research Centre, Wageningen, the Netherlands.

van Balen, B. 1999c. Synthesis: survival on overpopulated islands. Pages 131-146. Birds of fragmented islands: Persistence in the forests of Java and Bali. PhD dissertation. Wageningen University and Research Centre, Wageningen, the Netherlands.

van Balen, B. and D. Holmes. 1993. Status and conservation of pheasants in the Greater and Lesser Sundas. Pages 40-49 in D. Jenkins, editor. Phesants in Asia 1992. World Pheasant Association, Reading, UK.

van Bemmel, A. C. V. 1949-1950. Revision of the rusine deer in the Indo-Australian archipelago. Treubia 20:191 - 262.

van der Hoeven, C. A., H. H. de Iongh, V. Nijman, and B. van Balen. 2000. Biodiversity in disturbed ecosystems. A literature review of the use of faunal indicators for the assessment and monitoring of the levels of human disturbance in Bornean tropical lowland forests. Tropenbos Documents no. 16. NWO and the Tropenbos Foundation, Wageningen, The Netherlands.

van der Pijl , I. 1935. Zaadverspreiding door vleermuizen. De Tropische Natuur 24:131-138.

van Dijk, P. P., B. L. Stuart, and A. G. J. Rhodin. 2000. Asian turtle trade: Proceedings of the Workshop on Conservation and Trade of Freshwater Turtles and Tortoises in Asia. Chelonian Research Monographs 2:1-164.

van Gardingen, P. R., M. J. Clearwater, T. Nifinluri, R. Effendi, P. A. Ruswantoro, K. Ingleby and R. C. Munro. 1998. Impacts of logging on the regeneration of lowland dipterocarps forest in Indonesia. Commonwealth Forestry Review 77:71-82. 
Van Gardingen, P. R., M. J. McLeish, P. D. Phillips, D. Fadilah, G. Tyrie, and I. Yasman. 2003. Financial and ecological analysis of management options for logged-over Dipterocarp forests in Indonesian Borneo. Forest Ecology and Management 183:1-29.

van Heist, M. and E. Wollenberg. 2000. Action research on negotiating conflict and community empowerment in forest areas: Participatory mapping of the villages along the Malinau River, East Kalimantan. Preliminary report to ITTO. CIFOR, Bogor, Indonesia.

Van Horn, R. N. and G. G. Eaton. 1979. Reproductive physiology and behavior in prosimians. Pages 79-122 in G. A. Doyle, and R. D. Martin, editors. The Study of Prosimian Behavior. Academic Press, New York, USA.

van Marle, J. G. and K. H. Voous. 1988. The birds of Sumatra. An annotated check-list. British Ornithologist Union Checklist No. 10.

van Nieuwstadt, M. G. L., D. Sheil, and K. Kartawinata. 2001. The ecological consequences of logging in the burned forests of East Kalimantan, Indonesia. Conservation Biology 15:11831186.

van Nieuwstadt, M. G. L., K. Kartawinata, and D. Sheil. 2002. Konsekuensi ekologis pembalakan dalam kawasan hutan yang terbakar di Kalimantan Timur. Jurnal Hutan Indonesia (Indonesia Forest Journal). August 2002:1-4.

van Noordwijk, M. A., C. K. Hemelrijk, L. Herremans, and E. H. M. Sterck. 1993. Spatial position and behavioral sex differences in juvenile long-tailed macaques. Pages 77-85 in M. E. Pereira, and L. A. Fairbanks, editors. Juvenile Primates: Life history, development, and behavior. Oxford University Press, New York, USA.

Van Putten, G. 2000. An ethological definition of animal welfare with special emphasis on pig behaviour in M. Hovi, and R. G. Trujillo, editors. Diversity of livestock systems and definition of animal welfare. Proceedings of the Second NAHWOA Workshop, Cordoba, 8-11 January 2000. Spain.

van Schaik, C. P., P. S. Assink, and N. Salafsky. 1992. Territorial behavior in Southeast Asian langurs: resource defense or mate defense? American Journal of Primatology 26:233-242.

van Strien, N. J. 2001. Indoaustralian mammals. A taxonomic and faunistic reference and atlas. ETI, Amsterdam, The Netherlands.

Vasconcelos, H. L., J. M. S. Vilhena, and G. J. A. Caliri. 2000. Responses of ants to selective logging of a central Amazonian forest. Journal of Applied Ecology 37:508-514.

Vidal, E., J. Johns, J. J. Gerwing, P. Barreto, and C. Uhl. 1997. Vine management for reduced-impact logging in eastern amazonia. Forest Ecology and Management 98:105-114.

Vidal, J. 2003. Forced from rich forests into squalor. Tribal people are paying a high price for parks created to protect Africa's wilderness. The Guardian Weekly 2-8 October 2003: 26.

Vitt, L. J. and J. P. Caldwell. 1994. Resource utilization and guild structure of small vertebrates in the Amazon forest leaf litter. Journal of Zoology 234:463-476.

Vitt, L. J. and J. P. Caldwell. 2001. The effects of logging on tropical forest ungulates in R. A. Fimbel, A. Grajal, and J. G. Robinson, editors. The cutting edge: conserving wildlife in logged tropical forest. Columbia University Press, New York, USA.

Wadley, R. L., C. J. P. Colfer, and I. G. Hood. 1997. Hunting primates and managing forests - the case of Iban forest farmers in Indonesian Borneo. Human Ecology 25:243-271.

Waits, L. P. 1996. A comprehensive molecular study of the evolution and genetic variation of bears. PhD thesis. University of Utah, Salt Lake City.

Waits, L. P., J. Sullivan, S. J. O’Brien, and R. H. Ward. 1999. Rapid radiation events in the family Ursidae indicated by likelihood phylogenetic estimation from multiple fragments of mtDNA. Molecular Phylogenetics and Evolution 13:82-92.

Walsh, P. D., K. A. Abernethy, M. Bermejo, R. Beyersk, P. De Wachter, M. E. Akou, B. Huljbregis, D. I. Mambounga, A. K. Toham, A. M. Kilbourn, S. A. Lahm, S. Latour, F. Maisels, C. Mbina, Y. Mihindou, S. N. Obiang, E. N. Effa, M. P. Starkey, P. Telfer, M. Thibault, C. E. G. Tutin, L. J. T. White, and D. S. Wilkie. 2003. Catastrophic ape decline in western equatorial Africa. Nature 422:611-614.

Walston, J. L. and J. W. Duckworth. 2003. The first record of small-toothed palm civet Arctogalidia trivirgata from Cambodia, with notes on surveying the species. Small Carnivore Conservation 28: $12-13$.

Walter, O. 2000. A study of hunting and trade of freshwater turtles and tortoises (Order Chelonia) at Danau Sentarum. Borneo Research Bulletin 31:323-335. 
Waterman, P. G. 1983. Distribution of secondary metabolites in rain forest plants; towards an understanding of cause and effect. Pages 167-179 in S. L. Sutton, Whitmore, T.C. and Chadwick, A.C., editor. Tropical rain forest ecology and management. Special Publication number 20 of the British Ecological Society. Blackwell Scientific Publications, Oxford, UK.

Waterman, P. G., J. A. M. Ross, E. L. Bennett, and A. G. Davies. 1988. A comparison of the floristics and leaf chemistry of the tree flora in two Malaysian rainforests and the influence of leaf chemistry on populations of Colobine monkeys in the Old World. Biological Journal of the Linnean Society 34:1-32.

WCS. 1998. Malaysian state of Sarawak bans commercial hunting of wildlife. WCS press release 28 May 1998. http://www.mered.org.uk/saraweb/issues/WCS\%20on\%20trade\%20ban.htm. Accessed on 9 March 2004.

Webb, C. O. and D. R. Peart. 2001. High seed dispersal rates in faunally intact rainforests: theoretical and concervation implications. Ecology Letters 4: 491-499.

Webb, E. L. 1997. Canopy removal and residual stand damage during controlled selective logging in lowland swamp forest of Costa Rica. Forest Ecology and Management 95:117-129.

Wells, D. R. 1974. Bird report: 1970 and 1971. Malayan Nature Journal 27:30-49.

Wells, D. R. 1998. The birds of the Thai-Malaysian Peninsula. Academic Press, London, UK.

Wells, D. R. 1999. The birds of the Thai-Malay Peninsula. Academic Press, London, UK.

Wells, K. L. 2002. Diversity, dynamics and spacing patterns of a small mammal community in a primary rainforest in Sabah; comparing an arboreal and terrestrial habitat. MSc thesis. Lehrstuhl für Tierökologie und Tropenbiologie der Bayerischen Julius-Maximilians-Universität in Würzburg, Würzburg, Germany.

Wetterer, J. K., P. D. Walsh, and L. J. T. White. 1999. Wasmannia auropunctata (Roger) (Hymenoptera: Formicidae), a destructive tramp-ant, in wildlife refuges of Gabon. African Entomology 7:292-294.

Wharton, C. H. 1966. Man, fire and wild cattle in north Cambodia. Pages 23-65. 5th Annual Tall Timbers Fire Ecology Conference, Tallahassee, Florida, USA.

Wharton, C. H. 1968. Man, fire and wild cattle in Southeast Asia. Pages 107-167. Proceedings of the 8th Annual Tall Timbers Fire Ecology Conference. Tallahassee, Florida, USA.

White, L. J. T. 1994. The effects of commercial mechanized selective logging on a transect in lowland rainforest in the Lope Reserve, Gabon. Journal of Tropical Ecology 10:313-322.

Whitman, A. A., J. M. Hagan, and N. V. L. Brokaw. 1998. Effects of selection logging on birds in Northern Belize. Biotropica 30:449-457.

Whitmore, T. C. 1984. Tropical rain forests of the Far East. Oxford University Press, Oxford, U.K.

Whitmore, T. C. 1990a. Tropical rain forest dynamics and its implications for management. Pages 67-89 in A. Gomez-Pompa, T. C. Whitmore, and M. Hadley, editors. Rain forest regeneration and management. Man and the Biosphere Series, Volume 6. Parthenon Publishing Group, Paris, France.

Whitmore, T. C. 1990b. An introduction to tropical rainforests. Clarendon Press, Oxford, UK.

Whitmore, T. C. 1997. Tropical forest disturbance, disappearance, and species loss in W. F. Laurance, and R. O. Bierregaard, editors. Tropical Forest Remnants: Ecology, Management, and Conservation of Fragmented Communities. University of Chicago Press, Chicago, USA.

Whitmore, T. C. 1998. An introduction to tropical rain forests. Second Edition. Oxford University Press, New York, USA.

Whitmore, T. C. and J. A. Sayer 1992. Tropical deforestation and species extinction. Chapman and Hall, London, UK.

Whitmore, T. C. and N. D. Brown. 1996. Dipterocarp seedling growth in rain forest canopy gaps during six and a half years. Philosophical Transactions of the Royal Society of London - Series B: Biological Sciences 351:1195-1203.

Whitney, K. D. and T. B. Smith. 1998. Habitat use and resource tracking by African Ceratogymna hornbills: implications for seed dispersal and forest conservation. Animal Conservation 1:107-117.

Whitney, K. D., M. K. Fogiel, A. M. Lamperti, K. M. Holbrook, D. J. Stauffer, B. D. Hardesty, V. T. Parker, and T. B. Smith. 1998. Seed dispersal by Ceratogymna hornbills in the Dja Reserve, Cameroon. Journal of Tropical Ecology 14:351-371.

Whitten, A. J., S. J. Damanik, A. Jazanul, and H. Nazaruddin. 1987. The ecology of Sumatra. Gadjah Mada University Press, Yogyakarta, Indonesia. 
Whitten, J. E. J. 1981. Ecological separation of three diurnal squirrels in tropical rainforest on Siberut Island, Indonesia. Journal of Zoology 193:405-420.

Whitten, J. E. J. and A. J. Whitten. 1987. Analysis of bark eating in a tropical squirrel. Biotropica 19: 107-115.

Whitten, T., R.E. Soeriaatmadja, and S.A. Afiff, 1996. The ecology of Java and Bali. Periplus Editions, Singapore.

Wich, S. A. and C. P. Schaik van. 2000. The impact of El Niño on mast fruiting in Sumatra and elsewhere in Malesia. Journal of Tropical Ecology 16:563-577.

Wiens, J. A. 1989. The ecology of bird communities. Cambridge University Press, Cambridge, UK.

Wiens, J. A. 1992. Ecological flows across landscape boundaries; a conceptual overview in A. J. Hansen, and F. di Castri, editors. Landscape Boundaries: Consequences for Biotic Diversity and Ecological Flows. Springer-Verlag, New York, USA.

Wiens, J. A. 1997. Metapopulation dynamics and landscape ecology in I. A. Hanski, and M. E. Gilpin, editors. Metapopulation biology: Ecology, genetics, and evolution. Academic Press, San Diego, CA, USA.

Wildlife Conservation Society (WCS) and Sarawak Forest Department. 1996. A masterplan for wildlife in Sarawak. Sarawak Forest Department, Kuching, Malaysia.

Wilkie, D., E. Shaw, F. Rotberg, G. Morelli, and P. Auzel. 2000. Roads, development, and conservation in the Congo Basin. Conservation Biology 14:1614-1622.

Wilkie, D. S. and J. F. Carpenter. 1999. Bushmeat hunting in the Congo Basin: an assessment of impacts and options for mitigation. Biodiversity and Conservation 8:927-955.

Wilkie, D. S., J. G. Sidle, G. C. Boundzanga, P. Auzel, and S. Blake. 2001. Defaunation, not deforestation: Commercial logging and market hunting in Northern Congo. Pages 375-399 in R. Fimbel, A. Grajal, and J. G. Robinson, editors. The cutting edge: Conserving wildlife in logged tropical forest. Columbia University Press, New York, USA.

Wilkinson, R., G. Dutson, and B. Sheldon. 1991. The avifauna of Barito Ulu Central Borneo. ICBP Study Report 48, Cambridge, UK.

Wilson, C. C. and W. L. Wilson. 1975. The influence of selective logging on primates and some other animals in East Kalimantan. Folia Primatologia 23:245-274.

Wilson, W. L. and A. D. Johns. 1982. Diversity and abundance of selected animal species in undisturbed forest, selectively logged forest and plantations in East Kalimantan, Indonesia. Biological Conservation 24:205-218.

Winarni, N. 2002. Abundance and distribution of great argus Argusianus argus. Tragopan:15.

Winkler, H., D. A. Christie, and D. Nurney 1995. Woodpeckers: a guide to the woodpeckers, piculets and wrynecks of the world. Pica Press, Mountfield, East Sussex, UK.

Wirawan, A. 1993. The hazard of fire. Pages 242-260 in H. Brookfield, and Y. Byron, editors. The search for sustainability. United Nations University Press, New York.

Wirawan, N. 1987. Good forest within the burned forest area in East Kalimantan. Pages 413-425 in A. J. G. H. Kostermans, editor. Third Round Table Conference on Dipterocarps. UNESCO, Jakarta, Indonesia.

Wolfheim, J. H. 1983. Primates of the world: Distribution, abundance, and conservation. University of Washington Press, Seattle, USA.

Wollenberg, E., D. Edmunds, L. Buck, J. Fox, and S. Brodt, editors. 2001. Social learning in community forests. CIFOR and the East West Center, Bogor, Indonesia.

Wong, A. in press a. The impact of forestry practices on frog communities in Sabah, Malaysia. PhD Dissertation. Universiti Putra Malaysia, Kota Kinabalu, Malaysia.

Wong, A. in press b. Species diversity and abundance of frogs in different forestry practices In Sabah, Malaysia. In International Conference on Bornean Herpetology 16-17 December 2003. Universiti Malaysia Sabah, Kota Kinabalu, Malaysia.

Wong, M. 1985. Understorey birds as indicators of regeneration in a patch of selectively logged West Malaysian rain forest. Pages 249-263 in A. W. Diamond, and T. E. Lovejoy, editors. Conservation of Tropical Forest Birds. ICBP Technical Publication No. 4. International Council for Bird Preservation, Cambridge, UK.

Wong, M. 1986. Trophic organization of understorey birds in a Malaysian dipterocarp forest. Auk 103: $100-116$. 
Wong, S. T. 2002. The ecology of Malayan sun bears (Helarctos malayanus) in the lowland tropical rainforest of Sabah, Malaysian Borneo. MSc thesis. University of Montana, USA.

Wong, S. T., C. Servheen, and L. Ambu. 2002. Food habits of malayan sun bears in lowland tropical forest of Borneo. Ursus 13:127-136.

Wong, S. T., C. Servheen, and L. Ambu. 2004. Home range, movement and activity patterns, and bedding sites of Malayan sun bears, Helarctos malayanus in the rainforest of Borneo. Biological Conservation 119:169-181.

Woodruffe, R. and J. R. Ginsberg. 1998. Edge effects and the extinction of populations inside protected areas. Science 280:2126-2128.

Woodruffe, R. and J. R. Ginsberg. 2000. Ranging behaviour and vulnerability to extinction in carnivores. Pages 125-140 in I. M. Gosling, and W. J. Sutherland, editors. Behaviour and conservation. Cambridge University Press, Cambridge, UK.

Woods, P. 1989. Effects of logging, drought, and fire on structure and composition of tropical forests in Sabah, Malaysia. Biotropica 21:290-298.

Worth, W., C. Sheppard, A. Kemp, S. Ellis, and U. Seale. 1994. Hornbill conservation and management plan. IUCN/SCC Captive Breeding Specialist Group., Apple Valley. Texas, USA.

Wrangham, R. W., J. L. Gittleman, and C. A. Chapman. 1983. Constraints on group size in primates and carnivores: population density and day range as assays of exploitation competition. Behavioral ecology and Sociobiology 32:199-209.

Wright, P. C., M. K. Izard, and E. L. Simons. 1986. Reproductive cycles in Tarsius bancanus. American Journal of Primatology 11:207-215.

Wu, D. L., J. Luo, and B. J. Fox. 1996. A comparison of ground-dwelling small mammal communities in primary and secondary tropical rainforests in China. Journal of Tropical Ecology 12:215-230.

Wyatt-Smith, J. 1963. Manual of Malayan silviculture for inland forests. Malayan Forest Records No. 23. Forest Research Institute Malaysia, Kuala Lumpur, Malaysia.

Wyatt-Smith, J. 1987. The management of tropical moist forest for the sustained production of timber: some issues. Tropical Forestry Policy Paper 4. IUCN/IIED.

Wyatt-Smith, J. 1995. Manual of Malayan Silviculture for Inland Forests, 2nd Edition. Malayan Forest Record No. 23. FRIM, Kuala Lumpur, Malaysia.

Yasuda, M., N. Ishii, T. Okuda, and N. Azman Hussein. 2003. Small mammal community: habitat preference and effects after selective logging. Pages 533-546 in T. Okuda, N. Manokaran, Y. Matsumoto, K. Niiyama, S. C. Thomas, and P. S. Ashton, editors. Ecology of a lowland rain forest in southeast Asia. Springer-Verlag, Tokyo, Japan.

Yasuma, S. 1996. An invitation to the mammals of Brunei Darussalam. Part I. Indoor information. Brunei Forest Research After Care Project. Special Publication No. 1. Japan International Cooperation Agency and Forestry Department, Ministry of Industry and Primary Resources, Brunei Darussalam.

Yasuma, S. and M. Andau. 2000. Mammals of Sabah, part 2. Habitat and ecology. Japan International Cooperation Agency and Sabah Wildlife Department, Kuala Lumpur, Malaysia.

Yatim, S. H. 1993. The status and distribution of pheasants in Peninsular Malaysia. Pages 28-39 in D. Jenkins, editor. Pheasants in Asia 1992. World Pheasant Association, Reading, UK.

Yeager, C. 1996. Feeding ecology of the Long-tailed Macaque (Macaca fascicularis) in Kalimantan Tengah, Indonesia. International Journal of Primatology 17:51-62.

Yeager, C. 1999. Research report Lalut-Birai Field Station 1997-1999. WWF Indonesia, KayanMentarang National Park Project, Jakarta, Indonesia.

Yeom, F. B. C. and C. Chandrasekharan. 2001. Achieving sustainable forest management in Indonesia. ITTO Newsletter.

Yi-Ching, M. 1983. The status of bears in China. Acta Zoologica Fennica 174:165-166.

Zou, X., C. P. Zucca, R. B. Waide, and W. H. McDowell. 1995. Long-term influence of deforestation on tree species composition and litter dynamics of a tropical rain forest in Puerto Rico. Forest Ecology and Management 78:147-157.

Zubaid, A. 1993. A comparison of the bat fauna between a primary and fragmented secondary forest in Peninsular Malaysia. Mammalia 57: 201-206.

Zubaid, A. and M. Khairul Effendi Ariffin. 1997. A comparison of small mammal abundance between a primary and disturbed lowland rain forest in Peninsular Malaysia. Malayan Nature Journal 50: 201-206. 

Tropical rainforests are the most species-rich terrestrial ecosystems on earth. Yet, with land clearing for timber, agriculture and other uses, these rainforests are disappearing at a rate of 12 million hectares a year-an area almost the size of Greece.

As the forests disappear so too may the many services and needs provided by their rich biodiversity. One solution has been to establish strictly protected areas. But protected areas are not a panacea. They cannot conserve the full biological diversity found within tropical forests. In fact, the fate of many species found in protected areas depends upon what happens to other forestlands.

But as the world's unprotected forests continue to be exploited for timber and non-timber forest products or for conversion to agriculture, changes in the world's flora and fauna are inevitable. Fortunately, the extent of that change can be controlled to a large extent through improved forest management choices and operational practices.

Focusing on the wildlife of Malinau District, the most forest rich area remaining on the island of Borneo, this book considers how vertebrate species are affected by logging and other associated activities, such as road building and hunting. As an area still rich in biodiversity but increasingly under threat from timber harvesting, Malinau is a prime site for studying both the effects of logging on wildlife populations, and the conservation opportunities that exist through improved forest management.

Drawing on a vast and diverse literature and a broad array of expertise, this book provides the best available synthesis to date on logging and wildlife in the region. Compiling these data allows a number of new and original analyses.

The book evaluates what makes a species vulnerable to certain interventions, and proposes how changes in concession management can benefit wildlife and improve the conservation value of logged over forest. It also gives detailed management recommendations for a list of species with high local importance, protected by Indonesian law, or threatened by global extinction.

In presenting a new guide to improved production forest management in the Asian tropics, this book represents a major step forward. In addition, it identifies where the most important knowledge gaps exist, and how these should be addressed in future research.

\section{ISBN $979-336 z-5 b-5$

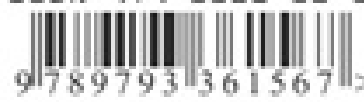
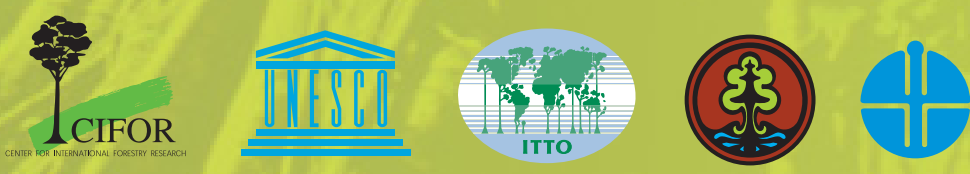

Lembaga

IImu Pengetahuan

Indonesia

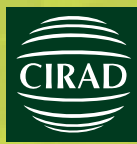

